\title{
Die Rettung des Bildes im Wort
}

Bruno Schulz' Bild-Idee in seinem prosaischen und bildnerischen Werk

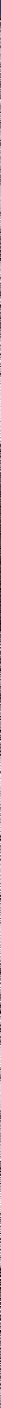


V\&R Academic 


\section{Schnittstellen}

Studien zum östlichen und südöstlichen Europa

Herausgegeben von

Martin Schulze Wessel und Ulf Brunnbauer

Band 3 
Anna Juraschek

\section{Die Rettung des Bildes im Wort}

Bruno Schulz' Bild-Idee in seinem prosaischen und bildnerischen Werk

Vandenhoeck \& Ruprecht 
Mit 20 Abbildungen

Bibliografische Information der Deutschen Nationalbibliothek

Die Deutsche Nationalbibliothek verzeichnet diese Publikation in der Deutschen Nationalbibliografie; detaillierte bibliografische Daten sind im Internet über http://dnb.d-nb.de abrufbar.

ISBN 978-3-666-30085-1

Der Druck dieses Buches wurde ermöglicht durch einen Druckkostenzuschuss aus Mitteln der von der Deutschen Forschungsgemeinschaft (DFG) finanzierten Graduiertenschule für Ost- und Südosteuropastudien.

Umschlagabbildung: Bruno Schulz, Selbstporträt, aus der Sammlung des Emanuel Ringelblum Jewish Historical Institute in Warschau.

(C) 2016, Vandenhoeck \& Ruprecht GmbH \& Co. KG, Theaterstraße 13, D-37073 Göttingen

Dieses Werk ist als Open-Access-Publikation im Sinne der Creative-Commons-Lizenz BY-NC-ND International 4.0 (»Namensnennung - Nicht kommerziell - Keine Bearbeitungen«) unter dem DOI 10.13109/9783666300851 abzurufen. Um eine Kopie dieser Lizenz zu sehen, besuchen Sie https://creativecommons.org/licenses/by-nc-nd/4.0/. Jede Verwertung in anderen als den durch diese Lizenz zugelassenen Fällen bedarf der vorherigen schriftlichen Einwilligung des Verlages.

Satz: textformart, Göttingen | www.text-form-art.de 


\section{Inhalt}

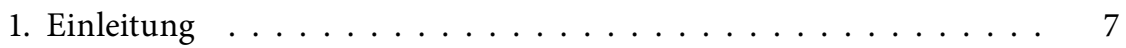

1.1 Beobachtungen und Forschungsstand $\ldots \ldots \ldots \ldots$

1.2 Thesen und Fragestellungen $\ldots \ldots \ldots \ldots \ldots$

1.3 Werkproblematik und biografische Kontextualisierung . . . . 18

1.4 Theorie und Methode . . . . . . . . . . . . . . . . . . . 29

1.5 Vorgehensweise . . . . . . . . . . . . . . . . 35

2. Schulz' Sprach- und Kunstverständnis in seinen theoretischen Schriften im Kontext der Modernekritik . . . . . . . 39

2.1 Sprache, Kunst und Bild . . . . . . . . . . . . . . . . . 40

2.2 Trümmerfeld der Moderne . . . . . . . . . . . . . . . . . . . . . . . . . 47

2.3 Das Erstarren der Bilder . . . . . . . . . . . . . . . . . 65

3. Bildreflexionen in Bildern $-» X i e ̨ g a$ Bałwochwalcza $\ldots$. . . . . . 81

$3.1 »$ Cliché-verre« als Form des Dazwischen . . . . . . . . . . . 84

3.2 Pygmalions Traum oder die Grenze zwischen Bild,

Mythos und Wirklichkeit . . . . . . . . . . . . . . 88

3.3 Das $»$ Marmorbild $« \ldots \ldots \ldots$

3.4 Die Grafiken als Metabilder . . . . . . . . . . . . . . 96

3.5 Idolatrische Bücher und Bilder in Interaktion . . . . . . . . . 109

3.6 Bild im Bild . . . . . . . . . . . . . . . . . . . . . 112

3.7 Zwischenfazit . . . . . . . . . . . . . . . 121

4. Die Welt der Kataloge - UUlica Krokodyli« und »Księga» . . . . . . . 127

4.1 Die Illustrierten und ihre Wirkung - »Ulica Krokodyli« . . . . . . 129

4.2 Magie der Reklame -»Księga" . . . . . . . . . . . . . . . . . . 144

4.3 Der Warenfetisch - Pilger und Panienki . . . . . . . . . . . 160

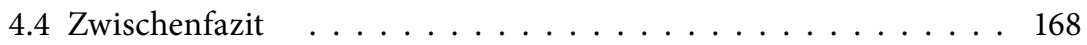

5. Wortmalerei - Beziehung zwischen Bild und Sprache . . . . . . . . . 173

5.1 Ekphrasis im Wandel der Zeit . . . . . . . . . . . . . . 179

5.2 Von visualisierenden Beschreibungen zur Wortmalerei . . . . . 186

5.3 Gemälde-Ekphraseis . . . . . . . . . . . . . . . . . . . . . . 189 
5.4 Farbe und Erscheinung $\ldots \ldots \ldots$. . . . . . . . . 200

5.5 Perspektive und Wahrnehmung . . . . . . . . . . . 206

5.6 Illusionen in Bild und Sprache . . . . . . . . . . . . . . 213

5.7 Zwischenfazit . . . . . . . . . . . . . . . . . . . . 219

6. Rettung des Bildes im Wort - Fazit . . . . . . . . . . . . . . 225

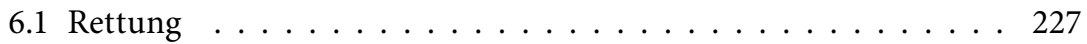

6.2 Bild in Sprache . . . . . . . . . . . . . . . . . 228

Danksagung ........................ 233

Literatur . . . . . . . . . . . . . . . . . . 235

Bildnachweis . . . . . . . . . . . . . . . . . . 251

Register .......................... 253 


\section{Einleitung}

"Es war ein Zeichnen voller Grausamkeiten, Hinterhalte und Überfälle. Wenn ich so dasaß, in äußerster Anspannung, reglos und lauernd, und in der Sonne um mich her die Papiere grell flammten, dann genügte schon die winzigste Fluchtbewegung einer der Zeichnungen, die mein Bleistift festgenagelt hatte. Und meine vor neu erwachten Instinkten und Impulsen zuckende Hand warf sich wütend wie eine Katze, schon nicht mehr zu mir gehörig, verwildert und raubtierhaft auf sie, um die Abtrünnige, die sich ihr unter dem Bleistift wegstehlen wollte, blitzschnell totzubeißen. Sie löste sich erst dann vom Papier, wenn die schon leblosen und reglosen Kadaver, wie in einem Herbarium, ihre farbige und phantastische Anatomie in einem Heft entfaltet hatten." ${ }^{1}$

Obwohl Bruno Schulz (1892-1942) nicht nur als Schriftsteller und Essayist in Erscheinung getreten ist, sondern zuerst als Grafiker und plastischer Künstler, zehrt sein Ruhm bis heute vor allem von seiner Sprachkunst. So sind sein Prosawerk, seine Poetologie wie auch sein Sprachverständnis besonders gut untersucht und vielfach analysiert worden. Seine Bilder sind jedoch weniger gut erforscht; vor allem fehlt bisher eine Analyse des Bildes, die vergleichbar zum Sprachverständnis und Poetologie auch das Bildverständnis und die Bildsprache untersucht.

Dabei hat Schulz trotz seines weitaus beträchtlichen schriftstellerischen Erfolges das Malen und Zeichnen nie aufgegeben. Schulz' Zeitgenosse, der Künstler und Kunstkritiker Ignacy Witz, der seine Bildwerke in verschiedenen Ausstellungen gesehen hat, geht sogar von einer Übersetzung der bildnerischen Ausdrucksform in die literarische aus. Ihm zufolge bilden Schulz' grafisches und schriftstellerisches Werk eine Einheit und sollten nicht unabhängig voneinander gelesen werden. ${ }^{2}$

1 Schulz, Bruno: Das Sanatorium zur Sanduhr. (Aus dem Poln. von Doreen Daume). München 2011, 32f. »Było to rysowanie pełne okrucieństwa, zasadzek i napaści. Gdy tak siedziałem napięty jak łuk, nieruchomy i czatujący, a w słońcu dookoła mnie płonęły jaskrawo papiery - wystarczyło, aby rysunek, przygwożdżony mym ołówkiem, uczynił najlżejszy ruch do ucieczki. Wówczas ręka moja, cała w drgawkach nowych odruchów i impulsów, rzucała się nań z wściekłością jak kot i już obca, zdziczała, drapieżna, w błyskawicznych ukąszeniach zagryzała dziwoląga, który chciał się jej wymknąć spod ołówka. I dopiero wtedy odluźniała się od papieru, gdy martwe już i nieruchome zwłoki rozkładały, jak w zielniku, swą kolorową i fantastyczną anatomię na zeszycie.« Jarzębski, Jerzy (Hg.): Proza. Kraków 1973, 140.

2 Vgl. Witz, Ignacy: Obszary malarskiej wyobraźni. Kraków 1967, 38. 
Wie sehr Schulz' plastisches Werk bis heute im Schatten seiner Literatur steht, zeigt beispielhaft das 2006 von Władysław Bolecki herausgegebene "Słownik schulzowski«" (Schulz-Wörterbuch). Dieses verzeichnet lexikonartig Einträge zu wesentlichen Aspekten von Schulz' Leben, Umfeld und Werk. Dort finden sich Einträge zu »słowo« (Wort), "poezja« (Poesie) oder "metafora, metaforyzacja, metaforyczność « ${ }^{4}$ (Metapher, Metaphorisierung, Metaphorischkeit), keine jedoch $\mathrm{zu} »$ Bild«, »Malerei« oder »Expressionismus«, also zum erweiterten Bereich seines plastischen Werks. Neben dieser Vernachlässigung des Bildwerks finden sich auch aktive Abwertungen seiner Grafiken. So schreibt Jerzy Ficowski, Biograf ${ }^{5}$, Herausgeber ${ }^{6}$ und SchulzForscher, in der Einleitung zur deutschen Ausgabe der "Xięga Bałwochwalcza« (Buch vom Götzendienst):

»In der Schriftstellerei konnte Schulz mit ungewöhnlicher Perfektion in die Wirklichkeit an der Grenze zwischen Wachen und Traum eindringen, Visionen von unterschiedlicher Spannung und materieller Dichte dosieren, zu vieldeutigen Empfindungswinkeln vordringen. Einen solchen Grad des Sehens, eine solche Meisterschaft der künstlerischen Sprache hat er in seinen bildnerischen Arbeiten nicht erreicht, obwohl sie das Gebiet seiner ersten, übrigens lebenslangen künstlerischen Initiation und Erfahrung waren. ${ }^{7}$

Als Grund für dieses Ungleichgewicht nennt Ficowski einerseits die Genialität im sprachlichen Ausdruck, die Schulz für den plastischen Bereich fehle, andererseits auch die Thematik, da das grafische Werk schlicht seine sexuelle Orientierung verbildliche.

»Eine andere Sache ist es, daß manche Graphiken des `Götzenbuchs` etwas zu wörtlich, irgendwie ohne mythengebärende Perspektiven, die elementaren, instinktiven Obsessionen des Autors veranschaulichen. ${ }^{8}$

3 Vgl. Bolecki, Włodzimierz: Słownik schulzowski. Gdańsk 2006.

4 Neben einer Häufung literaturwissenschaftlicher und sprachtheoretische Begriffe, lässt sich eine Dominanz biografischer und psychoanalytischer Schlagworte feststellen. Über die naheliegenden Begriffe wie "masochizm» (Masochismus) und »sadyzm» (Sadismus) hinaus, finden sich auch Einträge zu "autokastracja« (Selbstkastration), »eros« (Eros), »ung Carl Gustav«, "narcyzm» (Narzismus) und "psychoanaliza» (Psychoanalyse).

5 Von Jerzy Ficowski stammen die umfangsreichsten Materialsammlungen. Sein biografisches Standartwerk »Regiony wielkiej herezji« (Vgl. Ficowski, Jerzy: Regiony wielkiej herezji. Kraków 1967) ist bis heute in mindestens drei erweiterten Auflagen erschienen, die neuste von 2002. Vgl. Ficowski, Jerzy: Regiony wielkiej herezji i okolice. Bruno Schulz i jego mitologia. Sejny 2002.

6 Er hat sowohl die gesammelten Briefe als auch die gesammelten Bilder herausgegeben.

7 Ficowski, Jerzy: Einführende Worte zum »Götzenbuch«. In: Ders. (Hg.): Das Götzenbuch. (Xięga bałwochwalcza). Warszawa 1988, 4-59, hier 40.

8 Ebd., 48. 
Damit meint Ficowski Schulz' vermeintliche masochistische Neigung, die das eigentliche Thema der Grafiken sei. Auch Jerzy Jarzębski, der in seinem 2005 erschienenem Buch »Prowincja Centrum« die malerische Sprache untersucht, kommt zu dem Schluss, dass die »Wortmalerei« (malowanie słowem ${ }^{9}$ ) mit den Grafiken oder überhaupt mit existierenden Gemälden keine Berührung hätte. Die Grafiken hingegen »erfüllen in beträchtlichem Ausmaß die Funktion der Befriedigung geheimer (erotischer) Wünsche. ${ }^{10}$

Vor diesem Hintergrund wundert es nicht, dass Jan Gondowicz das Zusammenlesen des plastischen und literarischen Werks als Hauptproblem der Forschung bezeichnet, ${ }^{11}$ denn wie genau können zwei so unterschiedliche Oeuvres, wie sie Schulz' Bildwerk und seine Literatur auf den ersten Blick darstellen, als Einheit verstanden werden?

Dieser Frage geht die vorliegende Arbeit nach. Sie greift auf verschiedene Aufsätze und Monografien zu Einzelaspekten der Fragestellung zurück. Da eine umfassende Literaturdarstellung ob der Fülle der vorliegenden Veröffentlichungen nicht möglich ist, ${ }^{12}$ werden im Folgenden hauptsächlich jene Arbeiten vorgestellt, die im Kontext der Bildidee relevant sind. Die Reihenfolge richtet sich nicht nach der Bedeutung, sondern folgt einem argumentativen Aufbau, der zeigt, wo überall das »Bild» in Schulz' Werk eine Rolle spielt.

\subsection{Beobachtungen und Forschungsstand}

In den Grafiken der "Xięga Bałwochwalcza» sowie in den Porträts aus der Frühphase lassen sich verschiedene Auseinandersetzungen mit Bildern entdecken, die auf unterschiedlichen Ebenen ausgetragen werden. So finden sich im Hintergrund vieler Porträts auffällig große Gemälde mit mythologischen Szenen, die eine »Bild-in-Bild» Struktur zeigen, welche nach Ariko Kato auf

9 Vgl. Jarzębski, Jerzy: Prowincja centrum. Przypisy do Schulza. Kraków 2005, 26-50.

$10 »$ Te ostatnie [grafiki] pełniły w sporej mierze funkcję spełniania ukrytych marzeń (erotycznych).«Ebd., 26. (Übers. A. J.)

11 Vgl. Gondowicz, Jan: Schulz. Warszawa 2006, 46. „Główny problem dociekań nad dziełem Schulza stanowi związek jego prac rysunkowych ze światem prozy.«»Das Hauptproblem der Forschung zum Werk von Schulz stellt die Verbindung zwischen seinen zeichnerischen Arbeiten mit der prosaischen Welt dar.« (Übers. A. J.) Gondowicz sieht die Klammer zwischen beiden Ausdrucksbereichen in den dionysischen Orgien.

12 Auf der Homepage www.brunoschulz.org sind fast 100 Seiten Bibliografie verzeichnet, sodass die Kenntnis der gesamten Literatur nicht mehr möglich ist. Gleichzeitig kann man sich dort einen guten Überblick über die veröffentlichten Werke und bearbeiteten Themenfelder verschaffen. 
eine theoretische Auseinandersetzung mit der Bildkunst hinweise. ${ }^{13}$ Die Grafiken wiederum bilden einen Zyklus, der durch das wiederholte Auftauchen derselben Personen die diskursive Form einer Erzählung annimmt, wie Matthias Freise gezeigt hat. ${ }^{14}$ Gleichzeitig thematisieren sie in Titel und Motiven das alttestamentarische Bildverbot und den Götzendienst, den Kris Van Heuckelom im Kontext eines »cross overs « zwischen Buch und Bild interpretiert hat. ${ }^{15}$ Kitowska-Łysiak ${ }^{16}$ und Dariusz Sikorski ${ }^{17}$ konnten beide einige Bildvorlagen zu Schulz' plastischem Werk identifizieren, verstehen diese Zitate aber abweichend einmal im Kontext einer Mythologie oder einer Symboltheorie.

Auch in Schulz' literarischem Werk lassen sich viele und sehr unterschiedliche Bildauseinandersetzungen finden. Paolo Caneppeles Buch »Die Republik der Träume. Bruno Schulz und seine Bilderwelt $\aleph^{18}$ listet eine lange Reihe an nachweisbaren oder potentiellen Bildvorlagen für Schulz' Erzählungen wie Werbebilder, Malerei und Postkarten auf. Mit Fokus auf die expressionistische Malerei und Literatur hat auch Jerzy Speina schon 1974 in seinem Buch »Bankructwo realności« Gemälde und theoretische Subtexte für die Erzählungen identifiziert. ${ }^{19}$ Beide erkennen in der Darstellung des nächtlichen Sternenhimmels in der titelgebenden Erzählung "Sklepy cynamonowe« (Die Zimtläden) ein van Gogh-Zitat samt Farbauftrag und Komposition. ${ }^{20}$

13 Vgl. Kato, Ariko: Obraz i Księga: O autoreferencyjności w twórczości Brunona Schulza. In: Kitowska-Łysiak, Małgorzata (Hg.): Białe plamy w SCHULZologii. Lublin 2010, 151-182.

14 Vgl. Freise, Matthias: Bruno Schulz zwischen Literatur und Bildender Kunst: Versuch einer Annäherung. In: Schwaetzer, Harald (Hg.): Aisthesis. Die Wahrnehmung des Menschen; Gottessinn Menschensinn Kunstsinn; ein interdisziplinäres Symposion. Regensburg 1999, 113-134.

15 Vgl. Van Heuckelom, Kris: In Defense of Idolatrous Creativity: Bruno Schulz's Xięga Bałwochwalcza and Traktat o manekinach albo Wtóra Księga Rodzaju. In: Latek, Stanisław (Hg.): Bruno Schulz. New readings, new meanings [proceedings of the International Conference, Montréal, Québec, Canada, May 4-5, 2007]. Montréal 2009, 69-83, sowie Van Heuckelom, Kris: Artistic Crossover in Polish Modernism. The Case of Bruno Schulz's Xięga Bałwochwalcza (The Idolatrous Booke). Online Magazine of the Visual Narrative - ISSN 1780-678X 2006, http://www.imageandnarrative.be/inarchive/iconoclasm/ heuckelom.htm vom 30.1.2012.

16 Vgl. Kitowska-Łysiak, Małgorzata: Bruno Schulz - ১Xięga Bałwochwalcza`: wizja forma - analogie. In: Kitowska-Łysiak, Małgorzata (Hg.): Bruno Schulz in memoriam. Lublin 1992, 133-151.

17 Vgl. Sikorski, Dariusz K.: Symboliczny świat Brunona Schulza. Słupsk 2004.

18 Vgl. Caneppele, Paolo: Die Republik der Träume. Bruno Schulz und seine Bilderwelt. Graz 2010.

19 Vgl. Speina, Jerzy: Bankructwo realności. Proza Brunona Schulza. Warszawa, Poznań 1974.

20 Auf die Ähnlichkeit in Motiv und Stil zwischen den gemalten Nachthimmeln van Goghs und den beschriebenen Himmeln in den Erzählungen »Wiosna» und »Sklepy cynamonowe " haben sowohl Speina als auch Caneppele hingewiesen. Vgl. ebd., 25; 99. Siehe ebenfalls Caneppele, Die Republik der Träume, $15 \mathrm{f}$. 
Darüber hinaus finden sich Ekphraseis ${ }^{21}$ von Gemälden der "Neapolitanischen Schule« in der Erzählung »Druga jesień« (Der andere Herbst), die mit dem Wolkenhimmel und Theatervorhängen und -kulissen in Beziehung gebracht werden. Rembrandt, Dürer und Breughel werden in Schulz' Prosa auch namentlich erwähnt. ${ }^{22}$

In »Manekiny« (Die Schneiderpuppen) und auch in »Wiosna» (Der Frühling) werden Schneiderpuppen und Wachsfiguren in ihrer Identität und Eigenart untersucht. In ihrem Werk »Erzählte Phantastik« ${ }^{23}$ untersucht Renate Lachmann die häretischen Schöpfungsexperimente des Vaters, die er auf Grundlage der Schneiderpuppe beginnt, im Kontext eines für Schulz typischen Mythen-Synkretismus. Dass für die Erzählung "Księga« (Das Buch) verschiedene Reklamen aus der Zeit der Habsburger Monarchie als Vorbild dienten, ist nicht zuletzt durch die Forschungsarbeit von Kitowska-Łysiak bekannt. ${ }^{24}$ In der Erzählung »Ulica Krokodyli« (Krokodilstraße) sind es hingegen unbestimmte Bilder der Illustrierten und Modemagazine, die untersucht werden.

Trotz dieser vielen Bildbezüge äußert sich Schulz in seinen theoretischen Schriften und auch in seinen Literaturkritiken ${ }^{25}$ zur Malerei- oder Bildtheorie eher selten; anders als zur Sprache und Poetologie. ${ }^{26}$ In seinem offenen Brief an Stanisław Ignacy Witkiewicz erörtert Schulz den Ursprung seiner Bilder und von Bildern im Allgemeinen und verortet diese doppelt im mythologischen Nebel (der Kindheit) wie in literarischen Quellen. Anschließend betont er, dass sein Bildwerk eng mit seiner Prosa verknüpft ist, er sich aber in der Prosa vollständiger ausgedrückt habe. ${ }^{27}$

21 Die Ekphrasis ist eine aus der Antike stammende Form des Sprechens, die ein Visualisieren eines Vorgangs, Gegenstandes oder Bildes zum Ziel hatte. Dadurch wurde der Zuhörer zum Zuschauer. Im Laufe der Geschichte hat sich die gängige Bedeutung der Ekphrasis jedoch verändert. Heute bezeichnet sie vor allem eine sprachliche Wiedergabe eines Gemäldes. Vgl. Ekphrasis. In: Pfisterer, Ulrich (Hg.): Lexikon Kunstwissenschaft. Ideen, Methoden, Begriffe. Stuttgart 2003, 76-80.

22 Vgl. Schulz, Bruno: Sanatorium pod Klepsydrą. In: Jarzębski, Jerzy (Hg.): Proza. Kraków 1973, hier 219, 287, 300.

23 Vgl. Lachmann, Renate: Erzählte Phantastik. Zu Phantasiegeschichte und Semantik phantastischer Texte. Frankfurt a.M. 2002.

24 Vgl. Kitowska-Łysiak, Małgorzata: Schulzowskie marginalia. Lublin 2007, 47-64.

25 In einer Rezension schreibt er, es sei der Verdienst der Schriftstellerin Maria Kuncewiczowa, dass sie in ihrem Roman »Cudzoziemka« (Die Fremde) das Porträt einer Frau wie ein Rembrandt-Bild gemalt habe. Vgl. Schulz, Bruno: Aneksja podświadomości: (Uwagi o Cudzoziemce Kuncewiczowej). In: Kitowska-Łysiak, Małgorzata (Hg.): Szkice krytyczne. Lublin 2000, 34-41, hier 34.

26 Vgl. Schulz, Bruno: Mityzacja rzeczywistości. In: Kitowska-Łysiak: Szkice krytyczne, $11 \mathrm{f}$.

27 Vgl. Schulz, Bruno: Bruno Schulz do St. I. Witkiewicza. In: Kitowska-Łysiak: Szkice krytyczne, 18-21, hier 19. 
»Auf die Frage, ob in meinen Zeichnungen derselbe Einschlag sich offenbart wie in der Prosa, möchte ich bejahend antworten. Es ist doch auch dieselbe Wirklichkeit, nur in einem etwas anderen Ausschnitt. Das Material und die Technik wirken hier als selektives Filter. Die Zeichnung setzt durch ihr Material engere Grenzen als die Prosa. Deshalb glaube ich, mich in der Prosa vollständiger ausgesprochen zu haben. ${ }^{28}$

Dieser Selbsteinschätzung zum Trotz gibt es nur wenige Forschungsarbeiten, die das Werk unter einer verbindenden Fragestellung beleuchten. $\mathrm{Zu}$ diesen wenigen gehört Janis Augsburger mit ihrer Dissertation »Masochismen. Mythologisierung als Krisen-Ästhetik bei Bruno Schulz « ${ }^{29}$ (2008), deren Klammer eine "masochistische Ästhetik« darstellt, die sie aus der Krisenerfahrung der Zwischenkriegszeit ableitet, sowie Jan Gondowicz, der das Gesamtwerk im Kontext dionysischer Motive und Nietzeanischer Philosophie untersucht. ${ }^{30}$

Schwerpunkte der Sekundärliteratur bilden hingegen die poetische Sprache und Sprachphilosophie, zu denen eine Vielzahl von Monografien und Aufsätzen erschienen sind. ${ }^{31}$ Ein Meilenstein in der Erforschung der Poetologie bildet Boleckis Untersuchung von Schulz' Prosa vor dem Hintergrund der polnischen Avantgarde. ${ }^{32}$ Nicht weniger wichtig, gerade im Zusammenhang mit der Sprache, sind die vielen Arbeiten mit theologischen, kabbalistischen oder auch jüdisch-modernistischen Fragestellungen. Karen Underhill beispielsweise vergleicht Schulz in ihrer Dissertation »Bruno Schulz and Jewish Modernity ${ }^{33}$ (2011) mit Walter Benjamin und erarbeitet auf Grund-

28 Schulz, Bruno: Bruno Schulz an St. I. Witkiewicz. (Aus dem Poln. v. Mikolaj Dutsch u. Josef Hahn). In: Ficowski, Jerzy (Hg.): Gesammelte Werke. Die Wirklichkeit ist Schatten des Wortes. Aufsätze und Briefe. München 1992, 89-93, hier 91. »Na pytanie, czy w rysunkach moich przejawia się ten sam wątek, co w prozie, odpowiedziałbym twierdząco. Jest to ta sama rzeczywistość, tylko różne jej wycinki. Materiał, technika działają tutaj jako zasada selekcji. Rysunek zakreśla ciaśniejsze granice swym materiałem niż proza. Dlatego sądzę, że w prozie wypowiedziałem się pełniej.«Schulz, Bruno Schulz do St. I. Witkiewicza, 19.

29 Vgl. Augsburger, Janis: Masochismen. Mythologisierung als Krisen-Ästhetik bei Bruno Schulz. Humboldt-Univ., Diss. Berlin, 2006. Hannover 2008.

30 Vgl. Gondowicz, Schulz.

31 Mit zu den ersten Forschern, die die besondere Sprache und Ästhetik von Schulz untersucht haben, gehört Wiesław Szymański, der Schulz' Sprache im Kontext der Zeit untersucht. Vgl. Szymański, Wiesław P.: Outsiderzy i słowiarze. Wrocław 1973, 97-120. Die Sprachursprungstheorie und den Zusammenhang zur polnischen Avantgarde untersucht Herta Schmid. Vgl. Schmid, Herta: Sprachursprungstheorien bei Bolesław Leśmian und Bruno Schulz. In: Grözinger, Karl E. (Hg.): Sprache und Identität im Judentum. Wiesbaden 1998, 43-57.

32 Vgl. Bolecki, Włodzimierz: Poetycki model prozy w dwudziestoleciu międzywojennym. Wrocław [u.a.] 1982, 170-242.

33 Vgl. Underhill, Karen: Bruno Schulz and Jewish Modernity. Dissertation. 
lage von Michael Löwys Thesen ${ }^{34}$ eine spezifisch jüdisch modernistische Lesart. ${ }^{35}$ Adam Lipszyc liest im Kapitel seines Buches »Rewizja procesu Józefiny K. « ${ }^{36}$ (2011) (Revision des Prozesses von Józefina K.) Schulz' Literatur mithilfe Benjaminscher Hermeneutik. Władysław Panas deutet in seiner Monografie "Księga Blasku «"37 (Buch des Glanzes) Schulz' Werk im Kontext der Kabbala. Wesentliche Ideengeber sind ihm Gershom Scholems Arbeiten, insbesondere über die Lurianische Mystik. Jörg Schulte hingegen liest die Prosa im rabbinischen Narrativ einer Kalender-Chronik. ${ }^{38}$ Die chassidischen Bezüge hat Alfred Sproede herausgearbeitet. ${ }^{39}$

Verschiedene Konferenzbände wie "Bruno Schulz in memoriam ${ }^{40}$ (1992), "Czytanie Schulza ${ }^{41}$ (1994) (Schulz lesen), »W ułamkach zwierciadła « ${ }^{42}$ (2003) (In den Scherben des Spiegels), »(Un)masking Bruno Schulz «3 (2009), »Bruno Schulz. New readings $\ll^{44}$ (2009), »Białe plamy w Schulzologii ${ }^{45}$ (2010) (Weiße Flecken in der Schulzologie) sowie "Schulz forum $\aleph^{46}$ (2013) zeigen, dass das Interesse an Schulz ungebrochen ist. Trotz dieser umfassenden Sekundärliteratur behauptet Michał Paweł Markowski in seinem 2013 veröffentlichten

34 Vgl. Löwy, Michael: Erlösung und Utopie. Jüdischer Messianismus und libertäres Denken. Eine Wahlverwandtschaft. Berlin 2002.

35 Monika Tokarzewskas Aufsatz vergleicht Bruno Schulz und Walter Benjamin. Sie konzentriert sich dabei auf die Untersuchung der kabbalistischen Motive. Vgl. Tokarzewska, Monika: Bruno Schulz i Walter Benjamin: Między zachodnioeuropejską metropolią a środkowoeuropejską prowincją. In: przegląd filozoficzno-literacki (2010), 243-263.

36 Vgl. Lipszyc, Adam: Rewizja procesu Józefiny K. i inne lektury od zera. Warszawa 2011, 64-80.

37 Vgl. Panas, Władysław: Księga blasku. Traktat o kabale w prozie Brunona Schulza. Lublin 1997.

38 Vgl. Schulte, Jörg: Eine Poetik der Offenbarung. Isaak Babel’ Bruno Schulz Danilo Kiš. Wiesbaden 2004.

39 Vgl. Sproede, Alfred: Between Avantgarde and Hassidic Redemption. In: De Bruyn, Dieter/Van Heuckelom, Kris (Hg.): (Un)masking Bruno Schulz. New combinations, further fragmentations, ultimate reintegrations. Amsterdam 2009, 473-498.

40 Vgl. Kitowska-Łysiak, Małgorzata (Hg.): Bruno Schulz in memoriam. Lublin 1992.

41 Vgl. Jarzębski, Jerzy (Hg.): Czytanie Schulza. Materiały Międzynarodowej Sesji Naukowej Bruno Schulz - w Stulecie Urodzin i w Pięćdziesięciolecie Śmierci, Kraków, 8-10 czerwca 1992. 1. Aufl. Kraków 1994.

42 Vgl. Kitowska-Łysiak, Małgorzata/Panas, Władysław (Hg.): W ułamkach zwierciadła. Bruno Schulz w 110 rocznicę urodzin i 60 rocznicę śmierci. Lublin 2003.

43 Vgl. De Bruyn, Dieter/Van Heuckelom, Kris (Hg.): (Un)masking Bruno Schulz. New combinations, further fragmentations, ultimate reintegrations. Amsterdam 2009

44 Vgl. Latek, Stanisław (Hg.): Bruno Schulz. New readings, new meanings [proceedings of the International Conference, Montréal, Québec, Canada, May 4-5, 2007]. Montréal 2009.

45 Vgl. Kitowska-Łysiak, Małgorzata (Hg.): Białe plamy w SCHULZologii. Lublin 2010.

46 Vgl. Fundacja Terytoria Książki (Hg.): Schulz forum. Gdańsk 2013. 
Aufsatz »Schulz - pisarz jako filozof» (Schulz - Der Schriftsteller als Philosoph), dass die Forschung nach wie vor am Anfang sei. ${ }^{47}$

»Meiner Meinung nach hat bis zu diesem Zeitpunkt noch niemand Schulz philosophisch gelesen, das heißt, so gelesen, wie er es verdient; niemand hat zugegeben, dass Schulz uns etwas sehr Wichtiges zu sagen hat, über die Welt, über uns, darüber, wie die Wirklichkeit gebaut ist, welchen Sinn das alles hat und wie wir uns in dem Ganzen wiederfinden sollten. $\aleph^{48}$

Auch wenn Markowskis Kritik zu weit geht, so ist seine Forderung nach neuen Deutungsansätzen berechtigt. Vor allem biografische Lesarten - wie sie für Schulz' Werk bis heute häufig sind - verstellen den Blick für die inhärente Gesellschaftskritik, aber auch für viele philosophische Fragestellungen. Die Kunsthistorikerin Kitowska-Łysiak beispielsweise, die sich am ausführlichsten mit dem Bildwerk von Schulz befasst hat, übernimmt teilweise die biografische Deutung und spricht den Grafiken darüber hinaus einen gesellschaftlichen Kontext ab. ${ }^{49}$

"Bruno Schulz ist hingegen kein Illustrator der Epoche. Seine Werke sind frei vom sogenannten gesellschaftlichen Kontext. Sie stellen ein Bild der eigenen Erlebnisse und Erfahrungen des Autors dar. ${ }^{50}$

Diese Deutung gilt es in dieser Arbeit zu hinterfragen. So soll Markowskis Aufruf eine Ermutigung sein, in einem überfischten Gewässer dennoch auf die Jagd nach einem großen Fang zu gehen. Die gute Forschungslage nutzend soll daher eine der übergeordneten Ideen bearbeitet werden, die so zentral für das Werk ist und dennoch im Schatten der Sprache bisher ein kaum beleuchtetes Dasein fristete - die Bildidee.

47 Vgl. Markowski, Michał P.: Schulz - pisarz jako filozof. In: Fundacja Terytoria Książki (Hg.): Schulz forum. Gdańsk 2013, 7-14, hier 9-11.

48 »Moim zdaniem nikt do tej pory nie przeczytał filozoficznie Schulza, to znaczy nie przeczytał tak, jak on na to zasługuje; nikt nie uznał, że Schulz ma coś bardzo ważnego nam do powiedzenia o świecie, o nas samych, o tym, jak zbudowana jest rzeczywistość, jaki to wszystko ma sens i jak my w tym wszystkim powinniśmy się odnaleźć.« Ebd., 10. (Übers. A.J.)

49 Sie liest das Werk sehr biografisch und psychoanalytisch. Vgl. Kitowska-Łysiak, Schulzowskie marginalia, 20-26. Während Schulz' Vorbilder wie Goya moralisierende und erzieherische Bilder angefertigt hätten, seien Schulz' vergleichbar drastische Darstellungen masochistisch und dienten der Selbsttherapie. Vgl. Kitowska-Łysiak, Bruno Schulz, $136-138$.

50 Ebd., 148. „Bruno Schulz nie jest natomiast ilustratorem epoki [...]. Jego prace pozbawione są tak zwanej wymowy społecznej. Stanowią [...] obraz własnych przeżyć i doświadczenia autora.« (Übers. A.J.) 


\subsection{Thesen und Fragestellungen}

Schulz setzt sich in seinem Gesamtwerk intensiv mit den Bedingungen des Bilderschaffens, aber auch mit der Existenz von Bildern und ihrer Verwandlung auseinander. Ihr Ursprung, ihr Wirken, Werden und Vergehen werden in unterschiedlichen Ausschnitten seines prosaischen wie bildnerischen Werks untersucht. Dabei geht es ihm nicht allein um materielle Bilder wie Fotografien, Gemälde und Zeichnungen, sondern auch um die sogenannten »inneren Bilder ${ }^{51}$ wie Träume, Erinnerungen und Vorstellungen. ${ }^{52}$ Beide sind gleichermaßen Quellen und geistiges Material für den schaffenden Künstler sei er Bildhauer, Maler oder Schriftsteller. ${ }^{53}$

Die dieser Arbeit zugrundeliegende Ausgangsthese lautet, dass Schulz in seiner Gegenwart ein »Erstarren der Bilder« wahrnimmt, welchem er versucht entgegenzutreten, indem er programmatisch und auf vielfältige Weise die Funktion, das Wirken, die Wandlung und die Gefahr von Bildern aufzeigt und hinterfragt. »Erstarren« bedeutet in diesem Zusammenhang eine Vereindeutigung des Bildes, das heißt, dass Bilder ähnlich wie Sprache zunehmend als abbildendes Zeichen für etwas wahrgenommen werden. Auf diese Tendenz antwortet Schulz, indem er mit den verschiedenen Möglichkeiten, Bilder in Sprache zu vermitteln, zu untersuchen und sogar zu malen, experimentiert.

Eine wichtige Rolle spielt dabei der zeitliche, philosophische und gesellschaftliche Kontext, auf den sich Schulz in seinen Essays und Literaturkritiken immer wieder explizit bezieht, der aber auch in der Literatur und auf den Bildern sichtbar wird. Es soll die Frage beantwortet werden, inwiefern Schulz seine Bilduntersuchungen im Licht spezifischer, zeitgenössischer Entwicklungen vollzieht. Welche Rolle spielen dabei die Erfindung der Fotografie, der Einfluss des Positivismus und der Werbeindustrie ${ }^{54}$ für das moderne Bildverständnis?

51 Dieser Begriff kommt aus Beltings "Bild-Anthropologie« und bezeichnet jene Bilder, die noch nicht die Grenze vom Menschenkörper zur Umwelt überschritten haben. Vgl. Belting, Hans: Bild-Anthropologie. Entwürfe für eine Bildwissenschaft. München 2001, 11.

52 Diese Trennung sieht auch Belting in seiner »Bild-Anthropologie« vor. Die Grenze zwischen inneren und äußeren Bildern ist der menschliche Körper. Vgl. ebd.

53 Das "Wörterbuch der unübersetzbaren Begriffe" führt auch das deutsche Wort "Bild» und zeigt den großen Bedeutungsreichtum auf, der mit diesem Begriff gemeint sein kann. Begonnen vom biblischen Gebrauch in der Bedeutung »zelem» oder »demut» als »Ebenbild«, über das Griechische »eidolon«, in welchem sich das Idol wiederfindet, zum Lateinischen Imago, gibt »Bild « im Deutschen eine große Variationsbreite an Bedeutungen wieder. Siehe Bild. In: Cassin, Barbara (Hg.): Dictionary of Untranslatables. A Philosophical Lexicon. Princeton, NJ [u. a.] 2014.

54 Walter Benjamin hat sich in seinen Forschungen dieser Frage gestellt und bringt verschiedene Aspekte in einen Zusammenhang. Dabei zeigt er auch auf, welchen Einfluss 
Einen zweiten wichtigen Kontext bildet die Kunsttradition und -theorie. In seinem plastischen und literarischen Werk zitiert Schulz immer wieder Gemälde von Tizian, Rembrandt und van Gogh. Gleichzeitig unterlegt er sein Werk mit deutlich erkennbaren mythischen und biblischen Subtexten, die er in aktuelle Fragestellungen überführt. Die darin prominenten Bild-Begriffe, wie sie sich im Pygmalion-Mythos oder im biblischen Bilderverbot finden, werden wiederum in beiden Ausdrucksbereichen beleuchtet. Gerade im Bezug zum zeitgenössischen Kontext stellt sich die Frage, welche Bedeutung diese Motive in Schulz' Gegenwart haben und wie er sie in einen sinnvollen Zusammenhang bringt.

Eine zentraler Bereich ist die Beziehung des Bildes zur Sprache in Schulz' Werk. Da sowohl seine poetische Sprache besonders bildaffin ist, aber auch die Bilder starke Bezüge zum Sprachlichen aufweisen, soll untersucht werden, ob von einer $»$ Rettung ${ }^{55}$ des Bildes gesprochen werden kann. Die Wortwahl bezieht sich dabei direkt auf den Kulturphilosophen Benjamin, der in seinen Schriften zu Kunst und Geschichte eine Idee der "Rettung « entwickelt. ${ }^{56}$ »Rettung « heißt, dass eine in einer bestimmten Gegenwart stattfindende Umschichtung von Bedeutungen, Begriffen oder Vorstellungen wahrgenommen, reflektiert und tradiert wird..$^{57}$ Eine Umschichtung verändert die kollektive Auffassung eines »Normalen«, weshalb anschließend die Schwierigkeit besteht, die frühere Erfahrung einer späteren Generation zugänglich zu machen. ${ }^{58}$ Die große Herausforderung ist es also, eine Form zu finden, in der jener frühere Begriff kontrastiv und verständlich zum neu etablierten steht und

diese Entwicklungen auf das Kunstbild und sein Selbstverständnis haben. Vgl. Benjamin, Walter: Anmerkungen zu Malerei und Photographie. In: Tiedemann, Rolf (Hg.): Gesammelte Schriften VII. Nachträge. Frankfurt a. M. 1991, 815-823, hier 819.

55 Vgl. Benjamin, Walter: Das Passagen-Werk. In: Tiedemann, Rolf (Hg.): Gesammelte Schriften V. Das Passagen-Werk. Frankfurt a. M. 1991, hier 576.

56 Vgl. Mosès, Stéphane: Benjamins Judentum. In: Weidner, Daniel (Hg.): Profanes Leben. Walter Benjamins Dialektik der Säkularisierung. Berlin 2010, 141-151, hier $144 \mathrm{f}$.

57 Vgl. Kaulen, Heinrich: Rettung und Destruktion. Untersuchungen zur Hermeneutik Walter Benjamins. Tübingen 1987, $19 \mathrm{f}$.

58 Hans Blumenberg, der den Wirklichkeitsbegriff im Kontext der Entwicklungen in der Literatur untersucht, definiert hierzu: »in dem Augenblick, in dem einem praktischen Verhalten, einem theoretischen Satz ihr Realitätsbezug bestritten wird, kommt zutage, unter welchen Bedingungen jeweils von Wirklichkeit gesprochen werden kann. Also gerade dadurch, daß dem poetischen Gebilde von allem Anfang unserer Tradition an seine Wahrheit bestritten worden ist, ist die Theorie von der Dichtung zu einem systematischen Ort geworden, an dem der Wirklichkeitsbegriff kritisch hereinspielen und aus seiner präformierten Implikation heraustreten muß. Im Grunde geht es um das, was einer Epoche als das Selbstverständlichste und Trivialste von der Welt erscheint und was ausgesprochen ihr nicht der Mühe wert wird, was also gerade deshalb die Stufe der überlegten Formulierung kaum je erreicht.« Blumenberg, Hans: Wirklichkeitsbegriff und Möglichkeit des Romans. In: Jauß, Hans R./Forschungsgruppe Poetik und Hermeneutik (Hg.): Nachahmung und Illusion. München 1964, 9-27, hier 10. 
beide sich gegenseitig erhellen. ${ }^{59}$ Man kann dies auch als zeitverständliche Übersetzung einer vergangenen "Selbstverständlichkeit» begreifen. Ziel ist es, damit ein kritisches Licht auf die Gegenwart zu werfen und ihre Konventionen als solche sichtbar zu machen. ${ }^{60}$ Gleichzeitig werden so aber auch ältere Haltungen und Bedeutungen aufgezeigt, die sich in eine neue Form verschoben haben. ${ }^{61}$

Die "Rettung" des Bildes impliziert also eine Sichtbarmachung gegenwärtiger und älterer Bild-Begriffe. Rettung im Wort ist eine Erweiterung dieser Idee, die davon ausgeht, dass diese Rettung nicht durch eine "puristische« Bildvorstellung zustande gebracht werden kann, sondern im Gegenteil, durch die Betonung und Überzeichnung der Beziehung zum Sprachlichen. Auf verschiedenen Ebenen soll dies untersucht werden. Erstens in Bezug auf die spezifischen Medien $^{62}{ }^{62}$ Bild und Sprache, die Hülle oder Träger eines Anschaulichen oder Diskursiven sind. Hans Belting unterscheidet in seiner "Bild-Anthropologie« das Medium (picture) vom Bild (image). Hier stellt sich die Frage, wie sich das Medium Sprache zum Bild verhält. Und anders herum, wie sich das Medium Bild (Grafik, Malerei, Zeichnung, Fotografie) zum Diskursiven, Theoretischen und Erzählten verhält. Inwieweit können beide ihre Mittel dem Gegenstand so anpassen, dass eine »Übersetzung " eines Bildes in Sprache und eines Gedankens ins Bild gelingt?

Nicht weniger wichtig als die Beobachtung der Medien, ist die Untersuchung der Bild- und Sprachbegriffe im Kontext einer Beziehung zum Menschen. Was passiert mit der Wahrnehmung der Wirklichkeit, wenn die Medien der Bilder, die Bedeutung der Begriffe ${ }^{63}$ und die Beziehung von Sprache und Bild verändert werden? Die vielfältigen Manipulationen von Wahrnehmung, Perspektive, Bedeutungskontext sowie Zeit- und Raumvorstellung, die sich in Schulz' Werk finden, lassen sich auch als Manipulation an der Vorstel-

59 Vgl. Kaulen, Rettung und Destruktion, 11.

60 Vgl. Habermas, Jürgen: Bewußtmachende oder rettende Kritik - die Aktualität Walter Benjamins. In: Unseld, Siegfried (Hg.): Zur Aktualität Walter Benjamins. Aus Anlaß des 80. Geburtstags von Walter Benjamin. Frankfurt a. M. 1972, hier 189.

61 Vgl. Benjamin, Das Passagen-Werk, $112 \mathrm{f}$.

62 Medialität bedeutet, dass Bilder nicht als Reales, sondern als Vermitteltes wahrgenommen werden. Sie werden über bestimmte Medien transportiert - die Malerei, die Grafik oder die Fotografie. Nach Belting realisiert jedes Medium ein Bild nach bestimmten Möglichkeiten seines Ausdruckscharakters. Reklamebilder, die häufig im fotografischen Medium realisiert werden, haben die Tendenz, ihre Medialität transparent werden zu lassen, sodass der Betrachter die Gemachtheit vergisst. Vgl. Boehm, Gottfried: Wie Bilder Sinn erzeugen. Die Macht des Zeigens. Darmstadt 2010, 15.

63 Historischer Index ist ein Begriff von Benjamin und bedeutet, dass alle Gegenstände, aber auch alle Worte und Bilder in der Geschichte sind. Sie sind nicht allein, was sie in einem Moment bedeuten, sondern tragen auch frühere Bedeutungen an sich. Vgl. Benjamin, Das Passagen-Werk, $577 \mathrm{f}$. 
lung Bild und Sprache deuten. Der Mensch bleibt immer Referenzfigur, die dargestellte Wirklichkeit richtet sich stets an ihn.

Welche Rolle spielt in diesem Zusammenhang das Mythisieren, auf welches Schulz immer wieder zu sprechen kommt, wenn er beispielsweise seine Literatur als "private Mythologie « ${ }^{64}$ bezeichnet? Dabei fällt auf, dass Schulz der empirischen und intersubjektiven Wahrnehmung häufig eine subjektive, voranalytische Wahrnehmung entgegensetzt. Wahrnehmungsmomente sind häufig mit diskursiven Metaerklärungen verflochten. Damit vernichtet er immer wieder die Illusionen, die er zuvor mühevoll errichtet. Wie genau diese vielen paradoxen Verflechtungen von Theorie und Praxis, von Bild und Sprache, von Illusion und Illusionsbruch zusammenhängen, sollte am Ende dieser Analyse deutlich werden.

\subsection{Werkproblematik und biografische Kontextualisierung}

»Ich bin Maler von der Ausbildung her und aus Berufung und, wie es in der bildenden Kunst manchmal so ist, bin ich seit einer gewissen Zeit, geleitet von einem inneren Impuls und einem Bedürfnis nach Ausdruck, auf einen Weg literarischer Versuche und Experimente gewiesen worden. ${ }^{65}$

Die folgende Skizze der Künstlerkarriere und Kontakte von Schulz dient der Kontextualisierung. Dieser Arbeit liegt die Annahme zugrunde, dass weniger seine persönliche Einsamkeit ${ }^{66}$, gestörte Sexualität ${ }^{67}$ oder Provin-

64 So deutet Schulz selbst seine »Sklepy cynamonowe« in einem Exposé seines Erzählbandes. Schulz, Bruno: Exposé über das Buch `Zimtläden`von Bruno Schulz. In: Ficowski (Hg.): Gesammelte Werke, 325-327, hier 326.

65 Schulz, Bruno: Brief an das Kuratorium des Lemberger Schulsprengels vom 20.3.1935. (Aus dem Poln. von Mikolaj Dutsch). In: Ficowski (Hg.): Gesammelte Werke, 15f., hier 15. "Jestem malarzem z wykształcenia i powołania i, jak to się czasem zdarza w ewolucji artystycznej plastyków, skierowany zostałem od pewnego czasu przez impuls wewnętrzny i potrzebę wyrazu na drogę prób i eksperymentów literackich.«Ficowski, Jerzy (Hg.): Księga listów. 3. Aufl. Gdańsk 2008, 219.

66 Mehrere Interpreten stellen die Einsamkeit als Spezifikum von Schulz' Biografie und Literatur heraus. Grund hierfür ist mitunter die Erzählung »Samotność« (Einsamkeit), die Schulz zuvor unter dem Titel »O sobie« (Über mich) veröffentlicht hat. Da er darüber hinaus sein Werk als autobiografisch bezeichnet hat, wird dieses sehr häufig biografisch gelesen und dieser zusätzliche Hinweis gewinnt daher verstärktes Gewicht. Vgl. Lipszyc, Rewizja procesu Józefiny K., 71.

67 Gondowicz beispielsweise ist der Auffassung, Schulz' Bildkunst sei aus den Tiefen seiner Psychologie entsprungen. Deswegen hätten ihn auch Witkiewicz und Nałkowska entdeckt, deren Werk ebenso durch den ersten Weltkrieg beeinflusst und deren Biografien durch die Erfahrung des Symbolismus und der Psychoanalyse geprägt worden seien. 
zialität $^{68}$ sein Werk bestimmen, sondern vielmehr seine Teilhabe an den greifbaren, europäischen Geistesströmungen und Debatten über philosophische Fragen. Schulz hatte leichten Zugang zu den Erfahrungen seiner Zeitgenossen in Berlin, Wien, Krakau und Warschau, da er einerseits viel reiste und mehrere Sprachen beherrschte, ${ }^{69}$ andererseits die Entwicklungen der Moderne auch in Drohobycz stattfanden. Drittens schreibt sich sein Werk in eine europäische Moderne ein und auch die Schriftsteller und Künstler, auf die er sich beruft, sind in der Regel Zeitgenossen, die heute zu den Größen der europäischen Literatur zählen. ${ }^{70}$

Schulz' erhaltenes künstlerisches Gesamtwerk umfasst heute zwei Erzählbände sowie drei einzeln veröffentlichte Erzählungen, einen Grafikzyklus, hunderte von Zeichnungen, eine umfangreiche Sammlung an literaturkritischen Essays und kurzen philosophischen Betrachtungen, eine Anzahl an Briefen und genau ein Ölgemälde. Bedacht werden müssen aber auch die vernichteten und verschollenen Briefe, Erzählungen und Bilder sowie unvollendete Vorhaben. ${ }^{71}$ Unter den verlorengegangenen Schriften befinden sich auch die auf Deutsch verfasste Erzählung »Die Heimkehr« und die Skizzen

Gondowicz zufolge, erkannten sie daher im Gegensatz zu anderen Kritikern, die Schulz Realismus und Traditionalismus unterstellten, auch das innovative Potential seiner Bilder, das Neue an ihnen. Schulz' Bildkunst persönlich zu nennen ist Gondowicz zufolge zu wenig, sie sei intim. Vgl. Gondowicz, Schulz, 16.

68 Sandauer ist der Auffassung, Schulz sei niemals aus seiner Kleinstadthematik herausgekommen und habe sich nie von den Vorzügen der Provinz befreit. Vgl. Sandauer, Artur: Rzeczywistość degradowana: (Rzecz o Brunonie Schulzu). In: Jarzębski, Jerzy (Hg.): Proza. Kraków 1973, 6-35, hier 18.

69 Neben muttersprachlichem Polnisch und Deutsch lernte er in der Schule Altgriechisch und Latein, womöglich Hebräisch im Religionsunterricht. In französischer Sprache ist ein auf den 3.8.1938 datierter Brief von Schulz an Elio Ganzerlo erhalten, der auch Kenntnisse des Französischen nachweist. Dieser befindet sich im Literaturarchiv und wurde als Kopie auch im Ausstellungskatalog abgedruckt. Vgl. Chmurzyński, Wojciech (Hg.): Bruno Schulz 1892-1942. Katalog-Pamiętnik Wystawy Bruno Schulz. Ad. Memoriam w Muzeum Literatury im. Adama Mickiewicza w Warszawie. Warszawa 1995, 152.

70 In seinen Briefen weist Schulz immer wieder auf seine Begeisterung für Rainer Maria Rilke, Franz Kafka und Thomas Mann hin. Vgl. Schulz, Księga listów, 59. Gerade Mann beeinflusst Schulz insbesondere mit seinen Joseph-Romanen, in denen Mann sich intensiv mit jüdischer Tradition und Mythologie auseinandersetzt. Schulz liest Manns Literatur nicht nur begeistert, sondern kommentiert sie auch in seinem Werk. Lipowski weist auf den Einfluss Alfred Kubins und seines Romans »Die andere Seite« hin. Vergleichbar macht beide nicht nur ihre Doppelbegabung, sondern auch die Thematisierung der Frau im grafischen Werk, die Utopie einer alternativen Traumwirklichkeit sowie die Atmosphäre des Verfalls und Untergangs im literarischen Werk. Vgl. Lipowski, Krzysztof: Demiurg jest dwoistością. Alfred Kubin i Bruno Schulz - próba porównania. In: Fundacja Terytoria Książki (Hg.): Schulz forum. Gdańsk 2013, 35-49. Aber auch französische Literatur hat er gelesen und in seinen Kritiken kommentiert, so Aragon und Proust.

71 Eine umfangreiche Biografie, die auch die zerstörten Werke thematisiert, hat Jerzy Ficowski verfasst. Vgl. Ficowski, Regiony wielkiej herezji. 
zu einem Buchprojekt, das Schulz er unter dem Titel »Mesjasz« (Messias) veröffentlichen wollte. ${ }^{72}$

Insbesondere die Briefe lassen sich nach Ficowski zum literarischen Frühwerk des Autors zählen, da in diesen die Grundlage für die späteren Erzählungen gelegt worden sei. Der Briefwechsel zwischen Schulz und der Philosophin und Dichterin Debora Vogel $^{73}$ spielt hier eine außerordentliche Rolle, da aus diesem fast vollständig die Erzählungen der "Sklepy cynamonowe« hervorgegangen sein sollen. ${ }^{74}$ Schulz selbst unterteilt sein epistemologisches Schaffen in zwei Phasen, jene vor und jene nach der Veröffentlichung seines ersten Erzählbandes. ${ }^{75}$ Der Forschung stehen dabei fast ausschließlich Briefe aus der späteren Phase zur Verfügung, in welcher Schulz nach eigenen Angaben schon nicht mehr jene reichen und poetischen Texte verfassen konnte, die ihn zum Schriftsteller gemacht hatten. ${ }^{76}$ Verloren sind nicht nur (fast) alle Briefe von und an Debora Vogel, sondern auch der Austausch mit der Schriftstellerin und zentralen Figur der Warschauer Intellektuellenszene Zofia Nałkowska ${ }^{77}$, seinem Freund und Schriftsteller Władysław Riff ${ }^{78}$ und

72 Vgl. Mesjasz. In: Bolecki, Słownik schulzowski, 213-215.

73 Die studierte Philosophin Debora Vogel (1902-1942) ist in den 1920er und 1930er Jahren in Lemberg als Schriftstellerin und Kunsttheoretikerin tätig, veröffentlicht in polnischer und jiddischer Sprache Poesie, kleine Prosa und kunsttheoretische Aufsätze und reist viel durch Europa. Ihre Doktorarbeit verfasst sie über den »Erkenntniswert der Kunst bei Hegel und dessen Modifikation durch den polnischen Dichter Joseph Kremer« (»Znaczenie poznawcze sztuki u Hegla i jego modyfikacje u J. Kremera«) an der Jagiellonen Universität in Krakau. Vogel hat sich die jiddische Sprache erst im Erwachsenenalter aus kulturpolitischer Überzeugung heraus angeeignet. Sie ist sehr gut im Lemberger und Krakauer Milieu vernetzt, Teil der Künstlergruppe »Artes« und steht in engem Austausch mit verschiedenen Malern und Dichtern. Ihre Gedichtbände hat der galizische Künstler und Maler Henryk Streng (Marek Włodarski) mit kubistischen Drucken illustriert. Vgl. Szymaniak, Karolina: Być agentem wiecznej idei. Przemiany poglądów estetycznych Debory Vogel. Kraków 2006.

74 Vgl. Ficowski, Regiony wielkiej herezji, 59.

75 Siehe der Brief von Schulz an Romana Halpern vom 15.11.1936, vgl. Schulz, Księga listów, 134.

76 Vgl. Ficowski, Jerzy: Wprowadzenie do Księgi listów. In: Ders. (Hg.): Księga listów. 3. Aufl. Gdańsk 2008, 5-27, hier 7. Anhand einer Sequenz über den Herbst an Zenon Waśniwski lässt sich die frühere Schreibform erahnen. Vgl. Schulz, Księga listów, 74.

77 Zofia Nałkowska (1885-1954) war eine bekannte Warschauer Schriftstellerin und Publizistin. In Schulz' Leben nimmt sie vor allem deshalb eine außerordentliche Rolle ein, weil sie ihm zu seinem literarischen Beginn verhalf, indem sie seine Texte dem Verlag Rój zur Veröffentlichung vorgeschlagen hat. Sie soll auch eine erotische Beziehung mit Schulz gehabt haben. Vgl. Nałkowska, Zofia. In: Bolecki, Słownik schulzowski, $234 \mathrm{f}$.

78 Władysław Riff (1901-1927) war einer der wichtigsten Freunde von Schulz in den 1920er Jahren. Da Riff gerade sein literarisches Leben mit Erzählungen und Gedichten begann, tauschten sich beide über Themen der Literatur und Kunst aus. Er verstarb krankheitsbedingt früh und sein Nachlass wurde im Zuge der Desinfektion schon 1927 vernichtet. Vgl. Riff, Władysław. In: ebd., $311 \mathrm{f}$. 
seiner Verlobten Józefina Szelińska ${ }^{79}$, sodass Ficowski diesen Briefen in der Einleitung zu Schulz' Briefkorrespondenz mehr Raum widmen muss als den erhaltenen. ${ }^{80}$ Es ist schwer zu beurteilen, welcher Anteil des Briefwechsels fehlt, aber von drei Vierteln des Gesamtvolumens auszugehen ist vermutlich noch eine sehr vorsichtige Schätzung. ${ }^{81}$ Diesen gewaltigen Lücken zum Trotz wurde Schulz' Biografie fast ausschließlich aus den Fragmenten seiner Korrespondenz rekonstruiert:

»Fast die gesamte uns heute bekannte Biographie von Schulz wurde anhand seiner Briefe rekonstruiert, aus Erinnerungsbruchteilen jener, die länger als er lebten und aus wenigen Dokumenten. Sogar so grundlegende Fakten wie das Geburtsdatum des Schriftstellers wurden in unterschiedlichen Versionen übermittelt oder mit einem Fragezeichen versehen. ${ }^{82}$

Mitunter aus diesem Grund hält sich in vielen Publikationen nach wie vor das Gerücht, Schulz sei ein Masochist gewesen, ${ }^{83}$ obwohl schon mehrere For-

79 Józefina Szelińska (1905-1991) war Lehrerin in Drohobycz, wo sie Schulz kennenlernte und sich mit ihm verlobte. Gemeinsam teilten sie viele Freunde der polnischen Literaturund Kunstszene in Warschau, Zakopane und Lemberg. Sie gilt als die eigentliche Übersetzerin von Kafkas »Der Prozeß « ins Polnische, auch wenn diese unter Schulz' Namen veröffentlicht wurde. In ihrem Nachlass befänden sich nach Jarzębski noch einige Bilder und Erinnerungen, die die Familie aber nicht zugänglich machen wolle. Vgl. Szelińska, Józefina. In: ebd., 367-368.

80 Vgl. Ficowski, Wprowadzenie do Księgi listów, 13. In seiner Schulz-Biografie zählt Ficowski weitere Korrespondenzpartner auf, deren Briefe verloren gingen: Thomas Mann, Adam Ważyk, Emil Zegadłowicz, Joseph Roth, Bolesław Leśmian, Józef Wittlin, Wacław Berent und Samuel Lieberwerther. Vgl. Ficowski, Regiony wielkiej herezji, 203.

81 Die Tatsache, dass Schulz an Romana Halpern allein im Jahr 193821 Briefe geschrieben hat, zeigt, was für ein aktiver Briefeschreiber er gewesen ist. Aus der Zeit vor 1932 ist von der privaten Korrespondenz nur ein einziger Brief erhalten. Außerdem sind die meisten Briefe an Schulz verloren oder vernichtet, was allein schon ca. 50 Prozent seines Austausches ausmacht.

82 „Właściwie cała znana nam dziś biografia Brunona Schulza została zrekonstruowana z jego listów, z ułamkowych wspomnień tych, którzy go przeżyli, oraz z nielicznych dokumentów. Nawet tak elementarne dane, jak data urodzin pisarza, podawane były w różnych wersjach lub opatrywane znakiem zapytania."Ficowski, Wprowadzenie do Księgi listów, 5. (Übers. A.J.)

83 Das »Słownik Schulzowski« (Schulz-Wörterbuch) vermerkt unter dem Stichwort »Masochismus« die Ausprägung dieser sexuellen Orientierung, die Schulz' Privatangelegenheit geblieben wäre, wenn Artur Sandauer sie nicht zum Ausgangspunkt seiner Deutung gemacht hätte. Gleichzeitig übernimmt das Wörterbuch diese Einschätzung unkritisch und diagnostiziert Schulz einen ausgeprägten Masochismus, Fetischismus und Minderwertigkeitskomplex. Vgl. Masochizm. In: Bolecki, Słownik schulzowski, 202-204. Sandauer geht sogar so weit, Schulz' Ermordung durch die Nazis im Kontext des eigenen Todeswunsches zu lesen. Vgl. Sandauer, Rzeczywistość degradowana, 32. Ficowski verbreitet das Gerücht, dass Schulz die Grafiken als Illustrationen zur Venus angefertigt habe, um seine eigenen Phantasien zu verbergen. "Da er ihnen [den Schülern] verheim- 
scher, unter ihnen Kato, Robertson oder Augsburger, dieses Vorurteil dekonstruiert haben. ${ }^{84}$ Auch deshalb wird in dieser Arbeit ein biografisches Argumentieren weitestgehend vermieden, obwohl Schulz selbst seine Literatur als autobiografisch beschreibt. ${ }^{85}$

Viele der Mythisierungen um Schulz gehen mit einer Mythisierung der Region Galizien einher. Da die jüdische Welt im Zuge der Vernichtungen der Shoa nicht nur hinsichtlich der Bevölkerung, sondern auch der Sprachen, des Wissens, der Kultur und der Städte große Verluste erlitten hat, ist es wenig verwunderlich, dass sich ihre Geschichten nur mühsam rekonstruieren lassen. Auch emotionale Aspekte spielen dabei keine untergeordnete Rolle. ${ }^{86} \mathrm{Ge}$ rade Galizien und seine Bewohner wurden schon im 19. Jahrhundert Gegenstand vieler Projizierungen, mitunter auch verstärkt durch die Literatur seiner Einwohner. Nach Ezra Mendelsohn hätten insbesondere Karl Emil Franzos, Leopold von Sacher-Masoch und Joseph Roth zur Mythisierung der Region beigetragen. ${ }^{87}$

lichen wollte, daß die Grafiken des >Buches` seiner eigenen künstlerischen Phantasie entsprungen waren, sagte er den Knaben, es seien Illustrationen für den Roman >Venus im Pelz`von Sacher-Masoch, einem zweitrangigen österreichischen Schriftsteller, von dessen Name man den Begriff `Masochismus`ableitet, einer abwegigen Veranlagung, die Schulz selbst nicht fremd war."Ficowski, Einführende Worte zum »Götzenbuch«, 6. Auch seine Freunde Stanisław I. Witkiewicz und Witold Gombrowicz haben das Ihrige dazu beigetragen, Schulz im Kontext des Masochismus darzustellen, wobei hier durchaus eine ironische Note wahrnehmbar ist. So schreibt Witkiewicz, Schulz' Grafiken seien Poesien auf die Grausamkeit des Beins. Aber weil sich die Frauen zwei Mal am Tag die Beine waschen würden, sei es nicht ganz so schrecklich. Vgl. Witkiewicz, Stanisław I.: Wywiad z Brunonem Schulzem. In: O znaczeniu filozofii dla krytyki i inne artykuły polemiczne. Warszawa 1976, 184-188, hier 185.

84 Stellvertretend sei hier Kato genannt, die akribisch Quellen der Verwechslung beleuchtet. So habe mitunter auch die tendenziöse polnische Übersetzung von Sacher-Masochs Roman »Venus im Pelz« zur Überzeugung beigetragen, Schulz selbst sei ein Masochist. Vgl. Kato, Ariko: The Early Graphic Works of Bruno Schulz and Sacher-Masoch's Venus in Furs. In: De Bruyn/Van Heuckelom: (Un)masking Bruno Schulz, 219-249, hier 230-235.

85 Vgl. Schulz, Bruno Schulz do St. I. Witkiewicza, 20.

86 Ruth Gruber untersucht in ihrer Studie zur Wiedergeburt der jüdischen Kultur in Europa die Stereotype, die sich in der Forschung durchgesetzt hätten. Sie fokussiert dabei insbesondere auf Polen und versucht die verschiedenen Dilemmata zu erfassen, denen die Forscher gegenüberstanden. So musste eine jüdische Welt beschrieben werden, die so gar nicht mehr existierte und an deren Zerstörung Personen Anteil hatten, die nach wie vor einflussreich waren. Gleichzeitig war mit dem Ende des Krieges nicht das Ende des Antisemitismus und der Vorurteile. So mischte sich in die Forschertätigkeit häufig eine Form von Trauerarbeit. Diese konnte unterschiedlich ausfallen - von einer Glorifizierung über Mystifizierung hin zu einer Ghettoisierung der jüdischen Lebenswelt. Vgl. Gruber, Ruth E.: Odrodzenie kultury żydowskiej w Europie. Sejny 2004, 19-89.

87 "In the eyes of many, both Jews and non-Jews, the galitsianer was the very embodiment of the strange and threatening Ostjude, the East European Jew, whose outlandish dress, fanatical orthodoxy, and uncouth Yiddish speech marked him out of the civilized Jews 
Schulz' Heimatstadt Drohobycz sei, so Mendelsohn, ab der zweiten Hälfte des 19. Jahrhunderts entgegen dem Stereotyp mitnichten mehr als ein typisch jüdisches Schtetl zu verstehen. ${ }^{88}$ Vielmehr handele es sich nach Lemberg und Krakau um die wirtschaftlich drittwichtigste Stadt Galiziens. Im späten 19. Jahrhundert wurde Drohobycz schlagartig von der industriellen Revolution und dem Kapitalismus eingeholt. Durch die Ölförderung im Nachbarort Borysław veränderten sich das Stadtbild und die wirtschaftliche Situation der Bevölkerung rasant. ${ }^{89}$ Auch Mitglieder von Schulz' Familie arbeiteten in der Ölraffinerie "Galicja «. ${ }^{90}$ Die häufig anzutreffende Stilisierung Drohobyczs als Provinz ${ }^{91}$ mag demnach aus der Perspektive Warschaus begründet sein, aus galizischer Sicht allerdings handelte es sich um eine sich schnell entwickelnde Stadt und einen wichtigen Industriestandort mit einer interessanten und vielfältigen Kunst- und Literaturszene. Bruno Schulz, Maurycy und Leopold Gottlieb ${ }^{92}$, Ivan Franko ${ }^{93}$, Juliusz Wit ${ }^{94}$, Kazimierz

of the West. [...] Its rank-and-file Jewish population was also admired by some Western Jewish intellectuals for having resisted assimilationist blandishments and for remaining an sauthentic Jewish folk community, loyal to its inherently beautiful folkways." Mendelsohn, Ezra: Painting a people. Maurycy Gottlieb and Jewish art. Waltham, Mass 2002, $8 \mathrm{f}$.

88 Vgl. Mendelsohn, Ezra: Gespräch Mai 2013 in Jerusalem, Hebrew University.

89 Vgl. ebd., $20 \mathrm{f}$. Mendelsohn zitiert zur Illustrierung auch den aus Drohobycz stammenden David Horovitz, einen der Gründungsväter des Zionismus und seiner Jugendbewegung »Hashomer Hatsair.« Dieser schreibt über die Stadt: »Drohobycz was, so far as social life in the small towns of Galicia is concerned, an exceptional case. On the surface it was like all other such places: melancholy, and a gloomy atmosphere of hopelessness, reigned. All the usual elements of Galician society were present: hasids and enlightened Jews, an intelligentsia looking with curious astonishment both to the east and to the west, assimilationists entranced by the charms of foreign culture, signs of an emerging Zionist movement, liberals and conservatives, religious functionaries and merchants, rich and poor. And yet it was different, all the various elements within society had more energy than elsewhere, the pace was faster. Everything was somehow sharper, more varied, more conspicuous. It was clear that there was more drive and ferment here than in other Galician cities. The oil emerging from the ground in the neighboring small town of Borysław created social and economic change unknown elsewhere."

90 Vgl. Borysław. In: Bolecki, Słownik schulzowski, 53.

91 Sandauer, Rzeczywistość degradowana, $17 \mathrm{f}$.

92 Die Gottliebs waren Brüder und beide als Maler tätig. Internationale Bekanntheit genießt vor allem Maurycy Gottlieb (1856-1879), der gerade in der jüdischen Wahrnehmung als Maler der polnischen, jüdischen Spiritualität galt. Vgl. Mendelsohn, Painting a people, 19-44.

93 Ivan Franko (1856-1916) war ein Schriftsteller, Übersetzer und Intellektueller, der auf Ukrainisch schrieb und zur Gründung der ukrainischen Volksliteratur und -kultur beitrug.

94 Juliusz Wit (eigentl. Witkower) (1901-1942) war ein Dichter aus Drohobycz. Seine Poesie veröffentlichte er vor allem in jüdischen Publikationsorganen. Wit verfasste für Schulz ein Gedicht und Schulz für Wit eine Rezension seiner Poesie. Wit, Juliusz. In: Bolecki, Słownik schulzowski, 412-114. 
Wierzyński ${ }^{95}$ sowie E. M. Lilien sind deren bekannteste Vertreter. Betrachtet man allein die Maler, so fallen die Spannbreite der Stile und die Weltgewandtheit der Künstler auf. Während Ephraim Lilien über Berlin nach Palästina ausgewandert ist, um in Jerusalem die Kunsthochschule Bezalel mit aufzubauen, studierte und lebte Maurycy Gottlieb in Wien, Rom, München und Krakau. ${ }^{96}$ Es gab somit eine ganze Reihe möglicher Lebensentwürfe gerade in der jüdisch-säkularen Bevölkerungsschicht. ${ }^{97}$

Auch bei Schulz' Familie handelt es sich um eine an die polnische Kultur angepasste jüdische Familie ${ }^{98}$ mit Mitgliedern in Wien und Berlin. ${ }^{99}$ Dass Schulz Interesse an der chassidischen Tradition hatte, zeigt sich sowohl im literarischen als auch im plastischen Werk. ${ }^{100}$ Władysław Panas weist auch auf die vielen Anleihen der jüdischen Mystik hin, mythisiert dabei aber gleichzeitig Schulz, indem er diesen als Verkörperung einer Figur der religiösen Legenden deutet:

»Es ist schwer auf diesem Gebiet auch nur irgendwas zu beweisen, aber es gibt gewisse Hinweise, um begründet zu behaupten, dass Schulz in den Jahren zwischen

95 Kazimierz Wierzyński (1894-1969) war ein polnischer Schriftsteller und Poet sowie Herausgeber der Zeitschrift »Kultura.« Wie Tuwim war er Vertreter der Poetengruppe "Skamander." Er studierte Philosophie in Krakau und Wien und war im ersten Weltkrieg russischer Kriegsgefangener. Vgl. Dedecius, Karl (Hg.): Die Dichter Polens. Hundert Autoren vom Mittelalter bis heute. Frankfurt a. M. 1996, 176.

96 Vgl. Baskind, Samantha/Silver, Larry: Jewish Art. A Modern History. London 2011, 52-57; 70-72.

97 Es gab eine große Gruppe an Chassidim, aber ebenso Zionisten, Bundisten, Jiddischisten, Kulturzionisten sowie Bewohner jüdischer Herkunft, die ganz andere Interessen verfolgten. Vgl. Mendelsohn, Painting a people, $20 \mathrm{f}$.

98 Vgl. Lindenbaum, Shalom: Wizja mesjanistyczna Schulza i jej podłoże mistyczne. In: Jarzębski (Hg.): Czytanie Schulza, 33-67, hier 48 f. Shalom Lindenbaum verortet Schulz und sein Werk in der jüdischen Aufklärung. Er stellt die These auf, dass Schulz' Familie, beginnend mit dem Vater, sich von der Assimilation gelöst hätte und aufs Neue mystische und gnostische Texte zu lesen begonnen hätte. Er vermutet, dass die Familie über Marcus Ehrenpreis, den Onkel Dobora Vogels, Kenntnisse zur jüdischen Mystik erlangt hätte. Dieser war Rabbiner in Stockholm und mit der »Wissenschaft des Judentums« assoziiert.

99 Shalom Lindenbaum behauptet, dass Schulz Anfang der 1920er Jahre auch in Berlin gewesen sei und auch dort Anschluss an die Avantgarde gesucht habe. Gewohnt habe er bei seiner Familie mütterlicherseits, den Kuhmerkers. Schulz sei sich nach Lindenbaum der provozierenden Motive seiner Grafiken bewusst gewesen und habe deshalb versucht in den liberaleren Metropolen seine Kunst auszustellen. Wie genau dieser Aufenthalt und seine Bemühungen ausgesehen haben, ist unbekannt, allein der Versuch deutet aber darauf hin, dass sich Schulz mit der europäischen Avantgarde identifizierte und in diesem Kontext zu lesen ist. Vgl. Lindenbaum, Shalom: Bruno Schulz w Berlinie. In: KitowskaEysiak: Szkice krytyczne, 11-18, hier 11.

100 Vgl. Sproede, Between Avantgarde and Hassidic Redemption, 466. 
1933-1939 einer der Sechsunddreißig Gerechten gewesen sein könnte, dank welchen in jener Zeit die Literatur existierte. ${ }^{101}$

Definitiv war Schulz sehr gut mit jüdisch polnischen Kulturschaffenden und Intellektuellen wie Julian Tuwim ${ }^{102}$, Bolesław Leśmian ${ }^{103}$ und Maria Chazen vernetzt. Gerade Vogel, die sich wie Schulz in ihrem essayistischen und wissenschaftlichen Werk intensiv mit der Frage nach einer modernen Formensprache und Bildwirklichkeit auseinandergesetzt hat, gehörte zur Gruppe der avantgardistischen Dichterinnen in jiddischer Sprache. ${ }^{104}$ Schon 1918 trat Schulz der Künstlergruppe »Kalleia« bei, in der sich junge Kunstliebhaber und Vertreter der jüdischen Intelligenz Drohobyczs zusammenfanden. ${ }^{105}$ Sein Studium der Architektur, welches er vor dem Krieg in Lemberg begonnen und während des Krieges in seinem fast dreijährigen Aufenthalt in Wien wenigsten nominell fortgesetzt hatte, war in dieser Zeit schon ad Acta gelegt. ${ }^{106}$ In den Jahren um 1920-1922 arbeitet er intensiv an einer Reihe von

101 »Trudno w tej dziedzinie cokolwiek udowodnić, ale chyba są pewne przesłanki, aby zasadnie podejrzewać, że Schulz w latach 1933-1939 mógł być jednym z tych Trzydziestu Sześciu Sprawiedliwych, dzięki którym istniała wówczas literatura."Panas, Księga blasku, 38. (Übers. A. J.)

102 Julian Tuwim (1894-1953) stammt aus Łódź und war der bedeutendste Vertreter der Poetengruppe Skamander. Er schrieb Poesie, Kinderbücher, Satire, trat aber auch als Übersetzer und Herausgeber in Erscheinung. Vgl. Dedecius, Die Dichter Polens, 170.

103 Bolesław Leśmian (1978-1937) war ein jüdisch-polnischer Dichter und Märchenschreiber, der vor allem von der russischen, aber auch der französischsprachigen Kultur und Literatur geprägt war. Großen Einfluss auf ihn hatte beispielsweise Bergson. Vgl. ebd., 166.

104 Vgl. Szymaniak, Być agentem wiecznej idei, 77-82.

105 »Do ugrupowania należeli m. in.: Maria Budratzka (Tempele) - późniejsza śpiewaczka operowa osiadła w Austrii; Emanuel Pilpel - student prawa, meloman, koneser literatury i sztuki; Michał Chajes - późniejszy adwokat; Stanisław Weingarten, bliski przyjaciel Schulza, kolekcjoner jego prac plastycznych, mecenas sztuki, a także muzycy tworzący zespół kameralny, którym dyrygował Otokar Jawrower - późniejszy tłumacz literatury polskiej na język hiszpański.« Kalendarium życia i twórczości Brunona Schulza. In: Chmurzyński (Hg.): Bruno Schulz 1892-1942, 38-45, hier 38. »Zu dieser Gruppe gehörten u.a.: Maria Budratzka (Tempele) - spätere Opernsängerin in Österreich; Emanuel Pilpel - Jurastudent, leidenschaftlicher Musikliebhaber, Kenner der Literatur und Kunst; Michał Chajes - späterer Anwalt; Stanisław Weingarten, enger Freund von Schulz, Sammler seiner plastischen Kunst, Kunstmäzen und ebenso Musiker eines Kammerorchesters, dirigiert von Otokar Jawrower - dem späteren Übersetzer polnischer Literatur ins Spanische.« (Übers. A. J.)

106 Mit Ausbruch des ersten Weltkriegs wird auch Drohobycz Kriegsgebiet und die Familie geht für fast drei Jahre nach Wien, wo Schulz sich an der technischen Hochschule einschreibt, ohne jedoch Prüfungen zu absolvieren. »Die Entdeckung, dass sich Schulz zwischen den Jahren 1914 und 1923 insgesamt dreieinhalb Jahre in Wien aufhält, noch dazu in dem ausschlaggebenden Alter zwischen 22 und 31 Jahren, zwingt uns wohl dazu, das Klischeebild des verlorenen galizischen Autodidakten einer genaueren Untersuchung 
Grafikmappen, die er unter dem Titel »Xięga Bałwochwalcza« stückweise an Interessierte verschenkte oder verkaufte. ${ }^{107}$ Bevor seine Karriere als Schriftsteller im Jahre 1933 beginnt, hat Schulz seine Bildkunst schon in einer Reihe von Ausstellungen in Lemberg (1922; 1930; 1935), Krakau (1930; 1931), Vilnius (1923), Bad Kudowa (1922), Truskawiec (1928) und Warschau (1922) der Öffentlichkeit zugänglich gemacht. ${ }^{108}$ Die häufig dargestellte sexuelle Thematik war in jener Zeit nicht ungewöhnlich, sondern ist nach Robertson gerade in der Vermengung mit der Groteske als Zitat populärer Motive von Werken der Jahrhundertwende lesbar. ${ }^{109}$ Marchesani erkennt ebenfalls einen großen Einfluss insbesondere des Expressionismus auf Schulz' Bildwerk: ${ }^{110}$

zu unterziehen.« Caneppele, der den weitverbreiteten Mythos dekonstruiert, Schulz' Schaffen sei nur in der galizischen Provinz möglich gewesen, die Schulz nie für längere Zeit verlassen habe, konstruiert selbst dabei einen neuen, indem er die Biografien von Schulz und Adolf Hitler miteinander in Beziehung bringt. Caneppele, Die Republik der Träume, 32; 37-41.

107 Die Anfertigung und das Zirkulierenlassen solcher Grafikmappen war in dieser Zeit ein übliches Verfahren, um kostensparend eigene Originale an viele Menschen zu bringen und sich so einen Namen zu machen. Es wurde vor allem unter Expressionisten angewandt und ging mit einer Aufwertung der Grafik von einer Reproduktionsform zu einem Original-Kunstwerk einher. Vgl. Kaufmann, Susanne: Die Mappe als Kunstform der Moderne: Überlegungen zu einem unterschätzen graphischen Ausdrucksmedium des 20. Jahrhunderts. In: Kaufmann, Susanne/Höpner, Corinna (Hg.): Kandinsky, Klee, Schiele... Graphikmappen des frühen 20. Jahrhunderts. Stuttgart 2014, 9-22.

108 Vgl. Kalendarium życia i twórczości Brunona Schulza, 38-45.

109 "The grotesque mingled easily with the sexual topoi of early Modernism at the turn of the twentieth century. In this view, the trappings of masochism in Schulz's visual art can be understood as a >quoting < of popular motifs extracted from literary and artistic tradition, as well as from the iconography of turn of the century mass culture. Rather than representing clinical states, Schulz's art represents a sophisticated play with the modernist context in which the female organizes and hierarchizes the space; man, subject to her, exists at the periphery while she is at the center.« Robertson, Theodosia: Bruno Schulz's Intimate Communication: From the sTrue Viewer of Xięga bałwochwacza to the sTrue Reader of `Księga‘. In: De Bruyn/Van Heuckelom: (Un)masking Bruno Schulz, 441-462, hier 452.

110 "L'aver sperimentato l'instabilità del mondo fece sì che egli si interrogasse nella propria opera sulla stabilità dei sistemi di valori e sul senso dell'esistenza. Leggeva assiduamente gli scritti di Schopenhauer, Nietzsche, Bergson, Goethe i Rilke, probabilmente conosceva le opere degli autori di moderne viennese: Meyrink, Kubin, Hoffmansthal.« Marchesani, Pietro: Bruno Schulz il profeta sommerso. Milano 2000, 59. »Das Erfahren der Unbeständigkeit der Welt führte dazu, dass er sich in seinem eigenen Schaffen Fragen zur Stabilität von Wertesystemen und dem Sinn des Lebens stellte. Er las kontinuierlich Texte von Schopenhauer, Nietzsche, Bergson, Goethe und Rilke, wahrscheinlich kannte er die Werke von Autoren der Wiener Moderne: Meyrink, Kubin, Hoffmansthal.« (Übers. A.J.) Dass Schulz Meyrink gelesen hat, lässt sich unschwer nachweisen, denn Schulz bezieht sich auf diesen in einer Literaturkritik zu einem Buch Leonhard Franks. Diesem unterstellt er ein Mystiker im Sinne Meyrinks zu sein, der diese Mystik 
»Der Aufenthalt in Wien wird für Schulz zur Gelegenheit, die Kunst der bekanntesten Maler des Wiener Jugendstils kennen zu lernen: Die Malerei von Gustav Klimt, die Architektur von Otto Wagner, aber auch die Kunst der Expressionisten Egon Schiele und Oskar Kokoschka. Wenn man den Grundton des figürlichen Werks von Schulz analysiert, so kann man feststellen, dass dieser sich in die Atmosphäre der Dekadenz der Kunst in der Übergangszeit vom 19. ins 20. Jahrhundert einschreibt, mit seinem Katastrophenklima, dem durch die biologischen Bedürfnisse konditionierten Körper, bis zur `nackten`, leidenden Seele. Schulz interessiert sich vor allem für jene Künstler, die dem Symbolismus und Expressionismus nahestehen: Edvard Munch, Félicien Rops, Max Klinger, Alfred Kubin. Die expressiven Beschreibungen der Stadt in Schulz' Erzählungen, kann man als Kommentar zu den Visionen der Metropole verstehen, die auf den Leinwänden von Expressionisten wie Munch repräsentiert sind. Diese Aufmerksamkeit für den Expressionismus ist in seinen Exlibris sichtbar, die vom Künstler gezeichnet wurden und seiner Persönlichkeit entsprechen. ${ }^{111}$

Spätestens ab den 1930er Jahren richten sich seine Karrierebemühungen vornehmlich auf einen Platz in der Warschauer Avantgarde. So weist Thomas Anessi überzeugend nach, dass sich Schulz vor allem in Richtung der Künstlergruppe »Skarmander« orientierte. ${ }^{112}$ Früh steht er in Kontakt mit Vertretern

nicht wie Kafka aus der Erfahrung beziehe, sondern ironisch, hedonistisch und salonartig einsetze. Aber während Meyrink noch ein gewisses philosophisches Gerüst habe, seien Franks Ideen irrational, ein waberndes Gemisch aus Freudismen, psychiatrischen Ideen und platonischer Mystik. Vgl. Schulz, Bruno: Towarzysze snów. In: KitowskaŁysiak: Szkice krytyczne, 80 f., hier 80.

$111 »$ Il soggiorno viennese divenne per Schulz occasione d'incontro con l'arte dei più illustri artisti del >liberty vienneses: la pittura di Gustav Klimt, l'architettura di Otto Wagner, nonché l'arte degli espressionisti: Egon Schiele e Oskar Kokoschka. Analizzando il tono generale dell'opera figurativa di Schulz, si può affermare che esse s'iscrive nell'atmosfera decadente dell'arte del periodo a cavallo tra l'Ottocento ed il Novecento con il suo clima catastrofista, corpo, condizionato dalle esigenze della biologia, alla ınuda anima sofferente. Schulz s'interessò soprattutto per gli artisti legati al simbolismo ed all'espressionismo: Edvard Munch, Félicien Rops, Max Klinger, Alfred Kubin. Le espressive descrizioni della città nei racconti di Schulz possono essere considerate come un commento alle visioni della metropoli rappresentante sulle tele degli espressionisti, per esempio di Munch. Quest'attrazione per l'espressionismo è visibile anche negli ex libris disegnati dall'artista ed è consona alla sua personalità.« Marchesani, Bruno Schulz il profeta sommerso, 59. (Übers. A. J.)

$112 »$ Schulz did share much in common with the Skamander poets. Among these commonalities are features often used by critics as markers of Schulz's place on the margins, including his origins in Drohobycz (shared with Wierzyński) and his Jewish heritage, shared by three of the movement's founders (Tuwim, Słonimski, Lechoń) and Grydzewski. The connections, however, extend much further.« Anessi, Thomas: The Great Heresy of the Varsovian Center. In: De Bruyn/Van Heuckelom: (Un)masking Bruno Schulz, 387-408, hier 390. 
der polnischen Avantgarde ${ }^{113}$ wie dem Maler und Dramatiker Stanisław Ignacy Witkiewicz ${ }^{114}$ und den Schriftstellern Witold Gombrowicz ${ }^{115}$ und Maria Kuncewiczowa. ${ }^{116}$ Über den vermittelten Kontakt zu Zofia Nałkowska kann er sein literarisches Debüt 1933 in einer der wichtigen polnischen Literaturzeitschriften »Wiadomości Literackie» (Literarische Nachrichten) beginnen und wenig später den Erzählband »Sklepy cynamonowe« im Verlag Rój publizieren. ${ }^{117}$ Spätestens im Jahr 1934 ist er ein landesweit geachteter und bekannter Schriftsteller.

"Over a period of five years (1934-1939), Schulz signed his name to 27 pieces in the journal (including seven of his stories), more than Wierzyński himself. If one adds Schulz's contributions to Poland's oldest and most prestigious literary review, Tygodnik Ilustrowany, in which he published three of his stories and several reviews, including the three on Piłsudski, the Drohobyczan writer could be found every second or third month in one of the two journals, each of which had a circulation of ten to fifteen thousand. He also published his stories and essays in the Warsaw-based Skamander and Pion, as well as in Studio, Sygnaty (Signals), and Kamena. ${ }^{118}$

1937 erscheint sein zweites Buch »Sanatorium pod Klepsydrą" ${ }^{119} 1938$ fährt Schulz auf eine einmonatige Paris-Reise, die in seinen übermittelten Briefen ${ }^{120}$

113 Vgl. Drews, Peter: Die slawische Avantgarde und der Westen. Programme der russischen, polnischen und tschechischen Avantgarde und ihr europäischer Kontext. München 1983, 60 .

114 Stanisław Ignacy Witkiewicz (1885-1939) war der Sohn eines Malers und Kritikers. Nach seiner privaten Ausbildung studierte er an der Kunstakademie in Krakau. 1918-1922 war er Haupttheoretiker der avantgardistischen Maler- und Dichtergruppe »Formisten« (Formiści) und war wie Schulz in mehreren Ausdrucksbereichen aktiv. Neben der Malerei war er Schriftsteller, Dramaturg, Philosoph und Gründer einer Theatergesellschaft. Er experimentierte mit Rauschgiften und ihrem Einfluss auf die Kunst und Wahrnehmung. Vgl. Dedecius, Die Dichter Polens, 196.

115 Witold Gombrowicz (1904-1969) war ein polnischer Schriftsteller. Sein berühmtestes Werk »Ferdydurke« rezensierte Schulz enthusiastisch. Beide lernten sich 1934 im Kreis Nałkowskas kennen. Gombrowicz beförderte den Mythos um Schulz' Masochismus wesentlich mit, nicht allein durch den öffentlichen Briefwechsel, sondern auch durch seine Tagebucheinträge. Vgl. Gombrowicz, Witold. In: Bolecki, Słownik schulzowski, 129-131.

116 Vgl. Anessi, The Great Heresy of the Varsovian Center, 390.

117 Vgl. ebd., 392.

118 Ebd., 401.

119 Darüber hinaus gelingen ihm noch viele Vorhaben, mithin die Veröffentlichung der von seiner Verlobten Józefina Szelińska angefertigten Übersetzung von Kafkas »Prozeß« ins Polnische. Mit ihr ist er ab 1934 verlobt und tritt, um sie heiraten zu können, aus der israelitischen Gemeinschaft aus. Vgl. Józefina Szelińska, in: Bolecki, Słownik schulzowski, 368.

120 Vgl. Brief Schulz an Ramona Halpern vom 29.8.1938, Schulz, Księga listów, 171 f. 
und in der Sekundärliteratur als erfolglos angesehen wird, weil er weder eine Galerie noch einen Übersetzer finden konnte. Andererseits trifft er dort auf Persönlichkeiten wie Siegfried Kracauer. ${ }^{121}$

Mit Kriegsbeginn 1939 wird Drohobycz erst von der Roten Armee und anschließend von der Wehrmacht besetzt. Die Nationalsozialisten errichten dort ein Ghetto, um Menschen entsprechend ihrer Ideologie auszusondern und zu töten. Schulz wird in dieser Zeit zum Sklaven eines hohen GestapoOffiziers und fertigt für dessen Sohn Fresken mit Märchenmotiven im Kinderzimmer einer unrechtmäßig beschlagnahmten Villa an. ${ }^{122} 1942$ wird Schulz auf offener Straße erschossen. Auch die Nachgeschichte ist für die Überlieferung seines Werkes katastrophal. Durch die "Westverschiebung" Polens nach dem Zweiten Weltkrieg und die endgültige Inkorporation Galiziens in die sowjetische Ukraine waren die neuen lokalen Kulturfunktionäre vor allem damit beschäftigt, die Erinnerung an die ukrainischen Söhne und Töchter der Region zu bewahren und die an die polnischen und jüdischen zu verdrängen. ${ }^{123}$ Dadurch gingen weitere Briefe, Manuskripte und Spuren verloren.

\subsection{Theorie und Methode}

Dieser Arbeit liegt ein bildwissenschaftlicher Untersuchungsansatz zugrunde. Um zu erkennen, welche Diskurse und Begriffe die Wahrnehmung und Funktion des Bildes zu Schulz' Zeit prägten, werden ihm zeitgenössische Untersuchungen zum Bild herangezogen. Ab der Jahrhundertwende gibt es aufgrund der fundamentalen Erschütterung der alten Bild-Ordnung eine regelrechte Welle an Auseinandersetzungen mit der Bildidee, mit Kunstmedien und Bildphänomenen, die sich in zahlreichen und mannigfaltigen Studien zu Bild- und Kunstbegriffen niederschlagen. ${ }^{124}$

121 Vgl. ebd., 290.

122 Vgl. Kitowska-Łysiak, Małgorzata: Uwagi w sprawie kanonu: Brunona Schulza szkicownik młodzieńczy i freski w willi Landaua. In: Fundacja Terytoria Książki (Hg.): Schulz forum. Gdańsk 2013, 63-78, hier 70-72.

123 Vgl. Mendelsohn, Painting a people, 1.

124 In der Aufsatzsammlung »Ideengeschichte der Bildwissenschaft« werden unterschiedliche namhafte Forscher porträtiert, die sich im 20. Jahrhundert theoretisch mit »Bildern« befasst haben. Dabei fällt die Palette an Begriffen wie auch an Untersuchungsgegenständen auf, die über materielle Bildmedien deutlich hinausreicht. Darunter fallen Forschungen zu Metaphern, zur Bildpraxis, zu Fotografien, zu kunstgeschichtlichen Anschauungstheorien, sowie zu Bildern als Dokumente oder Aussagen. Angesichts der Heterogenität der Untersuchungsgegenstände, an denen eine mögliche Bildidee sich manifestieren soll, fällt es schwer einheitliche Kriterien zu bestimmen, die allgemein- 
Die in dieser Arbeit hauptsächlich verwendeten Analysen aus Schulz' Zeit stammen von Walter Benjamin, Gisèle Freund und Erwin Panofsky. Alle drei werfen ein unterschiedliches Licht auf verschiedene Bildbegriffe. Panofsky beispielsweise untersucht in seiner Studie "Idea" die Entwicklung der Beziehung der Kunsttheorie zur "Ideenlehre» und "Nachahmungstheorie« und zeichnet den langen Wandlungsprozess und das Nachwirken antiker Konzepte bis in die gegenwärtige Kunsttheorie und -praxis nach. ${ }^{125}$ Er zeigt, dass in unterschiedlichen Epochen »Ideen " entweder metaphysisch als a priori gegeben begründet werden, theologisch als Grundpfeiler eines göttlichen Plans oder aber wissenschaftlich/erfahrungsbasiert als aus der Natur durch den menschlichen Verstand abgeleitet verstanden werden. ${ }^{126}$ Dadurch wirft er ein Licht auf den Zusammenhang von Begriffen und Kunstkonzepten. Freund hingegen konzentriert sich in ihren Studien auf die Wechselbeziehung zwischen der Fotografie und der Kunst. Sie weist nach, wie die Fotografie die Wahrnehmung des technischen Bildes als Mittler der Wirklichkeit verändert und welche Funktionen die Malerei an die Fotografie abtritt. Dabei wirft sie ein Licht auf die gesellschaftliche und politische Dimension dieser Umschichtungsprozesse. ${ }^{127}$

Walter Benjamin schließlich gehört zu den zentralen Denkern, die die Verschiebungen an der Bildidee durch die Erfindung der Fotografie in mehreren Aufsätzen beleuchtet. ${ }^{128}$ Er untersucht dabei nicht nur Kunst- und Pressebilder, sondern auch die Werbung und Architektur im Kontext gesellschaftlicher Wandlungen. ${ }^{129}$ Seine bildtheoretischen Überlegungen lassen sich

gültige Aussagen zulassen. So bleiben auch Probst und Klenner eine übergeordnete Fragestellung, die eine vergleichende Perspektive auf die unterschiedlichen Ansätze erlaubte, schuldig. Auch wenn die Frage, welche "Bildtypen« nun genau unter die Idee des Bildes fallen, erst einmal unbeantwortet bleibt, so leistet der Sammelband zweierlei: Erstens zeigt er deutlich, dass die Frage nach der Idee des Bildes seit der Jahrhundertwende virulent ist und zweitens, dass neue Formen der Bildanalyse entstehen, die die alten kunsthistorischen Ansätze um kultur- und kunsttheoretische Fragestellungen ergänzen. Vgl. Probst, Jörg/Klenner, Jost P. (Hg.): Ideengeschichte der Bildwissenschaft. Siebzehn Porträts. Frankfurt a. M. 2009.

125 Vgl. Panofsky, Erwin: Idea. Ein Beitrag zur Begriffsgeschichte der älteren Kunsttheorie. Berlin 1985.

126 Hans Blumenberg untersucht ebenfalls diesen Zusammenhang am Beispiel des Romans und zeigt auf, welchen Einfluss die Ideenlehre und die Vorstellung von Kunst auf das Wirklichkeitsbild und andersherum haben. Vgl. Blumenberg, Wirklichkeitsbegriff und Möglichkeit des Romans.

127 Vgl. Freund, Gisèle: Photographie und Gesellschaft. Reinbeck 1979, $210 \mathrm{f}$.

128 Zentral sind hier seine Aufsätze »Das Kunstwerk im Zeitalter seiner technischen Reproduzierbarkeit«, »Die kleine Geschichte der Photographie« sowie »Über einige Motive bei Baudelaire."

129 Zwar stellt Sigrid Weigel zu Recht fest, dass Benjamin wenige reelle Bilder als Gegenstand seiner Untersuchung dienen, dennoch befasst er sich mit der Bildkunst und Fotografie als Reflexionsgegenstände genauso intensiv wie mit »inneren Bildern«. Dialek- 
innerhalb seiner Modernekritik verstehen und andersherum. ${ }^{130}$ Nach $\mathrm{Mi}$ chael Makropoulos kritisiert Benjamin den Verlust eines transzendenten Ordnungssystems, an welchem sich die Begriffe der Gegenwart ausrichten und überprüfen ließen. ${ }^{131}$ Gleichzeitig wirkten religiöse beziehungsweise mythische Strukturen unerkannt in der Gegenwart nach. ${ }^{132}$ Daher begreift Benjamin das Studium vergangener und älterer Begriffe nicht allein als historische Forschertätigkeit, sondern sucht darin die Möglichkeit, Denkgewohnheiten der Gegenwart in ein kritisches Licht zu rücken. ${ }^{133}$ Umso mehr vergangene und aktuelle Begriffe einer Sache einem Forscher(kollektiv) gegenwärtig seien, desto umfangreicher sei die Idee erfasst und desto sicherer vor einem ideologischen Missbrauch geschützt. ${ }^{134}$ Daher sei es die dauerhafte Aufgabe des Menschen aktuelle und historische Begriffe zu erarbeiten, verstehen und zu übersetzen/bewahren, um die sich in steter Wandlung befindlichen Vorstellungen nicht als selbstverständliche/einzige Wirklichkeit zu

tische und Denkbilder wiederum sind hermeneutische Kategorien. »Angesichts der großen Bedeutung, die Bilder für das Denken und Schreiben Walter Benjamins haben, ist es bemerkenswert, welch geringen Raum die Malerei in seinem Werk einnimmt. Während der Begriff des Bildes in seinen Schriften eine Art Leitmotiv darstellt - sei es als Bild der Erinnerung, als Denkbild oder dialektisches Bild, sei es in der Rede von Bilderwelten, vom Bildraum oder Traumbild -, zählen dagegen Gemälde, Kunstwerke und andere materielle Bilder nicht unbedingt zu den wichtigsten Themen und Gegenständen seiner kunstphilosophischen und kulturtheoretischen Überlegungen.«Weigel, Sigrid: Bildwissenschaft aus dem "Geiste wahrer Philologie«: Benjamins Wahlverwandtschaft mit der »neuen Kunstwissenschaft« und der Warburg-Schule. In: Schöttker, Detlev (Hg.): Schrift, Bilder, Denken. Walter Benjamin und die Künste. Frankfurt a. M., Berlin 2004, 112-127, hier 113.

130 Vgl. Kaulen, Rettung und Destruktion, $18 \mathrm{f}$.

131 Vgl. Makropoulos, Michael: Modernität als ontologischer Ausnahmezustand? Walter Benjamins Theorie der Moderne. München 1989, 18-24.

132 Eines der Ziele seines »Passagen-Werks« war es, die Umschichtung mythischer und religiöser Vorstellungen in das Zeitalter der Technik und Information nachzuzeichnen. Benjamin vertritt die These, dass das religiöse Bewusstsein durch den Schwund der institutionellen Religionen nicht weniger wird, sondern sich in andere Bereiche verlagert. Vgl. Benjamin, Walter: Paris, die Hauptstadt des XIX. Jahrhunderts. In: Tiedemann, Rolf (Hg.): Gesammelte Schriften V. Das Passagen-Werk. Frankfurt a.M. 1991, 45-59, hier 46. So erkennt er in dem Glauben an die Technik, an den mit ihr so anschaulich wahrnehmbaren Fortschritt, aber auch im Wirken der Mode und der Medienindustrie religiöse Strukturen, denen aber im Gegensatz zur konfessionellen Religion die Ausrichtung an kanonischen Texten fehlt. Vgl. Makropoulos, Modernität als ontologischer Ausnahmezustand?.

133 Vgl. Benjamin, Das Passagen-Werk, 574f.

134 Auf Ideen und ihre Beziehung zu Begriffen geht Benjamin ausführlich in seinem Werk "Ursprung des deutschen Trauerspiels" ein. Sich auf Platon und Goethe beziehend definiert er sie sowohl als »dunkel« und »verborgen« als auch als »darstellbar«. Man könne auf sie mittels der Begriffe zugreifen, die wiederum nur Teilaspekte von ihnen darstellten. 
verstehen. Im Ideal wäre es möglich, »Ideen zu schauen«, wenn durch ein abgeschlossenes Studium alle Materialisierungsformen bekannt sind. Benjamin verbindet eben jenes Einsammeln der Phänomene mit der »Rettung«.

"Die Ideen - im Sprachgebrauche Goethes: Ideale - sind die faustischen Mütter. Sie bleiben dunkel, wo die Phänomene sich zu ihnen nicht bekennen und um sie scharen. Die Einsammlung der Phänomene ist die Sache der Begriffe und die Zerteilung, die sich kraft des unterscheidenden Verstandes in ihnen vollzieht, ist um so bedeutungsvoller, als in einem und demselben Vollzuge sie ein Doppeltes vollendet: die Rettung der Phänomene und die Darstellung der Ideen. ${ }^{135}$

"Ideen « sind demnach allgemeine, übergeordnete Vorstellungen, die sich nur partiell in historisch wandelbaren Begriffen konkretisieren. ${ }^{136}$ Daher wird auch für die Untersuchung von Schulz' Werk nicht von einem festen Bildbegriff ausgegangen, den es zu analysieren, beweisen oder zu definieren gilt, sondern die Suche nach der Bildidee wird mittels verschiedener Begriffsanalysen vonstattengehen.

Da sich im Zuge des "iconic turns«, der um 1900 mit der intensiven Befassung mit Bildbegriffen eingeleitet wurde, ein eigener Zweig der Forschung herausgebildet hat, der eine systematische Begrifflichkeit für die Bild-Forschung entwickelt hat, sind der zweite theoretische Pfeiler dieser Arbeit aktuellere bildwissenschaftliche Forschungen von Gottfried Boehm, Hans Belting und William Mitchell.

Der »iconic turn « bezeichnet nach Mitchell einerseits einen Paradigmenwechsel in den Wissenschaften selbst, andererseits auch das Phänomen einer Kultur, die im Zeitalter der Massenmedien einer großen Anzahl an Bildern ausgesetzt ist und daher eine verstärkte Untersuchung von Bildern erfordert. ${ }^{137}$ Somit sind eine kulturhistorische sowie eine wissenschaftstheoretische Komponente zu unterscheiden, die beide unter einen Begriff fallen.

135 Benjamin, Walter: Ursprung des deutschen Trauerspiels. In: Tiedemann, Rolf/Schweppenhäuser, Hermann (Hg.): Gesammelte Schriften I. Abhandlungen. Frankfurt a.M. 1991, 203-430, hier 215. In seinem "Passagen-Werk« geht er auf die Aufgabe des Forschers stichpunktartig wie folgt ein: »Zur Elementarlehre des historischen Materialismus. 1) Gegenstand der Geschichte ist dasjenige, an dem die Erkenntnis als dessen Rettung vollzogen wird. 2) Geschichte zerfällt in Bilder, nicht in Geschichten. 3) Wo ein dialektischer Prozeß sich vollzieht, da haben wir es mit einer Monade zu tun. 4) Die materialistische Geschichtsdarstellung führt eine immanente Kritik am Begriff des Fortschritts mit sich. 5) Der historische Materialismus stützt sein Verfahren auf die Erfahrung, den gesunden Menschenverstand, die Geistesgegenwart und die Dialektik." Benjamin, Das Passagen-Werk, $595 \mathrm{f}$.

136 Idee. In: Krings, Hermann/Baumgartner, Hans M. u.a. (Hg.): Handbuch philosophischer Grundbegriffe. München 1973, $709 \mathrm{f}$.

137 Vgl. Mitchell, William: Picture Theory. Essays on Verbal and Visual Representation. Chicago 1995, 12-14. 
Klaus Sachs-Hombach findet darüber hinaus eine dritte Dimension des »iconic turns", nämlich die Sensibilisierung für das Bild als anthropologische Grundkonstante, die ähnlich wie die Sprache für die Epistemologie und die Abgrenzung des Menschen von Tieren eine zentrale Rolle spielt. ${ }^{138}$ Gerade im Vergleich zum »linguistic turn« stellt Sachs-Hombach die Existenz eines methodischen Paradigmenwechsels in Frage, da Bilder nach ihm nur über Sprache verstanden werden können, ${ }^{139}$ während Gottfried Boehm andersherum den Einfluss der Bilder auf die Vorstellungs- und damit auf die Begriffswelt betont. ${ }^{140}$ Während Boehm, wie Mark Halawa gezeigt hat, eher eine Trennung zwischen Bild und Sprache betont und einen puristischen Bildbegriff entwickelt, hält Mitchell eine Abgrenzung oder Hierarchisierung der beiden Ausdrucksmittel Sprache und Bild für falsch. Er konzentriert sich stärker auf die stattfindenden, empirisch belegbaren Umschichtungen, die an Bild- und Sprachbegriffen sichtbar werden und betont, dass diese immer mit-

138 Wegweisend für diesen Ansatz ist vor allem Hans Jonas' Aufsatz »Die Freiheit des Bildens. Homo pictor und die differentia des Menschen «, in welchem er darlegt, inwiefern das Vermögen des Menschen Bilder zu sehen und zu schaffen, ihn von anderen Lebewesen abhebt und Grundlage seines Abstraktions-, Ordnungs-, Vernunft- und Kreativitätsvermögens ist. Vgl. Jonas, Hans: Die Freiheit des Bildens: Homo pictor und die differentia des Menschen. In: Ders.: Zwischen Nichts und Ewigkeit. Drei Aufsätze zur Lehre vom Menschen. Göttingen 1963, 26-43.

139 In der Einleitung zum Sammelwerk »Bildtheorien. Anthropologische und kulturelle Grundlagen des Visualistic Turn" untersucht Klaus Sachs-Hombach die »Rede vom turn « und was darunter zu verstehen sei. Dabei geht er auf eine Reihe von Arbeiten ein, die sich mit dem bildwissenschaftlichen Ansatz als aktuelles Paradigma befassen und arbeitet die unterschiedlichen Denkvoraussetzungen heraus, mit welchen diese ihre Be-

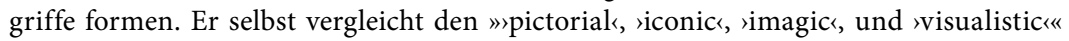
turn mit dem »linguistic turn«, dessen Bedeutung und Relevanz weniger umstritten sei, um den "Stellenwert und die Berechtigung einer Wende zum Bild beurteilen zu können«. Sachs-Hombach, Klaus: Einleitung. In: Ders. (Hg.): Bildtheorien. Anthropologische und kulturelle Grundlagen des Visualistic Turn. Frankfurt a. M. 2009, 7-14, hier 7. Ihm geht es darum festzustellen, ob über die kulturhistorische Entwicklung, dass es mehr Bilder im öffentlichen und privaten Raum gibt, die es zu untersuchen gilt, auch ein methodisch-theoretischer Wandel in den Wissenschaften hinsichtlich des Bildes stattgefunden hat, den man berechtigterweise als "turn« bezeichnen kann. Gerade die epistemologische Bedeutung, die dem »linguistic turn" zukommt, kann Sachs-Hombach nicht für den "pictorial turn « feststellen, insbesondere weil Bild immer mit Sprache zusammenhängt. »Bilder modifizieren vor allem in ihrer erkenntnisleitenden und erkenntnisstrukturierenden Funktion die jeweiligen Erkenntniszusammenhänge (und halten uns in dieser Funktion mitunter gefangen); in Geltungszusammenhängen, also etwa der Begründung von Gesetzesaussagen, besitzen sie, wie ich meine, aber eine höchstens untergeordnete Bedeutung. Obschon zur (didaktischen) Vermittlung von großem Wert, ist es daher schwer vorstellbar, daß sie jemals die Rolle übernehmen können, die der Sprache traditionell zukommt bei der intersubjektiven Prüfung unserer Erkenntnisse.« Ebd., 9.

140 Vgl. Boehm, Wie Bilder Sinn erzeugen, 14. 
einander zusammenhängen. ${ }^{141}$ Den Versuch "puristische« Sprach- und Bildbegriffe $^{142} \mathrm{zu}$ entwickeln, bezeichnet Mitchell als »utopisch", aber typisch für die Moderne. ${ }^{143}$ Wenn sich die Funktion und Bedeutung von Bildern im gesellschaftlichen Gebrauch verändern, führe dies automatisch auch zu einer Neuformung der Begriffe über Sprache, sowie zu einer Neubewertung von Traditionen, Vorstellungen und damit der Erkenntniswege.

"Whatever the pictorial turn is, then, it should be clear that it is not a return to naive mimesis, copy or correspondence theories of representation, or a renewed metaphysics of pictorial spresences: it is rather a postlinguistic, postsemiotic rediscovery of the picture as a complex interplay of visuality, apparatus, institutions, discourse, bodies, and figurality. It is the realization that spectatorship (the look, the gaze, the glance, the practices of observation, surveillance, and visual pleasure) may be as deep a problem as various forms of reading (decipherment, decoding, interpretation, etc.) and the visual experience or svisual literacy< might not be fully explicable on the model of textuality."144

Belting hingegen konzentriert sich in seiner Bild-Anthropologie ${ }^{145}$ stärker auf die Beziehung zwischen Mensch und Bild. Er weist nach, dass jedes »Bild« seine Bedeutung wandeln kann, wenn der Kontext sich ändert. Dabei fundiert er seine Untersuchung auf der Unterscheidung zwischen Medium und Dargestelltem, die für diese Arbeit ebenfalls relevant ist.

Hier wird schon deutlich, dass die Bildidee nur über Sprache zu ermitteln ist und Bild und Sprache eng miteinander verwoben sind. ${ }^{146}$ Die Wende zum

141 Der menschliche Wahrnehmungs- und Sinnstiftungsapparat könne nicht getrennt betrachtet werden, da er im Menschen untrennbar verwoben ist. Dieser in erster Näherung einfachen Aussage misst Halawa eine bedeutende Rolle zu. »Tatsächlich liegt ein wesentliches Verdienst Mitchells nicht etwa nur darin, gezeigt zu haben, wie hartnäckig sich Momente des Ikonischen in scheinbar rein diskursive Phänomene einzunisten pflegen; vielmehr konnte er ebenfalls unter Beweis stellen, mit welcher Beharrlichkeit Faktoren des Diskursiven selbst in den scheinbar puristischsten Bildwelten zur Geltung kommen [...]. Die Vorstellung einer prinzipiellen Andersheit zwischen Bild und Sprache ist Mitchell daher ebenso fremd wie der Rückgriff auf eine medienpuristische Rhetorik." Halawa, Mark: Angst vor der Sprache: Zur Kritik der sprachkritischen Ikonologie. In: IMAGE (2014), 3-32, hier 21.

142 Für ein "puristisches« Sprachverständnis tritt vor allem Lessing in seiner Schrift »Laokoon« ein, das mit einer gleichzeitigen Abwertung des Bildes an sich und alles Bildlichen in der Sprache verbunden ist, während Gottfried Böhm tendenziell ein "puristisches" Bildverständnis vertritt und das Bild gegen den Anspruch zu verteidigen versucht, dass "alles Text sei.«

143 Vgl. Mitchell, Picture Theory, 5.

144 Ebd., 16. (Hervorh. Mitchell)

145 Vgl. Belting, Bild-Anthropologie.

146 Diese Grundannahme wird nicht von allen geteilt oder mit dieser Deutlichkeit formuliert. Sie resultiert einerseits aus der Tatsache, dass Wissenschaft in Sprache formuliert 
Bild ist in Mitchells Lesart eine von vielen Wenden, die es in der Geschichte der religiösen, philosophischen und wissenschaftlichen Betrachtung von Bildern (und Sprache) gegeben hat. Um die Bildidee in Schulz' Gesamtwerk zu ermitteln, werde ich in unterschiedlichen Kapiteln einzelne Bild-Experimente untersuchen. Aus der analysierten Bildpraxis werden theoretische Annahmen abgeleitet, die die Bausteine einer Theorie bilden. Die Deutung, die sich daraus ergibt, erhebt weder den Anspruch vollständig noch in allen Punkten die einzig mögliche zu sein. Sie soll aber den Weg für weitere Interpretationen und alternative Lesarten von Schulz' Werk ebnen und kann von anderen Wissenschaftlern ergänzt, erweitert und modifiziert werden.

\subsection{Vorgehensweise}

$\mathrm{Zu}$ Beginn untersuche und kläre ich zentrale Begriffe und Grundannahmen, die für die weitere Behandlung der Bildidee von Wichtigkeit erscheinen. ${ }^{147}$ Die These lautet, dass Schulz' Haltung gegenüber dem, was er unter »Positivismus« versteht, Ausgangspunkt für seine Kunst ist. Hierzu werden einleitend die wichtigsten Ideen des Positivismus, aber auch seine Weiterentwicklung aufgezeigt. ${ }^{148}$ Auf Grundlage der zeitnahen Untersuchungen von Walter Benjamin und Gisèle Freund zum Einfluss der Fotografie und des Positivismus auf die Wahrnehmung von Bildern und Wirklichkeit sowie unter Hinzuziehung neuerer bildwissenschaftlicher Forschungen werde ich diese Umschichtungsprozesse aufzeigen, die sich auch in Schulz' Schaffen nachweisen lassen. Ausgangspunkt ist die These, dass sich um die Jahrhundertwende die

wird, andererseits auch, dass das menschliche Denken sprachlich und bildhaft zugleich ist und somit sowohl der Bildmacher als auch der Bildleser diese Verbindungen automatisch macht. Drittens fließen sprachlich verfasste Texte in Bilder ein. Diese wesentliche Verflechtung hat besonders William Mitchell hervorgehoben und zu seinem Ausgangspunkt gemacht. Vgl. Mitchell, Picture Theory, 5.

147 Die Auswahl ergibt sich aus Schulz' theoretischen Texten, die kaum Material zur Bildidee, deutlich mehr hingegen zu Begriffen wie Sprache, Sinn, Wirklichkeit, Kunst und Kultur liefern. Da das theoretische Material von Schulz recht dünn ist, er aber deutlich an Themen seiner Zeit interessiert ist, werden zum Vergleich Texte seiner Zeit herangezogen und damals aktuelle Diskurse aufgezeigt.

148 Schulz lässt sich in jene Riege der Kritiker des Positivismus und »Fortschrittsglaubens« einreihen, die sich in ihrem Werk, aber auch theoretisch mit der Frage nach der Beziehung des Menschen zu seiner Umwelt befassen und den Einfluss der Technik und naturwissenschaftlicher Erkenntnisse auf das Selbstverständnis und die Wahrnehmung des Menschen kritisch sehen. Vgl. Hermand, Jost: Literaturwissenschaft und Kunstwissenschaft. Methodische Wechselbeziehungen seit 1900. Stuttgart 1971, 3-5. 
Vorstellung von dem, was ein Bild ist, radikal ändert ${ }^{149}$ und deshalb auch Schulz dazu animiert, gerade die Bildidee neu zu diskutieren. In mehreren Schritten untersuche ich anschließend unterschiedliche Aspekte des Schulzschen Bild-Denkens.

Im dritten Kapitel wird das bildnerische Werk von Schulz genauer analysiert. Den Ausgangspunkt bilden die Grafiken, die nicht nur chronologisch am Anfang seines Schaffens stehen, sondern auch selbst eine mediale Bildstruktur aufweisen. Das Medium, in welchem die Bildidee verhandelt wird, spielt dabei eine zentrale Rolle, daher wird seine spezifische Sprache untersucht. Dabei zeigt sich gleich zu Beginn, dass die Grafiken wesentliche Subtexte auch in der Literatur und der Mythologie finden, also ein intermedialer Bezug zwischen Grafiken und Literatur besteht. Über eine Untersuchung von Tizians Kunst wird gezeigt, wie Schulz Motive der Malerei vermittels Sacher-Masochs Novelle »Venus im Pelz« zitiert und verwandelt und damit die Grenzen zwischen Wirklichkeit und Kunst, aber auch zwischen Bild und Text befragt. Diese Untersuchung bettet er zugleich in einen religiösen Kontext, indem er das alttestamentarische Bildverbot im Titel anspricht. Gleichzeitig wird in seinen Porträts das aus der Renaissance stammende Motiv des »Bildes im Bild « analysiert, welches wiederum für eine im Bild stattfindende Selbstreflexion steht. ${ }^{150}$ Aus diesen unterschiedlichen Aspekten speist sich die These, dass Schulz die Bildidee im Bild gleichzeitig in einem künstlerischen, biblischen, mythischen und modernen Kontext untersucht und theoretischen Fragestellungen zuführt.

Anschließend überprüfe ich Schulz' literarisches Werk daraufhin, ob sich die Thesen zu der Bildidee aus den Grafiken in seinen Erzählungen bestätigen, vertiefen oder erweitern lassen. Im vierten Kapitel bearbeite ich die Auseinandersetzung mit den spezifischen neuen Bildmedien wie der Werbung, Illustrierten und Modebildern. So findet sich in »Ulica Krokodyli« eine Diskussion über den Wirklichkeitsgehalt und die Wirkung von Fotografien und Werbebildern auf die städtische Selbstwahrnehmung. Über einen Vergleich mit Walter Benjamins Untersuchungen in seinem "Passagen-Werk« und einigen seiner Aufsätze zeige ich, dass sich verschiedene Motive als »dialektische Bilder« lesen lassen, das heißt als Gegenstände, an denen sich ein kultureller Umschichtungsprozess und eine dialektische Spannung nach

149 Vgl. Boehm, Gottfried: Die Wiederkehr der Bilder. In: Ders. (Hg.): Was ist ein Bild? 2. Aufl. München 1994, hier $15 \mathrm{f}$.

150 Vgl. Stoichiţă, Victor I.: Das selbstbewußte Bild. Vom Ursprung der Metamalerei. München 1998, 190. »Die Darstellung eines `Gemäldes-im-Gemälde kann also als ein auf einen meta-artistischen Diskurs abzielender Vorgang angesehen werden, einen Diskurs, der die Extremfälle der entblößten Wand und des pikturalen Bildes ins Spiel bringt. Dieser Vorgang wirft, indem er eine Pfropfung emblematischen Typs vornimmt, das Problem der Konstruktion auf.« 
verfolgen lassen. Anhand der Untersuchungen zur Reklame in der Erzählung "Księga" wird das mythische Potenzial dieser modernen Bildmedien herausgearbeitet. Im Ergebnis dieser Analyse erweisen sich einige Grafiken als Auseinandersetzung mit dem Warenkult der kapitalistischen Gesellschaft.

Im fünften Kapitel steht hingegen die spezifische malerische Sprache von Schulz im Zentrum. Untersuchungsgegenstand sind die visualisierenden Beschreibungen, die Gemäldedarstellungen, aber auch die kunsttheoretischen Überlegungen, die sich vor allem in der Erzählung »Genialna epoka« (Die geniale Epoche) finden lassen. Diesem Kapitel wird eine intensive Untersuchung zur Bild-Sprache-Beziehung vorangestellt, die auch die Frage nach der Möglichkeit, mittels Sprache zu malen, einschließt. Mithilfe des Konzepts der Ekphrasis zeige ich auf, welche unterschiedlichen Traditionen der visualisierenden Sprache es in der Vergangenheit gibt. Die leitende These für Schulz' Werk lautet, dass er programmatisch versucht, die Grenze zwischen den Ausdrucksbereichen Bild und Sprache aufzubrechen. Dies tut er, indem er in der Sprache ein Äquivalent für Verfahren und Mittel der Malerei findet. Indem er Kunsttheorien der Jahrhundertwende innerhalb der Literatur zitiert und Experimente mit Bildern in Sprache realisiert, entstehen eine Reihe von unterschiedlichen Sprachbildern, die sich als Wortmalerei, Bildzitat, visualisierende Beschreibung oder als maltheoretisches Experiment interpretieren lassen.

Abschließend wird die Idee einer »Rettung « des Bildes im Wort untersucht. Hier lautet die These, dass Schulz eine Veränderung der Vorstellung von dem, was Sprache und Bild sind, in seiner Gegenwart feststellt. Immer wieder weist er auf ein Erstarren der Bedeutungen hin, welches er kritisch auffasst, weil damit auch eine Reduzierung der kreativen Freiheiten und Möglichkeiten des Menschen verbunden ist. ${ }^{151}$ Ziel seiner poetischen Sprachanwendung, zu der programmatisch ein partielles Aufheben der Grenze zwischen Bild und Wort gehört, sowie seiner Betonung der kreativen Befähigungen des Menschen, wie Fabulieren, Träumen und Erinnern, ist es, die Offenheit und Wandelbarkeit der Bedeutungen zurückzuerlangen. Gerettet wird damit eine bestimmte Erfahrung und Bedeutung am Bild und an der Sprache, die er synthetisch in sein Werk zu senken und seinem Leser, den er immer wieder adressiert, zu vermitteln versucht. 



\section{Schulz' Sprach- und Kunstverständnis in seinen theoretischen Schriften im Kontext der Modernekritik}

In mehreren kürzeren Essays, Interviews und Kritiken hat Schulz sich zu Themen seiner Gegenwart geäußert, die für die Untersuchung der Bildidee von Relevanz sind. Von besonderer Bedeutung ist sein programmatischer, überwiegend sprachphilosophischer Aufsatz "Mityzacja rzeczywistości «" (Die Mythisierung der Wirklichkeit), in dem sein Verständnis von Sprache und Wirklichkeit deutlich wird. Da Schulz hier auf Entwicklungen in den Wissenschaften und der Philosophie seiner Zeit Bezug nimmt und diese mitunter kritisch kommentiert, wird die Relevanz des gesellschaftlichen und ideengeschichtlichen Kontexts für Schulz' Werk besonders deutlich. In weiteren kurzen Essays und Kritiken geht Schulz dabei namentlich auf den Positivismus, Freuds Psychoanalyse sowie auf die Geschichts- und Naturwissenschaften ein und wirft ihnen einen negativen Einfluss auf die Beziehung des Menschen zur Wirklichkeit vor. ${ }^{2}$ Diese Motive werden in den folgenden zwei Unterkapiteln zum Sprachbegriff und zur Metapher der »Kulturtrümmer« untersucht. Weil das Material relativ dünn ist, kann die Deutung nicht von empirischer Evidenz sein. Daher ist der Vergleich mit zeitgenössischen Vorstellungen und Ansichten wichtig, der zeigt, dass Schulz in keiner isolierten Position ist, sondern weitverbreitete Ideen aufnimmt und verarbeitet.

Im Unterkapitel zum »Erstarren der Bilder" gehe ich auf die Bedeutungswandlung am Bildbegriff ein, die durch die Erfindung der Fotografie noch verstärkt wurde. Dass Schulz seinem Grafikzyklus den Namen "Xięga Bałwochwalcza" (Buch vom Götzendienst) gibt, gleichzeitig aber sehr moderne Motive wie den Masochismus aufnimmt, macht eine Verortung in den seinerzeit populären Diskursen über die Magie und Macht von (fotografischen) Bildern möglich. Daher wird durch Untersuchungen zum Bild aus Schulz' Zeit, wie auch durch aktuellere bildwissenschaftliche Analysen ein Rahmen gesetzt, in welchem anschließend das Werk untersucht wird.

1 Vgl. ebd. Eine deutsche Übersetzung von Doreen Daume befindet sich im Anschluss an das Buch »Die Zimtläden«. Vgl. Schulz, Bruno: Die Zimtläden. (Aus dem Poln. von Doreen Daume). München 2009, $149 \mathrm{f}$.

2 Siehe insbesondere seinen Aufsatz »Powstają legendy« (»Legenden entstehen«), den er aus Anlass von Piłsudskis Tod verfasst hat. Vgl. Schulz, Bruno: Powstają legendy. In: Kitowska-Łysiak: Szkice krytyczne, 113-116. 


\subsection{Sprache, Kunst und Bild}

Der erst 1936 veröffentlichte, sprachphilosophische Aufsatz ${ }^{3}$ über die »Mythisierung der Wirklichkeit« hat einen kunstprogrammatischen Charakter, richtet sich aber - so scheint es - weniger an den Bildkünstler oder Literaten als an den Philosophen. ${ }^{4}$ Dies wird aus mehreren Aspekten ersichtlich: Erstens entwickelt Schulz darin Ansätze einer Erkenntnis-, Sprach- und Wahrnehmungstheorie, die sich nur teilweise mit einer künstlerischen Programmatik decken, zweitens geht er auf die Frage des »Wesens« der Sprache und den Ursprung der Wirklichkeitsvorstellung ein und drittens wendet er sich im letzten Absatz an die Philosophie, die seines Erachtens eine Philologie sei, eine "schöpferische Wortforschung." ${ }^{5}$

Schulz' Aufsatz behandelt dabei sehr viele Aspekte, die aufgrund der Fülle der Begriffe und der Kürze des Traktats viele Fragen offen lassen. Zentraler Gegenstand des Textes ist die Wirklichkeit und ihre Genese. Die Wirklichkeit ist in Schulz' Darstellung nicht in erster Linie empirisch oder durch naturwissenschaftliche Methoden erfassbar, sondern Resultat der Sprachfähig-

3 Der Erstdruck dieses äußerst kurzen Aufsatzes erschien 1936 in der Zeitschrift »Studio«. Schulz hatte sich in dieser Zeit schon lange als Schriftsteller in der Kunstszene etabliert. Trotz des literarisch-philosophischen Manifestcharakters der Schrift fehlen eine direkte Bezugnahme auf das eigene Schaffen und - wie im "Schulz-Wörterbuch « betont wird - auch Begriffe wie »Prosa«, »Erzählung« oder »Roman«, die man durchaus erwarten könnte. Darüber hinaus fehlt das Wort »Wahrheit«, was angesichts eines erkenntniskritischen Anspruchs zumindest verwundert. Stattdessen sind die zentralen Kategorien »Sinn«, »Sprache« und »Poesie«. Vgl. Mityzacja rzeczywistości. In: Bolecki, Słownik schulzowski, 224.

4 Wiesław Paweł Szymański erkennt in Schulz' Manifest eine Wortontologie, die die Vieldeutigkeit der Worte als ihre eigentliche Charakteristik erkennt. »Im Bewusstsein, dass das Wort der poetische Stoff ist, dass man das Wort an sich - >Ding an sich $<$ - nicht erkennen kann, weil es kein statischer Fakt ist, sondern eine dynamische Realität, welche den historischen Prozessen unterliegt, mit wandelbarer emotionaler Färbung. Vor allem aber unterliegt es dem Kontext der umgebenden Wörter. Ein Wort vermittelt nur bis zu einem bestimmten Grade eine Information, es ist der Vieldeutigkeit, dem Symbol näher als der eindeutigen Definition. Das Wort ist einzig eine gewisse Kraft, Möglichkeit, die sich im Kontext des gesamten Wortkomplexes realisiert, und ist damit von dieser Wortanordnung abhängig." (Übers. A. J.) »W świadomości, że tworzywem poetyckim jest słowo, że słowa jako takiego, Ding an sich, nie da się uchwycić, bo nie jest ono faktem statycznym, ale rzeczywistością dynamiczną, uległą procesowi historii, zmiennym zabarwieniem emocjonalnym, przede wszystkim może - kontekstowi słów sąsiadujących. Słowo tylko do pewnego stopnia przekazuje informacje, bliższe jest wieloznaczności, symbolowi niż jednoznacznemu określeniu. Słowo jest jedynie pewną potencją, możliwością, która realizuje się w kontekście całego zestawu słów, a więc jest od tego zestawu słów uzależnione." Szymański, Outsiderzy i słowiarze, $97 \mathrm{f}$.

5 Im Original heißt es »twórczym badaniem słowa«. Schulz, Mityzacja rzeczywistości, 12. 
keit des Menschen. Der Mensch kreiert mit Worten Sinn, welcher wiederum Wirklichkeit schafft. Als das absolut Gegebene, als Kern und Wesen des Daseins, setzt Schulz den »Sinn«. Dieser steht hierarchisch noch über den Ideen, welche nur ein Derivat der sinnverleihenden Mythologien seien. "Selbst das kleinste Körnchen unserer Ideen ist aus der Mythologie hervorgegangen - ist seinerseits verwandelte, verstümmelte, ungeformte Mythologie. " "Sinn" ist somit der Ur-Impuls der Wirklichkeit; von ihm geht alle Kunst, Philosophie, Wissenschaft aus und diese schaffen wiederum den Sinn. ${ }^{7}$

In dem Verständnis, dass ein Phänomen erst dann Bedeutung erlangt, wenn es durch Sprache in einen Sinnzusammenhang gebracht wird, ist der Satz zu deuten: "Das Unbenannte existiert für uns nicht. $\aleph^{8}$ Schulz schließt damit die Existenz einer vor-wörtlichen Wirklichkeit jedoch nicht aus. Er markiert lediglich die Sprache als vermittelndes Symbol zwischen Gegenstand und Mensch. ${ }^{9}$ Wichtig in diesem Zusammenhang ist die Bedeutung des polnischen Worts "rzeczywisty« (wirklich). In die Einzelwörter zerlegt und übersetzt bedeutet es »Dinge« und »sehend/sichtbar.« Darüber hinaus ist das polnische Wort »rzecz« mit dem Stamm »rzec« verwandt, was wiederum sprechen, sagen, kommunizieren bedeutet. ${ }^{10}$ Anders ausgedrückt wird durch Sprache die Sache sichtbar, also wirklich.

Woher die Sprache kommt, lässt Schulz dabei offen. ${ }^{11}$ Darüber hinaus sind es nicht die einzelnen Worte, die für Schulz Wirklichkeit schaffen, sondern

6 Schulz, Bruno: Die Mythisierung der Wirklichkeit. In: Die Zimtläden, 149-152, hier 150. »Nie ma ani okruszyny wśród naszych idei, która by nie pochodziła z mitologii - nie była przeobrażoną, okaleczoną, przeistoczoną mitologią."Schulz, Mityzacja rzeczywistości, 11.

7 In dieser Definition kommt Schulz Hans Blumenbergs Definition der Aufgabe des Mythos sehr nahe. "Alles Weltvertrauen fängt an mit den Namen, zu denen sich Geschichten erzählen lassen. Dieser Sachverhalt steckt in der biblischen Frühgeschichte von der paradiesischen Namensgebung. Er steckt aber auch in dem aller Magie zugrunde liegenden Glauben, wie er noch die Anfänge von Wissenschaft bestimmt, die treffende Benennung der Dinge werde die Feindschaft zwischen ihnen und dem Menschen aufheben zu reiner Dienstbarkeit. Der Schrecken, der zur Sprache gefunden hat, ist schon ausgestanden."Blumenberg, Hans: Arbeit am Mythos. Frankfurt a. M. 2001, $40 \mathrm{f}$.

8 Schulz, Die Zimtläden, 149. »Nienazywane nie istnieje dla nas. «Schulz, Mityzacja rzeczywistości, 11.

9 Der Mensch ist bei Schulz weniger ein Erkennender und Vollendender, denn ein Schaffender und Formender. So ist es die ursprünglichste Aufgabe des Geistes Geschichten und Märchen zu erfinden - »bajanie« und »majaczenie.»

10 Rzec. In: Długosz-Kurczabowa, Krystyna: Nowy słownik etymologiczny języka polskiego. Warszawa 2003, 449-453.

11 Dies weist darauf hin, dass ihn vor allem die Funktion, weniger der Ursprung der Sprache interessiert. Die Ursprungsfrage war jedoch in seiner Zeit Gegenstand unterschiedlichster Untersuchungen. Benjamin untersucht in seinem Aufsatz »Probleme der Sprachsoziologie« unterschiedliche Forschungsansätze zur Erklärung der Sprache und entwickelt in seinem kurzen Aufsatz über das "mimetische Vermögen« einen Erklärungsansatz für 
die erzählende, sinnerzeugende Sprache als Gesamtkörper, weshalb eine Herleitung seines mythenschaffenden Sprachbegriffs aus der Kabbala nicht eindeutig ist. ${ }^{12}$ Als Bürgen dieser »erzählenden Sprachschöpfung « ruft Schulz darüber hinaus die »alten Kosmogonien ${ }^{13}$ auf und markiert damit eine Allgemeingültigkeit seiner Abhandlung, die sich keinesfalls allein auf die biblische, sondern auch auf die griechische und andere Mythologien stützt. ${ }^{14}$ Dieses für Schulz typische Vorgehen nennt Renate Lachmann »Mythen-Synkretismus « ${ }^{15}$. Wichtiger als eine konkrete Erklärung - beispielsweise der Sprachfähigkeit des Menschen durch das göttliche Einhauchen des Odems -,

die Entstehung der Schrift. Vgl. Benjamin, Walter: Probleme der Sprachsoziologie. In: Tiedemann-Bartels, Hella (Hg.): Gesammelte Schriften III. Kritiken und Rezensionen. Frankfurt a. M. 1991, 452-480, sowie Benjamin, Walter: Über das mimetische Vermögen: (2). In: Tiedemann, Rolf/Schweppenhäuser, Hermann (Hg.): Gesammelte Schriften II. Aufsätze, Essays, Vorträge. Frankfurt a.M. 1991, 210-213. Nietzsche wiederum weise nach Schlüpmann in seinen frühen Schriften darauf hin, dass der Ursprung der Sprache noch in der Philosophie der Aufklärung mit einer Gottessprache erklärt wurde, also die Philosophie nicht über den mythologischen Horizont zu blicken vermocht habe. Vgl. Schlüpmann, Heide: Nietzsches ästhetische Opposition. Stuttgart 1977, 19-22.

12 Panas begreift das Traktat selbst als ein kabbalistisches. Vgl. Panas, Księga blasku, 128. Gershom Scholem weist in seinen Schriften wiederholt darauf hin, dass es nicht nur eine einzige Kabbala oder die jüdische Mystik gebe, sondern eine Vielzahl an Strömungen. In seinem Hauptwerk "Die Jüdische Mystik in ihren Hauptströmungen « zeigt er, dass allen Mystikern eine pantheistische Grundhaltung gemein ist, die auch in Dingen der Erde göttliches Wirken oder Wesen sieht. Dieser Pantheismus hängt in der jüdischen Lesart gerade mit der Schöpfung durch Gottes Wort zusammen. Die hebräische Sprache wird als göttliche betrachtet. "Alles Lebendige besteht letzten Endes durch die Sprache Gottes, und was könnte letzten Endes Offenbarung anderes offenbaren als Gottes Namen?« Scholem, Gershom: Die jüdische Mystik in ihren Hauptströmungen. Frankfurt a. M. 1993, 19.

13 Der altgriechische Terminus "Kosmogonien « ruft die antike Vorstellung vom Ursprung der Welt hervor, allerdings gehört der Satz "am Anfang war das Wort « deutlich zum gängigen Zitaterepertoire des Neuen Testaments, das sich direkt auf die erste Genesis bezieht: "Im Anfang war das Wort, und das Wort war bei Gott, und Gott war das Wort." Evangelium nach Johannes 1,1.

14 Nach Karen Underhill vermeidet Schulz die Offenlegung der mystischen Struktur und Herkunft seines Sprachbegriffs. "Schulz, interestingly, is the one of this pair [Benjamin und Schulz, A. J.] who wants to avoid using Judeo-Christian theological language to describe this key aspect of his language philosophy, and so selects the word ss e n s, and also the idea of primordial smyth. I believe the choice of this vocabulary belongs to the gesture of concealment that is also central to Schulz's messianic textual strategies. Again, in both cases we are dealing with a very similar idea: we can call it the messianic surplus of language; or language as such as messianic surplus.« K. Underhill, Bruno Schulz and Jewish Modernity, $68 \mathrm{f}$.

15 Seine Schneiderpuppen Erzählungen untersuchend schreibt sie: „Schulz' Mythen-Synkretismus und die gleitende Semantik seiner ausschweifenden Spekulationen manifestieren sich vor allem in der Plurivozität der einzelnen Elemente. Diese verweisen immer in mehrere Richtungen zugleich.«Lachmann, Erzählte Phantastik, 358. 
ist die Rolle des mythologischen Textes als solcher, der sinnschaffend den Ereignissen und Handlungen eine Erklärung gibt. Erst damit werden die Dinge Teil der bewussten Wirklichkeit und so untersuch- und verhandelbar. ${ }^{16}$

»Das isolierte Wort, das Wort als Mosaikstein, ist ein späteres Produkt, es ist bereits ein Resultat der Technik. Das ursprüngliche Wort war ein Phantasiegebilde, das den Sinn der Welt[/des Lichts $\left.{ }^{17}\right]$ umkreiste. ${ }^{18}$

16 Dass Schulz sich nicht direkt an die biblische Tradition anlehnt oder ihr gegenüber anderen Mythologien Vorrang gibt, zeigt sich nicht nur im Werk selbst, das immer wieder parallel mehrere kulturelle Folien zitiert, sondern auch im Klappentext zum »Sanatorium pod Klepsydrą" (Sanatorium zur Sanduhr), in welchem er explizit darauf hinweist, dass er sich aus vielen Mythologien gleichwertig bediene und diese zu einem neuen Werk vereine. "Der neue Prosaband von Bruno Schulz ist dem Traum von der Erneuerung der Welt durch die Kraft der Verzückung und das Entfesseln der Inspiration entsprossen, dem uralten Glauben der Menschen daran, daß die verhinderte, verborgene und gezügelte Schönheit der Dinge nur auf einen inspirierten Menschen wartet, um sich befreit als beglückende Invasion über die ganze Welt zu ergießen. Dieser alte Glaube der Mystiker gewinnt in dem Buch Gestalt, er formiert sich zu einer eigenen Eschatologie, zu einem aus den Bruchstücken aller Kulturen und Mythologien gewebten Legendenkreis, er entfaltet sich zu einer komplizierten und überwältigenden Fabulistik.» Die Übersetzung findet sich im Nachwort von Doreen Daume in Schulz, Das Sanatorium zur Sanduhr, 344f. »U korzeni tego nowego tomu prozy Schulza leży marzenie o odnowieniu świata przez moc zachwytu, przez rozpętanie inspiracji, prastara wiara ludzka, że zatamowana i ukryta, powściągnięta piękność rzeczy czeka tylko na natchnionego, ażeby wyzwolona wylać się na świat cały uszczęśliwiającą inwazją. Ta stara wiara mistyków obleka się w tej książce w ciało, formuje się w swoistą eschatologie, w krąg legendarny utkany $\mathrm{z}$ fragmentów wszystkich kultur i mitologij, rozwija się $\mathrm{w}$ fabulistykę pogmatwaną i oszałamiającą." Schulz, Bruno: [U korzeni tego nowego tomu prozy Schulza]. In: Kitowska-Lysiak: Szkice krytyczne, 8.

17 In der Originaldruckfassung von Schulz' Manifest steht, dass das ursprüngliche Wort um den »Sinn des Lichts« (»sensu światła») kreist, wobei sich die meisten Interpreten einig sind, dass dies ein Druckfehler sei und es »Sinn der Welt«, also »sensu świata» heißen müsse. So übersetzt beispielsweise Doreen Daume diese Stelle mit »Welt« und nicht mit »Licht" ins Deutsche. Sie begründet diese Wahl folgendermaßen: »Die polnischen Wörter świat (Welt) und światło (Licht) unterscheiden sich im Genitiv świata (der Welt) bzw. światła (des Lichts) nur durch das ł. Tatsächlich kommt ısens światła (`Sinn des Lichts $`$ nur ein einziges Mal hier, am Beginn des Aufsatzes vor, später ist vom `Sinn der Welt die Rede, übrigens auch in anderen Texten, etwa in dem Schreiben an Witkacy vom Winter 1934/35 (Schulz, Księga listów, S. 100), worin Schulz, auf Witkacys Bitte hin, ebenfalls versucht, seine Zimtläden sphilosophisch zu interpretieren<. - Möglicherweise handelt es sich an dieser Stelle (laut Herausgeber Jerzy Jarzębski) um einen Druckfehler in der polnischen Ausgabe. Dies scheint plausibel, in der Übersetzung wird das 1 ignoriert.« Vgl. Daume, Doreen: Anmerkungen, in Schulz, Die Zimtläden, $201 \mathrm{f}$. (Hervorh. D.D.) Die Argumentation erschiene auch einzig schlüssig, würde nicht im Johannesevangelium das Licht eine zentrale Rolle einnehmen. Schulz' Manifest übernimmt einerseits die Poesie der Anfangsverse des Evangeliums, andererseits auch die zentrale Position des »Wortes« und des »Lichts. «Im Anfang war das Wort, und das Wort war bei Gott, und das Wort war Gott. Im Anfang war es bei Gott. Alles ist durch das Wort geworden, und ohne das Wort wurde nichts, was geworden ist. In ihm war das Leben, und 
Das isolierte, mosaikhafte Wort ist für Schulz eine spätere Erfindung. Im Zuge der Moderne und der Entwicklungen in Wissenschaft und Technik haben sich eine falsche Sprachvorstellung und damit auch ein falscher Sprachgebrauch durchgesetzt, welcher notwendig Einfluss auf die Sinnerzeugung und damit auf die Wirklichkeit habe. Die neue Sprache ist Schulz zufolge funktional und an alltagspraktischen Interessen orientiert und erzeugt daher nur eine reduzierte Wirklichkeit.

»Die Sprache ist das metaphysische Organ des Menschen. Doch das Wort erstarrt im Lauf der Zeit, es verfestigt sich, zieht keinen neuen Sinn mehr nach sich. Der Dichter gibt den Worten die Führung durch die Spannungen zurück, die aus Kumulationen entstehen. Die Symbole der Mathematik erweitern das Wort um neue Bereiche. Auch das Bild ist ein Derivat des ursprünglichen Wortes, eines Wortes, das noch kein Zeichen war, sondern Mythos, Geschichte, Sinn. ${ }^{19}$

Mit dem »Erstarren« der Worte geht auch ein Sinnverlust einher..$^{20}$ Der Dichter hingegen belebt die Sprache durch poetische Anwendung und restituiert

das Leben war das Licht der Menschen. Und das Licht leuchtet in der Finsternis, und die Finsternis hat es nicht erfasst." Evangelium nach Johannes 1,1-5. "Licht" steht in biblischer Lesart für Gottes »Offenbarung und Lebensspendung."Vgl. Schnackenburg, Rudolf: Das Johannesevangelium. T. 1 Einleitung u. Kommentar zu Kapitel 1-4. Freiburg im Breisgau 2001, 221. In »Wiosna " findet sich eine komplexe Licht- und Dunkelheitsmetaphorik, die diese Lesart mit reflektiert. Gleichzeitig wird der christliche Kontext durch die Nennung anderer Kontexte wieder aufgehoben. "Świat" und "światło" sind dabei in allen slavischen Sprachen verwandte Wörter, sodass die Konntotation von Licht und Welt in Abgrenzung von Dunkelnheit und Nicht-Welt besonders weite Verbreitung habe. Vgl. Świat. In: Długosz-Kurczabowa, Nowy słownik etymologiczny języka polskiego, 488-490. Zu diesem Zusammenhang im Kontext der "Weltanschauung siehe Kowalewicz, Michel H.: Weltbilder, Weltanschauung und Mind: Freuds Via regia versus Ars interpretandi oder Voyage au bout de la nuit. In: Lang, Hermann/Dybel, Paweł/Pagel, Gerda (Hg.): Hermeneutik und Psychoanalyse. Perspektiven und Kontroversen. Würzburg (im Druck), 33-72.

18 Schulz, Die Mythisierung der Wirklichkeit, 149. "Izolowane, mozaikowe słowo jest wytworem późnym, jest już rezultatem techniki. Pierwotne słowo było majaczeniem, krążącym dookoła sensu światła, było wielką uniwersalną całoścą." Schulz, Mityzacja rzeczywistości, 11.

19 Schulz, Die Mythisierung der Wirklichkeit, $151 \mathrm{f}$. »Jednakowoż słowo z biegiem czasu sztywnieje, ustala się, przestaje być przewodnikiem nowych sensów. Poeta przywraca słowom przewodnictwo przez nowe spięcia, które z kumulacji powstają. Symbole matematyki są rozszerzeniem słowa na nowe zakresy. Także obraz jest pochodną słowa pierwotnego, słowa, które jeszcze nie było znakiem, ale mitem, historią, sensem.« Schulz, Mityzacja rzeczywistości, 12.

20 Bolecki hat wie viele andere Wiessenschafter auf Schulz' doppelten Sprachbegriff hingewiesen, den der Alltagssprache und den der Ursprungssprache. Poesie ist die Regeneration der ursprünglichen Sprache in der Gegenwart, wobei der Poesiebegriff wieder anders als in der Literaturwissenschaft nicht für die Dichtung steht, sondern für dichterisches Erzählen - für Kunst. Vgl. Bolecki, Poetycki model prozy, $173 \mathrm{f}$. 
damit ihre ursprüngliche Funktion. ${ }^{21}$ In dieser Ursprache waren Mythos, Geschichte und Sinn noch eines, wie es auch Bild und Sprache waren. Die Poesie ist damit nicht Ursprache, sondern Gebrauchssprache, die sich der früheren Sprachmagie öffnet. Damit verfasst Schulz eine Erklärung und Etymologie der Sprachkunst. ${ }^{22}$ Schulz geht aber noch weiter und stellt die empirische Gültigkeit der durch Wissenschaft und Technik erzeugten Wirklichkeit infrage, da auch die Wissenschaften auf einer Sprachanwendung beruhen und sich das urtümliche Element nicht aus der Sprache bereinigen lässt, wie es der logische Positivismus postulierte. ${ }^{23}$ Damit sind nach Schulz die Wissenschaften ebenfalls Teil der großen Mythologie.

"Doch auch die Wissenschaft [das Wissen, A.J.] ist nichts anderes als das Errichten eines Welt-Mythos, denn der Mythos liegt schon in den bloßen Elementen, und wir können aus dem Mythos nicht heraus. ${ }^{24}$

$21 »[D]$ iesen Drang zurück zum Ursprungsort, seine zurückgeandte Sehnsucht, die Sehnsucht nach der Urheimat nennen wir Poesie.« Schulz, Die Mythisierung der Wirklichkeit, 150. "[T]ę dążność słowa do matecznika, jego powrotną tęsknotę, tęsknotę do praojczyzny słownej, nazywamy poezją.«Schulz, Mityzacja rzeczywistości, 11.

22 Bolecki betont, dass neben der sprachphilosophischen Ebene dieser Aufsatz vor allem ein kunsttheoretischer sei und zeigt die deutlichen Anleihen aus Nietzsches Philosophie auf. »Das Ziel des Mythisierens sei die Wiedererlangung der Einheit, der Mythos ist also in Schulz' Kunstauffassung eine ursprüngliche Wirklichkeit. In dieser ursprünglichen Wirklichkeit liege der Daseinssinn verborgen, den es in der modernen Kunst nicht gebe, die aus unzusammenhängenden Fragmenten alter Kulturen und Mythen erreichtet sei. Um also zur Ursprünglichkeit vorzudringen, zum Mythos, zum Sinn, so Schulz, müsse man zuerst den Schein abwerfen, den die Sprachen der modernen Zivilisation schaffen. Das ist die Schulzsche Spielart der Kritik der apollinischen Kunst. Zu zentralen Kategorien werden für Schulz der Mythos, verstanden als Ursprünglichkeit und die ganzheitliche Idee einer Rückkehr in den Zustand jener Ursprünglichkeit. Es steht außer Zweifel, dass diese Vorstellung eine weitere Variante des nietzscheanischen Gedankens der >ewigen Wiederkehr` ist." Bolecki, Włodzimierz: Das sprincipium individuationis`: Nietzscheanische Motive im Werk von Bruno Schulz. In: Schultze, Brigitte/Göbler, Frank (Hg.): Polnische Literatur im europäischen Kontext. Festschrift für Brigitte Schultze zum 65. Geburtstag. München 2005, 13-33, hier 25.

23 Der logische Positivismus der Wiener Schule baute zwar auf den Schriften Comtes und Machs auf, fokussierte aber verstärkt auf die Logik und Mathematik, welche ihnen zufolge erfahrungsunabhängig seien. Insbesondere die Ausrichtung auf sprachanalytische Untersuchungen führte sie zu der Annahme, dass metaphysische Probleme vor allem sprachliche seien, die man durch eine Kontrolle der Sprache eliminieren könne. Wahrheit über die Wirklichkeit zu erlangen sei Sache der Wissenschaften und nicht der Philosophie. Vgl. Haller, Rudolf: Neopositivismus. Eine historische Einführung in die Philosophie des Wiener Kreises. Darmstadt 1993, 2 f. Siehe ebenso Stemmer, Peter: Sprachanalytische Philosophie (20. Jahrhundert). In: Borsche, Tilman (Hg.): Klassiker der Sprachphilosophie. Von Platon bis Noam Chomsky. München 1996, 401-420, hier $401 \mathrm{f}$.

24 Schulz, Die Mythisierung der Wirklichkeit, 151. "Ale i wiedza nie jest niczym innym, jak budowaniem mitu o świecie, gdyż mit leży już w samych elementach i poza mit nie możemy w ogóle wyjść.« Schulz, Mityzacja rzeczywistości, 12. 
Durch die universale Bedeutung, die Schulz dem Mythos zuschreibt, wird deutlich, dass es ihm nicht um konkrete Mythen oder Mythologien geht, sondern um deren besondere Form, der Welt der Phänomene einen sinnvollen Narrativ gegenüber zu stellen. ${ }^{25}$ Anstelle eines Gottesbegriffs transzendiert Schulz das Wort »sens" (Sinn) und misst diesem größtmögliche Bedeutung zu; die Sprache wiederum ist Trägerin dieses Sinns. Im vorletzten Absatz geht er noch auf die Mathematik und die Bilder ein, welche ebenfalls Sinnerzeuger seien, allerdings im Sinne einer Ausdehnung des ursprünglichen Wortes auf neue Bereiche. ${ }^{26}$ Fieguth weist darauf hin, dass dieser sprach- und textfokussierte Aufsatz nicht hinreichend ist, die Bildwelt von Schulz zu erklären, die doch die eigentliche Poetizität seines Prosawerks ausmacht.

"Buch, Text, Silben einerseits und Bild, Farbe, Himmel, Weite andererseits gehen hier mühelos auseinander hervor und ineinander über. Dies hat zum einen den Effekt einer Veranschaulichung, einer Verbildlichung des Sprachlichen und Textuellen in dieser Prosa wie in orientalischen Buchminiaturen oder in moderner bildender Kunst, wenn sie Wirklichkeitsimitate und graphische Zeichen kombiniert. Zum anderen eignet dem allem beständig die Wollust der Versündigung gegen das biblische Bildverbot. ${ }^{27}$

Damit wird deutlich, dass zum Manifest weitere Erklärungen und Erläuterungen notwendig sind, um Schulz' Werk zu verstehen, und dass eine fokussierte Untersuchung der Bilder in Bildwerk, Prosa und Theorie ein sinnvolles Komplementär ist. Die Deutung des Aufsatzes »Mityzacja rzeczywistości« wird daher an dieser Stelle skizzenhaft bleiben und im Laufe der Analysen weiter ergänzt und vertieft.

25 Herta Schmid untersucht die »Sprachursprungstheorie« von Schulz im Vergleich zu Bolesław Leśmian und betont, dass beide schon deshalb keine Mythologien im herkömmlichen Sinne schreiben, da ihnen die dazugehörige "gebundene« Geisteshaltung fehle, »denn beide reflektieren ihr eigenes schriftstellerisches Tun, in den poetischen Werken wie auch außerhalb dieser in Traktaten und theoretischen Aufsätzen." Schmid, Sprachursprungstheorien, 45.

26 Vgl. Schulz, Mityzacja rzeczywistości, 12.

27 Vgl. Fieguth, Rolf: Eine Art Zusammenhangsheimweh: Notizen zu Intertextualität, Komposition und Sprachkonzeption bei Bruno Schulz. In: Grübel, Rainer/Schmid, Wolf/Hansen-Löve, Aage A. (Hg.): Wortkunst, Erzählkunst, Bildkunst. Festschrift für Aage A. Hansen-Löve. München 2008, 310-326, hier 323. 


\subsection{Trümmerfeld der Moderne}

"Die Epoche stand unter dem Zeichen der Mechanik und der Elektrizität, und eine ganze Flut von Erfindungen quoll unter den Flügeln des menschlichen Genius hervor und ergoß sich über die Welt. ${ }^{28}$

Schulz grenzt sich wie viele seiner Zeitgenossen in seiner Theoriebildung direkt und explizit vom Positivismus ab. ${ }^{29}$ Dabei ist nicht der polnische Positivismus $^{30}$ gemeint, der im 19. Jahrhundert zur Zeit der Teilung für eine nationale Identitätsarbeit eintrat, ${ }^{31}$ sondern die aus Frankreich stammende philosophische Strömung, die in ganz Europa weiten Widerhall fand und teilweise mit einer religiösen Technik- und Wissenschaftsgläubigkeit einherging. ${ }^{32}$

28 Schulz, Sanatorium pod Klepsydrą, 312. „Epoka stała pod znakiem mechaniki i elektryczności i cały rój wynalazków wysypał się na świat spod skrzydeł geniuszu ludzkiego." Schulz, Bruno: Kometa. In: Jarzębski, Jerzy (Hg.): Proza. Kraków 1973, 310-325, hier 312.

29 In seinen theoretischen Schriften findet sich eine explizite Auseinandersetzung und Ablehnung des Positivismus in dem Aufsatz "Legenden entstehen " (Powstają legendy), sowie in der Kritik »Wanderungen eines Skeptikers« (Wędrówski Sceptyka). Auch in den Erzählungen finden sich ironische Auseinandersetzungen mit Technik und Technikgläubigkeit, beispielsweise in den Schneiderpuppen-Traktaten sowie in der Erzählung "Der Komet«.

30 Als Begründer der philosophischen Hauptströmung gilt Auguste Comte (1798-1957), der im Zuge des Fortschritts der Technik und der exakten Wissenschaften eine »wissenschaftliche Weltanschauung" entwarf, die er selbst als "positive Philosophie« bezeichnete. Die kritische Wendung gegen die Theologie und die Metaphysik, die lange Zeit die Deutungshoheit über die Natur-, Gesellschafts- und Geisteswissenschaften hatten, schlug teilweise um in eine problematische Negation ihrer Methoden und Erkenntnisse insgesamt und in eine Aufoktroyierung der »szientistischen " Ansätze auf alle Bereiche. Theologie und Metaphysik sind im Zeitalter des 'positiven Geistes` als Theorien minderer Erklärungskraft überholt und haben nur noch historische Bedeutung. Klassische Erkenntnistheorie im Sinne einer Selbstreflexion des erkennenden Subjekts wird abgelöst durch eine Methodologie der Wissenschaften, als deren Sinnkriterium der technisch-wissenschaftliche Fortschritt fungiert. Vgl. Positivismus. In: Ritter, Joachim/ Gründer, Karlfried (Hg.): Historisches Wörterbuch der Philosophie. Darmstadt 1989, 1119.

31 Der polnische Positivismus entwickelte sich in Folge der Teilungen und der missglückten Aufstände. Die »Inteligencja» suchte durch »organische Arbeit» breite Bevölkerungsschichten humanistisch zu erziehen. Dabei ging es auch um die Bewahrung und Gründung einer nationalen Identität als Antwort auf den Verlust der Souveränität. Stil und Themenspektrum orientieren sich am Realismus. Vgl. Positivismus. In: Langer, Dietger: Polnische Literaturgeschichte. Ein Abriss. München 2010, 101-118.

32 Auf die Grundzüge dieser "Gläubigkeit" geht Walter Benjamin in seinem Opus Magnum, dem »Passagen-Werk«, ein. Dabei zeigt er auf, wie einerseits die theologische Transzendenz an Bedeutung verliert, andererseits die Vorstellung eines Menschheitsfortschritts aber stärker wird. Darin erkennt er eine Verschiebung der religiösen Sphäre 
»Die positivistische Philosophie der Geschichte und der Kultur, wie sie insbesondere von Comte begründet worden ist, nimmt einen Stufengang der geistigen Entwicklung an, durch den die Menschheit allmählich von den ’primitiven` Phasen des Bewußtseins bis zur theoretischen Erkenntnis und damit zur vollendeten geistigen Beherrschung der Wirklichkeit emporgeführt wird. Von den Fiktionen, von den Phantasmen und Glaubensvorstellungen, die jene ersten Phasen erfüllen und kennzeichnen, führt der Weg immer bestimmter zur wissenschaftlichen Erfassung der Wirklichkeit, als einer Wirklichkeit reiner $>$ Tatsachen $\longleftarrow .{ }^{33}$

So beschreibt Ernst Cassirer die Grundannahme der positivistischen Anschauung, von der er seine Philosophie explizit abgrenzt. ${ }^{34}$ Dieser Auffassung setzt er eine wertungsfreiere Systematik der Welterfassungsformen entgegen. ${ }^{35}$ Er zeigt, dass die verschiedenen symbolischen Formen wie Sprache, Musik, Bild, aber auch Mythos, Religion, Kunst, Wissenschaft parallel existieren und sich partiell überschneiden, da sie unterschiedliche Funktionen in der kulturellen Erfahrung der Umwelt haben. Die Idee des in allen Feldern gleichzeitig stattfindenden Fortschritts, der Überwindung der Religion oder des Mythos und der ausschließlich wissenschaftlichen Weltanschauung, ist nach Cassirer selbst Teil einer mythischen Vorstellung. ${ }^{36}$

Eine ähnliche Grundhaltung findet sich auch bei Schulz. Auch er sucht mit seinem künstlerischen Werk und seinen theoretischen Schriften eine Antwort auf die Herausforderung des Bruchs mit der "positivistischen« Welt-

in die Technik und Wirtschaft. Michael Makropoulos hat auf sehr tiefgehende Weise Benjamins Modernekritik heraus gearbeitet. Vgl. Makropoulos, Modernität als ontologischer Ausnahmezustand?

33 Cassirer, Ernst: Das mythische Denken. Darmstadt 1994, 282.

34 Cassirer, Ernst: Der Begriff der Symbolischen Form im Aufbau der Geisteswissenschaften. In: Saxl, Fritz (Hg.): Vorträge der Bibliothek Warburg. Repr. 1967. Leipzig, Berlin 1920/21, 11-39, hier $12 \mathrm{f}$.

35 Cassirer, Ernst: Wesen und Wirkung des Symbolbegriffs. Darmstadt 1956, 5 f. Cassirer geht in seiner Untersuchung auf die historische Erkenntnis ein und stellt fest, dass Geschichte immer konkrete Geschichte eines bestimmten Subjekts ist: "Sie ist die Geschichte des Staates oder des Rechts, der Sprache oder der Kunst, der Religion oder der Wissenschaft. Aber alle diese Gebilde gehen nun nicht in der bloßen Äußerlichkeit ihrer mannigfachen historischen Erscheinungsformen auf, sondern sie offenbaren in dieser Äußerlichkeit ein inneres geistiges Prinzip. Die Sprache und die Religion, die Kunst und der Mythos besitzen je eine selbständige, von anderen geistigen Formen charakteristisch unterschiedene Struktur - sie stellen jede eine eigentümliche Modalität der geistigen Auffassung und der geistigen Formung dar.« Blicke man ganzheitlich auf die geistigen Formen der Weltauffassung, so müsse man anerkennen, dass es neben der theoretischwissenschaftlichen Erkenntnis auch noch die oben genannten gebe und jede dieser Formen ihre »besondere[n] Aufgabe[n] « und ihre »besondere[n] Recht[e]« als Organe des Weltverständnisses besäßen.

36 Vgl. Cassirer, Das mythische Denken, 283. 
erklärung ${ }^{37}$ und der neueinsetzenden Wertkontingenz. ${ }^{38}$ Allerdings ist nicht davon auszugehen, dass Schulz sich fundiert mit den positivistischen Theorien und Ansätzen befasst hat, da seine theoretischen Schriften spezifische Kenntnisse vermissen lassen und sich eher polemisch-intuitiv gegen das richten, was er als Positivismus wahrnimmt. ${ }^{39}$ Darunter fallen naturwissenschaftliche Ansätze wie die nichteuklidische Geometrie, die Relativitätstheorie sowie die Psychoanalyse. ${ }^{40}$ Somit kritisiert er den ideologischen »Szientismus«, der für die weit verbreitete Geisteshaltung steht, aus der (relativen) intellektuellen wie materiellen Naturbeherrschung die Möglichkeit abzuleiten, auch das Soziale (Geschichte, Individuum, Erziehung) und Geistige (Sprache, Ideen, Vorstellungen) beherrschen zu können. ${ }^{41}$ Theologie und Philosophie verlieren in ihr an Bedeutung.

Mit seiner umfassenden Positivismusskepsis steht Schulz nicht allein, sondern lässt sich in eine Strömung von Intellektuellen seiner Zeit einreihen, die in ihrer radikalen Ablehnung des Positivismus weit über das Ziel hinaus-

37 Dabei ist Schulz selbst am direktesten mit dem logischen Positivismus beziehungsweise Neopositivismus der Wiener Schule in Berührung gekommen, da er sich zur Hochzeit ihres Wirkens in Wien aufgehalten hat. Schulz hat sich zwischen den Jahren 1914 und 1923 laut städtischem Meldeverzeichnis insgesamt dreieinhalb Jahre in Wien aufgehalten. Caneppele vermutet, dass er diese Zeit genutzt haben wird, die Wiener Kunstszene, Theater, Kinofilme und Ausstellungen zu besuchen und sich mit den Theorien der Intellektuellen auseinanderzusetzen. Vgl. Caneppele, Die Republik der Träume, $32 \mathrm{f}$.

38 Michael Makropoulos untersucht die »Deontologisierung « um die Jahundertwende und die Reaktionen auf diese Erosion der Wertüberzeugungen exemplarisch am Werk von Walter Benjamin. Zur "Eigendynamik des Kontingenztheorems" siehe Makropoulos, Modernität als ontologischer Ausnahmezustand?, 152. Dabei geht er intensiv auf Michel Löwys Untersuchung zur jüdischen Moderne und zum libertären Denken ein, welches auch die Grundlage für Underhills Vergleich von Walter Benjamins und Bruno Schulz bildet. Siehe Löwy, Erlösung und Utopie sowie K. Underhill, Bruno Schulz and Jewish Modernity.

39 Vgl. Augsburger, Janis: Ein anti-analytisches Bedürfnis: Bruno Schulz im Grenzbereich zwischen Poetik und Politik. In: Hein-Kircher, Heidi/Hahn, Hans H. (Hg.): Politische Mythen im 19. und 20. Jahrhundert in Mittel- und Osteuropa. Marburg 2006, 25-43, hier 27-30. Augsburger weist auf den Mangel an Differenziertheit hin, die Schulz' MythosTheorem problematisch werden lässt.

40 Vgl. Schulz, Bruno: Wędrówki sceptyka. In: Kitowska-Łysiak: Szkice krytyczne, 47-48, hier 47.

41 Den Szientismus als weit verbreitete Grundhaltung untersucht der Psychologe und Sozialwissenschafter Friedrich von Hayek in seinem Werk »Mißbrauch und Verfall der Vernunft«: »Es soll noch bemerkt werden, daß diese Worte in dem Sinn, in dem wir sie gebrauchen werden, eine Haltung beschreiben, die natürlich ganz unwissenschaftlich im wahren Sinn des Wortes ist, da sie eine mechanische und unkritische Anwendung von Denkgewohnheiten auf andere Gebiete, als in denen sie sich herausgebildet haben, zur Folge hat.« Hayek, Friedrich A. von: Mißbrauch und Verfall der Vernunft. Ein Fragment. Frankfurt 1959, $15 \mathrm{f}$. 
schießen. ${ }^{42}$ Sowohl in seinen theoretischen Schriften als auch in seinen literarischen Werken betont Schulz die mythischen Strukturen, die der »wissenschaftlichen« Weltanschauung eigen sind und bindet sie damit eng an die europäische Kulturtradition an. ${ }^{43}$ Dies wird in seiner Erzählung »Kometa» (Der Komet) besonders deutlich, worin die um die Jahrhundertwende immer wieder neueinsetzende Angst der "Fortschrittsgeister ${ }^{44}$ vor einem Kometeneinschlag polemisch kritisiert wird. Wie Alfred Sproede ${ }^{45}$ und Paolo Caneppele nachgewiesen haben, bezieht sich Schulz auf konkrete historische Ereignisse seiner Gegenwart. »In der Epoche des Positivismus verängstigt der Komet nicht mehr auf eine abergläubische Art, sondern vielmehr wissenschaftlich begründet. « ${ }^{46}$ Indem Schulz die wissenschaftlich begründete Weltuntergangssorge in direkten Zusammenhang mit Visionen und Darstellungen der Apokalypse bringt, verknüpft er sie wieder mit den alten Erzählungen und Mythologien und macht so den mythischen Kern der modernen Phänomene sichtbar.

"Ich bitte um Verzeihung, wenn ich bei der Beschreibung dieser Szenen mit ihren ungeheuren Türmungen und Tumulten ins Übertreiben gekommen bin, ich habe mich

42 »Überall stößt man in diesen Jahren auf das Motto `Los vom Positivismus`, das schnell $\mathrm{zu}$ einem Kampfruf aller antimaterialistischen Forschungsrichtungen wurde, die sich aus den biographisch-empirischen `Niederungen` des späten 19. Jahrhunderts wieder zu den Höhen der >reinen Gedankenwelt erheben wollten. Wie bei jedem radikalen Umbruch verfiel man dabei häufig aus einem Extrem in das andere und gab mit dem vulgärmaterialistischen Konzept von Ursache und Wirkung zugleich die historischen Voraussetzungen aller geistigen Phänomene auf.« Hermand, Jost: Literaturwissenschaft und Kunstwissenschaft. Methodische Wechselbeziehungen seit 1900. Stuttgart 1971, 1.

43 Einen vergleichbaren Ansatz verfolgen Adorno und Horkheimer in ihrem Werk »Dialektik der Aufklärung «, deren Kritik sich ebenfalls gegen den Szientismus richtet, den sie als logische Fortführung der Aufklärungsideen verstehen. »Wie die Mythen schon Aufklärung vollziehen, so verstrickt Aufklärung mit jedem ihrer Schritte tiefer sich in Mythologie. Allen Stoff empfängt sie von den Mythen, um sie zu zerstören, und als Richtende gerät sie in den mythologischen Bann."Horkheimer, Max/Adorno, Theodor: Dialektik der Aufklärung. Philosophische Fragmente. Frankfurt a. M. 2010, 18.

44 Schulz, Das Sanatorium zur Sanduhr, 320.

45 "In the collection of his tales Cinnamon Shops and in two of his stories not included in his narrative circles ('The Republic of Dreams`, 'The Comet), the author operates with almost all conceptions and slogans circulating among intellectuals and artists between Jugendstil and the beginning totalitarian movements. His style navigates between labels and programmatic attractions like decandence and Young Poland; art nouveau and fashion; progress, the cult of the machine, and avant-garde.« Sproede, Between Avantgarde and Hassidic Redemption, $490 \mathrm{f}$.

46 »Von den Astronomen wird das Zusammentreffen der Erde mit dem MeteoritenSchwarm der Leoniden im Jahr 1899 mit Spannung erwartet. Die Zeitschriften publizieren Sternkarten, um die wohlhabenden, neugierigen Blicke durch die Teleskope zu leiten, die möglichst viel von dem Spektakel Tausender auf die Erde fallender, flammender Sternschnuppen zu erhaschen versuchen. Das groß angekündigte Rendezvous entpuppt sich jedoch als Enttäuschung.« Caneppele, Die Republik der Träume, $47 \mathrm{f}$. 
dabei unwillkürlich an die alten Stiche aus dem großen Buch der Katastrophen und Destaster des Menschengeschlechts angelehnt. Freilich zielen diese auf ein Urbild hin, und die megalomanische Übertreibung, das ungeheure Pathos der Szenen zeigt es: Wir haben den Boden des ewigen Erinnerungsfasses, des mythischen Urfasses ausgeschlagen, wir sind bis zur vormenschlichen Nacht mit ihrem geschwätzigen Element, mit ihrer gluckernden Anamnesis durchgedrungen und können die schwellenden Fluten nicht mehr aufhalten. ${ }^{47}$

Später entpuppt sich der Komet als Käse, Gehirnpräparat, Embryo und wird von der personifizierten »Mode« im Fluge überholt. Dadurch verliert sich der Komet in Bedeutungslosigkeit und Vergessenheit. Die Epoche der Elektrizität und Mechanik verblasst. ${ }^{48}$

Wie viele seiner Zeitgenossen bedient sich auch Schulz bei der Untersuchung der gegenwärtigen Situation der weit verbreiteten Metapher der »Kulturtrümmerlandschaft. ${ }^{49}$ Besonders anschaulich wird dies in seinem Aufsatz »Wędrówki sceptyka« (Wanderungen eines Skeptikers). Zu zwei unterschiedlichen Zeitpunkten entwirft Schulz eine Kulturtrümmerlandschaft, zu denen ein jeweiliger »Skeptiker« gehört, der die Trümmer deutet und mit ihnen hantiert. ${ }^{50}$ Während der erste Interpret nur eine leichte Skepsis gegen-

47 Schulz, Kometa, 322. »Proszę mi wybaczyć, jeśli opisując te sceny pełne ogromnego spiętrzenia i tumultu wpadam w przesadę, wzorując się mimo woli na pewnych starych sztychach w wielkiej księdze klęsk i katastrof rodzaju ludzkiego. Wszak zmierzają one do jednego praobrazu, i ta megalomaniczna przesada, ogromny patos tych scen wskazuje, że wybiliśmy tu dno odwiecznej beczki wspomnień, jakiejś prabeczki mitu, i włamaliśmy się w przedludzką noc pełną bełkocącego żywiołu, bulgocącej anamnezy, i nie możemy już wstrzymać wezbranego zalewu.« Ebd., $321 \mathrm{f}$.

48 Vgl. ebd., 325.

49 "This view of culture in ruins is common to numerous twentieth-century artists and thinkers (Adorno, Bataille). [...] This new fragmentariness is historical and results from the state of culture." Jarzębski, Jerzy: Schulz: Universality and the Poetics of the Fragment. In: Latek, Stanisław (Hg.): Bruno Schulz. New readings, new meanings [proceedings of the International Conference, Montréal, Québec, Canada, May 4-5, 2007]. Montréal 2009, 39-54, hier 52. Besonders verbreitet ist die Metapher unter den Expressionisten. Siehe die expressionistische Gedicht-Anthologie "Menschheitsdämmerung", die 1919/20 von Kurt Pinthus herausgegeben wurde. Vgl. Pinthus, Kurt (Hg.): Menschheitsdämmerung. Ein Dokument des Expressionismus. rev. Ausg. Hamburg 1991. Auch Gershom Scholem benutzt diese Metapher in seinem Tagebuch. Vgl. Scholem, Gershom: Tagebücher; nebst Aufsätzen und Entwürfen bis 1923. Frankfurt a. M. 1995, $223 \mathrm{f}$.

50 Die Kritik »Wędrówki sceptyka« vermittelt den Anschein, eine Rezension zu Aldous Huxleys Essayband »Music at Night« zu sein, tatsächlich aber handelt es sich um Impressionen oder einen gefundenen Anlass, über die eigene Sicht auf den Zustand der Kultur zu reflektieren. Vgl. Kommentar von Jerzy Jarzębski zu »Wędrówki Sceptyka» in seinem Oberseminar für Examenskandidaten an der Jagiellonen Universität Krakau im Herbst 2010. Marta Bartosik ordnet diese Kritik den poetischen Rezensionen zu. Diese sind in Schulz' Literatursprache verfasst und geben somit weniger selbst eine Deutung, wie sie zu deuten sind. Vgl. Bartosik, Marta: Bruno Schulz jako krytyk. Kraków 2000, 30 f. 
über der Welt hat, die noch in menschlichen Kategorien bemessen und nur oberflächlich angegriffen ist, so ist der zweite Skeptiker schon bösartig, zynisch und zerstörerisch. Seine Welt ist in Trümmern und der Kern der Lebensdogmen durch eine eindeutige Weltsicht ersetzt.

"Der Kern der Lebensdogmen war [in der früheren Version, A. J.] noch unangetastet. Der weise Alte wusste noch nichts von der Hinterhältigkeit der Naturwissenschaften, er pflegte einen treuherzigen und naiven Glauben an Atome und Materie. Sein Kosmos hatte im Vergleich zum Kosmos des Kobolds vergleichsweise menschliche Proportionen. Er war in den Kategorien menschlicher Denkkraft bemessen. Seit der Zeit des guten Alten ist die Welt durch viele kleinlöchrige Siebe gegangen, in welchen sie Schritt für Schritt ihre Konsistenz verlor. Freud und die Psychoanalyse, die Relativitätstheorie und Mikrophysik, Quantentheorie und nichteuklidische Geometrie. Das, was noch durch die Siebe durchsickern konnte, war nun eine der Welt sehr unähnlich gewordene Welt, eine schleimige und formlose Fauna, Plankton mit fließenden und wogenden Konturen..$^{51}$

Die porträtierten Skeptiker lassen sich als die jeweils herrschende, personifizierte "Weltanschauung ${ }^{52}$ verstehen ${ }^{53}$ als die wirklichkeitsgarantierende Instanz, als dasjenige, was eine Mehrheit der Menschen als unumstößliche Tatsache, als Selbstverständlichkeit und damit das Wirkliche erachtet. ${ }^{54}$ Schulz

51 »Trzon dogmatów życiowych był jeszcze nie naruszony. Mądry starzec nie wiedział jeszcze o zdradliwości nauk przyrodniczych, żywił prostoduszną i naiwną wiarę w atomy i materię. Jego kosmos miał w porównaniu do kosmosu kobolda stosunkowo ludzkie proporcje. Był wymierzony w kategoriach myśli ludzkiej. Od czasów dobrego starca przeszedł świat przez wiele sit o ciasnych okach, w których zostawiał stopniowo swą konsystencję. Freudyzm i psychoanaliza, teoria względności i mikrofizyka, kwanty i geometria nieeuklidesowa. To, co przesączyło się przez te sita, to już był świat niepodobny do świata, fauna śluzowata i bezforemna, plankton o konturach płynnych i falujących." Schulz, Wędrówki sceptyka, $47 \mathrm{f}$. Weil die existierende Übersetzung von Hahn zu ungenau ist, wird hier von der Verfasserin übersetzt.

52 Über den Begriff der Weltanschauung und seine Abgrenzung zu Weltbildern siehe Kowalewicz, Weltbilder, Weltanschauung und Mind, 33-72. Siehe ebenso Ders.: Übersetzungsprobleme des Begriffs >Weltanschauung`. In: Archiv für Begriffsgeschichte (2013), 237-250 sowie Ders.: Weltanschauung und Psychoanalyse: Zu den nicht nur sprachlichen Verwirrungen solch einer intellektuellen Konstruktion< in der analytischen Praxis. In: Lang, Herrmann/Dybel, Paweł/Pagel, Gerda (Hg.): Grenzen der Interpretation in Hermeneutik und Psychoanalyse. Würzburg 2014, 113-135.

53 Diese Deutung wird durch verschiedene Hinweise im Text gestärkt. So schreibt Schulz von der »Welt, an welche der Skeptiker glaubte« (»Świat, w który wierzył»). Sein »Glaube» an die Welt ist damit entscheidend für die Gestalt, die durch »Lebensdogmen« bestimmt ist. Das Pendant zum biblischen Turmbau zu Babel ist der Bau an Ideen, welche die Schöpfung nach eigenen Kriterien neu erfinden wollen.

54 Die Frage danach, was für eine Epoche das Wirkliche ausmacht, wurde gerade in den 1920er Jahren erneut virulent. Nach Hans Blumenberg fällt sie mit einem Epochenumbruch zusammen, durch den das zuvor noch natürlich Gegebene grundsätzlich in- 
spricht der naturwissenschaftlichen Deutung ab, eine ganzheitliche Interpretation der Welt zu ermöglichen. ${ }^{55}$ Ihr steht keine übergeordnete ethische oder transzendente Vorstellung mehr gegenüber, an der sich die Experimente und Deutungen ausrichten ließen. ${ }^{56}$

Trotz der geballten und unpräzisen Kritik zählt Schulz mitnichten zu den Pessimisten. Ganz im Gegenteil nimmt er den »katastrophalen Zustand « zum optimistischen Ausgangspunkt, um »Neues« aufzubauen.

»Und vielleicht war es gut so, dass alles in Schutt gelegt wurde, dass es schon keine Heiligkeiten mehr gibt, keine Fesseln, Normen oder Dogmen, dass alles erlaubt ist und man alles erwarten kann, dass man sein Haus nach Lust und Laune aus den Trümmern wiederaufbauen kann - ganz nach Gutdünken oder schlechter Stimmung, die man noch nicht vorausahnt. ${ }^{57}$

Das Experiment im wertfreien Raum kann dann zu neuen Einsichten führen, wenn die Wertefreiheit auch tatsächlich erkannt und benannt wird. ${ }^{58}$ Auf

frage gestellt wird, ohne dass sofort eine gültige neue Gesetzlichkeit parat gestanden habe. Die Kunst reagiert nach Blumenberg auf diese Unsicherheit, indem sie nicht mehr versucht, Wirklichkeit wiederzugeben, sondern die Unverfügbarkeit des Wirklichen thematisiert. Vgl. Blumenberg, Wirklichkeitsbegriff und Möglichkeit des Romans.

55 Vgl. Augsburger, Ein anti-analytisches Bedürfnis, 50.

56 Diese Sicht auf Prozesse der Moderne wird von vielen Intellektuellen seiner Zeit geteilt. Gerade unter Künstlern wird die reine, wissenschaftliche Analyse häufig als ein "Zersetzen« gebrandmarkt. Hierzu schreibt Hermand: »Hinter den vielfältig aufgesplitterten Disziplinen und ihrer emsigen Fächerbetriebsamkeit taucht daher in steigendem Maße ein philosophisches Einheitsstreben auf, das sich weniger um die positivistisch zertrümmerten Einzelfakten als um das Grundsätzliche und Weltanschauliche bemüht. Aus diesem Grunde wird die Analyse immer stärker durch die Synthese abgelöst.« Vgl. Hermand, Literaturwissenschaft und Kunstwissenschaft, $4 \mathrm{f}$. Hannah Arendt erkennt im »Trümmerhaufen der Kultur» auch eine spezifisch jüdische Sichtweise, die mit der gescheiterten Assimilation in die europäische Kultur zusammenhänge. Die Metapher bringt sie im Zusammenhang mit Walter Benjamin und dessen Generation jüdischassimilierter Intellektueller. Diesen sei eine Trägerfunktion für die Kultur übergeben worden, die sie nicht erfüllen könnten. »Und an dieser Schwelle [des Weltgerichts] haben im Grunde alle gestanden, die dann die Meister der sneuen Zeit « wurden, sie haben ihren Anbruch vor allem als Untergang gesehen und die Geschichte mitsamt ihren Traditionen, die zu ihm führte, als einen Trümmerhaufen."Arendt, Hannah: Walter Benjamin. In: Walter Benjamin, Bertolt Brecht. 2 Essays. 2. Aufl. München 1986, hier 47.

57 » może dobrze się stało, że wszystko legło w gruzy, że nie ma już żadnych świętości, więzów, praw i dogmatów, że wszystko jest dozwolone i wszystkiego można się spodziewać, że wolno raz według swego kaprysu odbudować się z gruzów - według swego widzimisię, według chimery, której się jeszcze nie przeczuwa.« Schulz, Wędrówki sceptyka, 48. (Übers. A. J.)

58 In diesem Sinne lassen sich auch die Experimente mit der Materie und der Schöpfung des Vaters in den Erzählungen über die "manekiny« [Schneiderpuppen] verstehen. Vgl. Schulz, Bruno: Sklepy cynamonowe. In: Jarzębski, Jerzy (Hg.): Proza. Kraków 1973, 82-91, hier 56-71. 
diese Weise charakterisiert Schulz die Kunst auch in seinem offenen Brief an den Künstlerkollegen Stanisław Ignacy Witkiewicz. Darin schreibt er, dass die Kunst in den vormoralischen Tiefen operiere, wo sich die Werte erst »in statu nascendi « befänden. ${ }^{59}$

Dieses zuletzt beschworene Bild des Aufbauens aus Trümmern und Schutt erinnert wiederum deutlich an den Aufsatz "Mityzacja rzeczywistości«, in welchem die Worte metaphorisch als Bruchstücke von Götterstatuen und -skulpturen ${ }^{60}$ charakterisiert werden. ${ }^{61}$ Schulz bricht für die Geschichte wie auch für die Sprache mit der Vorstellung einer abgeschlossenen Vergangenheit und einer fortschrittlichen Zukunft und betont vielmehr die Gegenwärtigkeit alles Alten und Vergessenen. Darin zeigt sich auch die Möglichkeit zur Rettung beziehungsweise zur »Regression ${ }^{62}$, da sich die Worte ihres Ursprungs erinnern und das alte »sinnstiftende« Potential in sich bergen. In diesem Ansatz erkennt Karen Underhill Schulz' Messianismus und Verwurzelung in der jüdischen Moderne. ${ }^{63}$

59 Vgl. Schulz, Bruno Schulz do St. I. Witkiewicza, 20.

60 Die Bedeutung und Funktion von Götternamen ist ein in den 1920er Jahren intensiv erforschtes und weit diskutiertes Motiv. Eine wichtige Schrift und Anstoß zur Auseinandersetzung war Hermann Useners Werk "Götternamen. Versuch einer Lehre von der Religiösen Begriffsbildung «, das breit gelesen und diskutiert wurde. Usener begründet die Entstehung der Mythologie aus dem Bedürfnis des Menschen nach Erklärungen, die ihm die alltäglichen Kulturhandlungen sinnvoll machen. Er prägt damit die Vorstellung von der mythischen Phase als "Kindheitsstufe der Völker" - ein Bild, das von vielen Forschern und Intellektuellen aufgenommen wird. Vgl. Usener, Hermann: Götternamen. Versuch einer Lehre von der religiösen Begriffsbildung. Bonn 1896, V.

61 Vgl. Schulz, Mityzacja rzeczywistości, 11.

62 »Ale gdy jakimś sposobem nakazy praktyki zwalniają swe rygory, gdy słowo, wyzwolone od tego przymusu, pozostawione jest sobie i przywrócone do praw własnych, wtedy odbywa się w nim regresja, prąd wsteczny, słowo dąży wtedy do dawnych związków, do uzupełnienia się w sens - i tę dążność słowa do matecznika, jego powrotną tęsknotę, tęsknotę do praojczyzny słownej, nazywamy poezją." Ebd. "Doch wenn die Gebote der Praxis auf die eine oder andere Weise ihre Zügel lockern, wenn das Wort, von diesem Zwang befreit, sich selbst überlassen ist und wieder den eigenen Gesetzen zurückgegeben wird, dann regrediert es, strömt zurück, strebt nach früheren Verbindungen, möchte wieder vollständig zu Sinn werden - und diesen Drang des Wortes zurück zum Ursprungsort, seine zurückgewandte Sehnsucht, die Sehnsucht nach der Urheimat des Wortes nennen wir Poesie.« Schulz, Die Mythisierung der Wirklichkeit, $149 \mathrm{f}$.

63 Karen Underhill untersucht Schulz' Texte im Kontext einer jüdischen Moderne, die religiöses Gedankengut (vor allem aus der Kabbala) säkularisiert und mit Theorien der Moderne (Kritik am Positivismus, an der Technik etc.) mischt. Dabei stützt sie sich insbesondere auf Michael Löwys Forschungen (Vgl. Löwy, Erlösung und Utopie). Den Intellektuellen sei ein sprachphilosophischer Ansatz eigen, der sich in der Idee der »Offenbarung in Sprache« ausdrücke und Sprache als weltschaffend begreife. Gleichzeitig sei die kabbalistische Theorie der zerbrochenen Gefäße Ansatz, aus der als brüchig wahr- 
Gerade in dieser Aufstellung sind sich Bruno Schulz und Walter Benjamin erstaunlich ähnlich. In seinem "Engel der Geschichte« in seinen Thesen zur Geschichte $^{64}$, sowie in seinem Aufsatz aus dem Frühwerk »Über die Sprache überhaupt und über die Sprache des Menschen ${ }^{65}$ finden sich neben deutlichen Unterschieden bemerkenswerte Parallelen. Wie Schulz bedient Benjamin fast zeitgleich das Bild des Trümmerfelds der Kultur. ${ }^{66}$

In der IX. These »Über den Begriff der Geschichte« blickt anstelle des Skeptikers der »Engel der Geschichte « auf diese Trümmerlandschaft. In seinen Augen findet kein Fortschritt statt, sondern ein Verfall. Anders als Schulz' Skeptiker ist Benjamins Engel kein temporärer Deuter, sondern er wirft aus einer sehr distanzierten Perspektive einen transzendenten Blick auf das Geschehen. ${ }^{67}$ Damit scheint Benjamins Vergleichspunkt eher eine göttliche Perspektive zu sein, während Schulz' Referenzpunkt in erster Linie im Geistigen, das heißt im menschlichen Bewusstsein, verortet ist - als temporäre, normendefinierende Weltanschauung. Dies zeigt sich auch deutlich in seinem Aufsatz »Powstają legendy (Legenden entstehen), in welchem Schulz erneut den Positivismus und die Naturwissenschaften mit einem »Zersetzen« in Verbindung bringt und der gesamten Epoche seit dem 19. Jahrhundert einen »Geist der Kleinheit« (duch małości) unterstellt.

genommenen Gegenwart wieder ein Ganzes zu fügen. Der dritte Punkt sei der Messianismus und vor allem die Vorstellung, dass die Erlösung jede Sekunde kommen könnte. Das dialektische Denken im Messianismus, das heißt die Wiederherstellung des Alten unter Hinzufügung eines Neuen (Utopischen) sei hier das ausschlaggebende Moment. Vgl. K. Underhill, Bruno Schulz and Jewish Modernity, 3-19.

64 Vgl. Benjamin, Walter: Über den Begriff der Geschichte. In: Tiedemann, Rolf/Schweppenhäuser, Hermann (Hg.): Gesammelte Schriften I. Abhandlungen. Frankfurt a.M. 1991, 690-704.

65 Vgl. Benjamin, Walter: Über die Sprache überhaupt und über die Sprache des Menschen. In: Tiedemann, Rolf/Schweppenhäuser, Hermann (Hg.): Gesammelte Schriften II. Aufsätze, Essays, Vorträge. Frankfurt a. M. 1991, 140-157.

66 Siehe Benjamins IX. These in »Über den Begriff der Geschichte«, die anders als die meisten anderen Thesen stark allegorisch-symbolisch angelegt ist und den Thesen insgesamt eine theologische (religiöse) Bedeutung verleiht. Vgl. Benjamin, Über den Begriff der Geschichte, 697.

67 In seinem Aufsatz "Der Blick des Engels« weist Jürgen Ebach darauf hin, dass Benjamin für die Blickrichtung des Engels sich an Figuren der hebräischen Bibel orientiert hat. »Dem Hebräer« liege die Vergangenheit vor Augen, die Zukunft aber im Rücken. »Ist der Angelus einer, der von der hebräischen Bibel herkommt, so mußte er sich nicht umwenden. Und wäre der Blick des Engels der, den der kritische Historiker oder die materialistische Geschichtsauffassung - wenn sie es vermöchten - einzunehmen hätten, so fänden sie ein Korrelat in der Weise, in der Texte der hebräischen Bibel von der Vergangenheit reden.« Ebach, Jürgen: Der Blick des Engels: Für eine »Benjaminsche« Lektüre der hebräischen Bibel. In: Bolz, Norbert (Hg.): Walter Benjamin. Profane Erleuchtung und rettende Kritik. Würzburg 1985, 67-101, hier 73. 
»Es wohnt uns ein Geist der Kleinheit inne, der zerstückelt, wühlt, gräbt und werkt, bis er den Felsen der Größe zerkleinert, unterspült und abgetragen hat. [...] Um $\mathrm{zu}$ verstehen, muß der Mensch verkleinern. Die Leidenschaft des Begreifens und der Assimilation ist eine elementare Kraft und eine automatische Funktion der Menschheit. ${ }^{68}$

In direkter Kritik der »Glaubenswelt « des Positivismus ruft Schulz zu einem politischen Überwinden dieser Epoche auf. Anders aber als Benjamin schwebt ihm nicht eine Befreiung der Menschheit vor, indem die herrschende Ideologie zerstört wird, sondern eine Befreiung der Macht, indem er seine Sehnsucht nach einem Helden formuliert, dessen politische Taten einer Idee der »Größe« folgen. ${ }^{69}$

"At the heart of the essay's argument is humanity's tendency toward small-mindedness - the ideal of which would be petit-bourgeois creature comforts - unless a powerful force can act to create a sense of greatness. ${ }^{70}$

Neben Napoleon gilt der Aufsatz in Aussparung seines Namens der Glorifizierung Piłsudskis kurz nach dessen Tod. ${ }^{71}$ Die »Größe« wird als eine Kraft eingeführt, die alle Konventionen - die politischen, geistigen und gesellschaftlichen - überwindet. Dabei zeigt sich Schulz in seinem Vokabular und in seiner Argumentation stark von Nietzsches Ideen beeinflusst, wenn er von »Wola potęgi« (»Wille zur Macht«), »nadludzka ambicja« (»übermenschliche Ambition«) und einer Unterwerfung unter das Nichtverstandene schreibt, wie Janis Augsburger überzeugend nachgewiesen hat. ${ }^{72}$ Sie argumentiert,

68 Schulz, Bruno: Legenden entstehen. (aus dem Poln. Josef Hahn). In: Ficowski (Hg.): Gesammelte Werke, 227-230, hier 227. »Jest w nas jakiś duch małości, który rozdrabnia, ryje, podgryza, kruszy, aż póki nie rozdrobi, nie rozniesie, nie przeryje skały wielkości... [...] Ażeby zrozumieć, musi człowiek pomniejszać. Pasja rozumienia, asymilacji jest elementarną siłą, automatyczną funkcją ludzkości.«Schulz, Powstają legendy, 113.

69 In namentlicher Nennung Napoleons und indirekter Nennung Piłsudskis baut Schulz sich Nietzscheanischer Begriffe und Ideen bedienend - einen Mythos des Helden auf, des Sohns der Nation, der zum Übervater wird. Vgl. ebd., $114 \mathrm{f}$.

70 Anessi, The Great Heresy of the Varsovian Center, 403.

71 Das im Gegensatz zum unter den katholischen Politikern Polens weitverbreiteten Antisemitismus relativ gemäßigte Auftreten Piłsudskis brachte ihm weitreichende Unterstützung von der jüdischen Bevölkerung Polens ein, wie Ezra Mendelsohn anmerkt. Vgl. Mendelsohn, Painting a people, 179.

72 So zeige sich das Wesen der Größe in den Antinomien, der Widersprüchlichkeit und Unbegreiflichkeit, sodass man sich dieser nur über die negative Beschreibung unter dem Vorzeichen »nie-» [nicht-] nähern könne. Vgl. Schulz, Powstają legendy, 114. Augsburger erkennt in Nietzsche einen wichtigen Ideengeber für Schulz' Werk. Vor allem dessen dionysischer Weltentwurf findet sich in seinen Bildern und literarischen Texten reflektiert. »Im Gegensatz zu Nietzsche scheint für Schulz die dionysische Option aber nur noch 
dass im Ästhetischen eine »Mythisierung« andere Implikationen hat als im Politischen:

»die erkenntnistheoretische Rechtfertigung des Mythischen erhält bei Schulz durch die postulierte Allgemeinheit und Kollektivität der mythischen Poesie einen metaphysischen Charakter, der die befreiende Dimension des Mythos ins Dogmatische umschlagen läßt. ${ }^{73}$

Im Gegensatz zur Literatur fehle im Piłsudski-Aufsatz auch der ironische Bruch. Gerade das Pathos, mit dem er für eine Machtpolitik argumentiert, lässt die vielen Verlierer und Schwachen, die unter dem Recht des Stärkeren leiden, vergessen. Damit argumentiert Schulz aus der Position einer Siegerideologie, die die unterdrückten Bedürfnisse und Opfer verdrängt. ${ }^{74}$

Trotz ähnlicher Bilder und Kritikpunkte könnten sich Benjamin und Schulz an dieser Stelle kaum stärker unterscheiden. Nach Makropoulos ist es gerade die Suche nach einer neuen Totalität, die zu den Ideologien der Moderne führte. ${ }^{75}$ Benjamin kritisiert eine Geschichtsbetrachtung, die die Vergangenheit für den Sieger in Beschlag nimmt. Der Historiker müsse weiter blicken:

sprachlich offen zu sein. In der poetischen Entgrenzung kann das musikalisch-tänzerische Mysterium der Einheit nur noch angedeutet werden. Der zerbrochene Mensch bleibt dahinter immer präsent, genauso wie die zerbrochene Welt, der es an historischem Sinn mangelt. Schulz' Prosa enthält diejenigen Dinge, die in der positivistischen Erkenntniskritik, im instrumentellen Denken keinen Platz mehr haben. Gleichzeitig werden sie auf gewisse Weise verdrängt, indem sie nur noch den Ausgangspunkt für Phantasien einer anderen Welt bilden.« Augsburger, Masochismen, 53.

73 Ebd., 51.

74 In seiner II. These untersucht Benjamin die Neigung im Politischen, immer an die $\mathrm{Zu}-$ kunft zu denken. Dabei zeigt er, dass dieses Argument eines der Herrschenden ist, um mit dem zukünftigen Glück der Enkel die Masse zu kontrollieren. Hier wirkt die Fortschrittsideologie wie ein Narkotikum. Benjamin pocht hingegen auf die Revolution in der Gegenwart, die ein Unterbrechen der alten geistigen und materiellen Ordnung bedeutet. Benjamin, Über den Begriff der Geschichte, 700-702.

75 »Das `Trümmerfeld der neuzeitlichen Welt, so könnte man Benjamins Argumentation zusammmenfassen, gibt dem Leben keine evidente metaphysische Orientierung mehr. Sofern aber weiterhin die >Gesinnung zur Totalität existiert, muß dieser `Sinn`, von dem Benjamin und Lukács sprechen, gefunden, wenn nicht sogar erst geschaffen werden. Erzählen lassen sich aber nur Begebenheiten, Ereignisse und Geschichten. Der Versuch einer Neuverwurzelung des einzelnen in sich selbst und die damit verbundene Suche nach einer Orientierung, die Kontingenz aufheben könnte, die Suche nach `Sinn`, die als Wille zur Totalität noch das ganze 19. Jahrhundert prägt und mit der Katastrophe des Ersten Weltkriegs und der Inflation der 20er Jahre für Benjamin zur einschneidenden Erfahrung des Zerfalls des bürgerlichen Welt- und humanistischen Menschenbildes wurde, ist nicht erzählbar. Ebensowenig ist es die offene gesellschaftliche Situation der Moderne, die nach dem Ersten Weltkrieg in Deutschland unwiderrufliche Wirklichkeit geworden war.« Makropoulos, Modernität als ontologischer Ausnahmezustand?, 115. 
"Denn was er an Kulturgütern überblickt, das ist ihm samt und sonders von einer Abkunft, die er nicht ohne Grauen bedenken kann. Es dankt sein Dasein nicht nur der Mühe der großen Genien, die es geschaffen haben, sondern auch der namenlosen Fron ihrer Zeitgenossen. Es ist niemals ein Dokument der Kultur, ohne zugleich ein solches der Barbarei zu sein. Und wie es selbst nicht frei ist von Barbarei, so ist es auch der Prozeß der Überlieferung nicht, in der es von dem einen an den andern gefallen ist. ${ }^{76}$

In der Figur des »Engels der Geschichte« lässt sich daher auch eine Allegorie auf einen Historiker finden, der auf die Geschichte in seinem gesamten Spektrum schaut. ${ }^{77}$ Indem Benjamin den Sturm, welcher den Engel aus der Richtung des Paradieses weg in die Zukunft bläst, »Fortschritt« nennt, greift er einen der wesentlichen »Glaubensbegriffe» des Positivismus auf und dreht dessen Bedeutung um. Aus der Perspektive einer Geschichtstheologie bedeutet die Beherrschung der Natur keinen Fortschritt, sondern einen Verfall. ${ }^{78}$ Während Gershom Scholem Benjamins Thesen vor allem im Kontext der jüdischen Mystik und des Messianismus versteht ${ }^{79}$ betont Stéphane Mosès,

76 Benjamin, Über den Begriff der Geschichte, 696.

77 Eine umfassende Deutung, die auch Gershom Scholems Erläuterungen zu biografischen Bezügen aufnimmt, findet sich in Haselberg, Peter v.: Benjamins Engel. In: Bulthaup, Peter (Hg.): Materialien zu Benjamins Thesen `Über den Begriff der Geschichte`. Beiträge und Interpretationen. Frankfurt a. M. 1975, 337-356.

78 Vgl. Gfrereis, Heike: Double bind: Anmerkungen zu Benjamins Schreibweise. In: Schöttker (Hg.): Schrift, Bilder, Denken, 186-193, hier 190. Damit ist aber nicht zwangsläufig eine negative Teleologie in Abgrenzung zur positiven gemeint, sondern eine generelle Infragestellung der Idee des Fortschritts. "Die Vorstellung eines Fortschritts des Menschengeschlechts in der Geschichte ist von der Vorstellung ihres eine homogen und leere Zeit durchlaufenden Fortgangs nicht abzulösen. Die Kritik an der Vorstellung dieses Fortgangs muß die Grundlage der Kritik an der Vorstellung des Fortschritts überhaupt bilden."Benjamin, Über den Begriff der Geschichte, 701. Benjamin greift diesen Begriff immer wieder auf und verleiht ihm neuen Inhalt. »Der Begriff des Fortschritts ist in der Idee der Katastrophe zu fundieren. Daß es sso weiter geht, ist die Katastrophe. Sie ist nicht das jeweils Bevorstehende sondern das jeweils Gegebene. / Strindbergs Gedanke: die Hölle ist nichts, was uns bevorstünde - sondern dieses Leben hier. Die Rettung hält sich an den kleinen Sprung in der kontinuierlichen Katastrophe." Benjamin, Walter: Zentralpark. In: Tiedemann, Rolf/Schweppenhäuser, Hermann (Hg.): Gesammelte Schriften I. Abhandlungen. Frankfurt a. M. 1991, 655-690, hier 683.

79 Scholem versteht das "Zusammenfügen der Trümmer der Geschichte« sowohl im Kontext des Barock (Geschichte des Verfalls) als auch der Kabbala (Tikkun). Dabei bemerkt er, dass es in der Kabbala der Messias wäre, der die zerbrochenen Gefäße zusammen fügt, bei Benjamin ist es der Engel. »Alles Historische, Nicht-Erlöste hat seinem Wesen nach fragmentarischen Charakter. [...] Es ist gerade der `Fortschritt‘, der den wirklichen Tikkun der Erlösung zum immer drohenderen Problem werden läßt. Dessen Lösung liegt dann in der Sprache der Theologie beim Messias, in der Sprache des historischen Materialismus, für den Benjamin die Theologie annektiert, aber in dem dialektischen Sprung sunter dem freien Himmel der Geschichte`, bei der Revolution, die für Benjamin der 
dass es sich um eine profanierte Form der aus der jüdischen Mystik entlehnten Vorstellungen handelt. ${ }^{80}$ Nach Benjamin müssen die vergessenen und unterdrückten Elemente der Kultur und Geschichte erinnert, gedeutet und damit gerettet werden. Dadurch könnte man die Ideologie der Sieger brüchig machen und die Möglichkeiten zur bewussten Richtungsänderung erhöhen. ${ }^{81}$ Rettung von Wissen bedeutet damit immer eine intellektuelle Umkehr im Sinne eines Bruchs mit dem Kontinuum, die Übersetzung einer aktuellen oder vergangenen Erfahrung. ${ }^{82}$ Es geht um die bewusste Erfahrung der Jetztzeit im Vergangenen, das nicht abgeschlossen ist, sondern andauert. Auch für Benjamin dauert das Vergangene in der Gegenwart an und seine Wirkung zeigt sich erst, wenn die Verschränkung beider erkannt wird. Benjamin bedient sich in diesem Kontext wiederholt theologischer Begriffe und Vorstellungen, wie der "profanen Erleuchtung" und des "Erkennens der Namen. ${ }^{83}$

Für Benjamin wie für Schulz ist dabei die Rolle der Sprache zentral. Beide betonen, dass der Mensch in Sprache die Welt erfasst, sie ihm also durch Sprache wirklich wird, und beide dehnen den Sprachbegriff auf weitere Felder denn die Wortsprache aus. ${ }^{84}$ Ohne in Tiefe auf Benjamins Sprachphilosophie

dialektische >Tigersprung ins Vergessene ist, wie es in der vierzehnten These heißt." Vgl. Scholem, Gershom: Walter Benjamin und sein Engel. In: Unseld, Siegfried (Hg.): Zur Aktualität Walter Benjamins. Aus Anlaß des 80. Geburtstags von Walter Benjamin. Frankfurt a. M. 1972, 87-138, hier 133.

80 Vgl. Mosès, Stéphane: Eingedenken und Jetztzeit: Geschichtliches Bewußtsein im Spätwerk Walter Benjamins. In: Haverkamp, Anselm/Lachmann, Renate/Herzog, Reinhart (Hg.): Memoria. Vergessen und Erinnern. München 1993, 385-405, hier 401-405.

81 Vgl. Benjamin, Über den Begriff der Geschichte, 697.

82 »Benjamins kritisches Verfahren heißt rettend, weil es, dialektisch immanent, nicht negiert, sondern interpretiert. Rettende Kritik geht nicht in bestimmter Negation zu je neuen Formen über; denn die geschichtsphilosophische Verlaufsfigur, der sie einbeschrieben ist, meint nicht mehr Hegels Selbstaufstufung des Geistes, sondern dessen Zerfall. Rettend ist Kritik im Denken des Untergangs als Übergang; sie baut durch Abbruch. >Profane Erleuchtung und rettende Kritikı verwischt nicht die Fronten zwischen Aufklärung und Mystik, dient nicht der `Einübung ins Ununterscheidbare` (Rumpf), sondern bezeichnet den hochpolitischen Punkt des Umschlags von Mystik in Aufklärung." Bolz, Norbert: Einleitung: Links schreiben. In: Bolz, Norbert (Hg.): Walter Benjamin. Profane Erleuchtung und rettende Kritik. Würzburg 1985, 9-33, hier 10.

83 Vgl. Kaulen, Rettung und Destruktion, 108. Siehe ebenso Bossart, Rolf: Die theologische Lesbarkeit von Literaturen im 20. Jahrhundert. Studien zu einer verdrängten Hermeneutik. Würzburg 2009, 95-110.

84 Walter Benjamin schreibt hierzu: "Sprache bedeutet in solchem Zusammenhang das auf Mitteilung geistiger Inhalte gerichtete Prinzip in den betreffenden Gegenständen: in Technik, Kunst, Justiz oder Religion. Mit einem Wort: jede Mitteilung geistiger Inhalte ist Sprache, wobei die Mitteilung durch das Wort nur ein besonderer Fall, der der menschlichen, und der ihr zugrunde liegenden oder auf ihr fundierten (Justiz, Poesie), ist. [...] Das Dasein der Sprache erstreckt sich aber nicht nur über alle Gebiete mensch- 
eingehen zu können, lassen sich schon durch einen punktuellen Vergleich einige interessante Rückschlüsse auf Schulz' Sprachbetrachtung ziehen. ${ }^{85}$ Während Benjamins Sprachbegriff auch die Natur, Kunst und die Technik umfasst, ${ }^{86}$ ist Schulz' Sprachbegriff allein auf den Menschen bezogen. Benjamin untersucht den Ursprung der Sprache und nimmt die Genesis als eine Sprachursprungstheorie mit auf. ${ }^{87}$ Schulz fragt nicht nach dem Ursprung, seine Sprachtheorie kommt ohne sprachschöpfenden Anfang aus, wenn sie selbst auch schöpferisch ist. ${ }^{88}$ Ihre ursprüngliche und eigentliche Funktion ist das Sinn-Schöpfen. Auch Benjamin unterscheidet zwischen einem ursprüng-

licher Geistesäußerung, der in irgendeinem Sinn immer Sprache innewohnt, sondern es erstreckt sich auf schlechthin alles. Es gibt kein Geschehen oder Ding weder in der belebten noch in der unbelebten Natur, das nicht in gewisser Weise an der Sprache teilhätte, denn es ist jedem wesentlich, seinen geistigen Inhalt mitzuteilen.« Benjamin, Über die Sprache überhaupt und über die Sprache des Menschen, $140 \mathrm{f}$.

85 Benjamins Sprachbegriff wurde in mehreren Aufsätzen und Monografien umfangreich untersucht. Zur theologischen Deutung der Sprache siehe vor allem Hallacker, Anja: Es spricht der Mensch. Walter Benjamins Suche nach der lingua adamica. München 2004. Zur Geschichte und Rezeptionsgeschichte des Aufsatzes siehe Steiner, Uwe: Über Sprache überhaupt und über die Sprache des Menschen. In: Lindner, Burkhardt (Hg.): Benjamin-Handbuch. Leben - Werk - Wirkung. Stuttgart, Weimar 2011. Den Übersetzerbegriff hat Heinrich Kaulen in seinem Buch über Benjamins Hermeneutik herausgearbeitet: Kaulen, Rettung und Destruktion. Ein wichtiger Meilenstein in der Interpretation der Sprachphilosophie stammt von Menninghaus, Winfried: Walter Benjamins Theorie der Sprachmagie. Frankfurt a. M. 1980.

86 Dabei unterscheidet Benjamin zwischen einer stummen Sprache der Natur und Technik und einer lauthaften Wortsprache beispielsweise des Menschen. Dazwischen fänden sich auch lauthafte Sprachen wie das Vogelgezwitscher oder die Musik, die aber - um zu Bedeutung zu gelangen - vom Menschen gehört werden müssen. Benjamin, Über die Sprache überhaupt und über die Sprache des Menschen, $140 \mathrm{f}$.

87 In seinen Aufsätzen über das mimetische Vermögen hingegen sucht er den Ursprung der Sprache auch in der Fähigkeit des Menschen, Dinge nachzuahmen. Bei der mimetischen Nachahmung geht es nach Benjamin nicht ausschließlich um Nachahmung von etwas Sinnlichem, sinnlich Gleichem. Es werden auch Ähnlichkeiten in unähnlichen Dingen gesucht, wie den Sternen und dem Erdenlauf. So würden Zusammenhang und Deutung auf magische Weise geschaffen. Deshalb ist es möglich, aus dem Tanz, aus den Sternen oder Eingeweiden Wissen abzulesen. Dies sei der magische Zustand, der sich über die Zeit schrittweise in Sprache und Schrift auflöste. »Die Schrift ist so, neben der Sprache, ein Archiv unsinnlicher Ähnlichkeiten, unsinnlicher Korrespondenzen geworden." Benjamin, Über das mimetische Vermögen, 213.

88 Damit folgt Schulz dem von Thomas Mann in seiner Roman-Tetralogie »Joseph und seine Brüder« entwickelten Mythos-Begriff. Dort verlieren sich die Anfänge der Kultur in den mythischen Nebeln. Die Offenbarungstheorie, wie sie in der Tora formuliert wurde, ist eine Mythologie neben anderen. Der Protagonist des ersten Bandes und Stammvater Jakob erkennt in der Tora - die er wie Schulz das Original nennt - nicht das eigentliche Dokument Gottes, sondern dieses war schon immer eine Abschrift, versehen mit Zusätzen, Glossen und Kommentaren. Das ursprüngliche Original ist verschüttet und nicht mehr zugänglich. Vgl. Mann, Thomas: Joseph und seine Brüder. Frankfurt a.M. 2008, 15. 
lichen und einem heutigen Sprachverständnis und vergleicht dabei die erstere Version mit der »lingua adamica. ${ }^{89}$ Während die ursprüngliche (adamitische) Namensprache rein und das Wesen erkennend war, treten in der nachparadisischen Zeit die Sprache und Erkenntnis auseinander. ${ }^{90}$

"Alle menschliche Sprache ist nur Reflex des Wortes im Namen. Der Name erreicht sowenig das Wort wie die Erkenntnis die Schaffung. Die Unendlichkeit aller menschlichen Sprache bleibt immer eingeschränkten und analytischen Wesens im Vergleich mit der absoluten uneingeschränkten und schaffenden Unendlichkeit des Gotteswortes. ${ }^{91}$

Damit ist Benjamins Sprachverständnis des Menschen auf die Erkenntnis ausgerichtet, in Schulz' Konzeption hingegen auf das Kreieren von Sinn und Wirklichkeit. ${ }^{92}$ Beide erkennen ein Nachklingen der ursprünglichen Sprache in der modernen Gebrauchs- und Begriffssprache. Während bei Benjamin aber die Trennung fast perfekt und nur ein magischer Reflex noch möglich ist, so ist bei Schulz die volle Regeneration denkbar - wenn auch nur durch künstlerische Manipulation.

Damit löst Schulz seine Sprachtheorie und sein künstlerisches Programm aus einem rein religiösen Kontext, auch wenn eine starke religiöse Dimension erhalten bleibt. Obwohl die Wortmagie der biblischen Namensprache bzw. »lingua adamica " angedeutet wird und auch in der Allusion auf das JohannesEvangelium auftaucht, so fehlen der vorgeschichtliche Sündenfall oder die Gottesfigur. Stattdessen steht für ihn das Sprechen als »metaphysisches Organ

89 Anja Hallacker untersucht die adamitische Namensprache der biblischen Tradition, die in die Sprachtheorien aller Epochen Eingang gefunden hat. Sie ist von Gott an den Menschen durch das Einhauchen des Odems verliehen und der Mensch vollendet die göttliche Schöpfung durch das Erkennen der Namen der Tiere und Dinge. »Die benennende adamitische Sprache ist keine Kommunikation im Sinne der Verständigung zweier Wesen. Sie ist die Erfüllung der Aufgabe, die JHWH Adam zugemessen hat. [...] Der Anteil des Menschen am Schöpfungsmedium `Sprache` ist allerdings auch im zweiten Bericht begrenzt: er schließt die primäre Erschaffung der Dinge sowie die urteilende Erkenntnis aus." Hallacker, Es spricht der Mensch, 111. Erst durch das Essen vom Baum der Erkenntnis folgt die Unterscheidung zwischen Gut und Böse. Dadurch wird die lingua adamica durch die kommunikative Sprache ersetzt. Adam und Eva erkennen nicht mehr das Gute in Gottes Schöpfung, sondern schämen sich ihrer Nacktheit.

90 »Das Wissen von Gut und Böse verläßt den Namen, es ist eine Erkenntnis von außen (...) Sprache und Erkenntnis treten auseinander. Der Mensch ist, da er nach dieser Erkenntnis verlangte, verantwortlich für das Zerbrechen der Namensprache, die das Wesen der Dinge erkannte, diese aber nicht beurteilte.« Ebd., 115.

91 Benjamin, Über die Sprache überhaupt und über die Sprache des Menschen, 149.

92 Nach Bolecki betont Schulz wie Bolesław Leśmian den ursprünglichen Kontakt der Sprache mit der Natur, als diese noch eine Einheit bildeten und weniger den "poznawczy charakter« (erkennenden Charakter). Vgl. Bolecki, Poetycki model prozy, $174 \mathrm{f}$. 
des Menschen ${ }^{93}$ im Mittelpunkt und der sprachtheoretische Sündenfall ist vor allem ein - freilich lösbares - Paradigmenproblem. Die Lösung findet sich in der Kunst, die sich einem rationalen Pragmatismus entzieht: »Poesie - das sind Kurzschlüsse des Sinns zwischen den Worten, die schlagartige Generation der ursprünglichen Mythen. ${ }^{94}$

In seinem »offenen Brief" an Witkacy, der eine Selbstinterpretation darstellt, geht Schulz auch auf die Ursprünge seiner Bilderwelt ein. So schreibt er, dass ihn seit früher Kindheit bestimmte Bilder und Vorstellungen begleiteten, die das "geistige Kapital« seiner Kunst ausmachten, wie eine Pferdedroschke oder Goethes »Erlkönig«. Gleichzeitig würden die Anfänge seines Zeichnens in einem mythologischen Nebel verschwinden. Durch diese Verortung der Bilder in einem unzugänglichen und undurchsichtigen Bereich macht er erneut die Bestimmung eines konkreten Anfangs unmöglich. Damit verhindert er - beziehungsweise versucht es - eine verbindliche UrsacheWirkung-Interpretation in seiner Kunst und der handwerklichen Bildkunst im Allgemeinen.

»Solche Bilder stellen ein Programm dar, bilden das eiserne Kapital des Geistes, das uns sehr früh, in Form von Gefühlen und halb bewußter Erkenntnis verliehen wird. Mir scheint, daß der ganze Rest des Lebens damit vergeht, diese Einblicke zu interpretieren, sie ihrem ganzen Gehalt nach auseinanderzunehmen und durch die ganze Spannweite des Intellekts zu geleiten, die uns zusteht. Diese frühen Bilder bestimmen den Künstlern die Grenzen ihres Schaffens. Ihr Schaffen ist eine Ableitung aus fertigen Voraussetzungen. Später entdecken sie nichts Neues mehr, sondern lernen nur immer besser das ihnen am Eingang anvertraute Geheimnis verstehen und machen ihr Schaffen zu einer ständigen Exegese und zu einem Kommentar über diesen einzigen Vers, der ihnen aufgegeben wurde. Übrigens entwickelt die Kunst dieses Geheimnis niemals bis zum Ende. Es bleibt ungelöst. ${ }^{95}$

93 Schulz, Die Mythisierung der Wirklichkeit, 151. "Mowa jest metafizycznym organem człowieka.«Schulz, Mityzacja rzeczywistości, 12.

94 Schulz, Die Mythisierung der Wirklichkeit, 150. „Poezja - to są krótkie spięcia sensu między słowami, raptowna regeneracja pierwotnych mitów.« Schulz, Mityzacja rzeczywistości, 11.

95 Schulz, Bruno Schulz an St. I. Witkiewicz, $90 \mathrm{f}$. »Takie obrazy stanowią program, statuują żelazny kapitał ducha, dany nam bardzo wcześnie w formie przeczuć i na wpół świadomych doznań. Zdaje mi się, że cała reszta życia upływa nam na tym, by zinterpretować te wglądy, przełamać je w całej treści, którą zdobywamy, przeprowadzić przez całą rozpiętość intelektu, na jaką nas stać. Te wczesne obrazy wyznaczają artystom granice ich twórczości. Twórczość ich jest dedukcją z gotowych założeń. Nie odkrywają już potem nic nowego, uczą się tylko coraz lepiej rozumieć sekret powierzony im na wstępie i twórczość ich jest nieustanną egzegezą, komentarzem do tego jednego wersetu, który im był zadany. Zresztą sztuka nie rozwiązuje tego sekretu do końca. Pozostaje on nierozwikłany.« Schulz, Bruno Schulz do St. I. Witkiewicza, 19. 
Damit bringt Schulz die Kunst in direkten Zusammenhang mit einer religiösen Tätigkeit, aber wieder in allgemeinster Form. Die Exegese - das Interpretieren des heiligen Textes - richtet sich auf einen Vers, auf ein Motiv des Alltags oder der Literatur und aus diesen fast unsichtbaren und ursachenlosen Impulsen webt sich die Kunst. ${ }^{96}$ Durch den Bezug auf die Mythologie ähnelt das Konzept der integralen Universalpoesie der Romantik. ${ }^{97}$ Gleichzeitig führt Schulz innerhalb seiner Literatur und Bildkunst immer wieder Brüche und Abgründe ein, die dieser Deutung widersprechen. Seine Faszination für Skurriles, Absurdes und Trashiges ${ }^{98}$, seine Tendenz zur Dekonstruktion und Theoretisierung des Dargestellten machen seine Welt und seine Kunst brüchig.

Zusammenfassend lässt sich konstatieren, dass Schulz den Widerspruch in den Mittelpunkt stellt, der zwischen dem totalitären Erklärungswillen einer »szientistischen Anschauung«, ihrer Selbstwahrnehmung als kritisches Korrektiv zu einer irrationalen Metaphysik und ihrem religiösen Dogmencharakter herrscht. Aus überzeugter Ablehnung einer positivistisch objektiven Wirklichkeitsvorstellung korrumpiert er mit Ironie und Sarkasmus die Konvention. Seine alternative Wirklichkeit ist damit aber nicht bloß fantastisch, sondern durch eine Umgewichtung von Wertigkeiten erzeugt, durch Perspektivwechsel und Sprachexperimente, die in Bereiche des Voranalytischen, Nichtanalysierbaren und noch nicht Vorgestellten vorzudringen versuchen. ${ }^{99}$ Die Fähigkeit des Sprechens und Bildmachens wird als a priori

96 Błoński interpretiert diesen Aspekt im Kontext der jüdischen Exegese. Das Kommentieren der Welt als sei sie ein Text, sei eine jüdische Geste. Gleichzeitig müsse dies nicht heißen, dass Schulz gläubig sei. Błoński, Jan: Świat jako księga i komentarz. In: Jarzębski (Hg.): Czytanie Schulza, 68-84, hier 84.

97 Zum Poesie-Begriff der Romantik und insbesondere zum Begriff der Kunstkritik siehe Benjamin, Walter: Der Begriff der Kunstkritik in der deutschen Romantik. In: Tiedemann, Rolf/Schweppenhäuser, Hermann (Hg.): Gesammelte Schriften I. Abhandlungen. Frankfurt a. M. 1991, 7-122.

98 Auch wenn »Trash" ein Modewort der heutigen Zeit ist, so gibt dieses um einiges besser die Bedeutung von »tandeta « wieder als das antiquiertere Wort »Ramsch«. In der Deutung der "tandeta" folge ich eher Theodosia Robertson, die darin ein popkulturelles Element gesehen hat, als Andreas Schönle, für welchen darin - in Abgrenzung zum Kitsch ein authentischer und ästhetischer Kern steckt. Schönle, Andreas: Sklepy Cynamonowe Brunona Schulza: apologia tandety. In: Kitowska-Łysiak, Małgorzata (Hg.): Bruno Schulz in memoriam. Lublin 1992, 59-77, hier 60. Siehe ebenso Robertson, Bruno Schulz's Intimate Communication, 444.

99 Rolf Fieguth vergleicht Schulz mit Kafka hinsichtlich seiner Tendenz, »alternative Wirklichkeiten« zu schaffen. Nach Fieguth kritisiere Schulz in seiner Literatur teilweise Kafka. Dabei markiert er gerade die Unterschiede zwischen den beiden Autoren. »Es ist, so meine ich, Schulz und nicht Kafka, der eine Wirklichkeit neben der Wirklichkeit erfindet. Der Roman Der Prozeß kennt nur eine einzige, heillose, unentrinnbare Welt, in der kein Raum ist für manipulatorische Freiheiten des Einzelnen. 
in der Geschichte der Menschheit gegeben angenommen. Letztlich ist auch die Sprache der Naturwissenschaft eine Form poetischer Sprache, da in ihr immer wieder die Grenzen des Sagbaren überschritten werden müssen, damit neuer Sinn entsteht. ${ }^{100}$

Dem diagnostizierten Übergewicht der Analyse stellt Schulz ein Übergewicht des Assoziativen und Verbindenden gegenüber. Diesen Ansatz setzen viele Forscher mit einer "privaten Mythologie ${ }^{101}$ gleich, in Anlehnung an seine Selbstdeutung. ${ }^{102}$ Dass diese Deutung zu kurz gegriffen ist und Schulz

Dagegen ist es Schulzens Sache nicht, die Vernichtung und Verdunkelung des Menschen durch das übermenschliche Licht der göttlichen Ordnung darzustellen. Sein Thema ist das Licht, das der Mensch selbst durch eine Metaphysik der niederen Sphären gewinnen kann, und dieses Licht kann ebenso ein Abbild des göttlichen Lichts sein wie auch ein Trugbild gottlosester Ketzerei. Kafkas von Schulz so genannter Pseudorealismus ist trotz aller kafkaschen Ironie ebenfalls Schulzens Sache nicht. Der Autor der Zimtläden überzieht seine Ersatz- und Parallelwirklichkeiten nicht mit der Epidermis der obsessiven Illusionsbildung, sondern er zeigt den schöpferischen Akt des Herbeimanipulierens seiner Parallelwirklichkeiten."Fieguth, Rolf: Bruno Schulz und seine heimliche Kritik an Kafka. In: Ritz, German/Matuszek, Gabriela (Hg.): Recepcja literacka i proces literacki. Literarische Rezeption und literarischer Prozess. O polskoniemieckich kontaktach literackich od modernizmu po okres międzywojenny. Kraków 1999, 243-270, hier 255.

100 Ähnlich wie es Thomas Mann in seiner Roman-Tetralogie "Joseph und seine Brüder» vorführt, bedarf es eines visionären Geistes, der sich nicht existente Formen, Funktionen, Möglichkeiten vorstellen kann, damit sich der praktische, technische Geist an eine Umsetzung dieser Ideen machen kann. "Seit langem, aus dunklen und schmalen Tagen des Ursprungs her, war sie [die ägyptische Stadt Wese, A. J.] im Zunehmen und auf dem Wege zu voller Schönheit; aber noch manches fehlte bis zu dem Punkte, wo ihre Herrlichkeit nicht mehr zu wachsen vermochte, unmöglich ferner zu steigern war, sondern vollendet stehenblieb und eines der sieben Weltwunder darstellte: im Ganzen sowohl wie auch bereits, und zwar hauptsächlich, durch einen ihrer Teile - die beispiellose Prunksäulenhalle ungeheuren Umfanges, die ein späterer Pharao mit Namen Ra-messu oder `Die Sonne hat ihn erzeugt ‘ dem Bautenkomplex des großen Amuntempels im Norden mit einem Kostenaufwand hinzufügte, der dem erreichten Höchstmaß der Schwere dieses Gottes entsprach. Von dieser also sahen Josephs Augen so wenig, wie die von den Vergangenheiten in der Umgebung der Pyramiden gesehen hatten, nur eben aus entgegengesetztem Grunde: weil sie nämlich noch nicht Gegenwart gewonnen und niemand Mut hatte, sie sich einzubilden. Denn damit dies möglich würde, mußte erst noch manches errichtet werden, was dann durch die hieran schon gewöhnte und zunehmend ungenügsame Einbildungskraft des Menschen überboten werden konnte.« Mann, Joseph und seine Brüder, 563.

101 So deutet Schulz selbst seine Erzählungen in einem auf Deutsch verfassten Exposé über die »Zimtläden«. Schulz versuchte, einen Verlag und damit auch einen Übersetzer ins Deutsche und Italienische zu finden, daher ist das Exposé nicht nur eine Zusammenfassung, sondern auch ein Reklametext für das eigene Werk. Ob die Deutungen daher tatsächlich Ausdruck der Erzählungen sind oder schlichtweg notwendige Vereinfachung ist, steht der Interpretation offen. Vgl. Schulz, Exposé über das Buch `Zimtläden`, 326.

102 Vgl. Kitowska-Łysiak, Małgorzata: Bezlik nieskończonych historyj: O reinterpretacji mitologicznych pierwowzorów na kartach Xięgi Bałwochwalczej. In: Dunin, Teresa/ 
vielmehr an einem intersubjektiv bedeutsamen Kulturbegriff arbeitet, sollte jetzt schon erkennbar geworden sein. Vielmehr nimmt die Literatur dieses Gewand an, ist aber von der Grundkonzeption so gestrickt, dass es dem Leser gelingt ein ganzes Fadennetz an literarischen, philosophischen, theologischen, mythologischen und bildplastischen Bezügen zu entdecken, die der philosophischen Vertiefung dienen, worauf er im letzten Satz seines Manifests hingewiesen hat.

\subsection{Das Erstarren der Bilder}

"Jede Fotografie ist eine Art memento mori. Fotografieren bedeutet teilnehmen an der Sterblichkeit, Verletzlichkeit und Wandelbarkeit anderer Menschen (oder Dinge). Eben dadurch, daß sie diesen einen Moment herausgreifen und erstarren lassen, bezeugen alle Fotografien das unerbitterliche Verfließen der Zeit. ${ }^{103}$

Zum Fortschrittsglauben, den Entwicklungen in der Industrie und Technik und zum Einfluss des szientistischen Weltbildes auf die Gesellschaft tritt ab Mitte des 19. Jahrhunderts eine Erfindung hinzu, deren Wirkung kaum zu unterschätzen ist: die Fotografie. ${ }^{104}$ Sie verstärkt die verschiedenen ohnehin stattfindenden Veränderungsprozesse und bildet diese gleichzeitig ab, sodass viele Intellektuelle verstärkt über das Wesen des fotografischen Bildes nach-

Kosienkowska, Halina (Hg.): Mityzacja rzeczywistości. Bruno Schulz 1892-1942; wystawa ze zbiorów Muzeum Literatury im. Adama Mickiewicza w Warszawie; Muzeum Lubelskie w Lublinie listopad-grudzień 2002. Lublin 2002, 9-22, hier 13. Zur Selbstdeutung in seinem auf Deutsch verfassten Exposés siehe Schulz, Exposé über das Buch `Zimtläden<, 326.

103 Sontag, Susan: Über Fotografie. (aus dem Amerikanischen von Mark W. Rien). Frankfurt a. M. 2011, 21.

104 Gisèle Freund untersucht in ihrer Dissertation, die 1936 unter dem Titel »La Photographie en France au dix-neuvième siecle« publiziert wurde, den Einfluss der Fotografie auf die Gesellschaft im Kontext der bildhistorischen Entwicklungen. »Parallel $\mathrm{zu}$ den sozialen und wirtschaftlichen Veränderungen innerhalb der bürgerlichen Gesellschaft des 19. Jahrhunderts ging eine Änderung des Bewußtseins einher. Die Entwicklung der Industrie, die mit der Entwicklung der Technik Hand in Hand ging, der Fortschritt in den Naturwissenschaften, die sich zu gleicher Zeit mit den Bedürfnissen, die die wachsende Industrialisierung an rationale Wirtschaftsformen stellt, vergrößerte, veränderte auch die Vorstellung des bürgerlichen Menschen von der Natur und wandelte seine Beziehung zu ihr. Ein neues Realitätsbewußtsein und eine neue Bewertung der Natur begann sich durchzusetzen, der in der Kunst eine dem Wesen der Photographie entsprechende Wendung zum Gegenständlichen folgte.« Freund, Photographie und Gesellschaft, $82 \mathrm{f}$. 
denken. ${ }^{105}$ In der Tiefe untersuchten diese Wandlungen zu Schulz' Zeiten Walter Benjamin und Gisèle Freund, in der Nachkriegszeit Roland Barthes ${ }^{106}$ und Susan Sontag ${ }^{107}$ und unter den neueren Bildwissenschaftlern vor allem Hans Belting. ${ }^{108}$

Verschiedene Aspekte des Fotografiediskurses sind für den Zusammenhang dieser Untersuchung von besonderer Relevanz, die hier aber nur in einer abrissartigen Darstellung hervorgehoben werden können. Die Dringlichkeit der Auseinandersetzung war vor allem durch technische Neuerungen bedingt. Durch die Möglichkeit, die Bildproduktion vom handwerklichen Geschick zu trennen, entsteht eine neue Form von Bildern, mit der Objektivität, Präzision und Abbildungscharakter verbunden werden. ${ }^{109}$ Darüber hinaus wird die technische Bildproduktion zunehmend billiger, schneller und genauer, sodass nicht nur sehr viele Bilder von sehr vielen angefertigt werden können, sondern auch einer großen Zahl von Menschen zugänglich gemacht. Durch die Pressebilder lernt die Masse die Welt im Bild kennen, Werbebilder erzeugen Bedürfnisse wie Konsum und die Modefotografie gestaltet neue Körperideale. ${ }^{110}$ Aber auch im privaten Gebrauch steigt und wandelt sich der Bildkonsum - Familienereignisse, Porträts und Reisen werden im Erinnerungsfoto fixiert. Sie stellen in der Wahrnehmung des einzelnen zum Teil eine »Emanation des vergangenen Wirklichen: als Magie dar. $^{111}$

Die Fotografie hat aber auch Einfluss auf die Kunst, denn sie macht Kunstwerke plötzlich unbegrenzt im Abbild zugänglich und beeinflusst sowohl die Beziehung zwischen Kunstbild und Betrachter als auch zwischen Künstler und Betrachter. ${ }^{112}$ Der Künstler ist nicht mehr vornehmlich Auftragnehmer

105 »Ohne Zweifel war das 20. Jh. das erste, das in einer früheren Jahrhunderten völlig unbekannten Weise den Gesamtbereich des Audiovisuellen reproduzierbar, speicherbar und kommunizierbar gemacht hat. Der Bildhunger, der Hunger nach dem authentisch und live Geschehenen, hat die Illustrierte hervorgebracht und wird durch Computer und Internet verstärkt. [...] Benjamin sieht durch die fortgeschrittene Reproduzierbarkeit ein neuartiges Bedürfnis erzeugt: das `Bedürfnis [...] des Gegenstands aus nächster Nähe im Bild, vielmehr im Abbild, in der Reproduktion habhaft zu werden` (I,440 a. F.). Es entsteht ein massenhaftes Verlangen, das auf Verkleinerung, auf Transportierbarkeit und auf nächste Nähe des Fernen ausgerichtet ist."Lindner, Burkhardt: Das Kunstwerk im Zeitalter seiner technischen Reproduzierbarkeit. In: Lindner, Burkhardt (Hg.): Lindner (Hg.): Benjamin-Handbuch, hier 235.

106 Vgl. Barthes, Roland: Die helle Kammer. Bemerkungen zur Photographie. Frankfurt a. M. 2014.

107 Vgl. Sontag, Über Fotografie.

108 Vgl. Belting, Hans: Das echte Bild. Bildfragen als Glaubensfragen. München 2005.

109 Vgl. ebd., $7 \mathrm{f}$.

110 Vgl. Freund, Photographie und Gesellschaft, 117.

111 Barthes, Die helle Kammer, 99. (Hervheb. im Orig.)

112 Vgl. Benjamin, Walter: Das Kunstwerk im Zeitalter seiner technischen Reproduzierbarkeit: (erste und dritte Fassung). In: Tiedemann, Rolf/Schweppenhäuser, Hermann (Hg.): Gesammelte Schriften I. Abhandlungen. Frankfurt a. M. 1991, 431-508, hier 436. 
eines Individuums, vielmehr richtet er seine Kunst zunehmend an die Masse, die diese in Museen, Ausstellungen und Zeitungen rezipiert und kommentiert. ${ }^{113}$ Die Fotografie hat Einfluss auf die Vorstellung von dem, was ein Bild ist, denn mit ihr ist alles abbildbar geworden, was zur optischen Welt gehört. Durch Vergrößerung und Verkleinerung dringt die Fotografie sogar in Bereiche vor, die dem menschlichen Auge zuvor nicht zugänglich waren. ${ }^{114}$ Weil fotografische Bilder scheinbar nicht mehr den Weg durch den menschlichen Körper über das Auge und die Hand nehmen, sondern außerhalb desselben produziert werden, stellt sich die Frage nach ihrer Beziehung zum Menschen. ${ }^{115}$ Dies veranlasst auch die Frage nach der Beziehung zur Sprache. ${ }^{116}$

In Schulz' Erzählungen finden sich immer wieder Stellen, die sich mit den neuen Bildmedien befassen. In der Erzählung »Ulica Krokodyli« werden Fotografien und Illustrierte untersucht, die im Kontext der städtischen Moderne, der anonymen Masse, der erotischen Frau und des Konsums auftreten. ${ }^{117}$ Reklamebilder sind Gegenstand der Erzählung "Księga«, in denen »erstarrte Landschaften « vorkommen. ${ }^{118}$ Seine Untersuchung der neuen Medien wird Gegenstand des vierten Kapitels sein.

Dass Bilder als Gefahr, Magie, Verheißung und Bedrohung wahrgenommen werden, ist nach Mitchell zugleich eine spezifisch neue Entwicklung als auch eine kulturelle Grundkonstante, die sich bis in Mythologie und Bibelgeschichten rückverfolgen lässt. ${ }^{119}$ Durch radikale Entwicklungen und Wandlungen des Bildbegriffs werden alte Motive wie die Frage nach der Macht der Bilder wieder aktuell. Dies zeigt sich auch in Schulz' Werk, der seinen Grafikzyklus im Kontext des »Bildverbots" des Alten Testaments diskutiert und damit ein in seiner Zeit weit verbreitetes Motiv aufnimmt. ${ }^{120}$ Das biblische »Bildverbot« wird in der Fachliteratur häufig dogmatisch verstanden und

113 Vgl. ebd., $444 \mathrm{f}$.

$114 »$ Das Stroboskop, die Video-Apparate, die Cerox-Maschinen, die Laserstrahlen, die Objektive, die es ermöglichen, das kleinste Partikel zu vergrößern und erkennen zu lassen, erlauben oft überraschende, zuweilen sehr poetische Aufnahmen. Der Flug einer Gewehrkugel oder der Fall eines Milchtropfens, im millionstel Teil einer Sekunde aufgenommen - eine Technik, von der Wissenschaft für sie erfunden -, kann zu einem künstlerischen Erlebnis werden.« Freund, Gisèle: Memoiren des Auges. Frankfurt a. M. 1977, 133.

115 Vgl. Belting, Bild-Anthropologie, $213 \mathrm{f}$.

116 Vgl. Mitchell, Picture Theory, 285.

117 Vgl. Schulz, Sklepy cynamonowe, 107; 108; 111.

118 Schulz, Sanatorium pod Klepsydrą, 126.

119 Vgl. Mitchell, Picture Theory, 15.

120 Vgl. Benjamin, Walter: Kleine Geschichte der Photographie. In: Tiedemann, Rolf/ Schweppenhäuser, Hermann (Hg.): Gesammelte Schriften II. Aufsätze, Essays, Vorträge. Frankfurt a. M. 1991, 368-385, hier 369. Auf diesen Aspekt wird weiter unten noch eingegangen. 
die jüdische Kultur als bildfeindlich beschrieben. ${ }^{121}$ Kalman Bland weist in seinem Werk »The artless Jew« eindrucksvoll nach, dass die »Idee« eines bildlosen Judentums ein Mythos vor allem des 19. Jahrhunderts ist und vornehmlich aus dem deutschsprachigen Raum stammt - vertreten von jüdischen wie nichtjüdischen Intellektuellen, vorgetragen mit antisemitischer wie affirmativer/apologetischer Motivation. ${ }^{122}$ Während für die einen das Bildverbot für Kulturlosigkeit stand, so konstruierten die anderen daraus eine geistige Überlegenheit. Nach Joseph Gutman stand schon in biblischen Zeiten das Zweite Gebot nicht für ein generelles Bildverbot, sondern lediglich für ein Verbot der Darstellung Gottes oder der Anbetung anderer Götter. ${ }^{123}$ Liest man beispielsweise die Beschreibungen des Tempels in Könige 6, so stellte König Salomon in das Innere zwei Cherubim-Statuen und ließ die Wände mit Blumen, Cherubim und Palmenschnitzereien verzieren. ${ }^{124}$ Bemalungen, Fresken und Mosaike lassen sich auch in Synagogalbauten verschiedener Jahrhunderte und Gegenden nachweisen. ${ }^{125}$ Bilderverfolgungen wiederum finden sich auch in der christlichen Tradition, beispielsweise im Bildersturm der Reformations-

121 Bland widmet sein gesamtes Buch dem »Mythos des bildlosen Judentums « und dekonstruiert diesen als Produkt des 19. Jahrhunderts, das bis heute wirkungsvoll den Diskurs über das moderne wie das alte Judentum bestimmt. Während die ersten Kapitel den Ursprung dieser Dichotomie zwischen visuellem Christentum und schriftgläubigem Judentum gewidmet sind, sind die späteren der Bildkunst und Ästhetik der Juden in mittelalterlichen Schriften und Artefakten gewidmet. Bland listet insbesondere deutschsprachige Verfechter der Idee eines »bildfeindlichen Judentums« auf. Von jüdischer Warte wird dabei die angebliche Bildlosigkeit zu einer tieferen Erkenntnis Gottes hochstilisiert. Als einflussreichen Vertreter der jüdisch-affirmativen Haltung zitiert Bland Hermann Cohen. In Anlehnung an Lessing erkläre dieser das jüdische Bildverbot zum Dogma und als Kerngebot der Religion und Identität. Stattdessen habe man Poesie verfasst, die ohnehin der plastischen Kunst überlegen sei. Vgl. Cohen, Hermann: Die Religion der Vernunft aus den Quellen des Judentums. Frankfurt a. M. 1929, 62-66, sowie Bland, Kalman P.: The artless Jew. Medieval and modern affirmations and denials of the visual. Princeton, NJ [u.a.] 2000, $18 \mathrm{f}$.

122 Vgl. ebd., 14-32.

123 Vgl. Gutmann, Joseph: The ssecond commandment and the image in Judaism. In: Hebrew Union College Annual 32 (1961), 161-174, hier 164. Gutmanns Argument ist, dass die Vernichtung von Bildern nicht in erster Linie dazu diente, das zweite Gebot umzusetzen, sondern vor allem dazu, den halbnomadischen Charakter des israelischen Volkes aufrecht zu erhalten, der dieses von den umgebenden Völkern abgrenzt. Insofern sieht auch Gutmann im zweiten Gebot ein konstituierendes Moment in der jüdischen Identitätsbildung, aber sehr viel eingeschränkter. »The conclusion to which one is inevitably drawn from an examination of the surviving material, both literary and archeological, from the Biblical and Hellenistic-Roman periods, is that a rigidly and uniformly anti-iconic attitude on the part of the Jews remains as much a myth as the Procrustean bed on which Jewish art history has so often been made to lie.« Ebd., 174.

124 Vgl. Könige 6.

125 Vgl. Baskind/Silver, Jewish Art, 15-24. 
zeit im 16. Jahrhundert. ${ }^{126}$ Eine partielle oder temporäre Bildabstinenz bedeutet somit nicht zwangsläufig eine bildlose Kultur, wie Victor Stoichiţă am Beispiel des protestantischen Bildersturms darlegt:

»Die Zerstörung der Bilder durch die Protestanten geht mit der Wiederentdeckung ihrer persuasiven und propagandistischen Möglichkeiten durch die Katholiken einher. Die erneute Infragestellung der Kultbilder ist jedoch lediglich ein Aspekt eines Aufruhrs von weit größerer Tragweite, der auf vielen Ebenen des Imaginären stattfindet. Die schweigende Wand der protestantischen Kirchen ist nicht nur oder bloß Mauer. Sie ist übertünchte, entfernte, `weggemachte` Malerei: abwesende Malerei. Von diesem `Nullpunkt der Malerei haben wir auszugehen, wenn wir in das spezifische Selbstbewußtsein, welches die Kunst des XVII. Jahrhunderts erlangt hatte, eindringen wollen. ${ }^{127}$

Und auch die Trennung der Ost- und Westkirche entbrannte aus einem Bilderstreit. ${ }^{128}$ Das Zweite Gebot regt zu einer gesteigerten und kritischen Auseinandersetzung mit Bildern und ihren Wirkungen $a^{129}$, es bedeutete mitnichten eine Kultur ohne Kunst und ohne Bild. Gershom Scholem wiederum zeigt in seinem Buch "Die jüdische Mystik in ihren Hauptströmungen« eine parallele Entwicklung in der Sprache. Die Blüte der bildaffinen Mystik sei eng mit der Herausbildung eines zunehmend rationalen jüdischen Traditionsverständnisses verbunden ${ }^{130}$ und lasse sich als Gegenreaktion auf eine "gereinigte Sprache verstehen. ${ }^{131}$

126 Vgl. Götterbild. In: Klauser, Theodor/Dassmann, Ernst u.a. (Hg.): Reallexikon für Antike und Christentum. Sachwörterbuch zur Auseinandersetzung des Christentums mit der antiken Welt. Stuttgart 1981, $775 \mathrm{f}$.

127 Stoichiţă, Das selbstbewußte Bild, 110.

128 Im 8. Jahrhundert kommt es zum Bilderstreit und zum Bruch der Ost- und Westkirche. In der Ostkirche wird das Christusbild verehrt. Nach Kurt Bauch entwickelt sich in dieser Zeit die Hypostasis als neuer Grundbegriff: „Das Bild ist von dem Dargestellten zwar der Substanz nach verschieden, hypostatisch aber, nach Sinn und Bedeutung, gleich.» In der Ikone sei Christus »vergegenwärtigt und wird als solcher in ihr verehrt.» Bauch, Kurt: Imago. In: Boehm, Gottfried (Hg.): Was ist ein Bild? 2. Aufl. München 1994, 275-299, hier 284. Damit die Grenze zur Idolatrie gewahrt bliebe, durften nur Bilder gemalt und keine Figuren angefertigt werden. In Rom hingegen wurden Bilder eher als Lehrwerke begriffen, die dem Leseunkundigen die Inhalte der Bibel vermitteln sollten. Das Mysterium und die Verehrung wurden dabei nicht auf das Bild übertragen, sondern galten allein der Verkündigung Gottes im Bild. Verehrt dagegen wurden die Reliquien und heiligen Symbole wie das Kreuz oder die heilige Schrift.

129 Vgl. Brumlik, Micha: Schrift, Wort und Ikone. Wege aus dem Verbot der Bilder. Frankfurt a. M. 1994, 27.

130 Vgl. Scholem, Die jüdische Mystik in ihren Hauptströmungen, $20 \mathrm{f}$.

131 Diese Dichotomie, wie sie sich in der jüdischen Geschichte sowohl im Mittelalter mit der Entwicklung der durch die arabisch-wissenschaftliche Kultur und griechische Philosophie beeinflusste Rationalisierung herausbildete und ihren Gegensatz in der 
So wandelbar die Deutung des Zweiten Gebots in der Geschichte ist, ${ }^{132}$ so schwierig ist auch eine abschließende Bestimmung, was genau verboten ist. ${ }^{133}$ Ganz allgemein geht es um eine im Bild dargestellte und verehrte Autorität, in der Präsentation und Repräsentation, Anwesenheit und Darstellung verwechselt werden. Das zentrale Moment ist mitunter nicht das Bild selbst, sondern die Haltung zum bildlich Dargestellten. ${ }^{134}$

Kabbala fand, wiederholt sich in abgewandelter Form in der Gegenwart mit dem Positivismus und der Hoffnung auf eine von allem Symbolischen gereinigten Sprache und einem eindeutigen, wirklichkeitstreuen Bild. So habe es neben einer materiellen Bildtradition auch eine sprachlich-mystische gegeben. Vgl. Scholem, Gershom: Zur Entwicklungsgeschichte der kabbalistischen Konzeption der Schechinah. In: Fröbe-Kapteyn, Olga (Hg.): Mensch und Energie. Zürich 1952, 45-67.

132 Zur theologischen Deutung des Bildverbots im Judentum schreibt Gerhard Langer: »Unterschiedliche Tendenzen, Haltungen und Strömungen stehen nicht nur zeitlich hinter-, sondern auch nebeneinander. Der Einfluss priesterlicher Kreise ist ebenso feststellbar wie die Bedeutung rabbinischer (und außerrabbinischer) Textwelten. Nicht zuletzt ist es die kritische Auseinandersetzung mit dem Christentum und seiner auch im Bild festgehaltenen Theologie, die das Judentum zu einer selbstbewussten Stellungnahme herausfordert." Langer, Gerhard: Helios, Orpheus und Aphrodite: Von Bildern und Verboten im antiken Judentum. In: Dohmen, Christoph/Wagner, Christoph (Hg.): Religion als Bild - Bild als Religion. 1. Aufl. Regensburg 2012, 11-30, hier 27.

133 »Die Sonderstellung, die das Judentum gegenüber dem B[ild]. einnahm, war in einer religiösen Haltung bedingt, die ihren grundlegenden Ausdruck in den pentateuchischen Bilderverboten findet. Daß diese aber tatsächlich nur auf die Herstellung von (plastischen) Darstellungen des Göttlichen selbst zielen, ist bei Ex. 20,4f.; Lev.26,4; Dtn. 5,8 nicht minder eindeutig klar als bei den bloß von ‘goldenen gossenen Göttern redenden Stellen Ex. 23,23; Lev. 19,4.« Bild, jüdisch. In: Klauser, Theodor (Hg.): Reallexikon für Antike und Christentum. Sachwörterbuch zur Auseinandersetzung des Christentums mit der antiken Welt. Band II: Bauer -Christus. Stuttgart 1954, 287. Im Hebräischen gibt es feststehende Begriffe für die verbotenen Bilder, nämlich "Pesel« und "Massekah", die auf Guss- und Schnitzbilder zielen. Sie betonen das Gemachtsein und nicht die Ähnlichkeitsbeziehung zwischen Bild und Gott. Erst in dem Moment, wo sie angebetet oder durch ein Ritual »belebt« werden, können sie zu Kultbildern werden. Jan Assman betont die Relevanz der Haltung zum Schnitzund Gussbild. Assmann, Jan: Altägyptische Bildpraxen und ihre impliziten Theorien. In: Sachs-Hombach (Hg.): Bildtheorien, hier $98 \mathrm{f}$.

134 Dies wird in der Unterscheidung der zwei Komponenten "Bilderdienst « und »Verehrung anderer Götter" deutlich, wobei die zweite Komponente die wichtigere Position einnimmt. Vgl. Götzendienst. In: Klauser u.a., Reallexikon für Antike und Christentum, 828-295. »Die Diskussion um bildliche Darstellung erscheint immer im Zusammenhang mit Fremdkult. Kunstwerke, die als >Götzenbilder` (miss)verstanden werden und somit Juden zu Akten des Götzendienstes veranlassen könnten, sind daher verboten. Unterschiede zwischen den rabbinischen Anschauungen entstehen allerdings in der Frage, wo die Trennung zwischen verbotenen und erlaubten Abbildungen zu ziehen sei: zwischen zwei- und dreidimensionalen Bildern; zwischen Bildern von Tieren und Menschen; oder zwischen jeglicher darstellbarer Form und bloßer Verzierung.« Langer, Helios, Orpheus und Aphrodite, 15. 
Die moderne Ausprägung der Diskussion um die Macht der Bilder untersucht Hans Belting in seiner Monografie »Das echte Bild. Bildfragen als Glaubensfragen ${ }^{135}$ sowie in seinem Aufsatz Idolatrie heute. ${ }^{136}$ Dabei verknüpft er das Wiederaufkommen religiöser Kategorien wie Ikone und Idol mit dem Aufkommen der Fotografie, die in veränderter Form die Frage nach »echten Bildern« in Abgrenzung zu "falschen" virulent werden lässt. Auf der einen Seite gäbe es die Tendenz, in fotografischen Bildern die Wirklichkeit besonders direkt und wahrheitsgetreu wiedergegeben zu erkennen, auf der anderen Seite die Tendenz, diese als manipulativen Schwindel und Lüge der Mächtigen zu begreifen. Hinter diesen Haltungen erkennt Belting eine »religiöse Form ", denn letztlich ist das Bild in beiden Annäherungen nicht in erster Linie Bild, sondern repräsentiert entweder Wahrheit oder Lüge am Maßstab der außerbildlichen Wirklichkeit. ${ }^{137}$ Dem Betrachter fehlt es dann an reflektierender Distanz. Ähnlich sieht es Boehm, nur dass er diese Qualität den Bildern selbst zuweist - in Form einer aktiv wollenden und handelnden Kraft -, anstatt diese Haltung beim Betrachter zu verorten. Darin zeigt sich seine Bereitschaft, Bildern eine (magische) Eigenständigkeit gegenüber dem Betrachter zuzuweisen.

"In der spannungsvollen Beziehung, die sich im visuellen Grundkontrast zeigt, gibt es, wie wir sahen, die Möglichkeit, daß Bilder ganz selbstvergessen in der Illusionierung von etwas Dargestelltem aufgehen oder - umgekehrt - ihr bildliches Gemachtsein betonen. In extremis verleugnet sich das Bild als Bild ganz, um die perfekte Repräsentation einer Sache zustandezubringen. Dieses Ziel erreicht es, wenn wir als Betrachter getäuscht werden, das Bild für das Dargestellte selbst halten, es als Bild gleichsam übersehen. ${ }^{138}$

Damit betonen beide Bildwissenschaftler - explizit wie implizit - die Notwendigkeit, am Bild das Medium wahrzunehmen und zu reflektieren. Nach Boehm liege es in der Intention der Medienindustrie, dass sie

»eine Bilderflut in Gang setzt, deren Grundtendenz auf Suggestion zielt, auf bildlichen Realitätsersatz, zu dessen Kriterien seit jeher gehörte, die Grenzen der eigenen Bildlichkeit zu verschleiern. Das vielbeschworene neue Zeitalter des Bildes, - nach demjenigen Gutenbergs -, ist ikonoklastisch, auch dann, wenn es seine Enthusiasten nicht einmal bemerken. ${ }^{139}$

135 Vgl. Belting, Das echte Bild.

136 Vgl. Ders.: Idolatrie heute. In: Ders. (Hg.): Der zweite Blick. Bildgeschichte und Bildreflexion. München 2000, 273-280.

137 Vgl. Ders., Das echte Bild, $7 \mathrm{f}$.

138 Boehm, Die Wiederkehr der Bilder, 34.

139 Ebd., 35. 
Indem Boehm die $»$ Bilderflut ${ }^{140}$ als Ikonoklasmus bezeichnet, verwendet er einen theologischen Begriff und deutet diesen um. Er steht nicht mehr für eine Bildabstinenz im materiellen Sinne, sondern für eine scheinbare »Unsichtbarkeit« des Bildmediums, wodurch eine parallele Realität der »echten« gegenübergestellt wird und diese sogar überscheint. ${ }^{141}$ Mit der gleichen Intensität, mit der er die Fotografien skeptisch betrachtet, wertet Boehm die modernen Kunstbilder auf.

Dass diese Debatte um die Idolatrie der Fotografie schon zu Schulz' Zeiten aktuell war, zeigt Walter Benjamin in seinem Aufsatz »Die kleine Geschichte der Photographie.« Darin geht er unter anderem auf die damals virulente Frage ein, ob die technische Abbildung des menschlichen Gesichts als »Ebenbild « Gottes frevelhaft sei. Die moralisierende Ebene dieser Frage ablehnend, ${ }^{142}$ untersucht er die magische Seite der Fotografie in Abgrenzung zu der der Kunstgemälde.

»[D]ie exakteste Technik kann ihren Hervorbringungen einen magischen Wert geben, wie für uns ihn ein gemaltes Bild nie mehr besitzen kann. Aller Kunstfertigkeit des Photographen und aller Planmäßigkeit in der Haltung seines Modells zum Trotz fühlt der Beschauer unwiderstehlich den Zwang, in solchem Bild das winzige Fünkchen Zufall, Hier und Jetzt, zu suchen, mit dem die Wirklichkeit den Bildcharakter gleichsam durchgesengt hat, die unscheinbare Stelle zu finden, in welcher, im Sosein

140 Mit der Bilderflut ruft er zudem eine biblische Metapher auf, die in der Sintflut eine eindeutig negative, bedrohliche Konnotation hat. Damit vermischt auch er seine wissenschaftliche Terminologie mit mythologischen Begriffen und implementiert selbst partiell eine mythische Ebene.

141 Ganz ähnlich argumentiert Belting in seinem Artikel »Idolatrie heute«, nur im Kontext eines anderen aus der Theologie entlehnten Begriffs. Die Haltung, Bilder nicht mehr als solche wahrzunehmen, sondern direkt als Fakt, als dargestellte Realität zu verstehen, mache sie zum Realitätsersatz. Um aber von Idolatrie reden zu können, müsse zwischen "wahren" und "falschen" Bildern unterschieden werden. Diese Unterscheidungsmöglichkeit sei nach Belting in der Moderne deswegen nicht gegeben, weil fotografische und bewegte Bilder gar nicht als Bilder, sondern als Fakt wahrgenommen würden. »Wenn aller Bildgebrauch idolatrisch wird, gibt es keine Idolatrie mehr im engeren Sinne. Idolatrie enthält den Vorwurf, daß Bilder über alle Maßen, oder gegen ihren geborgenen Sinn als Bilder, verehrt werden. Der Vorwurf bezieht sich also auf den Umgang mit Bildern, der heute zum exzessiven Bildgebrauch geworden ist.«Belting, Idolatrie heute, 274. Gleichzeitig geht er in seiner historischen Perspektivierung darauf ein, dass Bilder schon immer eine Wirklichkeit erfanden. Wieso dem modernen Menschen die Vergleichsfolie Realität in größerem Maße abhanden gekommen sei als dem prätechnisierten Menschen, bleibt unklar.

142 Benjamin zitiert den Leipziger Anzeiger mit einem "plumpen« Idolatrievorwurf, der sich gegen die Fotografie wendet. Dies sei ein fetischistischer, antitechnischer Kunstbegriff, "mit dem die Theoretiker der Photographie fast hundert Jahre lang die Auseinandersetzung suchten«, ohne Ergebnis. Benjamin, Kleine Geschichte der Photographie, 369. 
jener längstvergangenen Minute das Künftige noch heut und so beredt nistet, daß wir, rückblickend, es entdecken können. Es ist ja eine andere Natur, welche zur Kamera als welche zum Auge spricht; anders vor allem so, daß an die Stelle eines vom Menschen mit Bewußtsein durchwirkten Raums ein unbewußt durchwirkter tritt. ${ }^{143}$

Dabei unterscheidet er zwischen dem Bild der Kunst und dem Abbild der Fotografie, ohne dabei zu behaupten, dass es keine Kunstfotografie gäbe. ${ }^{144}$ Während das Gemälde durch Einmaligkeit und Dauer charakterisiert sei, ist es das fotografische Abbild durch Flüchtigkeit und Wiederholbarkeit. Für den Menschen leichter zu fassen sei das fotografische Bild und dies gelte sogar für die fotografische Reproduktion eines Kunstbildes. Benjamin nennt diese Reproduktionsmethode daher eine "Verkleinerungstechnik ${ }^{145}$, die dem Menschen den Eindruck einer Herrschaft über den Gegenstand vermittelt. Weil Kunstbilder immer interpretierend zur Wirklichkeit stehen und Abbilder in erster Linie wiedergebend, sagen letztere weniger über die Wirklichkeit aus, obwohl ihre Beziehung zu ihr enger zu sein scheint. Die Welt erstarrt in den Fotografien vielmehr in ihre einzelnen, äußeren Momente, die Zusammenhänge und Funktionen hingegen treten in den Hintergrund. ${ }^{146}$ Susan Sontag fasst dieses Phänomen wie folgt zusammen:

»Die Fotografie fördert eine nominalistische Sicht der gesellschaftlichen Realität, so, als bestände diese aus kleinen, offenbar unendlich vielen Einheiten - wie ja auch die Zahl von Fotos, die von etwas gemacht werden können, unbegrenzt ist. Durch Fotografien wird die Welt zu einer Aneinanderreihung beziehungsloser, freischwebender

143 Ebd., 371.

144 Benjamin rezensiert Freunds Werk über »Photographie und Gesellschaft«. Er stellt fest, dass sie eine gute Frage an ihren Gegenstand stellt. »Die Frage, ob die Photographie Kunst sei, wurde damals mit dem leidenschaftlichen Anteil eines Lamartine, Delacroix, Baudelaire verhandelt, die Vorfrage wurde nicht erhoben: ob nicht durch die Erfindung der Photographie der Gesamtcharakter der Kunst sich verändert habe. Die Verfasserin hat das Entscheidende gut gesehen.« Benjamin, Walter: Gisèle Freund, La photographie en France au dix-neuvième siècle. Essai de sociologie et d'estétique. In: Tiedemann-Bartels, Hella (Hg.): Gesammelte Schriften III. Kritiken und Rezensionen. Frankfurt a.M. 1991, 542-544, hier 542.

145 Benjamin, Kleine Geschichte der Photographie, 382.

146 Ebd., $382 \mathrm{f}$. Diesen Aspekt vertieft Benjamin anhand Brechts Analyse über Firmenfotografien: »Denn die Lage, sagt Brecht, wird >dadurch so kompliziert, daß weniger denn je eine einfache $>$ Wiedergabe der Realität $`$ etwas über die Realität aussagt. Eine Photographie der Kruppwerke oder der A.E. G. ergibt beinahe nichts über diese Institute. Die eigentliche Realität ist in die Funktionale gerutscht.« Auf diesen Aspekt eingehend arbeitet Susan Sontag die paradoxe Eigenschaft heraus, dass »die von der Kamera aufgezeichnete Realität« mehr verbirgt als sie enthüllt. »Die `Realität ‘ der Welt liegt nicht in ihren Abbildern, sondern in ihren Funktionen. Funktionen sind zeitliche Abläufe und müssen im zeitlichen Kontext erklärt werden. Nur was fortwährend geschildert wird, kann von uns verstanden werden.«Sontag, Über Fotografie, 29. 
Partikel, und Geschichte, vergangene und gegenwärtige, zu einem Bündel von Anekdoten und faits divers. Die Kamera atomisiert die Realität, macht sie »leicht zu handhaben und vordergründig. ${ }^{147}$

Gisèle Freund, Benjamins Zeitgenossin und Leserin, vertieft genau diesen Aspekt, indem sie ihre Untersuchung "Photographie und Gesellschaft" der Veränderung des Wirklichkeitsverständnisses durch die Pressefotografie widmet. Durch die Fotografie erweitert sich der Blick des einzelnen Menschen; ferne Ereignisse und Personen werden ihm im Bild bekannt. Gleichzeitig formt das Bild auch die Vorstellung und Wahrnehmung, da es den Gegenstand nur aus einer bestimmten Perspektive und nur selektiv zeigt. ${ }^{148}$ Was nicht auf dem Foto ist, nimmt nicht Anteil an der Nachrichtenwirklichkeit. ${ }^{149}$ Reklame, Modekataloge und die illustrierten Zeitschriften sind zudem fotografische Bildformate, die weniger an einer Darstellung oder Interpretation denn an der Schaffung eines Wirklichkeitsbildes interessiert seien.

Dabei untersucht Freund ebenso wie Benjamin in seinem Aufsatz $»$ Das Kunstwerk im Zeitalter seiner technischen Reproduzierbarkeit« den Einfluss, den die Fotografie auf die Wahrnehmung und Rolle des Kunstbildes in der Gesellschaft hat. Sie argumentiert, dass die Fotografie bestimmte Tendenzen in der Malerei nur verstärkt, die ohnehin stattgefunden hätten. ${ }^{150}$ So wirkten sich der Positivismus und der Glaube an den Fortschritt auch unabhängig von der technischen Bildproduktion auf die Kunst aus. »[M]it der Forderung nach Exaktheit in den Wissenschaften [wurde] die Forderung nach wirklichkeitsgetreuer Wiedergabe in den Kunstwerken erhoben. ${ }^{151}$ Der sich ausprägende Realismus stellte Gegenstände der sichtbaren Wirklichkeit dar, Fantasiemotive traten zurück. ${ }^{152}$ Auch aus diesem Grund verlor (passiv wie aktiv) die Malerei einen wesentlichen Bereich ihres Aufgabenrepertoires an die Fotografie, die gerade für diese Zwecke geeigneter ist. Gleichzeitig und

147 Ebd., 28.

148 Freund, Photographie und Gesellschaft, $6 \mathrm{f}$.

149 Vgl. ebd., 117.

150 Vgl. ebd., $82 \mathrm{f}$. »Parallel zu den sozialen und wirtschaftlichen Veränderungen innerhalb der bürgerlichen Gesellschaft des 19. Jahrhunderts ging eine Änderung des Bewußtseins einher. Die Entwicklung der Industrie, die mit der Entwicklung der Technik Hand in Hand ging, der Fortschritt in den Naturwissenschaften, die sich zu gleicher Zeit mit den Bedürfnissen, die die wachsende Industrialisierung an rationale Wirtschaftformen stellt, vergrößerte, veränderte auch die Vorstellung des bürgerlichen Menschen von der Natur und wandelte seine Beziehung zu ihr. Ein neues Realitätsbewußtsein und eine neue Bewertung der Natur begann sich durchzusetzen, der in der Kunst eine dem Wesen der Photographie entsprechende Wendung zum Gegenständlichen folgte.«

151 Ebd., 83.

152 Siehe auch Hofstätter, Hans H.: Malerei und Graphik der Gegenwart. Baden Baden 1969, $16 \mathrm{f}$. 
auch dadurch verschob sich die Erwartungshaltung an das gemalte Kunstbild. Das Gefühl, dass Malerei und Grafik subjektiv seien, wuchs mit dem Gefühl, die Fotografie sei objektiv. ${ }^{153}$ "Nüchterne empirische Information und künstlerische Verkörperung wurden zunehmend gegeneinander ausgespielt. ${ }^{154}$ Diese neue Kluft ruft den Eindruck des Erstarrens hervor, denn das technische Bild scheint Fakten zu zeigen, selbst Beweis zu sein, das Kunstbild wird fiktiv, zum Ausdruck einer Künstlerpersönlichkeit.

»Innerhalb großer geschichtlicher Zeiträume verändert sich mit der gesamten Daseinsweise der historischen Kollektiva auch ihre Wahrnehmung. Die Art und Weise, in der die menschliche Wahrnehmung sich organisiert - das Medium, in dem sie erfolgt ist nicht nur natürlich sondern auch geschichtlich bedingt. ${ }^{155}$

Diese Untersuchung des Mediums spielt auch in Schulz' Erzählungen und Bildern eine übergeordnete Rolle. Gemälde der klassischen Kunst tauchen in den Porträts der Freunde im Hintergrund auf und innerhalb der Erzählungen. In »Druga jesień" (Der andere Herbst) analysiert der Erzähler verschiedene Bilder der barocken Malerei und bringt diese in den Zusammenhang mit der Bildproduktion der Natur. Bilder der Kunst werden dabei in sehr unterschiedlichen und durchaus nicht krisenfreien Kontexten beschrieben oder nacherzählt. Eine genauere Untersuchung dieses Zusammenhangs findet sich in fünften Kapitel.

Die Krise der Malerei, ${ }^{156}$ die mit einem Teilverlust ihrer Selbstverständlichkeit einhergeht, führt zu einer gesteigerten Theoriebildung und zu neuen Darstellungsformen und -motiven. "Mit der Entgrenzung hatten die Bilder an Universalität rapide gewonnen, ihre Selbstverständlichkeit aber eingebüsst. $^{157}$ Dies zeigt sich deutlich in den vielen, um die Jahrhundertwende verfassten Künstlermanifesten, Programmen und Aufrufen, die die Rolle der Kunst in der Moderne neu zu bestimmen versuchen. ${ }^{158}$ Auch Schulz' pro-

153 Benjamin, Paris, die Hauptstadt des XIX. Jahrhunderts, 49.

154 Die Auswirkung dieser Entwicklung auf die Geschichtswissenschaften hat Hayden White untersucht und aufgezeigt, wie sich auch historisch gesehen die Vorstellung von Geschichte und ihrer Vermittlung gewandelt hat. Vgl. White, Hayden V.: Die Bedeutung der Form. Erzählstrukturen in der Geschichtsschreibung. Frankfurt a. M. 1990, 11-40.

155 Benjamin, Das Kunstwerk, 439. (Hervorh. im Orig.)

156 Nach Belting ist nicht die Fotografie Auslöser der »Krise des Bildes«, auch wenn beide oft miteinander in Bezug gesetzt werden. Vielmehr arbeiten sich die Zeitgenossen noch an dem hohen Anspruch ab, den sie an das Medium stellen. Weder ist die Fotografie eine Indexierung der Natur, noch eine wahrheitsgemäße Abbildung der Welt. Vgl. Belting, Bild-Anthropologie, 213-220.

157 Boehm, Gottfried (Hg.): Was ist ein Bild? 2. Aufl. München 1994, 13.

158 Vgl. Beyme, Klaus v.: Das Zeitalter der Avantgarden. Kunst und Gesellschaft 1905-1955. München 2005, 221-235. 
grammatisches Manifest »Mityzacja rzeczywistości« lässt sich in diesem Kontext lesen. Diese Krise mündet gleichzeitig in eine gesteigerte Ausdruckkraft, indem die Malerei - stückweise entwurzelt aus der Tradition - neue Bildwelten für sich entdeckt. ${ }^{159}$

Diese radikale Veränderung gegenüber vorherrschenden Bildbegriffen führt zu einer wissenschaftlichen Neubefassung mit dem »Bild" als spezifischem kulturellen Ausdruck, der dem Menschen neben der Sprache die Welt vermittelt. Jörg Probst und Jost Klenner setzen den Beginn einer »Bildwissenschaft" am Anfang des 20. Jahrhunderts an, in der eine Reihe von wissenschaftlichen und philosophischen Arbeiten entstehen, die der Frage nachgehen, welche kulturelle, epistemologische und gesellschaftliche Rolle das Bild in der Gegenwart spielt. ${ }^{160}$ Neben Benjamin hat das Werk von Erwin Panofsky einen besonderen Stellenwert. In seiner Ikonologie entwickelt Panofsky frühzeitig ein Begriffsinstrumentarium, welches die Vorstellungswelt des bildmachenden Künstlers mit der Darstellungsweise seines Bildes in Bezug setzt und diese sowohl im Kontext der historischen Gegenwart, aber auch im Wandel der Zeit und mit Blick auf zukünftige Entwicklungen analysiert. $^{161}$

159 Vgl. Hofstätter, Malerei und Graphik der Gegenwart, 19-22.

160 Vgl. Probst/Klenner, Ideengeschichte der Bildwissenschaft. Zu den in ihrem Band untersuchten Intellektuellen gehören unter anderem Aby Warburg, Hans Blumenberg, Edgar Wind, Heinrich Wölfflin und Friedrich Gundolf, aber auch Roland Barthes, Pierre Bourdieu und Michel Foucault.

161 Vgl. Mitchell, Picture Theory, 16-19. Wesentlich zu diesem Forschungsfeld haben auch die anderen Wissenschaftler der Bibliothek Warburg beigetragen. Neben Panofsky untersuchte beispielsweise Ernst Cassirer in seiner »Philosophie der Symbolischen Formen« den Grund für die Wandlungen am Bild-, Sprach-, und Mythosbegriff und entwickelte einen systematischen Zusammenhang zwischen dem epochenspezifischen Wirklichkeitsverständnis und Weltbewusstsein und den Ausdrucks- und Erklärungsformen des Menschen. Vgl. Cassirer, Der Begriff der Symbolischen Form. In diesem 1920/21 in den Vorträgen der Bibliothek Warburg veröffentlichten Aufsatz entwickelt Cassirer einen systematischen Zugriff auf Bedeutungssysteme und Sinngebungsprozesse, den er anschließend in seinem Hauptwerk "Philosophie der Symbolischen Formen « vertieft. Cassirers Aufgabenstellung und Ansatz sind unbedingt aus seiner Zeit heraus zu lesen. Er selbst weist in seinem Aufsatz auf die Bedeutung hin, die der »Positivismus« als Abgrenzungsfolie seines Denkens einnimmt. Während der Positivismus bemüht sei »die Materie der Tatsachen« darzustellen, wollte Cassirer über diesen Ansatz hinausgreifen. Ausgangslage ist das Datenmaterial, das die Forschergenerationen im 19. Jahrhundert über verschiedene Sprachen, Völker und Riten gesammelt hatten. Aus einer vergleichenden Sprachbetrachtung ergibt sich, dass in Sprachen ohne verwandtschaftliche oder lokale Berührung dennoch Ähnlichkeiten feststellbar seien. Auch die vergleichende Mythenforschung zeige ein ähnliches Ergebnis. Nicht hinsichtlich des Materiellen, aber hinsichtlich bestimmter »Elementargedanken« ließen sich in den verschiedenen Mythologien der Völker Analogien feststellen. Man könne einen "Kerngehalt« und »Prinzipien« der Mythenbildung herausarbeiten. Diese konstitutive Einheit 
In Abgrenzung zum Paradigma des 19. Jahrhunderts steht in den neueren bildwissenschaftlichen Ansätzen des 20. Jahrhunderts somit nicht so sehr die kunsthistorische und ästhetische Deutung des einzelnen Bildes oder eines Künstlerwerks im Zentrum des Interesses, sondern die Frage nach dem Grund der jeweils verwendeten Ausdrucksform, das heißt nach der dahinterliegenden Bewusstseinsenergie ${ }^{162}$ Gleichzeitig interessiert die Bildwissenschaftler auch der Einfluss von Bildmedien auf die Wahrnehmung und das Verständnis der Welt. Bild wird sowohl als Ergebnis eines kulturellen Symbolisierungsaktes, Träger eines Dargestellten, wie auch als Impulsgeber für eine bestimmte Wirklichkeitsdeutung aufgefasst. ${ }^{163}$ Es steht in wirkender Beziehung zum Menschen. ${ }^{164}$ Damit wird auch die Kunst zunehmend theoretisiert und epistemologischen Fragestellungen zugeführt. ${ }^{165}$ Gleichzeitig weitet sich der Kontext, in dem die Bildidee untersucht wird, stark aus. Neben Gemälden, Fotografien, Stichen und Drucken gewinnen auch Alltagsgegenstände in Bildformat wie Briefmarken, Schilder, Werbung und Wissenschaftsillustrationen an Aufmerksamkeit. ${ }^{166}$ Damit tritt immer deutlicher eine Unterscheidung verschiedener Aspekte zutage, die allesamt mit dem Wort »Bild « bezeichnet werden. Am wichtigsten ist die Unterscheidung zwischen dem Medium (Bildträger) und dem Dargestellten/Visualisierten. Im Englischen kommt dies durch die Bezeichnungen "picture» und »image« deutlich zum

des mythischen Denkens ließe sich nicht auf herkömmlichem Weg, von den mythischen Objekten her, bestimmen, sondern allein von der Funktion her. Dies zu erledigen sei die Aufgabe einer allgemeinen Systematik der symbolischen Formen.

162 Vgl. Schneider, Pablo: Begriffliches Denken - verkörpertes Sehen: Edgar Wind (19001971). In: Probst/Klenner: Ideengeschichte der Bildwissenschaft, 53-74, hier $56 \mathrm{f}$.

163 Es strukturiert eine Wahrnehmung auf bestimmte Weise und liefert einen »Vorentwurf» der Welt. Vgl. Boehm, Wie Bilder Sinn erzeugen, 14.

164 Hans Belting hat in seinem Buch "Bild-Anthropologie" diese Wechselbeziehung zwischen Mensch und Bild untersucht und gleichzeitig daraus eine Theorie entwickelt. Dabei bezieht er sich maßgeblich auf die Philosophen und Theoretiker der Zwischenkriegszeit, auf die Forscher aus dem Kreis um Aby Warburg und auf die Frankfurter Schule, darunter Walter Benjamin. Vgl. Belting, Bild-Anthropologie.

165 Boehm leitet die Entstehung der Bildwissenschaften auch aus dem Einfluss von Kants Philosophie her. »Wir erinnern nur daran, dass die neuere Wende zum Bild (iconic turn`) vom Muster einer Verlaufsfigur geprägt ist, deren Prototyp Kant schuf, als er die kritische Rückführung der Metaphysik auf die Struktur des menschlichen Bewusstseins mit der Vorgehensweise der kopernikanischen Revolution verglich. Im 20. Jahrhundert ist mit dem Zurückbuchstabieren komplexer Phänomene auf Bedingtheiten und Strukturen der Sprache, der psychischen Dynamik, des Aktes der Anschauung, des menschlichen Daseins, des Körpers, der Medialität oder der Gesellschaft ein dichtes argumentatives Geflecht entstanden, durch welches auch Bild und Imagination immer wieder in ein neues Licht gesetzt werden.« Boehm, Wie Bilder Sinn erzeugen, 17.

166 Vgl. Sachs-Hombach, Klaus (Hg.): Bildwissenschaft. Disziplinen, Themen, Methoden. Frankfurt a.M. 2005. 
Ausdruck. ${ }^{167}$ Das Medium bedingt durch die Grenzen und Möglichkeiten seines Materials die Realisierung einer Bildvorstellung. Dass auch Schulz über den Zusammenhang zwischen Medium und Inhalt nachgedacht hat, zeigt sich in seinem öffentlichen Briefwechsel mit Witkiewicz: »Das Material und die Technik wirken hier als selektives [sic] Filter. Die Zeichnung setzt durch ihr Material engere Grenzen als die Prosa. ${ }^{168}$ Diese Medienreflexionen setzen sich in seinem Werk und in den Briefen fort.

"Der Realismus als ausschließliche Tendenz zum Kopieren der Wirklichkeit scheint mir eine Fiktion zu sein. Nie hat es einen solchen gegeben. Der Realismus wurde zu einem Alp, zum Schreckbild der Nicht-Realisten, zu einem wahren Satan des Mittelalters, grellfarben an alle Wände gemalt. Ich würde vorschlagen die Bezeichnung >Realismus` als rein snegativen Terminus zu verwenden: es ist eine Methode, die bemüht ist, ihre Mittel im Bereich einer bestimmten Konvention unterzubringen, die beschlossen hat, eine bestimmte Konvention nicht $\mathrm{zu}$ brechen, die wir Wirklichkeit, gesunder Menschenverstand oder Wahrscheinlichkeit nennen. Im Bereich dieser Grenzen bleibt ihm eine sehr breite Skala von Mitteln, wie breit beweist Mann, der alle Sphären und Höllen ausschöpft, ohne die realistische Konvention zu durchbrechen. ${ }^{169}$

Dieser Zusammenhang zwischen Medium/Mittel und Gegenstand wird ebenfalls in verschiedenen Mikrotraktaten innerhalb der Erzählungen beleuchtet. In den Grafiken übersetzt Schulz Motive einer Novelle in Bildform und in den

167 Vgl. Belting, Bild-Anthropologie, 13-15. Dabei versteht Belting das Dargestellte und das Medium der Darstellung als zwei Seiten einer Münze. Bilder werden in seiner Konzeption nicht nur durch materielle Medien wie Gemälde und Briefmarken, sondern auch durch »innere Bilder« wie Träume und Erinnerungen repräsentiert. Beide sind nach Belting verwandt und ein äußeres Bild kann in ein inneres umgewandelt werden und umgekehrt. Die Trennlinie verläuft über den Körper des Menschen. Die verschiedenen Gattungen (Plastik, Radierung, Musik, Poesie) sind nur unterschiedliche Techniken der Umsetzung einer Bildidee. Sie sind Medien, die das Bild tragen und ihre Materialgesetze haben Einfluss auf die Darstellbarkeit. Vgl. ebd., 20.

168 Schulz, Bruno Schulz an St. I. Witkiewicz, 91. »Materiał, technika działają tutaj jako zasada selekcji. Rysunek zakreśla ciaśniejsze granice swym materiałem niż proza.« Schulz, Bruno Schulz do St. I. Witkiewicza, 19.

169 Ders.: Brief an Anna Płockier vom 6.11.1941. (Aus dem Poln. v. Mikolaj Dutsch). In: Ficowski (Hg.): Gesammelte Werke, 192-194, hier 192. „Wydaje mi się, że realizm, jako wyłączna tendencja do kopiowania rzeczywistości - jest fikcją. Nigdy nie było takiego. Realizm stał się zmorą i straszakiem nie-realistów, istnym szatanem średniowiecza malowanym na wszystkich ścianach jaskrawymi barwami. Proponowałbym dla określenia realizmu [użyć] terminu czystego negatywnego: jest to metoda, która stara się pomieścić swe środki w odrębie pewnych konwencji, postanawia nie łamać pewnej konwencji, którą nazywamy rzeczywistością lub zdrowym rozsądkiem, lub prawdopodobieństwem. W obrębie tych granic pozostaje mu bardzo szeroka skala środków, jak szeroka, dowodzi właśnie Mann, który wyczerpuje wszystkie sfery i piekła, nie łamiąc konwencji realistycznej.«Schulz, Księga listów, 198. 
Erzählungen übersetzt er Gemälde in Sprachform. Durch den Wechsel der Ausdrucksmedien werden dabei spefizische Möglichkeiten der Medien sichtbar, vergleichbar und theoretisierbar.

Alle produzierten Bilder nehmen nach Belting - der sich in seiner Bild-Anthropologie auf Benjamin und die Warburger Schule bezieht - Anteil an der Kultur und unterliegen immer einem Symbolisierungsakt. "Auch die photographischen Bilder symbolisieren unsere Wahrnehmung der Welt und unsere Erinnerung an die Welt. $«{ }^{170}$ Dies zeige sich vor einem größeren Horizont der Bildgeschichte und gelte auch für technisch produzierte Bildmedien, weil Bilder zwei Symbolisierungsprozessen unterliegen - bei der Produktion und der Betrachtung.

"Kunstwerk und Betrachter kommen unter Bedingungen zusammen; sie sind keine klinisch reinen und isolierten Einheiten. Und so wie der Betrachter sich dem Werk nähert, so begegnet ihm das Kunstwerk: antwortend und seine Tätigkeit anerkennend. ${ }^{171}$

Der Betrachter erkennt und ordnet Motive, Formen und Aussagegehalte des Bildes entsprechend seiner Bildung, Sozialisation und Bewusstsein sowie abhängig vom Betrachtungskontext. Ikonen können sowohl als Hypostase oder nur als verweisende Darstellung Gottes verstanden werden, in einem nichtchristlichen Kontext, beispielweise durch einen Marsianer, auch als Porträt eines Menschen oder auch gar nicht verstanden werden. Dabei dringt das Bewusstsein des Rezipienten ins Bild und das Bild ins Bewusstsein des Rezipienten. »Wir selbst sind der Ort der Bilder, denn das Bild ist auf andere Weise anwesend, als es sein Medium ist. Es wird erst zum Bild, wenn es von seinem Betrachter animiert wird. $«{ }^{172}$ Mit Symbolisierungsprozessen ist die Bewusstseinsenergie gemeint, die bestimmten Bildern eine bestimmte Rolle zuweist, denn dass eine Fotografie als Abbild der Wirklichkeit verstanden wird, ist

170 Belting, Bild-Anthropologie, 214. »Es sind die symbolischen Bilder der Imagination, die von weither gekommen sind, wenn sie in dieses technische Medium einwandern. [...] Die menschliche Wahrnehmung hat sich immer wieder neuen Bildtechniken angepaßt, aber sie transzendiert solche medialen Grenzen ihrer Natur gemäß. Bilder selber sind von Hause aus intermedial. Sie wandern zwischen den historischen Bildmedien weiter, die für sie erfunden werden. Die Bilder sind die Nomaden der Medien. Sie schlagen in jedem neuen Medium, das in der Geschichte der Bilder eingerichtet wurde, ihre Zelte auf, bevor sie in das nächste Medium weiterziehen. Es wäre ein Irrtum die Bilder mit diesem Medium zu verwechseln. Die Medien selber sind aber ein Archiv von toten Bildern, die wir erst in unserem Blick animieren. Auch die photographischen Bilder nehmen ihren Platz in dem alten Schauspiel ein, das wir das Theater der Bilder nennen können.«

171 Kemp, Wolfgang: Kunstwerk und Betrachter: Der rezeptionsästhetische Ansatz. In: Belting, Hans/Kemp, Wolfgang/Dilly, Heinrich u.a. (Hg.): Kunstgeschichte. Eine Einführung. Berlin 1986, 203-221, hier $203 \mathrm{f}$.

172 Belting, Bild-Anthropologie, 30. 
einer gesellschaftlichen Konvention geschuldet. ${ }^{173}$ Das heißt, dass historische Bildbegriffe gleichfalls Symbolisierungen eines bestimmten Wirklichkeitsund Kulturverständnisses sind, die sich unbewusst am Gegenstand niederschlagen. Die Bildwissenschaft untersucht daher das in Bildartefakten zum Ausdruck gekommene Welt- und Wirklichkeitsverständnis sowie die von Bildern im weiteren Sinne ausgehenden Wirkungen. Probst und Klenner fassen es prägnant in dem Satz zusammen: »Von Bildern angeregte Theoriebildung ist Bildwissenschaft. ${ }^{174}$

Wie genau die Grafiken und Zeichnungen zu einer Theoriebildung beitragen, ist der Gegenstand der folgenden Analyse. Dabei wird deutlich, dass ihre Motive eng mit literarischen Vorlagen verbunden sind. Diese Beziehung zur Sprache wird in den darauffolgenden Kapiteln stets intensiver, sodass im fünften schon die »Wortmalerei«, also Bilder im Medium der Sprache, Gegenstand der Theoriebildung ist.

173 Cassirer hat mit seiner »Philosophie der symbolischen Formen« umfassend die Funktion der Medien Bild und Sprache in Verbindung mit der Religion, Kunst, Wissenschaft und des Mythos als spezifische Bewusstseinsform untersucht und eine Systematik der kulturellen Bedeutungs- und Sinnproduktion verfasst. „Unter einer >symbolischen Form` soll jede Energie des Geistes verstanden werden, durch welche ein geistiger Bedeutungsgehalt an ein konkretes sinnliches Zeichen geknüpft und diesem Zeichen innerlich zugeeignet wird. In diesem Sinne tritt uns die Sprache, tritt uns die mythischreligiöse Welt und die Kunst als je eine besondere symbolische Form entgegen. Denn in ihnen allen prägt sich das Grundphänomen aus, daß unser Bewußtsein sich nicht damit begnügt, den Eindruck des Äußeren zu empfangen, sondern daß es jeden Eindruck mit einer freien Tätigkeit des Ausdrucks verknüpft und durchdringt. Eine Welt selbstgeschaffener Zeichen und Bilder tritt dem, was wir die objektive Wirklichkeit der Dinge nennen, gegenüber und behauptet sich gegen sie in selbständiger Fülle und ursprünglicher Kraft.« Cassirer, Der Begriff der Symbolischen Form, 15.

174 Probst, Jörg/Klenner, Jost P.: Vorwort. In: Probst/Klenner: Ideengeschichte der Bildwissenschaft, 7-9, hier 8 . 


\section{Bildreflexionen in Bildern - "Xięga Bałwochwalcza»}

Die Grafiksammlung »Xięga Bałwochwalcza ${ }^{1}$ ist in der ersten Hälfte der 1920er Jahre in Drohobycz entstanden und Schulz' eigentliches Erstlingswerk. Der Titel weist darauf hin, dass sowohl das »Buch« als auch das »Bild» eine zentrale Rolle spielen. Dennoch wurden die Grafiken über einen langen Zeitraum hinweg fast ausschließlich psychologisch gelesen und das masochistische Motiv biografisch als sexuelle Orientierung des Autors gedeutet. Diese Form des Zugangs begründet sich durch eine tendenziöse Übersetzung des Romans »Venus im Pelz« ins Polnische, wie Ariko Kato herausgefunden hat, ${ }^{2}$ durch zweideutige Selbstzeugnisse, ${ }^{3}$ weiterhin durch eine zu unkritische Adaption psychoanalytischer Theorien in die Literatur- und Kunstwissenschaft ${ }^{4}$ sowie durch eine grundsätzliche Tendenz, Schulz' Werke biografisch zu lesen. Obwohl Krystyna Kulig-Janarek in einem Aufsatz schon 1992 den »Mythos« des Masochisten Schulz erforscht und dekonstruiert hat, hält er sich bis heute standhaft.

»Den Anfang über die Legende des Masochisten Schulz machte Stanisław Ignacy Witkiewiczs Artikel. Nach dem Krieg festigte sich diese Meinung durch Artur Sandauer, für den Schulz’ Auffassung von Masochismus Maßstab seines Stellenwerts und seiner Modernität war. $\aleph^{5}$

1 Aus einem Fundus von insgesamt 30 verschiedenen Grafiken, die zur Sammlung gehören, setzt sich jedes »Buch« neu zusammen und besteht in der Regel aus ca. 20 Grafiken, die als Zyklus komponiert sind. Der Titel »Xięga Bałwochwalcza« lässt sich sowohl als »Buch vom Götzendienst«, als "götzendienerisches Buch«, evtl. als »abgöttisches Buch» oder »Götzenbuch" übersetzen. "Xięga" ist eine abgewandelte Schreibweise des Wortes "Księga«, das sowohl als Buch im Allgemeinen, aber auch als religiöses Buch oder Foliant interpretierbar ist. Das antiquierte $\mathrm{X}$, welches im polnischen Alphabet nicht existiert, weist zusätzlich auf eine ältere oder bedeutendere Buchart hin.

2 Ariko Kato erklärt in ihrem Aufsatz »The Early Graphic Works of Bruno Schulz and SacherMasoch's Venus in Furs« mit großer Überzeugungskraft, woher die gängige Fehlannahme namhafter Forscher wie Ficowski, Kitowska-Łysiak, Sandauer oder Jarzębski kommt, dass Schulz seinen eigenen Masochismus darstelle. Vgl. Kato, The Early Graphic Works.

3 In seinem öffentlichen Austausch mit Gombrowicz machen beide ironische Andeutungen, Schulz könne masochistisch veranlagt sein. Vgl. Schulz, Bruno: Do Witolda Gombrowicza. In: Kitowska-Łysiak: Szkice krytyczne, 13-17.

4 Eine ausführliche Kritik an dieser Haltung findet sich bei Augsburger, Masochismen, 130.

5 »Początek ^legendy^ o Schulzu-masochiście dał artykuł Stanisława Ignacego Witkiewicza, a po wojnie opinię tę utrwalał Artur Sanauer, dla którego Schulzowskie ujęcie masochizmu 
Angeknüpft haben daran Jerzy Ficowski ${ }^{6}$, Małgorzata Kitowska- Łsiak $^{7}$ sowie Jerzy Jarzębski ${ }^{8}$, der noch im 2006 herausgegebenen "Słownik Schulzowski» (Schulz-Wörterbuch) den Mythos des masochistischen Künstlers erneuert hat.' Obwohl Schulz explizite Zweifel an der Anwendbarkeit psychoanalytischer Theorien und Methoden für die Literatur geäußert hat, ${ }^{10}$ wurden er und sein Werk oft ohne Unterscheidung zwischen Autor und Erzähler Gegenstand der Psychoanalyse.

Inzwischen gibt es eine Reihe von Forschungsarbeiten, die sich jenseits des Masochismus mit der Deutung der Grafiken befassen. Janis Augsburger untersucht in ihrer Arbeit den Masochismus als Krisenästhetik, die auf Mythologiesierungsverfahren zurückgreift. ${ }^{11}$ Vor allem Ariko Kato hat in ihren zwei wegweisenden Aufsätzen »Obraz i Księga ${ }^{12}$ (Bild und Buch) sowie

było wyznacznikiem pozycji i nowoczesności tego twórcy.« Kulig-Janarek, Krystyna: Erotyka - groteska - ironia - kreacja. In: Kitowska-Łysiak: Bruno Schulz in memoriam, 153-177, hier 154. (Übers. A. J.)

6 Vgl. Ficowski, Regiony wielkiej herezji, $109 \mathrm{f}$.

7 Vgl. Kitowska-Łysiak, Bruno Schulz, 136-138.

8 Laut Jarzębski sei Schulz selbst masochistisch veranlagt, weshalb die auf den Grafiken dargestellten erotischen Szenen ihm zufolge direkt sein erotisches Leben darstellen. Die Grafiken dienen ihm der Bewusstwerdung; sie seien keine realistische Wiedergabe seiner Welt, "sondern eher seine weitgehende Transformation oder Adaption." (Übers. A. J.) "ale raczej jego daleko idącą transformacją czy adaptacją." Jarzębski, Prowincja centrum, $26 \mathrm{f}$.

9 Im »Słownik Schulzowski« findet sich unter dem Stichwort Masochismus folgende Diagnose: „Eine krankhafte Schüchternheit, verbunden mit einem Minderwertigkeitskomplex, führte bei Schulz zur Herausbildung eines Typs masochistischer Erotik, die sich in seiner Beziehung zu Frauen in Demut und Unterwürfigkeit voll offenbarte und in der Neigung zu Partnerinnen mit starker Persönlichkeit, die im Leben und intellektuell unabhängig waren. [...] Der Masochismus wäre Schulz' Privatangelegenheit geblieben, wenn Artur Sandauer nicht darin den Schlüssel zu Schulz' Weltanschauung erblickt und diesen deshalb auf weite Bereiche ausgedehnt hätte: auf den familiären, sexuellen, gesellschaftlichen, literaturgeschichtlichen und ästhetischen. Damit machte er Schulz zu einem Dichter, der seine Niederlage in vielen Gebieten austrägt und seinen Ausdruck im universellen Gefühl der Minderwertigkeit findet. (Übers. A. J.) »Chorobliwa nieśmiałość połączona z kompleksem niższości prowadziła u Schulza do wykształcenia się masochistycznego typu erotyki, przejawiającego się w pełnym pokory i czołobitności w stosunku do kobiet, w upodobaniu do partnerek o silniej osobowości, niepodległych życiowo i intelektualnie. [...] Masochizm pozostałby prywatną osobliwością erotyki Schulza, gdyby Artur Sandauer nie uczynił go kluczem do światopoglądu pisarza i nie rozpisał na różnych płaszczyznach: rodzinnej, seksualnej, społecznej, historycznoliterackiej i estetycznej, czyniąc Schulza piewcą rozgrywającej się w wielu wymiarach klęski, wyrazicielem uniwersalnego poczucia niższości.« Vgl. Masochizm. In: Bolecki, Słownik schulzowski, 202-204.

10 Vgl. Dybel, Paweł: Bruno Schulz i psychoanaliza. In: Teksty drugie (2013), 241-256, hier $244 \mathrm{f}$.

11 Vgl. Augsburger, Masochismen.

12 Vgl. Kato, Obraz i Księga. 
"The Early Graphic Works of Bruno Schulz and Sacher-Masoch's Venus in Furs $«^{13}$ schon weite Teile des Bilddiskurses offengelegt und gezeigt, dass sich Schulz intensiv mit der Tradition und dem Konzept der »Mimesis« sowie des "mise en abyme ${ }^{14}$ auseinandergesetzt hat. Kris Van Heuckelom fokussierte eher auf die theologische Fragestellung hinter dem Idol-Motiv. ${ }^{15}$ Krystyna Kulig-Janarek untersucht die Groteske als Kontext und Form, in welcher sich die Grafiken verorten lassen. ${ }^{16}$ Jan Gondowicz ergänzt diese Ansätze noch um die Analyse der Bedeutung der dionysischen Kultur, die vor allem durch Friedrich Nietzsche eine neue Interpretation erfahren habe. ${ }^{17}$ Dariusz Sikorski hingegen untersucht die Grafiken im Kontext einer Symboltheorie. ${ }^{18}$

An dieser Stelle gilt es also die wichtigsten Ergebnisse zu bündeln und zu erweitern. Insbesondere der Technik »Cliché-verre ${ }^{19}$, aber auch dem Umgang mit den verschiedenen Bild- und Textvorlagen soll besondere Aufmerksamkeit gewidmet werden. Der Fokus des hier verfolgten Ansatzes liegt dabei auf der in den Bildern erkennbaren Theoriebildung. Diese zeigt sich in der spezifischen Verwendung verschiedener Subtexte und Bildzitate, der Aufrufung des Idolatrie-Kontextes, der Anbindung an mythologische Stoffe sowie in der Interaktion zwischen Maler und Kunstwerk. Weitere Beobachtungen, beispielsweise, dass Schulz in seinen Grafiken eine Narration erkennbar werden lässt, rücken auch die Frage nach der Beziehung zum Sprachlichen und seinen eigenen Erzählungen in den Raum. Insbesondere das wiederholte Auftauchen derselben Figuren erinnert an eine Erzählung, die aus der Warte des Protagonisten "Schulz« - dargestellt im Selbstporträt - erzählt wird. ${ }^{20}$

Gleichzeitig theoretisiert Schulz das Kunstschaffen durch das auffällig häufige Motiv des »Bildes im Bild«, welches für einen artistischen Metadiskurs im Medium der plastischen Kunst steht. Dieses ist besonders markant in seinen Porträts aus derselben Schaffenszeit, die noch deutlicher als die Grafiken die Frage nach der Wechselbeziehung von Kunst und Wirklichkeit stellen. Metabilder sind nach Mitchell "pictures that refer to themselves

13 Vgl. Dies., The Early Graphic Works.

14 Auf die Bedeutung von »Mise en abyme« wird genauer im Kapitel 3.6 »Bild im Bild» eingegangen.

15 Vgl. Van Heuckelom, In Defense of Idolatrous Creativity.

16 Vgl. Kulig-Janarek, Erotyka - groteska.

17 Vgl. Gondowicz, Schulz.

18 Vgl. Sikorski, Symboliczny świat.

19 »Cliché-verre« ist eine fotoreproduzierbare Grafiktechnik. Die genauere Erläuterung erfolgt im Unterkapitel 3.1 "Cliché-verre" als Form des Dazwischen.

20 Vgl. Freise, Schulz zwischen Literatur, 116. Genauso wie die Erzählungen keine tatsächliche Autobiografie darstellen, so kann man auch die Grafiken nicht autobiografisch lesen, sondern sie geben eine bestimmte Deutung auf Grundlage einer autobiografisch angelegten »Erzählung.» 
or to other pictures, pictures that are used to show what a picture is. ${ }^{21}$ Dabei legt Schulz einen besonderen Schwerpunkt auf die Untersuchung der Beziehung des Kunstbildes zum Künstler. ${ }^{22}$ Der Frage, wie Schulz die Interaktion zwischen Kunstwerk, Wirklichkeit und Künstler darstellt und welche Bedeutungen sich daraus ableiten lassen, wird nachgegangen. Dies führt zu der zu untersuchenden These, dass Schulz in seinem Grafikwerk und Porträts eine Bildtheorie in Bildsprache verfasst hat.

Dabei wählt Schulz ein untypisches und in seiner Unbekanntheit schon avantgardistisch zu bezeichnendes Medium - die »Cliché-verre« - und führt seine Grafiken im Stil der Groteske aus. ${ }^{23}$ Diese unterschiedlichen Facetten der Bilddiskussion sollen nun im Folgenden genauer untersucht werden.

\section{1 „Cliché-verre« als Form des Dazwischen}

Die Grafiken wurden mit der Verarbeitungstechnik »Cliché-verre« angefertigt, wohinter sich eine Glasradierung verbirgt, die nicht gedruckt, sondern auf lichtempfindlichem Papier entwickelt wird. ${ }^{24}$ Die Hochzeit dieser Tech-

21 Mitchell, Picture Theory, 35. Ausführlich befasst sich Mitchell mit den »Metabildern« auf den Seiten 35-50.

22 Ein wesentlicher Entwicklungsstrang der »Venus im Pelz« - und auch der UndulaGruppe der Grafiken - ist die kreative Arbeit. Der Leser begleitet einen Künstler beim Finden und Ergründen seines Ideals, das er anschließend gestaltet. Das Werk »Wanda als Venus im Pelz« emanzipiert sich aber zunehmend vom Künstler und verharrt nicht in den ihm zugewiesenen Grenzen. Die »Bild-Diskussion« wird auf die Mann-Frau-Beziehung übertragen und auf sehr unterschiedlichen Ebenen untersucht, von der Genese über die Entwicklung, Ausformung und Emanzipation bis hin zur Abwendung des Werks vom Urheber (und Geliebten). Diese Beobachtungen geben zu der These Anlass, dass Schulz, indem er gerade diese Novelle und die in ihr verhandelten Bilder zum Subtext seiner Grafiken macht, bewusst die Grenzen des Bildes untersucht, indem er den Schaffensprozess selbst, den Verwandlungsprozess des Bildes, das Wirken des Bildes und seine Emanzipation vom Künstler zum Thema seiner Bilder macht. In der Vereigenständigung des Kunstbildes gegenüber dem Künstler lässt sich eine Nähe zu Roland Barthes Thesen in seinem Aufsatz »Der Tod des Autors « erkennen. In Schulz' Grafiken der "Xięga Bałwochwalcza" wird allerdings stärker die Beziehung des Künstlers zu seinem Werk denn die des Rezipienten untersucht. Vgl. Barthes, Roland: Der Tod des Autors. In: Wirth, Uwe (Hg.): Performanz. Zwischen Sprachphilosophie und Kulturwissenschaften. Frankfurt a.M. 2002, 104-110.

23 Vgl. Vogel, Debora: Bruno Schulz. In: Chmurzyński (Hg.): Bruno Schulz 1892-1942, $165 \mathrm{f}$., hier 165.

24 »Eigentlich heißt Cliché-verre nichts anderes als `Negativ aus Glas`, und das Vorgehen scheint in seinem Verfahren gar nicht so kompliziert. Es stellt eine Verbindung aus Photo- und Radiertechnik dar. Eine Glasplatte wird mit einer lichtundurchlässigen Schicht abgedeckt und dann mit einer Radiernadel und anderen Instrumenten, die die 
nik fiel in Frankreich mit dem Untergang der Porträtmalerei und der Erfindung der Fotografie zur Mitte des 19. Jahrhunderts zusammen. ${ }^{25}$ Obwohl die Cliché-verre in ihrer Technikaffinität progressiv war, blieb sie nach Agnes Matthias thematisch den sonstigen Grafiken verbunden. ${ }^{26}$ "So sind es überwiegend Landschaften im Modus einer >paysage intime`, die die Cliché-verre zeigen. ${ }^{27}$ Damit ist die Cliché-verre die erste fotoreproduzierbare GrafikTechnik überhaupt, aber zu Schulz' Zeiten schon lange veraltet. ${ }^{28}$ Gerade deswegen stellt sich berechtigterweise die Frage, wieso Schulz ausgerechnet auf sie zurückgegriffen hat.

Die Cliché-verre markiert auf ihre Weise die Grenze zwischen zwei Epochen der Bildproduktion, nämlich zwischen handwerklich und technisch angefertigten Bildern. Damit ist sie als Schwellen-Technik lesbar, an der die Wandlungen am Bildmedium sichtbar zutage treten. In den Versuchen, malerische Effekte zu erzielen, obwohl die Materialbedingungen andere Stilmittel begünstigen, spiegelt sich die Unbeholfenheit, die auch in den Anfängen der Porträtfotografie vorherrschte. Diese simulierte zu Beginn ebenfalls eine Gemäldekomposition, indem der gesamte Bildhintergrund mit Gegenständen und Requisiten ausstaffiert wurde. ${ }^{29}$ Das diskursive Feld um die Cliché-verre war nach Matthias von Beginn an durch Skepsis geprägt; lange Zeit wurde ihr der Kunstcharakter abgesprochen, weil den Zeitgenossenunklar blieb, ob es sich um ein Original oder eine Reproduktion handelt. ${ }^{30}$ Nach Theodosia Robertson war dies ein Grund für Schulz' Rückgriff, da er eine Vorliebe für

Druckschicht perforieren, zeichnerisch bearbeitet. Die Platte wird anschließend wie ein photographisches Negativ behandelt und auf lichtempfindliches Papier kopiert, sodass aus der Weißzeichnung, der transparenten Zeichnung auf Glas, eine Schwarzzeichnung auf Papier wird." Vgl. Vorwort in: Matthias, Agnes/Mason, Rainer M. (Hg.): Zeichnungen des Lichts. Kupferstich-Kabinett. München 2007, 5 f. Entgegen dieser Darstellung klagt Schulz gegenüber seinem Künstlerkollegen Zenon Waśniewski über den Aufwand und die Kosten. Vgl. Schulz, Księga listów, 64.

25 Vgl. Benjamin, Kleine Geschichte der Photographie, 376.

26 Vgl. Matthias, Agnes: Eine besondere graphische Technik: Zur Rezeptionsgeschichte des Cliché-verre. In: Dies./Mason, Rainer M. (Hg.): Zeichnungen des Lichts. KupferstichKabinett. München 2007, 7-22, hier 10.

27 Ebd., 11.

28 Vgl. ebd., 7.

29 Vgl. Benjamin, Kleine Geschichte der Photographie, 374.

30 Vgl. Matthias, Eine besondere graphische Technik, 7. Weil die Cliché-verre-Drucke im Gegensatz zur Radierung zumindest theoretisch unendlich oft reproduzierbar waren, wurden solcherlei Grafiken im 19. Jahrhundert lange nicht als Kunst akzeptiert und auch von manchen Galeristen und Künstlern gar nicht in den Katalogen geführt. Praktisch hingegen gingen die Glasplatten schnell zu Bruch und die Beschichtung nutzte sich ab, wie sich auch an Schulz' Grafik »Odwieczna baśn I " (Das ewige Märchen I) nachvollziehen lässt (Abb. 6). 
außergewöhnliche und fragwürdige Gegenstände hatte, gerade wenn sie den Ruf des Unechten und Anrüchigen tragen. ${ }^{31}$

"Schulz's use of discarded photographic plates for the cliché-verres of The Idolatrous Book bridged high and low culture (as we so often see in his fiction). The Idolatrous Book literally grew from tandeta strash since Schulz availed himself of discarded commercial photographic plates to produce his own cliché-verres. Research into the technical side of Schulz's graphic work shows how literally Schulz's art emerged from popular culture: ordinary commercial photographic plates and refuse from the waste bins of Bertold Schenkelbach's photography studio. ${ }^{32}$

Dies legt die Deutung nahe, dass es gerade diese Zwischenposition der Technik war, die Schulz veranlasste, diese neu-alte, schwarz-weiße Grafik-Fotografie auszuwählen, um darin seine "Xięga Bałwochwalcza» anzufertigen, in welcher ebenso die Dichotomien zwischen dem Verbalen und Visuellen, dem Heiligen und Häretischen sowie dem Mythos und der Wirklichkeit aufgelöst werden. Bildästhetisch ermöglicht diese Technik ein ausgeprägtes Spiel von Hell und Dunkel; die Kratzer auf der Glasoberfläche können recht schnell und spontan ausgeführt werden. Bei unterschiedlicher Oberflächenbeschichtung können sogar malerische Effekte erzielt werden. ${ }^{33}$

Wie Krystyna Kulig-Janarek zeigt, lehnte sich Schulz sowohl in der Themenwahl als auch in der Umsetzung an die Groteske an. Das Wiederaufkommen der Groteske ging in den 1920er Jahren mit dem Zerfall der intersubjektiv gültigen Wirklichkeitsvorstellung sowie mit dem Verfall der Werte und der Ideologien einher, ${ }^{34}$ drückte Fremdheit und Fremdwerdungssituationen aus. Wolfgang Kayser nennt drei Epochen, in welchen die Groteske als künstlerische Ausdrucksform besonders verbreitet war:

»Es sind drei Epochen, die nicht mehr an das geschlossene Weltbild und die bergende Ordnung der vorangehenden Zeit glauben konnten. Man braucht keinen einheitlichen Geist des Mittelalters zu konstruieren und wird doch zugeben, daß das 16. Jahrhundert aus Erfahrungen lebt, die in den vorherigen Sinngebungen des Daseins ungedeutet blieben. Sturm und Drang und Romantik wandten sich in bewußter Opposition gegen die rationalistischen Weltbilder, die in der Aufklärungszeit ent-

31 Auf Schulz' Vorliebe für Abfall, Tand, Weggeworfenes und Trödel haben schon verschiedene Forscher aufmerksam gemacht. Stellvertretend sei hier Schönles Artikel angeführt: Schönle, Sklepy Cynamonowe Schulza, 59-77.

32 Robertson, Bruno Schulz's Intimate Communication, 444. (Fußnote). Robertson bezieht sich hier auf den Artikel von Włodarska, Małgorzata/Włodarski, Zbigniew: Xiega Bałwochwalcza Brunona Schulza: Kilka uwag o technologii i praktyce techniki >clichéverre«. In: Chmurzyński (Hg.): Bruno Schulz 1892-1942, 222 f., hier 223.

33 Vgl. Gondowicz, Schulz, 20.

34 Vgl. Kulig-Janarek, Erotyka - groteska, 170. 
worfen worden waren, und schon gegen die Legitimation der Ratio zu einem solchen Unterfangen. Die Moderne bekämpfte die Geltung der anthropologischen und die Zuständigkeit der naturwissenschaftlichen Begriffe, mit denen das 19. Jahrhundert seine Synthese versucht hatte. Die Gestaltungen des Grotesken sind der lauteste und sinnfälligste Widerspruch gegen jeden Rationalismus und gegen jede Systematik des Denkens. Es war eine Absurdität in sich selber, wenn der Surrealismus versuchte, daraus ein System zu entwickeln. ${ }^{35}$

An typisch grotesken Motiven finden sich Wesen in Metamorphose, skurrile Tiergestalten, Personen und Themen der Mythologie und Religion, sowie weibliche Gewalt. Deutlich wahrnehmbar ist die verstörende Atmosphäre, die Düsternis und Fremdheit. ${ }^{36}$ Gleichzeitig fehlt auf den Grafiken die Darstellung der die Zwanziger Jahre prägenden Technik, Industrieanalagen oder andere Motive, die bis auf die Grafiktechnik selbst einen offensichtlichen Bezug zur Moderne bilden. Da Schulz in seinen Grafiken an die literarische wie malerische Tradition anknüpft, wird deutlich, dass er keine hermetische oder rein selbstbezügliche Kunst schafft. Ignacy Witz beobachtet sogar, dass sich Schulz im Stil an der klassischen Malerei orientiere. ${ }^{37}$

Als Vorbilder für Schulz' Grafiken werden häufig Künstler wie Alfred Kubin, Goya, Dürer oder Rembrandt genannt. ${ }^{38}$ Stanisław I. Witkiewicz ordnet Schulz in die Gruppe der »Dämonologen« ein, zu denen im 19. Jahrhundert vor allem Rops, Munch und Beardsley zählen, die sich allesamt lieber den höllischen als den himmlischen Themen zugewandt hätten. ${ }^{39}$ Schulz' Figurenzeichnungen sind auch in ihren obszönen Gesten häufig in realistischer Manier ausgeführt, sodass das groteske Moment eher subtil seinen Ausdruck findet. Ironische, selbstkritische Distanz geht einher mit einer ernsten, sakralen und gewaltvollen Atmosphäre und irritiert den Leser mit zweideutigen Botschaften. Dies zeigt sich gerade in der Betitelung der Grafiken, die mitunter ganz unterschiedliche Kontexte aufruft. Eine Grafik heißt beispielsweise sowohl »Mademoiselle Cyrce i jej trupa« (Mademoiselle Circe und ihre Truppe) als auch »Cyrk« (Zirkus). ${ }^{40}$ Damit wird die erste eindeutige Verortung in der griechischen Mythologie durch die zweite in Zweifel gezogen beziehungsweise parodiert. Der Zirkus gehört zur Welt der Verkleidung und des Unernsten, die Göttin Circe/Kirke zur antiken Mythologie, wo Ver-

35 Kayser, Wolfgang: Versuch einer Wesensbestimmung des Grotesken. In: Weisstein, U1rich (Hg.): Literatur und bildende Kunst. Ein Handbuch zur Theorie und Praxis eines komparatistischen Grenzgebietes. Berlin 1992, 173-179, hier 179.

36 Vgl. ebd., 173-176.

37 Witz, Obszary malarskiej wyobraźni, 38.

38 Vgl. Gondowicz, Schulz, 19.

39 Vgl. Witkiewicz, Wywiad z Brunonem Schulzem, 184.

40 Vgl. Ficowski, Jerzy (Hg.): Księga obrazów. Gdańsk 2012, 258. 
wandlungen von Menschen in Tiere stattfinden. ${ }^{41}$ Gleichzeitig findet hier ein Sprachspiel statt, denn »Cyrk« und »Cyrce« klingen im Polnischen sehr ähnlich. Kitowska-Łysiak liest diese Grafik deshalb als Verwandlung aus dem griechischen Mythos in die Gegenwart, in welcher die Hexe durch eine Zirkusdame ersetzt worden sei.

»In Schulz' Auffassung verliert die Göttin an Besonderheit. Sie wird zu ihrer entthronten fernen Verwandten - einer Figur der Popularmythologie. Sie ist jetzt eine junge Zirkusdame, Dompteuse, die mit dem Knallen der Peitsche einige Athleten zum Gewichteheben zwingt und die Durchführung der im Programm vorgesehenen `Nummern einfordert.. ${ }^{42}$

Damit unterläuft Schulz in Technik, Stil, Benennung und - wie zu zeigen sein wird - auch in Inhalt immer wieder stabile Zuordnungen. Weder der mythische noch der religiöse oder der masochistische ikonologische Code ermöglichen eine widerspruchsfreie Zuordnung, sondern eine paradoxe Doppel- bis Dreifachstruktur durchzieht die Grafiken.

\subsection{Pygmalions Traum oder die Grenze zwischen Bild, Mythos und Wirklichkeit}

Im Folgenden soll durch eine fokussierte Analyse und durch einen Vergleich mit der Novelle »Venus im Pelz« der spezifische Bild-Diskurs bei Schulz aufgezeigt werden. Dieser deutet sich zwar auch in den Grafiken an, so durch die Darstellung von »Undula u artystów« (Undula bei den Künstlern); dass der spezifische Bild-Diskurs aber das bestimmende Thema ist, erschließt sich erst durch den Vergleich.

Die Novelle »Venus im Pelz«, in der immer wieder die Grenzen zwischen Wach- und Traumwelt sowie zwischen Kunst und Wirklichkeit aufgehoben werden, beginnt mit der Schilderung eines Traumes, in dem ein Mann einer beseelten Marmorvenus begegnet. ${ }^{43}$ Diese Szene stellt sich anschließend als

41 Vgl. Ovidius Naso, Publius: Metamorphosen. Düsseldorf [u.a.] 2009, Buch XIV, Vers 308-440.

42 Kitowska-Łysiak, Bezlik nieskończonych historyj, 15. (Übers. A. J.) »W ujęciu Schulza boginka traci wyjątkowość, stając się swoją zdetronizowaną daleką krewną - postacią z mitologii popularnej. Jest teraz młodą cyrkówką, treserką, która trzaśnięciem bata zmusza kilku atletów do podnoszenia ciężkich sztang, egzekwując wykonanie przewidzianych programem `numerów ‘."

43 Um den Kenner des Werkes nicht zu lang mit deskriptiven Schilderungen aufzuhalten, gleichzeitig dem Nichtkenner das Verstehen nicht allzu sehr zu erschweren, sei eine kurze Zusammenfassung der Handlung in dieser Fußnote angeführt. 
Parabel auf das im Tagebuch festgehaltene Künstlerleben des Protagonisten Severin heraus, dessen Schicksal Jahre zuvor in einem Bild festgehalten worden war, welches wiederum Anlass für den Traum gab. Daraufhin überreicht Severin seinem träumenden Freund sein Tagebuch, das die Geschichten um jenes Venusbild enthält. Albrecht Koschorke hält dabei eine wichtige Beobachtung zur Struktur der Novelle fest.

"Und wie schon die Binnenhandlung als ganze, eingerahmt durch das gemütliche Philosophieren der Freunde am Kamin, die Form eines Buches im Buch hat, so knüpft sich auch die Liebesgeschichte, aus der sie besteht, an die Übermittlung durch ein Buch. ${ }^{44}$

Diese Form des Buches im Buch spiegelt sich vielfältig, in Bildern im Bild, durch Bücher im Bild und Bilder im Buch, sodass eine intermediale Referenzstruktur und damit verschiedene, hierarchisierbare Ebenen der Repräsentation eröffnet werden. ${ }^{45}$ In Buch, Traum, Bild und Mythos werden dem Leser

Der Maler und Poet Severin lernt Wanda, seine spätere Liebe, auf einer Reise kennen. Er kann nicht mehr malen und betet nun allabendlich eine steinerne Venusstatue im Garten an. Zuvor liest er die Geschichten um Delilah und Samson, Judith und Holfernes sowie Pygmalion. In seiner Melancholie entdeckt ihn Wanda, die über ein kleines Tizian-Bildchen samt selbstverfasstem Gedicht von seiner Vorliebe für Venusfrauen mit Pelz erfährt. Sie verkleidet sich als solche Venus und erscheint ihm so im Garten. Dies ist der Beginn ihrer seltsamen Beziehung, denn Wanda ist eigentlich gar nicht interessiert an Severin. Was sie trotzdem auf dieses Verhältnis eingehen lässt, sind Severins Ideen, seine überbordende Fantasie. Das beeindruckt Wanda, sodass sie sich entsprechend seiner Vorstellung ab und zu in eine machtvolle, gewalttätige und schöne Venus mit Pelz und Peitsche verwandelt. In dieser Zeit gelingt es Severin auch wieder zu malen und er fertigt ein Porträt von ihr an.

Nun entwickelt sich die Beziehung weiter: Wanda stellt immer mehr Forderungen, drängt Severin immer weiter in die Distanz und reduziert ihre warmen und herzlichen Liebeszuwendungen an ihn. So gesehen verwandelt sie sich immer weiter in die steinerne Venusdame, das Ideal wird immer realer. Ihre Füße, die zu Beginn noch das Objekt der Hingabe und Verehrung Severins waren, werden zum Machtmittel. In dieser absoluten Machtposition lässt sich Wanda in einem Gemälde festhalten. Severin ist aber nicht einmal mehr der Maler dieses Bildes, sondern seine Muse hat ihn unterworfen. Er wird selbst Gegenstand des Bildes, welches ein anderer Maler anfertigt. Auf diesem Bild liegt Severin nackt und geknechtet zu den Füßen von Venus, die auf einer Ottomane sitzt und ihren Fuß auf seinen Nacken stellt. Er selbst ist nicht mehr der Herr seiner Phantasie, sondern sie diktiert die Regeln. Anschließend wendet sich Wanda ganz von Severin ab und geht eine Beziehung mit einem »echten Griechen« ein. Um ihm eine "heilsame« Enttäuschung zu bescheren, lässt sie ihn von ihrem neuen Geliebten auspeitschen und demütigen, woraufhin es Severin gelingt, sich seiner Fantasien zu entledigen. Somit finden mehrere Verwandlungsprozesse statt: Eine Frau verwandelt sich in eine steinerne Göttin, ein Maler, der normalerweise seine Fantasie selbst erzeugt und malt, wird zum Objekt seiner Kunst, Kunst wird Wirklichkeit und Wirklichkeit wird Kunst und der Traum des Freundes stellt sich als Erlebnis Severins heraus.

44 Koschorke, Albrecht: Leopold von Sacher-Masoch. Die Inszenierung einer Perversion. München [u.a.] 1988, 92.

45 Vgl. Mitchell, Picture Theory, 42. 
die Protagonisten vorgestellt und jede dieser Ebenen reicht in die erste Ebene der präsentierten Wirklichkeit hinein.

Der Protagonist Severin tritt als doppelbegabter Dichter und Maler in Erscheinung. ${ }^{46}$ Er steht für den »christlichen Norden«, die Moderne, die Reflexion, die Zerstörung, aber auch für die Leidenschaft, Fantasie, Kreativität und das Märtyrertum. Die Antagonistin Wanda steht sowohl für das "nackte Heidentum« als auch für »die göttliche Heiterkeit«, Fruchtbarkeit, Kunst, Natur, Antike und Unabhängigkeit, aber auch für die Tyrannei und den Verrat. ${ }^{47}$ Sie ist vor allem die Projektionsfläche für Severins »Ideal ${ }^{48}$ einer steinernen Venus, die er als Künstler-Pygmalion für sich erschaffen möchte. Von Beginn an ist sie die aktive Interpretin seines Ideals, denn sofort, als sie über Tizians Bild »Venus mit Spiegel« von seiner Fantasie erfährt, verkleidet sie sich in die Venus seiner Träume und erscheint ihm so im Park.

»[W]ie ich [Severin, A.J.] seitwärts in einen der grünen Gänge einbiegen will, sitzt Venus, das schöne, steinerne Weib, nein, die wirkliche Liebesgöttin, mit warmem Blute und pochenden Pulsen, vor mir auf einer steinernen Bank. Ja, sie ist mir lebendig geworden, wie jene Statue, die für ihren Meister zu atmen begann; zwar ist das Wunder erst halb vollbracht. Ihr weißes Haar scheint noch von Stein und ihr weißes Gewand schimmert wie Mondlicht, oder ist es Atlas? «" ${ }^{49}$

46 Schvey weist darauf hin, dass das Thema der Doppelbegabung um die Jahrhundertwende offensiver diskutiert wurde. Gerade der Expressionismus habe eine Reihe doppelbegabter Künstler hervorgebracht, die bemerkenswerterweise häufig auf die Begabung des Sehens rekurrieren. Da es sich bei Schulz ebenfalls um einen Künstler handelt, der in zwei Ausdrucksbereichen aktiv ist, ist diese Parallel zum Protagonisten von Sacher-Masoch sicher kein Zufall. Vgl. Schvey, Henry I.: Doppelbegabte Künstler als Seher: O. Kokoschka, D. H. Lawrence und W. Blake. In: Weisstein (Hg.): Literatur und bildende Kunst, 73-85, hier 78.

47 Die Figur des Weiblichen wird im Laufe der Erzählung mit verschiedenen Folien der Geschichte, Mythologie und Bibel belegt, so mit Judith, Delilah, Venus, Salome, Psyche, Astarte sowie Katharina der Großen oder Lola Montez. Sacher-Masoch, Leopold von: Venus im Pelz. Frankfurt a. M. 1957, 8-10.

48 Severin nennt zwei Frauenideale. »Kann ich mein edles, sonniges, eine Frau, welche mir treu und gütig mein Schicksal teilt, nicht finden, nun dann nur nichts Halbes oder Laues! Dann will ich lieber einem Weibe ohne Tugend, ohne Treue, ohne Erbarmen hingegeben sein. Ein solches Weib in seiner selbstsüchtigen Größe ist auch ein Ideal. Kann ich nicht das Glück der Liebe voll und ganz genießen, dann will ich ihre Schmerzen, ihre Qualen auskosten bis zur Neige; dann will ich von dem Weibe, das ich liebe, mißhandelt, verraten werden, und je grausamer, um so besser. Auch das ist ein Genuß!« Sacher-Masoch, Leopold von: Venus im Pelz. Dresden 1904, 49. Dieses Ideal hat er sich aus der Lektüre der griechischen Mythologie und der biblischen Geschichten sowie durch Bilder und Szenen seiner Kindheit angeeignet. Das Kirchengewölbe, die Gipsvenus in seines Vaters Arbeitszimmer und die Brust der Amme haben ihren Beitrag geleistet. Zu seiner Fantasie gehört auch ein Pelz, den er als Attribut von Macht und Adel beschreibt. Dies kenne er von den Gemälden Raffaels und Tizians, die ihre Geliebten in Pelz hüllten. Vgl. ebd., 58.

49 Sacher-Masoch, Venus im Pelz (1957), $28 \mathrm{f}$. 
Diese Szene schildert die Verwandlung der steinernen Venusplastik im Garten in die lebendige Venus Wanda und knüpft damit direkt an Ovids »Metamorphosen « an. ${ }^{50}$ Die Geschichte Pygmalions steht nach Boehm für den seit der Antike existierenden Wunsch eines Künstlers, dass sein Bild werde, was es zuvor lediglich repräsentiert hat. ${ }^{51}$ Kultermann fasst ihn als Grundmythos für das Kunstschaffen schlechthin auf: »Pygmalion als Mythos steht für den Glauben an die Macht der Kunst, ızu erschaffen, und nicht nur nachzuahmen. $\ll^{52}$ Ähnlich sieht es Lachmann, die darauf hinweist, dass Pygmalions Frau kein Vorbild in der Natur hatte, sondern nach einem »Ähnlichkeitsmaßstab ohne Original ${ }^{53}$ geschaffen wurde. Im zweiten Schritt steigt Pygmalions Kunst vom Sockel herab und wird Teil des Lebens.

"Oder anders: das Herabsteigen bedeutet, daß die Kunstwerkbelebung das Herauslösen aus einer primären Isolation provoziert und damit die Eingliederung eines einzelnen Kunstwerks in einen sozialen Raum ästhetischer Kommunikation bewirkt. ${ }^{54}$

Pygmalions Kunstwerk-Frau kann damit auch als Sinnbild für die Überwindung der Ebenen aus dem plastischen Kunstbereich in das Leben verstanden werden. Gleichzeitig verbleibt die Verwandlung aber im Medium des mythologischen Textes und ist somit auch eine sprachliche Bildillusion.

Mehrere plastische Kunstgegenstände spielen im Verlauf von Sacher-Masochs Novelle eine entscheidende Rolle. Am Anfang steht die Marmorstatue der Venus im Garten, die Severins Ideal verkörpert. Zu dieser Zeit ist der Maler und Poet Severin von einer Schaffenskrise geplagt und von Depressionen verfolgt. Von einem Händler erwirbt er eine kleine Fotoreplik von Tizians "Venus im Spiegel«, die ihn inspiriert und belebt. Nach Beginn der Beziehung zwischen Wanda und Severin erblühen seine Kreativität und Schaffenskraft wieder und er fertigt ein Porträt von ihr an. ${ }^{55}$ Wanda verwandelt sich parallel immer weiter in die steinerne Venus ${ }^{56}$, wird immer grausamer und kaltherzi-

50 Dort findet sich, neben der »Pygmalion«-Erzählung, auch die Erzählung von »Iphis und Anaxate«, welche die entgegengesetzte Verwandlung einer schönen, aber lieblosen Frau schildert, die zu Stein wird. Diese Statue wird anschließend in den Tempel der Wachenden Venus« getragen. Vgl. Ovidius Naso, Metamorphosen, Buch XIV; Vers 697-771.

51 Vgl. Boehm, Die Wiederkehr der Bilder, 34.

52 Kultermann, Udo: Kleine Geschichte der Kunsttheorie. Von der Vorgeschichte bis zur Gegenwart. Darmstadt 1988, 13.

53 Lachmann, Erzählte Phantastik, 338.

54 Ebd., 339.

55 Vgl. Sacher-Masoch, Venus im Pelz (1904), 76. Zudem tauchen im Garten und im Interieur eine Reihe von Figuren und Möbelstücken auf, die auf einen mythologischen Kontext verweisen, wie eine Uhr, auf der ein Amor mit verschossenem Pfeil sitzt, eine Venus in einem kleinen Tempel in Florenz oder ein Gemälde von Delilah und Samson in der Villa.

56 " D Du weißt es jaく, entgegnete sie boshaft, `ich bin ein Weib aus Stein, >Venus im Pelz‘, dein Ideal, knie nur und bete mich an.« Ebd., 177. 
ger und beauftragt in dieser Phase einen jungen »deutschen Maler«, ein Bild von ihr und ihrem Sklaven Severin, der schon in Gregor umbenannt wurde und wie ein Hund ${ }^{57}$ behandelt wird, anzufertigen. Genau in diesem Bild, das auf dem Höhepunkt der Machtumkehrung zwischen Künstler und »Kunstwerk« entsteht und welches auch die Novelle im Traum des Freundes eingeleitet hat, kulminiert der bildtheoretische Diskurs.

Liest man die Novelle als Auseinandersetzung eines Künstlers mit der Kunst, so zeigen sich nun verschiedene Parallelen zu Schulz' Grafikzyklus und insbesondere zur Undula-Gruppe. Der Künstler-Protagonist ist sowohl in der Novelle wie in den Grafiken ein unfreier, schwacher, von Fantasien und seinem Talent geplagter Geist, der von seinem (Kunst)Ideal beherrscht wird. In beiden Formaten tritt er als »Erzähler« auf und schildert Wanda beziehungsweise Undula aus seiner Wahrnehmung. Sie ist gleichzeitig Projektionsfläche, Interpretin und Muse, sowohl Mensch als auch Kunstwerk. Dabei emanzipiert sie sich vom Künstler und macht diesen selbst zum Objekt der Kunst. ${ }^{58}$ Somit wird die Entmachtung des Künstlers vorgeführt, der zwar der Urheber des Bildes bleibt, aber nicht der Herrscher darüber ist. In seiner Rezension zu Tadeusz Brezas Roman »Adam Grywałd» beschreibt Schulz diese Eigenständigkeit eines Kunstwerks in Bezug auf die Literatur.

"Im Grunde besitzt jede Prosa einen eignen Ton ihres Monologs, verliehen durch den speziellen Lippenbau, durch die dem Autor eigene Gedankenanatomie; gleichzeitig kennzeichnet aber die gewöhnliche Romanprosa, dass sie die Form, die ihr die Lippen verliehen hat, nur so kurz behält, wie das Wasser die Form der Lippen seiner Quelle. Kaum ist sie artikuliert, schon nimmt sie die Form des Flussbettes an, in das sie sich ergießt und tritt in die Welt objektiver Inhalte und verflüchtigt sich, während der semantische Inhalt auf deren Kosten wächst und sich formt, scheinbar bereits unabhängig vom Autor.

Diese scheinbare Naivität, dieser Ausweg aus irgendeinem absoluten Anfang, ist ein verblüffender und wesentlicher Zug dieses Monologs. Ich drücke mich schlecht aus, wenn ich von der scheinbaren Naivität spreche. Es ist nämlich eine wesentliche Naivität, die wahre Naivität eines Künstlers, der verwundert ist über seinen Gegenstand. ${ }^{59}$

57 Hunde tauchen nicht nur auf den Grafiken häufiger auf, sondern auch in Schulz' Erzählungen und auch auf Tizians Gemälden.

58 Damit ist das Motiv nicht unbedingt biografisch-psychologisch zu lesen, sondern als eine Verkörperung des Konflikts zwischen Künstler und Bildnis, übertragen auf eine Geschlechteropposition.

59 »W gruncie rzeczy posiada każda proza odrębny ton swego monologu, nadany mu przez specjalną budowę ust, przez właściwą autorowi anatomię myśli, ale cechą przeciętnej prozy powieściowej jest to, że tak krótko zachowuje kształt nadany jej przez usta, jak woda kształt ust źródlanych i ledwie zartykułowana już przyjmuje formę łożyska, w które się wlewa, przechodzi w świat obiektywnych treści, ulatnia się, podczas gdy jej kosztem rośnie i formuje się treść znaczeniowa już jakby niezależnie od autora. 
Damit »befreit« Schulz ein Kunstwerk einerseits aus der Individualität des Künstlers, andererseits misst er ihm eigene Wirkkraft und Eigenständigkeit zu. Das künstlerische Schaffen ist dabei geprägt durch Abhängigkeiten von "Vorbildern « und dominierenden Ideen, vor allem aber durch die anhaltend wirksamen mythisch-magischen Reminiszenzen. Der Künstler in Schulz' Lesart bleibt damit der Tradition der Themen, Motive und Bilder unterworfen. ${ }^{60}$

\subsection{Das »Marmorbild»}

Eine zweite Novelle, die fast 50 Jahre vor der »Venus im Pelz« von Joseph von Eichendorff unter dem bedeutsamen Titel »Das Marmorbild « verfasst wurde, ist erneut gemeinsamer Subtext von Sacher-Masoch und Bruno Schulz. ${ }^{61} \mathrm{Ihr}$ Protagonist Florio ist ebenfalls ein Dichter, der den körperlichen und poetischen Reizen einer steinernen, mythischen Venus erliegt. ${ }^{62}$ Erneut sind es

Ta pozorna naiwność, to wyjście z jakiegoś absolutnego początku jest uderzającym i istotnym rysem tego monologu. Źle się wyrażam, mówiąc o naiwności pozornej. Jest to naiwność istotna, prawdziwa naiwność artysty zadziwionego nad swym przedmiotem." Schulz, Bruno: Książka o miłości. In: Kitowska-Łysiak: Szkice krytyczne, 90-93, hier 90. (Übers. A. J.)

60 Idol und Künstler werden als präformierte Rollen wahrnehmbar, in welche sich Schulz durch das Selbstporträt einfügt. Belting deutet Schulz' Zeitgenossen, den Maler Max Beckmann, als einen erzählenden Maler. Dieser habe einen Ich-Erzähler in seinen Bildern, der die Ereignisse aus seinem Bewusstsein heraus schildere. Damit erzähle dieser immer von sich, seinen Visionen und Fiktionen, von einer Welt, wie sie sich in seinem Bewusstsein spiegele. Dies sei nach Belting dem Verfahren der Literatur näher als der Malerei. Auch sähe sich Beckmann nicht als freien Künstler, sondern als Rollenspieler. »Die Rollen sind verteilt. Das Stück wiederholt sich. Es ist nicht Beckmanns Stück. Aber es wird sein Stück, wenn er es von seiner Rolle aus schildert. Wenn er sich selbst in dieser Rolle sieht, hebt er sie durch Reflexion und Distanz auf.« Belting, Hans: Max Beckmann. Die Tradition als Problem in der Kunst der Moderne. München 1984, 58.

61 Während für die »Venus im Pelz« die Beziehung zu »Das Marmorbild « schon untersucht wurde, ist der Verfasserin bisher keine Forschung bekannt, die diese Verknüpfung auch für Schulz' Werk bearbeitet hat. Vgl. Sauter, Michiel: Marmorbilder und Masochismus: Die Venusfiguren in Eichendorffs >Das Marmorbild und in Sacher-Masochs ,Venus im Pelzr. In: Neophilologus 75 (1991), 119-127. Auch in Stefan Chwins Untersuchung der romantischen Subtexte findet sich keine größere Bearbeitung dieses Themas. Vgl. Chwin, Stefan: Romantyczna przestrzeń wyobraźni. Bydgoszcz 1989.

62 »Das Marmorbild« ist die Geschichte des Träumers Florio, dem zu Lucca einige merkwürdige Begegnungen geschehen. Sein Name rekurriert auf Flora, die Göttin des Blühens und Reifens aller Pflanzen. In Eichendorffs Novelle lernt Florio den Sänger Fortunato auf seiner Reise kennen und empfindet eine tiefe Zuneigung zu ihm. Auf einem Gartenfest begegnet ihm ein Mädchen mit Blumenkranz, das ihm später als Bianka vorgestellt wird und als »Bild des Frühlings« beschrieben wird. Aber anstatt mit ihr glücklich zu werden, bricht die Nacht, personifiziert durch den Ritter Donato, in das Fest ein und nimmt 
die Einbildungskräfte des kreativen Protagonisten, die ihn anfällig für den Zauber der mythischen Welt machen ${ }^{63}$ und die Fantasie soweit in die Wirklichkeit eindringen lassen, dass Florio diese nicht mehr trennen kann. Über die Gewalt seiner Träume vergisst er seine geliebte Bianka, welche für die christliche, reine Liebe und Moral steht. Schließlich findet sich Florio im Tempel der Venus wieder. Dort hängen verschiedene Bilder der Venus an den Wänden. Erst durch Fortunatos Lied erhält er die Fähigkeit zurück, zwischen Bildern der Kunst und der Wirklichkeit zu unterscheiden.

»Da flog es ihn [Florio, A. J.] plötzlich wie von den Klängen des Liedes [Fortunatos, A. J.] draußen an, daß er zu Hause in früher Kindheit oftmals ein solches Bild gesehen, eine wunderschöne Dame in derselben Kleidung, einen Ritter zu ihren Füßen, hinten einen weiten Garten mit vielen Springbrunnen und künstlich geschnittenen Alleen, gerade wie vorhin der Garten draußen erschienen. [...]

Er erzählte es nicht ohne tiefe Bewegung der Dame. >Damalsı, sagte er, in Erinnerung verloren, ‘wenn ich so an schwülen Nachmittagen in dem einsamen Lusthause unseres Gartens vor den alten Bildern stand und die wunderlichen Türme der Städte, die Brücken und Alleen betrachtete, wie da prächtige Karossen fuhren und stattliche Kavaliers einherritten, die Damen in den Wagen begrüßend - da dachte ich nicht, daß das alles einmal lebendig werden würde um mich herum $[\ldots]<->$ Laß das! sagte hier die Dame wie in Zerstreuung, >ein jeder glaubt mich schon einmal gesehen zu haben, denn mein Bild dämmert und blüht wohl in allen Jugendträumen mit herauf.« ${ }^{64}$

Auch in der Novelle "Das Marmorbild « sind es alte Kunstgemälde, welche auf das Geschehen einwirken. Bemerkenswert ist die Erklärung der Venus, dass ihr Bild in allen Jugendträumen blühe. Sie deutet sich somit selbst als zum festen, unüberwindbaren Repertoire der Kultur zugehörig. ${ }^{65}$ Ihre Macht ist vor allem dann groß, wenn nicht nach ihrem Wesen geforscht würde, wenn sie also nicht interpretiert, sondern sinnlich-ästhetisch wahrgenom-

Florio mit. Unterwegs begegnet ihm eine schöne Marmorstatue, die ihm lebendig erscheint und Florio wird von ihrem Zauber verführt. Er träumt fortan von dieser Venus und sucht sie in der Stadt. Darüber vergisst er seine Liebe zu Bianka. Als er im Tempel der Venus ist, befreit ihn das Lied seines Freundes Fortunato von dem Zauber und er erkennt, dass er einem Trug erlegen ist. Lucca verlassend, trifft er auf die als Junge verkleidete Bianka und entdeckt seine Liebe wieder. Damit siegt die Liebe über den Mythos und das Christentum über das Heidentum. Vgl. Eichendorff, Joseph v.: Das Marmorbild. In: Werke. Ahnung und Gegenwart. Erzählungen. Frankfurt a. M. 1985, 383-428.

63 Eichner, Hans: Joseph von Eichendorff. In: Riemen, Alfred (Hg.): Ansichten zu Eichendorff. Beiträge der Forschung 1958-1988. Sigmaringen 1988, 296-332, hier 304.

64 Eichendorff, Das Marmorbild, $418 \mathrm{f}$.

65 Anschließend erkennt Florio aber die mythische Magie und flieht mit der Hilfe Fortunatos vor der Kraft der heidnischen Gottheit, um in den Händen seiner Geliebten Bianka zu landen. Am Ende siegt das gesungene Lied über das Bild und die Herzensliebe über die körperliche Schönheit. Vgl. ebd., 419-428. 
men wird ${ }^{66}$ Das heißt, dass Florio, anders als Severin, die Venus gar nicht als Marmorfigur wahrnimmt, sondern von Beginn an durch seine übersteigerte Fantasie als belebt und Teil der Wirklichkeit sieht. Die pygmalionsche Verwandlung findet ohne Kenntnis des Künstlers statt, die Ebenen sind in Florios Wahrnehmung von Beginn an fest verwoben und trennen sich erst durch äußeren Einfluss. Dieser bildkritische Ansatz ist nach Mitchell in der Literatur der Romantik weit verbreitet.

»For all the talk of simagination in theories of romantic poetry, it seems clear that images, pictures, and visual perception were highly problematic issues for many romantic writers. ${ }^{67}$

Schulz' deutlichste Bezugnahme auf diese Novelle findet sich in seiner Erzählung »Wiosna« (Frühling). ${ }^{68}$ Im vordergründigen Handlungsstrang der Erzählung vertreiben sich zwei Jungen die Langeweile in den Sommermonaten, indem der Protagonist Józef auf Grundlage von Rudolfs Briefmarkenalbum die inoffizielle Geschichte der Habsburger Familie erzählt. Die darin auftretende Bianka, eine klare Bezugnahme auf Eichendorffs Figur, entspringt ebenfalls einem Bildmedium - diesmal aber den Briefmarkenbildern. ${ }^{69}$ Die Geheimnisse ihrer Abkunft zu lüften ist das Abenteuer der zwei Kinder. Während Bianka am Anfang vor allem passiv auftritt und Projektionsfläche ist, wird sie im Laufe der Geschichte immer dominanter und hintergeht am Ende sogar den Erzähler, der damit die Macht über die Entwicklungen seiner Briefmarkeninterpretationen verloren hat. Erneut tritt damit eine Figur der zweiten Ebene der Repräsentation in die erste Ebene der Handlung, aus dem Bild in die Prosa und verweist auf die Verwobenheit und das Ineinandergreifen der verschiedenen Kunstmedien und der Kunst auf das Leben. Anders

66 Dies zeigt sich auch in einer anderen Szene am Brunnen: »Kühn und vertraulich bat er sie nun, sich nicht länger zu verbergen, oder auch ihren Namen zu sagen, damit ihre liebliche Erscheinung unter den tausend verwirrenden Bildern des Tages ihm nicht wieder verloren ginge. Laßt das, erwiderte sie träumerisch, nehmet die Blumen des Lebens fröhlich, wie sie der Augenblick gibt, und forscht nicht nach den Wurzeln im Grunde, denn unten ist es freudlos und still.« Ebd., 411.

67 Mitchell, Picture Theory, 114.

68 »Wiosna« ist die längste Erzählung in Schulz' Werk und umfasst 40 Unterkapitel. Neben Eichendorffs Novelle »Das Marmorbild « finden sich weitere intertextuelle Bezüge: Friedrich Nietzsches »Geburt der Tragödie aus dem Geiste der Musik«; Richard Wagners »Götterdämmerung«; Franz Kafkas »Der neue Advokat« und »Der Prozess«; Thomas Manns »Joseph und seine Brüder«; Exodus 20 und Jesaja 40.3, Rainer Maria Rilkes »Die Entführung«; Johann W. v. Goethes »Der Erlkönig«; Bolesław Leśmians »Lalka«, Heinrich v. Kleists »Das Marionettentheater«; Bruno Schulz” »Manekiny«, »Księga«, "Sanatorium pod Klepsydrą«; das kabbalistische Buch »Zohar« und die "Lurianische Kabbala."

69 Dies wird sowohl innerhalb der Erzählungen deutlich, Schulz verweist aber auf diesen Zusammenhang auch in einer Selbstdeutung. Vgl. Schulz, Bruno: W pracowniach pisarzy i uczonych polskich. In: Kitowska-Łysiak: Szkice krytyczne, 9 f., hier 9. 
jedoch als bei Eichendorff fehlt die auflösende zweite Instanz, der vernünftige Musiker oder Philosoph, der die verwobenen Ebenen der Repräsentation und Wirklichkeit wieder trennt.

\subsection{Die Grafiken als Metabilder}

Diese Zuspitzung auf das Themenfeld Kunst/Künstler soll keinesfalls andere Deutungen ausschließen. Gerade die Annahme, dass es Schulz um die Rettung der Offenheit der Bilder geht, impliziert die Möglichkeit, das Beziehungsgeflecht zwischen den abgebildeten Männern und Frauen anders zu lesen. Dennoch erhärtet sich die These, dass Schulz in Anlehnung an Sacher-Masoch seine kunst- und bildtheoretischen Überlegungen in einen erotischen Gewalt- und Unterwerfungsdiskurs bettet. Ein wichtiges Motiv und in diesem Kapitel im Zentrum - ist dabei das Interferenzfeld von Bildzyklus (»Xięga Bałwochwalcza») und Erzählung (»Venus im Pelz«) einerseits, Buch (Xięga) und Bild (Idol) andererseits, sowie die Beziehung zwischen dem schreibenden Maler (Severin) und dem zeichnenden Schriftsteller (männliche Hauptfigur der »Xięga«). Durch Tizians Gemälde kommt auch die Beziehung zwischen Musik und Malerei hinzu und verstärkt letztlich auch das Themenfeld Mythos-Realität, welches im sprachphilosophischen Manifest zentral ist. Für alle bisher zitierten Werke spielt die Götterplastik eine herausragende Rolle, die jeweils im Wortbruchstück, in der idealisierten Frau, der Regentin oder im alternativen Kunstwerk aufgeht. Die intermediale Verflechtung zwischen den künstlerischen Ausdruckformen zieht sich somit durch mehrere Ebenen und Motive. ${ }^{70}$

Freise hat bereits auf die Besonderheit hingewiesen, dass in Schulz' Grafiken ein »Erzähler« auftritt, der gleichzeitig bildnerischer Künstler (»Undula $\mathrm{u}$ artystów«) als auch Schriftsteller (»Xięga Bałwochwalcza II«) ist. ${ }^{71}$ Dem männlichen Hauptcharakter hat Schulz dabei seine eigenen Züge verliehen. Vor dem Hintergrund der besprochenen Künstlernovellen bedeutet dies, dass der Protagonist immer als Künstler auftritt, auch dann, wenn er ohne Buch oder Bild erscheint. Betrachtet man nur die »Undula-Gruppe ${ }^{72}$, so kann man

70 Kris Van Heuckelom, der die Konkurrenz zwischen dem Verbalen und dem Visuellen insbesondere in einem theologischen Kontext liest, hat hierfür den Begriff des »crossovers" verwendet. Vgl. Van Heuckelom, Artistic Crossover in Polish Modernism.

71 Vgl. Freise, Schulz zwischen Literatur, 116.

$72 \mathrm{Zu}$ dieser Gruppe lassen sich die folgenden Grafiken mehr oder weniger präzise zuordnen: 1a) »Odwieczna baśń I« (Das ewige Märchen I), 1b) »Odwieczna baśń II«; Ideał (Das ewige Märchen II; Das Ideal), 2) »W garderobie Unduli«; »Jej garderobiana«; »Panna Hestia« (In Undulas Garderobe; Ihre Garderobenfrau; Fräulein Hestia), 3) »Undula, 


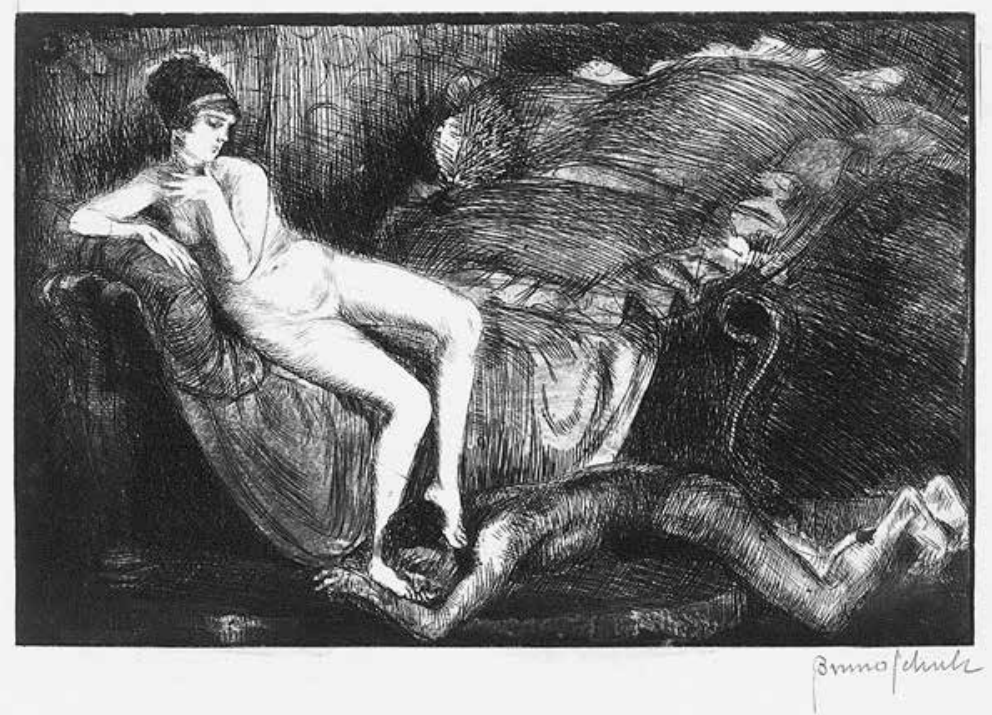

Abb. 1: Schulz, »Undula odwieczny ideał«; »Undula wieczysty ideał«; »Jeszcze raz Undula « (Undula das ewige Ideal; Undula das immerwährende Ideal; Noch einmal Undula), Cliché-verre (Cv), 10,3×15,3 cm, Jagiellonen Universitätsbibliothek (BJ).

in diesen Grafiken den Annäherungsversuch eines Künstlers an sein Kunstideal lesen. Wofür dieses Kunstideal stehen könnte, soll nun im Folgenden genauer erörtert werden.

Die Grafik »Undula, wieczysty ideał $\aleph^{73}$ (»Undula, das immerwährende Ideal«) bietet sich für den Einstieg in die Deutung an, weil sie einerseits im Titel

odwieczny ideał«; »Undula, wieczysty ideał«; »Jeszcze raz Undula« (Undula, das immerwährende Ideal; Undula, das ewige Ideal; Noch einmal Undula), 4) »Undula u artystów» (Undula bei den Künstlern), 5) »Ławka« (Die Bank), 6a) »Undula idzie w noc« (Undula geht in die Nacht), 6b) »Undula w nocy» (Undula nachts), 7a) »Xięga Bałwochwalcza I» (Das Buch vom Götzendienst I), 7b) »Xięga Bałwochwalcza II« (Das Buch vom Götzendienst II). Bei 1, 5 und 7 ist wegen des fehlenden Namensbezugs die Zuordnung zwar fraglich, scheint aber durchaus begründbar zu sein, da 1 und 7 beide auf Venusdarstellungen referieren sowie alle drei die charakteristische Frisur zeigen. Merkmale dieser Gruppe sind, dass die dargestellten Personen nicht deformiert sind und immer »Undula» und »Mann mit den Gesichtszügen von Schulz« in einer Konstellation auftreten. Interieur und Architektur sind häufig nur angedeutet oder im Hintergrund. Meistens wendet sich der Künstler Undula zu, während diese Distanz schafft oder wahrt. Sie tritt dabei selten als Unterdrückerin auf, eher desinteressiert.

73 Auch »Undula, odwieczny ideał (Undula, ewiges Ideal) und "Jeszcze raz Unula» (Noch einmal Undula). Schulz, Księga obrazów, 244. 
das Severinsche »Ideal« zitiert, andererseits hier jenes zentrale Bild wiedergegeben wird, welches dem Freund Anlass zum Traum war und in welchem die »Venus« Wanda den Maler Severin zum Objekt der Malerei macht - ihn also seiner Autonomie und Künstlerrolle beraubt.

"Ein schönes Weib, ein sonniges Lachen auf dem feinen Antlitz, mit reichem, in einen antiken Knoten geschlungenem Haare, auf dem der weiße Puder wie leichter Reif lag, ruhte, auf den linken Arm gestützt, nackt in einem dunkeln Pelz auf einer Ottomane; ihre rechte Hand spielte mit einer Peitsche, während ihr bloßer Fuß sich nachlässig auf den Mann stützte, der vor ihr lag wie ein Sklave, wie ein Hund, und dieser Mann, mit den scharfen, aber wohlgebildeten Zügen, auf denen brütende Schwermut und hingebende Leidenschaft lag, welcher mit dem schwärmerischen brennenden Auge eines Märtyrers zu ihr emporsah, dieser Mann, der den Schemel ihrer Füße bildete, war Severin, aber ohne Bart, wie es schien um zehn Jahre jünger. ${ }^{74}$

Die Haltungen der auf der Grafik abgebildeten Personen und auch das Mobiliar stimmen mit der Beschreibung überein. ${ }^{75} \mathrm{Im}$ Raum ist es dunkel, allein Undulas Körper leuchtet in hellem Weiß, sodass es den Anschein hat, als wäre sie aus Marmor. Vergleicht man sie mit dem nackten Mann, so sind auf ihrem Körper kaum Schraffuren gesetzt. ${ }^{76}$ Undula stützt sich ab, ein Arm liegt leicht angewinkelt vor der Brust und imitiert damit die Haltung der auch in der Novelle häufig zitierten »Venus mit Spiegel « von Tizian. ${ }^{77}$

Was Tizians Venus-Darstellungen mit den angeführten Vorlagen verbindet, ist, dass dieser häufig auf die typischen Venus-Attribute verzichtet hat und sie somit in zwei Kontexten lesbar macht - dem sinnlich-erotischen oder dem textuell-mythologischen. Andreas Prater zufolge sei dies durchaus beabsichtigt gewesen. ${ }^{78}$ In Abgrenzung zu anderen Venus-Darstellungen, deren Vorlagen meist griechische Steinskulpturen waren, habe Tizian der

74 Sacher-Masoch, Venus im Pelz (1904), 15.

75 Auf die große Übereinstimmung zwischen Szenen und Grafik haben schon Kulig-Janarek und Kato hingewiesen. Vgl. Kato, The Early Graphic Works, 221 sowie Kulig-Janarek, Erotyka - groteska, 155.

76 Dies kann ein Hinweis auf ihre marmorne Abkunft sein. Eine solche Lesart wird gestützt durch die fehlende Schambehaarung, die auch bei Statuen griechischer Göttinnen sowie bei Tizians Nackten/Göttinnen fehlt. Vgl. Suthor, Nicola: Augenlust bei Tizian. Zur Konzeption sensueller Malerei in der Frühen Neuzeit. München 2004, 87.

77 Im 16. Jahrhundert malte Tizian mehrere Venus-Variationen und andere Darstellungen mythologischer Frauen. Die Renaissance, die sich wieder auf die antike Mythologie und Kunst besann, überwand auch in der Malerei das Mittelalter und leitete eine neue Wahrnehmung des Menschen ein. Die Kunst stellte zunehmend Szenen aus dem nicht-religiösen Bereich dar und visualisierte fortan auch Bilder der Sagen- und Mythenwelt, des Alltags und vermehrt auch Porträts weltlicher einflussreicher Personen. Vgl. Panofsky, Idea, $23 \mathrm{f}$.

78 Vgl. Prater, Andreas: Im Spiegel der Venus. Velázquez und die Kunst einen Akt zu malen. München 2002, 14. 


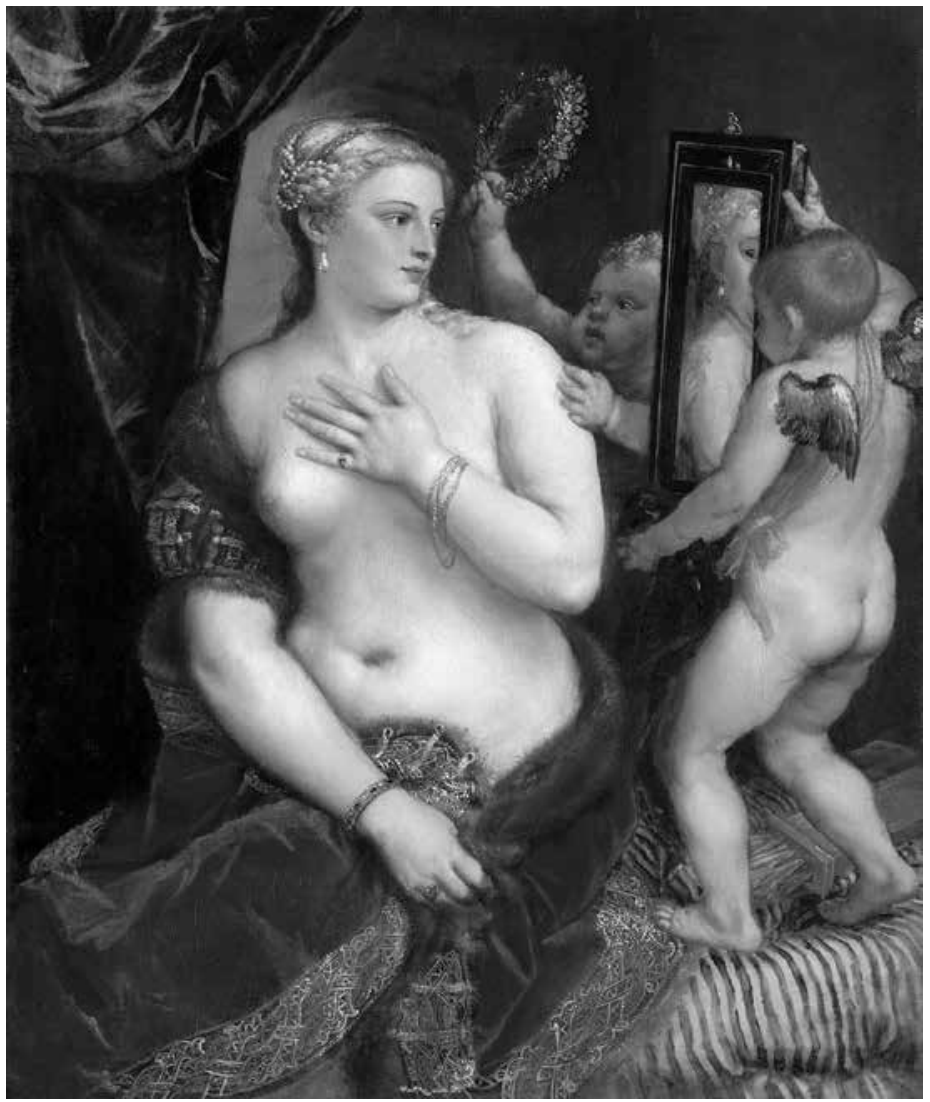

Abb. 2: Tizian, »Venus mit Spiegel«, um 1555, Öl auf Leinwand, $125 \times$ $105,5 \mathrm{~cm}$, National Gallery of Art, Washington, D. C.

Venus sehr menschliche Züge verliehen und ihre steinerne Haltung aufgebrochen. ${ }^{79}$ Bezugnehmend auf Tizians Gemälde »Heilige und profane Liebe«, das nach Panofsky die himmlische und die weltliche Venus darstelle, vergleicht Panofsky Tizian sogar mit Pygmalion, weil er aus einer steinernen Kunstfigur eine Frau von Fleisch und Blut gemacht habe.

"A new Pygmalion, Titian infused a piece of sculpture with the breath of life while on the marble basin of the fountain he constructs a relief, classical in style but freely invented, which remains a piece of sculpture. And this combination of an actual classical figure metamorphosed into a living woman with an imaginary event cast in the form of simulated classical relief raises the fateful question: What does it all mean? ${ }^{80}$ 
Sacher-Masochs Protagonist Severin deutet Tizians Bild »Venus mit Spiegel« ausschließlich als Darstellung einer schönen, lüsternen Frau, deren VenusAttribute lediglich ihre eigentliche Herkunft verschleiern sollten.

"Auch hier ,Venus im Pelz«", sprach er [Severin, A. J.] fein lächelnd, »ich glaube nicht, daß der alte Venezianer damit eine Absicht verbunden hat. Er hat einfach das Portrait irgendeiner vornehmen Messaline gemacht und die Artigkeit gehabt, ihr den Spiegel, in welchem sie ihre majestätischen Reize mit kaltem Behagen prüft, durch Amor halten zu lassen, dem die Arbeit sauer genug zu werden scheint.[...] Später hat irgendein Kenner der Rokokozeit die Dame auf den Namen Venus getauft, und der Pelz der Despotin, in den sich Tizians schönes Modell wohl mehr aus Furcht vor dem Schnupfen als Keuschheit gehüllt hat, ist zu einem Symbol der Tyrannei und Grausamkeit geworden, welche im Weibe und seiner Schönheit liegt.." ${ }^{81}$

Was in der Novelle als Scherz daherkommt, hat damit durchaus kunstgeschichtlichen Hintergrund. Tizians Venusdarstellungen ist es oftmals gar nicht anzusehen, dass sie solche sind. Manche wurden tatsächlich als weltliche Frauen gemalt und erst später zur Venus umbenannt. ${ }^{82}$ Damit verwischt auch bei Tizian die Grenze zwischen Mythos und realer Welt, die Venus wird zur "venere volgare«, zur weltlichen Liebesgöttin. ${ }^{83}$

In Tizians »Venus mit Spiegel« wird die Erotik zudem durch Venus Kommunikation mit dem Betrachter über einen Spiegel gesteigert. In diesem reflektieren sich am Rand ein Teil ihres Auges sowie ganz zentral das Ohr. Damit sind zwei Sinne angesprochen, das Sehen und das Hören. ${ }^{84}$ Der Rezipient wird zum Zeugen ihrer Toilette. Ihr Erröten kann dabei als scheinbar direkte Reaktion auf des Betrachters Blicke und Worte gelesen werden. ${ }^{85}$ Der Spiegel

81 Sacher-Masoch, Venus im Pelz (1957), $15 \mathrm{f}$.

82 Wenn allein Amor anwesend ist und sonst auf weitere Attribute der Venus verzichtet wird, dann liegt Prater zufolge auch die Möglichkeit vor, dass es sich um eine der Gunst der Liebesgöttin würdige Sterbliche handelt. Als Beispiel führt Prater die römische Hochzeitstradition an. Zu diesem Anlass wurden Bilder gemalt, die meist das Brautpaar zusammen mit einer Reihe von Symbolen und Allegorien für Fruchtbarkeit, Treue und Liebe darstellte. Mitunter wurde sogar die Braut selbst als Venus gemalt. Vgl. Prater, Im Spiegel der Venus, 41.

83 Vgl. Suthor, Augenlust bei Tizian, 62.

84 Gerade intersensuelle Elemente finden sich auch in Schulz' Erzählungen, indem immer wieder ineinandergreifende Bild-, Klang- und Geruchswelten beschworen werden.

85 Panofsky merkt in einem anderen Zusammenhang an, dass Tizian auch die »Konkurrenz« zwischen den Künsten - wie Malerei, Musik und Plastik -, die sich in der Konkurrenz zwischen den Sinnen spiegelt, thematisiere. So baue Tizian, der selbst auch $\mathrm{Mu}-$ sik gemacht habe, in seine Bilder immer wieder Musikinstrumente ein und betone die Gleichwertigkeit der Künste und damit auch der Sinne wie Sehen und Hören. Wenn in diesem Bild das Ohr ganz gespiegelt wird und das Auge nur halb, so verschiebt Tizian den Kommunikationsschwerpunkt auf den akustischen Sinn. Vgl. Panofsky, Problems 
wiederum ist auch Attribut der Venuspriesterinnen und steigert das erotische Potential des Bildes. ${ }^{86}$ Gleichzeitig ist er ein »Bild im Bild « und fügt dem Dargestellten eine zweite Bildebene hinzu.

Betrachtet man wieder die Grafik »Undula odwieczny ideał" (Undula, das ewige Ideal) (Abb. 1), so fällt im Vergleich zu Tizians als auch zu SacherMasochs Venus die Distanz sowie die Abwesenheit jeglicher erotischer Kontaktaufnahme mit dem Betrachter auf. Undula blickt nachdenklich und zurückhaltend auf den nackten Mann unter ihrem Fuß und zieht sich sogar ein wenig zurück. "Schulz schafft es, diesen [Blick] als einen vverweigerten Blick durch die Frau erscheinen zu lassen. ${ }^{87}$ Vielmehr noch als bei Tizian hat sie die Schulter eingezogen und von ihrer Göttlichkeit ist allein ihr leuchtender, marmorner Körper und der "griechische Knoten« im Haar geblieben. Der nackte, am Boden liegende Mann, der Undulas Füße küsst, verschwindet fast im Schatten des Raumes. Die Atmosphäre ist düster-gespannt. Beide Charaktere scheinen in ihren Bewegungen erstarrt.

Dass Undula Wanda darstellt, ist ohne die Textvorlage nicht erkennbar. Und ohne das Tizian-Zitat würde man sie auch kaum als Venus lesen. Auch in der Betitelung mit »Undula odwieczny/wieczysty ideał« (Abb. 1) (Undula, ewiges/immerwährendes Ideal) sowie "Jeszcze raz Undula" (Noch einmal Undula) spielt Schulz mit der Ungenauigkeit. Während der letzte Titel gar keinen Bezug herstellt, zitieren die ersten zwei immerhin das »Ideal« der literarischen Vorlage. Das »Ideal« wiederum ist nach Panofsky eine aus der Renaissance stammende Kategorie, die anstelle einer präexistenten Idee das Ideal setzt, welches eine Vollendung des Natürlichen darstelle, eine »Welt vergeistigter Wirklichkeiten. ${ }^{88}$ Damit wurde die Grundlage für die spätere Entwicklung des Künstler-Genie-Konzepts gelegt. Auf der Ebene der Präsentation ist damit eine schöne Frau dargestellt, die einen nackten Mann unterdrückt, auf der Ebene der meta-bildlichen Bedeutung hingegen befragt das Bild die Beziehung zwischen Ideal und Künstler und thematisiert damit ein eigenständiges Leben des Kunstideals.

In einer weiteren Grafik findet sich erneut ein direktes Tizian-Zitat. Die Grafik "Xięga Bałwochwalcza II" ist in der Komposition wie in der übertragenen Bedeutung Tizians "Venus mit Orgelspieler« sehr ähnlich. Dieser hat sein Bild (wie so viele seiner Gemälde) in verschiedenen Ausführungen gemalt, in denen sich bestimmte Motive verändern. Es zeigt eine nackte Frau auf einem Bett liegend. Unter ihr eine warme Decke, im Hintergrund ein

in Titian, 122-125. Ein ähnliches Spiel mit dem Rezipienten lässt sich unschwer in der "Xięga" beobachten. Auch hier blicken die Frauen, die sich einer eindeutigen Zuschreibung entziehen, zum Teil aus dem Bild hinaus auf den Betrachter.

86 Vgl. Prater, Im Spiegel der Venus, 14.

87 Augsburger, Masochismen, 189.

88 Panofsky, Idea, 36. 
barocker, samtener Vorhang und dahinter eine Parklandschaft. Zu ihren Füßen sitzt ein Musiker, der all seine Aufmerksamkeit auf sie richtet. Venus beachtet ihn nicht, je nach Bildversion spielt sie lieber mit einem Hund, einer Flöte oder kommuniziert mit Amor.

Ihre Beine liegen wie eine Trennung zwischen ihr und dem Künstler. Der Musiker, in den ersten Versionen noch ein Orgelspieler, rückt Venus dabei näher. Erst nachdem dieser durch den Lautenspieler ersetzt ist, kann er sich ihr voll zuwenden, ohne sich von seinem Instrument abzuwenden. Genau in dieser Haltung des Musikers zur Venus erkennt Panofsky eine sich verändernde Beziehung zwischen den Künsten. Da in den früheren Versionen der Organist sein Spiel unterbrechen müsse beziehungsweise nur unter großen Einschränkungen sein Instrument bedienen könne, stelle dieses Bild noch einen Triumph der sichtbaren Welt über die Welt des Klangs dar. Die Ersetzung des Orgelspielers durch den Lautenspieler in den späteren Versionen deutet Panofsky als radikalen Wandel in der Ikonologie.

»It means that a musician interrupted in the act of making music by the sight of visual beauty embodied in Venus has been transformed into a musician doing homage to the visual beauty embodied in Venus by the very act of making music." ${ }^{89}$

Auch bei der Venus hat sich die Szenerie verändert. Cupido krönt diesmal die Venus mit einem Blumenkranz, anstatt ihr etwas ins Ohr zu flüstern oder sie zu pflegen. Gleichzeitig ist auch Venus nun der Musik verfallen. In ihrer linken Hand hält sie eine Blockflöte, eine Viola da Gamba lehnt am Sofa und zwei Bücher mit Partituren liegen herum, eine ist mit »Tenor« überschrieben. In der Darstellung mit Lautenspieler ist damit eine fast perfekte Balance zwischen den Ausdrucksbereichen der Kunst vorzufinden. »Titian, musician as well as painter, has in the end accorded equal dignity to the senses of hearing and of sight. ${ }^{90}$ Das Bild knüpft damit an die "Paragone-Tradition" an, die den Wettstreit der Künste Poesie und Malerei bezeichnet, ${ }^{91}$ nur dass hier die Poesie durch die Musik ersetzt wurde.

In Schulz' Version dieses Bildes ist es ein Schriftsteller, der einer Nackten mit Peitsche in der Hand vorliest. Diese liegt ebenfalls auf einem weichen Bett, über ihrem Kopf hängt ein schwerer Vorhang. Wie bei Tizian öffnet sich der Raum nach hinten in die Landschaft, nur dass bei Schulz die Parkoder Naturlandschaft durch eine städtische Kulisse ersetzt ist. Damit markiert er einerseits die Moderne, andererseits auch den städtischen Kontext der

89 Vgl. Ders., Problems in Titian, 125.

90 Ebd.

91 Vgl. Jurt, Joseph: Frühgeschichte der Intermedialität: Flaubert. In: Degner, Uta/Wolf, Norbert C. (Hg.): Der neue Wettstreit der Künste. Legitimation und Dominanz im Zeichen der Intermedialität. Bielefeld 2010, 19-40, hier 21. 


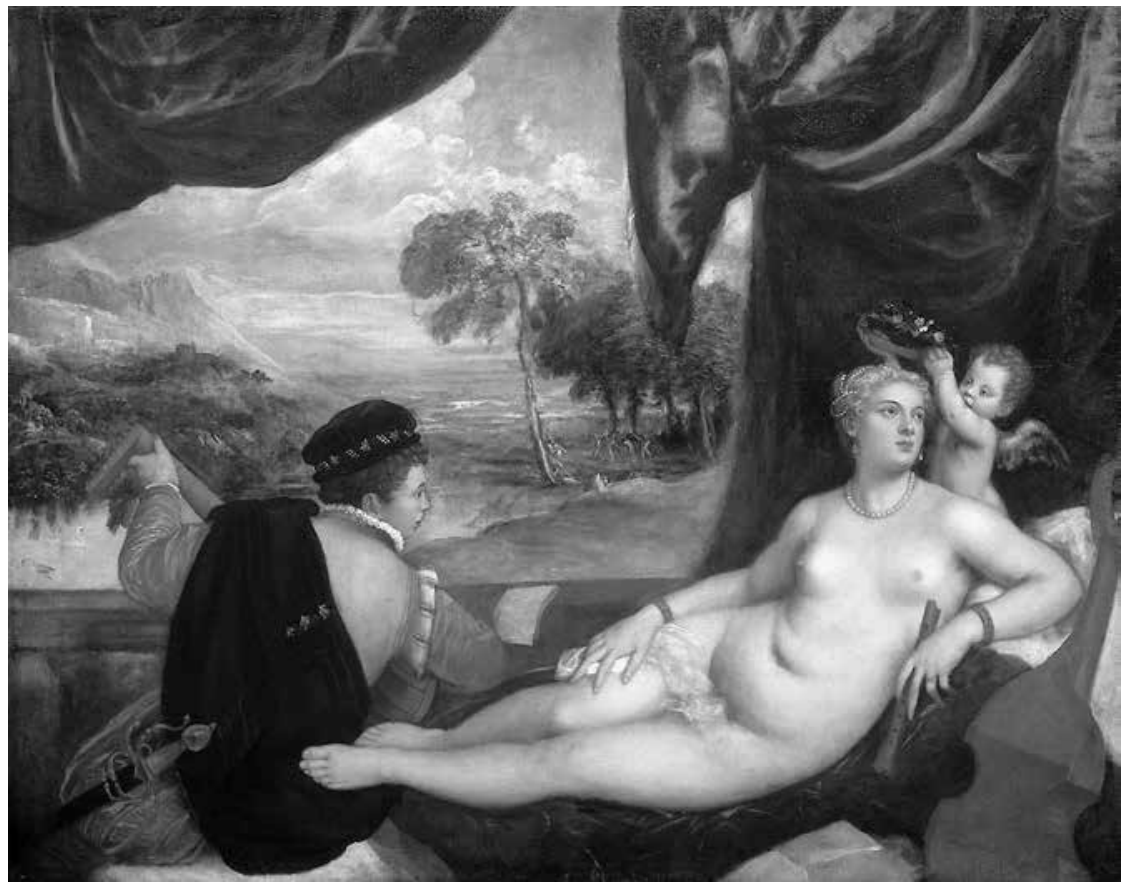

Abb. 3: Tizian, »Venus mit Lautenspieler«, um 1565-1570, Öl auf Leinwand, $165 \times 210 \mathrm{~cm}$, Metropolitan Museum of Art, New York.

Szene. ${ }^{92}$ Da die Grafik mit dem Titel der Grafiksammlung überschrieben ist, scheint das abgebildete Buch das götzendienerische Buch selbst zu sein, während das Idol die halbnackte Frau mit Peitsche darstellt. Deutet man dies im Kontext der ikonologischen Bedeutung von Tizians Vorbild, so scheint hier zudem ein Vergleich zwischen Malerei und Literatur thematisiert zu sein. ${ }^{93}$ Gleichzeitig tritt im Titel ein biblischer Kontext hinzu, sodass ebenfalls der theologische Konflikt zwischen dem Bilderdienst, dem Bilderverbot und der Buchreligion angesprochen ist. ${ }^{94}$

92 Vgl. Sikorski, Symboliczny świat, 25-29.

93 Da Schulz zu diesem Zeitpunkt noch nicht als Schriftsteller hervorgetreten ist, scheint es naheliegender, hier eine Konkurrenz zwischen der Buchreligion und der Malkunst im Kontext des Alten Testaments zu sehen.

94 Auf die verschiedenen Deutungsmöglichkeiten des biblischen Bilderverbots in der Geschichte wurde ausführlich im Unterkapitel 2.3. „Das Erstarren der Bilder« eingegangen. Hier sei noch einmal wiederholt, dass es keine einziggültige Deutung des Bildverbots gibt. Kernbereich des Verbots ist aber eine Abbildung Gottes, der weder genannt noch gezeigt werden darf. »Die Unnennbarkeit Gottes, trotz der Schreibbarkeit im Tetragramm, 


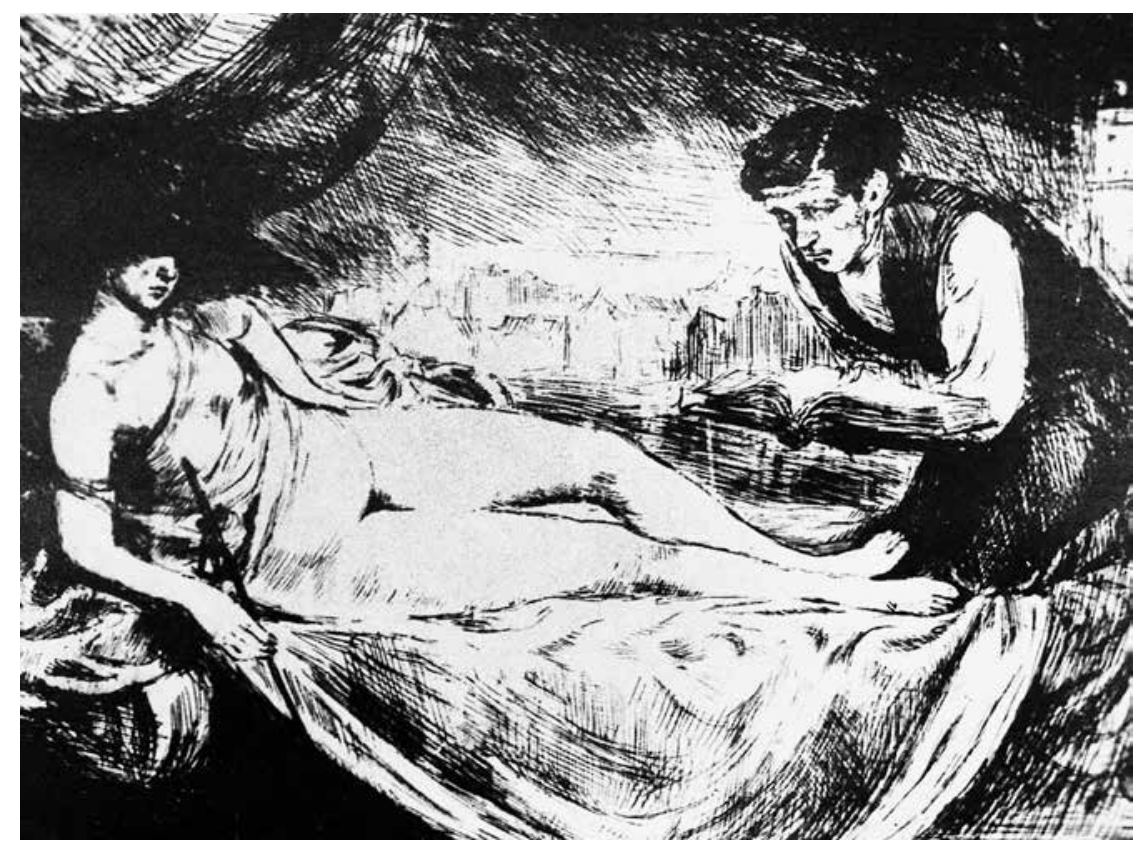

Abb. 4: Schulz, »Xięga bałwochwalcza II« (Das Götzendienerische Buch II), Cv, $14,4 \mathrm{~cm} \times 23,7 \mathrm{~cm}$, Inv. Nr. MNK III-ryc-7474, Nationalmuseum Krakau.

Ariko Kato weist darauf hin, dass sowohl Sacher-Masoch als auch Schulz den Mythos der Venus in ihren Werken neu schreiben. Die verschiedenen Zeitebenen und Verweisstrukturen "give[...] the reader the illusion that reality imitates artistic representation. ${ }^{95}$ Schulz parodiert damit auf modernistische Weise ${ }^{96}$ die »Mimesis«-Vorstellung des 19. Jahrhunderts und ersetzt sie durch eine Struktur der Interdependenz der Eindrücke und Ausdrücke, literarischer wie bildlicher Medien und vor allem zwischen Kunst und Leben. Der Künstler ist weder der freie, fast gottgleiche Künstler, der seine Inspiration aus sich selbst bezieht, ${ }^{97}$ noch ist er der Handwerker, der präexistente Ideen wieder-

spiegelt die Nichtabbildbarkeit und Nichtsagbarkeit Gottes wieder. Der transzendente Gott kann ebenso nicht gesagt werden, wie er gezeigt werden kann. Darum nenne man Gott auch einfach `ha-Schem Name, worin sich wiederspiegelt, dass er einzigartig ist, einen ganz eigenen und unverwechselbaren Namen besitzt.« Brumlik, Schrift, Wort und Ikone, 18.

95 Vgl. Kato, The Early Graphic Works, 228.

96 Nach Mitchell sei die meta-artistische Selbstreferenzialität das verbindende Thema der modernen Kunst. Vgl. Mitchell, Picture Theory, 36.

97 Das Ideal eines genialen Künstlers, der aus sich selbst heraus ganze Welten erfindet und nur den Ideen verpflichtet ist, hat vor allem Schopenhauer geprägt. »Das außer und unabhängig von aller Relation bestehende, allein eigentlich Wesentliche der Welt, der wahre 
gibt. Vielmehr nimmt er eine Zwischenposition ein. Er ist einerseits Knecht, andererseits Liebhaber und diese paradoxe Situation zieht sich durch die Grafiken. Dies zeigt sich auch in den Titelbildern der Grafikmappen, auf denen die Künstler eine idolatrisch-unterwürfige wie anbetende Haltung sowohl gegenüber den Frauen als Allegorien der plastischen Kunst als auch gegenüber Büchern und Musikinstrumenten einnehmen. ${ }^{98}$ In Bezug auf doppelbegabte Künstler schreibt Kurt Wais, dass diese stärker noch als Künstler, die nur in einem Ausdrucksbereich tätig werden, Inspiration aus dem anderen Medium holen sowie auf eine Symbiose hoffen.

"Die Künstler haben es immer gewußt und, wenn ihnen ihre Ausdrucksmittel unzulänglich schienen, bei den Nachbarkünsten nach optischen bzw. akustisch-klangmalerischen Ergänzungen getastet. Wie verführerisch ist der Traum, die drei Grundkünste, so schicksalhaft getrennt sie sind, auf einem Altar zu verehren [...] Und doch sind es nur letzte verzweifelte Anläufe, wenn die zerstörte Symbiose der Künste durch Mischgattungen künstlich neu belebt werden soll.«99

Um Anerkennung ihrer Kunst durch die personifizierte Kunst Undula wiederum ringen die dargestellten Künstler der Grafik »Undula u artystów« (Undula bei den Künstlern). Undula sitzt auf einem Sessel, diesmal aber in ein Tuch gehüllt, und betrachtet mit halber Aufmerksamkeit die Werke der heranschleichenden Künstler. Dabei liegen auf dem Boden schon allerhand Kunstwerke verstreut; eine Büste, vielerlei Bilder und auch eine Skulptur. Die Künstler blicken verschreckt auf die thronende Frau, die ihnen zwar ihren Fuß darreicht, aber ansonsten kaum eine Reaktion zeigt.

In der Grafik »Odwieczna baśń I« (»Das ewige Märchen I«) verschließt die dargestellte Venus dem Künstler sogar mit dem Fuß die Augen. Die nackte

Gehalt aller Erscheinungen, das keinem Wechsel Unterworfne und daher für alle Zeit und mit gleicher Wahrheit Erkannte, mit einem Wort, die Ideen, die unmittelbare und adäquate Objektität [sic] des Dinges an sich: das ist der Inhalt, der Gegenstand der Kunst.

Sie wiederholt in ihren Werken, die durch reine Kontemplation aufgefaßten ewigen Ideen, das Wesentliche und Bleibende aller Erscheinungen der Welt: je nachdem nun der Stoff ist, in dem sie wiederholt, ist sie bildende Kunst, Poesie oder Musik. Ihr einziger Ursprung ist Erkenntniß der Idee: ihr einziger Zweck, Mittheilung dieser Erkenntniß.«Schopenhauer, Arthur: Metaphysik des Schönen. München 1988, 65. Das »Słownik schulzowski" attestiert Schulz einen "Schopenhaueryzm", der sich insbesondere in Anleihen aus dem Buch »Welt als Wille und Anschauung « zusammensetze. In dieser Lesart dekonstruiert Schulz vielmehr Schopenhauer, als dass er als Anhänger seiner Ideen verstanden werden kann.

98 Die »Księga obrazów» (Buch der Bilder) druckt alle bekannten Titelbilder der »Xięga Bałwochwalcza«ab. Neben Büchern, Frauen, Tempeleingängen werden Instrumente verehrt. Wenn die Frauen als personifizierte Malerei verstanden werden, so sind alle Kunstbereiche Gegenstand der Verehrung. Schulz, Księga obrazów, 131-137.

99 Wais, Kurt: Symbiose der Künste: Forschungsgrundlagen. In: Weisstein (Hg.): Literatur und bildende Kunst, 34-53, hier 43. 


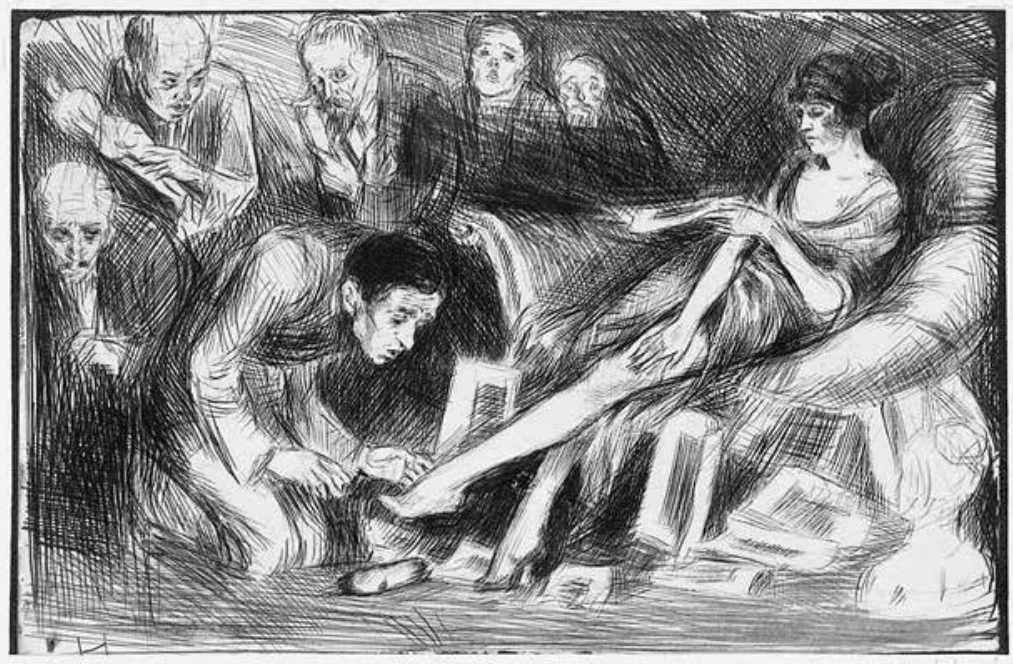

Abb. 5: Schulz, „Undula u artystów« (Undula bei den Künstlern), 1920-1922, Cv, $10 \times 15 \mathrm{~cm}, \mathrm{BJ}$.

Frau liegt auf einem surrealen, mit barocken Elementen versehenen Hochsofa. Am Ende des Sofas stützt sich eine engelsähnliche Gestalt ab, die Sikorski als Eros identifiziert, wobei Velazquez' Gemälde "Venus mit Spiegel« als Vorlage gedient habe. ${ }^{100}$ Anders als bei Velazquez handelt es sich hier nicht um ein Rückenporträt. Die Frau stützt sich vom Polster ab. Im Gegensatz zu den meisten anderen Undula-Bildern scheint sie sich hier aktiv zu bewegen, also Kraft für ihren Beinstreckakt aufzuwenden. Über die Schulter wirft sie einen Blick nach unten, um zu überprüfen, ob ihr die Handlung gelingt. Der Künstler hingegen ist eher passiv, wird von der Frau noch weiter in die Dunkelheit des Raumes gedrückt und ist zusätzlich seines Augenlichts beraubt. Dadurch wird erneut der Sehsinn betont. In der Grafik »Odwieczna baśń II« ist die Konstellation zwischen Künstler und Venus gleich geblieben, aber die engelsähnliche Gestalt ist verschwunden. Dafür trägt diese Zwillings-Grafik den zweiten Namen »Ideał« und knüpft damit wieder enger an die No-

100 Sikorski deutet diese Szene als Ausdruck von Schulz' privater Mythologie. Die Dame auf dem Bett liest er als Göttin, auf die eine geflügelte Gestalt aufpasst. Seines Erachtens sei es auch möglich, dass es sich dabei um einen Engel handelt, der sich in die Göttin beziehungsweise das Idol verliebt habe. Vgl. Sikorski, Symboliczny świat, $39 \mathrm{f}$. 


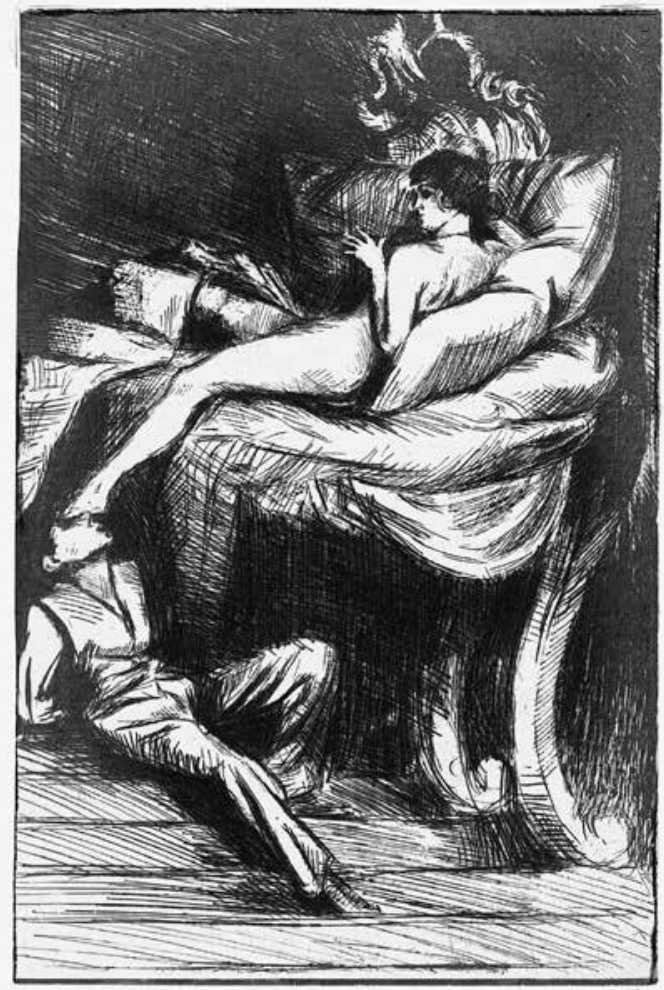

Abb. 6: Schulz, »Odwieczna baśń I« (Das ewige Märchen I), 1920-1922, Cv, 11,5 × 18 cm, BJ.

velle »Venus im Pelz« an. Das Ideal ist anwesend, zum Greifen nahe, aber dem Künstler nicht sichtbar.

Setzt man die vier näher analysierten Grafiken in die gedachte Reihenfolge ${ }^{101}$, so kann man eine Entwicklung erkennen. Während in der ersten Grafik »Odwieczna baśń « der Künstler noch »blind « ist, also wegen und trotz Undula nichts sieht, tritt er in der Grafik »Undula, odwieczny ideał" in den Bann der Venus und empfängt von ihr eine Aufgabe. In »Undula u arstystów« präsentiert er seine ersten Ergebnisse und in der Grafik »Xięga Bałwoch-

101 Diese ergibt sich durch eine erhaltene Inhaltsangabe auf einem Frontispiz von Schulz. Da er jede Grafikmappe allerdings neu bestückte, ist diese Reihenfolge nur eine Annäherung und keinesfalls verbürgt. Vgl. Schulz, Księga obrazów, 223. 
walcza II« schon das fertige Buch vom Götzendienst. In der zweiten Version dieser Grafik steigt die Venus sogar auf einer Art Altar über das Buch und den Schriftsteller-Künstler hinweg, emanzipiert sich hier vollständig vom Erschaffer und wird zum eigenständigen Werk.

»[O]ne might say that The Idolatrous Booke as an autoreferential artifact arouses reflections about its own artistic genealogy, and more specifically about the relation between the verbal and the visual in the creational process of the book. The striking fact that the book itself is visually represented within the book, combined with the peculiar features of this representation, makes it possible to shed a new light on the various binary structures recurring throughout the entire series of engravings. ${ }^{102}$

Van Heuckelom liest Schulz' künstlerisches Anliegen als Aufhebung der Trennung zwischen der plastischen und der verbalen Kunst. Indem Schulz diese Opposition mit dem alttestamentarischen Bildverbot verbinde, übertrage er auch den sexuellen Kontext, den man in der hebräischen Fassung lesen könne. So sei mit Gottes Verbot, andere Götter zu verehren, eine Eifersuchtsstruktur verbunden, die sich in der hebräischen Sprachversion zeige. ${ }^{103}$

»Schulz's understanding of art, on the other hand, is all about crossing boundaries and including the Other. Moreover, the overt sexual motifs recurring throughout the cycle of engravings allow to describe this idea of artistic crossover in a sexually connotated way as well. The Booke breaks its exclusive bond (marriage) with its age-old spouse, the Word, and commits adultery with the Idol (and its various visual representations). In this sense, the title The Idolatrous Booke might be aptly reformulated into The Adulterous Booke. This idea of a conjunction between the sphere of the verbal and the visual is clearly exposed in both versions of the final engraving 'Xiega Balwochwalczar (where the Book and the Idol get united). ${ }^{104}$

So erweisen sich die Grafiken der "Xięga Bałwochwalcza» als die Erzählung eines Künstlers, der die Grenzen zwischen Malerei und Literatur, zwischen Mythos und Religion, zwischen Kunst und Wirklichkeit aufbricht, indem er auf die verschiedenen Verbindungen in früheren Erzählungen und Mythen hinweist und ihr Nachwirken auf sein Schaffen und seiner Vorstellungswelt aufzeigt. Damit setzen sich die Grafiken mit dem Kunstschaffen und Bildermachen, aber auch mit dem Ursprung der Inspiration und der Ideen auseinander. Schulz vermischt die Grenzen zwischen Präsentation und Repräsen-

102 Van Heuckelom, Artistic Crossover in Polish Modernism. (Hervorh. im Orig.)

103 Dies begründet Van Heuckelom mit Margalit und Halbertals Studie »Idolatry«. Idolatrie (Avodah zarah) sei nach diesen auch mit dem Ehebruch konnotiert, weil es die Anpreisung eines fremden Gottes sei. So sei insgesamt das Sichtbare mit dem Sinnlichen und das Sprachliche mit dem Intelligiblen verbunden. Darin erkennt Van Heuckelom eine Verbindung zur Geschlechteropposition. Vgl. ebd.

104 Vgl. ebd. (Herv. im Orig.) 
tation und hinterfragt sowohl das Mimesis-Konzept als auch die Vorstellung des freischaffenden Künstlers. Gleichzeitig nimmt er das moderne IdolatrieThema mit auf und stellt seine Fragen vor dem Hintergrund einer religiösen Bildskepsis und Präferenz des Wortes.

\subsection{Idolatrische Bücher und Bilder in Interaktion}

Nun gilt es noch die kunst- und bildtheoretischen Überlegungen, die sich aus der Umarbeitung und Zitierung von Sacher-Masoch, Eichendorff und Tizian ergeben, mit jenen zum biblischen Bildverbot zusammenzubringen. Dabei stellt sich die Frage, ob der religiöse Rahmen der wichtigere ist oder ob alle Themenstränge ineinander übergehen?

Kris Van Heuckelom hat in seinem Aufsatz »Artistic Crossover in Polish Modernism" die Verhandlung des alttestamentarischen Abbildverbots innerhalb der Grafiken untersucht. Er weist auf den Umstand hin, dass Schulz im Titel "Xięga Bałwochwalcza» sowohl Bild als auch Buch aufruft. Gerade im Rückgriff auf die antiquierte Schreibweise verbindet Schulz zwei Pole einer Dichotomie miteinander, nämlich den Götzendienst und die Buchreligion. Diese Assoziation wird auch durch die Frontispize sowie durch die Titelgrafiken gestärkt, auf denen sowohl Körper als auch Bücher und Musikinstrumente angebetet werden. Van Heuckelom nennt mehrere Spannungsfelder, die gleichzeitig aufgebaut werden: die Opposition zwischen dem Verbalen und Visuellen, dem Buch und dem Idol, dem Kreativen und Passiven sowie zwischen dem Transzendenten und dem Weltlichen. Erstere werden dabei den männlichen Figuren der Grafiken zugeschrieben, während letztere mit den weiblichen korrespondierten.

Kulig-Janarek erkennt in dieser Binarität auch eine soziale Dimension. Die dargestellte Geschlechteropposition spiegele die philosophischen Thesen von Schopenhauer, Hartmann und Nietzsche wider. So stünde die Frau für die Materie, die Passivität und die Körperlichkeit; der Mann für den Geist, die Aktivität und das Schaffen. ${ }^{105}$ Während Kulig-Janarek und Van Heuckelom den Dualismus auflösen, macht Sandauer ihn zu Schulz' konstituierendem Moment: "Wir wissen, dass diese Antithesen den grundlegenden Dualismus in Schulz' Welt bezeugen. ${ }^{106}$ Gegen diese These spricht nicht nur der Titel, der den Dualismus Götzendienst und Buchreligion zum Paradox macht, sondern auch der Umstand, dass die verbotene »Bildverehrung« im Medium des 
Bildes verhandelt wird. Bałwochwalstwo (Götzendienst) leitet sich vom Wort »bałwan«ab, welches aus dem Sanskrit kommt und »Götterfigur» bedeutet. ${ }^{107}$

»Es ist eine prähistorische Entlehnung von den östlichen Völkern, eine Zusammensetzung aus dem kirgisischen balvan - >Kraftmensch‘, >Held‘, dem osttürkischem palvan, mit dem persischen pahlevan - `Kämpfer`, 'Held` und 'Säule zu seinen Ehren`, aber auch `Klotz«, `Klumpen` und `Dummkopf^, was - wie bekannt ist - als eine eigene kontrastierende Nebenbedeutung dieses Ausdrucks auch ins Slawische Eingang fand. ${ }^{108}$

Anstatt sich einer eindeutigeren hebräischen Begrifflichkeit wie "pesel« und "massekah ${ }^{109}$ oder aber des griechischen Äquivalents »eidolon ${ }^{110} \mathrm{zu}$ bedienen, bevorzugt Schulz eine persisch-slavische Variante, die in ihrer doppelten Bedeutung von Machtrepräsentanz und Dummkopf selbstparodierend bzw. selbstentkräftend ist. Damit weisen Titel wie Darstellungen nicht auf ein Bildverbot hin, sondern auf die Möglichkeit zweier Haltungen zum Bild. Die erste ist die verehrende Haltung, die im Bild eine Autorität wahrnimmt, die zweite ist eine kritische Distanz, die das Bild als Gemachtes erkennt - als »Klotz« und »Klumpen«. Matthias Freise weist auf eine weitere Bedeutungsschicht im Polnischen hin:

107 Vgl. Lokotsch, Karl: Etymologisches Wörterbuch der europäischen (germanischen, romanischen und slavischen) Wörter orientalischen Ursprungs. Heidelberg 1927, 129.

108 "Jest to prastara pożyczka od ludów wschodnich, zestawiana z kirgiskim palvan, balban - ssiłacz‘, ১bohater`, wschodniotureckim palvan, z perskim pahlevan - ১bojownikı,

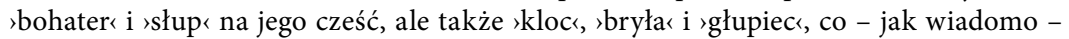
przeszło jako swoiście kontestacyjne uboczne znaczenie tego wyrazu i do Słowian." Gieysztor, Aleksander: Mitologia Słowian. Warszawa 1982, 186. (Übers. A. J.)

109 »Pessel (`Schnitzbild`, engl. graven image) und massekah ( $>$ Gussbild molten image) sind die hebräischen Bezeichnungen für (fremde) Kultbilder. Sie betonen das Gemachtsein, das Bild als Resultat eines handwerklichen Herstellungsprozesses, und nicht etwa die Ähnlichkeitsbeziehung zwischen Original und Abbild. Im Akkadischen heißt das Kultbild salmu, dasselbe Wort, das die Bibel in der masoretischen Vokalisierung selem für die Gottesebenbildlichkeit des Menschen verwendet. Daß das gemetzte und gegossene Machwerk etwas darstellt, wird durch den Zusatz temunah (`Figur`) verdeutlicht. Das Bild stellt etwas dar, aber natürlich nicht den unsichtbaren Gott, sondern irgendeine Figur dieser Welt. [...] Da Gott unsichtbar ist, kann es von ihm keine Bilder geben. Bilder können daher, was immer die Absichten ihrer Verehrer sein mögen, nur andere Götter darstellen und im Akt der Anbetung zur Einwohnung bringen.« Assmann, Altägyptische Bildpraxen und ihre impliziten Theorien, $98 \mathrm{f}$.

$110 » \mathrm{Da} \varepsilon i \delta \omega \lambda \mathrm{ov}$ schon im klassischen Griechisch weniger das Bild, die Darstellung einer Wirklichkeit, als die Illusion, das Produkt der Phantasie, bezeichnet, griffen die Übersetzer des AT diesen Ausdruck mit Vorliebe auf, um in abwertender, polemischer Weise den nichtigen Glauben an falsche Götter, gleich ob bildlich dargestellt oder nicht, zu bezeichnen. Mit der Verwendung von $\varepsilon ` \delta \omega \lambda$ ov haben die LXX [Schreiber der Septuaginta, A. J.] also nicht versucht, das Hebräische wörtlich wiederzugeben, sondern inhaltlich zu übertragen.« Götzendienst. Klauser u. a., Reallexikon für Antike und Christentum, 849. 
»Auch das Wort bałwochwalstwo läßt sich literarisch aufschlüsseln, es enthält mit dem Bałwan sprachlich nicht nur den Götzen, sondern auch den Schneemann und die Vogelscheuche. Das sind aufgrund ihrer Vergänglichkeit, ihrer Puppenhaftigkeit und der Billigkeit ihres Materials hochvalente Requisiten in Schulz' Prosa. Doch bałwan heißt auch Meereswoge. ${ }^{111}$

In Jesaja 44, 9-20 wird die idolatrische Einstellung beschrieben. Die Menschen schnitzen sich aus Holz einen Götzen und beten ihn an, dass er sie rette, auch wenn er sie nicht sättigt oder wärmt, wie es der Holzklotz getan hätte, würden sie ihn zum Backen oder Heizen nutzen. »Unwissend sind sie und ohne Verstand; denn ihre Augen sind verklebt, sie sehen nichts mehr, sie haben keine Erkenntnis und Einsicht.«" ${ }^{112}$ Damit kennzeichnet der Prophet den Unterschied zwischen mythischem und intellektuell-kritischem Wahrnehmen. Nach Cassirer, der in seiner Arbeit über das mythische Denken auf diese Bibelstelle eingeht, ist nicht die vernichtende Kritik an dem Konzept des Götzenbildes wegweisend, sondern die "Rückverlegung" in das "Herz« des Religiösen, »kraft dessen nunmehr die Bildwelt des Mythos als ein bloß Äußerliches und als ein bloß Dingliches sich zu erkennen gibt. " ${ }^{113}$ Damit wird erneut der Unterschied zwischen dem dinglichen Gegenstand und der symbolischen Zuweisung durch den Menschen betont. Idolatrie steht für eine Wahrnehmungsform, die im Dargestellten eine machtvolle Anwesenheit erwartet beziehungsweise anerkennt.

Wie schon früher angedeutet, sucht Schulz nicht den Ausweg über eine Bevorzugung des Buches als Symbol für die bildfreie Schriftlichkeit. Die dargestellten Bücher treten nicht in Konkurrenz, sondern im Vergleich zu den Frauen auf. Sie tragen eine ähnliche idolatrische Struktur. Frauen und Bücher liegen teilnahmslos herum, aktiv sind hingegen die Männer, die sie anbeten und verehren. Besonders deutlich wird dies in den Grafiken um die »jungen Mädchen « ${ }^{114}$, die im Titel wie in der Ikonologie einen religiösen Kontext aufrufen. $\mathrm{Zu}$ dieser Gruppe zählen die Grafiken »Procesja» (Die Prozession), »Pielgrzymi« (Die Pilger), »Plemię pariasów« (Das Volk der Paria), sowie »Święto bałwochwalców« (Das Fest der Götzenanbeter). Nicht die zentralen nackten Mädchen werden im Titel angesprochen, sondern die Pilger und

111 Freise, Schulz zwischen Literatur, 124. Freise weist damit auf den Zusammenhang zum Namen der Protagonistin Undula hin, der von lat. »Unda« (Welle) abgeleitet sei. Aber obwohl er auch den dazugehörigen Namen Undine nennt, öffnet er keinen Bezug zu de la Motte Fouqués gleichnamiger Erzählung, dessen Protagonistin wie Venus aus dem Wasser steigt. Vgl. La Fouqué Motte, Friedrich de: Undine. Lwów 1913.

112 Jesaja 44,19; Die Bibel. Nach der Übersetzung Martin Luthers; mit Apokryphen; [Bibeltext in der revidierten Fassung von 1984]. Stuttgart 2004.

113 Cassirer, Das mythische Denken, 288.

114 Auch die Frontispize zeigen religiöse Szenen, oft mit Priestern und Gläubigen. Schulz, Księga obrazów, 249-251; 264. 
Paria. Damit betont Schulz erneut die Rolle der Rezeption und Haltung. Die an den Gegenstand herangetragene Erwartung kreiert die Heiligkeit und Macht der Mädchen, Frauen oder Bücher. Da sich Schulz auch selbst in den Reihen der Paria und Pilger darstellt, nimmt er sich aus diesem Kult nicht aus. Er verweist auf die Magie und Macht von Bildern in der Geschichte und Gegenwart und die ambivalente Rolle, die ein Künstler als Bildmacher einnimmt.

Damit lassen sich die Grafiken als selbstreferentielle Metabilder verstehen, die mehrere Ebenen der Repräsentation aufrufen und das Bilderschaffen untersuchen.

»They are not merely epistemological models, but ethical, political, and aesthetic rassemblages that allow us to observe observers. In their strongest forms, they don't merely serve as illustrations to theory; they picture theory. ${ }^{115}$

Mitchell macht in seiner »Picture Theory« darauf aufmerksam, dass man, um solche Bilder zu untersuchen, sie ekphrastisch beschreiben müsse. Ein Wissenschaftler müsse die Metabildtheorie wieder in Sprache übersetzen, da er kein Bilderbuch verfassen könne und das Hauptmedium der Geisteswissenschaft die Sprache sei. Mit diesem Hinweis macht er zugleich auf eine dem Bildkünstler zur Verfügung stehende Möglichkeit aufmerksam, nämlich unter vollständigem Verzicht auf Schrift Bilder in Bildsprache zu theoretisieren.

\subsection{Bild im Bild}

Noch deutlichere Metabilder als die Grafiken sind die Porträtzeichnungen der Freunde aus derselben Schaffensphase Anfang der 1920er Jahre. Metabilder seien nach Mitchell typisch für die Moderne. Dabei zitiert er John Rajchman:

"To say sthe work of art is self-analytic is... to say that it consists in the crisis it goes through, that is punctuated by moments of breakthrough or revelation, which require that one question one's conception of who one is or how one has invested oneself in it. It is to say that a work is constituted through those events that arrest the selfevidence of one's identity and that open other possibilities that retroactively reinterpret it. ${ }^{116}$

In Schulz' Porträts und Autoporträts der Schaffensphase seines Grafikzyklus' Anfang der 1920er Jahre finden sich Zeichnungen, in deren Hintergrund my- 
thologische Szenen gezeigt werden, die jedoch so groß und präsent sind, dass sie in den Vordergrund rücken. Diese Zeichnungen verhandeln ähnlich zur "Xięga Bałwochwalcza» das Verhältnis von Künstler, Bild und Rezipient, allerdings mit einem anderen Fokus. Hierbei handelt es sich um die Bilder "Autoportret przy pulpicie rysowniczym « ${ }^{117}$ (Selbstporträt vor der Staffelei) von 1919, »Portret Stanisława Weingartena ${ }^{118}$ (Porträt von Stanisław Weingarten) von 1919, "Autoportret z przyjacielem Stanisławem Weingartenem i dwiema modelkami « ${ }^{119}$ (Selbstporträt mit dem Freund Stanisław Weingarten und zwei Modellen) von 1921 sowie »Portret Marii Budrackiej« ${ }^{120}$ (Porträt von Maria Budracka) von 1919. Ariko Kato hat in einem Aufsatz auf die auffällige Struktur des "mise en abyme ${ }^{121}$ hingewiesen, die eine Selbstbezogenheit und Selbstthematisierung des Autors im eigenen Werk bedeute. Die im Bildhintergrund zitierten Bilder, die traditionelle Malerei mit mythologischen und religiösen Genres zeigen, bilden einen Kontrast zum dargestellten Porträt und eröffnen erneut ein Spannungsverhältnis zwischen Kunst und Leben, Fiktion und Realität. ${ }^{122}$ Die »Bild in Bild-Technik« greift nach Stoichiţă auf eine lange Tradition der Malerei, vor allem in den Niederlanden, zurück. Solche Bilder im Bild hatten die Funktion, unabhängige Motive einzuarbeiten und gaben dem Maler mehr Freiraum. ${ }^{123}$ Stoichiţă zählt Gemälde, Spiegel und

117 Schulz, Księga obrazów, 119. Da Bruno Schulz diese Zeichnungen nicht selbst benannt hat, variieren die Titel. Das Sammelwerk »Księga obrazów» (Buch der Bilder) gibt den Titel für dieses Selbstporträt mit »Młodzieńcy autoportret ze sztalugami« (Jugendliches Selbstporträt mit Staffelei) an.

118 Ebd., 176.

119 Ebd., 160. Auch hier variiert der Titel. In der »Księga obrazów« steht eine längere Form: »W pracowni artysty - autoportret ze Stanisławem Weingartenem i dwiema modelkami« (Im Atelier des Künstlers - Selbstporträt mit Stanisław Weingarten und zwei Modellen).

120 Ebd., 173.

121 »Mise en abyme (frz., In-Abrund-Setzung), dieser von C. E. Magny geprägte und auch bereits von J. Ricardou verwendete Begriff bezeichnet eine Form v. a. literar. Rekursivität beziehungsweise Ähnlichkeit und damit Selbstreferenz, die sich in einem isolierbaren Segment auf einer ontologisch oder textologisch untergeordneten Ebene des Textes oder Kunstwerks manifestiert, so dass auf dieser mindestens ein in der Regel signifikantes Element (inhaltlicher oder formaler Natur) einer übergeordneten Ebene 'gespiegelt « erscheint (z. B. das Theaterspiel im dramatischen Spiel im Spiel, dramatische oder handlungsrelevante Elemente der diegetischen Ebene in hyperdiegetischen Erzählungen).« Mise en abyme. In: Nünning, Ansgar (Hg.): Metzler Lexikon Literatur- und Kulturtheorie. Ansätze, Personen, Grundbegriffe. 4. Aufl. Stuttgart 2008, 502.

122 Vgl. Kato, Obraz i Księga, $153 \mathrm{f}$.

123 Vgl. Stoichiţă, Das selbstbewußte Bild, 186-293. Ein bekanntes Beispiel sei Vermeers Gemälde »Die Malkunst«, in welchem sowohl Künstler, Bild und Modell anwesend sind. Im Hintergrund hängt eine große Landkarte. Aber auch van Gogh, auf den Schulz innerhalb seiner Literatur Bezug nimmt, hat Porträts und Selbstporträts mit Bildern im Hintergrund angefertigt. 
Landkarten, die im Hintergrund eines Gemäldes auftauchen, zu jenen Zeichen, die »im XVII. Jahrhundert einen intertextuellen Diskurs eröffnen, der nichts anderes ist als ein Dialog um den Status der Darstellung selbst. ${ }^{124} \mathrm{Da}-$ mit knüpft Schulz erneut auf ältere Formen dieser Bildsprache zurück.

Die im Hintergrund der Zeichnung "Autoportret przy pulpicie rysowniczym « hängenden Bilder zeigen zwei Szenen aus dem thematischen Umfeld der "Xięga Bałwochwalcza«. Das erste Bild zeigt eine mythologische Szene, deren Protagonistin Kato als Mischung aus griechischer Venus und biblischer Judith interpretiert. Sie sitzt zuoberst einer Muschel, die sich mit dem Blut eines geköpften Mannes füllt, dessen Rumpf zwei Frauen über die Muschel halten. Das zweite zeigt einen Mönch, der kniend eine nackte Frau anbetet.

"Schulz hat auf diese Weise eine Kluft zwischen der Form und dem erwarteten Inhalt geschaffen. Die zwei Bilder im Bild, welche zwei Gattungen der Malerei nachahmen, nämlich die religiöse und die mythologische, die in der akademischen Hierarchie wiederum als die 'gehobenen` wertgeschätzt wurden, erweisen sich tatsächlich als deren Neuauflage. ${ }^{125}$

Dabei übersieht Kato allerdings weitere Gegenstände der Kunst, die durchaus wichtig sein könnten. Eine Kinderstatue steht zu Füßen des Zeichners und hinter diesem befindet sich ein vollgestelltes Bücherregal. Damit sind schon wieder mehrere Kunstgattungen gleichzeitig anwesend - die Mythos- und Ikonenmalerei, Literatur und Plastik, das gezeichnete Autoporträt als Bild selbst. ${ }^{126}$ Der Künstler Schulz im Bild hat dabei den Stift noch angesetzt und blickt konzentriert seitlich aus dem Bild hinaus, als würde er gerade den Betrachter beim Analysieren seines Bildes zeichnen. Damit betont er den Akt des Zeichnens, die Handlung im Bild erster Ebene. Vor allem die Augen heben sich vom Rest der Zeichnung durch einen besonders präzisen und festen Strich $a b$, während der Rest eher weich gezeichnet ist. ${ }^{127}$ Diese Art des Blickens

124 Ebd., 197.

125 »Schulz stworzył w ten sposób przepaść między formą a oczekiwaną treścią. Te dwa obrazy w obrazie, naśladujące dwa gatunki malarstwa: religijne i mitologiczne, które w hierarchii akademickiej były cenione jako gatunki `wyższe`, okażą się właściwie ich odnowieniem.« Kato, Obraz i Księga, 153 f. (Übers. A. J.)

126 Diese Anordnung von Gegenständen finden sich auch in einigen Porträts der Renaissance, so beispielweise in Tizians »Portrait of Jacopo de Strada «, Hans Holbein »Portrait of Georg Gisze«, sowie Pietro della Vecchia »Imaginäres Selbstportrait von Tizian«. Vgl. Panofsky, Problems in Titian, $92 \mathrm{f}$.

127 Auf die Relevanz des Blickens in Schulz' plastischer Kunst hat Panas hingewiesen. Dabei analysierte er diejenigen Bilder, die eine Gruppe von Chassidim abbildeten, welche auf den Messias warten. Panas stellt fest, dass die Chassidim nicht in die Ferne des Horizonts blicken oder in Richtung Jerusalem, sondern zum Betrachter des Bildes, »in unsere Richtung.« »Nasza - i autorska - strona jest zatem u Schulza stroną mesjańską. W jakimś sensie patrzymy na ów świat oczyma Mesjasza lub też Mesjasz spogląda na tę 


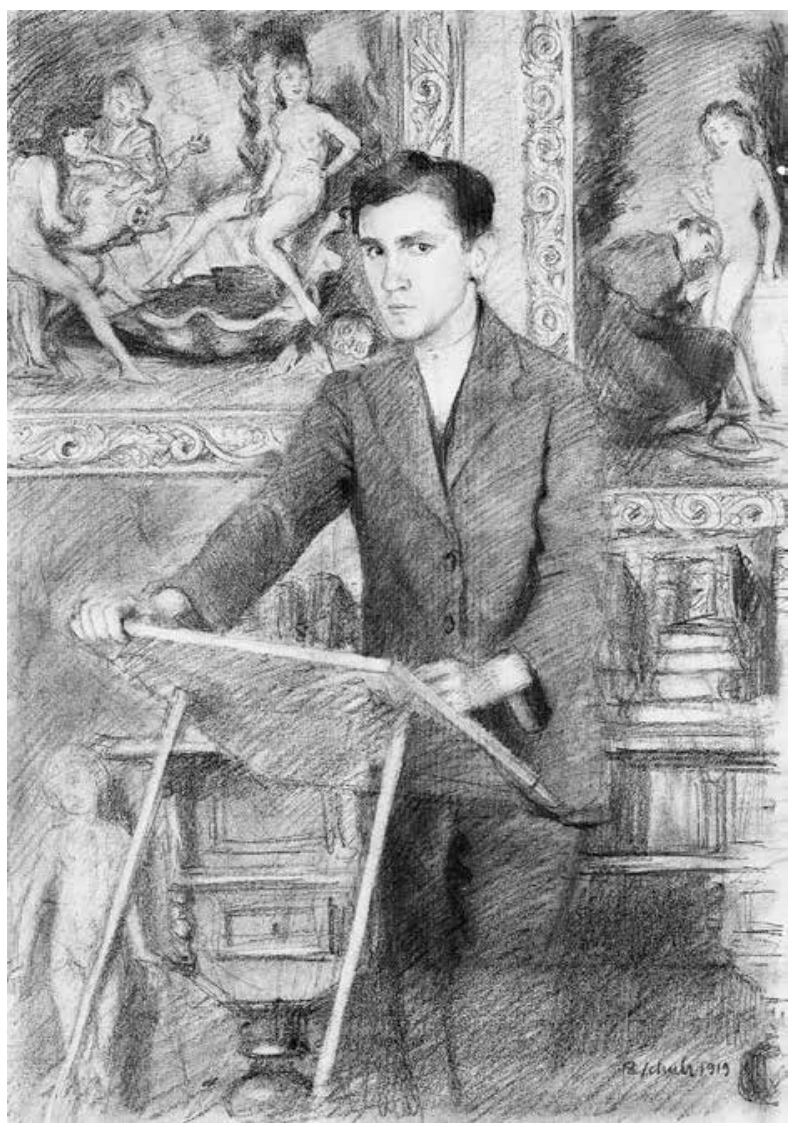

Abb. 7: Schulz, »Autoportret przy pulpicie rysowniczym«; »Młodzieńczy autoportret ze sztalugami« (Selbstporträt vor der Staffelei; Jugendliches Selbstporträt mit Staffelei), 1919, Bleistiftzeichnung, $43 \times 29 \mathrm{~cm}$, Jüdisches Historisches Institut, Warschau (JHI).

wird auch in Schulz' Erzählung »Samotność« (Einsamkeit) untersucht. Darin analysiert der Erzähler seinen eigenen Blick im Spiegel, als würde das Abbild nicht zu ihm gehören und wartete auf die befehlenden Worte. ${ }^{128}$

scenę naszymy oczami. Były to także oczy Brunona Schulza.« Panas, Księga blasku, 204. "Unsere - und die des Autors - Seite ist damit bei Schulz die messianische. In gewisser Weise blicken wir auf diese Welt mit den Augen des Messias oder auch der Messias blickt auf jene Szene mit unseren Augen. Dies waren auch die Augen von Bruno Schulz.» (Übers. A. J.)

128 Vgl. Schulz, Sanatorium pod Klepsydrą, 290. 
»Fremd stehst du da, schaust irgendwohin zur Seite und scheinst in die Tiefe hineinzulauschen, auf ein Wort zu warten, das von dort kommt, aus der gläsernen Tiefe, als gehorchest du einem anderen, als erwartest du Befehle von irgendwoher. ${ }^{129}$

Da diese Erzählung ursprünglich unter dem Titel »O sobie« (Über mich) veröffentlicht wurde, kann diese Untersuchung des Spiegelbildes umso mehr auf ein Selbstporträt bezogen werden. ${ }^{130}$ Auch hier wird die Kommunikationsstruktur betont, die Erwartung etwas zu hören. In beiden Werken wird also versucht Kontakt mit dem Leser/Betrachter aufzunehmen.

Auch auf der Zeichnung "Portret Stanisława Weingartena ${ }^{131}$ nimmt ein Gemälde nach Art der klassischen Malerei den gesamten Hintgerund ein. Dort sitzt in freier Natur eine Gruppe nackter Frauen auf einem Brunnen, ein Mann küsst die Füße einer Frau und am linken Rande liegt ein Harlekin ${ }^{132}$, lässig wie die Venusfrauen bei Tizian. ${ }^{133}$ Kato betont, an dieser Stelle seien

129 Ders., Das Sanatorium zur Sanduhr, 272. »Obcy i gdzieś w bok patrzący, stoisz tam i zdajesz się nasłuchiwać gdzieś w głąb, czekać na jakieś słowo, ale stamtąd, ze szklanej głębi, komuś innemu posłuszny, skądinąd czekający rozkazów."Schulz, Sanatorium pod Klepsydrą, 290.

130 Vgl. Schulz, Bruno: Samotność (O sobie). In: Chmurzyński (Hg.): Bruno Schulz 1892$1942,168$.

131 Stanisław Weingarten war ein Freund von Schulz und Kunstsammler. In seinem Auftrag hat Schulz sehr viele Arbeiten ausgeführt, mitunter eine Reihe von »Exlibris« und eben jene Porträts. Vgl. Ficowski, Regiony wielkiej herezji, 282-320.

132 Der Harlekin taucht in vielen von Schulz' Zeichnungen auf und auch auf zwei der Grafiken der »Xięga Bałwochwalcza«: »święto wiosny«; »wiosna« (Frühlingsfest; Frühling) sowie »bachanalia» (Bacchanalien). Beide Grafiken spielen im Titel auf den DionysosKult an und zeigen entfesselte Frauengruppen in der Nacht. Der Harlekin steht jeweils abseits und beobachtet das Geschehen. Auf den für Weingarten persönlich entworfenen »Exlibris« taucht dieser Harlekin ebenfalls auf und auf der Zeichnung »Portret Weingartena z książką i z Pierrotem " (Porträt von Stanisław Weingarten mit Buch und mit Pierrot) ist Weingarten sogar in die Kleider des Harlekin gewandet. Damit kann diese Figur mit Weingarten in Verbindung gebracht werden. Auf diese Weise wäre er sogar doppelt abgebildet: symbolisch als Harlekin und als Porträt. Dies könnte bedeuten, dass Schulz den Kunstsammler auch als Voyeur darstellt. In anderen Grafiken, in welchen einige Figuren das Gesicht von Weingarten tragen, tritt er auch in der Reihe der Kultanbeter auf.

133 Die Abbildung der Frauengruppe erinnert an Tizians Diana-Bilder. Gerade die Darstellung der Diana auf dem Gemälde »Diana und Kallisto« scheint in dieser Zeichnung aufgenommen worden zu sein. Auch der Tuchbaldachin über den Köpfen der Frauen findet sich in Tizians Vorlage. Interessanterweise ist ein großer schwarzer Hund abgebildet, während auf der Zeichnung sich eine Raubkatze zwischen den Füßen der Frauen windet. Diana verwandelte laut Mythologie Actaeon, der sie versehentlich beim Baden beobachtet, in einen Hirsch. In der Mappe der "Xięga Bałwochwalcza» findet sich auch die Grafik »Zuzanna przy tualecie« (Susanna bei der Toilette), die die Armbewegung von Tizians Diana aufnimmt. Im Titel wird die biblische Susanna zitiert, die ebenfalls beim Bade beobachtet wurde. Zwei Älteste und Richter sind so sehr von ihrem Bilde verzückt, 


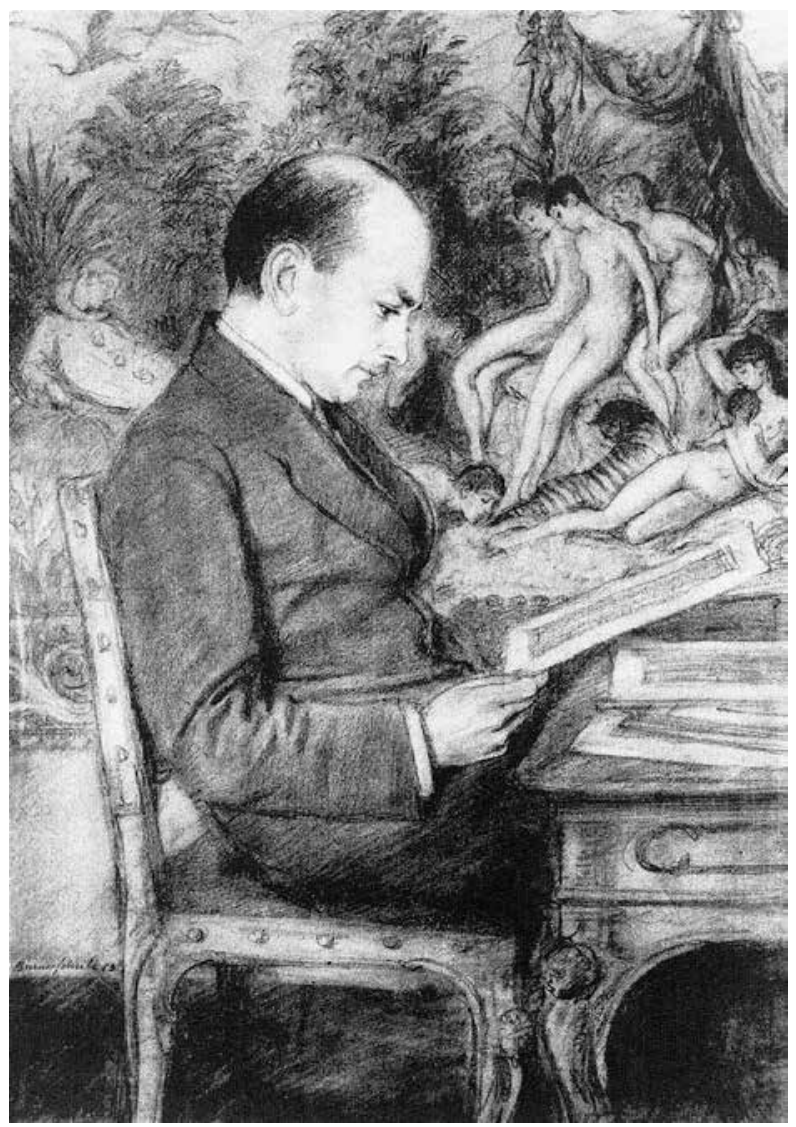

Abb. 8: Schulz, »Portret Stanisława Weingartena« (Porträt von Stanisław Weingarten), 1919, Bleistiftzeichnung, 42,5 × $29 \mathrm{~cm}$, Privatbesitz.

die Relationen vertauscht, sodass das Bild im Bild fast in den Vordergrund rücke. ${ }^{134}$ Darüber hinaus gehen die Bilder ineinander über. Die Zeichnungen auf dem Tisch vor Weingarten tragen in ihrer Position eine Dynamik, die sich in der Anordnung der Frauenkörper fortsetzt, als würden diese aus der Waagerechten in die Senkrechte aufsteigen. Dadurch, dass Weingarten beim Studium dieser Bilder festgehalten wird, wird der Rezeptionsprozess betont.

dass sie weder an Recht noch an Gott denken können und sie missbrauchen wollen. Susanna aber widersteht den Männern und wird dafür beinahe zum Tode verurteilt (Apokryphen Daniel 1). So vermischt Schulz erneut verschiedene Geschichten, die der mythischen Diana und der biblischen Susanna, und übersetzt diese in die Gegenwart. 


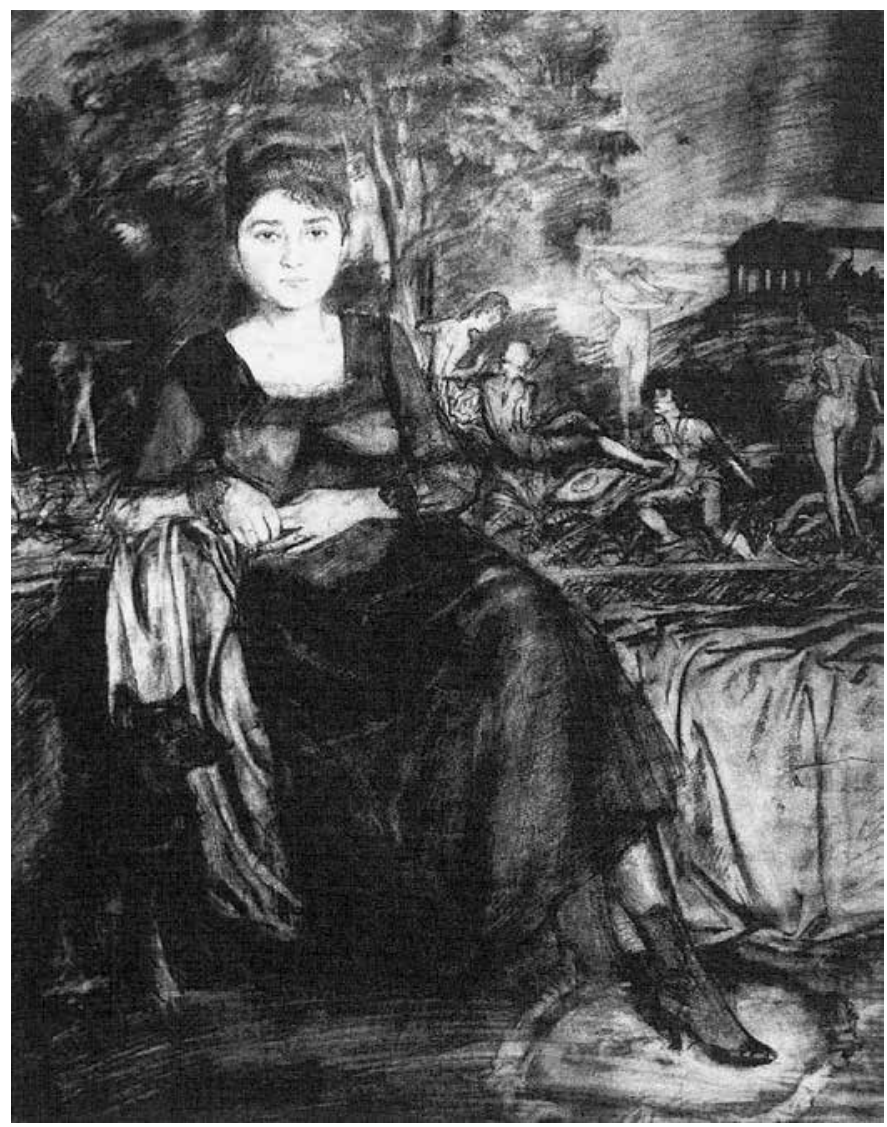

Abb. 9: Schulz, »Portret Marii Budrackiej« (Porträt von Maria Budracka), 1919, Bleistift- und Kreidezeichnung, $45 \times 30 \mathrm{~cm}$, Original verloren.

Eine ähnliche Illusion wird in dem »Portret Marii Budrackiej« erzeugt, wo ein Gemälde im Hintergrund über die gesamte Breite auf einem tuchbedeckten Podest steht. Das Bild zeigt erneut eine Szene der klassischen Malerei, in Anlehnung an Tizians »Venusfest « und Watteaus »Einschiffung nach Kythera». Ähnlich wie bei Watteau bewegt sich auch die Venusstatue auf dem Hintergrundbild als wäre sie lebendig. Dadurch, dass ein Bild im Bild vorhanden ist, auf dem ein »Marmorbild « beseelt agiert, wird die Grenze zwischen Kunstbild und Wirklichkeit doppelt gebrochen und eine dritte Ebene der Repräsentation eingeführt, die das Thema der "Xięga Bałwochwalcza» fortführt.

Als eine Verschiebung dieser Konstellation in die erste Ebene ist die Zeichnung »Autoportret z przyjacielem Stanisławem Weingartenem i dwiema 


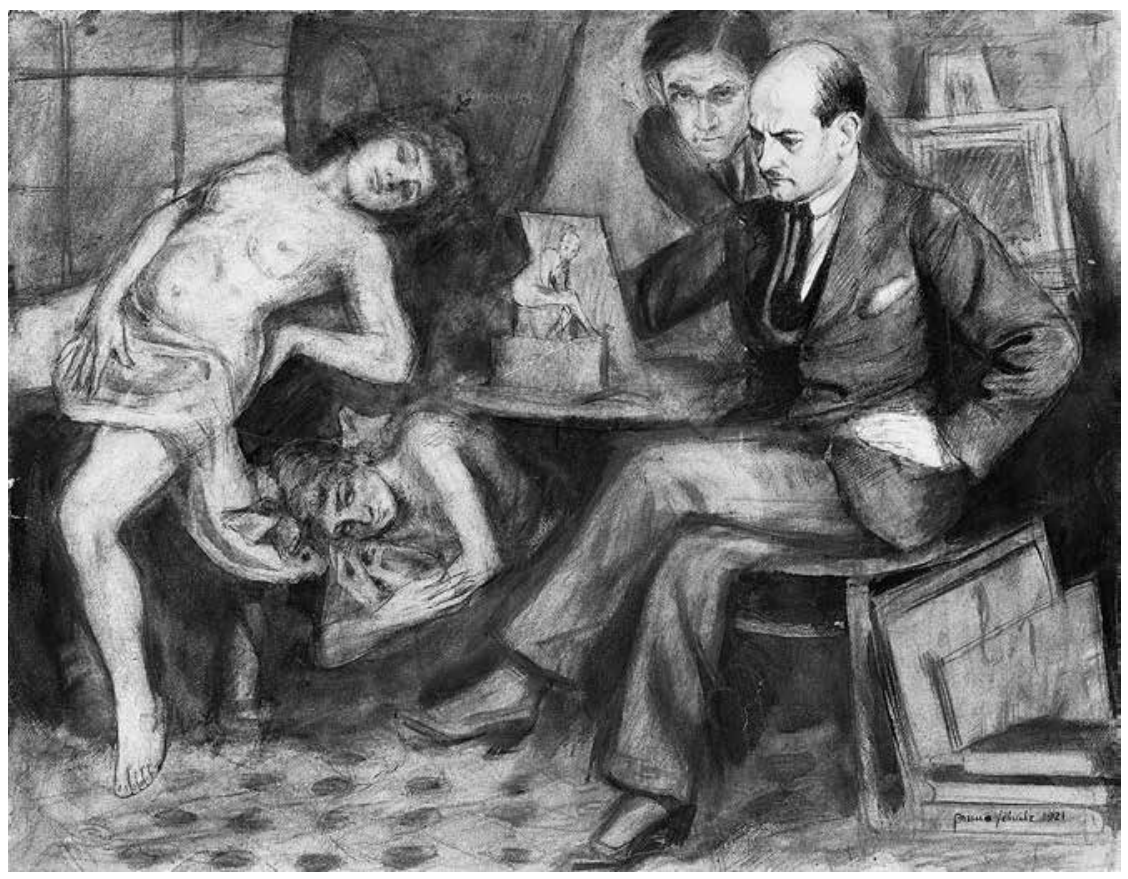

Abb. 10: Schulz, »Autoportret z przyjacielem Stanisławem Weingartenem i dwiema modelkami«; »W pracowni artysty« (Selbstporträt mit dem Freund Stanisław Weingarten und zwei Modellen; Im Atelier des Künstlers), 1921, Kreide- und Tuschezeichnung, $27 \times 33,5 \mathrm{~cm}$, JHI.

modelkami« lesbar. Nach Kato handelt es sich auch hier um ein »Bild im Bild «, denn dieselben Protagonisten der anderen Bilder treffen hier in einem Raum aufeinander. $\mathrm{Zu}$ sehen ist Weingarten, der sich ein Werk des ebenfalls abgebildeten Künstlers Schulz anschaut, der hinter Weingarten steht und intensiv aus dem Bild zum Betrachter hinausblickt. Die zwei nackten Frauen auf der linken Seite scheinen für ebenjenes Bild Modell gestanden zu haben, das Weingarten gerade betrachtet. Hinter dem Bild in Weingartens Hand versteckt sich noch eine kleine nackte Gestalt. Damit ist die Grenze zwischen der ersten und zweiten Ebene aufgehoben, das "Bild im Bild «, das Repräsentierte zweiter Ebene ist in der ersten anwesend und suggeriert damit auch die Möglichkeit, eine weitere Ebene zu überwinden und hinein in die außerbildliche Wirklichkeit eintreten zu können.

Weiter fällt die doppelte Lesestruktur auf. Wie alle anderen Weingartenporträts war auch dieses an Weingarten adressiert, weshalb der erwartungsvolle Blick des Künstlers auf den lebendigen Weingarten selbst gerichtet ist. Der vormals lebendige, reale Weingarten sieht sich somit selbst ein Bild be- 
trachten, dessen Bildinhalt unbekannt bleibt, wobei anzunehmen ist, dass dieser mit den Damen hinter dem Bild zu tun hat. Damit ist eine Spirale des Blickens in die Tiefe dargestellt. ${ }^{135}$ Gleichzeitig ahmt in diesem ersten, historischen Rezeptionsmoment, als Weingarten das Bild überreicht bekommt, die Wirklichkeit das Bild nach. Hier zeigt sich deutlich, wie bewusst und raffiniert Schulz mit der Überwindung der Ebenen spielt. Dass Kunst nicht nur Nachbild - Mimesis - sein muss, sondern auch Vorbild für eine Wirklichkeit sein kann, wird in diesem Moment sehr deutlich.

Die Kunst erweist sich als wirksam, als teilhabend an der Wirklichkeit und nicht im Rahmen des Bildes abgeschlossen. ${ }^{136}$ Nach Kato verschwindet die Grenze zwischen »der fiktiven Welt und der des Rezipienten als mise en abyme-Effekt, auch wenn er an keiner Stelle diesen Begriff expressis verbis erwähnt. « ${ }^{137}$ Sowohl die Zeichnungen als auch die Grafiken weisen eine Struktur auf, die den Prozess des Kunstschaffens, das Wirken der Bilder und die Beziehung von Kunst und Wirklichkeit reflektieren. In den Porträtzeichnungen wird der Rezeptionsprozess stärker betont, da sowohl der schaffende Künstler Schulz als auch der Rezipient Weingarten im Bild anwesend sind und den außerbildlichen Betrachter durch ihre Blickanordnung in die Komposition mit einbeziehen. Indem Schulz einerseits eine dreigliedrige Ebenenordnung der Repräsentation aufbaut und diese dann in eine Ebene führt, macht er die Bildgrenzen durchlässig. Damit weist Schulz auf die Möglichkeit von Bildern hin, zu wandern und sich zu wandeln, sich an neue Umgebungen anzupassen und neue Inhalte zu präsentieren. Belting fasst diese Eigenschaft von Bildern wie folgt:

»Bilder selber sind von Hause aus intermedial. Sie wandern zwischen den historischen Bildmedien weiter, die für sie erfunden werden. Die Bilder sind die Nomaden der Medien. Sie schlagen in jedem neuen Medium, das in der Geschichte der Bilder eingerichtet wurde, ihre Zelte auf, bevor sie in das nächste Medium weiterziehen. Es wäre ein Irrtum die Bilder mit diesem Medium zu verwechseln. Die Medien selber sind aber ein Archiv von toten Bildern, die wir erst in unserem Blick animieren. ${ }^{138}$

Das Animieren im Blick, die Wirkung des Bildes auf den Betrachter, die Interaktion zwischen Bildinhalt und Umgebung bildet ein wesentliches Kernmerkmal Schulzscher Metabilder.

135 Vgl. ebd., 157.

136 Vgl. Boehm, Wie Bilder Sinn erzeugen, 14.

137 »[...] światem fiktcyjnym a odbiorcą jako na efekt mise en abyme, choć w żadnym miejscu nie używał tego pojęcia expressis verbis. « Kato, Obraz i Księga, 157. (Hervh. A. K., Übers. A.J.)

138 Belting, Bild-Anthropologie, 214. 


\subsection{Zwischenfazit}

Auf der Ebene der »formalen Beschreibung « ${ }^{139}$ zeigen die Grafiken ein sadistisch-masochistisches Unterdrückungsverhältnis zwischen Mann und Frau. ${ }^{140}$ Da Schulz aber nicht nur den Masochismus zitiert, sondern auch dessen literarische Folie, ${ }^{141}$ den Roman Nenus im Pelz«, erweist sich eine psychopathologische Deutung schnell als unzulänglicher Ansatz. Der Roman beleuchtet auf mehreren Ebenen das Verhältnis zwischen Künstler und Kunstbild, zwischen Wirklichkeit und Mythologie und fügt zu diesem Zwecke mehrere und auch intermediale Ebenen der Repräsentation ein - ein Buch im Buch sowie Bilder im Buch. Darüber hinaus wird die Überschreitung der Ebene der Kunst in den Bereich des Lebens auch durch die Aufnahme des griechischen Pygmalion-Mythos thematisiert. ${ }^{142}$

In der »Xięga Bałwochwalcza« wird die mediale und künstlerische Selbstreflektion in vielerlei Hinsicht aufgegriffen und weitergeführt. Der dargestellte Künstler, als Selbstporträt auf allen Grafiken zu sehen, fungiert als eine Art Erzähler, dessen Perspektive für die Deutung des dargestellten Geschehens maßgeblich ist. ${ }^{143}$ In vielen Subtexten und Bildzitaten verbildlicht der Grafikzyklus literarisches Wissen und theoretische Überlegungen. Indem jene zentralen mythologischen und biblischen Motive aufgenommen wurden, die einen Umgang mit Bildern thematisieren - der Pygmalion-Mythos sowie das Bildverbot -, wird die bildtheoretische Reflexion auf eine höhere, allgemein bedeutende Ebene gehoben. Daher lässt sich mit Sicherheit konstatieren, dass

139 Panofsky entwickelt für die Kunstdeutung ein vierstufiges Interpertationsmodell, das zuerst das allgemein Gesehene, die »primäre« Sinnbeschreibung der dargestellten Formen erfasst. Hier ist die »Oberinstanz« die Region des Phänomensinns (Unterteilbar in Sach-Sinn und Ausdrucks-Sinn). Das Erkennen ist abhängig von der Übung. Anschließend sollen der Bedeutungssinn erfasst und der Dokumentsinn/Wesenssinn erarbeitet werden. Grundlage zur Deutung geben literarische Texte und Quellen, andere Bilder und Artefakte der Zeit, die Kenntnis zum weltanschaulichen Urverhalten etc. Zwar stellt Panofsky eine Systematik auf, deutet aber auch darauf hin, dass die Grenzen fließend verlaufen. Vgl. Panofsky, Erwin: Zum Problem der Beschreibung und Inhaltsdeutung von Werken der bildenden Kunst. In: Kaemmerling, Ekkehard (Hg.): Ikonographie und Ikonologie. Theorien, Entwicklung, Probleme 1979, 185-206.

140 Der Masochismus wiederum war ein modernes, avantgardistisches Motiv, mit dem Schulz auch in seinem öffentlichen Briefwechsel mit Gombrowicz ironisch gespielt hat. Vgl. Fuchs, Eduard: Die Frau in der Karikatur. München 1907, 29-31.

141 Als psychische Anomalie wurde der Masochismus erst wenige Jahre zuvor pathologisiert und bezieht sich im Namen auf Sacher-Masoch. Vgl. Krafft-Ebing, Richard: Psychopathia Sexualis. Mit besonderer Berücksichtigung der conträren Sexualempfindung. Eine medicinisch-gerichtliche Studie für Ärzte und Juristen. Stuttgart 1903, $101 \mathrm{f}$.

142 Vgl. Lachmann, Erzählte Phantastik, 339.

143 Vgl. Freise, Schulz zwischen Literatur, 116. 
die Grafiken keine "private Mythologie» darstellen, sondern die Rolle der Kunst mittels der Mythologien und Subtexte befragen. Während die Idolatrie eine Bildskepsis vermittelt, steht Pygmalion für eine Bildeuphorie. Diese Gegensätzlichkeit und Widersprüchlichkeit in der Haltung zu Bildern wird auf den Grafiken nicht aufgelöst. Beide Haltungen existieren parallel, so dass das wirkungsvolle und problematische Verhältnis von Kunst zum Künstler/Rezipienten in seiner Dilemma-Struktur dargestellt wird. Indem Schulz das Bild personifiziert und ihm einen Platz im Leben zuweist, deutet er an, dass die Bilder nicht beherrscht werden, nicht rein passive, verfügbare Gegenstände sind, sondern ein partielles Eigenleben haben. Daher lassen sich seine Undula-Grafiken wie auch die Zeichnungen als Metabilder lesen, die ihre eigene Verfasstheit reflektieren.

Dieses "Eigenleben " beschreibt Benjamin in seinem Kunstwerkaufsatz als die Einbettung in neue Zusammenhänge der Tradition. Am Beispiel der Venusstatue zeigt er auf, wie sie ihren Bedeutungszusammenhang in neuer Umgebung verändert. Während sie für die griechische Kultur als Darstellung der Göttin steht, wird sie im Mittelalter zum »unheilvollen Abgott«, in der Renaissance wiederum zum Symbol der reinen Schönheit. Allen drei Zeiten ist eine bestimmte Haltung gegenüber dem Kunstwerk eigen, der sich auch in einer bestimmten Form des Kultes äußert.

"Die Einzigkeit des Kunstwerks ist identisch mit seinem Eingebettetsein in den Zusammenhang der Tradition. Diese Tradition selber ist freilich etwas durchaus Lebendiges, etwas ganz außerordentlich Wandelbares. Eine antike Venusstatue etwa stand in einem durchaus andern Traditionszusammenhange bei den Griechen, die sie zum Gegenstand des Kultus machten, als bei den mittelalterlichen Kirchenvätern, die einen unheilvollen Abgott in ihr erblickten. Was aber beiden in gleicher Weise entgegentrat, war ihre Einzigkeit, mit einem andern Wort: ihre Aura. Die ursprünglichste Art der Einbettung des Kunstwerks in den Traditionszusammenhang fand ihren Ausdruck im Kult. Die ältesten Kunstwerke sind, wie wir wissen, im Dienst eines Rituals entstanden, zuerst eines magischen, dann eines religiösen. Es ist nun von entscheidender Bedeutung, daß diese auratische Daseinsweise des Kunstwerks niemals durchaus von seiner Ritualfunktion sich löst. Mit andern Worten: der einzigartige Wert des rechten Kunstwerks ist immer theologisch fundiert. Diese Fundierung mag so vermittelt sein wie sie will: sie ist auch noch in den profansten Formen des Schönheitsdienstes als säkularisiertes Ritual erkennbar. ${ }^{144}$

Nun verändert sich aber durch die Erfindung der Fotografie der Traditionszusammenhang. Technische Bildreproduktionen vermittelt das Kunstwerk dem Menschen und ändert so das Ritualverhalten des Rezipienten. Benjamin erkennt in der neuaufkommenden »l'art pour l'art«-Bewegung eine neuartige 
Theologie des Kunstwerks in Reaktion auf diese Erschütterungen. »Aus ihr ist dann weiterhin geradezu eine negative Theologie der Kunst hervorgegangen, in Gestalt der Idee einer reinen Kunst, die nicht nur jede soziale Funktion sondern auch jede Bestimmung durch einen gegenständlichen Vorwurf ablehnt. ${ }^{145}$ Eine "reine Kunst«, die auf nichts mehr referiert als auf sich selbst, bildet insofern neues Kultpotential, als dass sie sich scheinbar vom alten Traditionszusammenhang ablöst und selbst begründet. Weil nun der Rezipient nicht mehr nur Schönheitsdienst leisten muss, sondern nach Mitchell zum Verständnis ihrer Darstellungsformen auch ihre kunsttheoretischen Texte kennen musste, steigert sich der Kultdienst, weil er neue Grenzen zwischen der In- und Outgroup zieht, die er »believer« und "non-believer« nennt. ${ }^{146}$ Gleichzeitig hängen einst religiöse Kultbilder nun in den Museen und haben ihre ursprüngliche Funktion verloren. ${ }^{147}$

Diese Zusammenhänge zwischen einer kultischen Haltung des Künstlers und der Rezipienten gegenüber dem Kunstwerk werden auf einigen Grafiken reflektiert. Schulz nimmt sich und sein Umfeld aus der kultischen Haltung gegenüber dem Werk nicht aus. Einige der abgebildeten Personen sind Drohobyczer Freunde und im Hintergrund erkennt man Umrisse einer Stadt und von Gotteshäusern. Die Groteske sowie die Grafik-Technik Cliché-verre markieren diesen Schwellenzustand, in welchem die alte Ordnung zerfallen ist, die neue aber noch keine feste Normativität entwickelt hat. Dies zeigt sich auch in der Mehrfachbenennung einiger Grafiken, die einen verbürgten, eindeutigen Kontext wieder parodieren. Daher fehlt auch eine Ebene der Wertung oder Beurteilung des Verhaltens, weil der Deutungskontext instabil geworden ist.

Lassen sich die Grafiken dennoch - wie es Kitowska-Łysiak beispielweise tut - im Kontext eines der Romantik entlehnten Mann-Frau-Verhältnisses lesen? »Die wichtigste Analogie bleibt also die Verbindung der `Xięga Bałwochwalczaく mit der romantisch-modernistischen Idee der Frau als Männerfeind. ${ }^{148}$ Wohl vor allem deswegen nicht, weil Kitowaska-Łysiak explizit eine gesellschaftskritische Ebene ausschließt und die Bilder ihres Erachtens allein die Erfahrungen und Erlebnisse von Schulz illustrieren. ${ }^{149}$ Mitchell hat in seiner »Picture Theory« immer wieder Parallelen zwischen Kunsttheorie

145 »Als nämlich mit dem Aufkommen des ersten wahrhaft revolutionären Reproduktionsmittels der Photographie (gleichzeitig auch mit dem Anbruch des Sozialismus) die Kunst das Nahen der Krise spürt, die nach weiteren hundert Jahren unverkennbar geworden ist, reagierte sie auf das Kommende mit der Lehre vom l'art pour l'art, die eine Theologie der Kunst ist. "Ebd.

146 Vgl. Mitchell, Picture Theory, 227.

147 Vgl. Belting, Das echte Bild, $35 \mathrm{f}$.

148 »Najistotniejszą analogią pozostaje więc związek Xięgi Bałwochwalczej z romantycznomodernistyczną koncepcją kobiety wrogiej mężczyźnie."Kitowska-Łysiak, Bruno Schulz, 147. (Übers. A. J.)

149 Vgl. ebd., 148. 
und sozialer Frage gesucht und dargestellt, wie sich gesellschaftliche Machtverhältnisse auch in der Kunstproduktion und -interpretation niederschlagen. So werden Frauen häufig mit Bildern assoziiert; als passive, allein optisch reizvolle Objekte. Männer hingegen treten als aktive Künstler-Demiurgen auf, die als handelnde Subjekte den Objekten ihrer Umgebung Bedeutung verleihen. ${ }^{150}$ Schließt man den Masochismus als Bedeutungsinhalt für die Grafiken aus, so sieht man Frauen, die aus ihrem »Kunstobjektsein«-Zustand ausbrechen und selbst partiell zum Subjekt werden. So ließe sich der zitierte Pygmalion-Mythos auch gesellschaftskritisch lesen. Der Grundmythos des männlichen Künstler-Demiurgen, der eine Frau schafft, indem er ein Kunstobjekt allein oder mit Hilfe einer Gottesfigur belebt, bleibt einerseits erhalten, andererseits wird der Status des Künstlers degradiert. ${ }^{151}$

»Die Figur des erniedrigten Autors der Xięga-Grafiken wird zu einer Parodie älterer Konzepte des Künstler-Demiurgen. Der Autor kapituliert gegenüber seinem eigenen Werk. Der moderne Schöpfermythos wird auf diese Weise kompromittiert. « ${ }^{152}$

In einer bildtheoretischen Deutung weist Schulz auf das gekippte Machtverhältnis hin. Das geschaffene Bild übt anschließend auf den Künstler und Betrachter eigenständige Macht aus. Damit markiert Schulz den Rezeptionsprozess, beziehungsweise jene unmittelbare Wirkung, die ein Bild auf einen Betrachter hat. ${ }^{153}$ In der Terminologie von Austins "Sprechakttheorie« betont Schulz die performative Kraft von Bildern, ihr Wirken in der Wirklichkeit, die empirisch nicht quantifizierbare $» P e r l o k u t i o n « .{ }^{154}$ Die Distanz, Er-

150 Vgl. Mitchell, Picture Theory, 162-164.

151 Nach Udo Kultermann wird das Verhältnis von Bildkunst und Wirklichkeit in Ovids Version sowie in den Vergleichsmythologien immer in einer Dreier- oder Zweierkonstellation zwischen männlichem Künstler, weiblichem Kunstwerk und Gott verhandelt. Dieser Grundmythos sei auch in der finnischen Mythologie sowie mit der Schaffung von Eva aus einem Knochen im Alten Testament, aber auch im Pandorra-Mythos zu finden. Manchmal seien Künstler und Gott dieselbe Person, wie der finnische Götterschmied Ilmarinen oder der jüdische Gott in der Genesis. Vgl. Kultermann, Kleine Geschichte der Kunsttheorie, 1-15.

152 Kulig-Janarek, Erotyka - groteska, 167. »Postać zdeheroizowanego autora z grafik Xięgi staje się parodią dawniejszych koncepcji artysty-demiurga. Autor wydaje się kapitulować wobec własnego tworu. Modernistyczny mit kreatora poddawany jest w ten sposób kompromitacji.« (Übers. A. J.)

153 Kato weist in diesem Zusammenhang auch noch auf die Bordüre um die Zeichnung »Autoportret z przyjacielem Stanisławem Weingartenem i dwiema modelkami« (Abb. 10) hin. Auch der Rahmen trägt mit den abgebildeten nackten Frauenkörpern und den Männerköpfen einen Bildinhalt. Dies vergleicht sie mit Derridas "Parergon«-Theorie aus seinem Buch »Wahrheit in der Malerei.«Vgl. Kato, Obraz i Księga, 157. Leider ist der gemalte Rahmen in der abgedruckten Bildversion nicht enthalten.

154 Vgl. Austin, John L.: Zur Theorie der Sprechakte. Stuttgart 1972. An dieser Stelle ist auf die komplexe Theorie der performativen Intertextualität und -pikturalität zu verweisen, 
habenheit, Fremdheit und Gewalt, die von den Grafikfrauen ausgeht, kann damit sowohl als Projektion der Männer auf die "Bildfrau« als auch als eigenständige Wirkung der »Bildfrauen" gelesen werden. Mitchell weist in seiner "Picture Theory« darauf hin, dass Bilder den Betrachter immer herausfordern. "Power" ist eine variable Beziehungsgröße, die nicht einer Sache oder Person eigen ist, sondern zwischen Subjekt und Objekt oder zwischen zwei Subjekten situationsabhängig hergestellt wird. ${ }^{155}$

»But we also know that pictures have always been [...] also [...] idols, fetishes, magic mirrors - objects that seem not only to have a presence, but a >life of their own, talking and looking back at us. That is why the use of metapictures as instruments in the understanding of pictures seems inevitably to call into question the self-understanding of the observer. This destabilizing of identity is to some extent a phenomenological issue, a transaction between pictures and observers activated by the internal structural effects of multistability: the shifting of figure and ground, the switching of aspects, the display of pictorial paradox and forms of nonsense. We might call that rwildness of the metapicture, its resistance to domestication, and its associations with primitivism, savagery, and animal behavior. ${ }^{156}$

Indem Schulz seinen Grafikzyklus und seine Porträts durch Bild- und Textzitate, Selbstrefenzialität, Bild-in-Bild Motive, durch das Zitat des PygmalionMythos wie des biblischen Bildverbots, durch dargestellte Bücher und widersprüchliche Titel prägt, markiert er sie als Metabilder, die ihre eigene Bildlichkeit reflektieren und ihre Theorie darstellen. Der fehlende programmatische »Text« zur Bildkunst - das Pendant zu »Mityzacja rzeczywistości« - findet sich in der Bildkunst selbst dargestellt. Die Grafiken verbildlichen gleichzeitig Poesie und Theorie. Damit bilden sie eine Brücke zwischen der traditionellen und der modernen Malerei.

die Dorothee Gelhard in ihrem Buch »Zwischen Sagen und Zeigen - sakrale Repräsentationen « entwickelt. Hinter dieser Theorie verbirgt sich eine besondere Art der Sprachund Bildbetrachtung, die über die Text- beziehungsweise Bildebene hinausreicht. Diese entwirft Gelhard anhand jüdischer Autoren insbesondere der Zwischenkriegszeit und zeigt auf, wie ihr spezifischer Umgang mit der jüdischen Tradition in ihrem Werk zu deuten ist. Gelhard konfrontiert jüdische Bildkunst mit dem Bilderdenken des Midrasch, dessen Technik es sei »eines im Lichte des anderen zu sehen/zu zeigen.« Anhand Chagalls Bildern im jüdischen Theater in Moskau und anderswo zeigt sie, auf welche Weise Chagall Bedeutungen erwirkt, indem er bestimmte Bildsymbole miteinander kombiniert, sodass wieder eine umfangreiche Exegese der Gesamtkomposition nötig ist, um durch die Interpikturalität die Narration zu verstehen. Vgl. Gelhard, Dorothee: Zwischen Sagen und Zeigen - sakrale Repräsentationen. München im Druck.

155 Mitchell, Picture Theory, 324.

156 Ebd., 57. 



\title{
4. Die Welt der Kataloge - "Ulica Krokodyli« und »Księga»
}

\begin{abstract}
"Sind Bilder nicht bloß Objekte unseres Wissens, sondern auch Gefäße ihres eigenen Wissens? Ist es das, wonach wir suchen, wenn wir, in der Hoffnung, sie könnten uns belehren, uns etwas offenbaren, eine Photographie oder ein Kunstwerk betrachten? « ${ }^{1}$
\end{abstract}

Auch in seinen Erzählungen setzt sich Schulz intensiv mit Bildern auseinander und hier wird der Bezug zu modernen Bildformaten sehr viel deutlicher als in den Grafiken. Um Werbebilder geht es in den zwei Erzählungen »Ulica Krokodyli« (Die Krokodilstraße) und »Księga» (Das Buch). Darin werden an zentraler Stelle moderne Bilderzeugnisse wie die Illustrierten, die Fotografie und die Werbeanzeige untersucht und dargestellt. Zu Werbebildern zählen hier alle Bildformate, die zum Kauf einer Ware, eines Magazins, eines Theatertickets etc. anregen sollen, aber auch solche, die ein bestimmtes Schönheits-, Prominenz- oder Modeideal vermitteln und in Illustrierten, auf Plakaten, in Magazinen etc. abgedruckt sind.

Dabei offenbart sich im Vergleich der beiden Erzählungen in ihrem Umgang mit sehr ähnlichen Bildmedien ein spannender Kontrast. Während in »Ulica Krokodyli« eine verrufene, billige, städtische Schwarz-Weiß-Welt beschrieben und erkundet wird, dominiert in der Erzählung »Księga" eine magische, heilige Atmosphäre. So ordnet Władysław Panas die »Ulica Krokodyli« der kabbalistischen »sitra achra«, der »anderen Seite« zu, in der die Sünde herrsche, ${ }^{2}$ während er insbesondere die Erzählungen »Księga« und »Genialna epoka « im Kontext eines messianischen Restitutionsprozesses und kabbalistischen »Tikkuns" versteht. ${ }^{3}$ Wie ist dieser Widerspruch zu erklären, wenn die Beobachtung richtig ist, dass es sich in beiden Erzählungen um eine Auseinandersetzung mit Werbebildern handelt?

1 Mitchell, William: Bildtheorie. Frankfurt a. M. 2008, 399.

2 In Panas' Untersuchung der kabbalistischen Motive steht diese Erzählung für die gottlose, andere Seite, die »sitra achra.« »Bez wątpienia - to obraz zła, ১drugiej strony`, ১lewej strony«, tak, jak za sklepem z ubraniami skrywał się drugi sklep - magazyn rozpusty. [...] Na Ulicy Krokodyli zło reprezentowane jest przede wszystkim poprzez seks.«Panas, Księga blasku, $135 \mathrm{f}$. „Ohne jeden Zweifel ist dies ein Bild des Bösen, der sanderen Seiteく, der `linken Seite`, so, wie sich hinter dem Modegeschäft ein anderes Geschäft verbirgt ein Bordell. [...] Auf der Krokodilstraße ist das Böse vor allem durch den Sex repräsentiert." (Übers. A. J.)

3 Vgl. ebd., 221. 
Um diese Frage zu beantworten, wird in Anknüpfung an die Ergebnisse aus der Untersuchung der Metabilder erneut nach theoriegebenden Spuren gesucht, die die unterschiedliche Darstellung und Interpretation von sehr ähnlichen Bildmedien begründen. Auch hier stellt sich die Frage nach der Beziehung von Bild zur dargestellten Wirklichkeit, nach unterschiedlichen Ebenen der Repräsentation, nach der Kommunikationsebene zwischen Bildern und Rezipienten und vor allem nach dem Verhältnis zwischen Bildern und Sprache.

Um die zu Schulz' Zeit aktuellen Debatten und Diskurse zum Werbebild und seiner Funktion in der Gesellschaft zu beobachten, eignen sich wiederum Benjamins Forschungen zur Moderne. Dieser fokussiert stark auf die verwandelte Wiederkehr des »Ältesten, Gewesensten, Gewohntesten « ${ }^{4}$ im neuen Format und erkennt in der Werbe- und Modeindustrie, in ihren Bildern und der Architektur mythische Anleihen. Erwin Koppen, der die Anfänge der literarischen Auseinandersetzung mit der Fotografie untersucht, bemerkt drei Dominanten in den untersuchten Texten, »die man unter die Stichworte Magie, Erotik und Komik subsumieren könnte. $\aleph^{5}$ Vor allem knüpfe die Auseinandersetzung an die magische Bildgläubigkeit der frühen Menschheit an, die sich unter anderem in den Aufsätzen Benjamins, Sontags und Barthes zeige. $^{6}$

Als erstes soll die Erzählung "Ulica Krokodyli« untersucht werden. Neben den "Magazinen" (magazyny) stellen Frauen ein zentrales Motiv dar. Beide werden in Beziehung zu Benjamins »dialektischen Bildern« gebracht. Das zweite Unterkapitel befasst sich mit den spezifischen Werbegrafiken der "Księga«, des »mythischen Urbuchrests«, das der kindliche Erzähler auffindet. Darin steht die Reklame der Anna Csillag, die auch außerhalb der Realität der Erzählung existiert, im Mittelpunkt. Im Anschluss wird erneut ein Bogen zurück zu den Grafiken der »Xięga Bałwochwalcza" geschlagen, der nicht nur hinsichtlich des Gleichklangs mit der Erzählung "Księga« sinnvoll erscheint, sondern auch hinsichtlich der Motive, Thematik und Darstellungsweise.

4 Benjamin, Das Passagen-Werk, 112.

5 Koppen, Erwin: Über einige Beziehungen zwischen Photographie und Literatur. In: Weisstein (Hg.): Literatur und bildende Kunst, 231-245, hier 235.

6 Vgl. ebd. 


\title{
4.1 Die Illustrierten und ihre Wirkung - »Ulica Krokodyli«
}

\begin{abstract}
"Dieses Viertel ist deshalb so fatal, weil hier nichts zustande kommt und nichts sein Definitivum erreicht, jede angefangene Bewegung bleibt in der Luft hängen, alle Gesten erschöpfen sich vorzeitig und können den toten Punkt nicht überwinden. ${ }^{7}$
\end{abstract}

»Ulica Krokodyli $\aleph^{8}$ ist die zwölfte Erzählung aus dem Band »Sklepy cynamonowe« (Die Zimtläden) und hebt sich sowohl sprachlich als auch inhaltlich eklatant von den anderen Erzählungen ab. Insbesondere im Unterschied zur vorangehenden Titelerzählung "Sklepy cynamonowe « ${ }^{9}$ prägen hier nicht pralle Farben und üppige Vegetation die Ansicht der Umgebung, sondern Billigkeit, differenzloses Grau und nüchterne Formen. Die Darstellung der Krokodilstraße steht damit im starken Kontrast zu den bunten, vereinnahmenden und fantasievollen Schilderungen der Gassen um die Zimtläden, welche sich in derselben Stadt befinden. Während letztere geheimnisumwittert und offen für Verwandlungen sind, dominiert in der Krokodilstraße die Atmosphäre der Abgründigkeit, Eindeutigkeit und billigen Erotik.

Eingeleitet wird die Erzählung mit der Beschreibung einer alten Stadtkarte, die großzügig und in barocken Linien die Häuser und Gassen entlang des Flusses Tyśmiennica aus der Vogelperspektive nachzeichnet. Dabei betont der Erzähler, dass es sich um eine alte barocke Karte »in folio« handelt, deren Beschriftung in edler Antiqua ausgeführt wurde. Die auf der Karte beschriebene Altstadt erhebt sich in dreidimensionaler Ansicht aus dem Papier; an architektonischen Detailbeschreibungen wie Architraven, Archivolten und Pilastern wird nicht gespart. ${ }^{10}$ An der Stelle der Krokodilstraße jedoch leuchtet auf der Karte ein blinder Fleck - jenes leere Weiß, »mit dem man auf geographischen Karten üblicherweise die Umgebung der Pole kennzeichnet, der Länder, die noch unerforscht sind oder deren Existenz noch nicht gesichert ist. " $^{11}$ Dies ist die Einleitung in die genauere Ergründung der Krokodilstraße und

7 Schulz, Die Zimtläden, 112. »[F]atalnością tej dzielnicy jest, że nic w niej nie dochodzi do skutku, nic nie odbiega od swego definitivum, wszystkie ruchy rozpoczęte zawisają w powietrzu, wszystkie gesty wyczerpują się przedwcześnie i nie mogą przekroczyć pewnego martwego punktu.« Ders., Sklepy cynamonowe, 99.

8 Der Name dieser Straße wird von Władysław Panas biblisch gelesen. Er deutet die Benennung nach dem Krokodil als Symbol für das ägyptische Exil, also die Zeit der Sklaverei. Vgl. Panas, Księga blasku, $167 \mathrm{f}$.

9 Schulz, Sklepy cynamonowe, 82-91.

10 Vgl. ebd., $92 \mathrm{f}$.

11 Ders., Die Zimtläden, 101. »jaką na kartach geograficznych zwykło się oznaczać okolice podbiegunowe, krainy niezbadane i niepewnej egzystencji.« Ders., Sklepy cynamonowe, 92. 
ihres Charakters. Dabei ist auffällig, dass dieses Viertel des Kommerz und der Illustrierten gerade über die Beschreibung einer alten Karte eröffnet wird, also eines Bildformats in der Erzählung.

Verglichen mit der »Bild im Bild«-Motivik der Grafiken und Porträtzeichnungen setzt die Erzählung die intermediale Verflechtung fort. Nach Stoichiţă steht eine Landkarte in der Kunstgeschichte für das "wissenschaftlich betriebene panoramatische $\$ Sehen $\triangleleft{ }^{12}$ Sie ist eine Mischform aus Bild und Schrift, weil sie mit einer Legende versehen ist und samt den vielen Beschriftungen "gelesen« werden muss. Tritt sie als Bild im Bild auf, so überträgt sie die Bedeutung der intellektuellen Erfassung einer Ansicht. Als berühmtes Beispiel für Karten in der Malerei führt Stoichiţă unter anderem Vermeers "Atelier « ${ }^{13}$ an, welches wiederum so deutlich wie kaum ein anderes Bild der Malerei für einen metaartistischen Diskurs steht, da auch noch der malende Künstler, das Modell, sowie die Staffelei samt Bild zu sehen sind.

Wenn die Karte für eine intellektuelle Wahrnehmung im Gegensatz zur sinnlichen einer Landschaft steht, ${ }^{14}$ so folgt daraus, dass für die Krokodilstraße noch keine adäquate Form der Kartografierung gefunden wurde, diese also noch nicht kritisch erfasst worden ist. Der Erzähler nimmt ebendies in Angriff. Die Untersuchungen des neuen Viertels um die Krokodilstraße lassen sich als Metapher für die intellektuelle Erfassung der neuen Bildmedien samt ihres Einflusses auf die Wirklichkeitswahrnehmung lesen.

Die Beschreibung des Viertels erfolgt aus einer distanzierten Perspektive. Anders als in den vorangehenden Erzählungen tritt der Erzähler selbst nicht als Ich-Erzähler ${ }^{15}$ auf, sondern das "Ich « ist durch ein unpersönliches "man" oder "wir» ersetzt: "Wchodziło się « ${ }^{16}$ (Man betrat), »Nikt nas nie zatrzymuje « ${ }^{17}$ (Niemand hält uns auf) und »Ale dalecy jesteśmy od chęci demaskowania widowiska « ${ }^{18}$ (Aber wir sind weit davon entfernt, dieses Schauspiel entlarven zu wollen). ${ }^{19}$ Dabei bedient sich der Erzähler einer ähnlichen Wortwahl wie in den Positivismus-Kritiken »Wędrówki sceptyka«, »Powstają legendy« sowie »Mityzacja rzeczywistości. ${ }^{20}$

12 Stoichiţă, Das selbstbewußte Bild, 203.

13 Vgl. Broos, Ben/Wheelock, Arthur K. (Hg.): Vermeer. Das Gesamtwerk. Stuttgart 1995, 68.

14 Vgl. Stoichiţă, Das selbstbewußte Bild, 203.

15 Karin Dulaimi ist der Auffassung, dass es immer nur einen Ich-Erzähler, aber keine einheitliche Perspektive gebe. Das Ich, das wahrnimmt und das, das erzählt, ist nicht immer eine Person. Vgl. Dulaimi, Karin: Der Mythosbegriff im Werk von Bruno Schulz. Dissertationsschrift vorgelegt in München 1976, 153.

16 Schulz, Sklepy cynamonowe, 94.

17 Ebd., 96.

18 Ebd., 97.

19 Ders., Die Zimtläden, 107.

20 Siehe dazu in vorliegender Arbeit das Unterkapitel 2.2 »Trümmerfeld der Moderne.« 
»Es war ein Bezirk des Handels und der Industrie, dessen Charakter nüchterner Nützlichkeit durch schrille Töne hervorgehoben wurde. Der Geist der Zeit, der Mechanismus der Wirtschaft hatte auch vor unserer Stadt nicht haltgemacht und bereits seine gierigen Wurzeln in einem Abschnitt der Peripherie geschlagen, wo er ein parasitäres Viertel entstehen ließ.« ${ }^{21}$

So erscheint die »Ulica Krokodyli« als literarische Verkörperung jener Welt, die Schulz zum Werte- und Anschauungskanon der an der Praxis orientierten, funktionalistischen Moderne zählt. Deutlich formuliert der Erzähler seine Distanz zum Geschehen und seine Skepsis gegenüber den Formen des Kommerzialismus (»formy komercjalizmu«) und den Schöpfungen des Pseudoamerikanismus (»pseudoamerykanizm« ${ }^{22}$ ). Die nüchternen, nützlichen Formen, die als fremd und stumpfsinnig charakterisiert werden, erweisen sich bei genauerem Hinsehen als literarische Übersetzungen illustrierter Prospekte, worauf der Erzähler an mehreren Stellen hinweist.

»Es ist ein grauer Tag, wie immer in der Gegend, und die ganze Szenerie scheint in manchen Momenten ein Photo aus einer Illustrierten zu sein, so grau und so plan sind die Häuser, die Menschen und die Wagen. Diese Wirklichkeit ist dünn wie Papier, und jeder Spalt verrät, daß sie bloß imitiert ist. « ${ }^{23}$

Die Bilder aus Katalogen, Illustrierten und Reklamen dienen dieser Erzählung als Grundlage, um die von ihnen hervorgerufene Wirklichkeit zu literarischem Ausdruck zu bringen. Daher ist die Darstellung dieser Straße keinesfalls als Parodie auf das Drohobyczer Einkaufsstraßenpendant Ulica Stryjska ${ }^{24}$ zu verstehen ist, wie beispielsweise Ficowski es vorschlägt.

"Es ist unschwer sich zu vergewissern, wenn man durch Drohobycz wandert, dass die Schulz'sche Krokodilstraße, dieses 'parasitäre Viertel - eine mythologische Umsetzung der Stryjska Straße darstellt, die kitschige städtische City mit grotesken großstädtischen Ambitionen. ${ }^{25}$

21 Ebd., $101 \mathrm{f}$. »Był to dystrykt przemysłowo-handlowy z podkreślonym jaskrawo charakterem trzeźwej użytkowości. Duch czasu, mechanizm ekonomiki, nie oszczędził i naszego miasta i zapuścił korzenie na skrawku jego peryferii, gdzie rozwinął się w pasożytniczą dzielnicę.« Schulz, Sklepy cynamonowe, 93.

22 Ebd.

23 Ders., Die Zimtläden, 107. »Jest to szary dzień, jak zawsze w tej okolicy, i cała sceneria wydaje się chwilami fotografią z ilustrowanej gazety, tak szare, tak płaskie są domy, ludzie i pojazdy. Ta rzeczywistość jest cienka jak papier i wszystkimi szparami zdradza swą imitatywność.« Ders., Sklepy cynamonowe, 96.

24 Auch im »Słownik Schulzowski« werden die literarische und die historische Straße miteinander identifiziert. Vgl. Stryjska. In: Bolecki, Słownik schulzowski, 358-360.

25 »Nietrudno też upewnić się, krążąc po Drohobyczu, że Schulzowska ulica Krokodyli, owa spasożytnicza dzielnica - to mitologiczna transpozycja ulicy Stryjskiej, tandetna miasteczkowa city o groteskowych wielkomiejskich pretensjach." Ficowski, Regiony wielkiej herezji, 68. (Übers. A. J.) 
Es handelt sich vielmehr um eine grundlegende Erforschung des wirkenden Scheins, der durch die Werbebilder auf dieses fiktive Viertel des Konsums gelegt wird. Dieser Schein erweist sich nicht als billiger Zauber, der enthüllt und abgelegt werden kann, sondern als wesentliche Eigenschaft, die zu dieser Welt und ihren kulturellen Erzeugnissen gehört. Damit stellt Schulz einen Umschichtungsprozess dar. ${ }^{26}$ Die Dominanz der Werbebilder verursacht einen Bedeutungstransfer, der von den Darstellungsmitteln - sowohl hinsichtlich der Form als auch des Inhalts - auf die dargestellte Wirklichkeit übergeht. Konkret macht der Erzähler diese Wandlungsprozesse an den Frauen, der Architektur sowie den Läden der Stadt sichtbar.

Um diese These zu untersuchen, sollen im Folgenden Benjamins Untersuchungen hinsichtlich der Reklame und der Warenwirtschaft punktuell dargelegt werden. Zentraler Begriff für Benjamins Hermeneutik ist das »dialektische Bild. ${ }^{27}$ Dabei handelt es sich nicht um ein Bild im Sinne eines sinnlich erfassbaren Gegenstands oder eines Gemäldes, sondern um eine anschauliche Denkkonstellation. ${ }^{28}$ Dialektische Bilder fallen dem Betrachter zu, »sie blitzen

26 »Ende der zwanziger Jahre veränderte sich die Aufmachung der Illustrierten. Im Zentrum stand jetzt das fotografische Bild, das zum wichtigsten Faktor der Nachrichtendienste geworden war. Die neue Form der Fotoreportage hielt Einzug: Fotografien waren nicht mehr nur illustrierendes Beiwerk, sondern wurden selbst zu Nachrichten. Das hieß aber auch, dass nicht die Wichtigkeit eines Stoffes über die Auswahl und Annahme von Bildern entschied, sondern allein der Reiz des Bildes. Nicht der Wunsch nach Wissen, sondern die Schaulust wurde bedient. Die gesamte Branche der Illustrierten reagierte damit auf veränderte Bedürfnisse: Das Publikum war durch den Film für fotografische Bilder sensibilisiert worden.« Dewitz, Bodo v. (Hg.): Kiosk. Eine Geschichte der Fotoreportage. 1839-1973. Göttingen 2001, 112.

27 Detlev Schöttker weist auf die unterschiedlichen Gebrauchsformen des Begriffs »Bild « in Benjamins Philosophie hin. Neben den reellen Bildern untersuche er innere Bilder und forme Gedächtnisbilder (dialektische Bilder) der Geschichte. "Sein Interesse an einem umfassenden Bildbegriff basiert auf zwei Motiven: Zum einen wollte er seit seinem Aufsatz Über das Programm der kommenden Philosophie (1918) eine Theorie der Erfahrung entwickeln, in der innere Bilder eine zentrale Rolle spielen. Zum anderen hatten reale Bilder durch ihre massenhafte Reproduktion in Photographie, Film und Zeitschriften seit den Zwanziger Jahren großen Einfluss auf die Erfahrungsbildung, so daß sie eine Herausforderung für die Kulturtheorie darstellten, der Benjamin seine Theorie der Erfahrung zuordnen wollte. [...] Die kategoriale Grundlage für die Theorie der Geschichtsaneignung liefert der Begriff des `dialektischen Bildes`.» Es gehe ihm darum Geschichte nicht als Vorgang zu begreifen, sondern als Gedächtnisbild. Die lässt sich nicht in einem Zusammenhang erzählen, sondern sie zerfalle in Bilder.« Schöttker, Detlev: Einführung: Benjamins Bilderwelten. Objekte, Theorien, Wirkungen. In: Ders. (Hg.): Schrift, Bilder, Denken, 10-31, hier 10; 25.

28 "Mit seiner Theorie der Lesbarkeit und mit seiner Definition der dialektischen Bilder als gelesene betrachtet Benjamin Bilder nicht unter dem Aspekt der Repräsentation, sondern dem der Schrift: gleichsam als >chiffrierte Verräumlichung` oder aber als Konstellation.« Weigel, Sigrid: Entstellte Ähnlichkeit. Walter Benjamins theoretische Schreibweise. Frankfurt a. M. 1997, 52. 
auf. ${ }^{29}$ Das heißt, sie unterliegen keinem willkürlichen Konstruktionscharakter, sondern sie treten an einem Gegenstand in einer bestimmten Gegenwart zu Tage. ${ }^{30}$ Wird ein dialektisches Bild erkannt, so kann nach Benjamin ein Gedanke aus dem Traumbereich heraus in den Wachbereich überführt werden. ${ }^{31}$ Das heißt, dass ein meist historischer Gegenstand in seiner wirkenden Beziehung zum aktuellen »Normalen" verstanden wird und damit einerseits das Normale als Gewordenes kenntlich macht, andererseits auch selbst lesbar wird. ${ }^{32}$ Daher besteht auch eine Beziehung zwischen vermeintlich Vergangenem und dem Aktuellen.

Ausgangspunkt für das Auffinden dialektischer Bilder sind deshalb häufig - insbesondere im »Passagenwerk« - konkrete Gegenstände der sichtbaren Welt. Anhand verschiedener Motivanalysen versucht Benjamin Ansätze für eine Epochendeutung zu finden. ${ }^{33}$ So zeigt er am Beispiel des Phänomens der Pariser Passagen, die im 19. Jahrhundert entstanden und untergegangen sind, auf, welche Ideen hinter der Architektur stehen und welche neuen Vorstellungen sie mitunter auch erzeugt haben.

29 Blitzen steht dabei für eine konkrete Erfahrung am Gegenstand, die einen Menschen plötzlich überkommt. Vgl. Kaulen (1987): Rettung und Destruktion, S. 161. Nach LinkHeer grenzt es sich von Bergsons »durée» ab. "Aber anders Bergson, der die fließende >durée` im Auge hat, betont den Umschlag, das Blitzhafte, den Chock, die auch für seine Theorie des Erwachens konstitutiv sind, in der die Traumdimension mit dem sAugenblick der Gefahr` integriert ist.« Link-Heer, Ursula: Zum Bilde Prousts. In: Lindner (Hg.): Benjamin-Handbuch, 507-521, hier 517.

30 Um der Gefahr einer ideologischen Sicht auf die Gegenstände der Kultur oder der Geschichte zu entgehen, entwickelt Benjamin nicht nur seine neue Methodik, sondern auch eine neue Terminologie. Dies wird besonders in seinem Kunstwerkaufsatz deutlich: »Die im folgenden neu in die Kunsttheorie eingeführten Begriffe unterscheiden sich von anderen dadurch, daß sie für die Zwecke des Faschismus vollkommen unbrauchbar sind. Dagegen sind sie zur Formulierung revolutionärer Forderungen in der Kunstpolitik brauchbar." Benjamin, Das Kunstwerk, 435. (Hervorh. W. B.)

31 Diese Form des Denkens sucht nach der Unterbrechung, was bedeutet, dass man von den vorgegebenen Pfaden des Traums und der alten Erklärmuster abweicht und den Sachverhalt von einem nichtideologischen Standpunkt aus sieht. Vgl. Kaulen, Rettung und Destruktion, 19.

32 Weil dialektische Bilder aufblitzen, das heißt, nur in einem bestimmten Moment lesbar sind, müssen sie prompt "gerettet« werden, "[d]enn es ist ein unwiederbringliches Bild der Vergangenheit, das mit jeder Gegenwart zu verschwinden droht, die sich nicht als in ihm gemeint erkannte.« Benjamin, Über den Begriff der Geschichte, 695.

33 Mit dem Gelingen seines »Passagen-Werks« sah er nicht weniger erreicht, als »jene Gebiete urbar zu machen, auf denen bisher nur der Wahnsinn wuchert. Vordringen mit der geschliffenen Axt der Vernunft und ohne rechts noch links zu sehen, um nicht dem Grauen anheimzufallen, das aus der Tiefe des Urwalds lockt. Aller Boden mußte einmal von der Vernunft urbar gemacht, vom Gestrüpp des Wahns und des Mythos gereinigt werden. Dies soll für den des 19ten Jahrhunderts hier geleistet werden. « Ders., Das Passagen-Werk, $570 \mathrm{f}$. 
Als architektonische Form stehen sie für die Wandlung des Häuserbaus durch die Erfindung der Stahl- und Glasingenieurstechnik. Sie verbinden nicht nur den Wohn- mit dem Wirtschaftsraum, sondern heben auch die Trennung zwischen Innen und Außen auf: »Passagen: Häuser, Gänge, die keine Außenseite haben. Wie der Traum. ${ }^{34}$ Das heißt, dass These und Antithese im Gegenstand selbst vorzufinden und ineinander verschlungen sind; den Passagen ist kein antithetisches Pendant gegenübergestellt, sie sind in sich selbst dialektisch. In den Passagen als Struktur offenbaren sich die Spannungsverhältnisse und Bedeutungspole, die das dialektische Bild ausmachen. In ihnen treten das Neueste und das Alte (das »üngstvergangene ${ }^{35}$ ) hinsichtlich der Architektur und Ingenieurskonstruktion, der wirtschaftlichen und privaten Nutzung, des Waren- und Tauschwerts in eine bedeutungsvolle Beziehung. Sie stellen den Umschlagplatz aus der alten in die neue Epoche dar. Hier werden die neuesten Waren präsentiert und die Moderne zur Schau gestellt.

Auch in Benjamins Exposés und ersten Entwürfen stehen die Passagen im Zentrum der Reflexion. Anstatt ihre Entstehung vornehmlich anhand von Daten und Fakten zu erklären, untersucht er sie anhand von Bedeutungen und Bildern, Stimmungen und Vergleichen.

"Organische und anorganische Welt, niedrige Notdurft und frecher Luxus gehen die widersprechendsten Verbindungen ein, die Ware hängt und schiebt so hemmungslos durcheinander wie Bilder aus den wirresten Träumen[.] Urlandschaft der Konsumption. $\aleph^{36}$

Wenn Benjamin dabei von der »Urlandschaft« schreibt, so bedeutet das, dass mit jeder neuen Epoche und Generation der Symbolraum als das "Normale« oder als "Natur« neu einverleibt wird. ${ }^{37}$ Was dem zeitgenössischen Beobachter das Gewordene und Veränderte ist, wird dem Kind das unhinterfragt so Gegebene. Damit dekonstruiert Benjamin auch gleichzeitig die Vorstellung von Normalität als etwas Unabhängigem, Stabilem oder Objektivem.

Das sinnlich Gegebene ist immer ein historisch Gewordenes. Im dialektischen Bild soll der historische Gegenstand als solcher zur Lesbarkeit gelangen, das heißt, dass er nicht als abgeschlossenes Ereignis oder als eindeutiger Gegenstand einer bestimmten Zeit in einem bestimmen Kontext verstanden

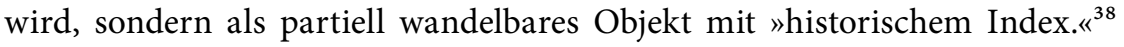
Dies gerade ist der Grund für seine Unabgeschlossenheit. ${ }^{39}$

34 Ebd., 1006.

35 Vgl. Benjamin, Paris, die Hauptstadt des XIX. Jahrhunderts, 47.

36 Ders., Das Passagen-Werk, 993.

37 Vgl. ebd., 576.

38 Ebd., 577.

39 Zur Abgeschlossenheit beziehungsweise Unabgeschlossenheit historischer Ereignisse zitiert Benjamin einen Brief von Horkheimer, der einen Unterschied hinsichtlich der Ab- 
»Der historische Index der Bilder sagt nämlich nicht nur, daß sie einer bestimmten Zeit angehören, er sagt vor allem, daß sie in einer bestimmten Zeit zur Lesbarkeit kommen. Und zwar ist dieses ızur Lesbarkeit` gelangen ein bestimmter kritischer Punkt der Bewegung in ihrem Innern. Jede Gegenwart ist durch diejenigen Bilder bestimmt, die mit ihr synchronisch sind: jedes Jetzt ist das Jetzt einer bestimmten Erkennbarkeit. In ihm ist die Wahrheit mit Zeit bis zum Zerspringen geladen. (Dies Zerspringen, nichts anderes, ist der Tod der Intentio, der also mit der Geburt der echten historischen Zeit, der Zeit der Wahrheit, zusammenfällt.) Nicht so ist es, daß das Vergangene sein Licht auf das Gegenwärtige oder das Gegenwärtige sein Licht auf das Vergangene wirft, sondern Bild ist dasjenige, worin das Gewesene mit dem Jetzt blitzhaft zu einer Konstellation zusammentritt. Mit anderen Worten: Bild ist die Dialektik im Stillstand. Denn während die Beziehung der Gegenwart zur Vergangenheit eine rein zeitliche ist, ist die des Gewesnen zum Jetzt eine dialektische: nicht zeitlicher sondern bildlicher Natur. Nur dialektische Bilder sind echt geschichtliche, d. h. nicht archaische Bilder. Das gelesene Bild, will sagen das Bild im Jetzt der Erkennbarkeit trägt im höchsten Grade den Stempel des kritischen, gefährlichen Moments, welcher allem Lesen zugrunde liegt. ${ }^{40}$

Diese ausführlichere Erklärung des dialektischen Bildes betont die Bewegung: einerseits die äußere historische Bewegung als Voranschreiten des Geschehens und der Veränderung der Gesellschaft, andererseits die innere historische Bewegung in einem Gegenstand, die sich öffnen, neue Bedeutungen entfalten, die nicht nur an sie herangetragen werden, sondern die von jeher potentiell in ihnen gesteckt haben. ${ }^{41}$ Zweitens betont Benjamin den Zusammenhang zwischen bildlichem Sehen und Lesen, indem das "gelesene Bild " erst das erkannte ist. Der Stillstand der Dialektik findet also zwischen zwei Bewegungen statt. Es ist nicht nur die Frage, welche neue Funktion ein Ge-

geschlossenheit bei negativen und positiven Ereignissen macht. So bleiben die Toten immer tot, dieses Faktum lässt sich nicht verändern, während positive Ereignisse unmittelbar der Vergänglichkeit ausgesetzt sind. Mit der Unabgeschlossenheit meint Benjamin vor allem die Deutung, wie ein bestimmtes Ereignis tradiert und erinnert wird. Die Phänomene müssten vor einer bestimmten Art der Überlieferung gerettet werden: Dazu gehört die Anbindung an »Kontinuität«, »Fortschritt«, »Schein der Wiederholung « und »Schein des Immer-Gleichen«; gerettet werden sie durch den Bruch. Vgl. ebd., 592.

40 Ebd., 578.

41 Dies korrespondiert auch mit Benjamins Kunstwerkverständnis, welches die Möglichkeit vorsieht, in anderen Umfeldern zu neuer Lesbarkeit zu kommen. Dies formuliert Benjamin in seinem Übersetzeraufsatz für die Poesie wie folgt: "Denn in seinem Fortleben, das so nicht heißen dürfte, wenn es nicht Wandlung und Erneuerung des Lebendigen wäre, ändert sich das Original. Es gibt eine Nachreife auch der festgelegten Worte. Was zur Zeit eines Autors Tendenz seiner dichterischen Sprache gewesen sein mag, kann später erledigt sein, immanente Tendenzen vermögen neu aus dem Geformten sich zu erheben."Benjamin, Walter: Die Aufgabe des Übersetzers. In: Rexroth, Tillman (Hg.): Gesammelte Schriften IV. Kleine Prosa, Baudelaire-Übertragungen. Frankfurt a.M. 1991, 9-22, hier $12 \mathrm{f}$. 
genstand in neuer Zeit und Umgebung bekommt, sondern auch, welche neue Bedeutung dieser Gegenstand der Jetztzeit und der Vergangenheit gibt. ${ }^{42}$

Die Industrie ist nach Benjamin das »Urphänomen« für die kulturellen Entwicklungen im 19. Jahrhundert, die er anhand verschiedener Motive deutlich macht. ${ }^{43}$ Damit ist für ihn eine "Natur« Ausgangspunkt des Denkens, wie sie sich im Zeitalter der Industrialisierung darstellt. Konsequenterweise lehnt er Ideen ab, die von der konkreten historischen Erfahrung unabhängig sind und ersetzt sie durch eine greifbare und in historischen Werken oder Gegenständen (Literatur, Philosophie, Architektur, Waren) ablesbare Wirklichkeitserfahrung. ${ }^{44}$

Das Benjaminsche Bild in dieser Konstellation unterscheidet sich gravierend von dem Metabild und Kunstbild, welches im dritten Kapitel untersucht wurde. Während diese noch eindeutig im Medium des Bildes zu finden waren und Theorie darstellten, durch Bild- und Textzitate starken Anteil an der Welt der Tradition, Literatur und Sprache hatten, so sind Benjamins »dialektische Bilder«, auch wenn sie sich an materiellen Gegenständen kristallisieren, keineswegs auch mediale Bilder. Sie artikulieren sich im Sprachlichen, auch wenn ihre Struktur eine räumlich-bildliche ist. Geradezu passend hat der Begriff »Passage « auch die Bedeutung einer Sprachform. ${ }^{45}$

Wenn sich Benjamins Bild-Überlegungen des »Passagenwerks« auf Schulz' Erzählung "Ulica Krokodyli« übertragen lassen, dann weil Schulz’ »Maga-

42 Die Kraft jener Anschauung wird deutlich, untersucht man den Totalitarismus mit seiner wirklichkeitsdefinierenden Ideologie. Hier ist ein Übergewicht von äußerer Zuschreibung auf den Gegenstand vorherrschend, eine Reflexion vom Gegenstand aus auf die Ideologie hin wird unterbunden. Nichts bleibt von einem solchen ideologischen Zugriff verschont, selbst die Sprache wird zum Instrument des Terrors und der Propaganda, die Literatur und Poesie des Humanismus spricht nicht mehr zum Verstand, sie wird von außen reglementiert. Vgl. Benjamin, Über den Begriff der Geschichte, 695.

43 Dabei bezieht er sich auch auf die Analysen von Marx. "Marx stellt den Kausalzusammenhang zwischen Wirtschaft und Kultur dar. Hier kommt es auf den Ausdruckszusammenhang an. Nicht die wirtschaftliche Entstehung der Kultur sondern der Ausdruck der Wirtschaft in ihrer Kultur ist darzustellen. Es handelt sich, mit andern Worten, um den Versuch, einen wirtschaftlichen Prozeß als anschauliches Urphänomen zu erfassen, aus welchem alle Lebenserscheinungen der Passagen (und insoweit des 19ten Jahrhunderts) hervorgehen.« Ders., Das Passagen-Werk, $573 \mathrm{f}$.

44 »Seit dem Ausgang des vorigen Jahrhunderts stellte sie [die Philosophie] eine Reihe von Versuchen an, der 'wahren/ Erfahrung im Gegensatze zu einer Erfahrung sich zu bemächtigen, welche sich im genormten, denaturierten Dasein der zivilisierten Massen niederschlägt. Man pflegt diese Vorstöße unter dem Begriff der Lebensphilosophie zu rubrizieren. Sie gingen begreiflicherweise nicht vom Dasein des Menschen in der Gesellschaft aus. Sie beriefen sich auf die Dichtung, lieber auf die Natur und zuletzt vorzugsweise auf das mythische Zeitalter.« Benjamin, Walter: Über einige Motive bei Baudelaire. In: Tiedemann, Rolf/Schweppenhäuser, Hermann (Hg.): Gesammelte Schriften I. Abhandlungen. Frankfurt a. M. 1991, 605-654, hier 608.

$45 \mathrm{Vgl}$. Arendt, Walter Benjamin, $18 \mathrm{f}$. 
zine« (magazyny) als Pendant zu den Passagen verstanden werden können, da sie im Polnischen sowohl für Warenhäuser als auch für illustrierte Hefte stehen. Damit sind ebenfalls Architektur und Textform zu einer Metapher verschmolzen. Die Doppeldeutigkeit der Verknüpfung von Elementen der Verkaufsläden mit Elementen der Reklame und der Modeblätter wird vielfach ausgespielt. Form und Inhalt sind in gleichem Maße wesentlich. Der Erzähler betont immer wieder das Material und die Ästhetik der Werbebilder sowie ihre Botschaft und Motive.

"Kaum jemand, der nicht darauf hingewiesen wurde, bemerkte eine seltsame Eigenheit des Viertels: Es gab keine Farben, als dürfe man sich an diesem abgeschmackten, zu schnell gewachsenen Ort einen derartigen Luxus nicht erlauben. Hier war alles grau, wie auf monochromen Photographien, wie in illustrierten Prospekten. Diese Ähnlichkeit war mehr als eine gewöhnliche Metapher, denn manchmal, wenn man durch den Stadtteil streifte, hatte man tatsächlich den Eindruck, man blätterte in einem Prospekt, in langweiligen, kommerziellen Anzeigenrubriken, zwischen die sich parasitär einige suspekte Annoncen, aufreizende Beschreibungen und fragwürdige Illustrationen gezwängt hätten; und diese Streifzüge waren ebenso schal und ergebnislos wie die Exzitationen der von den Spalten und Kolumnen pornographischer Schriften angestachelten Phantasie. ${ }^{46}$

Der Erzähler vergleicht die beschriebene Stadtszenerie mit Werbebildern der Illustrierten und analysiert, dass ihre Ähnlichkeit über eine gewöhnliche Metaphernfunktion hinausgeht. Damit eröffnet er erneut eine theoretische Ebene und reflektiert die Bedeutungen seiner gewählten Worte. Eine Metapher bezeichnet gewöhnlich ein Wort, das in einer "Abbild- oder Ähnlichkeitsrelation ${ }^{47}$ zum gemeinten Gegenstand steht. Ist diese Ähnlichkeitsrelation nicht nur symbolisch, dann weist der Erzähler einerseits auf die wirklichkeitswirksame Kraft der Bilder auf die Stadtlandschaft hin, andererseits auf die rhetorischen Mittel, die er zur Untersuchung und Illustration dieser Beziehung wählt. Die beiden getrennten Ebenen "Stadtansicht« und "Illustriertenansicht« werden dadurch miteinander verwoben, als gehörten sie zusammen.

46 Schulz, Die Zimtläden, 103. "Mało kto, nie uprzedzony, spostrzegał dziwną osobliwość tej dzielnicy: brak barw, jak gdyby w tym tandetnym, w pośpiechu wyrosłym mieście nie można było sobie pozwolić na luksus kolorów. Wszystko tam było szare jak na jednobarwnych fotografiach, jak w ilustrowanych prospektach. Podobieństwo to wychodziło poza zwykłą metaforę, gdyż chwilami, wędrując po tej części miasta, miało się w istocie wrażenie, że wertuje się w jakimś prospekcie, w nudnych rubrykach komercjalnych ogłoszeń, wśród których zagnieździły się pasożytniczo podejrzane anonse, drażliwe notatki, wątpliwe ilustracje; i wędrówki te były równie jałowe i bez rezultatu jak ekscytacje fantazji, pędzonej przez szpalty i kolumny pornograficznych druków.« Ders., Sklepy cynamonowe, 94 .

47 Vgl. Metapher. In: Nünning, Metzler Lexikon Literatur- und Kulturtheorie, $491 \mathrm{f}$. 
Eine solche Relation beschreibt Benjamin im »Passagenwerk», insbesondere aber in seinem Text »Zentralpark«:

»Die gegenständliche Umwelt des Menschen nimmt immer rücksichtsloser den Ausdruck der Ware an. Gleichzeitig geht die Reklame daran, den Warencharakter der Dinge zu überblenden. Der trügerischen Verklärung der Warenwelt widersetzt sich ihre Entstellung ins Allegorische. ${ }^{48}$

Reklame und Illustrierte sind die Bilderzeugnisse, die zur industrialisierten und marktwirtschaftlichen Gesellschaft gehören. Die Waren bringen die Bilder hervor, die Bilder verleihen den Waren Bedeutung. In Schulz' Erzählung wird dabei weniger auf die inhaltliche Seite des Bedeutungstransfers geschaut, sondern vor allem auf die Seite der Ästhetik und des Materials. Vom fotografischen Material werden die Billigkeit, Kurzlebigkeit, Farblosigkeit und der rasante Wechsel auf die Ansicht der Stadt übertragen, von der Ästhetik dagegen die »billige Erotik«, die Gleichförmigkeit und der permanente Reiz. ${ }^{49}$ Wie der Erzähler unterstreicht, ist kaum einen Unterschied zwischen den Ansichten der Straße und den Ansichten der Illustrierten auszumachen, da die Werbebilder ihre Botschaften direkt durch die Abbildung der Ware, Mode oder Ansichten darstellen. Auf diesen Zusammenhang weist Benjamin deutlich hin:

»Es gibt eine Fülle von Werbebildern, die durch ihren Reiz einprägsam wurden. Daß dieser Reiz nicht auf ihren freischwebenden künstlerischen Elementen sondern auf der Art und Weise beruht wie sie an die informatorischen gebunden ist, ändert die Qualität dieses Reizes, vermindert sie aber nicht. Jene informatorischen Elemente bestehen meistens im Bilde der Ware selbst. Und mehr und mehr vertraut man die bildmäßige Wiedergabe der Ware der Photographie an. Die Automobil-, die Zigaretten-, die Textilfirmen haben das Publikum allmählich dazu erzogen, bestimmte Warenqualitäten im Bild zu suchen. Sie haben die Photographie an die Stelle der Warenprobe gesetzt. ${ }^{50}$

48 Benjamin, Zentralpark, 671.

49 In seinen Baudelaire-Aufsätzen zeigt Benjamin auf, welche wesentliche Rolle der Reiz in der modernen, industrialisierten Gesellschaft einnimmt. Der Mensch in der Stadt werde dermaßen mit Reizen überflutet, dass er sie nicht mehr mit dem Bewusstsein verarbeiten könne, sondern abwehren müsse. Bezugnehmend auf die Gedächtnistheorien von Freud stellt er fest, dass die Reizschutzmechnismen wichtiger und besser ausgebaut seien als die Aufnahmemechanismen. Zu viele Reize gefährden den Menschen. Am größten ist die Bedrohung durch »Chocks«. "Je geläufiger ihre Registrierung dem Bewußtsein wird, desto weniger muß mit einer traumatischen Wirkung dieser Chocks gerechnet werden." Das bedeutet aber gleichzeitig, dass diese Eindrücke unerkannt auf das Bewusstsein - genauer auf das Unbewusste - wirkten. Vgl. Ders., Über einige Motive bei Baudelaire, 613.

50 Ders., Anmerkungen zu Malerei und Photographie, $819 \mathrm{f}$. 
Was Benjamin hier beschreibt, ist eine Ersetzung der eigenen Erfahrung am Gegenstand durch die im Werbebild vermittelte Erfahrung. Diese Wirkung wird dadurch potenziert, dass der fotografischen Abbildung eine größere Objektivität zugesprochen wird, sowie dadurch, dass einem die Bilder in großer Anzahl im öffentlichen wie privaten Raum begegnen. ${ }^{51}$ Diese Wirklichkeitsersetzung wird in der »Ulica Krokodyli« in der Beschreibung der städtischen Architektur und Bewohner vorgeführt. Dies zeigt sich in der stets präsenten Verknüpfung der Straßen, Magazine und Menschen mit bildmedialen Elementen wie Pigment oder Papier, direkten Vergleichen mit Zeitschriften und Postern, aber auch ästhetischen Anleihen wie Posen und weiblichen Reizen.

"Wir werden es ewig bereuen, daß wir damals das Konfektionsmagazin mit seiner verdächtigen Konduite für einen Augenblick verließen. Nie mehr werden wir dorthin zurückfinden. Von einem Ladenschild zum anderen werden wir irren, und Hunderte Male werden wir uns täuschen. Wir werden Dutzende von Magazinen besichtigen und immer wieder ganz ähnliche finden, wir werden zwischen Buchspalieren auf und ab gehen, Zeitschriften und Drucke durchblättern, lange und umständlich mit den Fräuleins konferieren, die viel überschüssiges Pigment haben, deren Schönheit Fehler aufweist und die unsere Wünsche nicht verstehen. ${ }^{52}$

In diesem Zitat wird der fließende Übergang von den Modeläden (magazyny konfekcji) zu den Modezeitschriften (magazyny) besonders deutlich. In der polnischen Fassung ist im Gegensatz zur deutschen Übersetzung keine Unterscheidung möglich, um welche der beiden Magazinvarianten es sich handelt. Auch die Durchwanderung der Stadt endet mit einem Durchblättern der Illustrierten. Sophie von Stackelberg weist darauf hin, dass der Begriff "Magazin" sich vom arabischen »machasin« ableitet, was so viel wie "Warenlager« heiße. »Damit ist ein Magazin im übertragenen Sinn eine Ansammlung verschiedener publizistischer $>$ Waren $<.{ }^{53}$

Damit führt die Erzählung vor, dass der Warenschein zur »Natur« der modernen Stadt und der Moderne gehört und mit ihr verbunden ist. »Jeder wahrhaft neuen Naturgestalt - und im Grunde ist auch die Technik eine

51 Vgl. Ders., Das Passagen-Werk, 114.

52 Schulz, Die Zimtläden, 113. »Będziemy wiecznie żałowali, żeśmy wtedy wyszli na chwilę z magazynu konfekcji podejrzanej konduity. Nigdy nie trafimy już doń z powrotem. Będziemy błądzili od szyldu do szyldu i mylili się setki razy. Zwiedzimy dziesiątki magazynów, trafimy do całkiem podobnych, będziemy wędrowali przez szpalery książek, wertowali czasopisma i druki, konferowali długo i zawile z panienkami o nadmiernym pigmencie i skażonej piękności, które nie potrafią zrozumieć naszych życzeń.« Ders., Sklepy cynamonowe, 100.

53 Stackelberg, Sophie v.: Illustrierte Magazine als Zeitschriftentyp und historische Quelle: Der »Uhu« als Beispiel. In: Kerbs, Diethart (Hg.): Fotografie und Bildpublizistik in der Weimarer Republik. Bönen 2004, 133-149, hier 135. 
solche, entsprechen neue $>$ Bilder $\triangleleft{ }^{54}{ }^{4}$ Um eine Epoche in ihren Wertverschiebungen $\mathrm{zu}$ verstehen, muss man nach Benjamin auch die Bilder betrachten, die diese hervorbringt. Was an den Werbebildern deutlicher zutage tritt, findet sich auch in der Malerei, für welche der Kunstmarkt in kommerzieller Hinsicht gleichfalls an Bedeutung gewinnt. ${ }^{55}$ Diese Wertverschiebung wird in Schulz' Erzählung nicht neutral beobachtend beschrieben, sondern wertend und kritisch begleitet. In der Schulzschen Einkaufsstraße wird die Architektur billig, die Menschen zur anonymen Masse, die Szenerie wird belanglos. ${ }^{56}$

Besonders deutlich wird die Kritik an der Wirkung der Werbebilder durch die Darstellung der Frauen. Die Frauen der »Ulica Krokodyli« treten in ihrer körperbetonten Sexualität im semantischen Feld der Prostitution auf. Dies gilt nicht allein für die Verkäuferinnen, die die Posen der Covergirls von Zeitschriften nachahmen, ${ }^{57}$ sondern alle porträtierten Frauen des Viertels tragen den Schleier der Käuflichkeit, worauf man durchaus stolz ist: »Sie behaupten, jede Frau des Viertels sei eine Kokotte. ${ }^{58}$ Selbst die Schulmädchen sind davon nicht ausgenommen..$^{59}$ Diese Wertverleihung passiert aktiv wie passiv, denn das vermittelte "Bild der verführerischen Frau« senkt sich durch seine Allgegenwart zunehmend in unbewusste Bereiche, wird »normal«. Rita Felskis Buch »Gender of Modernity« analysierend, welches sich mit dem Masochismus im Kontext einer Geschlechterordnung befasst, schreibt Augsburger:

»Parallel zur Feminisierung der Kunst stehe eine ,Verkünstlichung des Weiblichen Durch die zunehmenden Einflüsse der Modeindustrie habe sich in der Außenwahrnehmung die Frau von ihrem natürlichen Körper gelöst, das Augenmerk wurde zunehmend auch auf ihre modische Inszenierung gelenkt. ${ }^{60}$

Während weder Benjamin noch Schulz die Idee eines "natürlichen Körpers« unterstützen, so zeichnen sie doch beide den Wertverleihungsprozess auf, den der Frauenkörper der Ware gibt und die Ware dem Frauenkörper. Ein zen-

54 Benjamin, Das Passagen-Werk, 493.

55 Diese Entwicklung untersucht Benjamin im »Zweiten Pariser Brief« eingehend. Siehe Benjamin, Walter: Pariser Brief II: Malerei und Photographie. In: Tiedemann-Bartels, Hella (Hg.): Gesammelte Schriften III. Kritiken und Rezensionen. Frankfurt a. M. 1991, 495-507.

56 Vgl. Schulz, Sklepy cynamonowe, $96 \mathrm{f}$.

57 »Panienki demonstrują, jedna przed drugą, figury i pozycje rycin okładkowych, inne zasypiają już na prowizorycznych posłaniach.« Vgl. ebd., 96. »Die Mädchen demonstrieren der Reihe nach die Figuren und Stellungen auf den Illustrationen der Bucheinbände, andere schlafen bereits auf provisorischen Liegen ein.« Ders., Die Zimtläden, 106.

58 Ebd., 111. »Twierdzą oni, że każda kobieta w tej dzielnicy jest kokotą.« Ders., Sklepy cynamonowe, 99.

59 Vgl. ebd.

60 Augsburger, Masochismen, 169. 
trales »dialektisches Bild« in Benjamins Passagenarbeit ist die Prostituierte Verkäuferin und Ware in einem. ${ }^{61}$ Benjamin zeigt, wie in der Reklame der erotische Reiz der weiblichen Schönheit auf den Kaufreiz einer Ware übertragen wird. ${ }^{62}$ Gleichzeitig nimmt auf diese Weise der weibliche Körper selbst Bedeutungen der Warenkäuflichkeit an. ${ }^{63}$

»Dieser Warenschein der Natur ist es, der in der Hure verkörpert ist. `Geld macht sinnlich heißt es und diese Formel gibt selbst nur den gröbsten Umriß eines Tatbestandes, der weit über die Prostitution hinausreicht. Unter der Herrschaft des Warenfetischs tingiert sich der sex-appeal der Frau mehr oder minder mit dem Appell der Ware. [...] Die moderne Reklame erweist von einer Seite, wie sehr die Lockungen von Weib und von Ware mit einander verschmelzen können. ${ }^{64}$

Frauen sind als Vorführmodelle, Verführerinnen zum Warenkauf und als potentielle Käuferinnen die Hauptangesprochenen der Mode. ${ }^{65}$ Aber auch für andere Waren wird der Frauenkörper in der Reklame verdinglicht, denn der Reiz weiblicher Glieder wird für die Warenwerbung verkauft. ${ }^{66}$ In Fortführung von Mitchells sozialtheoretischem Ansatz erneuert sich in der Reklame das zuvor schon in der Malerei und Poesie ausprägte Machtverhältnis, in welchem die Frau in doppelter Hinsicht Objekt und Projektionsfläche wird. ${ }^{67}$

In Schulz' Erzählung ist die Welt der Kataloge zusätzlich gespickt von religiösen Motiven. In den Kaufhäusern spiegelt sich sakrale Architektur; ${ }^{68}$ die Ladenangestellten kommen untertänig wie die Kirchendiener zum Kunden und versuchen dessen Wünsche zu erfüllen. Man verirre sich nur an Tagen

61 Vgl. Benjamin, Paris, die Hauptstadt des XIX. Jahrhunderts, 55.

62 Dies betrifft in ganz besonderem Maße die städtische Frau, deren Körper »rücksichtslos in den Prozess der Warenproduktion« einbezogen wird. Vgl. Ders., Das Passagen-Werk, 400 .

63 Vgl. ebd., 427.

64 Ebd., $435 \mathrm{f}$.

65 Vgl. ebd., 400; 427; $435 \mathrm{f}$.

66 Nach Nöth wäre an dieser Stelle insofern eine parasitäre Beziehung zwischen Werbung und Frauen zu konstatieren, als dass sich die Werbung des körperlichen Reizes der Frauen bedient. Dabei überträgt die Werbung wiederum auf die Frau den Schein der Dinglichkeit und Käuflichkeit. Vgl. Nöth, Winfried: Werbung und die Künste: Parasitäre, symbiotische und paragonale Intermedialität. In: Degner, Uta/Wolf, Norbert C. (Hg.): Der neue Wettstreit der Künste. Legitimation und Dominanz im Zeichen der Intermedialität. Bielefeld 2010, 145-166, hier 161-163.

67 Vgl. Mitchell, Picture Theory, $165 \mathrm{f}$.

68 »Gewaltige, mehrstöckige Regale erheben sich in die unbestimmte Höhe der Halle.» Die Decke könnte ein Himmel sein und auch die "riesengroßen «, milchigen, vergitterten Fenster rufen das Bild einer großen Kathedrale auf. Diese sei aber stickig und lichtlos, wie mit Wasser gefüllt oder mit einem »indifferenten, grauen Zwielicht, das keinen Schatten wirft und keine Akzente.« Schulz, Sklepy cynamonowe, 94. (»indyferentną szarą poświatą, która nie rzuca cienia i nie akcentuje niczego.«) Ders., Die Zimtläden, 104. 
des Niedergangs (»upadek«) und der Versuchung (»pokusa») in dieses Viertel. ${ }^{69}$ An die Stelle der religiösen Symbole sind nun die "Schutzmarken" getreten und werben um die Anerkennung ihrer höheren Existenz. Manche der männlichen und weiblichen Verkäufer werden als Zwitterwesen beschrieben, eine Eigenschaft von Engeln..$^{70}$ Die Magazine seien eine Kulmination der Verderbtheit ${ }^{71}$ (»kulminac[ja] zepsucia $«^{72}$ ), die die Vorstellungskraft des Kunden übersteigt.

Unter Bezugnahme auf Reklame und Warenwelt fordert Benjamin eine theologische Interpretation ein. ${ }^{73}$ In seinem Exposé zum »Passagen-Werk" betont er die Funktion, die die Weltausstellungen und die Warenhäuser einnehmen. Sie seien die "Wallfahrtsstätten zum Fetisch Ware. $"{ }^{74}$ Anhand der Architektur, aber auch dem Verhalten des Menschen gegenüber der Ware und den Warenhäusern beschreibt er eine Verlagerung des religiösen Symbols aus den Kirchen in die Konsumlandschaft. ${ }^{75}$ Eine zentrale Rolle spielt dabei die "Ware«, die durch ihre industrielle Herstellungsweise und Rolle in der Gesellschaft nicht mehr so sehr ein Gegenstand der Erfahrung (durch die handwerkliche Herstellungsweise) ist, sondern ein (Ab-)Nutzgegenstand. Weil die Preise sinken und Waren über den Bedarf hinaus angeschafft werden, verändere sich nach Benjamin und Karl Marx das Verhältnis des Menschen zur Ware; diese erhält einen religiösen Fetischcharakter.

"Eine Ware scheint auf den ersten Blick ein selbstverständliches, triviales Ding. Ihre Analyse ergibt, daß sie ein sehr vertracktes Ding ist, voller metaphysischer Spitzfindigkeit und theologischer Mucken. [...] Um daher eine Analogie zu finden, müssen wir in die Nebelregion der religiösen Welt flüchten. ${ }^{76}$

69 »Ale w dniach upadku, w godzinach niskiej pokusy zdarzało się, że ten lub ów z mieszkańców miasta zabłąkiwał się na wpół przypadkiem w tę wątpliwą dzielnicę." Ders., Sklepy cynamonowe, 94. „Doch an Tagen des Niedergangs, in Stunden der Verlockung kam es vor, daß sich der eine oder andere Stadtbewohner halb zufällig in die zweifelhafte Gegend verirrte.« Ders., Die Zimtläden, 103.

70 „Subiekt, wyczerpawszy swą natarczywą aktywność, przechodził powoli do kobiecej bierności. Leży teraz na jednej z wielu kanap, porozstawianych wśród rejonów książek, w jedwabnej piżamie, odsłaniającej kobiecy dekolt. Ders., Sklepy cynamonowe, 96. »Der Gehilfe, der seine aufdringliche Aktivität erschöpft hat, verfällt langsam in weibliche Passivität. Er liegt auf einem der vielen Diwane, die inmitten der Bücher herumstehen, in seinem Seidenpyjama, der ein weibliches Dekolleté freiläßt.« Ders., Die Zimtläden, 106.

71 Ebd., 105.

72 Ders., Sklepy cynamonowe, 95.

73 Vgl. Benjamin, Das Passagen-Werk, 114.

74 Ders., Paris, die Hauptstadt des XIX. Jahrhunderts, 50.

75 Dabei weist er immer wieder auf die Durchdringung des Neuen mit dem Alten hin, dass es also keinen radikalen Bruch gibt, der die Moderne von der früheren Epoche trennt, sondern immer eine Umschichtung, die alte Ideen in die neuen integriert. Vgl. ebd., 47.

76 Marx, Karl: Das Kapital. Kritik der politischen Ökonomie. Frankfurt a. M. 1968, 85 f. 
Das bedeutet, dass der Ware eine »religiöse« Bedeutung anhaftet, die ihr nicht ursächlich ist, sondern "Ausdruck der Wirtschaft in ihrer Kultur. ${ }^{77}$ Diese Bedeutungszuschreibung wird einerseits durch die Werbebilder der Illustrierten und Prospekte potenziert, indem diese vorab gezielt die Vorstellung vom Gegenstand prägen und sich dabei bekannter Muster der Religionen bedienen, andererseits stellen sie diese Umschichtung auch dar und bilden das Bildpendant zum Prozess. ${ }^{78}$ Daher lohnt es sich, sie eingehend zu analysieren und ihre Umarbeitung der mythischen und religiösen Merkwelt zu studieren.

"Daß zwischen der Welt der modernen Technik und der archaischen Symbolwelt der Mythologie Korrespondenzen spielen, kann nur der gedankenlose Betrachter leugnen. [...] Das urgeschichtliche Moment im Vergangenen wird - auch dies Folge und Bedingung der Technik zugleich - nicht mehr, wie einst, durch die Tradition der Kirche und Familie verdeckt. Der alte prähistorische Schauer umwittert schon die Umwelt unserer Eltern, weil wir durch Tradition nicht mehr an sie gebunden sind. Die Merkwelten zersetzen sich schneller, das Mythische in ihnen kommt schneller, krasser zum Vorschein, schneller muß eine ganz andersartige Merkwelt aufgerichtet und ihr entgegengesetzt werden. So sieht unter dem Gesichtspunkt der aktuellen Urgeschichte das beschleunigte Tempo der Technik aus. ${ }^{79}$

77 Benjamin, Das Passagen-Werk, 574.

78 "Der Form des neuen Produktionsmittels, die am Anfang noch von der des alten beherrscht wird (Marx) entsprechen im gesellschaftlichen Überbau Wunschbilder, in denen das Neue sich mit dem Alten in phantastischer Art durchdringt. Diese Durchdringung erhält ihren phantastischen Charakter vor allem daher, daß das Alte im Zuge der gesellschaftlichen Entwicklung sich niemals scharf gegen das Neue abhebt, das letzte aber, im Bestreben sich gegen das Veraltete abzusetzen, archaische, urzeitliche Elemente erneuert. Die utopischen Bilder, die das Heraufkommen des Neuen begleiten, greifen gleichzeitig stets auf Urvergangnes zurück. In dem Traum, in dem jeder Epoche die ihr folgende in Bildern vor Augen tritt, erscheint diese vermählt mit Elementen der Urgeschichte. Die Spiegelungen des Unterbaus durch den Überbau sind also inadäquat nicht darum, weil sie durch die Ideologen der herrschenden Klasse bewußt verfälscht worden wären sondern weil das Neue, um sich bildhaft zu gestalten, seine Elemente stets mit solchen der klassenlosen Gesellschaft verbindet. Das kollektive Unbewußte hat an ihnen mehr Anteil als das Bewußtsein des Kollektivs. Aus ihm stammen die Bilder der Utopie, die in tausend Konfigurationen des Lebens von den Bauten bis zu den Moden, ihre Spur hinterlassen haben.« Ebd., $1224 \mathrm{f}$. (Im Orig. kursiv)

79 Ebd., 576. Über das Verhältnis von Vergangenheit und Zukunft in Benjamins Werk schreibt Peter Szondi, dass Benjamin zu jenem historischen Zeitpunkt zurück dringen will, als Technik noch nicht als die Beherrschung der Natur wahrgenommen und idealisiert wurde, sondern als sie noch für die Beherrschung des Verhältnisses von Natur und Mensch stand. Mit diesem Versuch würde er den Umschlag zeigen, als im Fortschritt der Rückschritt vollzogen wurde, und so eine Korrektur der Verhältnisse (insbesondere der geistigen/ideellen) ermöglichen. Die Urgeschichte der Moderne ist der Zeitpunkt, in der sich die "Merkwelten« neu formieren. Vgl. Szondi, Peter: Hoffnung im Vergangenen: Über Walter Benjamin. In: Schriften II. Frankfurt a. M. 1978, 275-294, hier 289. 
Die inhaltliche Analyse bleibt in der Erzählung »Ulica Krokodyli« noch deutlich nachgeordnet, sie fokussiert auf Verleihungen durch die Materialeigenschaften, Ästhetik und Atmosphäre. Dabei vergleicht Schulz ähnlich wie Benjamin die Straßenansichten und Architektur mit den Bildern und stellt einen Beziehungszusammenhang zwischen den Veränderungen an den Läden, Waren und Frauen der Stadt, sowie den Bildern der Illustrierten und der Werbung her. Beide Entwicklungen beobachtet der Erzähler aus kritischer Distanz. Dies steht in einem starken Kontrast zu den Analysen und Darstellungen der Werbebilder in der Erzählung »Księga«.

\subsection{Magie der Reklame - »Księga»}

Mit den konkreten Inhalten von Werbebildern setzt sich Schulz in seiner Erzählung "Księga" auseinander, in welcher die Makroperspektive der Straßenansicht und der illustrierten Magazine um die Mikroperspektive verschiedener Bild- und Textanalysen ergänzt wird. Die im Text analysierten Reklameanzeigen existieren dabei auch außerhalb der literarischen Wirklichkeit, was die These stützt, dass sich Schulz mit den neuen Bildmedien und ihren Wirkweisen in seiner Prosa auseinandersetzt. Erneut hebt der Erzähler vor allem den mythischen und theologischen Gehalt in der Gestaltung, der Erzählung und der Ikonologie der Reklamen hervor. Während die Modereklame selbst eine geringere Rolle spielt, verschiebt sich der Fokus auf kosmetische Schönheit und Gesundheit, Waren und Fertigkeiten.

»Księga« ist der Titel der ersten Erzählung in der Sammlung »Sanatorium pod Klepsydrą" und eine der meistgedeuteten. Den Mittelpunkt dieser Erzählung bildet das mystische Urbuch mit dem Namen »Autentyk« (Original), dessen Bedeutung unter den Literaturwissenschaftlern nach wie vor umstritten ist. Shalom Lindenbaum sieht darin eine präexistente Tora ${ }^{80}$ und Ficowski die "Bibel der eigenen verlorenen Kindheit. ${ }^{81}$ Augsburger hingegen deutet es als eine Art Wunschbuch, in dem sich die Sehnsucht nach Ganzheit ausdrücke und das so angelegt sei, dass jeder alles in ihm lesen könne. ${ }^{82}$ Panas und Underhill lesen das »Buch« in einem jüdisch-messianischen Kontext, ${ }^{83}$ während

80 Vgl. Lindenbaum, Wizja mesjanistyczna Schulza i jej podłoże mistyczne, 33-67.

81 Ficowski, Regiony wielkiej herezji, 32. „Księga jest biblią własnego zagubionego dzieciństwa.«

82 Augsburger, Janis: Poetical Fluidization and Intellectual Eclecticism in Bruno Schulz's Writings. In De Bruyn/Van Heuckelom: (Un)masking Bruno Schulz, 499-517.

83 Underhill liest das Buch im messianischen Kontext als Moment der Erlösung. Darum sei es auch nicht nur ein Buch, sondern viele Bücher und habe keine tatsächliche Materialität. "Schulz's image of the moment in which a child reads belongs to the messia- 
Kato einen Bezug zu Irzykowskis »Mutter-Buch«-Projekt findet. ${ }^{84}$ Ulrich Schmid wiederum interpretiert das Buch als Metapher für die Möglichkeit der Erkenntnis von Kants Ding-an-sich ${ }^{85}$, Jerzy Speina dagegen als Metapher des »Urworts" (prasłowo), die die dem Werk inhärente Theologie erläutert. ${ }^{86}$ Trotz zahlreicher Anspielungen auf die Bibel verneint der Erzähler, dass es sich dabei um diese handelt. ${ }^{87}$ Stefan Chwin schreibt:

"Das Buch, nach welchem sich der Held des Zyklus' sehnt, ist eine Metapher für einen kosmischen `Rückzugsort, der die Essenzen aller möglichen Geschichten, die auf ihre Verwirklichung warten, beinhaltet. ${ }^{88}$

Als letztes sei noch Rolf Fieguth erwähnt, demzufolge das vorgefundene Buch gar nicht das Original sei, auf das die sagenhafte Beschreibung passe. Vielmehr sei es ein Ersatz, eine Repräsentation, die zum Original gemacht wurde ${ }^{89}$ Hierzu passt auch die Urbuchkonzeption in Thomas Manns »Joseph und seine Brüder«, ein Roman, den Schulz immer wieder als höchst relevant für sich hervorhebt. ${ }^{90}$

"Nun war aber dies Original nicht eigentlich ein Original, nicht das Original, wenn man es recht betrachtete. Es war selbst schon die Abschrift eines Dokuments aus Gott weiß welcher Vorzeit, bei dem man denn also, ohne recht zu wissen, wo, als bei dem wahren Originale haltmachen könnte, wenn es nicht seinerseits bereits mit Glossen und Zusätzen von Schreiberhand versehen gewesen wäre, die dem besseren Verständnis eines wiederum urweit zurückliegenden Textes dienen sollten, wahrscheinlich aber im Gegenteil der modernen Verballhornung seiner Weisheit dienten - und so könnten wir fortfahren, wenn wir nicht hoffen dürften, daß unsere Zu-

nic constellation within his texts; and it is one of the clearer descriptions of the redemptive potential of literature: it describes a moment of potentiality, and absolutely fleeting recuperation." Underhill, Bruno Schulz and Jewish Modernity, 81. In ihrem Vergleich von Buber und Schulz erkennt sie, dass beide nach "Ganzheit« streben; Buber nach der Ganzheit des Menschen, Schulz nach der Ganzheit der Sprache. Vgl. Underhill, Karen: Ecstasy and Heresy: Martin Buber, Bruno Schulz, ans Jewish Modernity. In: De Bruyn/ Van Heuckelom: (Un)masking Bruno Schulz, 26-47, hier 37.

84 Vgl. Kato, Obraz i Księga, 161-163.

85 Vgl. Schmid, Ulrich: Die Realisierung der modernen Metaerzählungen bei Bruno Schulz (Kant, Kafka, Freud). In: Hodel, Robert (Hg.): Zentrum und Peripherie in den slavischen und baltischen Sprachen und Literaturen. Bern 2004, 119-134, hier $121 \mathrm{f}$.

86 Vgl. Speina, Bankructwo realności, 36.

87 Vgl. Schulz, Sanatorium pod Klepsydrą, 124.

88 »Księga, o której marzy bohater cyklu, jest metaforą kosmicznego >matecznika‘ zawierającego esencje wszystkich możliwych fabuł czekających na urzeczywistnienie."Chwin, Stefan: Schulz a Leśmian. In: Jarzębski (Hg.): Czytanie Schulza, 108-127, hier $111 \mathrm{f}$. (Übers. A. J.)

89 Vgl. Fieguth, Eine Art Zusammenhangsheimweh, 320.

90 Vgl. Schulz, Księga listów, 74, sowie Schulz, Bruno Schulz do St. I. Witkiewicza, 20; 106. 
hörer schon hier erfassen, was wir im Sinne haben, wenn wir von Küstenkulissen und Brunnenschlund reden. ${ }^{91}$

Die Deutungsheterogenität in der Sekundärliteratur kommt nicht von ungefähr, da der Erzähler die Buch-Metapher immer wieder aufgreift und auf weitere Gegenstände wie »Briefmarkenalben« oder »Zeichnungen« projiziert. Die hier vorgeschlagene Deutung unterscheidet sich deshalb von den anderen, weil die Leserichtung umgekehrt wird. Während in der Regel die Deutung von der Metapher »Autentyk « ausgeht und die Reklame als verwandelte Form jenes magischen Urbuchs gelesen wird, wird in dieser Interpretation die Reklame als der eigentliche, erste Gegenstand gelesen und untersucht, welche Deutungszuschreibungen sich dadurch für das Urbuch ergeben.

»Księga« nimmt anders als »Ulica Krokodyli« Anteil an der Entwicklung der Familiengeschichte um den Erzähler und Protagonisten Józef, seinen Vater Jakub und das Hausmädchen Adela. In fünf Unterkapiteln entwickelt sie einen Buch-Mythos und eine Buch-Analyse. Dabei finden sich vor allem im ersten und fünften Unterkapitel signifikante metatextuelle Erläuterungen und Erklärungen, direkte Ansprachen an den Leser und Kontextualisierungen. Innerhalb dieser Rahmenerzählung wird das Geschehen dargestellt, in welchem die mythischen Geschichten und Erlebnisse rund um das "Buch" vorgeführt werden. Ähnlich wie auf den Grafiken und auch in der Erzählung »Ulica Krokodyli« lassen sich dabei mehrere Ebenen der Repräsentation identifizieren, die durch Brüche in der Chronologie und durch die Unterscheidung zwischen erlebendem und kommentierendem Erzählen entstehen.

Weil im Polnischen deutlich zwischen »Księga» (Das Buch) und »książka» (Buch) unterschieden wird und es dafür kein gutes deutsches Äquivalent gibt, wird Księga im Folgenden nicht übersetzt und tritt ohne Anführungsstriche auf, wenn es das Buch bezeichnet und mit, wenn es sich um die Erzählung handelt. Um wiederum Księga, welche vor allem eine Metapher oder Idee darstellt, von dem beschriebenen materiellen Exemplar zu unterscheiden, wird für letzteres der polnische Begriff »szpargał« benutzt, der in der deutschen Übersetzung so viel wie "zerlesener Papierpacken" bedeutet. Dieser tritt dem herangewachsenen kindlichen Erzähler in Form einer unvollständigen, abgegriffenen und zerfledderten Illustrierten entgegen. ${ }^{92}$ Als Józef die Papiere genauer betrachtet, erkennt er in ihnen den Teil eines größeren Ganzen, dessen eigentlicher Text schon vernichtet wurde. Das einzige, was von der ursprünglichen Księga übrig geblieben ist, sind einige zerschlissene Seiten voll veralteter Anzeigen und Reklamen für Waren, Filme, Instrumente und

91 Mann, Joseph und seine Brüder, 15.

92 Der Urbuchrest wird als "nieurzędowy dodatek, tylna oficyna pełna odpadków i rupieci« beschrieben. Schulz, Sanatorium pod Klepsydrą, 126. Als »inoffizieller Anhang, das Hinterzimmer mit seinem Abfall und Gerümpel!« Ders., Das Sanatorium zur Sanduhr, 15. 
Bücher, deren inhaltliche Ausgestaltung voller biblischer oder magischer Bezüge ist.

Die im szpargał gedruckten Werbeanzeigen sind im Gegensatz zu den Werbebildern der Illustrierten der »Ulica Krokodyli« Text-Bild-Kombinationen, von denen nicht der eigentliche Text wiedergegeben wird, sondern das, was beim Erzähler Józef ankommt. Er fantasiert zum Teil die Inhalte weiter und bindet diese an Geschichten und Bilder an, die ihm aus der Bibel bekannt sind. Zudem beschreibt er seine Eindrücke und Emotionen während der Lektüre, die ähnlich wie in »Ulica Krokodyli« hauptsächlich durch Erotik $^{93}$, Erregung (»od ekstazy do ekstazy ${ }^{94}$ ), Benommenheit und Rausch (»oszołomienie ${ }^{95}$ ) geprägt sind. Dabei liest sich die Überbetonung der religiösen Motive und Anlehnungen an religiöse Text- und Bildformate ironisch als Markierung der den Werbemedien inhärenten biblischen und magischen Anleihen. So lautet die These, dass der Reklamekatalog als Ergebnis einer zeitkritischen Analyse in einen heiligen und mythischen Kontext gestellt wird, der allerdings ohne Moral und Ethik auskommt. Für diese These spricht, dass die untersuchten Werbebilder auch außerhalb der Textrealität existierten und sehr vielen Lesern bekannt waren. ${ }^{96}$

Insbesondere die Reklame der Anna Csillag genoss in ganz Mittelosteuropa eine große Popularität und war fest im Bewusstsein einer ganzen Generation verankert. ${ }^{97}$ Dass die religiöse Symbolik in der Zwischenkriegszeit von vielen Zeitgenossen wahrgenommen wurde, zeigt sich deutlich in den vielen Gedichten, Aphorismen und Bildern, die diese Motive betonen. ${ }^{98}$ Nach

93 Józef, dessen Sinn für Erotik gerade erwacht ist, trifft auf das Buch, indem er sich in erotischer Absicht der Haushälterin Adela nähert. Adela ignoriert seine Anzüglichkeit und zeigt sich vielmehr angetan von einer Haarwachs-Anzeige, die sofort in Adela den Wunsch weckt, selbst auch so lange Haare zu bekommen. Schulz, Sanatorium pod Klepsydrą, 125.

94 Ebd., 130.

95 Ebd., 129.

96 Vgl. Caneppele, Die Republik der Träume, 61-73.

97 Vgl. Offenthaler, Eva: Ich, Anna Csillag - ein k. k. Marketingstar. Institut Österreichisches Biographisches Lexikon 2012, http://www.oeaw.ac.at/oebl/Bio_d_M/bio_2012_04.htm vom 01.11.2014.

98 Vgl. Kitowska-Łysiak, Schulzowskie marginalia, 53. In Polen beispielsweise veröffentlichte 1933 Józef Wittlin ein Gedicht unter dem Titel A la recherche du temps perdu, in welchem er die Ikone der Reklame Anna Csillag als Heilige darstellt, als Göttin der Behaartheit [»bogini uwłosienia»] und als Zeugin der Kindertage. Dabei setzt er sich ironisch mit der Bedeutung der Reklame für seine Gegenwart auseinander. Vgl. Wittlin, Józef: A la recherche des temps perdu. In: Wiadomości Literackie (1933), 13. Auch Karl Kraus geht in seinem Text "Die Welt der Plakate" auf Anna Csillag ein und zitiert ihren sehr charakteristischen Anfang »Ich, Anna Csillag « inmitten einer Reihe anderer Parolen und Plakatslogans, die das Sprechen und Denken seiner Zeitgenossen beeinflussten. Vgl. Kraus, Karl: Die Welt der Plakate. In: Die chinesische Mauer. Schriften. Frankfurt a. M. 1987, 256-261. 
Benjamin hat diese Werbeanzeige sogar den Weg in einen Friseursalon der Pariser Passagen gefunden und auch er unterstreicht ihre mythologischen Anleihen.

"In den Auslagen der Friseurläden sieht man die letzten Frauen mit langen Haaren. Sie haben reich ondulierte Haarmassen, die sindéfrisablesı sind, versteinerte Haartouren. Kleine Votivtafeln sollten sie denen weihen, die eine eigene Welt aus diesen Bauten machen. Baudelaire und Odilon Redon, dessen Name selbst wie eine allzugut gedrehte Locke fällt. Statt dessen hat man sie verraten und verkauft und das Haupt der Salome zum Einsatz gemacht, wenn das, was dort von der Konsole träumt, nicht das einbalsamierte der Anna Czillag ist. ${ }^{99}$

Anna Csillag ist dabei nicht nur die Werbebildikone, sondern auch die Unternehmerin. ${ }^{100}$ Während der Text der Haarbalsam-Anzeige immer wieder an den kulturellen Kontext angepasst wurde, ${ }^{101}$ blieb das Bild, welches Csillag als »Allegorie des langen schönen Haares ${ }^{102}$ zeigt, über die Jahre unverändert.

Die Bezugnahme der Reklame auf die Religion - in den Motiven, in der Überzeugungsstrategie, im Appell an die Glaubensbereitschaft, aber auch in der Ikonologie - erfährt in Schulz' Erzählung eine deutliche Betonung. So wird die Nacherzählung der »Werbegeschichte« von Anna Csillag mit einem Bibelvergleich unterlegt. Damit wird die Reklamestory aber nicht, wie Kitowska-Łysiak deutet, auf eine religiöse Ebene gehoben, sondern die biblische Geschichte degradiert. ${ }^{103}$ Nachdem der Erzähler zuerst die Illustration beschrieben hat, beginnt er die "Nacherzählung" des ihr zugestoßenen Wunders, welche vielmehr eine Weiterentwicklung oder Assoziation auf Grundlage der Reklame ist.

99 Benjamin, Das Passagen-Werk, $270 \mathrm{f}$.

100 Offenthaler schreibt über die real-existierende Reklame: »Mit ihrem `185 Centimeter langen Riesen-Loreley-Haar trat Anna Csillag als ihr eigenes Testimonial auf und bewarb ihre Haarpflegeprodukte monarchieweit in deutscher, ungarischer, polnischer, tschechischer, slowenischer und russischer Sprache. Anzeigen mit dem einprägsamen Sujet finden sich in den Wiener Blättern ebenso wie etwa in der \Laibacher Zeitung`, im `Kurjer Łódzkiく oder in der `Vasárnapi Ujság`, ja selbst im finnischen `Hufvudstadsbladet « schaltete die Firma Inserate. Diese haben ihre Spuren im Bewusstsein vieler Zeitgenossen hinterlassen und Anna Csillag zu nahezu sprichwörtlicher Bekanntheit verholfen. Offenthaler, Ich, Anna Csillag - ein k. k. Marketingstar.

101 So wurde beispielsweise Anna Csillags Haar im deutschsprachigen Kontext mit Loreleys verglichen, im polnischen mit Rusałkas. Vgl. Ficowski, Regiony wielkiej herezji, 32.

102 Karner, Regina/Lindinger, Michaela: Mode und Kosmetik auf dem Weg ins 20. Jahrhundert: Zur Entstehung der modernen Konsumgesellschaft. In: Dies. (Hg.): Großer Auftritt. Mode der Ringstraßenzeit. Ausstellung Wien Museum Karlsplatz 10. Juni bis 1. November 2009. Wien Museum. Wien 2009, 35-51, hier 39.

103 Vgl. Kitowska-Łysiak, Schulzowskie marginalia, 55. 


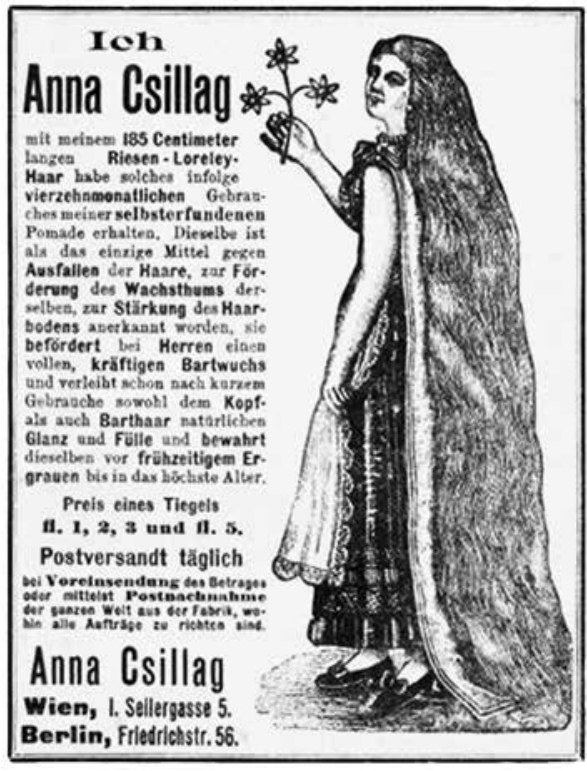

Abb. 11a: „Werbung der Anna Csillag«, Wiener Mode, 15. Jg. 1. Oktober 1901, S. 51, aus: Katalog »Grosser Auftritt. Mode der Ringstrassenzeit.« Hg. von Regina Karner u. Michaela Lindinger, Wien 2009, S. 39.

\section{Ja Anna Csillag}

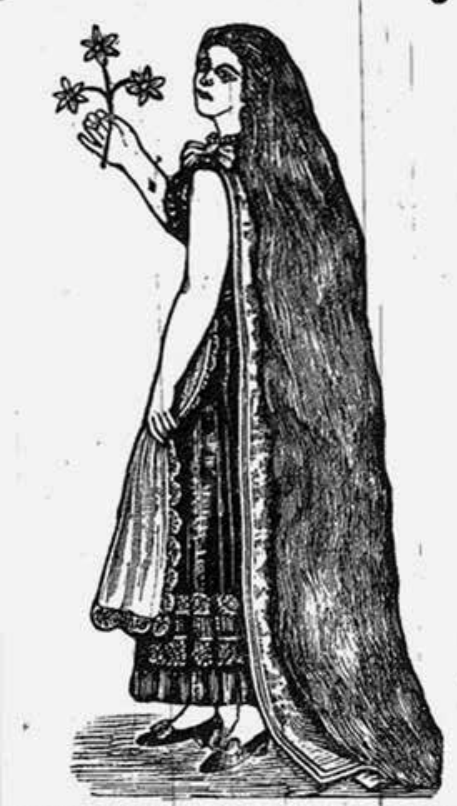

posiadam nlezwykle dłagie (185 ceatipetrów dła. gosei) wlosy; przypominające Loreley dzlęki 14 miesięexnemu uzywaniu specyjaluio przezemalo wgoalezionel pomady. Pomada'ta uzoara jako skz. teczay srodek przeeiw wspadasia whołów, dxiaka rówoocześnie na porost takowyeh $i$ wżnacoia ce. bulki włosowe; mežczyzni, dzięki tej pomadzie, mogą mié bojny 1 allny zarost brođy, a rówoieź (oawet po krotkiem ukywanig tejte) oaturaloy po: lyak wlosów da glowie I brodzíe; oproez tego po. mada ocbraula wlosy od wezeanel siwizoy bawet w starezyom wieku.

$$
\text { Cena siolka rubll } 3,518 .
$$

Po otrzymasiu paletnob́ct, wy^y\}s sie poozta codziennie we wazyatkie strony swiats wprost 2 fabrykl, do której należy sį̀ zwracać $z$ wazelklemi zamówieniami.

Anna Csillag, Wien I, Selllergasse 5.

Pozwoleoin Warsz. Urzęda Lokarakiego

Abb. 11b: "Werbung der Anna Scillag", vgl. Pogoń. 1900, Nr. 32 (22 IV), S. 4.

»[D]er Text daneben verkündete in fettgedruckten Worten: `Ich, Anna Csillag, geboren zu Karlowitz in Mähren, hatte spärlichen Haarwuchs...

Es war dies eine lange Geschichte, ähnlich konstruiert wie die Geschichte Hiobs. Anna Csillag, von einer Geißel Gottes geschlagen, hatte nur schütteres Haar. Das ganze Städtchen bedauerte diese Benachteiligung, die man ihr, wenngleich sie nicht gänzlich unverschuldet sein konnte, angesichts ihres untadeligen Lebenswandels nachsah. Und so geschah es, daß nach inständigen Gebeten dieser Fluch von ihrem Haupt genommen wurde. Die Gnade der Erleuchtung wurde Anna Csillag zuteil, sie 
erhielt allerlei Zeichen und Anweisungen und braute ein Spezifikum, ein Wundermittel, das ihrem Kopf die Fruchtbarkeit zurückgab. Das Haar begann wieder zu sprießen, und damit nicht genug, auch ihr Mann, ihre Brüder und ihre Vettern überzogen sich von einem Tag auf den andern mit dichtem, schwarzem, pelzigem Haarfilz. Auf der nächsten Seite war Anna Csillag sechs Wochen nach Erscheinung ihrer Rezeptur zu sehen, umgeben von ihren schnurrbärtigen Brüdern, Schwägern und Neffen, denen die Vollbärte bis zum Gürtel reichten, und man betrachtete voller Bewunderung diesen wahrhaftigen Ausbruch unverfälschter, bärenhafter Männlichkeit. Anna Csillag beglückte das ganze Städtchen, über das sich ein wahrer Segen in Gestalt wogender Schöpfe und wallender Mähnen ergoß, und deren Bewohner den Boden mit ihren Bärten wie mit breiten Besen fegten. Anna Csillag wurde die Apostolin der Behaarung. Nachdem sie ihr Heimatstädtchen beglückt hatte, wollte sie die ganze Welt beglücken und bat, ermunterte, flehte, um des Heiles willen, doch diese Gottesgabe anzunehmen, dessen Geheimnis nur sie allein kannte. ${ }^{104}$

Der Erzähler erkennt in der »Geschichte« Anna Csillags Parallelen zu Hiob, jenem Gottesfürchtigen, der im Anschluss an eine Wette zwischen Gott und Satan mit unermesslichen Plagen überhäuft wird und alle annimmt, ohne vom Glauben abzurücken. Nachdem ihm Besitz, Familie und Gesundheit genommen wurden, bekommt er von Gott alles in größerer Zahl wieder. ${ }^{105}$

Zwei bedeutende Unterschiede finden sich zwischen der biblischen HiobVorlage und der Csillag-Legende. Erstens ist Anna Csillag nur mit »schütterem Haar " geschlagen, ein rein äußerlicher Makel, kaum erwähnenswert im Vergleich zu den Plagen, die Hiob treffen. Wie in der biblischen Geschichte

104 Schulz, Das Sanatorium zur Sanduhr, 14 f. »[T]ekst wydrukowany obok tłustymi czcionkami głosił historię tego cudu i zaczynał się od słów: ১Ja, Anna Csillag, urodzona w Karłowicach na Morawach, miałam słaby porost włosów...

Była to długa historia, podobna w konstrukcji do historii Hioba. Anna Csillag z dopustu bożego dotknięta była słabym porostem. Całe miasteczko litowało się nad tym upośledzeniem, które wybaczano jej ze względu na nienaganny żywot, chociaż nie mogło ono być całkiem niezawinione. I oto stało się na skutek gorących modłów, że zdjęta była z jej głowy klątwa, Anna Csillag dostąpiła łaski oświecenia, otrzymała znaki i wskazówki i sporządziła specyfik, lek cudowny, który jej głowie przywrócił urodzajność. Zaczęła porastać we włosy i nie dość na tym, jej mąż, bracia, kuzynowie także z dnia na dzień opilśniali się tęgim, czarnym futrem zarostu. Na drugiej stronie pokazana była Anna Csillag w sześć tygodni po objawieniu jej recepty, w otoczeniu swych braci, szwagrów i bratanków, mężów brodatych po pas i wąsatych, i z podziwem patrzyło się na ten prawdziwy wybuch nie sfałszowanej, niedźwiedziej męskości. Anna Csillag uszczęśliwiła całe miasteczko, na które spłyneło prawdziwe bogosławieństwo w postaci falujących czupryn i grzyw ogromnych i którego mieszkańcy zamiatali ziemię brodami jak miotły szerokimi. Anna Csillag stała się apostołką włochatości. Uszczęśliwiwszy rodzinne miasto, zapragnęła uszczęśliwić świat cały i prosiła, zachęcała, błagała, aby przyjąć dla zbawienia swego ten dar boży, ten lek cudowny, którego sama jedna znała tajemnicę.« Ders., Sanatorium pod Klepsydrą, $125 \mathrm{f}$. (Hervorheb. im poln. Orig.)

105 Vgl. Buch Hiob. 
vermuten die Freunde sie nicht frei von jeder Schuld. Anna Csillag bleibt gottestreu, sodass ihr Gottes Erleuchtung zuteilwird und sie die heilende Pomade herstellen kann. Dass sie aus dem Segen ein Geschäftsmodell macht, ist die zweite große Abweichung: Die selbstlose "Apostolin der Behaarung" (»apostołk[a] włochatości«) »bat, ermunterte, flehte, um des Heiles willen « ${ }^{106}$, dass die ganze Welt ihr Wundermittel käuflich erwerben möge.

Auf den realen Csillag-Anzeigen sind die religiösen Motive sehr viel subtiler. Stattdessen wird mit einem säkularen Heilsversprechen, nämlich mit einem die Natur überwindenden Wunder für volles und gesundes Haar »bis ins höchste Alter«, zum Kauf der Ware angeregt. ${ }^{107}$ Dabei ist die religiöse Heilsbotschaft nicht mehr mit ethischen Werten verbunden, sondern mit einer Normierung des Äußeren, welche Einfluss auf den Sozialstatus hat. ${ }^{108}$ Den Beweis für die Wunderwirksamkeit erbringt der Reklametext mit einer Anzahl unüberprüfbarer Leserbriefe ${ }^{109}$ und abgedruckter Dankesschreiben, wodurch der Eindruck erweckt wird, dass sogar Mitglieder der adeligen und gehobenen Gesellschaft zu den Kunden der Firma zählen. ${ }^{110}$

Wie im Benjamin-Zitat deutlich wurde, erinnern die Danksagungen dabei an die Dankgebete und Votivtäfelchen, die Gläubige an Heilige richten, damit diese ihre Bitten erhören oder nach vollzogenem Wunder (Vgl. Abb. 13).

In Schulz' Erzählung wird diese Strategie im Zusammenhang der Anzeige für das »Elsa-Fluid« kommentiert. Elsa-Fluid - »miły dla oka obraz« (ein für das Auge angenehmes Bild) wird als eine »Wunder-Arznei gegen jegliche

106 Schulz, Das Sanatorium zur Sanduhr, 15. "prosiła, zachęcała, błagała, aby przyjąć dla zbawienia« Ders., Sanatorium pod Klepsydrą, 126.

107 Diese groteske Überformung der Reklame in eine biblische Wundergeschichte fasst eine deutliche Fortschrittskritik in sich. Einerseits hinterfragt Schulz die Sinnhaftigkeit der angepriesenen Produkte, denn würden sie tatsächlich jenen Effekt erzielen, den Anna Csillag verspricht, so müsste man aus zivilisatorischen Gründen tunlichst die langen Bärte und Haare wieder abschneiden. Andererseits weist er darauf hin, weshalb die Reklame dennoch die Aufmerksamkeit auf sich zieht, indem er das »Uralte und Wohlbekannte« in ihr aufzeigt, die Anbindung an religiöse Formate, die den Rezipienten auf einer ganz anderen Ebene ansprechen, als er erwarten würde.

108 Da auf die Selbstverschuldung ihrer Haarsituation explizit hingewiesen wird, ist der logische Schluss, dass man sie verbessern kann und damit auch muss. Der Appell richtet sich also an den Rezipienten, ein selbiges bei sich zu tun und so aus der selbstverschuldeten Hässlichkeit durch den Kauf einer wunderwirkenden Pomade herauszutreten. Hier zeigt sich deutlich die Verbindung zu Benjamins Untersuchungen der Frauen und Mode in der modernen Idustriegesellschaft. Vgl. Benjamin, Das Passagen-Werk, $1054 \mathrm{f}$.

109 »Der Beweis ihrer [der Pomade, A. J.] Wirksamkeit sind tausend Briefe der Anerkennung, die täglich aus der ganzen Welt eintreffen." "Skuteczności jej świadectwem są tysiące pism uznania wplywające codziennie z całego świata." Der Reklametext der Anna Csillag, abgebildet in Ficowski, Regiony wielkiej herezji, 213.

110 Vgl. Offenthaler, Ich, Anna Csillag - ein k. k. Marketingstar. 


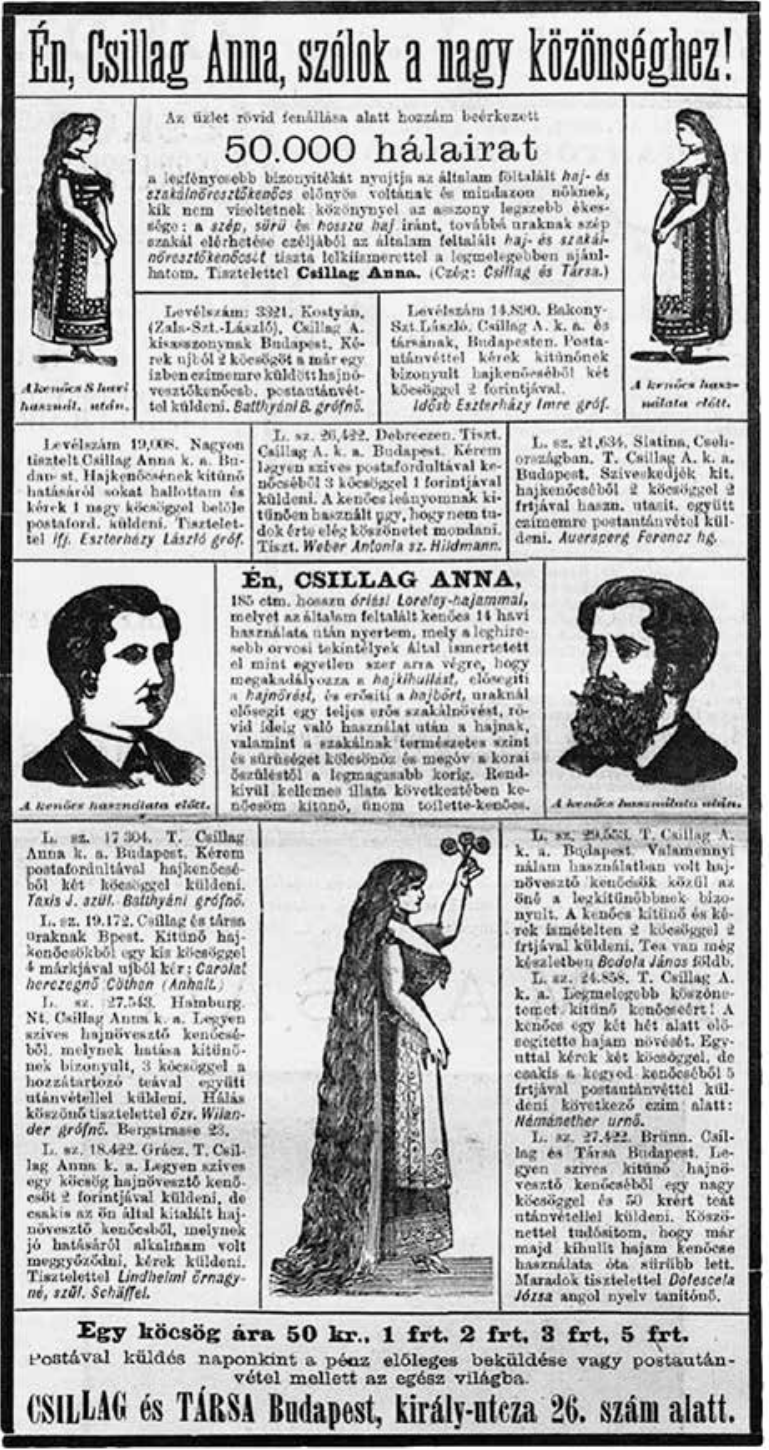

Abb. 12: „Werbung der Anna Csillag«, Vasárnapi Ujság, Nr. 8, 1887. Die ungarische Reklameversion druckt Leserbriefe, in denen über die gute Erfahrung mit der Pomade berichtet und Nachschub bestellt wird. 
Miky dla oka obraz

sily i świeżości przedstawia czlowiek zdrowy, niecierpiący. posiadający zapal do pracy i dobry apetyt. Natomiast obrazem nedzy jest czlowiek, kiedy wskutck bollu jest niezdolny do pracy i nie może chodzič. Znamy jednak doskonaty środet Fluid „Elsa" Fellera, który te cieruienia szybko usuwa, Także uśmierza i łagodzi bóle twarzy, w krzyżach i boku. Chroni teź od wszelkich dolegliwosici powstających wskutek przeziçbienia, wiatru, przecią.

gu, wilgoci w powietrzu

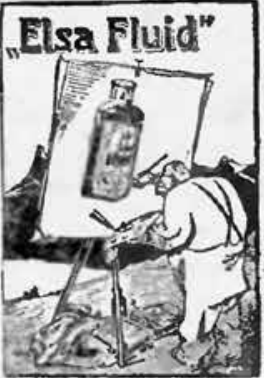

i w mieszkaniu, w szczegóiności kaszlu, kataru, zaflegmieniu i bólu gardła, i dlatego „Elsa" Fluid powinien być zawsze w dornu.

Przy znużeniu, osłabieniu, przeciążeniu pracą i bezsennosci wywołują zmvwania i masaże Fluidem „Elsa" rozkoszne samopoczucie.

Jak dobroczynnie działa Fluid „Elsa” przeciw bólom reumatycznym i dnie (gicht) swı dezą liczne listy dziękczunne, w których prawie codziennie donosza nam, że nawet zastarzate cierpicnia reumaty. czne usuniete zostaly przez Fluid ..Elsa”.

\section{Fluid Fellera}

$\mathrm{z}$ prawnie zastrzeiona marka ochronna .Elsa Fluid" jest do nabycia we wszystkich aptekach,

\section{Przeciw brakowi apetytu,}

zgadzc, odbijaniu sie pomagają skutecznie przeczyszczające pigulki rumbarbarowe z marką "Elsa-Pillen":

Polecamy pozatem:

Fellera pomade do twarzy nElsa",

Fellera "Etsa"s pomade do wlosúw,

Fellera "Filsa" mydlo z mleka liljowego,

Fellera "Elsa" mydlo buraksowe.

Fellera "Elsa" plaster turystycrny.

Fellera ,Elsa" tran $z$ wątroby dorsza,

Vellera, ,Elsa" szwedzkie krople,

Fellera ,Elsa" zagorjański syrup przeciw kaszlowi i bólon piersiowym,

Fellera ,Elsa" Mentolowy sztyfit.

C N V. Narazie nie moźemy podact stałych cen, jednaliże każdocześnie sprzedajemy po najniższych cenach.

\section{Miejsca sprzedaży:}

Prawilziwe preparaty .Elsa" aptekarza E, V. Fellera sạ do nabycia:

W Polsce: Polska Stacja Wysyłkowa nr. 833 preparatow "EIsa" BIeIsko, aptekarz
A. Gutwiňski, Rynek 15.

Dia wszystkich Innych krajow: Aptekarz

E. V. Feller, Stubica Donja Nr. 833 (Jugoslawia).

Abb. 13: „Werbung Elsa Fluid «, Grudządzki Kalendarz Maryański, 1934, S. 47. 
Krankheit und Gebrechen « ${ }^{111}$ angeboten. Wie bei der Reklame Anna Csillags ist auch diese Reklame mit einer Illustration versehen, die auf die merkwürdige Überschrift bezogen ist. Zu sehen ist ein voluminöser Maler, der auf eine Staffelei das Elsa-Fluid malt, worauf auch die Beschriftung hinweist. Die Szene ist in einer Berglandschaft angesiedelt, die der Reklame eine gesunde Atmosphäre verleiht. So liest sich das Bild als Prozess der Übersetzung der gesunden Bergluft in das kaufbare Fluid durch einen Malakt, gleichzeitig markiert es ironischerweise den »künstlichen« Charakter dieser Übertragung durch das Bild im Bild. Umso ironischer die im szpargał verzeichneten Reaktionen und Wirkungen:

»Die Seite war voller beglaubigter Zeugenaussagen, anrührender Berichte von Personen, an denen ein Wunder vollbracht worden war. [...] Sie gingen gebückt und bandagiert, schwangen ihre nicht mehr benötigten Krücken, rissen sich die Pflaster von den Augen und die Verbände von den Skrofeln. ${ }^{112}$

Deutlich wird auf die neutestamentarischen und nachbiblischen Wunderheilungsgeschichten rekurriert, nur dass nun nicht mehr Jesus oder ein Heiliger die Kranken erlöst, sondern das kapitalistische Heilwässerchen oder Kosmetik.

Nicht nur in den Werbetexten finden sich religiöse Anspielungen, auch die Abbildung der Anna Csillag knüpft deutlich an die Ikonenmalerei an. Gleichzeitig lässt sich in der Komposition ein bekanntes Gemälde der Kaiserin Elisabeth von Franz Xaver Winterhalter erkennen, sodass subtil suggeriert wird, auch diese habe die Pomade benutzt. ${ }^{113}$ Die abgebildete Anna Csillag trägt ein langes Gewand und umso längere Haare, die die Wirkkraft der Pomade auch im Bild bezeugen. In ihrer Hand hält sie eine Blume, die Józef Wittlin mit einer Lilie assoziiert, die Blume der Unschuld, Reinheit sowie der heiligen Maria. ${ }^{114}$ Damit wird in dieser Reklame der Glaube an Gott

111 »kartka poświęcona cudownemu lekowi na wszystkie choroby i ułomności« Schulz, Sanatorium pod Klepsydrą, 126.

112 Schulz, Das Sanatorium zur Sanduhr, 16. „Stronica pełna była świadectw uwierzytelnionych, wzruszających relacyj osób, na których cud się dokonał. [...] Szli obandażowani i zgarbieni, potrząsając już niepotrzebnym szczudłem, odrzucali plastry z oczu i opaski ze skrofuł.«Ders., Sanatorium pod Klepsydrą, 126.

113 Vgl. Franz Xaver Winterhalter, "Kaiserin Elisabeth (Sisi) mit langem offenem Haar«, 1865, Öl auf Leinwand, $158 \times 117 \mathrm{~cm}$, Sisi Museum, Wien. Diesen Hinweis verdanke ich Prof. Dr. Dorothee Gelhard. Winterhalter malte dabei eine ganze Reihe von Frauen mit langem, wallendem Haar und die Kaiserin gleich mehrmals. Vgl. Wurm, Sylvia: Düfte, Schminke und Hygiene. In: Forstner, Regina (Hg.): Drüber und Drunter. Wiener Damenmode von 1900-1914. Wien 1988, 14-18, hier 17.

114 »Stoję w gazetach twoich niby święta./Jak lilję trzymam gałązkę z gwiazdami,/Czas mej anielskiej urody nie zmienia:/ Puszysty włosów rozpuszczony dywan/Szumną kaskadą do stóp moich spływa,/Do bosych stóp bogini uwłosienia." Wittlin: A la recherche des 
durch einen Konsumglauben ersetzt. Das versprochene Heil kann käuflich erworben werden und tritt durch ritualisierte Anwendung schon auf Erden ein. Somit wird deutlich, dass die »Nacherzählung « dieser Werbung in Schulz' Erzählung, ebenso wie die Darstellung der Krokodilstraße, nicht als willkürliche oder private Mythisierung eines beliebigen Gegenstands zu verstehen ist, sondern als eine sehr genaue Analyse und Sichtbarmachung der religiösen Motive und Überzeugungsstrategien von Werbebildern.

Auch alle weiteren in der Erzählung behandelten Werbeanzeigen folgen diesem Muster. Instrumente, die einst den Engelschören gehörten, sind »heute dank dem Fortschritt der Industrie für den einfachen Mann zu populären Preisen erschwinglich « und dienen »dem gottesfürchtigen Volk zur Erbauung der Herzen und zur gesitteten Zerstreuung. ${ }^{115}$ Ein gewisser Herr Bosco aus Mailand, dessen Name im Polnischen wie "göttlich« klingt, bietet seine schwarze Magie feil. ${ }^{116}$ Zum Abschluss erfreut die Anzeige der Magda Wang $^{117}$ den Leser mit ihrem großzügigen Dekolleté, ihrer Fähigkeit, die

temps perdu, 13. »Ich stehe in deinen Zeitschriften wie eine Heilige./ Einen Zweig mit Sternen wie eine Lilie trage ich,/ Die Zeit verändert meine engelhafte Schönheit nicht:/ Ein Teppich offener flaumweicher Haare/ in einer rauschenden Kaskade zu meinen Füßen fließt,/ zu den nackten Füßen der Göttin der Behaartheit.« (Übers. A. J.)

115 Schulz, Das Sanatorium zur Sanduhr, 17. »dziś dzięki postępom przemysłu udostępnione po popularnych cenach prostemu człowiekowi, bogobojnemu ludowi dla pokrzepienia serc i godziwej rozrywki.« Ders., Sanatorium pod Klepsydrą, 127.

116 Caneppele, der sich um die Suche nach realen oder potentiellen Vorlagen zu Schulz' Erzählungen verdient gemacht hat, belegt, dass auch Bosco keine reine Einbildung ist. »Auch Schulz' literarischer Magier existierte tatsächlich. Zwischen 1830 und 1850 triumphiert der Turiner Zauberkünstler Bartolomeo Bosco (1793-1863) in ganz Europa. Sein Erfolg animiert zur Nachahmung und unter seinem Namen tauchen verschiedenste Epigonen auf. Der Ruhm des italienischen Magiers erreicht Polen im Jahr 1885, als dort das Büchlein Der Meister der schwarzen Magie Bosco, oder eine Sammlung von interessanten und verwunderlichen Zauberspielen veröffentlich wurde." Vgl. Caneppele, Die Republik der Träume, 66 f. (Hervorh. im Orig.)

117 Magda Wang ist die Protagonistin des dänischen Stummfilms "Afgrunden« (Der Abgrund) von Urban Gad aus dem Jahre 1910, gespielt von der damals weltbekannten Schauspielerin Asta Nielsen. Der Film porträtiert eine Frau, die den langweiligen Alltag an der Seite eines wohlhabenden und -gesitteten Mannes gegen das aufregende, wenn auch treulose Leben an der Seite eines Zirkusakrobaten eintauscht. Asta Nielsen war eine der ersten weiblichen Filmdarstellerinnen, die es zu großem Ruhm brachten. In der Erzählung »Noc Lipcowa» (Julinacht) beschreibt der Erzähler, der gerade die Matura erlangt hat, wie er aus dem Kino kommt und ein Filmplakat mit Asta Nielsen sieht. "Auf einem großen farbigen Plakat taumelt Asta Nielsen mit ihrem ewigen schwarzen Todesstigma auf der Stirn, ihr Mund ist für alle Zeiten geöffnet zum letzten Schrei, die Augen sind übermenschlich aufgerissen und endgültig schön. S Schulz, Das Sanatorium zur Sanduhr, 141. »Na wielkim kolorowym afiszu Asta Nielsen słaniała się już na zawsze z czarnym stygmatem śmiertelnym na czole, raz na zawsze usta jej były otwarte w ostatnim krzyku, a oczy wytężone nadludzko i ostatecznie piękne.« Ders., Sanatorium pod Klepsydrą, 206. 
stärksten männlichen Charaktere zu brechen und mit ihrem Buch, in welchem sie "die Resultate ihrer kolonialen Erfahrungen auf dem Gebiet der Menschendressur (dieses Wort mit Nachdruck und ironischem Augenblinzeln) « ${ }^{118}$ zum Besten gibt. Alle diese Anzeigen haben eine Entsprechung in der außerliterarischen Wirklichkeit und tauchen in unterschiedlichen künstlerischen und wissenschaftlichen Werken von Schulz' Zeitgenossen auf. ${ }^{119}$

Sind also die Werbebilder im szpargał Gegenstand der Untersuchung, so lässt sich die Księga als ihr Kommentar oder Deutung lesen. Schulz betont dabei die Adaption religiöser Überzeugungsstrategien. Nicht mehr im Gebet, sondern durch Konsum lässt sich das versprochene Gut erlangen. Alles ist käuflich: die Gesundheit, die Schönheit, die Liebe, selbst die Zukunft oder die Entscheidung. Auch wenn die Geschichten der Anzeigebilder euphorisch erzählt werden, findet sich dennoch eine deutliche Kritik. Das lange Haar der Csillag-Anhänger fegt den Boden, die Leierkastenkäufer spielen überall dieselben zwei Lieder und die letzten Seiten des szpargał arten »deutlich sichtbar in phantastisches Gefasel, in offenbaren Unsinn « ${ }^{120}$ aus. "[T]raurige, von Prosa und Alltag verhärtete Städte unter einem papierweißen Himmel « ${ }^{121}$ finden ihre religiöse Poesie in diesen Formaten, weil sie an der religiösen Welt keinen Anteil mehr haben. Die Reklamegeschichten sind dem Erzähler in der sonst tristen Wirklichkeit Inseln des Wunderglaubens und der Hoffnung in ihrer vollen Ambivalenz. Die magische Lesart der im Grunde geschmacklosen Anzeigen nennt der Erzähler daher auch "poetisch«, ganz in der Terminologie der »Mityzacja rzeczywistości.« »Die folgenden Seiten erhoben sich über die Sphäre der Alltäglichkeiten, weit hinein in die Regionen reiner Poesie. ${ }^{122}$ Auch hier offenbart sich somit ein dialektischer Blick auf die Inhalte der Reklameanzeigen. Das in ihnen vermittelte Neue und Begehrenswerte erweist sich als verwandelte Form des Altbekannten. In Abbildung und Text der Haarpomade steckt ein Appell an das mythische Bewusstsein, das auch in der rationalen Welt bereit sein soll, an Wunder zu glauben, die der Fortschritt

118 Ders., Das Sanatorium zur Sanduhr, 21. »rezultaty swych doświadczeń kolonialnych w dziedzinie tresury ludzi (ten wyraz z naciskiem i ironicznym błyskiem oczu) « Ders., Sanatorium pod Klepsydrą, 129.

119 Asta Nielsen beispielsweise taucht auch in Benjamins zentralem Aufsatz über »das Kunstwerk im Zeitalter seiner technischen Reproduzierbarkeit« auf. Vgl. Benjamin, Das Kunstwerk, 453.

120 Schulz, Das Sanatorium zur Sanduhr, 21. "w sposób widoczny popadały w majaczliwe bredzenie, w jawny bezsens. "Ders., Sanatorium pod Klepsydrą, 129.

121 Ders., Das Sanatorium zur Sanduhr, 16. »Poprzez te wędrówki kalek widziało się dalekie i smutne miasteczka o białym jak papier niebie, stwardniałe od prozy i codzienności." Ders., Sanatorium pod Klepsydrą, 130.

122 Ders., Das Sanatorium zur Sanduhr, 17. "Następne stronice wznosiły się ponad sferę spraw codziennych w regiony czystej poezji.« Ders., Sanatorium pod Klepsydrą, 127. 
verspricht. Diesem Glauben fügt Schulz noch den Kodex in Form der verschollenen, degradierten Księga hinzu und appelliert ebenfalls an die Glaubensbereitschaft seines Lesers, auch wenn er gleichzeitig dekonstruierende Hinweise gibt und Widersprüche und Ironie einbaut. Wie gut diese Überzeugungsstrategie funktioniert, zeigt sich an Kitowska-Łysiaks Interpretation der Anna Csillag:

"Anna Csillag verwirklicht die Wünsche des Erzählers, welche ihm bis zum Moment ihrer Erscheinung nur mythisch, irgendwie hypothetisch, und damit unerreichbar vorkamen, also ein Bild, das, wie er zugibt, in seiner Seele schwebte. Anna übernimmt gewissermaßen eine missionarische Funktion, um nicht zu sagen: messianische - die göttliche Gabe ist gleichzeitig eine Wundermedizin, wie sie selbst. Sie ist eine gute Fee (sie trägt einen Zauberstab in der Hand), eine Göttin und Heilige in einem. / Dank ihr findet der Erzähler das Urbuch, die Schatztrue der Weisheit, die einzige Quelle des geistigen Reichtums, den Stein der Weisen. ${ }^{123}$

Kitowska-Łysiak überliest die ironische Distanz und die Mythoskritik, indem sie die inhärenten und aufgedeckten religiösen Bezüge als Beweis für Anna Csillags Heiligkeit nimmt.

Um auf die Untersuchung der Erzählung »Ulica Krokodyli« zurückzukommen, in welcher die durch die Illustrierten erzeugte Wirklichkeit mit einer distanzierten Haltung betrachtet wird, so ist die inhaltliche Auseinandersetzung mit Werbebildern in "Księga" durch eine affirmative, intime Sprache geprägt. Der beharrlich wiederholte Appell an den Leser, an die Existenz des Buchs zu glauben, liest sich daher selbst als literarische Adaption der Werbestrategien. Indem er die Wirklichkeit kommentiert, macht er das mythische Element in den Gegenständen der Wirklichkeit sichtbar. ${ }^{124}$ Indem der Erzähler mit viel Nachdruck betont, die Księga sei nicht die Bibel, zeigt er auf, dass die Bibel in der Gegenwart ihren Zauber verloren hat. An ihre Stelle tritt der Reklamekatalog als neues magisches Buch, das die Wahrnehmung und das Handeln bestimmt. Daraus schlussfolgernd kann man die Księga als Metapher für die Buchform der Gegenwartsmagie verstehen. Gleichzeitig kann man sie auch als »dialektisches Bild « interpretieren, weil verschiedene kulturelle Bedeutungsverschiebungen der Gegenwart an dieser Metapher sichtbar werden. Das Anzeigenblatt stellt wie die Passagen einen Umschlagplatz

123 Kitowska-Łysiak, Schulzowskie marginalia, 55. (Übers. A.J.) »Anna Csillag realizuje marzenie narratora, które do momentu jej pojawienia się stanowiło tylko mityczny, niejako hipotetyczny, a więc nieuchwytny, obraz, który, jak wyznaje, płonął w jego duszy. Anna pełni poniekąd funkcje misjonarskie, żeby nie powiedzieć: mesjańskie darem bożym jest równo cudowny lek, jak ona sama. Jest dobrą wróżką (trzyma w dłoni różdżkę), boginią i świętą w jednym./ Dzięki niej narrator znajduje Księgę, skarbnicę mądrości, jedyne źródło duchowego bogactwa, kamień filozoficzny.«

124 Vgl. Błoński, Świat jako księga i komentarz. 
aus der alten in die neue Epoche dar. Benjamin vergleicht die Entwicklung der Reklame mit der der Kunst und stellt die These auf, dass die Kunst seit der Industrialisierung mit der Umspielung und Erforschung der entwickelten Waren nicht mehr nachkommt. Anders verhält es sich in der Reklame, die mit großer Dynamik neue Formen der Narration entwickelt. Eine Reklame für Bullrich-Salz analysierend, erklärt Benjamin, welche große Faszination von ihr auf ihn ausgeht.

»Vor vielen Jahren sah ich in einem Stadtbahnzuge ein Plakat, das, wenn es auf der Welt mit rechten Dingen zuginge, seine Bewunderer, Historiker, Exegeten und Kopisten so gut wie nur irgend eine große Dichtung oder ein großes Gemälde gefunden hätte. Und in der Tat war es beides zugleich. Wie es aber bei sehr tiefen, unerwarteten Eindrücken bisweilen gehen kann: der Chock war so heftig, der Eindruck, wenn ich so sagen darf, schlug so gewaltig in mir auf, daß er den Boden des Bewußtseins durchbrach und jahrelang unauffindbar irgendwo in der Dunkelheit lag. Ich wußte nur, daß es sich um »Bullrichsalz« handelte und daß die Originalniederlage dieses Gewürzes ein kleiner Keller in der Flottwellstraße war, an dem ich jahrelang mit der Versuchung vorbeifuhr, hier auszusteigen und nach dem Plakate zu fragen. Da gelangte ich eines verschossenen Sonntagnachmittags in jenes nördliche (?) Moabit, das wie für eben diese Tageszeit geisterhaft aufgebaut schon einmal vor vier Jahren mich betroffen hatte, damals als ich eine chinesische Porzellanstadt, die ich aus Rom mir hatte kommen lassen, in der Lützowstraße nach dem Gewicht ihrer emaillierten Häuserblocks zu verzollen hatte. Vorzeichen deuteten diesmal schon unterwegs darauf hin, daß es ein bedeutungsvoller Nachmittag werden müsse. Und so endete er denn auch mit der Entdeckungsgeschichte einer Passage, eine Geschichte, die zu berlinisch ist, als daß sie in diesem pariser Erinnerungsraum sich erzählen ließe. Vorher aber stand ich mit meinen bei den schönen Begleiterinnen vor einer poveren Destille, deren Auslagebuffet durch ein Arrangement von Schildern belebt war. Eines darunter war »Bullrich-Salz«. Es enthielt nichts als das Wort, aber um diese Schriftzeichen bildete sich plötzlich, mühelos jene Wüstenlandschaft des ersten Plakats. Ich hatte es wieder. So sah es aus: Im Vordergrunde der Wüste bewegte ein Frachtwagen sich vorwärts, den Pferde zogen. Er hatte Säcke geladen, auf denen »Bullrich-Salz« stand. Einer dieser Säcke hatte ein Loch, aus dem Salz schon eine Strecke weit auf die Erde gerieselt war. Im Hintergrunde der Wüstenlandschaft trugen zwei Pfosten ein großes Schild mit den Worten »Ist das Beste«. Was tat aber die Salzspur auf dem Fahrwege durch die Wüste? Sie bildete Buchstaben und die formten ein Wort, das Wort: »Bullrich-Salz«. War die prästabilierte Harmonie eines Leibniz nicht Kinderei gegen diese messerscharfe eingespielte Prädestination in der Wüste? Und lag nicht in diesem Plakate ein Gleichnis vor, für Dinge, die in diesem Erdenleben noch keiner erfahren hat. Ein Gleichnis für den Alltag der Utopie? « ${ }^{125}$

125 Fast wie eine Parabel beschreibt Benjamin die Faszination, die von manchen Reklameplakaten ausgeht: Benjamin, Das Passagen-Werk, $235 \mathrm{f}$. 
Ähnlich wie Schulz liest Benjamin die Reklame in einem biblischen Kontext, zumindest deutet seine Betonung der Wüstenlandschaft in Kombination mit den sich formierenden Schriftzeichen darauf hin. Wenn Exegeten sich dieser Bild-Text-Kombination widmen sollen, so spricht auch dieses für seine Wahrnehmung einer religiösen Bedeutung. Wie Schulz' Erzähler betont Benjamin die tiefe Ergriffenheit und Wirkung, die diese Reklame auf ihn hatte. So empfindet er ein Wiedertreffen mit ihr als schicksalhaft und fordert ihn zum Nachdenken über das Leben und den Glauben heraus.

Benjamin bezeichnet die "Reklame [...] die List, mit der der Traum sich der Industrie aufdrängt. « ${ }^{126}$ Auch er betont die Möglichkeit, neben der Reklamebotschaft ihr mythenschöpferisches Potential zu untersuchen. Sie verleiht der industriell gefertigten und verdinglichten Ware wieder einen Bezug zum Menschen, indem sie diese mit Bildern und Geschichten umspielt und belegt. Der Mode und ihren Bildern und Kreationen schreibt Benjamin sogar hellseherisches Potential zu, dass ähnlich wie ein Künstler kommende Entwicklungen schon in Bilder darzustellen vermöge. Daher verwundere es auch nicht,

»aß gerade in diesem trockensten, phantasielosesten Jahrhundert sich die gesamte Traumenergie einer Gesellschaft mit verdoppelter Vehemenz in $\mathrm{d}<\mathrm{as}>$ undurchdringliche lautlose Nebelreich der Mode geflüchtet hat, in $\mathrm{d}<$ as $>$ der Verstand ihr nicht folgen konnte. ${ }^{127}$

Die Mode und Reklame übernehmen das Tempo der Entwicklungen und stellen es damit dar. »Das neue Tempo des Lebens kündigte sich oft auf unvermute $<\mathrm{t}>$ ste Weise an. So in den Affichen. ${ }^{128}$

"An der Mode hat dieses rätselhafte Sensationsbedürfnis sich von jeher befriedigt. Auf den Grund aber wird ihm allein die theologische Untersuchung kommen, denn es spricht daraus ein tiefes, affektives Verhalten des Menschen dem Geschichtsablauf gegenüber. Man möchte dies Sensationsbedürfnis an eine der sieben Todsünden anschließen und man wundert sich nicht, wenn ein Chronist apokalyptische Prophezeiungen daran schließt und die Zeit verkündet, da die Menschen vo $<$ n $>$ der Überfülle von elektrische $<m>$ Licht blind und vom Tempo der Nachrichtenübermittlung wahnsinnig werden würden. ${ }^{129}$

Benjamin weist an verschiedenen Stellen immer wieder darauf hin, dass man Reklamebilder und Plakate theologisch deuten solle, weil sie so tief auf das Bewusstsein einwirkten. Die Bilder und Slogans beeinflussen wie die 
vielfach gehörten Bibelerzählungen das Assoziationsverhalten einer ganzen Generation.

Beide Erzählungen von Schulz, so lässt sich festhalten, untersuchen Werbebilder in sehr unterschiedlichen Kontexten. Beide betonen die Anknüpfung an mythische und biblische Motive und Strukturen, die verdeckt und verwandelt in den Darstellungen, in den Textbezügen und im Wunderglauben an Konsumgüter, Gesundheitswässerchen und Schönheitsversprechen sich darstellen. Während in »Ulica Krokodyli« alles billig, provisorisch und verrufen ist, dominiert in "Księga" das mythische, zum Teil theologische Moment Zauberkraft und Wunderglaube. Das Negativ-Positiv-Spiel löst sich in eine Dialektik durch den Vergleich auf. Sowohl die düstere Welt des Scheins, der billigen Materialien und der unreflektierten Warengläubigkeit als auch das lichte Spiel mit religiösen Narrativen, mit Wunderversprechen und der Hoffnung auf Erlösung in der Jetztzeit gehören zur Wirklichkeit der Werbebilder. Deutlich zeigt sich diese Dialektik an den Frauen, die in »Ulica Krokodyli« als Prostituierte auftreten und damit die Reizschau und Verdinglichung des weiblichen Körpers zu Werbezwecken problematisieren. In »Księga» hingegen erscheint Anna Csillag als Heilige und Apostolin. Wie auch in dem Roman "Venus im Pelz« und auf den Grafiken der "Xięga Bałwochwalcza» ist der weibliche Körper wieder Projektionsfläche und insbesondere Teil der Bilderwelt.

\subsection{Der Warenfetisch - Pilger und Panienki}

Daher lohnt sich von hier aus ein Blick zurück in die Grafiksammlung "Xięga Bałwochwalcza«, die durch den Gleichklang im Titel an die Erzählung »Księga « anschließt und mit »Ulica Krokodyli« durch die düstere, erotische, sündige Atmosphäre und die Darstellung der Frauen verbunden ist. Dies gilt insbesondere für die Gruppe der jungen Mädchen, ${ }^{130}$ die etwa im gleichen Alter wie die Ladenmädchen der »Ulica Krokodyli« sind. Liest man die Beschreibung der Ladenmädchen hinsichtlich einer Ähnlichkeit mit den Grafikmädchen, so fallen verschiedene Aspekte ins Auge.

»Die Ladenmädchen schieben sich immer häufiger zwischen die Buchreihen, sie sind grau und papieren wie die Illustrationen, doch in ihren liederlichen Gesichtern sind sie voll Pigment, dem dunklen Pigment der Brünetten, das von der fettigen Schwärze funkelt, die in ihren Augen lauert und plötzlich im Zickzack, wie glänzende Kaker-

130 Die Gruppe der jungen Mädchen setzt sich aus den Grafiken »Plemię pariasów« (Das Volk der Paria), »Pielgrzymi« (Die Pilger), »Procejsa« (Die Prozession) sowie »Święto bałwochwalców« (Das Fest der Götzenanbeter) zusammen. 
laken, aus ihnen weicht. Doch auch im gebrannten Wangenrot, in den pikanten Stigmen der Muttermale, in der beschämenden Zeichnung dunklen Bartflaums verriet sich die Rasse gestockten, schwarzen Blutes. ${ }^{131}$

Wie schon zuvor die Häuser und Läden der Krokodilstraße werden auch die Ladenmädchen mit Materialattributen der Illustrierten beschrieben. Sie sind grau und papieren, haben viel schwarzes Pigment und die fettige Schwärze erinnert an frischen Druck. Gleichzeitig sind dies auch die Eigenschaften von Grafiken. Obwohl sie so jung sind, sind sie schon liederlich und ihre Gesichter zeichnen sich durch Muttermalstigmen, Wangenrot und lauernde Augen aus.

»Die Mädchen demonstrieren der Reihe nach die Figuren und Stellungen auf den Illustrationen und Bucheinbänden [...]. Sie kehren ihm [dem Klienten] den Rücken oder die Seite zu und stellen sich in arrogantem Kontrapost auf, sie wechseln von einem Bein auf das andere, spielen mit ihrem koketten Schuhwerk, lassen die Gliedmaßen schlangenartig von oben nach unten über ihre schlanken Körper gleiten und attackieren mit diesem Spiel hinter der Fassade lässiger Unverantwortlichkeit den erregten Zuschauer, den sie ignorieren. ${ }^{132}$

Neben den Materialeigenschaften teilen die Grafik- mit den Ladenmädchen das zur Schau gestellte Desinteresse an den sie umgebenden Männern sowie auffällige Damenschuhe, die zu ihren kindlichen Körpern kaum passen. Die Männer der Grafiken hingegen suchen Kontakt zu den nackten Mädchen, welche in drei von vier Fällen in eine andere Richtung schauen. Während die Männer andächtig vor den Mädchen und ihrem Schuhwerk niederknien, stehen oder sitzen die Mädchen passiv da. Die »Grafikpilger« führen Banner mit sich, deren Emblem nur auf einer der Grafiken zu erkennen ist. "Procesja» zeigt schemenhaft erneut den Damenschuh als Symbol für Mode, Erotik und Konsum. An anderer Stelle tritt der Schuh in den Erzählungen im Kontext der Genesis auf. In »Genialna epoka« behauptet die Nebenfigur Szlomo, dass Gott seinen Schöpfungsplan am siebten Tage unterbrochen habe, weil ihm

131 Schulz, Die Zimtläden, 105. »Panienki sklepowe przesuwają się coraz częściej pomiędzy szeregami książek, szare i papierowe, ale pełne pigmentu w zepsutych twarzach, ciemnego pigmentu brunetek o lśniącej i tłustej czarności, która zaczajona w oczach, z nagła wybiegała z nich zygzakiem lśniącego karakoniego biegu. Ale i w spalonych rumieńcach, w pikantnych stygmatach pieprzyków, we wstydliwych znamionach ciemnego puszku zdradzała się rasa zapiekłej, czarnej krwi.« Ders., Sklepy cynamonowe, 95.

132 Ders., Die Zimtläden, 106. »Panienki demonstrują, jedna przed drugą, figury i pozycje rycin okładkowych [...]. Odwrócone do niego [klienta, A.J.] tyłem lub bokiem, przystawały w aroganckim kontrapoście, przestępowały z nogi na nogę, grając kokieteryjnym obuwiem, przepuszczały z góry na dół po smukłym ciele wężową grę członków, atakując nią spoza swej niedbałej nieodpowiedzialności podnieconego widza, którego ignorowały.« Ders., Sklepy cynamonowe, 95. 
ein »fremdes Motiv « ${ }^{133}$ untergekommen sei - ein Schuh. ${ }^{134}$ Szlomo lässt beim Anblick von Adelas Schuh die Księga, das heilige Buch, liegen und flieht mit dem Fetisch des Konsums und der Erotik. ${ }^{135}$ Eduard Fuchs, der die Gesellschaft und ihre Bilderzeugnisse historisch-materialistisch deutet ${ }^{136}$ und mehrere Werke zur erotischen Kunst und Frau im Bild verfasst hat, erkennt in den 1910er und 1920er Jahren den Höhepunkt einer Geschichte der Fuß- und Beinverehrung. Dies spiegele sich am direktesten in den Modebildern und illustrierten Zeitschriften wider. ${ }^{137}$ Gleichzeitig nimmt er die Darstellung der Frau in Bilderzeugnissen zum Maßstab, um eine gesellschaftliche Verfasstheit zu analysieren. Je stärker die Frau als Geschlechterwesen adressiert

133 Ders., Das Sanatorium zur Sanduhr, 43. »obcy wątek« Ders., Sanatorium pod Klepsydrą, 143.

134 Sikorski liest den Schuh im religiösen Kontext. »Der Schuh gehört, als Verlängerung des Beins, eher zur erotischen Symbolik als der Hut. Weil wir es in Schulz' Prosa mit vielen Bibelbezügen zu tun haben, müssen wir uns an dieser Stelle im Zusammenhang mit der Beinsymbolik erinnern, dass im Alten Testament, in Exodus, das hebräische Wort regel als Bein vorkommt, welches ein Euphemismus für ein Zeichen der sexuellen Symbolik, der Genitalien, ist.« (Übers. A. J.) »But należałby, jako przedłużenie nogi, bardziej do symboliki erotycznej niż kapelusik. Ponieważ w prozie Schulza mamy wiele odniesień do Biblii, trzeba napomknąć w związku z symboliką nogi, że w Starym Testamencie, w Księdze Wyjścia występuje hebrajskie słowo regel jako noga, które jest eufemizmem na oznaczenie symboliki seksualnej, genitaliów.« Sikorski, Symboliczny świat, 29. Für eine umfangreichere Untersuchung des Schuhs und des weiblichen Unterbeins siehe Juraschek, Anna: Wohin weist die Wade?: Eine Untersuchung der Bedeutung des Bereichs Knie abwärts im Werk von Bruno Schulz oder die Welt von der Wade aus betrachtet. In: Howanitz, Gernot/Kampkötter, Christian/Kirschbaum, Heinrich (Hg.): Slavische Identitäten. Paradigmen, Poetiken, Perspektiven. München 2014, 169-179.

135 Vgl. Schulz, Sanatorium pod Klepsydrą, $143 \mathrm{f}$.

136 Für Eduard Fuchs ist die Kunst eng verbunden mit der Ökonomie. Die herrschende Klasse habe ihr Geld in Kunstobjekten angelegt und präsentiere und manifestiere ihre Herrschaft in ebensolchen. "Daraus ergibt sich aber auch, dass es niemals eine Kunst im allgemeinen gibt, sondern stets eine Klassenkunst. Der Typ der anderen Klassen gestaltet sich im Zeitbilde stets gemäß der Logik der herrschenden Klasse, die sich einzig auf deren Herrschaftsinteressen aufbaut. Vulgär ausgedrückt: Man schaut die Dinge niemals absolut richtig, sondern eben stets mit den Augen sseiner Zeit an. Die Augen sseiner Zeit` sind aber stets die Augen der jeweils herrschenden Klasse. Denn jede herrschende Klasse zwingt ihre Ideologie ihrem Zeitalter als die allgemein gültige auf." Fuchs, Eduard: Geschichte der erotischen Kunst. Das zeitgeschichtliche Problem. München, 16.

137 »Das Frauenbein ist zu einem erotischen Symbol erhoben worden, das die elektrisierendsten Wirkungen so sehr an sich fesselt, daß es förmlich zu dem Szepter zu werden droht, das den größten Teil der Männerwelt unter seinen Herrscherwillen zwingt. Diesen heutigen Zustand spiegelt die Kunst in direkt verblüffender Weise. Ein einziger Blick in unsere Modejournale, in unsere illustrierten Zeitungen, die in ihrer großen Mehrzahl heute überall einen Stich ins Galante haben, in unsere Witzblattpresse usw. genügt." Fuchs, Eduard: Geschichte der erotischen Kunst. Das individuelle Problem. München ca.1923, 363. 
werde, desto weniger Anteil habe sie an den gesellschaftlichen Entscheidungsprozessen. ${ }^{138}$ Ähnlich wie Mitchell betont Fuchs den Einfluss der Herrschaftsverhältnisse in die Bilder einer Zeit.

Schaut man sich die dargestellten Geschlechterverhältnisse hinsichtlich einer Machtordnung an, fällt auf, dass die jungen Mädchen wohlgeformt sind, während die Männer grotesk deformiert sind. ${ }^{139}$ Sie kommen robbend, kriechend und in gebückter, andächtiger, betender Haltung zu den Mädchen, führen Banner mit sich und tragen so einen guten Teil zur kultischen Atmosphäre bei. Tatsächlich ist die religiöse Haltung allein bei ihnen zu beobachten, die Frauen hingegen nehmen von ihren Anbetungen kaum Notiz. Auf der Grafik »Procesja« sind die Männer sogar in religiöse Kutten gewandet, hinter dem nackten jungen Mädchen sieht man ein großes Gotteshaus. Auch in den Titeln werden nicht die Mädchen adressiert, sondern vornehmlich die pilgernden Männer: "Plemię pariasów« (Das Volk der Paria) (Abb. 14), »Pielgrzymi« (Die Pilger) (Abb. 15), »Procejsa« (Die Prozession) (Abb. 16) sowie "Święto bałwochwalców« (Das Fest der Götzenanbeter) (Abb. 17). ${ }^{140}$ Während in der »Undula-Gruppe« meist die Frau im Titel adressiert ist, sind es nun die Männer, die darüber hinaus im Kollektiv auftreten. Zwar findet sich unter ihnen der Künstler Schulz im Selbstporträt, er hebt sich aber von den anderen Figuren in seiner Rolle kaum ab.

Eine vergleichbare Darstellung einer Pilgergruppe findet sich wiederum in »Księga «. Dort treten im Kontext der Reklamen »Wanderungen von Krüppeln $\aleph^{141}$ auf, die in der starr und traurig gewordenen Prosa des Alltags nach Poesie suchen. Die auf den Grafiken scheinbar aktiveren Pilger sind in der Erzählung Teil der Reklamewelt und ihrer Sinnkonstruktion. ${ }^{142}$ Im Verlust der alten religiösen Ordnung fliehen sich die Pilger in die Ordnung und Bilderwelt des Konsums und der Reklame. ${ }^{143}$

»Doch zurück zu unseren Pilgern.

Wer kennt nicht diese alte Garde, die nomadischen Kimbern, diese tiefdunklen Männer mit ihren scheinbar gewaltigen Körpern aus saft- und kraftlosem Gewebe? Ihre

138 Dabei rechnete er jene Zeiten, in denen die religiösen Götzen weiblich waren, zu denen, in welchen die Frau in der Gesellschaft am wenigsten zählte. "In solchen Zeiten scheidet aus der Wertung der Frau alles menschlich Edle, alles Geistige und Seelische aus, sie ist erniedrigt zum bloßen Lustobjekt.«Ders., Die Frau in der Karikatur, 31.

139 Vgl. Augsburger, Masochismen, 181 f. »Dem weiblichen Part kommt in diesen Graphiken eine unrealistische Macht und Bedeutsamkeit zu, die kritisch als Fetischisierung und Verdinglichung beschrieben werden kann.«

140 Vgl. Schulz, Księga obrazów, 249-251; 264.

141 Ders., Das Sanatorium zur Sanduhr, 16. »wędrówki kalek« Ders., Sanatorium pod Klepsydrą, 126.

142 Ebd., $127 \mathrm{f}$.

143 Vgl. ebd., 131. 


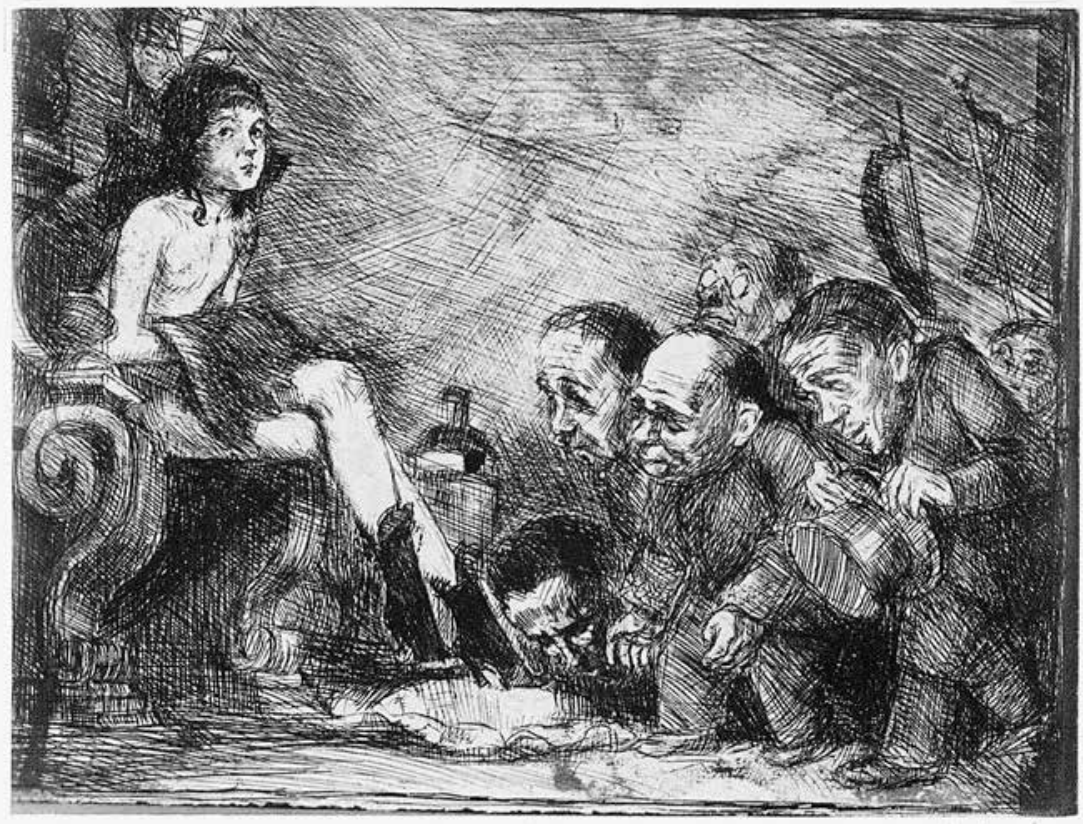

Abb. 14: Schulz, »Plemię pariasów« (Das Volk der Paria), 1920-1922, Cv, 8,8 × 12 cm, BJ.

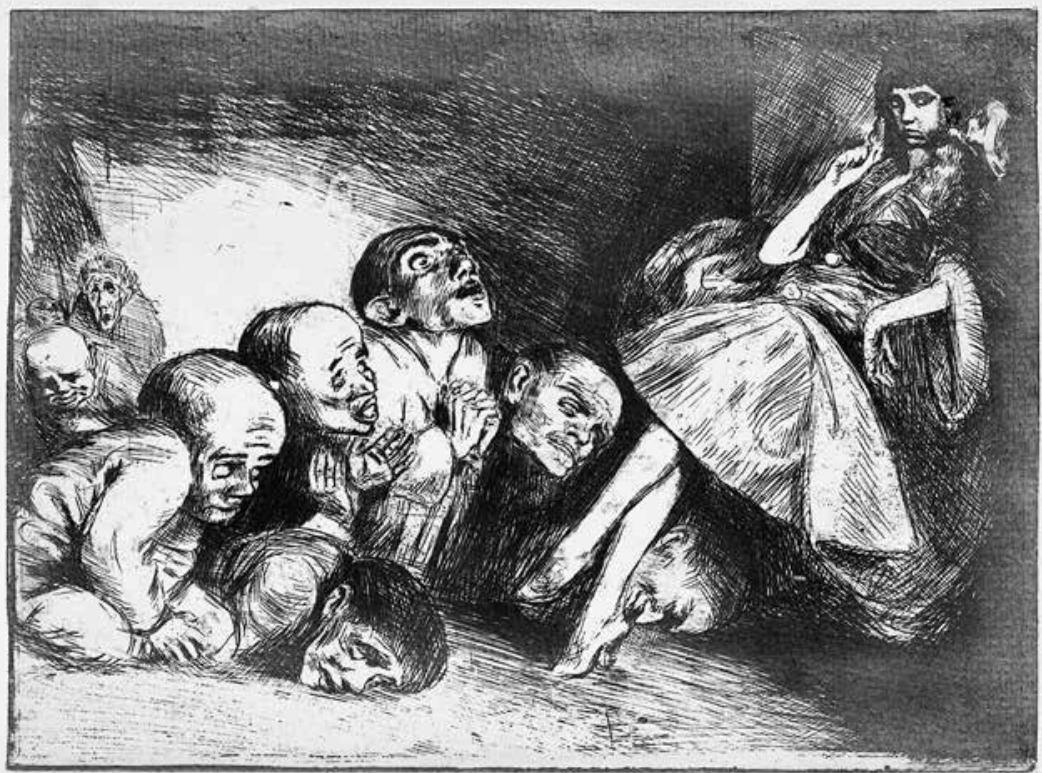

Abb. 15: Schulz, »Pielgrzymi« (Die Pilger), 1920-1922, Cv, 17,5 × 23,5 cm, BJ. 


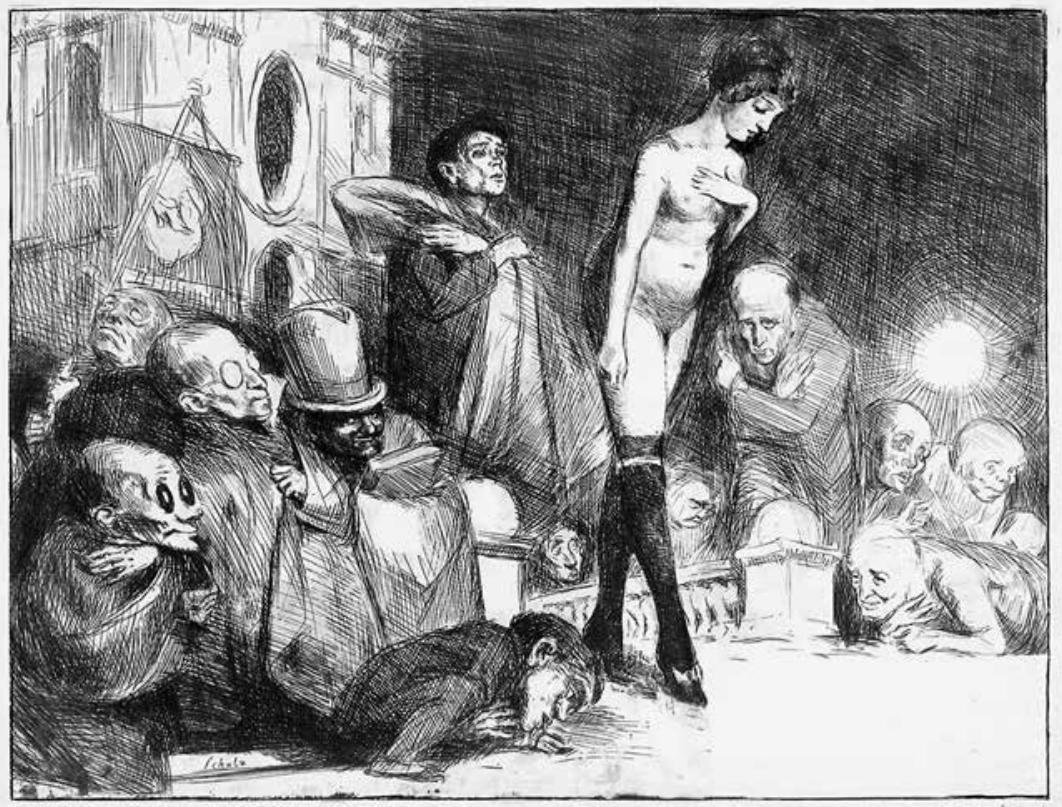

Abb. 16: Schulz, »Procesja» (Die Prozession), 1920-1922, Cv, $17 \times 23$ cm, BJ.

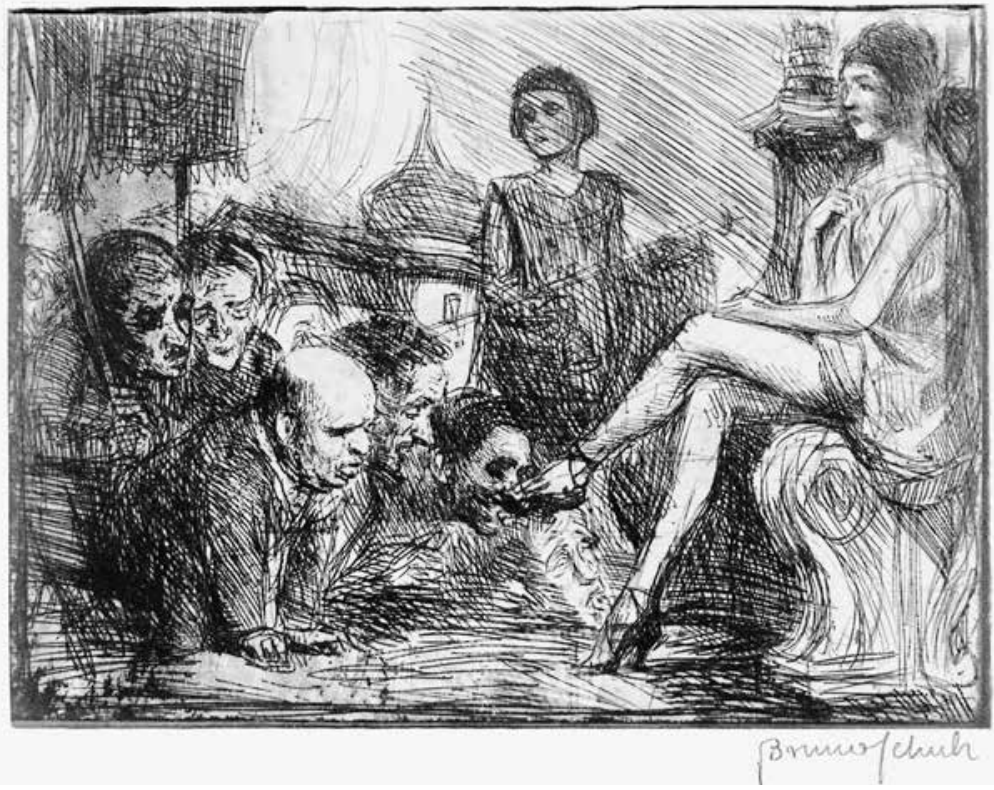

Abb. 17: Schulz, „Święto bałwochwalców« (Das Fest der Götzenanbeter), 1920-1922, Cv, $8,6 \times 11,7 \mathrm{~cm}, \mathrm{BJ}$. 
geballte Kraft ist in ihre Behaarung übergegangen. Die Anthropologen zerbrechen sich seit langem den Kopf über diese eigenartige, stets schwarz gewandete Rasse mit ihren dicken Silberketten um den Bauch und den massiven Siegelringen aus Messing an den Fingern. / Ich mag diese Menschen, die mal Kaspar und mal Balthasar sind, ich mag ihren tiefen Ernst und ihre funerale Dekorativität, ich mag diese prächtigen Mannsbilder mit ihren schönen Augen, die fettig glänzen wie gerösteter Kaffee, diesen edlen Mangel an Lebenskraft in ihren üppigen und schwammigen Körpern, die Morbidezza einer aussterbenden Sippe, ich mag ihren aus mächtiger Brust entweichenden, keuchenden Atem und sogar den Baldriangeruch, den ihre Bärte verströmen. ${ }^{144}$

Deutlich ähneln die deformierten Reklamepilger, die Gefolgschaft der Anna Csillag, den grotesken Pilgern auf den Grafiken. Gleichzeitig werden sie in eine religiöse Tradition gestellt, so dass die Formen der Gottes- und Konsumgläubigkeit miteinander verglichen werden. In beiden Darstellungen wird der irrationale Aspekt, der mit eingeübtem Ritualverhalten einhergeht, am Beispiel der Verehrung des Damenschuhs porträtiert. Dabei ist wichtig zu betonen, dass die Grafiken zwischen 1920 und 1922 entstanden sind, also erheblich früher als die Erzählungen veröffentlicht wurden. ${ }^{145}$ Die Grafiken sind deshalb auch nicht als Illustrationen der Erzählung zu verstehen, sondern als eigenständige, kritische Auseinandersetzung mit der Warenverehrung. Da die Grafikpilger keine identitätslose Masse darstellen, sondern bekannte Gesichter zitieren - wie so häufig Schulz selbst, aber auch den schon erwähnten Stanisław Weingarten, Mundek Pilpel und andere Drohobyczer, ${ }^{146}$ erweisen sie sich erneut als selbstkritisch und selbstironisch. Der Autor nimmt

144 Ders., Das Sanatorium zur Sanduhr, 24. »Ale powróćmy do naszych pielgrzymów./Któż nie zna tej starej gwardii, tych Cymbrów wędrownych, głębokich brunetów o potężnych na pozór ciałach, zrobionych $\mathrm{z}$ tkanki bez tężyzny i soków? Cała ich siła, cała moc weszła w uwłosienie. Antropologowie głowią się od dawna nad tą osobliwą rasą, odzianą zawsze w czarne ubrania, w grube, srebrne łańcuchy na brzuchach, z palcami w potężnych, mosiężnych sygnetach.

Lubię ich, tych na przemian Kasprów i Baltazarów, ich głęboką powagę, ich funebryczną dekoratywność, te wspaniałe okazy męskie z pięknymi oczami o tłustym połysku palonej kawy, lubię ten szlachetny brak żywotności w ciałach wybujałych i gąbczastych, morbidezzę wygasających rodów, ich sapiący oddech z potężnych piersi i nawet ten zapach waleriany, jaki roztaczają ich brody./Jak Aniołowie Oblicza stają czasem niespodzianie w drzwiach naszych kuchni, ogromni i sapiący, i prędko zmęczeni ocierają pot ze zroszonego czoła, przewracając niebieskimi białkami oczu, i w tym momencie zapominają swe poselstwo i zdziwieni, szukając wybiegu, pretekstu dla swego przybycia - wyciągają dłoń po jałmużnę.« Ders., Sanatorium pod Klepsydrą, 131.

145 Zwar wurden die Erzählungen erst in den 1930er Jahren veröffentlicht, aber nachweisbar bereits in den 1920er geschrieben. Es ist also durchaus möglich, dass Erzählung und Grafiken zeitlich nah zueinander entstanden sind.

146 Vgl. Silberner, Regina: Strzępy wspomień. Przyczynek do biografii zewnętrznej Brunona Schulza. London 1984, 11. 
sich und sein Umfeld von der Konsumgläubigkeit und Warenverehrung nicht aus. Auch dies befürwortet eine gesellschaftskritische Deutung dieser zwei Erzählungen.

Wie schon im dritten Kapitel ausgeführt, deuten sehr viele Schulz-Interpreten $^{147}$ die auf den Grafiken und in der Literatur dargestellte Beziehung zwischen Männern und Frauen als Materie-Geist-Dichotomie, die zum Zeitgeist gehöre. ${ }^{148} \mathrm{Im}$ Kontext aber der Werbung und Reklame bekommt die Geschlechteropposition nun neben der »Undula-Gruppe« auch für die »Gruppe der jungen Mädchen" eine andere Wendung. So lesen sich diese Grafiken eher wie eine Allegorie auf den Warenkonsum, wobei der rituelle Charakter durch die religiösen Bezüge hervorgehoben wird. ${ }^{149}$ Als zweites Ergebnis lässt sich festhalten, dass der Kontext in beiden Bild-Gruppen so unterschiedlich ist, dass man sie auch als getrennte Themengruppen bezeichnen kann, denen eine Übertragung ihrer Inhalte auf eine Mann-Frau-Opposition gemeinsam ist.

147 Vgl. Kulig-Janarek, Erotyka - groteska, $161 \mathrm{f}$. Während Kulig-Janarek und Van Heuckelom diesen Dualismus auflösen, macht Sandauer ihn zur »Weltanschauung.»»Wiemy, że antytezy te świadczą o zasadniczym dualizmie świata Schulzowskiego." Sandauer, Rzeczywistość degradowana, 27. »Wir wissen, dass diese Antithesen für den konstituierenden Dualismus in Schulz' Welt sprechen." (Übers. A. J.)

148 Insbesondere Kitowska-Łysiak deutet die Grafiken im Kontext einer romantischen Frauenfeindlichkeit. Vgl. Kitowska-Łysiak, Bruno Schulz, 147. Kulig-Janarek findet unter Hinzuziehung der Erzählung über die Schneiderpuppen (»Manekiny«) Hinweise, dass Schulz diese Materie-Geist-Dichotomie kenne und reproduziere. »Die Quellen modernistischer Misogynie stammen aus den Überzeugungen von damals hochgeschätzten Philosophen - Schopenhauer, Hartmann und Nietzsche, die das manichäische Motiv des ewigen metaphysischen Konflikts zwischen Geist und Materie, zwischen Aktivität und Passivität einführten, der mit Mann und Frau in Verbindung gebracht wurde. Nach dieser Konzeption war die Frau mit ihrem Biologismus und ihrer Sinnlichkeit das größte Hindernis zur Umsetzung der Ziele der Diener des Geistes und des Fortschritts, welche die Männer sein sollten. Die Frau, die für triviale Körperlichkeit und Biologismus stand, stellte für die Männer eine Bedrohung dar, weil sie eine Wirklichkeit repräsentierte, die sich nicht vollständig einer verstandesmäßigen Kontrolle unterwerfen ließ.« (Übers. A. J.) »Źródła modernistycznego mizoginizmu wypływały z przekonań cenionych ówcześnie filozofów - Schopenhauera, Hartmanna i Nietzschego, którzy przypomnieli manichejski motyw odwiecznego metafizycznego konfliktu między duchem a materią, aktywnośćią a pasywnością, kojarzonego z mężczyzną i kobietą. Według tych koncepcji kobieta wraz z jej biologizmem i zmysłowością była główną przeszkodą w realizacji celów rzeczników duchowości i postępu, jakimi mieli być mężczyźni. Kobieta uosabiająca trywialną cielesność i biologizm stanowić miała dla mężczyzn zagrożenie, gdyż reprezentowała rzeczywistość nie do końca poddającą się rozumowej kontroli.«Kulig-Janarek, Erotyka - groteska, 61 f. Auch Jerzy Speina folgt dieser Stoßrichtung. Vgl. Speina, Bankructwo realności, 105-107.

149 Raulet versteht die Prostitution als die Allegorie der Moderne bei Benjamin. Vgl. Raulet, Gérard: Chockerlebnis, mémoire involontaire und Allegorie: $\mathrm{Zu}$ Benjamins Revision seiner Massenästhetik in Über einige Motive bei Baudelaire. In: Zeitschrift für kritische Theorie (1996), 5-28, hier 23. 


\subsection{Zwischenfazit}

Als Ergebnis lässt sich festhalten, dass alle drei untersuchten Werkausschnitte sich direkt sowie im übertragenen Sinne mit Werbebildern auseinandersetzen. Dabei steht sowohl das spezifische Ausdrucksvermögen dieser neuen Bildformate als auch ihre Aufnahme und Umwandlung von Motiven, Bedeutungen und gesellschaftlichen Funktionen im Zentrum der künstlerischen Auseinandersetzung. Zu diesem Zwecke wendet Schulz mehrere Verfahren an. Er überträgt die Material- und Bildeigenschaften der illustrierten Werbebilder in »Ulica Krokodyli« auf eine städtische Straße und ihre Bewohner und Einkaufsläden. Dabei weist er immer wieder darauf hin, dass es sich um mehr als eine Metapher handelt, wenn die Straßen wie aus Fotografien entstanden anmuten. Damit macht Schulz auf die Wirklichkeitsrelevanz dieser Bildmedien aufmerksam, ihren Einfluss auf die Werteordnung, Wahrnehmung und damit auf die Qualität der gesellschaftlichen Konstituierung. Werbebilder formen aber nicht nur die Wahrnehmung, sie machen gleichzeitig Ideen der Zeit sichtbar und eignen sich damit als Gegenstand der Modernekritik.

Zweitens analysiert Schulz die umgewandelt aufgenommenen Narrative und ikonologische Tradition der Werbebilder. Diese Analyseleistung zeigt sich insbesondere in den Nach- und Weitererzählungen der Bild- und Textinhalte. Aufgezeigt werden dabei die biblischen Motive des Neuen und Alten Testaments wie die Hiob-Geschichte, die Engelschöre und die Wunderheilungen, die verwandelt und korrumpiert in den Werbebotschaften stecken. Dies ist besonders deutlich in der eingehenden Analyse der Werbeanzeige der Anna Csillag, die in der Erzählung "Księga« immer wieder aufgegriffen wird.

Ein drittes Verfahren bildet die fokussierte Darstellung typischer Symbole der Werbebilder. So wird der Damenschuh in der Erzählung »Ulica Krokodyli« und auf den Grafiken der Gruppe um das junge Mädchen in Beziehung zu den Frauen als Modelle und Verkäuferinnen und in Beziehung zur Gruppe der Männer als Rezipienten und Warenkäufer dialektisch untersucht. Alle drei Beteiligtengruppen, die Männer, Frauen und die "Waren", werden an unterschiedlichen Stellen gesondert betrachtet. In der Zusammenschau zeigen sich deutlich die Bezüge zwischen den Pilgern der "Księga" und den Grafikpilgern, den Ladenmädchen und den Grafikmädchen, sowie zwischen den Damenschuhen der Grafiken, der Haarpomade als Schönheitswunderelexier und den Schutzmarken der Magazine. Die "magazyny« wiederum lassen sich mit Benjamin als dialektisches Bild lesen. Sie sind sowohl der Raum, in dem die Waren verkauft werden als auch das Bildwerk, in dem die Waren dargestellt werden. Architektonisch übernehmen sie Elemente der Gotteshäuser, als Modeillustrierte beherbergen und verherrlichen sie die Magie der Moderne. Sie zeigen erotisch inszenierte Frauenkörper, die einer Ware oder 
Kleidung durch ihre bloße Anwesenheit geheimnisvollen und lüsternen Reiz verleihen.

Walter Benjamins Untersuchungen zur Moderne und sein Deutungsmodell für kulturelle Umschichtungsphänomene erweist sich konkret für diese Untersuchung als anwendbar und weiterführend. Auch Benjamin beobachtet die Wandlungen an konkreten Gegenständen und deckt auf, wie instabil Bedeutungen sind, auch solche, die scheinbar Ewigkeitswert haben. Daher muss die Deutung in jedem historischen Kontext neu ansetzen. Diese Einsicht hat Benjamin auch in seinem Übersetzeraufsatz für das Fortleben von Werken formuliert: »In völlig unmetaphorischer Sachlichkeit ist der Gedanke vom Leben und Fortleben der Kunstwerke zu erfassen. " ${ }^{150}$ Auch wenn Benjamin in diesem Aufsatz mit dem Original einen Anfangspunkt setzt, vom dem aus das Fortleben zu bestimmen ist, so betont er, dass auch Zusammenhänge zwischen diesem und früheren Werken erkannt und verstanden werden müssen. Schulz übersetzt nicht allein in einem ästhetischen, sondern auch in einem inhaltlichen Sinne das Nachleben und Neubedeuten der religiösen Texte und Bilder in der Reklame. Die Reklame wirft ihr Licht auf die Bibel und die Bibel ihrs auf die Reklame. Nur zusammen lassen sich die spezifische Magie und kulturelle Rolle der Werbebilder in der Moderne verstehen.

So wird deutlich, dass Schulz diese Wandlung nicht allein kritisiert, wie man durch die überwiegend negative Darstellung in der "Ulica Krokodyli« annehmen könnte. In der dialektischen Gegenüberstellung mit »Księga« zeigt sich deutlich, dass Schulz den neuen Werbebildern auch einiges abgewinnen kann. Sie tragen die "Traumenergie ${ }^{151}$ der Epoche in sich, haben mythenschaffendes Potential und führen die Geschichten der Bibel fort. Sie sind nicht allein lüstern, sondern auch innovativ in Text und Form, magisch verrätselnd und poetisch anregend. Dies zeigt sich deutlich in der affirmativen Haltung des Erzählers zum Werbekatalog in »Księga«. Hier findet eine vierte Strategie Anwendung: Schulz übernimmt die Dreistigkeit und den überbordenden Pathos, mit denen die Werbebilder zum Glauben an die von ihnen präsentierten Botschaften anhalten. Der Erzähler nimmt den Leser immer wieder bei der Hand, adressiert ihn persönlich, schmeichelt ihm, ${ }^{152}$ indem er ihn den

150 Benjamin, Die Aufgabe des Übersetzers, 11. »Denn von der Geschichte, nicht von der Natur aus, geschweige von so schwankender wie Empfindung und Seele, ist zuletzt der Umkreis des Lebens zu bestimmen. Daher entsteht dem Philosophen die Aufgabe, alles natürliche Leben aus dem umfassenderen der Geschichte zu verstehen. Und ist nicht wenigstens das Fortleben der Werke unvergleichlich viel leichter zu erkennen als dasjenige der Geschöpfe? Die Geschichte der großen Kunstwerke kennt ihre Deszendenz aus den Quellen, ihre Gestaltung im Zeitalter des Künstlers und die Periode ihres grundsätzlich ewigen Fortlebens bei den nachfolgenden Generationen. Dieses letzte heißt, wo es zutage tritt, Ruhm."

151 Ders., Das Passagen-Werk, 113.

152 Vgl. Robertson, Bruno Schulz's Intimate Communication, 456. 
»czytelnik prawdziwy «153 (wahren Leser) nennt, und verführt seinen Leser mit einer den Reklamen vergleichbaren Strategie, an die Księga und ihre Heiligkeit zu glauben. Indem er ihre Überzeugungsverfahren entlehnt, macht er aus Werbung Kunst. ${ }^{154}$

In seiner Prosa macht Schulz die Wirkweise der Werbebilder dialektisch sichtbar und offenbart dadurch einerseits die ohnehin anwesende mythische Struktur, mythisiert sie zusätzlich aber auch aktiv. Damit zeigt sich Schulz' große Kulturanalyseleistung, die er durch sein poetisches Verfahren partiell wieder verschleiert. »Mythisieren« bedeutet damit keinesfalls vornehmlich eine Vermengung mit dem Mythos oder eine Rückkehr zur mythischen Denkweisen, wie es mitunter Bolecki vorschlägt ${ }^{155}$ sondern viel grundlegender ein Wahrnehmen verborgener, anwesender mythischer Sinnes- wie Sinnstrukturen. Auch wenn sein poetologisches Manifest »Mityzacja rzeczywistości« anderes vermuten ließe, so zerstört Schulz mit gleicher Energie die Mythen und mythologischen Strukturen, wie er sie schafft. Zu einem ähnlichen Ergebnis kommt auch Underhill, die in Schulz' Mythenarbeit wiederum eine religiöse Ebene sieht.

"Thus, while Schulz enshrined the idea of mythicizing, in practice his narrative model is precisely also about escape from totalizing myths: it is a deep exploration not only of the sources of meaning and myth, but also of the process of critical selfdiscovery; liberation from suffocating and encrusted forms imposed by bourgeois society, or from existing aesthetic forms and prescriptions; and finally the empowerment, rather than the ensnarement, of the individual. In it, the transient singularity becomes the only place where the sprimordial nature of the word can be stasted again. In Schulzian terms, 'poetry< becomes the keyword for this liberating, messianicmythologizing text, which differentiates itself from prose. ${ }^{156}$

In seiner Literaturrezension von Gombrowiczs Roman »Ferdydurke« findet sich auch eine Interpretation von Schulz, die diese Deutung stützt. In »Ferdydurke« werden moderne Ideale und Begriffe wie Bildung und Modernität auf

153 Vgl. Schulz, Bruno: Sanatorium pod Klepsydrą. In: Jarzębski: Proza, hier 121; 133.

154 Vgl. Nöth, Werbung und die Künste, 161-163.

155 »Ziel des Mythisierens sei die Wiedererlangung der Einheit, der Mythos ist also in Schulz' Kunstauffassung eine ursprüngliche Wirklichkeit. In dieser ursprünglichen Wirklichkeit liege der Daseinssinn verborgen, den es in der modernen Kunst nicht gebe, die aus unzusammenhängenden Fragmenten alter Kulturen und Mythen errichtet sei. Um also zur Ursprünglichkeit vorzudringen, zum Mythos, zum Sinn, so Schulz, müsse man zuerst den Schein abwerfen, den die Sprachen der modernen Zivilisation schaffen. Das ist die Schulzsche Spielart der Kritik der apollinischen Kunst. Zur zentralen Kategorie wird für Schulz der Mythos, verstanden als Ursprünglichkeit. Es steht außer Zweifel, dass diese Vorstellung eine weitere Variante des nietzscheanischen Gedankens der >ewigen Wiederkehr ist. « Bolecki, Das sprincipium individuationis«, 25.

156 K. Underhill, Bruno Schulz and Jewish Modernity, 86. 
einer sprachlichen und inhaltlichen Ebene vorgeführt. Der Protagonist wird unter Einfluss dieser Ideen zunehmend verkindlicht und entwickelt sich trotz Fortschrittsglauben und Bildungsideal zurück. ${ }^{157}$

"Hier zeigt sich die Struktur der Mythologie in ihrer ganzen Misere, die in den Formen sprachlicher Syntax versteckte Willkür, der Terror und Raubzug der Phrase, die Allmacht der Symmetrie und der Analogie. Hier wird die Mechanik unserer Ideale gelüftet und klar, wie sehr sie auf die Dominanz naiver Buchstäblichkeit, auf Metaphern und ordinäre Nachahmung sprachlicher Formen gestützt ist.. ${ }^{158}$

Schulz demonstriert hier recht deutlich, was er meint, wenn er von der den Worten nachgeordneten Wirklichkeit spricht. Gombrowiczs Strategie, die Macht der Worte mit Ironie zu dekonstruieren, ergänzt Schulz durch eine alternative, poetische Verwendung der Sprache, um aus den frischen Worten neues Wirklichkeitspotential zu schöpfen. Daher bedeutet eine Übersetzung der Werbebilder in literarische Sprache auch partiell ihre Neudeutung und Umcodierung.

157 Vgl. Gombrowicz, Witold: Ferdydurke. Dzieła. Kraków u.a. 1986. Paweł Dybel hat Schulz' Beziehung zu Freuds Psychoanalyse untersucht und gezeigt, dass Schulz ein eher »konservatives Verhältnis« zu dieser Theorie pflegt. Auch in dieser Literaturkritik grenzt Schulz Grombrowiczs Analyseleistung von Freuds ab. Vgl. Dybel: Bruno Schulz i psychoanaliza, 250.

158 Schulz, Bruno: Ferdydurke. (Aus dem Poln. v. Mikolaj Dutsch). In: Ficowski (Hg.): Gesammelte Werke, 280-288, hier 282f. »Tu okazuje się w całej lichocie struktura mitologii, przemoc ukryta w formach składni językowej, gwałt i rozbój frazesu, potęga symetrii i analogii. Tu odsłania się gruba mechanika naszych ideałów, oparta na dominacji naiwnej dosłowności, na figurach metafor i ordynarnej imitacji form językowych." Schulz, Bruno: Ferdydurke. In: Kitowska-Eysiak: Szkice krytyczne, 94-100, hier 96. 



\title{
5. Wortmalerei - Beziehung zwischen Bild und Sprache
}

\begin{abstract}
"Ut pictura poesis meant an art of mutual imitation and collaboration between two ssister arts, both dwelling in the realm of the aesthetic; ut pictura theoria is an unequal relationship of mere convenience, between the master-work of abstract painting and the humble servant of critical prose. ${ }^{1}$
\end{abstract}

Nachdem im dritten Kapitel das Bild in Bildern und damit deren spezifische Bildsprache untersucht wurde, im vierten Kapitel hingegen die in Literatur und in Grafiken übersetzte und analysierte Wirkung, Ästhetik, gesellschaftliche Rolle und Überzeugungsstrategie von konkreten, außerliterarisch existenten Werbebildern, stellt sich im fünften Kapitel vor allem die Frage, ob noch eine dritte Beziehung zwischen Bild und Sprache bei Schulz existiert. Dieser Frage geht die Beobachtung voraus, dass Schulz' Prosa voller farbintensiver, visualisierender Beschreibungen ist, die oft auch über Material- und Farbauftragseigenschaften wie Pinselstrich, Farbnuancen und Komposition Auskunft gegeben, ohne dass notwendigerweise explizit Gemälde beschrieben werden. Als Beispiel sei hier eine Sequenz aus »Wiosna« zitiert, die eine Parkansicht bei Abenddämmerung beschreibt, in der die Farben als Agens vorgeführt werden. Ihr Auftritt wird mit dem der Schauspieler auf einer Bühne verglichen, die feierlich gekleidet und theatralisch emotional in ihre Szene schreiten.

»Wenn der Augenblick vor der eigentlichen Dämmerung gekommen ist, verschönern sich die Farben der Welt. Alle Farben haben für ihren Auftritt Kothurne angelegt, sie werden feierlich, inbrünstig und traurig. Schnell überzieht sich der Park mit rosarotem Firnis und Glanzlack, was die Dinge noch stärker koloriert und gleichzeitig illuminiert. Doch in diesen Farben ist bereits irgendein Blau etwas zu tief, irgendeine Schönheit etwas zu strahlend und schon verdächtig. Schon im nächsten Moment wird die rosafarbige Dämmerstunde von nacktem Geäst durchsetzt sein, von Parkdickicht, fast ohne junges Grün, sie wird sich mit dem Balsam der Kühle auskleiden, und mit der unbeschreiblichen Wehmut der ewigen und zum Sterben schönen Dinge wird sie sich bauschen. ${ }^{2}$

1 Mitchell, Picture Theory, 222.

2 Schulz, Das Sanatorium zur Sanduhr, 71. "Przychodzi chwila przed samym zmierzchem i kolory świata pięknieją. Wszystkie barwy wstępują na koturny, stają się odświętne, żarliwe i smutne. Szybko napełnia się park różowym werniksem, lśniącym lakierem, od którego rzeczy stają się naraz bardzo kolorowe i iluminowane. Ale już w tych barwach jest jakiś lazur zbyt głęboki, jakaś piękność zbyt jaskrawa i już podejrzana. Jeszcze chwila 
Diese dynamisierte Natur ist mehr als ein Hintergrundbild für eine Handlung. Die Naturdarstellung wird mit Worten aus dem semantischen Bereich des Theaters und der Malerei verbunden und so zu gesteigerter Anschaulichkeit geführt. Die Farben selbst treten aktiv auf und gestalten den Naturraum, der kurzzeitig zur Theaterbühne wird, bis die Dämmerung vorbei ist und die Farben verblassen.

Darüber hinaus finden sich in den Prosabänden einige Erzählungen, in denen eine Handlung fast völlig fehlt und die sich ganz der visualisierenden Darstellung eines Gartens, eines Zimmers oder einer Stimmung widmen, aber dennoch durch eine ununterbrochene Bewegung gekennzeichnet sind. ${ }^{3}$ Die Schwierigkeiten bei der Einordnung dieser Beschreibungsform zeigen sich deutlich in Boleckis Analyse der literarischen Mittel. Er weist nach, dass bei Schulz die Beschreibungen gegenüber der Handlung eine übergeordnete Position einnehmen. Oft sind sie Hauptgegenstand der bei Schulz typischen "Poetisierung«. Dinge, Landschaften und Natur werden personifiziert und belebt, mit Worten aus ganz anderen Bereichen beschrieben und ihre Farben, Komposition und Erscheinung beleuchtet. ${ }^{4}$

Auf diese malerische Sprachanwendung wurde in der Forschungsliteratur häufig hingewiesen und Jarzębski prägt mit »malowanie słowem $\aleph^{5}$ (Wort-

i gąszcz parku ledwie przysypany młodą zielenią, gałęzisty jeszcze i nagi, prześwieca cały na wskroś różową godziną zmierzchu, podbitą balsamem chłodu, napuszoną niewymownym smutkiem rzeczy na zawsze i śmiertelnie pięknych."Ders., Sanatorium pod Klepsydrą, 161.

3 Jarzębski weist auf den Umstand hin, dass Schulz Erzählungen verfasst hat, in denen es fast keine Handlung gibt, die Beschreibung der Szenerie aber dafür ausladend sei. "Zauważmy wpierw, że opis pełni u Schulza niezwykle ważną rolę, że istnieją opowiadania w gruncie rzeczy przez opis zdominowane, o fabule zredukowanej niemal do zera (Nemrod, Pan Karol, Noc lipcowa, Pan, Edzio, Druga jesień). Elementy opowiadania - jeśli się tam pojawiają - występują właściwie w funkcji wobec opisu służebnej i pomocniczej, pozwalają uplastycznić obraz przedstawianego bohatera, zaprezentować go w jego typowych czynnościach (Pan Karol, Edzio) albo w sam opis wprowadzić pewną procesualność, jakąś quasi-akcję będącą tylko pretekstem dla zdynamizowania perspektywy widzenia (Noc lipcowa, Pan). «Jarzębski, Prowincja centrum, 28. »Die Beschreibung spielt bei Schulz eine außerordentliche Rolle. Es gibt Erzählungen, die vollständig von der Beschreibung dominiert sind und fast keine Handlung enthalten (Nemrod, Herr Karol, Julinacht, Pan, Edzio, Der andere Herbst). Elemente der Erzählung - wenn es sie gibt - dienen allein der Beschreibung, sie lassen das Bild des Helden plastisch werden, zeigen ihn in seinen typischen Handlungen (Herr Karol, Edzio) oder tragen eine gewisse Prozessualität in die Beschreibung selbst, eine Quasi-Handlung, die aber nur Vorwand ist, um die Wahrnehmungsperspektive zu dynamisieren (Julinacht, Pan).« (Übers. A. J.; Hervorh. im Orig.)

4 Vgl. Bolecki, Poetycki model prozy, 226.

5 "Malowanie słowem « lautet die Überschrift seines Aufsatzes, den er als Kapitel in seinem Buch »Prowincja centrum « publizierte. An anderer Stelle hat er diesen einzeln veröffentlicht. Vgl. Jarzębski, Jerzy: Brunona Schulza Malowanie Słowem. In: Kitowska-Łysiak: Bruno Schulz in memoriam, 43-58. 
malerei) einen eigenen Begriff für dieses Phänomen. Zudem erhebt er das Verstehen dieser besonderen Beschreibungsform zu einem der Hauptinterpretationsschlüssel von Schulz' Prosa. ${ }^{6}$ Auch Rolf Fieguth erkennt in Schulz' malerischer, mythopoetischer und räumlicher Sprache ein zentrales Element seiner Poetologie, das noch genauer untersucht werden müsse.

»Zum einen wird [...] die Schicht der Worte, des Textlichen ständig verräumlicht, verwandelt sie sich in den großen, atemberaubenden Raum des Himmels. Zum anderen kehrt die Schulzsche Raumimagination dann häufig genug auch zurück in die Welt des Papiers, des gemalten bzw. gerubbelten Bildes, der Theaterkulisse, der Worte, jedoch ohne dort etwa endgültig zu verbleiben. Es besteht eine zirkuläre, fortwährend bewegte Verbindung zwischen dem Räumlich-Anschaulichen und dem TextlichMetaphorischen bei Schulz, eine grundsätzliche zyklische Ironie, die sicherlich noch genauere Erforschung verdient. $\aleph^{7}$

Diese besondere Beziehung von Schulz' Literatur zur Malerei haben nach Eugenia Prokop-Janiec insbesondere Interpreten der Zwischenkriegszeit wahrgenommen. ${ }^{8}$ Einige riefen sogar dazu auf, Schulz' Werk selbst als Gemälde zu lesen. Exemplarisch dafür sei hier ein Ausschnitt aus der Rezension von Schulz' Freund, dem Romanautor und Essayisten Tadeusz Breza ${ }^{9}$ angeführt.

"Von der ersten Seite der Zimtläden an fühlte ich mich in einer Wirklichkeit, die mich nicht nur mit Unruhe erfüllte, sondern die mir sozusagen svom Sehen bekannt war. Dieses Sehen verdanke ich Bildern. Einem ganzen Bündel zeitgenössischer malerischer Futurismen und Formismen. Schulz realisiert in Worten eine plastische Welt, eine wie de Chiricos. Es ist eine Welt komischer Straßen, wo es scheinbar niemanden gibt, aber gleichzeitig ist uns bewusst, dass dort jemand steht und uns mit einem Kohlestück in der Hand aufmerksam betrachtet. Es ist ein Himmelsgewölbe, welches beeindruckende Nächte und Perspektiven gebiert, flach wie ein Samtvorhang, aber gefährlich verirrt wie ein Labyrinth. Es ist dieselbe Gesellschaft imitierender Schneider, Schornsteinfeger und Verkäufer, die durch geschlossene Lippen flüstern, zischen und lispeln..$^{10}$

6 Vgl. Jarzębski, Prowincja centrum, $42 \mathrm{f}$.

7 Vgl. Fieguth, Eine Art Zusammenhangsheimweh, 323. Siehe auch Bolecki, Poetycki model prozy, 170-229.

8 Vgl. Prokop-Janiec, Eugenia: Schulz und der galizische Schmelztiegel der Kulturen. In: Gelhard, Dorothee (Hg.): In und mit der Fremde. Über Identität und Diaspora im Ostjudentum. Frankfurt a. M. 2005, 87-100.

9 Tadeusz Breza (1905-1970) ist ein Autor, Essayist und Literaturkritiker, der sehr früh Schulz' Werk gelobt hat. Schulz hat auch Brezas Roman »Adam Grywałd « aus dem Jahre 1936 rezensiert. Darüberhinaus sind Briefe von Schulz an Breza erhalten, die Respekt und Verbundenheit bezeugen. Vgl. Schulz, Księga listów, 48-57.

10 Breza: Sobowtór zwykłej rzeczywistości, zitiert in Speina, Bankructwo realności, 25. „Od pierwszej strony świata Sklepów poczułem się w rzeczywistości wyczuwanej nie tylko 
Einige Interpreten haben diese visuelle Sprachbildlichkeit schon aus einem kunsttheoretischen Blickwinkel betrachtet. Speina hat in seiner Monografie »Bankructwo realności« die Beziehung von Schulz' Prosa zur modernen, insbesondere zur expressionistischen Malerei und ihren Theorien untersucht, jedoch nicht hinsichtlich des Bild-Begriffs. ${ }^{11}$ Piotr Wróblewski, der alle Farbbelegstellen in Schulz' Werk aufwendig gezählt, statistisch aufbereitet und mit anderen Werken verglichen hat, dokumentiert einen überproportionalen Gebrauch von Farbwörtern. ${ }^{12}$ Dies weise auf einen malerischen Sprachgebrauch hin. In seiner Fokussierung auf die Farbe vernachlässigt er allerdings ihr gemeinsames Auftreten mit Gerüchen, Gefühlen und Geräuschen. Die Aussagekraft seiner sehr formalistischen Untersuchungsergebnisse bleibt daher fraglich. Renate Lachmann betrachtet die Poetologie von Schulz unter dem Aspekt der künstlichen und künstlerischen Schöpfung. Sie konzentriert sich vornehmlich auf die Projekte des literarischen Erzählervaters Jakub, der als Künstlerdemiurg mit Materie experimentiert, und dabei auf die Anleihen unterschiedlicher Schöpfungsmythologien wie der Kabbala, Gnosis und griechischen Mythologie. ${ }^{13}$ Schulz' Maler- und Schriftstellerfreund Witkiewicz deutet Schulz' Werk im Kontext seiner eigenen Kunsttheorie und bezeichnet einige von seinen $»$ Bilderreihen, die in den Satzreihen enthalten $\aleph^{14}$ sind, als »reine Kunst« und »reine Form«, die es für Prosa eigentlich nicht gäbe. ${ }^{15}$

Es sieht fast so aus, als sei auf diesem gut erforschten Feld der Wortmalerei und Poetologie von Schulz nicht mehr viel herauszufinden. Insbesondere Jarzębski und Bolecki haben das Feld der wortmalerischen Sprache gründlich bearbeitet. Untersucht man die Grundannahmen ihres Zugriffs jedoch ge-

niepokojem, lecz znanej, że tak powiem $>$ z widzeniar. Widzenie to zawdzięczam obrazom. Całemu bukietowi współczesnych malarskich futuryzmów i formizmów. Schulz realizuje w słowie plastyczny świat, choćby takiego Chirica. Jest to ten świat dziwacznych ulic, gdzie niby to nikogo nie ma, a wiadomo, że ktoś stoi i patrzy na nas uważnie zza węgla. Jest to nieboskłon, który rodzi zdumiewające noce i perspektywy, płaskie jak aksamitna kotara, choć niebezpieczne zabłąkaniem jak labirynt. Jest to to samo towarzystwo imitacyjnych krawców, kominiarzy i subiektów, którzy poprzez zamknięte wargi szepczą, syczą i seplenią.« (Übers. A. J.)

11 Vgl. ebd., 79-109.

12 Vgl. Wróblewski, Piotr: Stylistyczna funkcja określeń barw w prozie Brunona Schulza. In: Przegląd humanistyczny 22 (1978), 57-73, hier 62.

13 Vgl. Lachmann, Erzählte Phantastik, 338-370.

14 »zespoły obrazów zawarte w zespołach zdań.«Witkiewicz, Stanisław I.: Twórczość literacka Brunona Schulza. In: Ders., O znaczeniu filozofii dla krytyki i inne artykuły polemiczne. Warszawa 1976, 189-203, hier 189.

15 Vgl. ebd. In seinem großen Lob auf Schulz' Literatur setzt sich Witkiewicz aber auch immer wieder mit den eigenen Kunstkritikern auseinander und geht auf abweichende Themen ein, sodass man nur mit Mühe behaupten kann, dass allein Schulz Gegenstand der Untersuchung ist. 
nauer, so fällt auf, dass sie in ihrer theoretischen Konzeption von einer "natürlichen« Trennung der Ausdrucksformen Sprache und Malerei ausgehen. Dies zeigt sich bei Jarzębski besonders deutlich, wenn er die Existenz »obrazowych >cytatów` dosłownych « ${ }^{16}$ (wörtlicher Bildzitate) in Schulz' Literatur verneint selbst wenn der Autor auf die Existenz solcher hinweist. Auch glaubt er nicht, dass der Nachweis einer solchen Vorlage etwas ändern würde. »In ihrer tiefsten Struktur beruht die Bildkunst auf dem Erstarren, Ordnen und Mythologisieren. ${ }^{17}{ }^{7}$ Schulz' Wortbilder hingegen seien beweglich, in ständiger Metamorphose und nicht zu sehen im Sinne der Malerei. ${ }^{18}$ So ordnet Jarzębski sie der Sphäre des »Sinns« zu, jenem ersten Sein, das Schulz in seinem »Mityzacja rzeczywistości« noch vor den Ideen verortet. ${ }^{19}$

Vor dem Hintergrund der Ergebnisse des dritten und vierten Kapitels scheint es lohnenswert, diese Beziehung neu zu untersuchen. Die diesem Kapitel zugrundeliegende These lautet daher, dass Schulz' in seiner Prosa bewusst die Gemeinsamkeiten zwischen Malerei und Literatur sucht und die sich in der Philosophie und Kulturtheorie herausgebildete Trennung partiell aufhebt. ${ }^{20}$ Somit bietet es sich an, zur Analyse von Schulz' Wortmalerei auf Theorien und Begriffe zurückzugreifen, die eine Verflechtung, Gemeinsamkeit und Beziehung von Bildern und Sprache als konstitutiv betrachten. Beispielsweise existiert mit der Ekphrasis eine aus der Antike stammende Form, die das Ansinnen ausdrückt, Bilder so visualisierend $\mathrm{zu}$ beschreiben, dass der Zuhörer sie sieht. ${ }^{21}$ Das Bild im Sinne des Gesehenen oder Vorgestellten (image) ist ebenso sagbar wie malbar und kann daher vom Maler auf Leinwand oder vom Dichter mit Worten wiedergegeben werden. »Ut pictura poesis $\aleph^{22}$ - »wie ein Bild (sei oder ist) die Dichtung« - ist die dazugehörige Formel, die die Perspektive einer Verwandtschaft und Gleichheit zwischen Malerei und Dichtung einnimmt. Beide Formen unterliegen dabei der historischen Entwicklung. Die Vorstellung von Bild und Sprache und ihrer Verbindung beziehungsweise Trennung muss immer als Zeitparadigma verstanden

16 Jarzębski, Prowincja centrum, 49.

17 »W swych najgłębszych pokładach sztuka obrazu polega na unieruchomieniu, uporządkowaniu, mitologizacji.« Ebd., 26.

18 Ebd., $49 f$.

19 Vgl. Schulz, Mityzacja rzeczywistości, 11.

20 Mitchell weist in seinem Buch darauf hin, dass bis heute die Tendenz dominanter ist, die Medien getrennt zu verstehen und die Unterschiede zu betonen. Vgl. Mitchell, Picture Theory, 5 .

21 Vgl. Ekphrasis. In: Pfisterer, Lexikon Kunstwissenschaft, $76 \mathrm{f}$.

22 »Mit der Formel >ut pictura poesis`, nach Horaz' Ars poetica, wird in der europäischen Kunstliteratur und Dichtungstheorie seit der Renaissance auf die Ähnlichkeit von Malerei und Dichtung hingewiesen." Ut Pictura poesis. In: Pfisterer, Lexikon Kunstwissenschaft, 364. 
werden, sie ist keineswegs natürlich. ${ }^{23}$ Daher wird die Ekphrasis-Theorie, wie sie sich unter Voraussetzungen der Moderne darbietet, skizziert und anschließend werden die verschiedenen Wortbilder analysiert.

Hier darf schon vorweggenommen werden, dass sich in Schulz' Prosa erneut ganz unterschiedliche Bild-in-Wort-Beziehungen finden lassen, die von einer sprachlichen Nachahmung von Malerei über eine visualisierende Beschreibung einer Ansicht bis hin zu einer erneuten Theoriebildung durch Metatexte, aber auch durch vorgeführte Bildanfertigungsexperimente reichen. Die poetische Sprache, wie sie Schulz versteht, dient als Brücke, um die aktuelle Sprachform wieder gegenüber Bildern und Musik zu öffnen. „Wieder" bezieht sich dabei auch auf frühere Sprach-Bild-Beziehungen, die bei weitem nicht jene Radikalität der Trennung von Wort und Bild aufweisen, wie sie sich seit dem 18. Jahrhundert zunehmend durchgesetzt hat. ${ }^{24}$

Im ersten Unterkapitel werden die Ekphrasis-Theorie im historischen Wandel gezeigt und die Voraussetzungen und Ideen der visualisierenden Sprache vorgestellt. Dabei steht die Frage, welchen Einfluss eine Betonung der Unterschiede zwischen den Medien Sprache und Bild auf die EkphrasisKonzeption hat, im Vordergrund. Im Weiteren wird Schulz' besondere Beschreibungsform im Spiegel der Sekundärliteratur untersucht. Sowohl Bolecki als auch Jarzębski haben die Wortmalerei durch Begriffe der Literaturtheorie erklärt, die eine Trennung zwischen den Medien voraussetzt, und daher für Schulz' malerische Sprache eigene Begriffe geprägt. Um den Unterschied zwischen Ekphrasis und Beschreibung zu beleuchten, wird in den anschließenden Analysen die Beziehung zu allgemeiner Malerei und konkreten Gemälden sowie zur Kunsttheorie untersucht.

Als erstes werden hier jene Textstellen analysiert, die direkte Bezüge zur Malerei aufweisen, wie die Ekphraseis der barocken Malerei der Neapolitanischen Schule, ${ }^{25}$ sowie die Bezüge zu Rembrandt und van Gogh. Anschließend werden die vorwiegend malerischen Mittel wie Farbe, Perspektive und Pinselstrich, sowie Eigenschaften der Leinwand oder der Radierung untersucht. In der Ezählung "Genialna epoka« spielt der Erzähler, der die Ereignisse sowohl aus einer erlebenden Innenperspektive sowie aus einer distanzierten Außenperspektive darstellt, eine besondere Rolle. Sein Wechsel zwischen einer kindlichen Wahrnehmung und einer Erwachsenenperspektive

23 Boehm untersucht in seinem Werk »Bildbeschreibung« insbesondere ältere Konzepte der Ekphrasis, Mitchell hingegen konzentriert sich stärker auf die Entwicklung hin in die Gegenwart. Beide Ansätze zusammen ergeben eine interessante Perspektive, die noch ausgeführt wird.

24 Vgl. Weisstein, Ulrich: Einleitung: Literatur und bildende Kunst: Geschichte, Systematik, Methoden. In: Ders. (Hg.): Literatur und bildende Kunst, 11-31, hier 13-16.

25 Vgl. Schulz, Sanatorium pod Klepsydrą, 218-221. 
lässt sich auch innerhalb modernistischer Theorien deuten. Erneut werden die verschiedenen Farb-, Perspektiv- und Wahrnehmungsexperimente durch metapoetische Kommentare begleitet, deren Deutung mit in die Untersuchung aufgenommen wird. Abschließend werden die Verwandlungen sowie die auftretenden Wachsfiguren und Schneiderpuppen hinsichtlich des Zusammenspiels von Form und Inhalt untersucht.

Schon vor dem Hintergrund der Untersuchungen im dritten und vierten Kapitel wird daher die These formuliert, dass Schulz bewusst die Gemeinsamkeiten zwischen Sprache und Malerei sucht und betont. Zwar kann er die Mediengrenze nicht überwinden, er kann aber Bilder im Sinne von Vorstellungen, Visionen, Träumen, Gesehenem sprachlich so adäquat wiedergeben, dass die Sprache selbst Raum, Farbe, Perspektive und Emotion aufnehmen und übersetzen kann. ${ }^{26}$

\subsection{Ekphrasis im Wandel der Zeit}

Das Wort Ekphrasis kommt aus dem Griechischen und steht für eine Bild-inSprache-Form. ${ }^{27}$ Ein Gegenstand der visuellen Wirklichkeit wird durch einen Menschen so plastisch »beschrieben«, dass die Leser/Zuhörer diesen vor dem inneren Auge sehen. Damit findet eine doppelte intermediale Übersetzungsleistung aus dem Bildlichen in das Sprachliche und zurück in ein Bildliches statt, wobei das »innere Bild« bloße Vorstellung bleibt. Gegenstand, Rezipient und Sprecher sind somit Teil der Ekphrasis. ${ }^{28}$

"Das Ziel der E.[kphrasis] liegt nach Nikolas von Myra (5. Jh.) darin, den zu beschreibenden Gegenstand so >umständlich`zu schildern, dass >die Hörer zu Zuschauern` gemacht werden - im Gegensatz zur `kahlen Ausführung` der Erzählung. Die E.[kphrasis] zielt über die Mediengrenze hinaus: Worte werden Bild und mehr noch: Der lineare Ablauf der Sprache soll zur räumlichen Bewegung werden und eine

26 Um die Jahrhundertwende tritt das Phänomen, dass Künstler in zwei Ausdrucksbereichen tätig sind, gehäuft auf, was Schvey auf die expressionistischen Theorien der Wahrnehmung und des Sehens zurückführt. Vgl. Schvey, Doppelbegabte Künstler, $78 \mathrm{f}$.

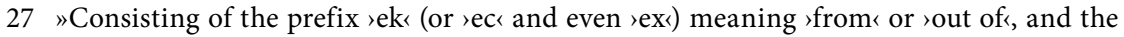
root term sphrasis, < a synonym for the Greek lexis or hermeneia, as well as for the Latin dictio and elocutio (the verb phrazein denotes sto tell, declare, pronounces), ekphrasis originally meant >a full or vivid description. It first appears in rhetorical writings attributed to Dionysius of Halicarnassus and then became a school exercise in rhetoric." Wagner, Peter: Introduction: Ekphrasis, Iconotexts, and Intermediality - the State(s) of the Art(s). In: Ders. (Hg.): Icons - Texts - Iconotexts. Essays on Ekphrasis and Intermediality. Berlin, New York 1996, hier 12.

28 Vgl. Mitchell, Picture Theory, 165. 
Beschreibung entstehen, >die einen herumführt (periegematikós) und den Gegenstand anschaulich (energés) vor Augen bringt` (Nikolaos). Sie wird durch die Anhäufung von Details, durch Vergleiche, Verlebendigung, sowie durch präsentische Rede erreicht [...]. Die Existenz des Beschriebenen ist dabei keinesfalls konstitutiv. ${ }^{29}$

Als eines der frühesten und wichtigsten Beispiele gilt dabei das Schild des Achilles aus Homers $» I l i a s "{ }^{30}$ Während die Ekphrasis in der Antike noch weitgefasst für eine visualisierende Beschreibung eines Gegenstandes (meist Vasen, Waffen, Rüstung etc.) steht, verengt sich im Laufe der Jahrhunderte die Bedeutung hin zu einer Gattung, die die anschauliche Wiedergabe von Kunstwerken und Bildern in Sprache bezeichnet. ${ }^{31}$ Durch Wandlungen am Bild- und Sprachbegriff, durch die Entstehung neuer Bildmedien wie Fotografie und Film, aber auch durch Entwicklungen in der Mal- und Poesietheorie, verändern sich die Bedingungen der ekphrastischen Bildbeschreibung. ${ }^{32}$

Murray Krieger, Mitchell und Boehm, die alle drei die Ekphrasis untersucht haben, sind sich darin einig, dass ab dem 18. Jahrhundert in der Philosophie und Literaturtheorie eine bildkritische Haltung und eine spracheuphorische

29 Ekphrasis. In: Pfisterer, Ulrich (Hg.): Lexikon Kunstwissenschaft. Ideen, Methoden, Begriffe. Stuttgart 2003, 76.

30 Vgl. ebd., 176. Über viele Verse hinweg wird plastisch die Darstellung ganzer Kriegslandschaften und die Welt der Götter beschrieben, die sich auf dem Schild zeigen. »Homer's whole point seems to be to undermine the oppositions of movement and stasis, narrative action and descriptive scene, and the false identifications of medium with message, which underwrite the fantasies of ekphrastic hope and fear. The shield is an imagetext that displays rather than concealing its own suturing of space and time, description and narration, materiality and illusionistic representation. [...] This is a utopin site that is both a space within the narrative, and an ornamented frame around it, a threshold across which the reader may enter and withdraw from text at will.« Ebd., 178.

31 Pfisterer, Lexikon Kunstwissenschaft, 77. Die Verwendung der Ekphrasis im Sinne einer »Gattung und eingeschränkt auf die spoetische Beschreibung eines malerischen oder plastischen Kunstwerks«" habe sich erst in Folge der Diskussionen um Gautiers Poesie entwickelt und sei nach Löhr eine Erfindung des Literaturwissenschaftlers L. Spitzer gewesen.

32 Krieger stellt fest, dass es seit Plato einen Konkurrenzkampf zwischen Sprache und Bild hinsichtlich ihres Darstellungswerts gibt. Während das mimetische Bild die Wirklichkeit direkter darstellen könne, müsse das Wort stärker vermitteln. Deshalb schien es lange Zeit begrenzt. »Es überrascht nicht, daß diese Art von Semiotik als höchste, durch die Sprachkunst erreichbare Tugend das rhetorische Mittel der enargeia propagiert. Das Hervorbringen von enargeia, d.h. die Verwendung von Wörtern in einer Weise, daß durch die Lebendigkeit der Beschreibung das dargestellte Objekt sozusagen buchstäblich vor dem inneren Auge des Lesers (Hörers) erscheint, ist das Höchste, was der Wortkünstler sich erhoffen kann: eine Darstellung, die fast so gut ist wie ein Bild, das seinerseits fast so gut ist wie das Objekt selbst." Krieger, Murray: Das Problem der Ekphrasis: Wort und Bild, Raum und Zeit - und das literarische Werk. In: Boehm, Gottfried/Pfotenhauer, Helmut (Hg.): Beschreibungskunst - Kunstbeschreibung. Ekphrasis von der Antike bis zur Gegenwart. München 1995, 41-57, hier 46. 
Sicht dominant werden. Lessing verfestigt die Trennung zwischen Sprachkunst und Malerei, indem er die Unterschiede betont und zu Polen formt. ${ }^{33}$ Die Grautöne der Zwischenformen brandmarkt er als Verunreinigungen der Kunst und Trübung des Verstandes. ${ }^{34}$

"Wenn es wahr ist, daß die Mahlerey zu ihren Nachahmungen ganz andere Mittel, oder Zeichen gebrauchet, als die Poesie; jene nehmlich Figuren und Farben in dem Raume, diese aber artikulirte Töne in der Zeit; wenn unstreitig die Zeichen ein bequemes Verhältniß zu dem Bezeichneten haben müssen: So können neben einander geordnete Zeichen, auch nur Gegenstände, die neben einander, oder deren Theile neben einander existiren, auf einander folgende Zeichen aber, auch nur Gegenstände ausdrücken, die auf einander, oder deren Theile auf einander folgen.

Gegenstände, die neben einander oder deren Theile neben einander existiren, heissen Körper. Folglich sind Körper mit ihren sichtbaren Eigenschaften, die eigentlichen Gegenstände der Mahlerey.

Gegenstände, die auf einander, oder deren Theile auf einander folgen, heissen überhaupt Handlungen. Folglich sind Handlungen der eigentliche Gegenstand der Poesie.." ${ }^{35}$

Lessing definiert hier formelle Unterschiede, die zwischen den Medien Malerei und Text herrschen, und knüpft diese an bestimmte Inhalte. Das Nachwirken dieser Distinktion bis in die Gegenwart lässt sich deutlich an Kriegers Ekphrasis-Konzeption nachvollziehen. Krieger nimmt Lessings Argumentation auf und weist auf das Dilemma hin, dass die Sprache im Zeitlichen, im Nacheinander verortet sei, während das Bild im Räumlichen, in der Gleichzeitigkeit zu finden sei. Eine Ekphrasis bedeute demnach eine stückweise Überwindung der Raum-Zeit-Achse. ${ }^{36}$ Im »Lexikon Kunstwissenschaft» steht zur Präzisierung des Begriffs »ut pictura poesis«:

»Während die Dichtung ein Argument vorträgt, einen Verlauf in zeitlicher Analogie schildert, ist die Malerei auf die Evidenz des Zeigens angewiesen. Malerei, sofern sie abbildend ist, basiert auf der Relation der Ähnlichkeit, während die Dichtung nur über die Aktivierung der Imagination des Lesers oder Zuhörers `bildhaft sein kann. ${ }^{37}$

33 Vgl. Pestalozzi, Karl: Das Bildgedicht. In: Boehm/Pfotenhauer: Beschreibungskunst Kunstbeschreibung, 569-591, hier 570. Siehe ebenfalls Boehm, Gottfried/Pfotenhauer, Helmut: Einleitung: Wege der Beschreibung. In: Dies.: Beschreibungskunst - Kunstbeschreibung, 9-19, hier 9.

34 Mitchell, William: Iconology. Image, text, ideology. Chicago 1986, 95-115.

35 Lessing, Gotthold E.: Laokoon. Oder Über die Grenzen der Malerei und Poesie. Stuttgart 2012, 115.

36 Vgl. Krieger, Das Problem der Ekphrasis, $43 \mathrm{f}$.

37 Ut pictura poesis. In: Pfisterer, Lexikon Kunstwissenschaft, 364. 
Dass diese Unterscheidung zwischen statischem, räumlichen Bild und zeitlicher, bewegter, diskursiver Literatur nicht faktisch ist, zeigt sich deutlich darin, dass sich die Malerei und Literatur bis zur Renaissance problemlos Themen, Stoffe und Motive geteilt haben ${ }^{38}$ aber auch in Schulz' diskursiver, selbstreflexiver Bildkunst. ${ }^{39}$ Die Vorstellung, dass Argumente nur durch Sprache wiedergegeben werden, Visualität nur durch Bilder, dass das eine Medium zeitlich und das andere räumlich sei, ist bis heute dominant, aber nicht »natürlich«, wie Mitchell darlegt:

"paintings can tell stories, make arguments, and signify abstract ideas; words can describe or embody static, spatial states of affairs, and achieve all of the effects of ekphrasis without any deformation of their naturak vocation (whatever that may be). ${ }^{40}$

Mitchell betont daher in seiner Ekphrasis-Theorie die Relevanz der Haltung. Neben einer neutralen Haltung, welche ergebnisoffen konkrete Ekphraseis nach ihrer Beziehung zum Bild untersucht, gebe es »ekphrastic hope«, die für den Wunsch steht, magisch die mediale Grenze der sprachlichen Präsentation zu durchbrechen und zu einem Bild zu gelangen, das mehr ist als ein Sprachbild. "Ekphrastic fear« hingegen steht für die Angst, dass ein Sprachbild eine so große Macht entwickelt, dass es idolatrisch als etwas anderes als Sprache wahrgenommen wird (»object worship $\aleph^{41}$ ). Beide Haltungen existieren in jeder Gesellschaft gleichzeitig, wobei eine davon meist dominanter ist. Eichendorffs kritische Darstellung der Wirkung der heidnischen Skulpturen auf den Verstand des Protagonisten Florio in "Das Marmorbild« kann als Ausdruck dieser »ekphrastischen Angst « verstanden werden. Nicht zufällig ist die Gegenmagie zum mythischen Bild in seiner Novelle die Musik, ${ }^{42}$ die mit Abstraktion und der Klarheit der Verstandeskraft assoziiert wird ${ }^{43}$ und nach Mitchell in der Romantik den neuen Vergleichspunkt für die Poesie bildet. Ein Gedicht sei demnach nicht mehr dann besonders gelungen, wenn es male-

38 Vgl. Wenzel, Horst: Zur Narrativik von Bildern und zur Bildhaftigkeit der Dichtung: Plädoyer für eine Text-Bildwissenschaft. In: Belting, Hans (Hg.): Bilderfragen. Die Bildwissenschaften im Aufbruch. München 2007, 317-331.

39 Siehe Kapitel 3 »Bildreflexionen in Bildern. - ১Xięga Bałwochwalcza«".

40 Mitchell, Picture Theory, 160.

41 Ebd., $154 \mathrm{f}$.

42 Siehe 3.3 »Das Marmorbild «.

43 Vgl. Krieger, Das Problem der Ekphrasis, 50-57. Dies zeigt sich deutlich in Schopenhausers »Metaphysik des Schönen«. Die Musik »steht ganz abgesondert von allen andern: wir erkennen in ihr nicht die Nachbildung, Wiederholung irgendeiner Idee der Dinge der Welt. Dennoch ist sie eine große und überaus herrliche Kunst, wirkt mächtiger als irgend eine andre auf das Innerste des Menschen, wird dort ganz, tief und innig verstanden, als eine ganz allgemeine Sprache, deren Verständniß angeboren ist und deren Deutlichkeit sogar die der anschaulichen Welt selbst übertrifft.« Schopenhauer, Metaphysik des Schönen, 214. 
risch wie ein Bild ist, sondern wenn es klar ist und klingt wie die Musik. ${ }^{44}$ Er nennt diese Entwicklung auch »aesthetic icoloclasm. ${ }^{45}$

Wie stark die Trennung zwischen den Kunstformen nachwirkt, zeigt sich auch in der Kunsttheorie. So konzeptualisiert Boehm die Entwicklung der modernen Malerei seit dem 19. Jahrhundert weiterhin als Trennungsgeschichte der Malerei von der Literatur, da die Malerei nicht mehr traditionelle, literarische Stoffe dargestellt habe, sondern Gefühlswelten, Stimmungen, Momentaufnahmen und Wahrnehmungsbedingungen. ${ }^{46}$ Eingeleitet durch den Impressionismus entstanden seines Erachtens Bilder, die sich zunehmend der Verbalisierbarkeit entzogen.

"In der Geschichte der Malerei war es ein Schlüsselereignis, als die französischen Impressionisten die künstlerische Annäherung an die sichtbare Natur unter der Devise betrieben, dasjenige, was man am jeweiligen Motiv sah, von dem zu trennen, was man von ihm wußte. Diese Scheidung eines konstatierenden Wahrnehmens (dessen Einsichten sprach- und begriffsförmig, d.h. beschreibbar sind), von einem sich realisierenden Sehen, das sich wenig an dingliche Sachverhalte hält, sondern die freien visuellen Latenzen am Geschehen vollzieht, bedeutet auch für die Kunst der Beschreibung einen Einschnitt. ${ }^{47}$

Solche Bilder, die in der Fortentwicklung in die abstrakte Malerei münden, visualisieren Sehensmodalitäten, thematisieren die Wahrnehmung des Sichtbaren, lassen sich also theoretisieren, aber nicht mehr beschreiben im Ereignis- und Stoffsinne. Darüber hinaus geht Boehm auf die vielen Kunstmanifeste seit der Jahrhundertwende ein, die darum bemüht sind, die Bildkunst aus sich selbst zu legitimieren. ${ }^{48}$

44 Vgl. Mitchell, Picture Theory, $115 \mathrm{f}$.

45 Ebd., 115.

46 Vgl. Boehm, Gottfried: Bildbeschreibung: Über die Grenzen von Bild und Sprache. In: Boehm/Pfotenhauer: Beschreibungskunst - Kunstbeschreibung, 23-40, hier 27.

47 Ebd., 26. (Hervorh. im Orig.)

48 Vgl. Boehm, Wie Bilder Sinn erzeugen, 60-62. Dass man diese "Selbstbezüglichkeit« der Kunst, die sich nur im künstlerischen Manifest realisieren kann, auch "Literarisierung" der Kunst bezeichnen kann, hat Beyme deutlich gezeigt. Vgl. Beyme, Das Zeitalter der Avantgarden, 221-223. Dies gilt auch für den polnischen Raum, wie Witkacys Text deutlich macht: „Wir leben in einer Zeit der Programmhaftigkeit: Noch ehe eine Kunstrichtung spontan entsteht, kann man schon oft beobachten, daß ihre Theorie relativ vollendet ist. Theorien beginnen Richtungen zu erzeugen und nicht umgekehrt. Früher hat es die >Richtungen` in unserem Sinne, hat es die verschiedenen `Ismen es gab starke Individualitäten und die aus ihren Mitarbeitern gebildeten Schulen. So war es zumindest in der Malerei. Es ist ein Kennzeichen der Kunst unserer Zeit, daß die schöpferischen Prozesse immer mehr intellektualisiert werden und die unmittelbaren Protuberanzen sich vorgefaßten Prinzipien beugen müssen."Witkiewicz, Stanisław I.: Einführung in die Theorie der reinen Form des Theaters. In: Wirth, Andrzej (Hg.): Verrückte Lokomotive. Ein Lesebuch. 2. Aufl. Frankfurt a. M. 1994, 43-83, hier 43. »Żyjemy 
»Mit dem abstrakten Bild verschwindet die ganze Gliederung der Wirklichkeit nach Geschichte, Individuum, Körper, Natur und Ding. Jetzt ist jedes einzelne Bild Metapher der Wirklichkeit schlechthin, repräsentiert eine Totalität, wie unbestimmt sie begrifflich auch sein mag. An ihrer visuellen Artikulation und Nachvollziehbarkeit dagegen gibt es keinen Zweifel. Mit dem abstrakten Bild eröffnet die Kunst der Moderne eine neue Direktheit: le tableau und le monde konfrontieren sich in einer unvergleichlichen Konstellation. ${ }^{49}$

Während nach Ansicht von Boehm die Theoretisierung der Malerei die Spaltung zwischen der sehbaren und der sagbaren Welt vorangetrieben habe ${ }^{50}$ und Bilder nun ohne Vermittlung der Sprache direkten Bezug zur Wirklichkeit suchten, betont Mitchell, dass die Malerei nur andere literarische Quellen habe - nämlich die Kunsttheorie. Ohne die Kenntnis der Manifeste verliert auch die abstrakte Kunst an Sinn und wird dekorativ.

"The project of abstract painting (as understood by some of its principal advocates) is only secondarily an overcoming of representation or illusion; the primary aim is the erection of a wall between the arts of vision and those of language. [...] [T] he wall erected against language and literature by the grid of abstraction only kept out a certain kind of verbal contamination, but it absolutely depended, at the same time, on the collaboration of painting with another kind of discourse, what we may call, for lack of better term, the discourse of theory. If we summarize the traditional collaboration of painting and literature under the classic Horatian maxim, ut pictura poesis, as in painting, so in poetry, then the maxim for abstract art is not hard to predict: ut pictura theoria. Or, as Wolfe expresses it: these days, without a theory to go with it, I can't see a painting...1 ${ }^{51}$

Weiter schreibt Mitchell »that the entire antiverbal ideology of abstraction, its depiction to a rigorous >barrier between vision and language, is a myth that

w czasach programowości: zanim spontanicznie powstanie kierunek jakiś w sztuce, można często obserwować teorię jego w stanie względnej doskonałości. Teorie zaczynają tworzyć kierunki, a nie odwrotnie. Zresztą w dawnych czasach nie było ’kierunków w naszym sensie znaczeniu, nie było różnych `izmów`, były potężne indywidualności i szkoły złożone z ich współpracowników. Tak przynajmniej było w malarstwie. Coraz większe przeintelektualizowanie procesów twórczych i naginanie bezpośrednich protuberancji do góry powziętych zasad jest charakterystyczną cechą naszych czasów w sztuce.« Witkiewicz, Stanisław I.: Wstęp do teorii czystej formy w teatrze. In: Ders., Teatr i inne pisma o teatrze. Warszawa 1995, 13-42, hier 13.

49 Boehm, Wie Bilder Sinn erzeugen, 171.

50 Nach Boehm verwirrte René Magritte die Beziehung von Bild und Sprache, indem er unter einen gemalten Hut das Wort Pfeife setzte und so die Bedeutung des Wortes und des Bildes nicht übereinstimmten. Die Beziehung der beiden läuft ins Leere. »Der Satz: `Das ist keine Pfeifer bestreitet, was das Gemälde doch zeigt. Mit welchem Recht? Mit dem Recht eines Satzes, der auf die bildliche Darstellung reflektiert. Tatsächlich handelt es sich lediglich um das Bild einer Pfeife.«Boehm, Bildbeschreibung, $28 \mathrm{f}$.

51 Mitchell, Picture Theory, 216-220. 
needs to be understood and not just debunked. ${ }{ }^{52}$ Einig sind sich Mitchell und Boehm hingegen in der Ansicht, dass es ein Grundzug der modernen Malerei ist, selbstreflexiv und in hohem Maße theoretisiert zu sein. ${ }^{53} "$ Die Moderne definiert sich geradezu als Zeitalter der Selbstbezüglichkeit der Künste: es beginnt im 18. Jahrhundert und dauert bis heute an. ${ }^{54}$ Indem Formen und Farben nicht mimetisch zur Visualisierung einer Handlung, eines Motivs oder eines Gegenstands eingesetzt werden, sondern selbst direkte Präsentation werden, verbreiten sich die Vorstellung und das Ideal von einer regelrechten, wesensimmanenten Unsagbarkeit im Kunstwerk - eines »Purismus«. Die Idee, dass Farbe nicht mehr "nur" Medium ist, sondern selbst Bild, kann als Versuch einer Verschmelzung von Medium und Inhalt im Bild gedeutet werden. ${ }^{55}$ Boehm zufolge entwickelte sich somit aus der Ekphrasis, einer reinen Bildbeschreibungsübung, eine Art bildsprachliche Erkenntnistheorie. ${ }^{56}$

Boehms Unterscheidung zwischen einer »literarischen Bildkunst « und einer "puren « funktioniert nach Mitchell allerdings nur dann, wenn man die theoretischen Texte zu den Bildern kennt und gleichzeitig ignoriert. ${ }^{57} \mathrm{Ge}$ nauso, wie es für das Verständnis von Historienmalerei unerlässlich ist, die biblischen Geschichten zu kennen, braucht es zum Verständnis der modernen, abstrakten Malerei ihre Manifeste und Theorien. ${ }^{58} \mathrm{Ob}$ man Malevichs Quadrate als Kunst oder als geometrische Form verstehe, ist nach Mitchell eine Frage, ob man Anhänger der Theorie ist oder nicht - »believer« oder "non-believer«. Als Gläubiger dieser Bildsprache gewinne abstrakte Kunst an Ausdruck und Fülle. ${ }^{59}$ Mitchell erkennt in den Grundannahmen, wie der Vorstellung des reinen, naiven Sehens, eine religiöse Haltung.

Eine parallele Entwicklung ist nach Klaus Peter Dencker auch in der Poetiktheorie zu finden. Die Trennung der Künste wurde als Befreiung gefeiert. $^{60} \mathrm{Im}$ italienischen und russischen Futurismus wurden die reine Sprache,

52 Ebd., 220.

53 Vgl. Boehm, Wie Bilder Sinn erzeugen, 13, sowie Mitchell, Picture Theory, 36.

54 Vgl. Boehm, Gottfried/Pfotenhauer, Helmut: Einleitung: Wege der Beschreibung. In: Dies.: Beschreibungskunst - Kunstbeschreibung, 9-19, hier 9.

55 Eine besondere Rolle hat hier auch Kandinsky gespielt, der eine eigengesetzliche Wirksamkeit der künstlerischen Mittel und besonders der Farben begründet. Diese Ideen münden in eine abstrakte Malerei. Vgl. Kultermann, Udo: Kleine Geschichte der Kunsttheorie. Von der Vorgeschichte bis zur Gegenwart. Darmstadt 1988, 229-232.

56 Vgl. Boehm, Bildbeschreibung, 24.

57 Panofsky zeigt in seiner Untersuchung "Idea« sogar eindrucksvoll, dass auch die Theoretisierung der Malerei keine rein moderne Entwicklung ist, sondern in der Renaissance schon einmal hochentwickelt war. Vgl. Panofsky, Idea, 23-38.

58 Vgl. Mitchell, Picture Theory, 223.

59 Ebd., $226 \mathrm{f}$.

60 Vgl. Dencker, Klaus P.: Optische Poesie. Von den prähistorischen Schriftzeichen bis zu den digitalen Experimenten der Gegenwart. Berlin 2011, $328 \mathrm{f}$. 
die Begriffs- und auch die Buchstabensprache gefeiert, Gedichte die nur aus Silben und Buchstaben oder aus nur einem Wort bestehen, waren der neue Nullpunkt der Sprachkunst. ${ }^{61}$

Dies ist der Hintergrund, vor dem die Untersuchung der Ekphraseis in Schulz' literarischen Texten sinnvoll erscheint. Mitchell und Boehm machen auf die sprach- und bildpuristischen Ideen aufmerksam, die großen Einfluss auf die Bild- und Wortkunst des 20. Jahrhunderts haben und bis heute nachwirken. Wie sieht Schulz vor diesem Hintergrund die Beziehung zwischen Sprache und Bild? Lassen sich die religiösen Elemente seines Textes grob formuliert "nur« als Bibelzitate oder im Sinne Mitchells als Haltungsform $^{62}$ verstehen? Gerade die Doppelbegabung von Schulz, sein Schaffen in den Bereichen Bild und Sprache, macht die Untersuchung der Ekphrasis umso spannender.

\subsection{Von visualisierenden Beschreibungen zur Wortmalerei}

»Rasch wird uns die Farbe in den Tiegeln und der Glanz in der Seele ausgehen, um die höchsten Akzente zu setzen, um die leuchtendsten, bereits transzendenten Konturen auf diesem Gemälde zu umreißen. ${ }^{63}$

Wo hört die Beschreibung auf und fängt die Ekphrasis an? Lässt sich ein klarer Unterschied zwischen Beschreibungen im klassischen Sinne und Ekphrasis finden? Zu diesem Zwecke werden nun einige ausgewählte Stellen in Schulz' Erzählungen untersucht. Dabei scheint die Unterscheidung bei Schulz nicht so sehr die zwischen Ekphrasis und Beschreibung zu sein, sondern zwischen Ekphrasis und Experiment der poetischen Sprache beziehungsweise die Motivation hinter der dynamisierten Beschreibung. Diese spielt deshalb eine entscheidende Rolle, weil es so viele metapoetische Erläuterungen zu den visualisierenden Passagen gibt. Daher ist der literarische Text sowohl Gegenstand der Untersuchung als auch Theorie zum Gegenstand und in dieser Verflochtenheit ist eine abschließende Deutung schwer.

Bolecki und Jarzębski haben sich beide intensiv mit der Beschreibungskunst von Schulz befasst und erkennen beide eklatante Unterschiede zu »klassischen« Beschreibungen. Diese dienten nach Bolecki für gewöhnlich der

61 Vgl. ebd., 335-345.

62 Oder in Cassirers Terminologie als »symbolische Form«. Vgl. Cassirer, Der Begriff der Symbolischen Form.

63 Schulz, Das Sanatorium zur Sanduhr, 25. »Wkrótce zabraknie nam w tyglach kolorów, a w duszy blasku, aby położyć najwyższe akcenty, nakreślić najświetlistsze i już transcendentalne kontury w tym malowidle.« Ders., Sanatorium pod Klepsydrą, 132. 
Plausibilisierung der Handlung. Sie hätten klar begrenzte Bereiche wie Naturbeschreibungen, Aussehen der Charaktere, Sachen sowie Hintergründe und auch entsprechende stilistische Mittel. Die Beschreibung sei der Gegenpart zur Handlung ${ }^{64}$, die der eigentliche Gegenstand der Erzählung sei. Weil die Handlung Aktionen und Ereignisse schildere, sei sie dynamisch, die Beschreibungen hingegen seien statisch, stellten den Zustand einer Sache dar, Charakteristika, Aussehen und Eigenschaften. Beschreibungen seien also komplementär zur Handlung.

»Die Erzählung informiert hauptsächlich über den zeitlichen Charakter der Elemente der vorgestellten Welt, d.h. sie dient der Darstellung der Änderungen (der Folge, des Zeitverlaufs), die Beschreibung hingegen stellt die Eigenschaften der Elemente dar, abstrahiert vom Ereignis- und Themenfluss. Wenn die Erzählung die zeitliche Struktur der epischen Überlieferung bedeutet, so informiert die Beschreibung über die Raumstruktur. ${ }^{65}$

In erneuter Anknüpfung an Lessings Unterscheidung weist Bolecki in diesem Zusammenhang auf die zahlreichen Abweichungen von Schulz' Beschreibungen zu "gewöhnlichen« hin. Sie finden sich in der Quantität, denn die Beschreibungen nähmen sehr viel mehr Raum ein und ganzen Erzählungen fehle eine Handlung. Die zweite große Abweichung sei die fehlende empirische Dimension, da viele Beschreibungen häufig bestimmten Wahrnehmungsbedingungen unterlägen und oft nicht unterschieden werde, ob eine Welt so ist oder aber sich nur so darstellt. Auch in den stilistischen Mitteln gäbe es Unterschiede, so in der Dominanz dynamischer Verben. ${ }^{66} \mathrm{Zu}$ den wichtigsten Stilmitteln in Schulz' Beschreibungen zählt Jarzębski belebende Personifikationen, Dynamisierungen und Wahrnehmungsbedingungen, die ins Fantastische umschlagen, Aufzählungen und Wiederholungen ähnlicher Motive, kontrastive Vergleiche, die häufig in Verschmelzungen münden, Assoziationen, die den Beschreibungen eine Palimpseststruktur verliehen, sowie synästhetische Assoziationen über Homonymien und Töne. ${ }^{67}$ Weil die Beschreibungen häufig auch ohne Anlass beginnen, sind sie nicht immer komplementär zu einer Geschichte zu verstehen, sondern stellen etwas Eigenständiges dar. Bolecki vermutet, dass die reine Sprachakrobatik, die "poetyckość" (Poetizität) Schulz wichtiger sei als eine stabile Bedeutung.

64 Vgl. Bolecki, Poetycki model prozy, 221.

65 »Opowiadania informuje głównie o czasowym charakterze elementów świata przedstawionego, tzn. służy prezentacij zmian (następstwa, narastanie w czasie), opis zaś przedstawia właściwości elementów wyabstahowane ze strumienia zdarzeniowo-tematycznego. Gdy opowiadanie wyznacza temporalną budowę przekazu epickiego, to opis informuje o jego budowie przestrzennej.«Ebd., 223 f. (Übers. A. J.)

66 Vgl. ebd., 221-231.

67 Vgl. Jarzębski, Prowincja centrum, $29 \mathrm{f}$. 
»Das ist vielleicht das größte Paradox im Zugang zur stilistischen `Poetizität von Schulz' Prosar. Es wird nämlich das Wort in seiner Narration zu einem semantisch leeren Zeichen, das heißt zu einem, welches man zur Beschreibung eines jeden Phänomens und Elements der Wirklichkeit verwenden kann. Die Vielzahl der textuellen Anwendungen der besprochenen lexikalischen Einheiten weist darauf hin, dass es bei Schulz zu einer Trennung von Zeichen und Bedeutung gekommen ist.. ${ }^{68}$

Jarzębski versteht die Funktion dieser Wortbilder als mystische Praxis, um den nicht-sagbaren, präexistenten Sinn, wie er in »Mityzacja rzeczywistości» formuliert wurde, zu erfassen.

»Ich denke dass, - oder vielmehr - ich bin der Meinung, dass man niemals verstehen kann, wie die Erzählungen von Schulz im Wesen verfasst sind, wenn man nicht das Problem des Bildes und der Verbildlichung begriffen hat. Warum? Weil man über die Bedeutung bestimmter Worte keinen direkten Zugang zum ganzheitlichen, vorgesetzlichen Sinn hat, von dem die Worte einst herstammten - genauso wie man keinen direkten Zugriff über bestimmte Büchern zum `Buch $\prec$ hat. Die vermittelnde Instanz ist dabei genau das Bild - das nicht so sehr als eine konkrete Ansichtigkeit zu verstehen ist, sondern als eine bestimmte räumliche Qualitätsanordnung, deren Domäne schon nicht mehr die Bedeutung, sondern der Sinn ist. " $"$ "99

Nach Jarzębski können daher nicht tatsächliche Bilder Vorlagen der dynamisierten Beschreibungen sein. Das wortmalerische Bild sei vielmehr »eine Struktur der Präsentation, die in bestimmten Raumkategorien vorzufinden ist, die man realisieren kann, in verschiedenen Substanzen verkörpern und durch Einsatz verschiedener Personen. ${ }^{70}$ Weil er die Wortmalerei ganz eng mit den Vorgaben des Manifestes verknüpft, findet er in den Wort-

68 »Jest to może najbardziej paradoxalny punkt dojścia ’poetyckościく stylu >prozy〈 Schulza. Okazuje się bowiem, że słowo w jego narracji staje się znakiem semantyzcnie pustym, tj. takim, który można wykorzytsać do określonego każdego zjawiska, do opisu każdego elementu rzeczywistości. Wielość tekstowych zastosowań omawianych jednostek leksykalnych wskazuje, że Schulz doprowadził jakby do rozdzielenia znaku i znaczenia." Bolecki, Poetycki model prozy, 203. (Übers. A. J.)

69 Jarzębski, Prowincja centrum, 42 f. "Sądzę, że tak i - co więcej - uważam, że bez dostrzeżenia problemu obrazu i obrazowania nie zrozumiemy nigdy, jak są w istocie zrobione opowiadania Schulza. Dlaczego? Otóż dlatego, że od znaczeń poszczególnych słów do całościowego, przedustawnego Sensu, z którego one kiedyś się wyłoniły, nie ma bezpośredniego przejścia - dokładnie tak samo, jak nie ma przejścia wprost od poszczególnych książek do Księgi. Instancja pośrednicząca jest właśnie obraz rozumiany niekoniecznie jako jakaś konkretna naoczność, ale jako pewien zestrój jakości, umieszczonych w przestrzeni, którego domeną jest już nie znaczenie, a sens.» (Übers. A. J.)

70 »Obraz, o jakim myślę, to raczej pewna ujęta w kategoriach przestrzennych struktura prezentacji, którą można realizować, ucieleśniać w rozmajtej substancji i z wykorzystaniem różnych osób.« Ebd., 48. 
bildern eine religiöse und mythische Struktur, eine »Sinn-Offenbarung«, die sich aufgrund des heiligen Charakters solcher Formen nicht konkreter fassen lasse. $^{71}$

Dieser Ansatz wird hier aus verschiedenen Gründen verworfen, einige davon liegen durch die Analysen der Werbebilder im vierten Kapitel schon auf der Hand. Erstens lässt sich eine Reihe von konkreten, materiellen Bildvorlagen auch für die beschreibenden Passagen der Erzählungen finden, zweitens dominieren in diesen Beschreibungen mitunter konkrete Farben, Pinselstriche und Perspektivanalysen, die nicht als Manifestation mythischmystischer Entitäten zu erklären sind, und drittens kommentiert der Erzähler, der mal Kind, mal Erwachsener ist, mal erlebend, mal analysierend auftritt, die Geschehnisse und gibt damit auch der Interpretation eine bestimmte Richtung.

Um genauer zu verstehen, wie die Wortbilder funktionieren und welch vielfältige Manifestation sie haben, werden nun beispielhaft einige analysiert. Dabei lassen sich drei Kategorien aufmachen: die Ekphraseis von Gemälden, die Ekphraseis mit starker Anlehnung an malerische Mittel, wie Farben, Malduktus und Raumdynamik, sowie die spezifische Form der »PerspektivEkphraseis«, die bestimmte Blickwinkel auf einen Gegenstand der Natur oder Wirklichkeit einnehmen und dadurch »magische» Ansichten ermöglichen.

\subsection{Gemälde-Ekphraseis}

Mit Gemälden der klassischen Malerei setzt sich die Erzählung »Druga jesień« (Der andere Herbst) auseinander. Auf der Handlungsebene entdeckt und untersucht der Vater die vergessenen barocken Gemälde einer kleinstädtischen Sammlung auf dem Dachboden und integriert sie in eine »allgemeine Systematik des Herbstes", die eine vergleichende Betrachtung der Meteorologie, konkret des herbstlichen Himmels, der Theatervorhänge und der barocken Malerei darstellt. Während der Vater mit Verzückung über diese Zusammenhänge nachdenkt, ist der Erzähler gegenüber den Bildern sehr reserviert.

Die aufgefundenen Bilder, überwiegend Schlachten- und Genremalereien, sind nach dem Erzähler allein von dritt- und viertklassigen Malern ausgeführt worden und Sackgassen der Kunstgeschichte. ${ }^{72}$ Seine kritische Sicht wird schon in der Einleitung deutlich, wenn er auf die Überreife, Langeweile und Vergessenheit, auf das malerische Fieber, die farbigen Delirien und den

72 Schulz, Das Sanatorium zur Sanduhr, 159. »ślepe uliczki historii szuki.« Ders., Sanatorium pod Klepsydrą, 219. 
kommenden Verfall jener Gemälde hinweist. ${ }^{73}$ Anschließend erfolgen drei Ekphraseis unbestimmter oder noch nicht bestimmter ${ }^{74}$ Bilder der "neapolitanischen Schule."

"Verglühter goldener Dämmer dunkelte auf den morschen Leinwänden, auf denen ganze Flotten von Galeeren und Karavellen in stehenden Buchten vermoderten und alte, vergessene Armadas auf ihren geblähten Segeln die Majestät längst untergegangener Republiken wiegten. Unter rauchigem und nachdunkelndem Firnis schimmerten, kaum zu erkennen, die Umrisse von Reitergefechten. Durch die Ödnis verbrannter Kampagnen, unter einem finsteren und tragischen Himmel zogen geballte Kavalkaden in drohender Stille durch die auf beiden Seiten emporschießenden und aufblühenden Artilleriefeuer. ${ }^{75}$

Beschrieben wird eine Schlacht, die in einer Meeresbucht ausgetragen wird und an der Segelschiffe und Kavallerie beteiligt sind. Das dargestellte vergangene Geschehen wird als aktiv stattfindend vorgeführt. Kein einziges Element des Bildes veranlasst den Erzähler zu farbkräftigen Assoziationsreihen, die vom Gegenstand wegführen. Auch fehlt eine Beschreibung der Farben und Maltechniken. Ähnlich wird mit zwei weiteren Gemälden verfahren.

"Auf den Bildern der neapolitanischen Schule altern die dunklen und geräucherten Nachmittage endlos, wie durch eine dunkle Flasche betrachtet. Die verfinsterte Sonne scheint in diesen verlorenen Landschaften zusehends zu welken, wie kurz vor einer kosmischen Katastrophe. Das ist der Grund für das nichtssagende Lächeln und die leeren Gesten der goldenen Fischerinnen, die mit manierierter Anmut den wandernden Komödianten gebündelte Fische verkaufen. Die ganze Welt ist schon längst

$73 »$ On [Jakub] pierwszy wyjaśnił wtórny, pochodny charakter tej późnej formacji, nie będącej niczym innym, jak pewnego rodzaju zatruciem klimatu miazmatami przejrzałej i wyradzającej się sztuki barokowej, stłoczonej w naszych muzeach.« Ebd., 218. »Er [Jakub] hatte als erster den sekundären und derivianten Charakter dieser späten Formation erklärt, die nichts anderes war, als eine Vergiftung des Klimas durch die Miasmen der überreifen und degenerierten barocken Kunst, mit der unsere Museen vollgestopft sind.«Ders., Das Sanatorium zur Sanduhr, 158.

74 Mir ist es nicht gelungen, in Werken zur Neapolitanischen Schule äquivalente Bildwerke zu identifizieren. Gewisse Ähnlichkeiten im Licht, in der Schiffs- und Hafenlandschaft und den handelnden Personen haben die Ekphraseis zu Claude Lorrains Malerei, insbesondere zu seinen Hafenansichten. Vgl. Röthlisberger, Marcel/Cecchi, Doretta (Hg.): L'opera completta di Claude Lorrain. Milano 1975.

75 Schulz, Das Sanatorium zur Sanduhr, 160. „Spalony złoty mrok ciemniał na tych zetlałych od starości płótnach, na których floty galer i karaweli, stare zapomniane armady butwiały w zatokach bez odpływu, kołysząc na wzdętych żaglach majestat dawno zaginionych republik. Spod zadymionych i pociemniałych werniksów majaczyły ledwo widoczne zarysy konnych potyczek. Przez pustkę spalonych kampanij, pod niebem ciemnym i tragicznym przeciągały w groźnej ciszy skłębione kawalkady, ujęte z obu stron w spiętrzenia i wykwity artyleryjskiego ognia.« Ders., Sanatorium pod Klepsydrą, 219. 
verurteilt, schon längst veraltet. Daher auch die unendliche Süße der letzten Geste, die allein noch geblieben ist - sich selbst fern und abhanden gekommen, immer wieder aufs neue ausgeführt und unabänderlich. ${ }^{76}$

Das Vergilben des Bildes wird als Alterungsprozess im Bildgeschehen dargestellt. Damit dynamisiert der Erzähler erneut das Gemälde als Gegenstand aus Leinwand und Farbe. Gleichzeitig betont er die vom Altern des Bildmaterials hervorgerufenen Sehensmodalitäten. Auch hier wird ein Geschehen beschrieben, in dem die Figuren ihre Gesten in ewiger Wiederholung ausführen. Damit wird das »Erstarren der Handlungen « auf dem Bild partiell wieder aufgehoben. Diesem Schema entspricht auch das dritte Bild, verändert ist nur das Thema. Diesmal sind Figuren der »Commedia dell'Arte« abgebildet, die sich »in diesem Land ohne Ernst und ohne Wirklichkeit " ${ }^{77}$ bewegen.

Vergleicht man diese Bildbeschreibungen mit denen der Werbebilder, so findet der Erzähler besseren Zugang zu letzteren. Weder die Themen noch die Farben oder die Komposition veranlassen den sonst recht assoziationsfreudigen Erzähler zu den bekannten Ausschweifungen. Anders verhält es sich mit dem Vater, der sich auf die Wolkenformationen konzentriert und diese auf den Himmel projiziert.

76 Ders., Das Sanatorium zur Sanduhr, 160. »Na obrazach neapolitańskiej szkoły starzeje się bez końca popołudnie smagłe i wędzone, jakby widziane przez ciemną butelkę. Pociemniałe słońce zdaje się więdnąć w oczach w tych straconych krajobrazach, jak w przeddzień kosmicznej katastrofy. I dlatego tak błahe są uśmiechy i gesty złotych rybaczek, sprzedających z manierycznym wdziękiem wiązki ryb wędrownym komediantom. Cały ten świat jest dawno osądzony i dawno za mierzchły. Stąd ta słodycz bezgraniczna ostatniego gestu, który sam jeden jeszcze trwa - sobie samemu daleki i zgubiony, wdąż na nowo powtarzany, już niezmienny.« Ders., Sanatorium pod Klepsydrą, 219.

77 Ders., Das Sanatorium zur Sanduhr, 160. „w tym kraju bez powagi i bez rzeczywistości« »A dalej jeszcze w głębi tego kraju, zamieszkałego przez beztroski lud wesołków, arlekinów i ptaszników z klatkami, w tym kraju bez powagi i bez rzeczywistości wyplaskują małe Turczynki pulchnymi rękami miodowe placki ułożone na deskach, dwaj chłopcy w neapolitańskich kapeluszach noszą kosz pełen gwarnych gołębi na kiju, który ugina się lekko pod tym gruchającym skrzydlatym ciężarem. A jeszcze głębiej, na samej krawędzi wieczoru, na ostatnim skrawku ziemi, gdzie na granicy mętnozłotej nicości chwieje się więdnący pęk akantu - toczy się jeszcze wciąż partia kart, ostatnia stawka ludzka przed wielką nocą, która nadciąga. "Ders., Sanatorium pod Klepsydrą, 219f. »Weiter im Inneren dieses Landes, in dem das sorglose Volk der Narren, der Harlekine und der Vogelfänger mit ihren Käfigen wohnt, klopfen kleine Türkinnen mit ihren rundlichen Händen auf Holzbrettern Honigplätzchen flach, zwei Bauern in neapolitanischen Hüten tragen einen Korb mit gurrenden Tauben an einer Stange, die sich unter der turtelnden, gefiederten Last leicht biegt. Und noch weiter in der Tiefe, ganz am Rande des Abends, auf dem letzten Zipfelchen Erde, wo an der Grenze zum mattgoldenen Nichts die welkenden Arkanthusranken schwanken - da ist noch eine Kartenpartie im Gange, ein letzter menschlicher Einsatz, bevor die große Nacht heraufzieht.« Ders., Das Sanatorium zur Sanduhr, 161. 
»Dieser andere Herbst unserer Provinz ist nichts anderes als eine kranke Fata Morgana, die durch die sterbende, in unsere Museen gesperrte Schönheit als übergroße Projektion an unserem Himmel strahlt. Dieser Herbst ist ein großes, wanderndes Theater, dessen Poesie uns belügt, er ist eine gewaltige, farbige Zwiebel, deren Häute sich eine nach der anderen lösen und jedesmal ein neues Panorama freigeben. Man gelangt nie zum Kern. Hinter jeder Kulisse, die welkt und sich raschelnd schält, zeigt sich ein neuer strahlender Prospekt, der kurz lebendig und echt ist, bevor er, im Dahinschwinden, seine papierne Natur preisgibt. Alle Perspektiven sind gemalt und alle Panoramen sind aus Pappe, nur der Geruch ist echt, der Geruch der welkenden Kulissen, der Geruch von großer Garderobe, von Schminke und Weihrauch. ${ }^{78}$

Worauf der Vater in seinem Vortrag aufmerksam macht, ist die Künstlichkeit und Kulissenhaftigkeit der dargestellten Welt. Dabei vermischt er die drei Bereiche Barockmalerei, Herbsthimmel und Theaterkulisse so gekonnt, dass sie gegeneinander austauschbar sind und nie eindeutig wird, ob er über alle drei gleichzeitig spricht oder nur über eins, welches er mit den anderen vergleicht. Setzt man jedoch die Malerei an den Ausgangspunkt dieser gedanklichen Exkurse, dann stellt der Vater die Frage nach der »Echtheit« des Dargestellten, dem Wesen der Illusion. "Echt« ist aber nur der Geruch der Leinwand, des Mediums also. Alle Bilder - inklusive der Wolkenbilder und der Bühnenbilder - sind wandelbar und von Beginn an interpretiert. Wie die »Wolkenbilder « unterliegen alle der Wahrnehmungsperspektive und Assoziation. ${ }^{79}$

Eine ähnliche Herbsthimmelsbeschreibung und Überlegung findet sich in der Erzählung »Emeryt« (Der Pensionist), in welcher der Herbsthimmel mit einer Radierung Rembrandts verglichen wird.

»Dann brachen endlich die Herbststürme los. [...] Wie auf den Radierungen von Rembrandt konnte man in diesen Tagen unter einem Streifen Helligkeit die fernen, mikroskopisch klaren Länder sehen, die im übrigen keiner gesehen hat und die jetzt, unter diesem hellen Himmelsspalt, hinter dem Horizont hervor, emporstiegen, über-

78 Ebd., 161f. »Ta druga jesień naszej prowincji nie jest niczym innym jak chorą fatamorganą, wypromieniowaną w wyolbrzymionej projekcji na nasze niebo przez umierające, zamknięte piękno naszych muzeów. Jesień ta jest wielkim wędrownym teatrem kłamiącym poezją, ogromną kolorową cebulą łuszczącą się płatek po płatku coraz nową panoramą. Nigdy nie dotrzeć do żadnego sedna. Za każdą kulisą, gdy zwiędnie i zwinie się z szelestem, ukaże się nowy i promienny prospekt, przez chwilę żywy i prawdziwy, zanim, gasnąc, nie zdradzi natury papieru. I wszystkie perspektywy są malowane i wszystkie panoramy z tektury i tylko zapach jest prawdziwy, zapach więdnących kulis, zapach wielkiej garderoby, pełen szminki i kadzidła." Ders., Sanatorium pod Klepsydrą, 220.

79 Michał Paweł Markowskis Untersuchungen des Zusammenhangs zwischen Theater und Text in Schulz' Prosa zeigen wie unterschiedlich seine Motive verstanden werden können. Vgl. Markowski, Michał P.: Text and Theater. The Ironic Imagination of Bruno Schulz. In: De Bruyn/Van Heuckelom: (Un)masking Bruno Schulz, 435-450. 


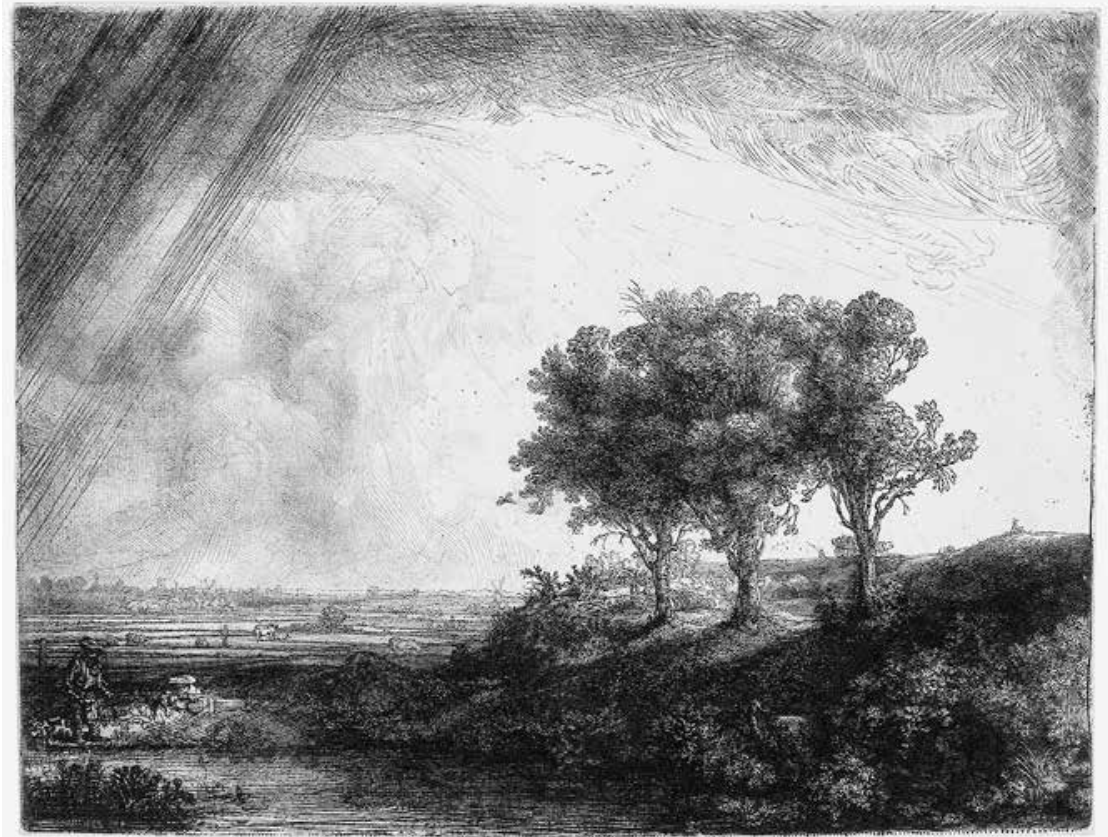

Abb. 18: Rembrandt, »Landschaft mit drei Bäumen«, 1643, Radierung, Kaltnadel und Kupferstich, ca. $21.5 \times 28.3$ cm, Inv. Nr. D 1146, Graphische Sammlung der ETH Zürich.

schüttet mit grellblassem und panischem Licht, wie aufgetaucht aus einer anderen Epoche und einer anderen Zeit, wie ein gelobtes Land, das den sehnsüchtigen Menschen nur für einen kurzen Moment gezeigt wird. ${ }^{80}$

Auch hier vermengt sich die Bildkunst mit der beschriebenen Landschaft und wird ununterscheidbar. Der Vergleich der Bildkunst mit dem Himmel weist auch darauf hin, dass ebenfalls die Natur mit Bildern der Kultur voll ist und dass jeder Himmel deswegen bedeutsam ist und keineswegs nur rein sich selbst darstellt.

Die Vorlage für diese Beschreibung des Herbsthimmels und der Landschaft ist möglicherweise Rembrandts Radierung "Landschaft mit drei Bäumen«. Nach Matthias Wohlgemuth habe Rembrandt sie in Anlehnung an römische

80 Schulz, Das Sanatorium zur Sanduhr, 266f. »Nastała wreszcie pora wichrów jesiennych. [...] Jak na sztychach Rembrandta widać było za dni tych pod tą smugą jasności dalekie, mikroskopijnie wyraźne krainy, które - zresztą nigdy nie widziane - podniosły się teraz zza horyzontu pod tą jasną szczeliną nieba, zalane jaskrawo-bladym i panicznym światłem, jak wynurzone z innej epoki i innego czasu, jak ukazany tęskniący ludom tylko na chwilę kraj obiecany.« Ders., Sanatorium pod Klepsydrą, $286 \mathrm{f}$. 
Ideallandschaften als ein »nördliches Arkadien« entworfen. Auffällig sind vor allem der weite Himmel mit dem hellen Gegenlicht und den dunklen Sturmwolken. Wohlgemuths Ekphrasis im Ausstellungskatalog liest sich wie folgt:

»Über der Weite der Landschaft hängen dunkle Sturmwolken - ziehen sie ab oder auf? [...] In die Gestaltung integriert sind die Reste einer nicht ganz getilgten älteren Platte: einzelne Figuren bleiben erkennbar und fügen sich zu bizarren Wolkenbildern. Schräg einfallende Licht- oder Regenstreifen, die in parallelen Linienbündeln mit Kaltnadel und Lineal gezogen sind, erzeugen eine dramatische Stimmung. In ihrer dichten Durcharbeitung ist dies Rembrandts >malerischste< Landschaftsradierung." ${ }^{81}$

Dass ausgerechnet Reste eines früheren Bildes am Himmel erkennbar sind, stützt die Vermutung, dass Schulz dieses Bild zur Vorlage diente. Rembrandts "malerischste« Radierung zeigt eine Landschaft, an der ein älteres Bild hinter oder in den Wolken zu erkennen ist, ein Bild im Bild beziehungsweise ein Bild im Himmel also, das sich in Jakubs Überlegungen aufs passendste einfügt. Rembrandts Radierung wirft Licht auf die Frage, wie sich die Bilder des Himmels zu den Bildern der Kunst verhalten. Sind die Wolkenbilder nur Illusionen, das heißt nur Wasser im gasförmigen Zustand wie die Bilder der Malerei nur Leinwand und Farbe sind? ${ }^{82}$ Oder ist das im Medium Wolke gesehene Bild im gleichen Maße wirklich wie das gemalte Bild auf der Leinwand?

Als letztes sei noch eine Passage aus der Erzählung "Jesień" (Herbst) angeführt, die diesen Kontext erneut aufgreift. Hier steht der Herbst in einer direkten Assoziationsreihe mit barocker Kunst, einer historischen Epoche und der damit verbundenen Wirklichkeitssicht sowie Lebenseinstellung.

»Die Grenzen deiner [des Herbstes] Universalität wurden sichtbar, dein großer Stil und dein schöner Barock, die in deinen guten Zeiten der Wirklichkeit entsprachen, erwiesen sich nun als bloße Manier. ${ }^{83}$

81 Ekphrasis der Radierung »Landschaft mit drei Bäumen«, 1643, in: Wohlgemuth, Matthias (Hg.): Rembrandt. [entstand aus Anlass der Ausstellung »Rembrandt - seine Epoche, seine Themen, seine Welt. Der Meister der Radierkunst im Spiegel der Malerei des Goldenen Zeitalters«, 26. November 2005 bis 26. März 2006, Kunstverein St. Gallen Kunstmuseum]. St. Gallen 2005, 116.

82 Solcherlei Projektionen eines Bildes an den Himmel, anschließend des Himmels auf den Theatervorhang oder die Kulissen und wieder zurück ins Gemälde finden sich zahlreich in Schulz' Literatur. Vor allem die Herbsterzählungen spielen mit diesem fließenden Medienwechsel unter Beibehaltung des Motivs oder Themas. In dem einzig erhaltenen Brief mit poetischen Versatzstücken aus der frühen epistemologischen Phase ist ebenfalls ein Herbsthimmel beschrieben, dessen Vögel sich in Schrift verwandeln. Vgl. Schulz, Księga listów, 74 .

83 Ders., Das Sanatorium zur Sanduhr, 287f. „Ukazały się granice Twej uniwersalności, Twój wielki styl, Twój piękny barok, który za dobrych Twych czasów był adekwatny rzeczywistości, okazał się teraz manierą.« Schulz, Bruno: Jesień. In: Jarzębski, Jerzy (Hg.): Proza. Kraków 1973, 298-302, hier 299. 
Der Herbst wird direkt angerufen, personifiziert und zum Ausgangspunkt einer Wirklichkeitssicht gemacht. Im Polnischen ist dies umso stärker akzentuiert, indem die Personalpronomen großgeschrieben sind. Der Herbst bietet dem Menschen nur eine bestimmte Farbpalette, die Düfte sind übertrieben, alles wird transzendent. An dieser Stelle ist der Herbst als Metapher für das Barock lesbar, dessen Ausdrucksart einer bestimmten Zeit und Wirklichkeitssicht entsprach. Diese Wirklichkeitssicht wird an anderer Stelle in den Vordergrund gerückt. Dann steht der Herbst für bestimmte Träume und Wünsche des Menschen nach vitaler Prallheit, himmlischer Transzendenz und höllischem Abgrund.

"Die Zeit der hübschen, klassischen Gesten, der lateinischen Phraseologie und der theatralischen Abrundung des Südens ist vorbei. Der Herbst sucht Prallheit, er sucht die ungehobelte Kraft der Dürers und der Breughels. Die Form birst vom Übermaß der Materie, die verhärtet sich zu Knoten und Knorren, sie packt die Materie mit Kiefern und Zangen, peinigt sie, vergewaltigt sie, walkt sie durch und entläßt sie, vom Kampf gezeichnet, aus ihren Händen, halb bearbeitete Klötze mit dem Stempel des ungeheuerlichen Lebens, mit den in hölzernen Gesichter eingeprägte Grimassen. ${ }^{84}$

Abschließend wird hier deutlich, dass sich die Untersuchungen des Erzählers der herbstlichen Wolkenlandschaften also auf barocke Kunst im Allgemeinen und Konkreten sowie auf die dazugehörige Wirklichkeitssicht beziehen.

Darstellungen des Himmels nehmen in Schulz' Prosa weiten Raum ein, immer wieder wird zwischen einem gemalten oder gezeichneten Bild, dem Theater und dem meteorologischen Himmel gewechselt. Neben barocken Wolkenbildern finden sich viele Darstellungen eines nächtlichen Himmels. Besonders anschauliche Ekphraseis von Sternenhimmeln finden sich in »Wiosna ${ }^{85}$ sowie in der Titelerzählung »Sklepy cynamonowe.»

"Ich trat in die von der Illumination des Himmels gefärbte Winternacht hinaus. Es war eine dieser hellen Nächte, in denen das bestirnte Firmament so ausgedehnt und weitverzweigt ist, als würde es zerfallen, auseinanderbrechen und sich in ein Labyrinth einzelner Himmelreiche aufgliedern, genug, um sie auf einen ganzen Monat von Winternächten zu verteilen und mit ihren silbernen und gemalten Lampenschir-

84 Schulz, Das Sanatorium zur Sanduhr, 288f. »Skończył się czas klasycznych gestów, łaczyńskiej frazeologii, południowych teatralnych zaokrągleń. Jesień szuka sobie jędrności, prostackiej siły Dürerów i Breugelów. Pęka ta forma od nadmiaru materii, twardnieje w węzły i sęki, chwyta ona materię w swe szczęki i kleszcze, gnębi ją, gwałci, ugniata i wypuszcza z swych rąk z śladami tej walki, kłody na wpół obrobione z piętnem niesamowitego życia, w grymasach, które im wycisnęła na drewnianych twarzach." Ders., Jesień, 300.

85 Vgl. Ders., Sanatorium pod Klepsydrą, $146 \mathrm{f}$. 
men alle nächtlichen Phänomene, Abenteuer, Szenen und Karnevale zu bedecken. [...] Der Himmel legte an diesem Tag seine innere Konstruktion aus vielen quasi anatomischen Präparaten bloß, er zeigte die Spiralen und Maserungen des Lichts, die Schnittflächen mattgrüner Nachtkörper, das Plasma der Atmosphäre, ein Gespenst aus nächtlichen Phantasiegebilden. ${ }^{86}$

Auch für die Sternenhimmel, insbesondere in der Beschreibung der Spiralen und Maserungen, lassen sich Gemäldevorlagen finden, die wegen des fehlenden namentlichen Bezugs jedoch nicht nachweisbar sind. Einzelne Motiv-, Kompositions- und Farbzitate erinnern aber stark an van Goghs Gemälde "Die Sternennacht" (Zypressen und Dorf). Caneppele und Speina finden in ihren Untersuchungen weitere Stellen, die sich an die Farbigkeit, Motivwahl und den Malduktus van Goghs anlehnen und stützen mit ihren Untersuchungen die These, dass sich Schulz auf Vorlagen der Malerei bezieht. ${ }^{87}$ Die starke Dynamik, die in van Goghs Bildern durch seinen charakteristischen Pinselstrich angelegt ist, wird in Schulz' Version aufgegriffen und betont. Gerade vor dem Hintergrund der Trennung zwischen Bild als räumlichem und Sprache als zeitlichem Medium wird hier durch die ekphrastische Wiedergabe gerade das dynamische Geschehen in van Goghs Bildern verstärkt. Van Goghs Himmelsdarstellungen sind von einer ununterbrochenen Bewegung charakterisiert, die sich in Spiralen und Wirbeln, aber auch in fluktuierenden Lichtpunkten konstituiert. Schulz' Erzählung nimmt sprachlich die Räumlichkeit auf und dehnt den Himmel durch die sukzessive Zergliederung und immer feineres Hineinfokussieren stetig weiter aus.

Nicht nur Landschaften, auch manche Personen werden nicht in ihren optischen Merkmalen dargestellt, sondern wie ein expressionistisches Porträt malerisch beschrieben. In ihren runzeligen Gesichtern schlägt sich ihre Stimmung und gesellschaftliche Position durch Farbigkeit und verfremdende

86 Ders., Die Zimtläden, 86-88. »Wyszedłem w noc zimową, kolorową od iluminacji nieba. Była to jedna z tych jasnych nocy, w których firmament gwiezdny jest tak rozległy i rozgałęziony, jakby rozpadł się, rozłamał i podzielił na labirynt odrębnych niebios, wystarczających do obdzielenia całego miesiąca nocy zimowych i do nakrycia swymi srebrnymi i malowanymi kloszami wszystkich ich nocnych zjawisk, przygód, awantur i karnawałów. [...] Niebo obnażało tego dnia wewnętrzną swą konstrukcję w wielu jakby anatomicznych preparatach, pokazujących spirale i słoje światła, przekroje seledynowych brył nocy, plazmę przestworzy, tkankę rojeń nocnych.« Ders., Sklepy cynamonowe, $83 \mathrm{f}$.

87 »Der alte, vom Winde verwehte Mann in der Erzählung Der Pensionist, erinnert an die fliegenden Gestalten von Chagall und die Beschreibung des Nachthimmels im Frühling erscheint wie die Prosaversion von Van Goghs Gemälde Terrasse du Café le soir, place du Forum à Arles, wo die Sternenwirbel das im Halbdunkel liegende Café überragen." Vgl. Caneppele, Die Republik der Träume, 15 f. Siehe auch Speina, Bankructwo realności, $25 ; 100$. 


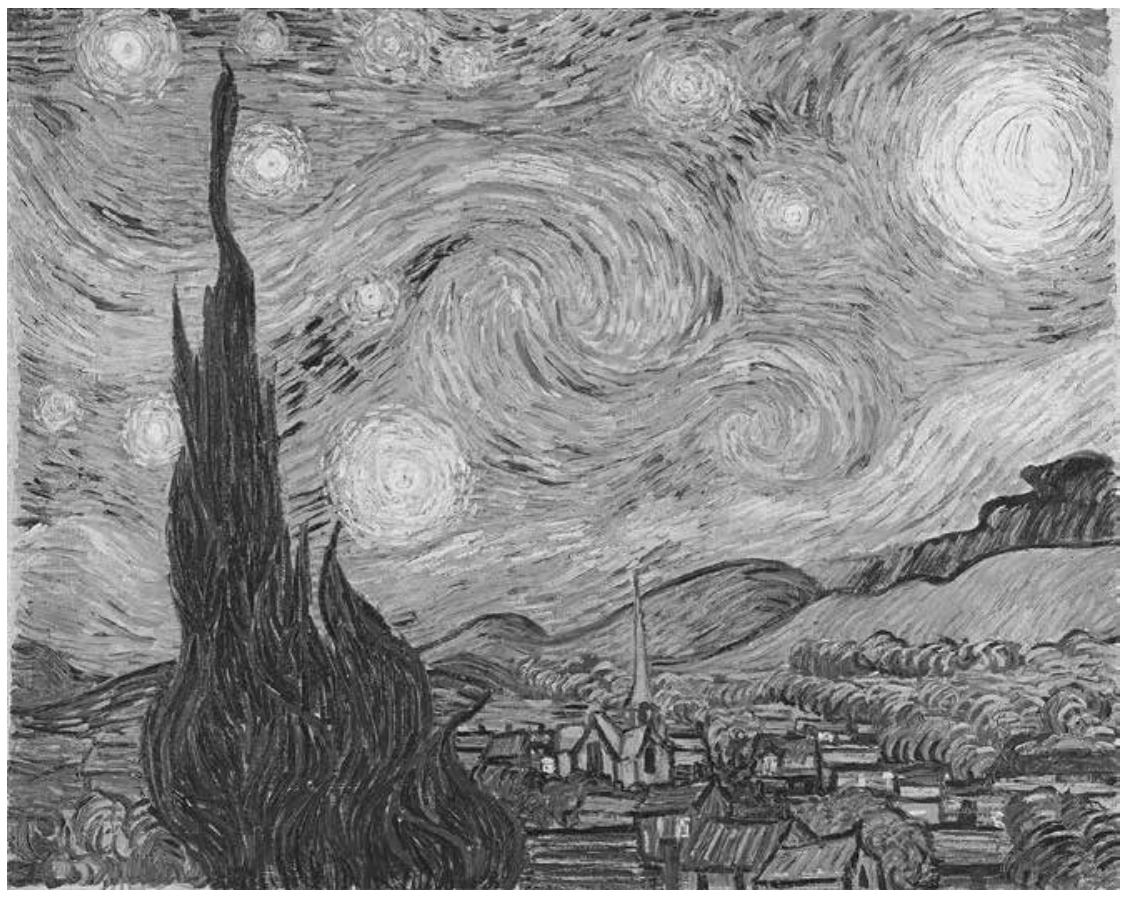

Abb. 19: Vincent van Gogh, „Die Sternennacht« (»Zypressen und Dorf«), Saint-Rémy, 1889, Öl auf Leinwand, $73 \times 92 \mathrm{~cm}$, Museum of Modern Art.

Verzerrungen nieder. ${ }^{88}$ Ihre Gesichter verhalten sich wie Knetmasse zu ihren Emotionen.

»Im Gesicht meines Vaters, das aufgewühlt vom Grauen der Dinge war, die er aus der Dunkelheit heraufbeschworen hatte, bildete sich ein Faltenwirbel, ein in die Tiefe wachsender Trichter, auf dessen Grund ein prophetisches Auge bedrohlich glomm.

88 Eine vergleichbare Personenbeschreibung findet sich in der Erzählung "Sierpień« (August) in der Landstreicherin Tłuja. »Tłuja sitzt zusammengekauert inmitten von gelbem Bettzeug und Lumpen. Von ihrem großen Kopf steht das schwarze Haar in Büscheln ab. Ihr Gesicht läßt sich zusammenziehen wie der Balg einer Ziehharmonika. Alle Augenblicke legt eine weinerliche Grimasse diese Ziehharmonika in tausend Querfalten, und das Erstaunen zieht sie wieder auseinander, glättet die Falten, enthüllt die Schlitze der winzigen Augen und das feuchte Zahnfleisch mit den gelben Zähnen unter der rüsselartigen, fleischigen Lippe.«Schulz, Die Zimtläden, 14. »Tłuja siedzi przykucnięta wśród żółtej pościeli i szmat. Wielka jej głowa jeży się wiechciem czarnych włosów. Twarz jej jest kurczliwa jak miech harmonii. Co chwila grymas płaczu składa tę harmonię w tysiąc poprzecznych fałd, a zdziwienie rozciąga ją z powrotem, wygładza fałdy, odsłania szparki drobnych oczu i wilgotne dziąsła z żółtymi zębami pod ryjowatą, mięsistą wargą.« Ders., Sklepy cynamonowe, 41 . 
Sein Bart war seltsam gesträubt, die haarigen Büschel und Pinsel, die aus den Warzen, Leberflecken und Nasenlöchern hervorschossen, hatten sich in ihren Wurzeln aufgestellt." ${ }^{89}$

Sowohl in der Erzählung »Traktat o manekinach. Ciąg dalszy« (Traktat über die Schneiderpuppen. Fortsetzung) als auch in der Erzählung »Sklepy cynamonowe« wird der Vater auf malerisch verfremdende Weise beschrieben.

"Sein Gesicht und sein Kopf waren damals wild und üppig mit grauem Haar bewachsen, das ihm in unregelmäßigen Büscheln, Borsten und langen Pinseln aus Warzen, Brauen und Nasenlöchern herausragte und seiner Physiognomie das Aussehen eines alten, struppigen Fuchses verlieh. ${ }^{90}$

Auch darin erinnern die Beschreibungen an einige Selbstporträts van Goghs. Sie zeigen ihn mit rotem, struppigem Bartwuchs, glimmenden Augen und Wirbeln im Hintergrund oder im Gesicht. Unabhängig davon, ob diese Bilder nun Vorlagen zu den zitierten Personenbeschreibungen sind oder nicht, orientieren sich die Vater-Porträts stärker an expressionistischen Gemälden, denn an typischen Beschreibungen. Da der Vater nicht in seinem empirischen Äußeren, sondern durch den Filter der Wahrnehmung des Sohnes und Erzählers dargestellt wird, finden malerische und literarische Verfahren gleichermaßen Anwendung. Die Visualisierung der Gefühle durch Verzerrungen der Mimik ruft unwillkürlich Assoziationen zum Expressionismus herauf. ${ }^{91}$

89 Ders., Die Zimtläden, 60. »W twarzy mego ojca, rozwichrzonej grozą spraw, które wywołał z ciemności, utworzył się wir zmarszczek, lej rosnący w głąb, na którego dnie gorzało groźne oko prorocze. Broda jego zjeżyła się dziwnie, wiechcie i pędzle włosów, strzelające z brodawek, z pieprzów, z dziurek od nosa, nastroszyły się na swych korzonkach."Ders., Sklepy cynamonowe, 67.

90 Ders., Die Zimtläden, 84. »Twarz jego i głowa zarastały wówczas bujnie i dziko siwym włosem, sterczącym nieregularnie wiechciami, szczecinami, długimi pędzlami, strzelającymi z brodawek, $\mathrm{z}$ brwi, z dziurek od nosa - co nadawało jego fizjonomii wygląd starego, nastroszonego lisa.« Ders., Sklepy cynamonowe, 82.

91 Obwohl nach Osterkamp die Zeit des Expressionismus, in welcher sich die Bildkunst immer weiter von den literarischen Grundlagen und mimetischen Darstellungen trennte, eine Dürreperiode der Bildbeschreibung darstellte, war sie auch eine Zeit großer Perlen der Beschreibungskunst: »dies aufgrund jener nicht eben häufigen Versuche einer neuen Form von Bildbeschreibung, die, auf Basis einer entschiedenen Zeitgenossenschaft, mit der künstlerischen Entwicklung Schritt zu halten sucht, also das Kunstwerk nicht mehr über seine zu einem sekundären künstlerischen Mittel herabgestufte Gegenständlichkeit erfassen will, sondern über die vom mimetischen Zwang befreite Form und die absolute Farbe, die als Ausdrucksträger, als Medium dargestellter Inwendigkeit, gelesen wird." Osterkamp, Ernst: Däubler oder die Farbe - Einstein oder die Form: Bildbeschreibung zwischen Expressionismus und Kubismus. In: Boehm/Pfotenhauer: Beschreibungskunst - Kunstbeschreibung, 543-568, hier 547. 
Speina deutet auch die Verwandlungen des Vaters in Tiere wie Kakerlaken und Vögel im Kontext expressionistischer Ideen.

"Die Magie dieser Verwandlungen beruht auf der kompletten Identifizierung der Gegenstände oder Ereignisse mit den durch diese ausgedrückten Emotionen, einer Identifizierung, die von den Künstlern des Expressionismus zum künstlerischen Hauptgesetz der poetischen Illustration anerkannt wurde. In Folge dessen wurde eine künstlerische Logik des Bildes in Abgrenzung zur verstandesmäßigen Logik akzeptiert. ${ }^{92}$

Auch auf der Handlungsebene befasst sich die Erzählung "Sklepy cynamonowe « mit der Bildkunst. Der Sohn verlässt den Theatersaal, um nach der Geldbörse des Vaters zu suchen, verirrt sich jedoch in der nächtlichen Stadt und landet in den Schulräumen des Zeichenlehrers Arndt. Dessen Bilder werden wiederum mit der nächtlichen Stadtlandschaft verglichen.

"Das zerstäubte Weiß des Lichts, das aus dem Schnee, der bleichen Luft und der milchigen Weite sprühte, glich dem grauen Papier eines Stiches, auf dem sich tiefschwarz die Striche und Schraffierungen dichten Gestrüpps vermengten. Die Nacht wiederholte jetzt, weit nach Mitternacht, die Serie der Nocturnes, der Nachtstiche des Professor Arndt, sie führten seine Phantasie weiter. ${ }^{93}$

Erneut wird der Übergang der Kunst zweiter Ebene in die erste vorgeführt; die Bilder in der Erzählung werden zu Bildern der Erzählung, zur beschriebenen Landschaft des Erzählers. Daher lassen sich an dieser Stelle erneut enge Verbindungen zwischen den Bildern der materiellen Welt und den Wortmalereien innerhalb der Erzählungen nachweisen, die theoretische Überlegungen zulassen. Die dargestellte Beziehung zwischen Bildern der Kunst und Landschaften der Literatur knüpft an Fragestellungen der Grafiken und Porträts über die Wirkweise von Bildern und ihren Einfluss auf die Wirklichkeitswahrnehmung an. Erneut wechseln die Ebenen der Repräsentation und der Medien.

92 »Magia tych przemian polega na całkowitym utożsamianiu przedmiotów czy zjawisk z wyrażonymi przez nie emocjami, utożsamianiu uznanym przez twórców ekspresjonizmu za naczelną zasadę artystyczną poetyckiego obrazowania, czego wynikiem było zaakceptowanie logiki artystycznej obrazu odmiennej od logiki rozsądku.« Speina, Bankructwo realności, 81.

93 Schulz, Die Zimtläden, 92. „Rozprószona biel tego światła, mżąca ze śniegu, z bladego powietrza, z mlecznych przestworzy, była jak szary papier sztychu, na którym głęboką czernią plątały się kreski i szrafirunki gęstych zarośli. Noc powtarzała teraz głęboko po północy te serie nokturnów, sztychów nocnych profesora Arendta, kontynuowała jego fantazje.« Ders., Sklepy cynamonowe, 87. 


\subsection{Farbe und Erscheinung}

Ein deutlicher Zusammenhang zur Malerei zeigt sich auch in der Untersuchung der Farbe. Farben spielen in fast allen Erzählungen eine außerordentlich wichtige Rolle ${ }^{94}$ und werden nach Wróblewski auf Grund der großen Ausdifferenzierung ihrer Nuancen malerisch eingesetzt. ${ }^{95}$ Darüber hinaus finden sich ganze Absätze und Erzählungen, die sich nur einer Farbe widmen. Bei genauerer Untersuchung lassen sich Anknüpfungspunkte zu theoretischen Überlegungen zu Farbe und Kunst aus Schulz' Gegenwart finden. Besonders deutlich wird dies in der Erzählung "Genialna epoka» (Geniale Epoche), die das künstlerische Erweckungserlebnis des kindlichen Protagonisten und Erzählers Józef beschreibt. So deutlich wie sonst selten wechselt sich hier der erlebende, »illusionsgläubige« mit dem kommentierenden »illusionsbrechenden« Erzähler ab. ${ }^{96}$ Durch diese Doppelstruktur wird die Frage nach der Wirklichkeit der Bilder in den Kontext des kindlichen, vorrationalen Wahrnehmens und Erlebens gestellt.

»Die verschiedenen grammatikalischen Formen der Erzählersprache erzeugen eine charakteristische 'Wellenbewegung der Narration - durch unterschiedlich präzise Bedeutungen, den Wechsel zwischen der Konvention der Erinnerung und des Bekenntnisses, den Übergang von der Erzählung des kindlichen Helden durch unpersönliches erzählerisches Niemandsland bis hin zur Erzählung des erwachsenen Helden, der philosophische Überlegungen spinnt und auf seinen Kindheitserinnerungen aufbauend Mikrodiskurse und Mikrotraktate verfasst. $"{ }^{97}$

Eingeleitet wird das Geschehen durch theoretische Überlegungen zu Zeit und Sprache. Dabei wird Lessings Idee aufgegriffen, dass die Zeit linear verliefe wie auch die »Narration, deren Seele aus Kontinuität und Sukzession besteht. ${ }^{98}$ Ereignisse, die in der chronologischen Zeit keinen Platz haben,

94 In der Erzählung »Wiosna« beispielsweise wird immer wieder auf die Farbe Rot eingegangen. Sie wird in der Regel mit Politischem konnotiert, der Revolution, dem Frühling, aber auch dem Himbeersaft, der Feuerwehr und anderem. Der Kaiser Franz Joseph habe die rote Farbe verboten. Vgl. Ders., Sanatorium pod Klepsydrą, 180.

95 Vgl. Wróblewski: Stylistyczna funkcja określeń barw w prozie Brunona Schulza, 68.

96 Vgl. Schmid, Sprachursprungstheorien, $51 \mathrm{f}$.

97 „Funkcją pojawiania się różnych form gramatycznych mowy narratora jest swoiste ১falowanie narracji - przemieszczanie jej precyzji znaczeniowej, przechodzenie od konwencji wspomnienia do konwencji wyznania, od narracji bohatera-dziecka, przez wysepki narracji niczyjej, bezosobowej po narrację opowiadacza dorosłego, snującego rozważania filozoficzne, budującego mikrotraktaty, mikrodyskursy nadbudowujące się nad wspomnieniami z czasów dzieciństwa.«Bolecki, Poetycki model prozy, 196. (Übers. A. J.)

98 Schulz, Das Sanatorium zur Sanduhr, 28. "narracji, której duszą jest ciągłość i sukcesja." Ders., Sanatorium pod Klepsydrą, 134. 
müssen auf ein »Nebengleis« der Zeit. Die in den Erzählungen wiederholt auftauchende Zugmetapher weist darauf hin, dass es sich um Ereignisse wie Erinnerungen, Träume und Fantasien handelt, die allesamt mit der inneren Bildwelt zu tun haben, einem Menschen Wirklichkeit sind und sich dennoch nicht an der Kette der Ereignisse auffädeln lassen. ${ }^{99}$

$\mathrm{Zu}$ diesen Ereignissen gehören auch die ersten Malerlebnisse des Kindes, die den gesamten Raum einbeziehen und das Kind in Verzückung und Ekstase versetzen. Dabei gehen Geschichten, Gegenstände und Bilder ineinander über. Das erlebende Kind fühlt sich von Gott persönlich inspiriert und berufen, der kommentierende Erzähler weist aber noch vor Beginn und erneut am Ende der Episode darauf hin, dass die Ereignisse anders stattgefunden haben als vom Kind erinnert. Barbara Breysach deutet die Offenbarungsszenen dennoch religiös und biographisch. Während der Vater für die Generation der assimilierten und säkularisierten Juden stehe, repräsentiere das Kind Józef wie der Autor Schulz jene Generation, die diese Entwicklung als Sackgasse betrachte. »Der Künstler wird hier zu einer Art Erlöser und Verkünder des Unaussprechlichen, vollkommen Rätselhaften und Widersprüchlichen. ${ }^{100}$ Diese Deutung ist vor allem dann plausibel, wenn man die Kommentare des erwachsenen Erzählers ignoriert oder gegenüber den Erlebnissen des Kindes abwertet. List man den Kommentar mit, lässt sich der Einbruch der religiösen Welt in das Familienleben als kindliche Fantasie verstehen, die auf der Bibel als Quellen- und Assoziationsmaterial beruht. Dass sich die Epiphanie in der Einbildungskraft des Kindes ereignet, zeigt sich auch an den Reaktionen der beobachtenden Erwachsenen, die die Wahrnehmung des Kindes nicht teilen. ${ }^{101}$

In diesem Kontext finden sich verschiedene Mikrotraktate und Untersuchungen zur Farbe. Das erlebende Kind behandelt die Farben synästhe-

99 Besonders deutlich wird dies in der Titelerzählung "Sanatorium pod Klepsydrą«, in welcher der Erzähler und Protagonist seinen Vater im "Sanatorium« besucht und mit dem Zug an- und auch wieder abreist. Das Sanatorium ist ein symbolischer Ort für die Erinnerung an den kürzlich gestorbenen Vater. Durch Trauer geprägt ziehen die Erinnerungen in besonderer Lebendigkeit vor dem inneren Auge des Sohnes vorbei und werden gleichzeitig durch das Vergessen zersetzt. Dieser Vergessensprozess zeigt sich in den Erinnerungslücken zwischen den Szenen, in den widersprüchlichen Bildern und Gefühlen, in der Entfernung und Entfremdung des Sohns von seinem Vater. Paweł Dybel interpretiert das Sanatorium als die »Welt der Schatten«, in die der Sohn flüchtet, um mit demjenigen Vater zusammen zu sein, nach dem er sich sehne. Aber selbst dort verhalte sich der Vater nicht wie vom Sohn gewünscht. Vgl. Dybel, Paweł: Seksualność zdegradowana, czyli perwersyjny świat prozy Schulza. In: Teksty drugie (2005), 204-218, hier 211.

100 Breysach, Barbara: Kunstobjekt und Metapher: Das Buch in Bruno Schulz Ästhetik der Grenzüberschreitung. In: Jaworski/Liska (Hg.): Am Rand. Grenzen und Peripherien in der europ. jüd. Literatur, 134-150, hier 144.

101 Vgl. Schulz, Sanatorium pod Klepsydrą, $136 \mathrm{f}$. 
tisch $^{102}$ und benutzt sie nicht zum mimetischen Einfärben, sondern malt aus ihren Eigenschaften heraus seine Bilder.

»Und wenn ich nach dem Blau griff, lief auf der Straße der Widerschein des kobaltfarbenen Frühlings durch alle Fenster, klingend öffneten sich die Scheiben, eine nach der anderen, voller Blau und Himmelsfeuer, die Gardinen erhoben sich wie zum Alarm und ein freudiger, leichter Lufthauch zog durch dieses Spalier, durch wogendes Musselin und durch die Oleanderbüsche auf den leeren Balkonen, als erschiene jemand in weiter Ferne am anderen Ende dieser langen und hellen Allee, und als käme er näher - strahlend, im Gefolge einer Nachricht, einer Ahnung, angekündigt vom Schwalbenflug, von leuchtenden, über Meilen hingestreuten Zweigen. ${ }^{103}$

Die blaue Farbe ist Ausgangspunkt für eine ganze Kette an Assoziationen, die Klang (dźwięczące szyby/klingende Scheiben), Bewegung (falującye muśliny/ wogendes Musselin), Geruch (oleandry/Oleanderbüsche), Gefühl (przeczucie/ Erwartung) und Lebendiges (jaskółki/Schwalben) umfassen. Diese Farbbetrachtung scheint von Kandinsky beeinflusst, dessen kunsttheoretische Schrift »Das Geistige in der Kunst« zu Beginn des 20. Jahrhunderts großen Einfluss auf die moderne Malerei und Avantgarde hatte und von vielen Intellektuellen gelesen wurde. ${ }^{104}$

102 Paul Hadermann stellt die These auf, dass jedes Wort von sich aus schon synästhetisch sei, weil der Mensch zu jedem Wort ein Bild zuordne und andersherum. Außerdem beginne mit einem Wort oft eine Assoziationskette, die automatisiert verschiedene Gegenstände in einen Zusammengang bringen. »Die gesprochene und gestische Sprache auch die Schrift ist eine Art Gestus - kann den Sinnes-Eindruck im sinnlichen Bereich, in dem er auftritt, reproduzieren. Wenn man sich jedoch auf die von unserer unmittelbaren Umgebung vermittelten Eindrücke und auf die fünf Sinne, durch die wir sie aufnehmen, beschränkt, wird die `Übersetzung` in vier von fünf Fällen synästhetischer Art sein. Eine Folge von Lauten oder ein Wort bilden, der sich schnell herausbildenden Konvention zufolge, die Entsprechung zu einem Blick, einer Berührung, einem Geruch oder einem Geschmack; und eine Reihe von Gesten oder anderen bildhaften Zeichen begleiten unsere hörbaren, fühlbaren, riechbaren oder schmeckbaren Eindrücke.«Hadermann, Paul: Synästhesie: Stand der Forschung und Begriffsbestimmung. In: Weisstein (Hg.): Literatur und bildende Kunst, 55-72, hier 55.

103 Schulz, Das Sanatorium zur Sanduhr, 37. »A gdy sięgałem po błękitną barwę - szedł ulicami przez wszystkie okna odblask kobaltowej wiosny, otwierały się, dźwięcząc, szyby, jedna za drugą, pełne błękitu i ognia niebieskiego, firanki wstawały jak na alarm i przeciąg radosny i lekki szedł tym szpalerem wśród falujących muślinów i oleandrów na pustych balkonach, jak gdyby na drugim końcu tej długiej i jasnej alei ktoś zjawił się bardzo daleki i zbliżał się - promienny, poprzedzany przez wieść, przez przeczucie, zwiastowany przez loty jaskółek, przez wici świetliste, rozrzucane od mili do mili« Ders., Sanatorium pod Klepsydrą, 140.

104 Loers, Veit: Vom Wesen der Kunst oder von der Kunst als Wesen. Ein Jahrhundert Kandinsky »Über das Geistige in der Kunst«. artnet.de 2011, http://www.artnet.de/magazine/ein-jahrhundert-kandinsky-uber-das-geistige-in-der-kunst/ vom 16.9.2012 
Kandinsky betont ebenfalls den synästhetischen Aspekt der Farben. Diese begleiten nach ihm bestimmte Gefühle, Bewegungen, Gemütszustände und vor allem Klänge. Gerade für die blaue Farbe hebt er den Hang zum Transzendenten und Unendlichen hervor. ${ }^{105}$ Kandinsky gehört auch zu denjenigen Theoretikern, die eine Trennung der Malerei von der Sprache und umgekehrt als Befreiung und Errungenschaft der zeitgenössischen Kunst betrachten. ${ }^{106}$ »Die ikonischen Elemente Farbe und Form emanzipieren sich [...] zu absoluten künstlerischen Mitteln, auch wenn die Bindung ans Gegenständliche noch nicht aufgegeben wird. ${ }^{107} \mathrm{Da}$ in Schulz' Literatur diese Farbexperimente im Medium der Sprache auftauchen, übernimmt er nur Elemente von Kandinskys Theorie, wie die Synästhesie und Farbbetrachtung.

In der Erzählung "Noc wielkiego sesonu« (Die Nacht der großen Saison) werden die herbstfarbenen Tuchballen im Laden des Vaters wiederum mit Klängen der Musik assoziiert.

»Es war ein gewaltiges Register aller Herbstfarben, übereinandergeschichtet und nach Tönungen sortiert, es lief wie auf klingenden Stufen nach oben und nach unten, durch die Tonleiter aller Farboktaven. Es begann tief unten, versuchte klagend und zaghaft die Töne des Alts, ging über zur verblichenen Asche der Ferne, zum Grün und Himmelblau von Gobelins und wuchs in immer ausladenderen Akkorden empor, erreichte tiefdunkle Blautöne, das Indigo ferner Wälder und den Flaum rauschender Parks, um dann durch alle Ocker-, Rötel-, Rostrot- und Sepiaschattierungen hindurch in die raschelnden Schatten welkender Gärten zu gelangen, zum dunklen Pilzgeruch, zum modrigen Hauch in den Tiefen der Herbstnacht, zur dumpfen Begleitung der allertiefsten Bässe. ${ }^{108}$

105 Über die blaue Farbe schreibt Kandisky, dass sie sich vertiefe, eine Bewegung in das Innere habe und beruhigend wirke. "Diese Vertiefungsgabe finden wir im Blau und ebenso erst theoretisch in ihren physischen Bewegungen 1. Vom Menschen weg und 2. Zum eigenen Zentrum. Und ebenso, wenn man Blau (in jeder gewünschten geometrischen Form) auf das Gemüt wirken läßt. Die Neigung des Blau zur Vertiefung ist so groß, daß es gerade in tieferen Tönen intensiver wird, desto mehr ruft es den Menschen in das Unendliche, weckt in ihm die Sehnsucht nach Reinem und schließlich Übersinnlichen. Es ist die Farbe des Himmels, so wie wir ihn uns vorstellen bei dem Klange des Wortes Himmel. Blau ist die typisch himmlische Farbe. Sehr tiefgehend entwickelt das Blau das Element Ruhe. Zum Schwarzen sinkend, bekommt es den Beiklang einer nicht menschlichen Trauer. [...] Musikalisch dargestellt ist helles Blau einer Flöte ähnlich, das dunkle dem Cello, immer tiefer gehend den wunderbaren Klängen der Baßgeige; in tiefer feierlicher Form ist der Klang des Blau dem der tiefen Orgel vergleichbar.« Kandinsky, Wassily: Über das Geistige in der Kunst. Bern 1963, $92 \mathrm{f}$.

106 Vgl. Becks-Malorny, Ulrike: Wassily Kandisky. 1866-1944. Aufbruch zur Abstraktion. Köln 2003, 24.

107 Osterkamp, Däubler oder die Farbe - Einstein oder die Form, 543.

108 Schulz, Die Zimtläden, 132. »Był to rejestr olbrzymi wszelakich kolorów jesieni, ułożony warstwami, usortowany odcieniami, idący w dół i w górę, jak po dźwięcznych schodach, po gamach wszystkich oktaw barwnych. Zaczynał się u dołu i próbował jękliwie 
In dieser synästhetischen Darstellung wird die Hierarchisierung zwischen Farbe und Klang aufgehoben, sodass im Laufe der Beschreibung nicht mehr deutlich ist, ob die Klänge mit den Farben oder die Farben mit den Klängen einhergehen. In der Tradition der Vergleiche zwischen Malerei und Poesie sowie Musik und Poesie, sieht Bolecki Schulz' Poesie-Begriff in Beziehung zur Musikalität.

»Musikalität ist nämlich in Schulz' System ein Syn ony m für die Poetizität. Erzählerische ‘Transpositionen der Musikı sind nach Schulz `Gipfel reinster Lyrik; Exstrakt der Poesie. « ${ }^{109}$

Klang und Farben vermischen sich allerdings gleichwertig in der Sprache, gehen ineinander über und entziehen sich der Hierarchisierung oder Trennung. In der Erzählung "Sierpień" (August) wird hingegen lautmalerisch die Ansicht des Ringplatzes beschrieben, der durch die Sonne in gelbe Farben eingetaucht ist.

"Man trat aus dem Dämmer des Flures plötzlich in das Sonnenbad des Tages. Die im Gold watenden Passanten hatten die Augen in der Glut zusammengekniffen, wie mit Honig verklebt, so daß die hochgezogenen Oberlippen Zähne und Zahnfleisch entblößten. Und alle trugen sie beim Waten im goldenen Tag diese Hitzegrimasse, als hätte die Sonne all ihren Anbetern ein und dieselbe Maske aufgesetzt - die goldene Maske der Sonnenbruderschaft; und alle, die heute durch die Straßen spazierten, einander begegneten, aneinander vorbeigingen, Alte und Junge, Kinder und Frauen, grüßten sich im Vorübergehen mit der dick aufgetragenen, goldfarbenen Maske im Gesicht und schnitten einander diese bacchantische Grimasse - die barbarische Maske eines heidnischen Kultes. ${ }^{110}$

i nieśmiało altowych spełzłości i półtonów, przechodził potem do spłowiałych popiołów dali, do gobelinowych błękitów i rosnąc ku górze coraz szerszymi akordami, dochodził do ciemnych granatów, do indyga lasów dalekich i do pluszu parków szumiących, ażeby potem poprzez wszystkie ochry, sangwiny, rudości i sepie wejść w szelestny cień więdnących ogrodów i dojść do ciemnego zapachu grzybów, do tchnienia próchna w głębiach nocy jesiennej i do głuchego akompaniamentu najciemniejszych basów." Ders., Sklepy cynamonowe, 113.

109 »Muzyczność bowiem jest w systemie Schulza synonimem poetyckości. Powieściowe stranspozycje muzyki to według Schulza sszczyty najczystszej liryki; sam ekstrakt poezji.« Bolecki, Poetycki model prozy, 186.

110 Schulz, Die Zimtläden, 10. »Z półmroku sieni wstępowało się od razu w słoneczną kąpiel dnia. Przechodnie, brodząc w złocie, mieli oczy zmrużone od żaru, jakby zalepione miodem, a podciągnięta górna warga odsłaniała im dziąsła i zęby. I wszyscy brodzący w tym dniu złocistym mieli ów grymas skwaru, jak gdyby słońce nałożyło swym wyznawcom jedną i tę samą maskę - złotą maskę bractwa słonecznego; i wszyscy, którzy szli dziś ulicami, spotykali się, mijali, starcy i młodzi, dzieci i kobiety, pozdrawiali się w przejściu tą maską, namalowaną grubą, złotą farbą na twarzy, szczerzyli do siebie ten grymas bakchiczny - barbarzyńską maskę kultu pogańskiego.« Ders., Sklepy cynamonowe, $38 \mathrm{f}$. 
Auffällig ist die Beschreibung der sonnenverzerrten Gesichter der Stadtbewohner, deren Grimassen der Erzähler mit Kultmasken vergleicht. Während Jan Gondowicz diese Vergleiche als Hinweise für Schulz' Interesse an heidnischen Kulten versteht, ${ }^{111}$ lässt sich die Darstellung des Platzes auch im Sinne expressionistischer Gestaltungskunst lesen. Farben und Formen werden hyperbolisch eingesetzt, die Betonung liegt auf der optischen Erscheinung der Gesichtszüge, die sich in der gleißenden Sonne verzerren. ${ }^{112}$ Die Bezugnahme auf die Masken erinnert wiederum an die Auseinandersetzung expressionistischer Maler und Kunsttheoretiker ${ }^{113}$ mit der afrikanischen Kunst und den Stammesmasken, beispielsweise eines Max Ernsts, Emil Noldes ${ }^{114}$ und Ludwig Kirchners. ${ }^{115}$

Während die zuletzt zitierten Textbeispiele kurze Beschreibungssequenzen innerhalb der einzelnen Erzählungen sind, findet sich auch eine Erzählung, die eine einzige Ansicht fast ausschließlich in Weiß visualisierend beschreibt. Auf der Handlungsebene der Erzählung "Pan Karol« (Herr Karol) ist dieser im Aufbruch zur Sommerfrische begriffen. Eingerahmt von dieser Entscheidung wird das Zimmer beschrieben, in welchem er sich die letzten Tage aufgehalten hat. Die Darstellung dieses Aufenthalts verschmilzt zu einer einzigen Ansicht, dem weißen Federbett, auf welches durch die weißen Vorhänge vor dem Fenster milchiges Licht fällt. In diesem Weiß lösen sich die Formen und Konturen auf, die Daunendecken verknoten sich zu einem weißlichen Teig, die Kissen breiten sich in eine riesige, weiße, flache Ebene aus und die Augen Karols reflektieren wie kleine Spiegel weiße Sonnenflecken. ${ }^{116}$ "Das Fenster konnte die weiße Glut nicht aufnehmen, und die Vorhänge waren unter dem helllichten Wogen ohnmächtig zusammengebrochen. ${ }^{117}$ Karol selbst ist in Lethargie und Unentschiedenheit versunken und dämmert in die Leere der Tage hinein. Dies überträgt sich auf seinen Körper, der sich ebenfalls zu

111 Vgl. Gondowicz, Jan: Magiczna bogini ciała. In: Kitowska-Łysiak (Hg.): Białe plamy w SCHULZologii, 184-212, hier 185.

112 Dies ist mit Bogner als ein typisches Verfahren der expressionistischen Literatur zu deuten. Vgl. Expressionismus. In: Bundorf, Dieter/Fasbender, Christoph u. a. (Hg.): Metzler Lexikon Literatur. Begriffe und Definitionen. 3. Aufl. Stuttgart, Weimar 2007, 223.

113 Vgl. Einstein, Carl: Negerplastik. In: Harrison, Charles (Hg.): Kunsttheorie im 20. Jahrhundert. Künstlerschriften, Kunstkritik, Kunstphilosophie, Manifeste, Statements, Interviews. Ostfildern-Ruit 1998, 147-152.

114 Vgl. Fluck, Andreas: ‘Absolute Ursprünglichkeit: Emil Noldes Studienzeichnungen im Berliner Vökerkundemuseum. In: Brugger, Ingried, Prinz von Hohenzollern, Johann Georg/Reuther, Manfred (Hg.): Emil Nolde und die Südsee. München 2002, 27-34.

115 Kultermann, Kleine Geschichte der Kunsttheorie, 241.

116 Schulz, Sklepy cynamonowe, 79.

117 Ders., Die Zimtläden, 82. »Okno nie mogło pomieścić tego białego pożaru i story omdlewały od jasnych falowań.« Ders., Sklepy cynamonowe, 80. 
deformieren beginnt. Die gesamte Erzählung ist durch diese Konturlosigkeit im alles überstrahlenden Weiß charakterisiert und liest sich als symbolische Visualisierung der Inhaltslosigkeit der Tage und Gedanken des Protagonisten.

\subsection{Perspektive und Wahrnehmung}

Eine andere Form der optischen Verfremdung findet sich bei Schulz im häufigen Wechsel der Perspektive, in der Vergrößerung, Verkleinerung oder Verwandlung. Besonders eindrücklich wird der Wechsel aus der Makro- in die Mikroperspektive in der Erzählung "Pan« (Pan) vorgeführt. Sie handelt vom Erkundungs- und Eroberungsfeldzug des kindlichen Erzählers im versteckten Garten hinter einem Haus. Dabei verzahnen sich narrative und deskriptive Elemente, die Natur wird personifiziert und belebt, sodass ein dynamisiertes Landschaftsbild entsteht.

»Lag man im Gras, war man völlig von der blauen Geographie der Wolken und der dahinziehenden Kontinente bedeckt, man atmete die ganze weitläufige Himmelskarte. Bei ihrem Dialog mit der Luft hatten sich die Blätter und Triebe mit zarten Härchen bedeckt, mit weichem Flaum und rauhen, borstigen Widerhäkchen wie zum Ergreifen und Festhalten des vorüberziehenden Sauerstoffs. Der zarte weißliche Belag vermählte die Blätter mit der Atmosphäre und verlieh ihnen den silbergrauen Schimmer von Luftwellen, von schattigen Grübeleien zwischen zwei Sonnenstrahlen. Und eine der luftgeblähten Pflanzen, gelb und mit milchigem Saft in den bleichen Stengeln, trieb aus ihren leeren Trieben nur Luft allein, nichts als Flaum in Gestalt fedriger Milchkugeln, die, von einem Windhauch zerstreut, lautlos in die hellblaue Stille sickerten. ${ }^{118}$

Der Übergang von der Wahrnehmung des Himmels durch den kindlichen Erzähler zur Nahperspektive auf die Pflanzen verläuft bruchlos. Dabei ist die erste Ansicht die der vollen Weite des Himmels aus der Froschperspektive, um dann mikroskopisch kleine Härchen und Häkchen der Pflanzenblät-

118 Ders., Die Zimtläden, 75. »Gdy się leżało w trawie, było się przykrytym całą błękitną geografią obłoków i płynących kontynentów, oddychało się całą rozległą mapą niebios. Od tego obcowania z powietrzem liście i pędy pokryły się delikatnymi włoskami, miękkim nalotem puchu, szorstką szczeciną haczków, jak gdyby dla chwytania i zatrzymywania przepływów tlenu. Ten nalot delikatny i białawy spokrewniał liście $z$ atmosferą, dawał im srebrzysty, szary połysk fal powietrznych, cienistych zadumań między dwoma błyskami słońca. A jedna z tych roślin, żółta i pełna mlecznego soku w bladych łodygach, nadęta powietrzem, pędziła ze swych pustych pędów już samo powietrze, sam puch w kształcie pierzastych kul mleczowych rozsypywanych przez powiew i wsiąkających bezgłośnie w błękitną ciszę.« Ders., Sklepy cynamonowe, 77. 
ter in den vergrößernden Fokus zu nehmen. Die Evolution verschiedener Formen wird als kluge Interaktion mit der Atmosphäre beschrieben, der Natur also menschliche Intelligenz zugeschrieben. Setzt man all die beschriebenen Einzelteile zusammen, erkennt man eine »Pusteblume.«An keiner Stelle wird ein wortwörtlicher Bezug zum Löwenzahn hergestellt, sondern dieser allein durch den milchigen Saft, den hohlen Stängel, den windanfällige Flaum und die gelbe Blüte - also durch Attribute der Erfahrung, des Wissens und der Sinne - beschrieben und aus diesen Einzelteilen zusammengesetzt, sodass erst am Ende das vollständige Bild der Pflanze in ihren unterschiedlichen Reifestadien vor Augen erscheint. ${ }^{119}$

Der unüblich nahe und erforschende Blick reicht, um die Natur als geheimnisvoll und magisch zu erleben. Die Mythisierung ist damit ein Kunstgriff der Perspektive. ${ }^{120}$ Dieser entdeckerische Blick in die Mikroskopie der Pflanzen hängt unter Umständen auch mit den Möglichkeiten der Fotografie und Mikroskopie zusammen, also mit technischen Entwicklungen. Benjamin betont, dass die technische Vergrößerung eines Ausschnitts unbekannte Ansichten hervorzubringen vermöge und so nicht nur wissenschaftlich, sondern auch künstlerisch wertvolle Bilder entstanden sind. ${ }^{121}$ Die technische Vergrößerungs- oder Verkleinerungsmöglichkeit steigerte daher die Wahrnehmung des Surrealen im Alltäglichen. Freund beschreibt dieses Erlebnis ähnlich.

"Der abstrakte und harmonische Graphismus von Kristallen, von Zellen und pflanzlichen Partikeln, tausendfach vergrößert, oder nur einfach der schillernde Reflex eines Öltropfens in einer Wasserpfütze und viele andere Details unserer täglichen Realität, an denen wir achtlos vorbeigehen, die aber vom Auge eines kreativen Photographen sichtbar gemacht worden sind, werden zu Bildern von seltener Schönheit.." ${ }^{122}$

119 Darin erinnert Schulz' Praxis an die von Šklovskij entwickelte Verfremdungstheorie. Am Beispiel von Tolstoi schreibt dieser: "Der Kunstgriff der Verfremdung bei Tolstoi besteht darin, daß er die Dinge nicht beim Namen nennt, sondern sie so beschreibt, als sähe er sie zum erstenmal; er stellt jedes Ereignis so dar, als geschehe es zum erstenmal; außerdem gebraucht er bei der Beschreibung eines Gegenstands nicht die üblichen Bezeichnungen seiner Teile, sondern benennt sie mit Worten, welche die entsprechenden Teile eines anderen Gegenstands bezeichnen.« Šklovskij, Viktor: Theorie der Prosa. Frankfurt a. M. 1966, 15.

120 So definiert Šklovskij das Mittel der Verfremdung: »Um für uns die Wahrnehmung des Lebens wiederherzustellen, die Dinge fühlbar, den Stein steinig zu machen, gibt es das, was wir Kunst nennen. Das Ziel der Kunst ist, uns ein Empfinden für das Ding zu geben, ein Empfinden, das Sehen und nicht nur Wiedererkennen ist. Dabei nutzt die Kunst zwei Kunstgriffe: Die Verfremdung der Dinge und die Komplizierung der Form, um die Wahrnehmung zu erschweren und ihre Dauer zu verlängern.« Ebd., 14.

121 Benjamin, Walter: Neues von Blumen. In: Tiedemann-Bartels, Hella (Hg.): Gesammelte Schriften III. Kritiken und Rezensionen. Frankfurt a. M. 1991, 151-153, hier $151 \mathrm{f}$.

122 Freund, Memoiren des Auges, 133. 
Entdeckerisch ist aber nicht nur die Mikroskopie, sondern auch die KinderPerspektive, wie im Bezug auf die Farbe schon angeführt wurde. Hofstätter weist darauf hin, dass das kindliche Sehen in den Kunsttheorien der Jahrhundertwende wegen der vermeintlich »naiven« Sichtweise, der Ungetrübtheit der Wahrnehmung durch Erziehung und der ungelenkten Assoziation, eine besondere Rolle spielt. ${ }^{123}$ Künstler erhofften sich in kindlichen Zeichnungen »reine« Bilder, sowie neue Stoffe und Perspektiven für die Malerei zu finden. Auch Benjamin untersucht die kindliche Wahrnehmung anhand der eigenen Erinnerungen. In seinem Buch »Berliner Kindheit um 1900« beschreibt er den Malakt des Kindes.

"Die Farben, die ich dann mischte, färbten mich. Noch ehe ich sie an die Zeichnung legte, vermummten sie mich selber. Wenn sie feucht auf der Palette ineinanderschwammen, nahm ich sie so behutsam auf den Pinsel, als seien sie zerfließendes Gewölk. [...] In unserem Garten gab es einen verlassenen, morschen Pavilion. Ich liebte ihn der bunten Fenster wegen. Wenn ich in seinem Innern von Scheibe zu Scheibe strich, verwandelte ich mich; ich färbte mich wie die Landschaft, die bald lohend und bald verstaubt, bald schwelend und bald üppig im Fenster lag. Es ging mir wie beim Tuschen, wo die Dinge mir ihren Schoß auftaten, sobald ich sie in einer feuchten Wolke überkam. Ähnliches begab sich mit Seifenblasen. Ich reiste in ihnen durch die Stube und mischte mich ins Farbenspiel der Kuppel bis sie zersprang. Am Himmel, mit einem Schmuckstück, in einem Buch verlor ich mich an Farben. Kinder sind ihre Beute auf allen Wegen. ${ }^{124}$

Die Darstellung zeigt, wie unterschiedlich der Mensch in seiner Entwicklung Farben und Gegenstände der Umgebung wahrnimmt. Die Dinge werden vom Kind nicht in ihrem Gebrauchswesen erfasst, sondern in ihren Farben und Formen spielend erlebt. Weiter geht Benjamin auf das Dekor des Chinaporzellans ein, das ihm als Kind ganze Geschichten erzählte. »So war auch ich bei meinen Näpfen und den Pinseln auf einmal ins Bild entstellt. Ich ähnelte dem Porzellan, in das ich mit einer Farbenwolke Einzug hielt. ${ }^{125}$ Diese Magie der Kindheit verblasst im Zuge des Erwachsenwerdens. Schulz unterstreicht in einem Brief, ihm sei es ein Anliegen, dieses kindliche Sehen für den Erwachsenen zu übersetzen. ${ }^{126}$

123 Hofstätter, Malerei und Graphik der Gegenwart, 38.

124 Benjamin, Walter: Berliner Kindheit um Neunzehnhundert. In: Rexroth, Tillman (Hg.): Gesammelte Schriften IV. Kleine Prosa, Baudelaire-Übertragungen. Frankfurt a.M. 1991, 235-304, hier $262 \mathrm{f}$.

125 Ebd., 262.

126 Vgl. Brief an Andrzej Pleśniewicz vom 4.3.1936. In: Schulz, Księga listów, 114. Ausführlich hat das Thema der Kindheit Anna Czabanowska-Wróbel behandelt. Vgl. Czabanowska-Wróbel, Anna: Dziecko. Symbol i zagadnienie antropologiczne w literaturze Młodej Polski. Kraków 2003. 
Inspiriert von den Entwicklungen in Psychologie und Technik suchte die Avantgarde offensiv nach neuen Formen, Inhalten und Perspektiven. ${ }^{127}$ Max Ernsts Frottagen-Technik beispielsweise ermöglicht die Gewinnung von Strukturen, die scheinbar vom Willen des Künstlers frei sind und so »der Imagination Spielraum geben, sie von jeder Bindung an einen vorgegebenen Sinn freimachen ${ }^{128}$ und damit nur Bild « sind. In diesem Ansinnen zeigt sich nach Mitchell deutlich der modernistische, utopische Wunsch, sprachfreie Bilder zu schaffen. ${ }^{129}$

Das Interesse an Kinderzeichnungen, ihrer Wahrnehmung und ihrem Umgang mit Farben war nach Hofstätter insbesondere in der expressionstischen Malerei weit verbreitet. ${ }^{130}$ Auch vor diesem Hintergrund ist Schulz' Kind-Erzähler und Protagonist höchst aufschlussreich. In seinem Blick vermengen sich Bild und Sprache und sind damit in Reinform nicht mehr vorhanden und schaffen ein neues Ganzes. Sowohl die Geschichten als auch die Bilder treten aus ihren medialen Grenzen heraus und manifestieren sich im Raum. Durch den kommentierenden Erzähler werden die magischen Geschehnisse zudem kontextualisiert. Schulz übernimmt somit das Interesse am Kinderblick, aber behält auch die Sicht des analytisch denkenden, gebildeten Erwachsenen bei. Zwar sieht und verräumlicht das Kind die Bibelgeschichten, aber die Magie ist nur begrenzt auf seine Sicht und diesen Moment.

"Es war die Bibel. Auf ihren Seiten sah ich die über Landstraßen strömende, sich in langen Zügen über ein fernes Land verzweigende Wanderung der Tiere, ich erblickte einen Himmel mit fliegenden, flatternden Formationen und eine riesengroße kopfstehende Pyramide, deren ferner Gipfel die Arche berührte. ${ }^{131}$

127 »Magie, Mystik, Animismus, indianisches `Mana<, kindliche Naivität, das Unbewußte, meditative Versenkung, Selbstvergessenheit und hypnotische Zustände: Das Vokabular, aus dem die Versuche schöpfen, um den im Kino produzierten Effekt einer Belebung der Dinge, einer Subjektivität der Gegenstände, der Fluidität des Universums zu beschreiben, ist symptomatisch." Kimmich, Dorothee: ^Nur was uns anschaut sehen wir: Benjamin und die Welt der Dinge. In: Schöttker (Hg.): Schrift, Bilder, Denken, 156-167, hier 159.

128 Asendorf, Christoph: Erfahrungen außer Kraft setzen. Max Ernst, Walter Benjamin, Robert Musil. In: Orchard, Karin/Ernst, Max (Hg.): Die Erfindung der Natur. Max Ernst, Paul Klee, Wols und das surreale Universum; [Sprengel-Museum Hannover 27. Februar - 8. Mai 1994 ...]. 1. Aufl. Freiburg im Breisgau 1994, 202-205, hier 203.

129 »The sinnocent eye of the ideal spectator was at once the unbiased eye of science and the spiritually purified eye of the individuals in a new social order to be produced by religious reformation and/or material revolution. The totems of this new religious/social order were to be the paintings themselves, now finally emergent as the dominant art form of advanced culture. As a not-so-incidental professional side effect, the traditional dominance of literature over the visual arts would be reversed; painting would not only >come into its own, « it would become the model for literature." Mitchell, Picture Theory, $227 \mathrm{f}$.

130 Vgl. Hofstätter, Malerei und Graphik der Gegenwart, 38.

131 Schulz, Das Sanatorium zur Sanduhr, 12. »Była to Biblia. Ujrzałem na jej kartach wielką wędrówkę zwierząt, płynącą gościńcami, rozgałęzioną pochodami po kraju dalekim, 
Wie Andrzej Sulikowski aufgezeigt hat, ist von entscheidender Bedeutung, dass das Kind die Landschaften »sieht" und nicht »liest«. Die geniale Phase des Kindes liegt noch vor der Alphabetisierung. ${ }^{132}$ Zugleich beginnt der kindliche Erzähler auch in Alltagserscheinungen magische Vorgänge zu beobachten, diese zu erzählen und zeichnerisch festzuhalten. So manifestiert sich in der Wahrnehmung des Kindes beispielsweise eine "Feuersäule« im Zimmer, auf die das Kind voll Entsetzen und Verzückung blickt und daraus eine göttliche Anwesenheit ableitet. Die »alltagswirkliche« Gestalt dieser Feuersäule wird nicht im Begriff benannt, sondern nur durch die plastische Beschreibung sichtbar gemacht. Es ist ein ins Zimmer fallender Sonnenstrahl, »leuchtend und voll tanzendem Staub. ${ }^{133}$ Indem das Kind den Sonnenstrahl mit Ereignissen und Motiven der biblischen Geschichten assoziiert, erscheint ihm das Geschehen magisch bedeutsam. Damit basiert diese Magie auf einer besonderen Form der Wahrnehmung, wie der Erzähler aus einer erwachsenen, reflektierten Perspektive in einem metanarrativen Kommentar noch vor Beginn der Erzählung erklärt. ${ }^{134}$

"Es ist ein Phänomen der Repräsentation und des Ersatzdaseins. Irgendein Ereignis, und sei es noch so klein und armselig, was seine Provenienz und seine Eigenmittel betrifft, kann doch aus der Nähe betrachtet in seinem Inneren eine unendliche und strahlende Perspektive eröffnen, wenn in ihm ein höheres Dasein heftig seinen Glanz aussendet, weil es bestrebt ist, sich auszudrücken. ${ }^{135}$

Der Erzähler betont die Rolle der Perspektive für die Wahrnehmung. Indem man aus der konventionellen Sichtweise heraustritt und eine andere Perspektive einnimmt, indem man sich beispielsweise einem Gegenstand stark nähert, können sich Ausschnitte der Alltagsumgebung als neu, geheimnisvoll

ujrzałem niebo w kluczach całe i w łopotach, ogromną odwróconą piramidę, której daleki wierzchołek dotykał Arki.« Ders., Sanatorium pod Klepsydrą, 124. (Hervorh. im deutschen Orig.)

132 Vgl. Sulikowski, Andrzej: Projekt Księgi: Irzykowski, Schulz, Falszen. Janowi Błońskiemu. In: Sawicki, S./Gotfryd, J. (Hg.): Biblioteka a literatura. Lublin 1986, hier 379.

133 Schulz, Das Sanatorium zur Sanduhr, 29. "pełna blasku i krążących w niej pyłów. "Ders., Sanatorium pod Klepsydrą, 135.

134 Schulz' Erzähler tritt sowohl handelnd und erlebend auf - dies meist als Kind - als auch kommentierend und verstehend - dies meist als Erwachsener. Dadurch ist es ihm möglich, gleitend zwischen unterschiedlichen Bewusstseinszuständen und Wahrnehmungsperspektiven zu wechseln. Oft adressiert der Erzähler zudem den Leser und fordert ihn auf, eine bestimmte Sichtweise einzunehmen oder aber zu hinterfragen Vgl. Bolecki, Poetycki model prozy, 90-92.

135 Schulz, Das Sanatorium zur Sanduhr, 26 »Zachodzi tu zjawisko reprezentacji i zastępczego bytu. Jakieś zdarzenie może być co do swej proweniencjii swoich własnych środków małe i ubogie, a jednak, zbliżone do oka, może otwierać w swoim wnętrzu nieskończoną i promienną perspektywę dzięki temu, że wyższy byt usiłuje w nim się wyrazić i gwałtownie w nim błyszczy.« Ders., Sanatorium pod Klepsydrą, $132 \mathrm{f}$. 
und ungesehen erweisen. ${ }^{136}$ Das funkelnde Licht des Kronleuchters, die Flecken an der Wand, die Pflanzen im Garten sind Gegenstand der Poetisierung und spiegeln häufig die Wahrnehmungsperspektive auf das Geschehen. ${ }^{137}$ In einem kurzen Artikel über seine künstlerische Arbeit schreibt er, dass die Vögel in der Erzählung "Ptaki« (Die Vögel) eine Assoziation aus Flecken an der Wand waren. Er weist darauf hin, dass der erste »Keim» seiner

"Vögel ein gewisses Flimmern der Tapeten [war], das auf dunklem Hintergrund pulsierte - nichts weiter. Dieses Flimmern besaß jedoch ein hohes Potential möglicher Inhalte, eine gewaltige Repräsentanz, Urzeitlichkeit, Anspruch darauf, durch sich selbst die Welt zum Ausdruck zu bringen. ${ }^{138}$

Boehm, der diese Technik am Beispiel Leonardo da Vincis beschreibt, unterscheidet dabei zwischen der Wahrnehmung ähnlicher Bilder, inspiriert durch die Flecken und die Wahrnehmung der Flecken selbst als Bilder.

"Einiges von dieser Macht der Bilder hatte wohl auch Leonardo da Vinci im Sinn, als er die Gesellen der Malerei mit dem Lehrstück der `Macchia konfrontierte, das heisst mit unwillkürlichen Flecken, wie man sie zum Beispiel auf dem Putz alter Wände beobachten kann. Er appellierte an die Schüler, diese Gebilde - ähnlich den Klecksogrammen des Rorschachtests - mit Hilfe der Imagination als Landschaften, Gesichter, Figuren, Ungeheuer usw. zu sehen. Aus der blossen Farbe einer Oberfläche wird etwas Doppelbödiges, das der Blick durch seine konstruktiven Möglichkeiten des 'Sehens-als` und des 'Sehens-in ikonisch zu realisieren vermag. Leonardo beschränkte seine Entdeckung der schematisierenden Wirkung von Flecken allerdings darauf, die Einbildungskraft des Künstlers zu trainieren und nicht etwa die Flecken selbst schon als Bild anzusehen. ${ }^{139}$

In Schulz' Literatur finden sich beide Formen der Wahrnehmung. Dem Tapetenflimmern entspringen einerseits fremde Bilder wie die Vögel, andererseits werden sie selbst als Bilder gesehen, deren Strukturen und Formen als

136 Vgl. Speina, Bankructwo realności, 100.

137 Besonders deutlich wird dies bei dem Kronleuchter, der manchmal das Zimmer mit »Regenbogensplittern« füllt, wie in »Księga«, mal »verwelkt und schwarz» geworden ist "wie alte Disteln«, wie in der Erzählung »Manekiny«, kurz nachdem Adela das Vogelexperiment des Vaters unterbrochen hat. Vgl. Schulz, Sklepy cynamonowe, 57 sowie Ders., Sanatorium pod Klepsydrą, 123.

138 Schulz, Bruno: In den Werkstätten polnischer Schriftsteller und Gelehrter: Wiadomości Literackie, Nr. 17, 809/ 16.04.1939. (aus dem Polnischen von Mikolaj Dutsch). In: Ficowski (Hg.): Gesammelte Werke, 328-329, hier 329. »Np. pierwszym zalążkiem moich Ptaków było pewne migotanie tapet, pulsujące w ciemnym polu widzenia - nic więcej. To migotanie posiadło jednak wysoki potencjał treści możliwych, ogromną reprezentacyjność, prawieczność, pretensję do wyrażenia sobą świata.«Schulz, W pracowniach pisarzy i uczonych polskich, 9.

139 Boehm, Wie Bilder Sinn erzeugen, 39. (Hervorh. G. B.) 
Ornamente, Pflanzenmuster und Arabesken ekphrastisch beschrieben werden. ${ }^{140}$ Gleichzeitig bleiben selbst die Ornamente und Arabesken niemals reines Bild, sondern auch ihre Form ist durchdrungen von älteren Formen, Assoziationen und der für Schulz typischen Dynamik.

"Die Tapeten in solchen Wohnungen müssen schon sehr verschlissen und von der unablässigen Wanderung durch alle Rhytmuskadenzen gelangweilt sein, so verwundert es nicht, daß sie auf die Abwege weit entfernter, riskanter Schwärmereien geraten. [...] Aus allen Fußbodenritzen, von allen Simsen und aus allen Leibungen schossen dünne Triebe hervor und durchdrangen die graue Luft mit dem flimmernden Spitzenbesatz filigranen Blattwerks, einem durchbrochenen Treibhausdickicht, erfüllt von Wispern, Glitzern und Gaukeln eines unechten Frühlings. ${ }^{141}$

Zwar entspringen diese Ornamente und Arabesken, die Knopsen und Blätter aus den Ritzen und Flecken der Wände und Böden, bleiben aber nicht dekorativ oder starr, sondern werden selbst wieder Anstoß für die nächste Bildassoziation, ein Minitraktat oder einen Handlungsrahmen. Somit kommen diese Ornamente nicht aus dem »Nichts«, wie Monika Tokarzewska es deutet, vielmehr liegen ihnen andere Bilder zugrunde. ${ }^{142}$ Lachmann weist darauf hin, dass die sprachlich kreierten Arabesken zu der extremen Räumlichkeit der Texte beitragen und gleichzeitig Metaphern für den Text selbst seien. ${ }^{143}$

"Mit seinen polymorphen, dezentrierten und dezentrierenden Bildern peilt Schulz etwas Nicht-Ähnliches an. Es ist, als probe er die Rückkehr ins Archaische, Infantile, eine Rückkehr freilich, die ihm ein Gestus der Ausschweifung und Verschwendung erlaubt, der seinen (Mikro- Makro-) Kosmos in Bildern verschlingt und mit der Generierung von falschen Welten, Text- und Bildsimulakren einen Umweg einschlägt. Der Verzicht auf ein die Texte ordnendes einheitliches semantisches Grundmuster und die Koordination der semantischen Bereiche, die jeweils entworfen werden, läßt eine ornamentale Struktur entstehen, zu deren Beschreibung eine massive Selbstthematisierung beiträgt. ${ }^{144}$

140 Vgl. Schulz, Proza, 47f; 56f; 69; 190; 192f; 227; 297.

141 Schulz, Die Zimtläden, $62 \mathrm{f}$. »Tapety muszą być w takich mieszkaniach już bardzo zużyte i znudzone nieustanną wędrówką po wszystkich kadencjach rytmów; nic dziwnego, że schodzą na manowce dalekich, ryzykownych rojeń. [...] Z wszystkich szpar w podłodze, $\mathrm{z}$ wszystkich gzymsów i framug wystrzelały cienkie pędy i napełniały szare powietrze migotliwą koronką filigranowego listowia, ażurową gęstwiną jakiejś cieplarni, pełnej szeptów, lśnień, kołysań, jakiejś fałszywej i błogiej wiosny.« Schulz, Sklepy cynamonowe, 69 .

142 Vgl. Tokarzewska: Bruno Schulz i Walter Benjamin, $255 \mathrm{f}$.

143 Vgl. Lachmann, Renate: Dezentrierte Bilder: Die ekstatische Imagination in Bruno Schulz' Prosa. In: Hansen-Löve, Aage A. (Hg.): Psychopoetik. Beiträge zur Tagung »Psychologie und Literatur« München 1991. Wien 1992, 339-461, hier 454.

144 Lachmann, Erzählte Phantastik, $366 \mathrm{f}$. 
Anstelle eines chronologischen oder logischen Texts mit rotem Ereignisfaden entwirft Schulz eine Vielzahl kleiner Bilder und Geschichten, die zwar als geschriebener Text eine gewisse Form der Linearität wahren, aber keinesfalls innerhalb der Beschreibungen und Handlungen. So stirbt in einigen Erzählungen der Vater, der Erzähler wechselt Alter und Perspektive und häufig wird der Handlungsfaden abrupt durch Beschreibungen oder Nebenstränge unterbrochen. ${ }^{145}$ Die Erzählungen als Ganzes haben so auch selbst eine bildliche oder mosaikhafte Struktur.

\subsection{Illusionen in Bild und Sprache}

Abschließend soll noch als ein letzter Punkt die Illusion betrachtet werden. Mitchell versteht die Illusion zusammen mit dem Realismus als Machtverhältnis zwischen Bild und Mensch. In beiden Fällen beeinflusse das Bild die Wahrnehmung des Menschen, in der Illusion, indem er an die Existenz einer Sache glaubt und im Realismus, indem die Wahrnehmung einer Sache durch das realistische Bild ersetzt wird.

»Illusionism is the capacity of pictures to deceive, delight, astonish, amaze, or otherwise take power over a beholder; in the trompe-l'oeil, or the special effects of cinema, for instance, the point is to provide a simulation of presence of objects, spaces, and actions, to trigger a responsive experience in the beholder. Realism, by contrast, is associated with the capacity of pictures to show the truth about things. It doesn't take power over the observer's eye so much as it stands in for it, offering a transparent window onto reality, an embodiment of a socially authorized and credible reyewitness perspective. ${ }^{146}$

Dies sind genau die Eigenschaften, die Boehm und Belting dem Werbebild und dem modernen Bilderstrom zuschreiben. Wenn in Nachrichtenbildern die Informationen als Wahrheiten »konsumiert « werden, wenn Bild und Fakt zu einer Einheit verschmelzen, wenn das Werbebild die Erfahrung einer Sache ersetzt, dann nehmen Illusion und Realismus ihres Erachtens »idolatrische« Ausmaße an. ${ }^{147}$ So schreibt Boehm, dass die "moderne Reproduktions-

145 Dies kündigt der Erzähler häufig mit einer Zug- oder Gleismetapher an. »Wer weiß vielleicht haben wir, während wir davon sprechen, diese unsaubere Manipulation schon hinter uns gebracht und fahren bereits auf so einem blinden Gleis dahin.« Schulz, Das Sanatorium zur Sanduhr, 29. "Kto wie - może, gdy o tym mówimy, już nieczysta manipulacja jest poza nami i jedziemy już ślepym torem. Schulz, Sanatorium pod Klepsydrą, 134.

146 Mitchell, Picture Theory, 325.

147 Vgl. Belting, Idolatrie heute, 254. 
industrie [...] das Bild als Abbild, als Double der Realität ${ }^{148}$ favorisiere. Diese Simulation würde zum Teil soweit gesteigert, dass im Bewusstsein der »Postmoderne tendenziell die Differenz zwischen Bild und Realität zu schwinden schien, factum und fictum konvergierten. ${ }^{149}$

Illusion und Illusionsbruch sind ein Kerngegenstand Schulzscher Poetik. Nach Licia Fabiani gilt dies auch für den zu Schulz' Lebzeiten entstehenden Kubismus, der sich von der mimetischen zugunsten einer analytischen Sicht »befreite. ${ }^{150}$ Bewusstseinszustände und Wahrnehmungen werden in Schulz' Werk ebenso wie Handlungen vorgeführt und analysiert. ${ }^{151}$ Die erlebende Wahrnehmung des Kinderzählers ist illusionistisch und illusionsgläubig, während der Metakommentar häufig eine »Antimagie« durch Kontextualisierungen und Entschleierungen erzeugt. ${ }^{152}$ Dies zeigt sich beispielsweise am wiederkehrenden Sujet der Verwandlung. Vor allem der Vater verwandelt sich immer wieder in unterschiedliche Tiere ${ }^{153}$ Naheliegenderweise wurde Schulz' Literatur daher immer wieder mit Werken Kafkas verglichen, gerade hinsichtlich der Verwandlung des Vaters in eine Kakerlake. Trotz offensichtlicher Parallelen zu Kafka finden sich jedoch entscheidende Unterschiede. Zwar werden die Verwandlungen in Schulz' Erzählungen anschaulich beschrieben, doch weist der Erzähler darauf hin, dass diese nur der äußere Ausdruck eines Gefühls oder »inneren Bildes ${ }^{154}$ sind, also in letzter Konsequenz nicht stattfinden. ${ }^{155}$ Die Verwandlung des Vaters in eine Fliege ist somit ironisch zu verstehen.

»Es war eine innere Geste, eine heftige und verzweifelte Demonstration, die allerdings mit einer minimalen Dosis Realität operierte. Man darf nicht vergessen: Das meiste, was wir hier erzählen, geht auf das Konto von sommerlichen Aberrationen, dieser Halbrealität der Hundstage, dieser verantwortungslosen Marginalien, die ohne jede Garantie entlang der Grenzlinien der toten Saison verlaufen. « $^{156}$

148 Boehm, Die Wiederkehr der Bilder, 35.

149 Ebd.

150 Fabiani, Licia: Rosso Fiorentino: Malerei als Schrift. In: Sepp, Hans R./Trinks, Jürgen (Hg.): Phänomenalität des Kunstwerks. Wien 2006, 233-242, hier $237 \mathrm{f}$.

151 Vgl. Lukas, Katarzyna: Mythos, Archetyp und Translation: Die Prosa von Bruno Schulz im Kontext der Ideen von Thomas Mann und Carl Gustav Jung. In: Convivium (2010), 213-234, hier 221.

152 Vgl. Schmid, Die Realisierung der modernen Metaerzählungen, 120.

153 Vgl. Sikorski, Symboliczny świat, 139-143.

154 Ojciec stał "pod wpływem samego obrazu wewnętrznego, którego nie mógł się oprzeć." Schulz, Sklepy cynamonowe, 53. Der Vater stand »unter dem Einfluß eines inneren Bildes, gegen das er sich nicht wehren konnte.« Schulz, Die Zimtläden, 35.

155 Der Bezug zu Kafkas Verwandlungen wird in den Erzählungen mehrmals explizit. Insbesondere die Verwandlung des Vaters in eine Kakerlake kann als Kommentar zu Kafka gelesen werden. Gleichzeitig entwirft Schulz aber eine eigene Begründung dieser Verwandlung. Vgl. Fieguth, Bruno Schulz und seine heimliche Kritik an Kafka, 255.

156 Schulz, Das Sanatorium zur Sanduhr, 175. »Był to raczej gest wewnętrzny, demonstracja gwałtowna i rozpaczliwa, operująca jednak minimalną dozą rzeczywistości. Nie trzeba 
Die Verwandlungen können bei Schulz also entweder Ausdruck eines »inneren Bildes« durch Einfühlung, experimentelle Annäherung an einen Gegenstand durch Mimesis und Mimikry sein, oder als Projezierung eines Vorurteils oder einer Erwartung auf ein Objekt verstanden werden. In der Titelerzählung »Sanatorium pod Klepsydrą" wird eine Rückverwandlung beschrieben. Der Erzähler erkennt, dass sich hinter dem Hund tatsächlich ein Mensch verbirgt. In der anschließenden Erklärung betont der Erzähler, dass die Verwechslung damit zusammenhängt, dass dieser Mensch tatsächlich Wesenseigenschaften eines Hundes hat.

"Wie groß doch die Kraft des Vorurteils ist! Wie mächtig die Suggestion der Furcht! Das war ja ein Mensch! Ein Mensch an der Kette, den ich in simplifizierender, metaphorischer, pauschaler Verkürzung unbegreiflicherweise für einen Hund gehalten hatte. Bitte mich nicht falsch zu verstehen. Es war ein Hund - zweifellos, aber in menschlicher Gestalt. Die Beschaffenheit des Hundes ist eine innere Eigenschaft und kann sich genauso gut in menschlicher wie in tierischer Gestalt manifestieren. ${ }^{157}$

Der Kommentar weist deutlich auf den Umstand hin, dass der Erzähler als Wahrnehmender einem Vorurteil und seiner eigenen Suggestion unterlegen ist. Sein »Bild« vom Buchhalter ist derart schlecht, dass er ihn symbolisch als Hund wahrnimmt und kurzzeitig aus dem Symbol eine Bildillusion geworden ist. ${ }^{158}$ Den fantastischen Elementen in Schulz' Literatur liegen zum Teil Wahrnehmungs- und Bewusstseinsexperimente zugrunde, wie diese metapoetischen Erklärungen verdeutlichen. ${ }^{159}$ Speina deutet die Verwandlungen auch im Kontext expressionistischer Theorien.

zapominać: większość tego, co tu opowiadamy, położyć można na karb tych aberracji letnich, tej kanikularnej półrzeczywistości, tych nieodpowiedzialnych marginaliów, przebiegających bez żadnej gwarancji na rubieżach martwego sezonu.« Schulz, Sanatorium pod Klepsydrą, 229.

157 Schulz, Das Sanatorium zur Sanduhr, 219. »Jak wielka jest moc uprzedzenia! [...] Toż to był człowiek. Człowiek na łańcuchu, którego w upraszczającym metaforycznym, ryczałtowym skrócie brałem niepojętnym sposobem za psa. Proszę mnie źle nie rozumieć. Był to pies - niezawodnie, ale w postaci ludzkiej. Jakość psia jest jakością wewnętrzną i może się manifestować równie dobrze w postaci ludzkiej jak zwierzęcej.« Schulz, Sanatorium pod Klepsydrą, 256.

158 Der Hund wurde schon vielfältig gedeutet. Liest man das Sanatorium als Hades, so versteht man den Hund als Cerberus. Shalom Lindenbaum weist aber auch auf die Möglichkeit hin, den Hund metaphorisch als »Ostjuden« zu lesen, da es mehrere bekannte Vergleiche zu Schulz' Lebzeit gegeben habe. Vgl. Lindenbaum, Shalom: Sanatorium pod Klepsydrą - Hades czy Sanatorium. In: Kitowska-Łysiak, Małgorzata/Panas, Władysław (Hg.): W ułamkach zwierciadła. Bruno Schulz w 110 rocznicę urodzin i 60 rocznicę śmierci. Lublin 2003, 47-74.

159 In seinem Nachwort zur Kafka-Übersetzung »Der Prozess« versteht Schulz Kafkas Roman als "poetische Magie«, deren subjektive Sprache es gelänge, Parallelwirklichkeiten zu bauen. Das Erleben bilde die Grundlage der Darstellung, Wahrnehmungsformen 
"Die Magie dieser Verwandlungen beruht auf der kompletten Identifizierung der Gegenstände oder Ereignisse mit den durch sie ausgedrückten Emotionen, einer Identifizierung, die von den Expressionisten zum künstlerischen Hauptgesetz der poetischen Illustration anerkannt wurde. Infolgedessen wurde die künstlerische Logik des Bildes, die anders als die verstandesmäßigen Logik war, akzeptiert.. ${ }^{160}$

So ist es nicht der Körper, der entscheidet, wer oder was einem entgegentritt, sondern das Wesen, der Charakter oder auch das Selbstbewusstsein. ${ }^{161}$ Fieguth wiederum, der Schulz' und Kafkas Texte vergleicht, unterstreicht ebenfalls die Unterschiede. Während Kafkas heillose Welt unentrinnbar ist, entwickelt Schulz eine Vielzahl an Parallelwirklichkeiten.

"Sein Thema ist das Licht, das der Mensch selbst durch eine Metaphysik der niederen Sphären gewinnen kann, und dieses Licht kann ebenso ein Abbild des göttlichen Lichts sein wie auch ein Trugbild gottlosester Ketzerei. Kafkas von Schulz sogenannter Pseudorealismus ist trotz aller Kafkaschen Ironie ebenfalls Schulzens Sache nicht. Der Autor der Zimtläden überzieht seine Ersatz- und Parallelwirklichkeiten nicht mit der Epidermis der obsessiven Illusionsbildung, sondern er zeigt den schöpferischen Akt des Herbeimanipulierens seiner Parallelwirklichkeiten. ${ }^{162}$

Dies zeigt sich auch in den Experimenten und Untersuchungen der Schneiderpuppen und Wachsfiguren. Gerade im Falle der Wachsfiguren untersucht der Erzähler den Zusammenhang zwischen der geformten Materie und der verliehenen Gestalt. In »Wiosna" wird die Ankunft eines »riesigen Illusionstheaters beschrieben ${ }^{163}$, dessen Wachsfiguren im Laufe der weiteren Handlung eine aktive Rolle spielen und vom Protagonisten Józef für seine Pläne eingespannt werden. Beim Eintritt in eben jenes Panoptikum wird die Kassiererin als »Büste« beschrieben, also verkünstlicht, während die ausgestellten Wachsfiguren belebt werden und als Soldaten an der Handlung teilnehmen.

werden nicht Konventionen unterworfen, sondern in ihrer höchst subjektiven Form dargestellt. Vgl. Schulz, Bruno: Posłowie do polskiego przekładu Procesu Franza Kafki. In: Kitowska-Łysiak, Małgorzata (Hg.): Szkice krytyczne. Lublin 2000, 22-25, hier 24.

160 »Magia tych przemian polega na całkowitym utożsamianiu przedmiotów czy zjawisk z wyrażonymi przez nie emocjami, utożsamianiu uznanym przez twórców ekspresjonizmu za naczelną zasadę artystyczną poetyckiego obrazowania, czego wynikiem było zaakceptowanie logiki artystycznej obrazu odmiennej od logiki rozsądku." Speina, Bankructwo realności, 81. (Übers. A. J.)

161 Nach De Bruyn zeige Schulz, wie Irzykowski, ein tieferes Interesse an der Beziehung zwischen Außenseite beziehungsweise Oberfläche und der »Tiefe«. Für beide Protagonisten der Erzählungen, Józef und Jakub, sei ihre Suche nach Wahrheit die Hauptsorge und beide gingen hierzu unterschiedliche Wege. Vgl. De Bruyn, Dieter: ‘The Lie Always Rises to the Surface like Oil. Toward a Metafictional Reading of Karol Irzykowski's Paluba and Bruno Schulz's Fiction. In: De Bruyn/Van Heuckelom: (Un)masking Bruno Schulz, 83-134, hier 93.

162 Fieguth, Bruno Schulz und seine heimliche Kritik an Kafka, 255.

163 Schulz, Das Sanatorium zur Sanduhr, 102. 
Der Erzähler untersucht ihre Existenz und stellt fest, dass »unter ihnen kein einziger authentischer Dreyfus, Edison oder Luccheni [war], bis zu einem gewissen Grad waren sie nichts als Simulanten. ${ }^{164}$ Die Überlegungen zur Identität der Wachsfiguren werden fortgeführt und dabei erneut die Ebenen vermischt. Wer das Original ist und wer die Kopie, ob die Wachsfiguren mit der ihnen verliehenen Gestalt identisch sind und wie sie dazu stehen, zeigt, wie gekonnt Schulz hier erneut verschiedene Ebenen der Repräsentation befragt. Eine vergleichbare Untersuchung der menschenähnlich geformten Materie findet sich in "Manekiny« (Schneiderpuppen). Dort ist es der Vater, der als Künstlerdemiurg die verschiedenen Möglichkeiten der Schöpfungsmanipulation untersucht. ${ }^{165}$

"Ahnt ihr den Schmerz, das stumme, eingesperrte Leid dieses Ungestüms, das nicht weiß, warum es ein solches ist und warum es in der gewaltsam aufgezwungenen Form verbleiben muß, die eine Parodie ist? Begreift ihr die Macht des Wortes, der Form, des Scheins, der tyrannischen Willkür, mit welcher der Schmerz sich auf den wehrlosen Holzklotz stürzt und ihn beherrscht wie eine eigene, tyrannische, überhandnehmende Seele? ${ }^{166}$

Nicht der Mensch leidet hier unter der Illusion, sondern die Materie, die entgegen ihrer Natur zur Figur oder zum Bild geformt wird. Damit wird das Machtverhältnis umgekehrt. »Diese Ähnlichkeit, dieser Schein, dieser Name beruhigt uns und erlaubt uns nicht die Frage, wer denn dieses Geschöpf in seinen eigenen Augen ist. « ${ }^{167}$ Der Vater weist damit auf die elementare und definierende Verflechtung von Sprache und Plastik hin, denn der Name ist es, welcher der Figur die Bedeutung und fremde »Identität« verleiht. ${ }^{168}$ Er hinter-

164 Ebd., 104. »Tak, nie byli to w samej rzeczy całkiem autentyczni Dreyfusi, Edisonowie i Luccheniowie, byli do pewnego stopnia symulantami.« Schulz, Sanatorium pod Klepsydrą, 182.

165 Eine ausführliche Untersuchung der verschiedenen Schöpfungstheoreme findet sich in Lachmann, Erzählte Phantastik, 337-374.

166 Schulz, Die Zimtläden, 57. „Czy przeczuwacie ból, cierpienie głuche, nie wyzwolone, zakute w materię cierpienie tej pałuby, która nie wie, czemu nią jest, czemu musi trwać w tej gwałtem narzuconej formie, będącej parodią? Czy pojmujecie potęgę wyrazu, formy, pozoru, tyrańską samowolę, z jaką rzuca się on na bezbronną kłodę i opanowuje, jak własna, tyrańska, panosząca się dusza?« Ders., Sklepy cynamonowe, 66.

167 Ders., Die Zimtläden, 59. »To podobieństwo, ten pozór, ta nazwa uspokaja nas i nie pozwala nam pytać, kim jest dla siebie samego ten twór nieszczęśliwy.« Ders., Sklepy cynamonowe, 67.

168 Der Vater untersucht die Materie, um zu durchschauen, welche Wirkprinzipien sie zu ihrer Form bringen. Diese Idee wird insbesondere in dem "Traktat o manekinach (Ciąg dalszy)« (Traktat über die Schneiderpuppen (Fortsetzung)) ausgeführt. Hier bespricht der Vater Wachsfiguren eines Panoptikums und leidet mit der Materie, die nach dem optischen Vorbild beispielsweise der Königin Draga geformt wurde. Aber könne diese Puppe denn überhaupt etwas von der Königin haben? Der Vater schlägt vor, dass es sich 
fragt letztlich die Illusion, indem er sie beschwört und anschließend wieder zerstört. Mit Mitchell lässt sich diese Methode dem Illusionismus zuordnen. "Illusionism, by contrast, is playing with illusions, the self-conscious exploitation of illusion as a cultural practice for social ends. ${ }^{169}$ Illusionismus trainiere das Auge und halte den Verstand wach für Fetischismus und Idolatrie aller Art; die Kraft des Irrealismus hingegen ist die negative Kritik am Realismus. »Irrealism has a more important role to play, not as a philosophy that ssupplants« realism, but as a therapeutic thorn in its side, a way of keeping realism honest. ${ }^{170}$ Sikorski deutet Schulz' Illusionismus wiederum als substanzielle Karnevalisierung des Lebens. Indem Schulz tote oder lebendige Materie als Schauspieler in einem Weltspektakel auftreten lasse und den Wechsel der Masken als ihre Natur darstelle, schreibe er gegen eine als gekannt und gegeben wahrgenommene Welt an und setze an ihre Stelle die Möglichkeit zur Umkehr und Restauration. Dies liest Sikorski in einem kabbalistischen Kontext. ${ }^{171}$ Dabei nähert er sich Jarzębskis Deutung an, der für die Wortmalerei den Sinn als Gegenstand bezeichnete. Sikorski hingegen erkennt darin den Zugang zu den »mitycznych mateczników « ${ }^{172}$ (mythischen Rückzugsorten).

Dieser Zusammenhang kann aber auch säkular gedeutet werden als philosophische Frage nach dem Zusammenhang zwischen Form und Inhalt. Gerade über den Realismus und den Zusammenhang zwischen der realistischen Form und dem literarischen Gegenstand äußert sich Schulz in einem Brief an die Freundin Anna Halpern. Am Beispiel von Thomas Manns Roman zeigt er auf, dass die realistische Form nicht zwangsläufig über den Gegenstand entscheide, dass dieser also auch »real« wäre.

"Der Realismus als eine ausschließliche Tendenz zum Kopieren der Wirklichkeit scheint mir eine Fiktion zu sein. Nie hat es einen solchen gegeben. Der Realismus wurde zu einem Alp, zum Schreckbild der Nicht-Realisten, zu einem wahren Satan des Mittelalters, grellfarben an alle Wände gemalt. Ich würde vorschlagen, die Bezeichnung >Realismus` als rein negativen Terminus zu verwenden: es ist eine Methode, die bemüht ist, ihre Mittel im Bereich einer bestimmten Konvention unterzubringen, die beschlossen hat, eine bestimmte Konvention nicht zu brechen, die

bei der Puppe um einen Anonymus handele, der mit Draga nichts zu tun habe. Das Hinweisschild mit dem Namen sei irreführend und sogar »vergewaltigend «. Somit polemisiert der Vater gegen die Idee der Mimesis nicht vom Standpunkt des Originals aus, sondern vom Standpunkt des Bildträgers - sei es die Leinwand, sei es die Plastik. Vgl. ebd, $66 \mathrm{f}$.

169 Mitchell, Picture Theory, 343.

170 Ebd., 362.

171 Vgl. Sikorski, Symboliczny świat, 140-142.

172 Ebd., 142. 
wir Wirklichkeit, gesunder Menschenverstand oder Wahrscheinlichkeit nennen. Im Bereich dieser Grenzen bleibt ihm eine sehr breite Skala von Mitteln, wie breit beweist Mann, der alle Sphären und Höllen ausschöpft, ohne die realistische Konvention zu durchbrechen. ${ }^{173}$

Schulz macht darauf aufmerksam, dass die realistische Konvention nicht zwangsläufig eine Darstellung des Realen bedeutet. ${ }^{174}$ Genausowenig bedeutet eine poetische Sprache eine Darstellung des Fantastischen im Sinne des »Nicht-Realen.« Das Fantastische hat im Erlebten, Geträumten und Fantasierten Anteil am Leben und es ist eine Frage der Sprach- und Bildkonvention, welcher Bereich diesem im Wirklichen zugewiesen wird. Sowohl das Wirkliche als auch die Formen sind also wandelbar. ${ }^{175}$ »Diese Wanderung der Formen ist das Wesen des Lebens. ${ }^{176}$

\subsection{Zwischenfazit}

Dass Schulz nicht zu den Sprach- und Bildpuristen zählt, sollte schon durch die Untersuchungen der Metabilder in den Grafiken und der Werbebilder in den Erzählungen deutlich geworden sein. Gleichzeitig bedeutet es nicht, dass er nicht auch unter dem Einfluss ihrer Ideen steht. Die Fokussierung des Ma-

173 Schulz, Brief an Anna Płockier vom 6.11.1941, 192. (Übers. Dutsch) »Wydaje mi się, że realizm, jako wyłączna tendencja do kopiowania rzeczywistości - jest fikcją. Nigdy nie było takiego. Realizm stał się zmorą i straszakiem nie-realistów, istnym szatanem średniowiecza malowanym na wszystkich ścianach jaskrawymi barwami. Proponowałbym dla określenia realizmu [użyć] terminu czystego negatywnego: jest to metoda, która stara się pomieścić swe środki w odrębie pewnych konwencji, postanawia nie łamać pewnej konwencji, którą nazywamy rzeczywistością lub zdrowym rozsądkiem, lub prawdopodobieństwem. W obrębie tych granic pozostaje mu bardzo szeroka skala środków, jak szeroka, dowodzi właśnie Mann, który wyczerpuje wszystkie sfery i piekła, nie łamiąc konwencji realistycznej.«Schulz, Księga listów, 198.

174 Sikorski, der den Abschnitt deutet, weist darauf hin, dass in diesem Zusammenhang die Wirklichkeit selbst zur unversiegbaren Quelle der Kunst wird. Vgl. Sikorski, Dariusz K.: »Humorysta przechadza się pośród nieskończoności« - Bruno Schulz wobec tworczości Tomasza Manna. In: Ruch Literacki 2006 (2006), 351-366, hier 352.

175 »Es reizt mich, die >Geschichten Jakobs« von Mann zu analysieren; eine großartiges Werk, man kann an ihm die Wandlung unseres Begriffs von der Wirklichkeit zeigen und die neue Anschauung über das Wesen des Lebens deuten."Schulz, Brief an Zenon Waśniewski vom 07.11.1934. In: Ficowski (Hg.): Gesammelte Werke, 63. »Kusi mnie zanalizować Jakubowe historie Manna - wspaniałą rzecz, na której można zademonstrować przemianę naszego pojęcia rzeczywistości i nowy pogląd na istotę życia.« Schulz, Księga listów, 74 .

176 Ders., Bruno Schulz an St. I. Witkiewicz, 92. "Ta wędrówka form jest istotą życia." Ders., Bruno Schulz do St. I. Witkiewicza, 20. 
nifests »Mityzacja rzeczywistości« auf die Sprache unterstützt diesen Eindruck. Daher wundert es auch nicht, dass Schulz' Werk vornehmlich sprachtheoretisch untersucht wurde. Wird das Manifest zu streng ausgelegt, dann ergeben sich zahlreiche Ungereimtheiten. Die außerordentliche Visualität der Sprache, ihre Beziehung zur Malerei, die inhärenten Ekphraseis und die metapoetischen Minitraktate zu bildtheoretischen Fragestellungen werden in ihrer Gänze erst dann verständlich, wenn die Schluzsche Poetologie hinsichtlich der Beziehung zum Bild untersucht wird.

Die Vorstellung, dass Sprache sukzessiv in der Zeitachse verortet sei und daher besser Argumente und Handlungen wiedergeben könne, während das Medium Bild räumlich sei und daher besser Ansichten und Stimmungen wiedergebe, entsteht aus einem reduzierten Verständnis des Mediums. Ein Bild (image) ist in dieser Argumentation starr, weil es auf eine Fläche gemalt wurde, eine Erzählung ist deshalb in der linearen Zeit verortet, weil sich die Buchstaben von links nach rechts aneinanderreihen. ${ }^{177}$ Diese polare Konzeption ist weder sinnvoll, weil das Medium nicht notwendigerweise der wesentliche Gegenstand eines Kunstwerks ist, noch ist sie natürlich, weil sich in der historischen Entwicklung auch andere Vorstellungen von Sprach- und Bildkunst herausgebildet haben.

Schulz umgeht mit seiner bildhaften Sprache die radikale Unterscheidung und führt die Sprache so nah wie möglich an die Malerei heran. Die vielen ekphrastischen Beschreibungen sind damit als Versuche zu verstehen, die Sprache möglichst bildhaft werden zu lassen, Bilder in Sprache zu übersetzen oder sogar Bilder in Sprache zu schreiben. ${ }^{178}$ Schulz entwickelt mehrere Ansätze des ekphrastischen Schreibens. Ein Ansatz ist die sprachlich visualisierende Wiedergabe von bekannten und unbekannten Kunstgemälden, wie am Beispiel der barocken Malerei der Neapolitanischen Schule oder der Übersetzungen der Sternenhimmel van Goghs gezeigt werden konnte. Davon abweichend werden Farbwirkungen und Farbeigenschaften untersucht und sogar ganze Erzählungen einfarbig gehalten, wie in »Pan Karol«. Auch die Perspektive, der Perspektivwechsel und die daraus resultierenden Wahrnehmungsbedingungen werden in ekphrastischen Beschreibungen analysiert. Welchen Einfluss die Benennung eines Werks auf die Bedeutung hat, zeigt sich an den Wachsfiguren, die neben dem Aussehen auch den identitätsstiftenden Namen einer berühmten Persönlichkeit tragen. Die Macht der Illusion wird in diesem

177 Mit Belting ausgedrückt bedeutet das eine Verwechslung des Bildes (image) mit dem Medium Bild (picture). Vgl. Belting, Bild-Anthropologie, 11-13.

178 So schreibt einer der bekanntesten Theoretiker des Expressionismus, Herwarth Walden: »Bilder lassen sich nicht beschreiben, denn erst das Schreiben der Bilder wäre wieder Kunst.« Walden, Herwarth: Einblick in Kunst. Expressionismus Futurismus Kubismus. Berlin 1924, 96. 
Zusammenhang nicht nur in Hinsicht auf den Rezipienten, sondern in Hinsicht auf die geformte und benannte Materie selbst untersucht.

Diese Experimente mit Mitteln der Malerei sowie mit bekannten Kunstwerken werden durch eine Reihe an Mikrotraktaten begleitet, die theoretische Überlegungen zu Farbe, Perspektive, dem Zusammenhang von Form und Sprache sowie zur Gewalt des Künstlers mit aufnehmen. Besonderer Fokus liegt dabei auf der Frage der Wahrnehmung und der Rolle »innerer Bilder« im Leben. Dies zeigt sich im doppelten Erzähler, der als Kind eine vorbewusste Innenperspektive, als Erwachsener hingegen eine reflektierte Außenperspektive einnimmt. So werden dem fantastischen Geschehen Kommentare zur Seite gestellt und die beschriebenen Ereignisse als Erlebnisperspektive des Kindes kontextualisiert. Die dargestellte Epiphanie ist somit zunächst nur die Wahrnehmung des Kindes, nicht aber des Erwachsenenkollektivs. ${ }^{179}$ Die Wirklichkeitsrelevanz ist also von der Betrachterperspektive abhängig. Damit wird in Schulz' Werk erneut die Rolle des Kunstwerks oder Gegenstands in einem Wahrnehmungsgeflecht diskutiert, wobei nicht nur mehr Künstler und Rezipient befragt werden, sondern auch die geformte Materie, das Medium des Kunstwerks als Entität mit eigenem Willen und möglicherweise auch eigener Identität. Dabei ist die Grenze zwischen Ironie und Ernsthaftigkeit so fließend, dass auch andere Deutungen möglich sind.

Mit der poetischen Sprache sind verschiedene Ziele verbunden. Sie bricht die Illusion einer bezeichnenden, linear vorgestellten Sprache und lenkt die Aufmerksamkeit auf die Beziehung zum Visuellen, Räumlichen und Bildschaffenden. ${ }^{180}$ Sprache kann das Medium für Bilder sein und hierfür Mittel bereitstellen, die zu einer gesteigerten Visualisierung beitragen, wie Metaphern, Vergleiche, Personifizierungen und Dynamisierungen. In Sprache geschriebene Bilder unterscheiden sich von Bildern der Malerei dahingehend, dass das Gesehene nur in der Vorstellung des Lesers realisiert wird. Diese Bilder sind damit auch nicht technisch reproduzierbar, sondern verbleiben allein in der Vorstellung. Damit sind die inneren und die Sprachbilder einem technischen Bildverfahren nicht zugänglich und bewahren somit ihre Magie der Einmaligkeit. ${ }^{181}$ Dies bedeute nach Lea Santini Ritter auch eine Form der Entmachtung bedrohlicher Vereinnahmungen.

179 Gelhard deutet die fantastische Sprache und auch das fantastische Geschehen als Begegnung mit der vergessenen jüdischen Kultur. Auf stilistischer wie inhaltlicher Ebene suche Schulz den Bruch und die Kontinuität mit der Tradition. Vgl. Gelhard, Dorothee: Spuren des Sagens. Studien zur jüdischen Hermeneutik in der Literatur. Frankfurt a. M. 2004, 65.

180 Vgl. Bolecki, Das 'principium individuationis`, 25.

181 Vgl. Greif, Stefan: Die Malerei kann ein sehr beredtes Schweigen haben. Beschreibungskunst und Bildästhetik der Dichter. München 1998, 29. 
»Die bildliche Faszination, in der Sprache historisch aufgehoben, lehrt das Mißtrauen gegen die Macht der Identifikation und befreit gleichsam die Bilder von ihrer einseitigen Inanspruchnahme. Die Bilder aber, die durch Texte gegangen sind, verlieren ihre visuelle Eindeutigkeit, um die Erinnerung der Worte anzunehmen; sie gehören dann auch dem literarischen Gedächtnis, das sie wieder - wie Shakespeares Meer - bewahrt und verwandelt: >those are pearls that were his eyes. ${ }^{182}$

Indem Schulz in seiner Literatur seine poetische Sprach- und Wahrnehmungstheorie sowohl in metapoetischen Kommentaren als auch innerhalb der Handlungen ständig erweitert, lässt sich ähnlich zu den Grafiken und Porträtzeichnungen ein komplexer Wechsel zwischen den Ebenen der Repräsentation feststellen. Was schon Philosophie ist, was noch Literatur, was Handlung, Erfahrung, Wahrnehmung, Traum oder Erinnertes ist, lässt sich nur partiell trennen und die Wirklichkeit der empirisch intersubjektiven Wahrnehmung wird der individuellen, erlebenden Sicht zumindest gleichgestellt. Ähnlich betont es auch Ulrich Schmid:

»Gerade Schulz' fragiler Wirklichkeitsbegriff weist darauf hin, dass Realität nichts Gegebenes ist, sondern Resultat einer ästhetischen Simulation, die nach Massgabe kollektiver Projektionen so oder anders ausfallen kann. Schulz' Erzählungen werden damit lesbar als künstlerische Offenlegungen der narrativen Verfasstheit der menschlichen Weltorientierungen. Das bedeutet gleichzeitig, dass man bei Schulz nicht nach einem alternativen Wahrheitsentwurf für die Metaerzählungen der Moderne suchen darf: Seine Leistung besteht darin, dass er das Funktionieren der menschlichen Wirklichkeitserfahrung in einem künstlerischen Akt der Realitätskonstitution nachvollzogen hat. ${ }^{183}$

Gerade weil sich Schulz der Konventionalität und daher auch der Instabilität von Bedeutungen bewusst ist, verbleiben seine Ideen im künstlerischen Experiment und er überführt sie nicht, wie so viele seiner Zeitgenossen, in eine eindeutigere Sprache oder kohärente Theorie. ${ }^{184}$ Schulz vermischt also nicht nur Bild und Sprache, sondern auch Kunst und Theorie mit dem Ergebnis, dass diese in einem sich gegenseitig befruchtenden und erweiternden Austausch stehen. Die dadurch erzeugte Mehrdeutigkeit wird durch die wechselnde Erzählperspektive verstärkt. Das analytische und fantastische Sehen

182 Ritter Santini, Lea (Hg.): Mit den Augen geschrieben. Von gedichteten und erzählten Bildern. München 1991, 10.

183 Schmid, Die Realisierung der modernen Metaerzählungen, 131.

184 Auch das Nichtformulieren einer Kunsttheorie ist in den 1920er und 30er Jahren als Theorie lesbar. So kritisiert der schon zitierte Herwarth Walden explizit eine Formulierung der Kunsttheorie, »weil die gestaltete Formen in Formeln verwandelt.» Sie würden das Kunsterlebnis durch Begriffe ersetzen und man blicke auf solche Bilder dann durch die Brille der Theorie und könne sie nicht mehr unverstellt sehen. Vgl. Walden, Einblick in Kunst, 123. 
wird mit dem erlebenden und erklärenden Beschreiben in Korrelation geführt und jede erste Eindeutigkeit durch eine Relativierung oder Gegenthese wieder aufgehoben, um schließlich die übergeordnete Frage zu stellen: Wie entstehen Bedeutungen in einem Interaktionssystem von Menschen, Gegenständen, Sprache und Bild? 



\section{Rettung des Bildes im Wort - Fazit}

»Es ist übrigens ein Postulat des Humanismus, den ganzen Bereich des Lebens zu humanisieren, auf daß es weniger Dinge gäbe, die das Licht des Gedankens meiden und das Wort scheuen." ${ }^{1}$

Ziel dieser Untersuchung war es, Licht auf einen bisher vernachlässigten Bereich von Bruno Schulz' Werk zu werfen - auf die Bildidee und ihre Beziehung zum Medium des Bildes und der Sprache, die über eine metaphorische Sprache hinausgeht. Dabei sollte die enge Verflechtung von Bildwerk und Erzählungen in Schulz' Werk verdeutlicht werden, denn in dieser Verflechtung steckt auch das theoretische Potenzial der Grafiken und Zeichnungen, die nach wie vor im Schatten seiner Literatur stehen. Schulz untersucht nicht nur die Wirkweise der symbolischen Formen Bild und Sprache, in denen der Mensch die Welt erfasst, sondern er versucht auch dominierende Begriffe von Sprache und Bild zu ändern, indem er mit Mischformen die Vorstellung von ihnen beeinflusst und erweitert.

Schulz hat sein Werk vor dem Hintergrund eines "Erstarrens der Bilder" angefertigt, welches er in seiner Zeit beobachtet. Wie im zweiten Kapitel ausführlich dargelegt wurde, bedingen technische Entwicklungen eine Veränderung in der Produktion und Reproduktion von Bildern. Damit einher geht eine Veränderung des bisher dominierenden Bildbegriffs, der Rolle des Bildes in der Gesellschaft und den Möglichkeiten des Darstellbaren. Im Zuge der Erfindung der Fotografie und der damit einsetzenden massenhaften Verwendung von technisch produzierten und reproduzierten Bildformaten in der Reklame, Presse, Porträt- und Dokumentarfotografie, aber auch durch den Einfluss positivistischer Ideen, verändern sich die Vorstellung von Bildern und ihre Funktion in der Gesellschaft. ${ }^{2}$ Diese Entwicklungen sind verbunden mit der Wahrnehmung und der Rolle der Bildkunst, welche ihre dokumentarische und abbildende Funktion an technische Bildverfahren abtritt. ${ }^{3}$ Die Bildkunst gerät dadurch einerseits - wie Boehm darlegt - in eine Sinnkrise, erlebt aber andererseits auch eine Blüte ihrer Ausdrucksmittel. ${ }^{4}$

1 Schulz, Bruno: Brief an Georges Rosenberg vom 28.8.1938. (Aus dem Poln. v. Mikolaj Dutsch). In: Ficowski (Hg.): Gesammelte Werke, 115-116, hier 115. »To jest zresztą postulat humanizmu, zhumanizowania całego obszaru życia, żeby coraz mniej rzeczy było unikających światła myśli i uchylających się przed słowem.«Schulz, Księga listów, 73.

2 Vgl. Makropoulos, Michael: Wirklichkeiten zwischen Literatur, Malerei und Sozialforschung. In: Graevenitz, Gerhard v. (Hg.): Konzepte der Moderne. Stuttgart 1999, 69-81, hier 79-81.

3 Vgl. Freund, Photographie und Gesellschaft.

4 Vgl. Boehm, Wie Bilder Sinn erzeugen, 13. 
Diese Entwicklungen in Technik, Philosophie und Kommunikation haben starken Einfluss auf die Betrachtung des Bildes und das Bewusstsein des Menschen. ${ }^{5}$ Das »Erstarren der Bilder« bedeutet vor diesem Hintergrund eine Wahrnehmung, die im technischen Bild eine Information sucht, das Gezeigte mit dem Realen verwechselt. Gleichzeitig werden in dieser Wahrnehmung Abbildungen im Kunstbild als fiktive verstanden und als solche vom Realen abgegrenzt. ${ }^{6}$ Diese Abgrenzungsbewegung findet auch in der Malerei statt, die sich in ihrer Zuwendung zum Abstrakten vermeintlich vom Sprachlichen und Dinglichen der Welt loslöst und »reines Bild « wird. Während Benjamin den neuen Bildern in Reklame, Presse und Kunstfotografie eine magische Schicht nachweist, die die Technik der Wirklichkeit abtrotzt, sieht er in der Entwicklung der abstrakten Kunst eine "negative Theologie der Kunst. ${ }^{7}$ Daher wundert es auch nicht, dass Schulz religiöse und mythologische Konzepte wie die Idolatrie und Pygmalions magische Belebung der Kunst neu befragt und in aktuelle Zusammenhänge bringt.

Schulz' werkimmanentes, produktives Neuverstehen des Bildes lässt sich als Benjaminsche »Rettung « verstehen, da Schulz mit einem vergleichbaren Verfahren wie Benjamin das Bild durch verschiedene Konstellationen und Perspektivverschiebungen, durch die Konfrontation mit älteren Bildbegriffen und -theorien sowie durch eine Analyse der Haltung zu unterschiedlichen Bildformaten untersucht. Schulz entwickelt dabei jedoch keinen alternativen Bildbegriff. Stattdessen setzt er eine Reihe von verschiedenen Bildrealisierungen um, die die Wahrnehmungsperspektiven des Künstlers und des Rezipienten, die Materie und Materialien sowie die Sprache mit einbeziehen. Diese verschiedenen Bildrealisierungen führen so in der Zusammenschau die Idee des Bildes vor.

5 Freund, Photographie und Gesellschaft, $82 \mathrm{f}$.

6 »Die Reproduktionstechniken greifen in die innere Struktur der Kunstwerke ein. Das Werk büßt einerseits seine raumzeitliche Individualität ein, andererseits gewinnt es an dokumentarischer Authentizität. Die Zeitstruktur von Flüchtigkeit und Wiederholbarkeit, die fürs autonome Kunstwerk typische Zeitstruktur von Einzigkeit und Dauer ersetzt, zerstört die Aura, >die einmalige Erfahrung einer ferne` und schärft den `Sinn für das Gleichartige in der Welt.« Habermas, Bewußtmachende oder rettende Kritik - die Aktualität Walter Benjamins, 184.

7 Benjamin, Das Kunstwerk, 441. Vgl. ebenfalls Ders., Kleine Geschichte der Photographie, 371. 


\subsection{Rettung}

In Anbetracht von Schulz' räumlich-sprachlichem Denken, das immer wieder neu ansetzt und das Bild von neuem erkundet, eignet sich für die Untersuchung seiner Bildidee Benjamins Begriff der "Rettung". Rettung bedeutet nach Benjamin ein Übersetzen vergangener Erfahrungen, Begriffe und Erkenntnisse in eine gegenwärtige Form, sodass Aspekte der Gegenwart mit früheren Überzeugungen konfrontiert werden können. Benjamin selbst hat diesen Begriff aus dem jüdischen Denken entlehnt, das die Geschichte nicht linear betrachtet, sondern zirkulär. Ereignisse sind somit nicht abgeschlossen, sondern wiederholbar und veränderbar. ${ }^{8}$ Ziel der Rettung ist es, die »Normalität« der aktuellen wie der früheren Vorstellungen zu dekonstruieren und auf diese Weise auf die Verflochtenheit des Vergangenen mit dem Gegenwärtigen aufmerksam zu machen sowie eine relative Freiheit gegenüber den Begriffen, Vorstellungen und der Überlieferung zurückzuerlangen. ${ }^{9}$ Die Gegenwart kommt so mit der Vergangenheit in eine dialektische Konstellation, und beide werfen ein kritisches Licht aufeinander. ${ }^{10}$ Dies bedeutet ein Aktualisieren, ein Neuverstehen der Bedeutungen durch ein produktives Neulesen von Vergangenem im Jetzt und von Aktuellem im Vergangenen. ${ }^{11}$

8 »Den aus der jüdischen Mystik abgeleiteten Begriffen kommt dabei genau die Funktion $\mathrm{zu}$, die historische Vernunft zu unterminieren, indem allem, was in der Vergangenheit unterdrückt und vergessen worden ist oder um das sich niemand gekümmert hat, eine neue Chance gegeben wird. In diesem Sinne nimmt der Benjaminsche Begriff des $>$ Eingedenkens die jüdische Kategorie des Zekher auf, die nicht meint, daß Begebenheiten der Vergangenheit im Gedächtnis aufbewahrt werden, sondern die ihre Reaktualisierung in der gegenwärtigen Erfahrung bezeichnet. Es sei die Aufgabe des Eingedenkens, schreibt Benjamin, ‘zu retten, was gescheitert ist‘, so wie die Erlösung für ihn nicht ein tangentiales Verhältnis zur Zukunft bezeichnet, sondern die gegenwärtige Möglichkeit, ızu vollenden, was uns vorenthalten worden ist.< Die messianische Hoffnung darf nicht aufgefaßt werden als das Anpeilen einer Utopie, deren Bestimmung es wäre, sich am Ende der Zeiten zu verwirklichen; vielmehr ist sie aufzufassen als eine äußerste Wachsamkeit und Wachheit, als eine Fähigkeit, das festzustellen, was in jedem Augenblick die rrevolutionäre Kraft» des Neuen erahnen läßt.«Mosès, Eingedenken und Jetztzeit, 392.

9 Benjamins »apodiktische Argumentationsweise will aber in der Unterbrechung gewohnter Denkabläufe gerade zum Innehalten eigenständiger Reflexion bewegen, sie ist polemisch gegen das konventionelle Verständnis gerichtet.« Kaulen, Rettung und Destruktion, 19.

10 Vgl. Benjamin, Zentralpark, 682.

11 "Zwischen der Gegenwart und ihrer Vorgeschichte kann und soll, zumindest im Medium der Geschichtsschreibung, eine `Stillstellung` der homogenen fortschreitenden Zeit stattfinden, die den rrechten Abstand (II, 439) zu beiden ermöglicht. Vergangenes wird aktualisiert, Gegenwart historisiert."Wohlfarth, Irving: Die Passagenarbeit. In: Lindner (Hg.): Benjamin-Handbuch, 251-274, hier 253. 
Weil in Benjamins Konzept der Fokus auf dem Werden und Verwandeln und nicht auf dem Zustand liegt, zeigen sich die Bedeutungen im offenen Raum der Geschichte und Tradition, der gestaltet werden kann und gedeutet werden muss. Dazu gehört auch das Erkennen des Wirkens mythischer und religiöser Strukturen, die sich wandlungsvoll in jede Gegenwart neu einfügen. Dies gilt sowohl für Motive und Inhalte der biblischen und mythologischen Texte, als auch religiöse und mythische Bewusstseinsformen. Rettung bedeutet demnach auch eine intellektuelle Durchdringung dieser Symbolformen am Gegenstand, um ihren Wirkungen nicht unvorbereitet zu begegnen. Die Gegenmagie zur mythischen Macht ist die Aufklärung und Distanzschaffung. ${ }^{12}$ Sinnverwandt, wenn auch in einem anderen Kontext, schreibt Cassirer:

"Die philosophische >Rettung des Mythos, die zugleich seine philosophische Aufhebung bedeutet, besteht jetzt darin, daß er als eine Form und eine Stufe des Wissens selbst gefaßt wird - und zwar als eine solche, die einem bestimmten Bereich von Gegenständen notwendig zukommt und ihm als adäquater Ausdruck entspricht. ${ }^{13}$

Benjamins Rettungsbegriff ist eng verschlungen mit dem der dialektischen Bilder. Seine Hermeneutik verlangt ein räumliches, verschränktes Denken, welches keine logische Kette entwickelt, sondern ein Widersprüche zulassendes Gedankengebäude. Hierfür muss der Reflexionsprozess immer wieder von neuem ansetzen und sich aus einer anderen Perspektive auf den Gegenstand zu- oder von ihm wegbewegen. Dieser ständige Perspektivwechsel ist es, welcher seine Hermeneutik für Schulz' Werk attraktiv werden lässt, weil er auch ein Licht auf das bildliche Arbeiten von Schulz wirft.

\subsection{Bild in Sprache}

Wie sich in allen vorgenommenen Mikroanalysen erwiesen hat, vertritt Schulz keine bild- oder sprachpuristische Vorstellung, sondern geht von einer wesentlichen Verbindung zwischen den beiden Ausdrucksbereichen aus. Dies zeigt sich deutlich in seinen Bildern, die eng mit literarischen Quellen verbunden sind, die gleichzeitig aber selbst eine Erzählform annehmen, insofern als verschiedene Protagonisten im Zyklus wiedererkennbar sind und sich diese durch ihre Selbstreferenzialität als »Metabilder« erweisen. Schulz' Annahme von einer Verwandtschaft zwischen Bild und Sprache zeigt sich aber auch in seiner Literatur, die mit ekphrastischen Beschreibungen die Sprache bildlich

12 Vgl. Habermas, Bewußtmachende oder rettende Kritik - die Aktualität Walter Benjamins, 188.

13 Cassirer, Das mythische Denken, 5. 
werden lässt und Anschauungsmomente intensiv und visualisiert wiedergibt. Zusätzlich finden sich theoretische Minitraktate, die eine Verwandtschaft von Sprache und Bild diskutieren.

Dementgegen ist aber auch ein deutlicher Einfluss der zu Schulz' Lebzeiten populären sprachidealistischen Theorien zu erkennen. Weil sich Schulz' programmatisches Manifest "Mityzacja rzeczywistości« vornehmlich auf die Sprache konzentriert ${ }^{14}$ und Konzepte wie eine Ursprache und reduzierte Alltagssprache stark an die biblische Sprachschöpfungs- und Sündenfalltheorie erinnern, wird Schulz' Sprachkonzept häufig allein im Kontext jüdischer Sprachphilosophie und -mystik gelesen. ${ }^{15}$ Schulz selbst betont mehrfach ausdrücklich, dass ihm verschiedene Mythologien als Grundlage dienten. ${ }^{16}$ Auch wenn eine maßgeblich auf jüdischen Quellen basierte Deutung des Manifests und der Literatur möglich ist, wie Underhill, Schulte, Błoński und Panas ${ }^{17}$ nachgewiesen haben, so sind zumindest im Kontext der Bilder mit vergleichbarer Relevanz auch die griechische Mythologie, romantische Novellen, europäische Bildkunst und Werbebilder Quellen seiner Untersuchungen in Bild und Sprache. Eine religiöse Haltung innerhalb der Literatur, Bilder und Theorien wird durch Mikrotraktate, Ironie, alternative Sichtweisen und konterkarierende Gegendarstellungen immer wieder dekonstruiert. So lässt sich feststellen, dass es Schulz nicht um die Restitution eines bestimmten Mythos oder einer mythischen Wahrnehmung geht - wie sich durch den Titel »Mityzacja rzeczywistości« durchaus annehmen ließe - sondern vielmehr im Sinne Benjamins um eine Bewusstwerdung der Wirklichkeitsrelevanz alter und moderner Mythologien.

Dies zeigt Schulz einerseits durch Zitate und Übersetzungen mythologischer und religiöser Motive in seinen Texten und Bildern, andererseits auch durch das Aufzeigen moderner »religiöser« Formen, wie sie sich im kapitalistischen Warenkult oder in der Verehrung des Schönen in der Kunst darstellen. Besonders deutlich wird das in der Verarbeitung der Werbebilder in den Erzählungen »Ulica Krokodyli« und »Księga" sowie in den Grafiken um das junge Mädchen. Dabei kritisiert Schulz nicht einseitig die Werbebilder, sondern zeigt auch ihr mythisch-magisches Potential auf. Die körperlichen Reize der Modebilder, die Heilsgeschichten und -versprechungen, die Anknüpfung an religiöse Ikonologie und Überzeugungsstrategien werden von Schulz sowohl kritisch beleuchtet als auch mit künstlerischer Anerkennung ihrer Leistung vorgeführt. Gerade das Kulthafte stellt Schulz überspitzt dar, indem er die Mädchen in ihrer anmutigen Haltung erstarren lässt, den Damenschuh

14 Vgl. Schulz, Mityzacja rzeczywistości, $11 \mathrm{f}$.

15 Vgl. Panas, Księga blasku, 128.

16 Vgl. Schulz, Exposé über das Buch `Zimtläden`.

17 Vgl. Panas, Księga blasku; Underhill, Bruno Schulz and Jewish Modernity; Schulte, Eine Poetik der Offenbarung; Błoński, Świat jako księga i komentarz. 
als religiösen Warenfetisch vorführt und die Männer in grotesker betender Deformation darstellt. Das heilige Buch (Księga) dieser Waren- und Konsumgesellschaft ist der Werbekatalog. Schulz nimmt sich aus diesem Kult erneut nicht aus, sondern bildet sich selbst mit anderen Gesichtern aus seinem Drohobyczer Umfeld unter den pilgernden Massen ab.

Bemerkenswert hierbei ist, dass sich der Kontext, in welchem Schulz das Entstehen und Wirken von Kunstbildern untersucht, nicht sehr stark von dem der Werbebilder und Grafiken der Gruppe der jungen Mädchen unterscheidet. Die Undula-Grafiken, die das Verhältnis zwischen Künstler, Kunstwerk, Wirklichkeit und Mythos auf mehreren Ebenen diskutieren, sind nicht weniger kritisch. Sie zitieren verschiedene literarische Folien, in denen die Macht von Kunstbildern und Götterplastiken auf einen Künstler vorgeführt wird. In der durch die Grafiken zitierten Novelle »Venus im Pelz« von Sacher-Masoch werden die Kunstwerdung einer Frau und die Vermenschlichung einer Venusskulptur dargestellt, an der der Künstler wesentlichen Anteil hat. Die Pygmalion-Mythologie wird abgewandelt, die Kunst-Frau wird nicht ihrem Erschaffer gehorsam, entwickelt also nicht nur ein Eigenleben, sondern hat auch einen eigenen Willen. Dies spiegelt sich sowohl in Schulz' Grafiken der "Xięga Bałwochwalcza» als auch in seiner Erzählung "Wiosna«, in der die Protagonistin Bianka - ursprünglich ein Motiv auf einer Briefmarke - aus ihrer Passivität ausbricht und eigene, vom Erzähler nicht vorhergesehene Entscheidungen trifft. Damit betont Schulz die Eigendynamik von Kunstwerken, die durch sich wandelnde Kontexte neue Bedeutungen mit aufnehmen und ihre illusorische Macht immer wieder neu entfalten.

Illusion ist in Schulz' Werk dabei häufig die Kehrseite einer Haltung oder Wahrnehmungsbedingung im Bewusstseinszustand. Sowohl die zitierten und verarbeiteten Novellen »Das Marmorbild« und »Venus im Pelz« als auch die Untersuchung der Wachsfiguren und nicht zuletzt der doppelte Erzähler markieren unterschiedliche Möglichkeiten, mit einem Bild in Beziehung zu treten. Wie Mitchell gezeigt hat, funktionieren Machtstrukturen nur in einer Beziehung zwischen Objekt und Subjekt oder zwei Subjekten. Diese Dialektik markiert auch Schulz, indem er sowohl die Macht untersucht, die der Künstler und Formgeber über die Materie ausübt, wenn er Wachs zu einer Skulptur formt und diese anschließend benennt, als auch die Macht, die das Kunstwerk auf den Betrachter haben kann, indem Bilder bestimmte Ansichten vorentwerfen.

Diese Selbstreflexivität des Künstlers gegenüber seinen Erzeugnissen lässt sich mit Boehm im Kontext der Moderne verstehen. »Die Isolierung und Verselbständigung der Künstlerexistenz verbindet sich mit einem gründlichen Nachdenken über die Prämissen der Gestaltung, die materiellen und konzeptuellen Bedingungen des Darstellens. ${ }^{18}$ In Form eines metakünstleri-

18 Boehm, Wie Bilder Sinn erzeugen, 60. 
schen Diskurses verbildlicht Schulz eine sehr komplexe Auseinandersetzung mit dem künstlerischen Bildschaffen. Die schon fast als Gegensätzlichkeit zu bezeichnende Spannung, die zwischen der präsentierten Erotik der Grafiken und der intellektuell zu ergründenden Sinnstruktur herrscht, spiegelt die Problematik der modernen Idolatrie. Schulz verführt den Rezipienten geradezu dazu, das Gezeigte als das Reale wahrzunehmen, den präsentierten Masochismus als Symbol der eigenen Sexualität zu lesen, ${ }^{19}$ gibt zugleich aber genügend Hinweise darauf, dass dies nicht der Gegenstand der Grafiken ist.

Da der Grafikzyklus den Namen »Xięga Bałwochwalcza« trägt, wird diese Idolatrie in verschiedenen Kontexten verständlich: Das Buch ist selbst idolatrisch, weil es Bilder zeigt. Das Buch zeigt, wie Kunstwerke zu mächtigen Idolen werden, und entlarvt damit die religiöse Bildverehrung. Das Buch verführt den Betrachter zur religiösen Verneigung vor dem Dargestellten. So wie das Manifest »Mityzacja rzeczywistości« eine Untersuchung der poetischen Sprache im Medium der Sprache darstellt, so lässt sich die »Xięga Bałwochwalcza« als Untersuchung des Bildes im Medium des Bildes verstehen.

Damit betont Schulz auch die Medialität der beiden Ausdrucksbereiche Bild und Sprache, die er in immer neue Beziehungen zueinander treten lässt. Die spezifische »Wortmalerei« seiner Erzählungen umfasst ebenfalls alle drei Ebenen der Auseinandersetzung, wie sie auch in den Metabildern der Grafiken und Porträts anzufinden sind. Die Erzählungen zitieren Bilder der Malerei, indem diese inhaltlich beschrieben werden (»Druga jesień«) oder indem ihre Darstellungsmittel in die visualisierende Beschreibung mit einfließen (»Sklepy cynamonowe«), sie imitieren malerische Mittel, indem Farben, Erscheinungsmomente, Material, Perspektiven sowie Räumlichkeit zu einer gesteigerten Anschaulichkeit beitragen, und sie nehmen in Mikrotraktaten Theorien zur Farbe, Malerei, Anschauung, Wahrnehmung und Wirklichkeit sowie zur Beziehung zum Raum und zur Zeit auf. Bildsprachliche Praxis und Theorie sind dabei eng ineinander verwoben. Besonders auffällig sind die Dynamik der Bilder und die Räumlichkeit der Sprache, die die Vorstellung einer "reinen « zeitlichen, linearen Sprache und einer »reinen" Räumlichkeit der Bildmedien aufhebt. Auch hier gehen oft Wahrnehmungsmomente in die Beschreibung mit ein. Nicht immer lässt sich unterscheiden, wann ein Bild »nur« eine Wahrnehmung darstellt und wann es Teil einer intersubjektiven Wirklichkeit ist. Dies zeigt sich genauso in den Verwandlungen wie in den Bildvisionen des Kindes, aber auch in den Arabesken auf den Tapeten. Manche der ekphrastischen Bilder existieren nur einen Moment und nur in einer bestimmten Perspektive, wie die Wolkenbilder am Himmel, andere sind gänzlich zeitlos und symbolisch, wie das weiße Zimmer Herrn Karols im Eindruck der emotionalen Trägheit und Unentschlossenheit. 
Dabei öffnet Schulz immer wieder eine mehrfache Ebenenstruktur der Repräsentation. Erstens kommen auf seinen Grafiken und Zeichnungen häufig Bilder und Bücher im Bild vor, so dass eine zweite und dritte Ebene der Repräsentation existiert, zwischen denen eine Kommunikation hergestellt wird. Zweitens treten die Figuren der Bilder mit dem außerbildlichen Rezipienten in Kontakt und binden diesen in die Bildstruktur mit ein. Drittens werden bildtheoretische Texte innerhalb des Dargestellten verarbeitet und somit existiert auch auf dieser Ebene eine intermediale Verflechtung. Ganz ähnlich ist es in der Literatur. Hier spricht der Erzähler den Leser immer wieder an und nimmt ihn bei der Hand. ${ }^{20}$ Dann wiederum zeigt der Erzähler aus der Innenperspektive seine Wahrnehmung. Bilder und Bücher sind identifizierbare Gegenstände der Handlung sowie Subtexte des Geschehens. In metatheoretischen Ausführungen werden die verschiedenen Ebenen miteinander in Beziehung gesetzt.

Die Idee des Bildes in Schulz' Werk ist also nicht in einem Begriff zu definieren, sondern ihre konkrete und abstrakte Materialisierung erfolgt über eine Vielzahl von Bildformen und Beziehungen zur Sprache, zum Mensch und zur Umwelt. Metabilder und Bildtexte weisen nach Mitchell in der Verflechtung von Kunstpraxis und -theorie auf die wesentliche Untrennbarkeit von Praxis und Theorie hin.

»The power of the metapicture is to make visible the impossibility of separating theory from practice, to give theory a body and visible shape that it often wants to deny, to reveal theory as representation. The power of the imagetext is to reveal the inescapable heterogeneity of representation, to show that the body we give to theory is an assemblage of prostheses and artificial supplements, not a natural or organic form. ${ }^{21}$

Indem Schulz in beiden Medien - in seinem Bildwerk wie in der Literatur - mehrere praktische wie theoretische Untersuchung des Bildes wiederholt, indem er Bildpraxis und Bildtheorie verflicht und nebeneinanderstellt, bekommt auch seine Theorie einen visuellen Charakter. Aus kleinen Mikroanalysen setzt sich ein Gesamtbild der Idee des Bildes zusammen. Diese Anschaulichkeit ist auch eines der Kernelemente der Benjaminschen Hermeneutik. ${ }^{22}$ Damit wird die wesentliche Verbindung zwischen Schulz' literarischem und plastischem Werk deutlich. ${ }^{23}$

20 Vgl. Robertson, Bruno Schulz's Intimate Communication, 456.

21 Mitchell, Picture Theory, 418.

22 Vgl. Benjamin, Das Passagen-Werk, 571, sowie Benjamin, Walter: Zum verlorenen Abschluss der Notiz über die Symbolik in der Erkenntnis. In: Tiedemann, Rolf/Schweppenhäuser, Hermann (Hg.): Gesammelte Schriften VI. Fragmente vermischten Inhalts. Autobiographische Schriften. Frankfurt a. M. 1991, 38-39, hier 39. Hanna Arendt bezeichnet dies als mosaikhaftes Denken. Vgl. Arendt, Walter Benjamin, $45 \mathrm{f}$.

23 Diesen Zusammenhang zu finden, schließt eine der großen Lücken in der Schulzforschung. Auf die fehlende Beantwortung der Frage, wie Bild und Prosa bei Schulz zusammenhängen, hatte vor allem Jan Gondowicz hingewiesen. Vgl. Gondowicz, Schulz, 46. 


\section{Danksagung}

Dieses Buch ist die überarbeitete Version meiner Dissertationsschrift, die an der Universität Regensburg angenommen und im Rahmen der Graduiertenschule für Ost- und Südosteuropastudien abgeschlossen wurde. Mehreren Personen, Institutionen und Förderern möchte ich meinen herzlichen Dank aussprechen.

Da eine spezifische Würdigung des konkreten Einsatzes den Rahmen der Danksagung sprengen würde und eine Hierarchisierung in der Nennung das Problem der Gerechtigkeit nicht löst, möchte ich in alphabetischer Reihenfolge allen danken, die ihren Anteil am Entstehen dieser Arbeit hatten, sei es durch Betreuung, kritisches Kommentieren der gesamten Arbeit oder einzelner Kapitel, Sprachlektorate, Ideen-Input, die Vorbereitung der Verteidigung oder der Veröffentlichung oder aber durch finanzielle, gutachterliche und strukturelle Unterstützung.

Ich danke herzlich Dr. Andreas Angerstorfer, Jordi Balada-Campo, Prof. Dr. Ulf Brunnbauer, Alice Buzdugan, Prof. Dr. Anna Czabanowska-Wróbel, Lisa Demetz, Katrin Döppe, David Franz, Angelika Frey, Dr. Heidrun Hamersky, Gitta Hemmers, Jupp Hemmers, Saskia Herklotz, Prof. Dr. Kris Van Heuckelom, Dr. Christoph Hilgert, Tünde Kaip, Prof. Dr. Jerzy Jarzębski, Katharina Juraschek, Christian Kampkötter, Dr. Petar Kehayov, Felix Kimme, Prof. Dr. Michel Henri Kowalewicz, Dr. Kathrin Krogner-Kornalik, Jan Kühne, Dušan Ladjević, Dr. Agnes Matthias, Paul Maurer, Jacqueline Nießer Prof. Dr. Jochen Mecke, Prof. Dr. Christoph Meinel, Prof. Dr. Ezra Mendelsohn, Prof. Dr. Riccardo Nicolosi, Jiř́ Petrášek, Dr. des Judith Poppe, Benno H. Pöppelmann, Miriam Sardina, Lena Scheer, Prof. Dr. Martin Schulze Wessel, Oana Sorescu Iudean, Magdalena Stojer-Brudnicka, Dr. Karolina Szymaniak, Dr. Berenika Szymanski-Düll, Emanuel Tatu, Nadja Telebak, Patricia Vidović, Matthias Wagner, Prof. Dr. Yfaat Weiss, Dr. des. Nina Weller, Judith Werner, Prof. Dr. Józef Wróbel. Herzlichen Dank für die selbstlose, unverzichtbare und produktive Unterstützung, ohne die das Entstehen dieser Arbeit so nicht möglich gewesen wäre!

Ebenso herzlich danke ich Herrn Prof. Dr. Michel Henri Kowalewicz, dem Leiter des Forschungszentrums für Ideengeschichte an der Jagiellonen Universität Krakau, für die Anstellung als Mitarbeiterin, den wissenschaftlichen Austausch, das Vertrauen, die langjährige Begleitung, die Kritik und die Gutachten. Dank gilt der Jagiellonen Universität Krakau für die Aufnahme als Gastforscherin und hier Prof. Dr. Jarzębski für die Betreuung und Unter- 
stützung. Dieser Aufenthalt wurde möglich gemacht durch ein DAAD-Kurzzeitstipendium für Doktoranden sowie durch ein Stipendium der Republik Polen, vermittelt durch das Bayerische Hochschulzentrum für Mittel-, Ostund Südosteuropa (BAYHOST), denen ich jeweils danke.

Mein bester Dank gilt dem Franz Rosenzweig Minerva Research Center für deutsch-jüdische Literatur und Kulturgeschichte an der Hebräischen Universität Jerusalem sowie der Leiterin Prof. Dr. Yfaat Weiss, den Mitarbeitern und Fellows für den wissenschaftlichen Austausch, die Kritik und die finanzielle und ideelle Förderung. Dem Van Leer Institut Jerusalem danke ich für die Zurverfügungstellung eines ruhigen und anregenden Arbeitsplatzes.

Aufrichtig danke ich der Graduiertenschule für Ost- und Südosteuropastudien und ihren Sprechern Prof. Dr. Ulf Brunnbauer und Prof. Dr. Martin Schulze Wessel für die Aufnahme als assoziiertes Mitglied, den Arbeitsplatz, die Fortbildungen und Seminare, das Abschlussstipendium, den Druckkostenzuschuss sowie für die Aufnahme meines Buches in die Reihe »Schnittstellen« im Verlag Vandenhoeck \& Ruprecht. Darüber hinaus danke ich den Doktoranden, Postdoktoranden und Professoren in der Graduiertenschule für den produktiven Austausch, die anregende Atmosphäre und die Kritik.

Meinen herzlichen Dank möchte ich auch der Universität Regensburg für die Unterstützung, den Druckkostenzuschuss durch die Gleichstellungsbeauftragte, die Aufnahme in das Promotionskolleg der Philosophischen Fakultäten PUR und die Fortbildungen aussprechen.

Dem Warschauer Mickiewicz-Literaturmuseum (MLM), dem Jüdischen Historischen Institut Warschau (ŻIH) sowie der Jagiellonen Universitätsbibliothek (BJ) danke ich für die Zugänglichmachung ihrer Archivbestände. Für die Druckerlaubnis der Bilder danke ich dem Jüdischen Historischen Institut Warschau, der Jagiellonen Bibliothek, dem Nationalmuseum Krakau, der National Gallery of Art in Washington DC, dem Metropolitan Museum of Art in New York, der Staatlichen Kunstsammlung Dresden und der ETH Zürich. 


\section{Literatur}

Kalendarium życia i twórczości Brunona Schulza. In: Chmurzyński, Wojciech (Hg.): Bruno Schulz 1892-1942. Katalog-Pamiętnik Wystawy Bruno Schulz. Ad. Memoriam w Muzeum Literatury im. Adama Mickiewicza w Warszawie. Warszawa 1995, 38-45.

Die Bibel. Nach der Übersetzung Martin Luthers; mit Apokryphen; [Bibeltext in der revidierten Fassung von 1984]. Stuttgart 2004.

Anessi, Thomas: The Great Heresy of the Varsovian Center. In: De Bruyn, Dieter/Van Heuckelom, Kris (Hg.): (Un)masking Bruno Schulz. New combinations, further fragmentations, ultimate reintegrations. Amsterdam 2009, 387-408.

Arendt, Hannah: Walter Benjamin. In: Walter Benjamin, Bertolt Brecht. 2 Essays. München 1986.

Asendorf, Christoph: Erfahrungen außer Kraft setzen. Max Ernst, Walter Benjamin, Robert Musil. In: Orchard, Karin/Ernst, Max (Hg.): Die Erfindung der Natur. Max Ernst, Paul Klee, Wols und das surreale Universum; [Sprengel-Museum Hannover

27. Februar - 8. Mai 1994]. Freiburg im Breisgau 1994, 202-205.

Assmann, Jan: Altägyptische Bildpraxen und ihre impliziten Theorien. In: SachsHombach, Klaus (Hg.): Bildtheorien. Anthropologische und kulturelle Grundlagen des Visualistic Turn. Frankfurt a. M. 2009.

Augsburger, Janis: Ein anti-analytisches Bedürfnis: Bruno Schulz im Grenzbereich zwischen Poetik und Politik. In: Hein-Kircher, Heidi/Hahn, Hans H. (Hg.): Politische Mythen im 19. und 20. Jahrhundert in Mittel- und Osteuropa. Marburg 2006, 25-43.

-: Masochismen. Mythologisierung als Krisen-Ästhetik bei Bruno Schulz. Hannover 2008.

-: Poetical Fluidization and Intellectual Eclecticism in Bruno Schulz's Writings. In: De Bruyn, Dieter/Van Heuckelom, Kris (Hg.): (Un)masking Bruno Schulz. New combinations, further fragmentations, ultimate reintegrations. Amsterdam: Rodopi 2009, 499-517.

Austin, John L.: Zur Theorie der Sprechakte. Stuttgart 1972.

Barthes, Roland: Der Tod des Autors. In: Wirth, Uwe (Hg.): Performanz. Zwischen Sprachphilosophie und Kulturwissenschaften. Frankfurt a. M. 2002, 104-110.

-: Die helle Kammer. Bemerkungen zur Photographie. Frankfurt a. M. 2014.

Bartosik, Marta: Bruno Schulz jako krytyk. Kraków 2000.

Baskind, Samantha/Silver, Larry: Jewish Art. A Modern History. London 2011.

Bauch, Kurt: Imago. In: Boehm, Gottfried (Hg.): Was ist ein Bild? München 1994, 275-299.

Becks-Malorny, Ulrike: Wassily Kandisky. 1866-1944. Köln 2003.

Belting, Hans: Max Beckmann. Die Tradition als Problem in der Kunst der Moderne.

München 1984. 
-: Idolatrie heute. In: Belting, Hans (Hg.): Der zweite Blick. Bildgeschichte und Bildreflexion. München 2000, 273-280.

-: Bild-Anthropologie. Entwürfe für eine Bildwissenschaft. München 2001.

-: Das echte Bild. Bildfragen als Glaubensfragen. München 2005.

Benjamin, Walter: Anmerkungen zu Malerei und Photographie. In: Tiedemann, Rolf (Hg.): Gesammelte Schriften VII. Nachträge. Frankfurt a. M. 1991, 815-823.

-: Berliner Kindheit um Neunzehnhundert. In: Rexroth, Tillman (Hg.): Gesammelte Schriften IV. Kleine Prosa, Baudelaire-Übertragungen. Frankfurt a. M. 1991, 235-304.

-: Das Kunstwerk im Zeitalter seiner technischen Reproduzierbarkeit: (erste und dritte Fassung). In: Tiedemann, Rolf/Schweppenhäuser, Hermann (Hg.): Gesammelte Schriften I. Abhandlungen. Frankfurt a. M. 1991, 431-508.

-: Das Passagen-Werk. In: Tiedemann, Rolf (Hg.): Gesammelte Schriften V. Das Passagen-Werk. Frankfurt a. M. 1991.

-: Der Begriff der Kunstkritik in der deutschen Romantik. In: Tiedemann, Rolf/ Schweppenhäuser, Hermann (Hg.): Gesammelte Schriften I. Abhandlungen. Frankfurt a. M. 1991, 7-122.

-: Die Aufgabe des Übersetzers. In: Rexroth, Tillman (Hg.): Gesammelte Schriften IV. Kleine Prosa, Baudelaire-Übertragungen. Frankfurt a. M. 1991, 9-22.

-: Gisèle Freund, La photographie en France au dix-neuvième siècle. Essai de sociologie et d'estétique. In: Tiedemann-Bartels, Hella (Hg.): Gesammelte Schriften III. Kritiken und Rezensionen. Frankfurt a. M. 1991, 542-544.

-: Kleine Geschichte der Photographie. In: Tiedemann, Rolf/Schweppenhäuser, Hermann (Hg.): Gesammelte Schriften II. Aufsätze, Essays, Vorträge. Frankfurt a.M. 1991, 368-385.

-: Neues von Blumen. In: Tiedemann-Bartels, Hella (Hg.): Gesammelte Schriften III. Kritiken und Rezensionen. Frankfurt a. M.: Suhrkamp 1991, 151-153.

-: Paris, die Hauptstadt des XIX. Jahrhunderts. In: Tiedemann, Rolf (Hg.): Gesammelte Schriften V. Das Passagen-Werk. Frankfurt a. M. 1991, 45-59.

-: Pariser Brief II: Malerei und Photographie. In: Tiedemann-Bartels, Hella (Hg.): Gesammelte Schriften III. Kritiken und Rezensionen. Frankfurt a. M. 1991, 495-507.

-: Probleme der Sprachsoziologie. In: Tiedemann-Bartels, Hella (Hg.): Gesammelte Schriften III. Kritiken und Rezensionen. Frankfurt a. M. 1991, 452-480.

-: Über das mimetische Vermögen: (2). In: Tiedemann, Rolf/Schweppenhäuser, Hermann (Hg.): Gesammelte Schriften II. Aufsätze, Essays, Vorträge. Frankfurt a.M 1991, 210-213.

-: Über den Begriff der Geschichte. In: Tiedemann, Rolf/Schweppenhäuser, Hermann (Hg.): Gesammelte Schriften I. Abhandlungen. Frankfurt a. M. 1991, 690-704.

-: Über die Sprache überhaupt und über die Sprache des Menschen. In: Tiedemann, Rolf/Schweppenhäuser, Hermann (Hg.): Gesammelte Schriften II. Aufsätze, Essays, Vorträge. Frankfurt a. M., 140-157.

-: Über einige Motive bei Baudelaire. In: Tiedemann, Rolf/Schweppenhäuser, Hermann (Hg.): Gesammelte Schriften I. Abhandlungen. Frankfurt a. M. 1991, 605-654.

-: Ursprung des deutschen Trauerspiels. In: Tiedemann, Rolf/Schweppenhäuser, Hermann (Hg.): Gesammelte Schriften I. Abhandlungen. Frankfurt a. M. 1991, 203-430. 
-: Zentralpark. In: Tiedemann, Rolf/Schweppenhäuser, Hermann (Hg.): Gesammelte Schriften I. Abhandlungen. Frankfurt a. M. 1991, 655-690.

-: Zum verlorenen Abschluss der Notiz über die Symbolik in der Erkenntnis. In: Tiedemann, Rolf/Schweppenhäuser, Hermann (Hg.): Gesammelte Schriften VI. Fragmente vermischten Inhalts. Autobiographische Schriften. Frankfurt a.M. 1991, 38-39.

Beyme, Klaus v.: Das Zeitalter der Avantgarden. Kunst und Gesellschaft 1905-1955. München 2005.

Bland, Kalman P.: The artless Jew. Medieval and modern affirmations and denials of the visual. Princeton, NJ [u.a.] 2000.

Błoński, Jan: Świat jako księga i komentarz. In: Jarzębski, Jerzy (Hg.): Czytanie Schulza. Materiały Międzynarodowej Sesji Naukowej Bruno Schulz - w Stulecie Urodzin i w Pięćdziesięciolecie Śmierci, Kraków, 8-10 czerwca 1992. Kraków 1994, 68-84.

Blumenberg, Hans: Wirklichkeitsbegriff und Möglichkeit des Romans. In: Jauß, Hans R./Forschungsgruppe Poetik und Hermeneutik (Hg.): Nachahmung und Illusion. München 1964, 9-27.

-: Arbeit am Mythos. Frankfurt a. M. 2001.

Boehm, Gottfried: Die Wiederkehr der Bilder. In: Boehm, Gottfried (Hg.): Was ist ein Bild? München 1994.

-: Was ist ein Bild? München 1994.

-: Bildbeschreibung: Über die Grenzen von Bild und Sprache. In: Boehm, Gottfried/ Pfotenhauer, Helmut (Hg.): Beschreibungskunst - Kunstbeschreibung. Ekphrasis von der Antike bis zur Gegenwart. München: Fink 1995, 23-40.

-: Wie Bilder Sinn erzeugen. Die Macht des Zeigens. Darmstadt 2010.

- /Pfotenhauer, Helmut: Einleitung: Wege der Beschreibung. In: Boehm, Gottfried/ Pfotenhauer, Helmut (Hg.): Beschreibungskunst - Kunstbeschreibung. Ekphrasis von der Antike bis zur Gegenwart. München 1995, 9-19.

Bolecki, Włodzimierz: Poetycki model prozy w dwudziestoleciu międzywojennym. Wrocław [u.a.] 1982.

-: Das >principium individuationis $₫$ Nietzscheanische Motive im Werk von Bruno Schulz. In: Schultze, Brigitte/Göbler, Frank (Hg.): Polnische Literatur im europäischen Kontext. Festschrift für Brigitte Schultze zum 65. Geburtstag. München: O. Sagner 2005, 13-33.

-: Słownik schulzowski. Gdańsk 2006.

Bolz, Norbert: Einleitung: Links schreiben. In: Bolz, Norbert (Hg.): Walter Benjamin. Profane Erleuchtung und rettende Kritik. Würzburg 1985, 9-33.

Bossart, Rolf: Die theologische Lesbarkeit von Literaturen im 20. Jahrhundert. Studien zu einer verdrängten Hermeneutik. Würzburg 2009.

Breysach, Barbara: Kunstobjekt und Metapher: Das Buch in Bruno Schulz' Ästhetik der Grenzüberschreitung. In: Jaworski/Liska (Hg.): Am Rand. Grenzen und Peripherien in der europ. jüd. Literatur, 134-150.

Broos, Ben/Wheelock, Arthur K. (Hg.): Vermeer. Das Gesamtwerk. Stuttgart 1995. Brumlik, Micha: Schrift, Wort und Ikone. Wege aus dem Verbot der Bilder. Originalausg. Frankfurt a. M. 1994. 
Bundorf, Dieter/Fasbender, Christoph/Moennighoff, Burkhard (Hg.): Metzler Lexikon Literatur. Begriffe und Definitionen. Stuttgart, Weimar 2007.

Caneppele, Paolo: Die Republik der Träume. Bruno Schulz und seine Bilderwelt. Graz 2010.

Cassin, Barbara (Hg.): Dictionary of Untranslatables. A Philosophical Lexicon. Princeton, NJ [u.a.] 2014.

Cassirer, Ernst: Der Begriff der Symbolischen Form im Aufbau der Geisteswissenschaften. In: Saxl, Fritz (Hg.): Vorträge der Bibliothek Warburg. Repr. 1967. Leipzig, Berlin 1920/21, 11-39.

-: Wesen und Wirkung des Symbolbegriffs. Darmstadt 1956.

-: Das mythische Denken (Philosophie der symbolischen Formen; Teil 2). Darmstadt 1994.

Chmurzyński, Wojciech (Hg.): Bruno Schulz 1892-1942. Katalog-Pamiętnik Wystawy Bruno Schulz. Ad. Memoriam w Muzeum Literatury im. Adama Mickiewicza w Warszawie. Warszawa 1995.

Chwin, Stefan: Romantyczna przestrzeń wyobraźni. Bydgoszcz 1989.

-: Schulz a Leśmian. In: Jarzębski, Jerzy (Hg.): Czytanie Schulza. Materiały Międzynarodowej Sesji Naukowej Bruno Schulz - w Stulecie Urodzin i w Pięćdziesięciolecie Śmierci, Kraków, 8-10 czerwca 1992. Kraków: TIC 1994, 108-127.

Cohen, Hermann: Die Religion der Vernunft aus den Quellen des Judentums. 2. Aufl. Frankfurt a.M. 1929.

Czabanowska-Wróbel, Anna: Dziecko. Symbol i zagadnienie antropologiczne w literaturze Młodej Polski. Kraków 2003.

De Bruyn, Dieter: 'The Lie Always Rises to the Surface like Oil.، Toward a Metafictional Reading of Karol Irzykowski's Paluba and Bruno Schulz's Fiction. In: De Bruyn, Dieter/Van Heuckelom, Kris (Hg.): (Un)masking Bruno Schulz. New combinations, further fragmentations, ultimate reintegrations. Amsterdam 2009, 83-134.

De Bruyn, Dieter/Van Heuckelom, Kris (Hg.): (Un)masking Bruno Schulz. New combinations, further fragmentations, ultimate reintegrations. Amsterdam 2009.

Dedecius, Karl (Hg.): Die Dichter Polens. Hundert Autoren vom Mittelalter bis heute. Frankfurt a. M. 1996.

Dencker, Klaus P.: Optische Poesie. Von den prähistorischen Schriftzeichen bis zu den digitalen Experimenten der Gegenwart. Berlin 2011.

Dewitz, Bodo v. (Hg.): Kiosk. Eine Geschichte der Fotoreportage. 1839-1973. Göttingen 2001.

Długosz-Kurczabowa, Krystyna: Nowy słownik etymologiczny języka polskiego. Wyd. 1. Warszawa 2003.

Drews, Peter: Die slawische Avantgarde und der Westen. Programme der russischen, polnischen und tschechischen Avantgarde und ihr europäischer Kontext. München 1983.

Dulaimi, Karin: Der Mythosbegriff im Werk von Bruno Schulz. Dissertationsschrift vorgelegt in München 1976.

Dybel, Paweł: Seksualność zdegradowana, czyli perwersyjny świat prozy Schulza. In: Teksty drugie (2005), 204-218.

-: Bruno Schulz i psychoanaliza. In: Teksty drugie (2013), 241-256. 
Ebach, Jürgen: Der Blick des Engels: Für eine »Benjaminsche« Lektüre der hebräischen Bibel. In: Bolz, Norbert (Hg.): Walter Benjamin. Profane Erleuchtung und rettende Kritik. Würzburg 1985, 67-101.

Eichendorff, Joseph v.: Das Marmorbild. In: Werke. Ahnung und Gegenwart. Erzählungen. Frankfurt a. M. 1985, 383-428.

Eichner, Hans: Joseph von Eichendorff. In: Riemen, Alfred (Hg.): Ansichten zu Eichendorff. Beiträge der Forschung 1958-1988. Sigmaringen 1988, 296-332.

Einstein, Carl: Negerplastik. In: Harrison, Charles (Hg.): Kunsttheorie im 20. Jahrhundert. Künstlerschriften, Kunstkritik, Kunstphilosophie, Manifeste, Statements, Interviews. Ostfildern-Ruit 1998, 147-152.

Fabiani, Licia: Rosso Fiorentino: Malerei als Schrift. In: Sepp, Hans R./Trinks, Jürgen (Hg.): Phänomenalität des Kunstwerks. Wien 2006, 233-242.

Ficowski, Jerzy: Regiony wielkiej herezji. Kraków 1967.

-: Einführende Worte zum »Götzenbuch«. In: Ficowski, Jerzy (Hg.): Das Götzenbuch. (Xięga bałwochwalcza). Warszawa: Wydawnictwo Interpress 1988, 4-59.

- (Hg.): Gesammelte Werke. Die Wirklichkeit ist Schatten des Wortes. Aufsätze und Briefe (= Band 2). München 1992.

-: Regiony wielkiej herezji i okolice. Bruno Schulz i jego mitologia. Sejny 2002.

- (Hg.): Księga listów. Gdańsk 2008.

-: Wprowadzenie do Księgi listów. In: Ficowski, Jerzy (Hg.): Księga listów. Gdańsk 2008, 5-27.

- (Hg.): Księga obrazów. Gdańsk 2012.

Fieguth, Rolf: Bruno Schulz und seine heimliche Kritik an Kafka. In: Ritz, German/ Matuszek, Gabriela (Hg.): Recepcja literacka i proces literacki. Literarische Rezeption und literarischer Prozess. O polsko-niemieckich kontaktach literackich od modernizmu po okres międzywojenny. Kraków 1999, 243-270.

-: Eine Art Zusammenhangsheimweh: Notizen zu Intertextualität, Komposition und Sprachkonzeption bei Bruno Schulz. In: Grübel, Rainer/Schmid, Wolf/HansenLöve, Aage A. (Hg.): Wortkunst, Erzählkunst, Bildkunst. Festschrift für Aage A. Hansen-Löve. München: Otto Sagner 2008, 310-326.

Fluck, Andreas: `Absolute Ursprünglichkeit`: Emil Noldes Studienzeichnungen im Berliner Vökerkundemuseum. In: Brugger, Ingried, Prinz von Hohenzollern, Johann Georg/Reuther, Manfred (Hg.): Emil Nolde und die Südsee. München 2002, 27-34.

Freise, Matthias: Bruno Schulz zwischen Literatur und Bildender Kunst: Versuch einer Annäherung. In: Schwaetzer, Harald (Hg.): Aisthesis. Die Wahrnehmung des Menschen; Gottessinn Menschensinn Kunstsinn; ein interdisziplinäres Symposion. Regensburg 1999, 113-134.

Freund, Gisèle: Memoiren des Auges. Frankfurt a. M. 1977.

-: Photographie und Gesellschaft. Reinbeck 1979.

Fuchs, Eduard: Geschichte der erotischen Kunst. Das zeitgeschichtliche Problem (Band 1). München.

-: Die Frau in der Karikatur. München 1907.

-: Geschichte der erotischen Kunst. Das individuelle Problem (Band 2). München ca.1923. 
Fundacja Terytoria Książki (Hg.): Schulz forum. Gdańsk 2013.

Gelhard, Dorothee: Spuren des Sagens. Studien zur jüdischen Hermeneutik in der Literatur (= Begegnung, Band 1). Frankfurt a. M. 2004.

-: Zwischen Sagen und Zeigen - sakrale Repräsentationen. München (im Druck).

Gfrereis, Heike: Double bind: Anmerkungen zu Benjamins Schreibweise. In: Schöttker, Detlev (Hg.): Schrift, Bilder, Denken. Walter Benjamin und die Künste. Frankfurt a. M., Berlin 2004, 186-193.

Gieysztor, Aleksander: Mitologia Słowian (= Mitoligie świata). Wyd. 1. Warszawa 1982. Gombrowicz, Witold: Ferdydurke. Dzieła. Kraków u. a. 1986.

Gondowicz, Jan: Schulz. Warszawa 2006.

-: Magiczna bogini ciała. In: Kitowska-Łysiak, Małgorzata (Hg.): Białe plamy w SCHULZologii. Lublin: Wydawn. KUL 2010, 184-212.

Greif, Stefan: Die Malerei kann ein sehr beredtes Schweigen haben. Beschreibungskunst und Bildästhetik der Dichter. München 1998.

Gruber, Ruth E.: Odrodzenie kultury żydowskiej w Europie. Sejny 2004.

Gutmann, Joseph: The ssecond commandment and the image in Judaism. In: Hebrew Union College Annual 32 (1961), 161-174.

Habermas, Jürgen: Bewußtmachende oder rettende Kritik - die Aktualität Walter Benjamins. In: Unseld, Siegfried (Hg.): Zur Aktualität Walter Benjamins. Aus Anlaß des 80. Geburtstags von Walter Benjamin. Frankfurt a. M. 1972.

Hadermann, Paul: Synästhesie: Stand der Forschung und Begriffsbestimmung. In: Weisstein, Ulrich (Hg.): Literatur und bildende Kunst. Ein Handbuch zur Theorie und Praxis eines komparatistischen Grenzgebietes. Berlin 1992, 55-72.

Halawa, Mark: Angst vor der Sprache: Zur Kritik der sprachkritischen Ikonologie. In: IMAGE (2014), 3-32.

Hallacker, Anja: Es spricht der Mensch. Walter Benjamins Suche nach der lingua adamica. München 2004.

Haller, Rudolf: Neopositivismus. Eine historische Einführung in die Philosophie des Wiener Kreises. Darmstadt 1993.

Haselberg, Peter v.: Benjamins Engel. In: Bulthaup, Peter (Hg.): Materialien zu Benjamins Thesen ,Über den Begriff der Geschichter. Beiträge und Interpretationen. Frankfurt a. M. 1975, 337-356.

Hayek, Friedrich A. von: Mißbrauch und Verfall der Vernunft. Ein Fragment. Frankfurt 1959.

Hermand, Jost: Literaturwissenschaft und Kunstwissenschaft. Methodische Wechselbeziehungen seit 1900. 2. Aufl. Stuttgart 1971.

Hofstätter, Hans H.: Malerei und Graphik der Gegenwart. Baden Baden 1969.

Horkheimer, Max/Adorno, Theodor: Dialektik der Aufklärung. Philosophische Fragmente. 19. Aufl. Frankfurt a. M. 2010.

Jarzębski, Jerzy (Hg.): Proza. Kraków 1973.

-: Brunona Schulza Malowanie Słowem. In: Kitowska-Łysiak, Małgorzata (Hg.): Bruno Schulz in memoriam. Lublin 1992, 43-58.

-: Czytanie Schulza. Materiały Międzynarodowej Sesji Naukowej Bruno Schulz w Stulecie Urodzin i w Pięćdziesięciolecie Śmierci, Kraków, 8-10 czerwca 1992. Kraków 1994. 
-: Prowincja centrum. Przypisy do Schulza. Kraków 2005.

-: Schulz: Universality and the Poetics of the Fragment. In: Latek, Stanisław (Hg.): Bruno Schulz. New readings, new meanings [proceedings of the International Conference, Montréal, Québec, Canada, May 4-5, 2007]. Montréal: Polish Inst. of Arts and Sciences in Canada [u. a.] 2009, 39-54.

Jonas, Hans: Die Freiheit des Bildens: Homo pictor und die differentia des Menschen. In: Zwischen Nichts und Ewigkeit. Drei Aufsätze zur Lehre vom Menschen. Göttingen 1963, 26-43.

Juraschek, Anna: Wohin weist die Wade?: Eine Untersuchung der Bedeutung des Bereichs Knie abwärts im Werk von Bruno Schulz oder die Welt von der Wade aus betrachtet. In: Howanitz, Gernot/Kampkötter, Christian/Kirschbaum, Heinrich (Hg.): Slavische Identitäten. Paradigmen, Poetiken, Perspektiven. München 2014, 169-179.

Jurt, Joseph: Frühgeschichte der Intermedialität: Flaubert. In: Degner, Uta/Wolf, Norbert C. (Hg.): Der neue Wettstreit der Künste. Legitimation und Dominanz im Zeichen der Intermedialität. Bielefeld 2010, 19-40.

Kandinsky, Wassily: Über das Geistige in der Kunst. 7. Aufl. Bern 1963.

Karner, Regina/Lindinger, Michaela: Mode und Kosmetik auf dem Weg ins 20. Jahrhundert: Zur Entstehung der modernen Konsumgesellschaft. In: Karner, Regina/ Lindinger, Michaela (Hg.): Großer Auftritt. Mode der Ringstraßenzeit. Ausstellung Wien Museum Karlsplatz 10. Juni bis 1. November 2009. Wien Museum. Wien 2009, 35-51.

Kato, Ariko: The Early Graphic Works of Bruno Schulz and Sacher-Masoch's Venus in Furs. In: De Bruyn, Dieter/Van Heuckelom, Kris (Hg.): (Un)masking Bruno Schulz. New combinations, further fragmentations, ultimate reintegrations. Amsterdam 2009, 219-249.

-: Obraz i Księga: O autoreferencyjności w twórczości Brunona Schulza. In: Kitowska-Łysiak, Małgorzata (Hg.): Białe plamy w SCHULZologii. Lublin: Wydawn. KUL 2010, 151-182.

Kaufmann, Susanne: Die Mappe als Kunstform der Moderne: Überlegungen zu einem unterschätzen graphischen Ausdrucksmedium des 20. Jahrhunderts. In: Kaufmann, Susanne/Höpner, Corinna (Hg.): Kandinsky, Klee, Schiele... Graphikmappen des frühen 20. Jahrhunderts. Stuttgart 2014, 9-22.

Kaulen, Heinrich: Rettung und Destruktion. Untersuchungen zur Hermeneutik Walter Benjamins. Tübingen 1987.

Kayser, Wolfgang: Versuch einer Wesensbestimmung des Grotesken. In: Weisstein, Ulrich (Hg.): Literatur und bildende Kunst. Ein Handbuch zur Theorie und Praxis eines komparatistischen Grenzgebietes. Berlin 1992, 173-179.

Kemp, Wolfgang: Kunstwerk und Betrachter: Der rezeptionsästhetische Ansatz. In: Belting, Hans/Kemp, Wolfgang/Dilly, Heinrich u.a. (Hg.): Kunstgeschichte. Eine Einführung. Berlin 1986, 203-221.

Kimmich, Dorothee: `Nur was uns anschaut sehen wirı: Benjamin und die Welt der Dinge. In: Schöttker, Detlev (Hg.): Schrift, Bilder, Denken. Walter Benjamin und die Künste. Frankfurt a. M., Berlin 2004, 156-167.

Kitowska-Łysiak, Małgorzata: Bruno Schulz - ১Xięga Bałwochwalcza`: wizja - forma - 
analogie. In: Kitowska-Łysiak, Małgorzata (Hg.): Bruno Schulz in memoriam. Lublin 1992, 133-151.

-: Bruno Schulz in memoriam. Lublin 1992.

-: Bezlik nieskończonych historyj: O reinterpretacji mitologicznych pierwowzorów na kartach Xięgi Bałwochwalczej. In: Dunin, Teresa/Kosienkowska, Halina (Hg.): Mityzacja rzeczywistości. Bruno Schulz 1892-1942; wystawa ze zbiorów Muzeum Literatury im. Adama Mickiewicza w Warszawie; Muzeum Lubelskie w Lublinie listopad - grudzień 2002. Lublin: Wydawnictwo Uniw. Marii Curie-Skłodowskiej 2002, 9-22.

-: Schulzowskie marginalia. Lublin 2007.

-: Białe plamy w SCHULZologii. Lublin 2010.

-: Uwagi w sprawie kanonu: Brunona Schulza szkicownik młodzieńczy i freski w willi Landaua. In: Fundacja Terytoria Książki (Hg.): Schulz forum. Gdańsk 2013, 63-78.

- /Panas, Władysław (Hg.): W ułamkach zwierciadła. Bruno Schulz w 110 rocznicę urodzin i 60 rocznicę śmierci. Lublin 2003.

Klauser, Theodor (Hg.): Reallexikon für Antike und Christentum. Sachwörterbuch zur Auseinandersetzung des Christentums mit der antiken Welt (Band II: BauerChristus). Stuttgart 1954.

-: /Dassmann, Ernst/Kremer, Christian J. (Hg.): Reallexikon für Antike und Christentum. Sachwörterbuch zur Auseinandersetzung des Christentums mit der antiken Welt (Band XI: Girlande-Gottesnamen). Stuttgart 1981.

Koppen, Erwin: Über einige Beziehungen zwischen Photographie und Literatur. In: Weisstein, Ulrich (Hg.): Literatur und bildende Kunst. Ein Handbuch zur Theorie und Praxis eines komparatistischen Grenzgebietes. Berlin 1992, 231-245.

Koschorke, Albrecht: Leopold von Sacher-Masoch. Die Inszenierung einer Perversion. Orig.-Ausg. München [u.a.] 1988.

Kowalewicz, Michel H.: Weltbilder, Weltanschauung und Mind: Freuds Via regia versus Ars interpretandi oder Voyage au bout de la nuit. In: Lang, Hermann/ Dybel, Paweł/Pagel, Gerda (Hg.): Hermeneutik und Psychoanalyse. Perspektiven und Kontroversen. Würzburg (im Druck), 33-72.

-: Übersetzungsprobleme des Begriffs >Weltanschauung`. In: Archiv für Begriffsgeschichte (2013), 237-250.

-: Weltanschauung und Psychoanalyse: Zu den nicht nur sprachlichen Verwirrungen solch einer sintellektuellen Konstruktion in der analytischen Praxis. In: Lang, Herrmann/Dybel, Paweł/Pagel, Gerda (Hg.): Grenzen der Interpretation in Hermeneutik und Psychoanalyse. Würzburg: Könighausen \& Neumann 2014, 113-135.

Krafft-Ebing, Richard: Psychopathia Sexualis. Mit besonderer Berücksichtigung der conträren Sexualempfindung. 12. Aufl. Stuttgart 1903.

Kraus, Karl: Die Welt der Plakate. In: Die chinesische Mauer. Schriften. Frankfurt a. M. 1987, 256-261.

Krieger, Murray: Das Problem der Ekphrasis: Wort und Bild, Raum und Zeit - und das literarische Werk. In: Boehm, Gottfried/Pfotenhauer, Helmut (Hg.): Beschreibungskunst - Kunstbeschreibung. Ekphrasis von der Antike bis zur Gegenwart. München 1995, 41-57. 
Krings, Hermann/Baumgartner, Hans M./Wild, Christoph (Hg.): Handbuch philosophischer Grundbegriffe. München 1973.

Kulig-Janarek, Krystyna: Erotyka - groteska - ironia - kreacja. In: Kitowska-Łysiak, Małgorzata (Hg.): Bruno Schulz in memoriam. Lublin 1992, 153-177.

Kultermann, Udo: Kleine Geschichte der Kunsttheorie. Von der Vorgeschichte bis zur Gegenwart. 2. Aufl. Darmstadt 1988.

La Fouqué Motte, Friedrich de: Undine. Lwów 1913.

Lachmann, Renate: Dezentrierte Bilder: Die ekstatische Imagination in Bruno Schulz' Prosa. In: Hansen-Löve, Aage A. (Hg.): Psychopoetik. Beiträge zur Tagung "Psychologie und Literatur« München 1991. Wien 1992, 339-461.

-: Erzählte Phantastik. Zu Phantasiegeschichte und Semantik phantastischer Texte. Frankfurt a. M. 2002.

Langer, Dietger: Polnische Literaturgeschichte. Ein Abriss. München 2010.

Langer, Gerhard: Helios, Orpheus und Aphrodite: Von Bildern und Verboten im antiken Judentum. In: Dohmen, Christoph/Wagner, Christoph (Hg.): Religion als Bild - Bild als Religion. Regensburg 2012, 11-30.

Latek, Stanisław (Hg.): Bruno Schulz. New readings, new meanings [proceedings of the International Conference, Montréal, Québec, Canada, May 4-5, 2007]. Montréal 2009.

Lindenbaum, Shalom: Wizja mesjanistyczna Schulza i jej podłoże mistyczne. In: Jarzębski, Jerzy (Hg.): Czytanie Schulza. Materiały Międzynarodowej Sesji Naukowej Bruno Schulz - w Stulecie Urodzin i w Pięćdziesięciolecie Śmierci, Kraków, 8-10 czerwca 1992. Kraków 1994, 33-67.

-: Sanatorium pod Klepsydrą - Hades czy Sanatorium. In: Kitowska-Łysiak, Małgorzata/Panas, Władysław (Hg.): W ułamkach zwierciadła. Bruno Schulz w 110 rocznicę urodzin i 60 rocznicę śmierci. Lublin: Towarzystwo Naukowe Katolickiego Uniwersytetu Lubelskiego 2003, 47-74.

-: Bruno Schulz w Berlinie. In: Kitowska-Łysiak, Małgorzata (Hg.): Białe plamy w SCHULZologii. Lublin: Wydawn. KUL 2010, 11-18.

Lindner, Burkhardt: Das Kunstwerk im Zeitalter seiner technischen Reproduzierbarkeit. In: Lindner, Burkhardt (Hg.): Benjamin-Handbuch. Leben - Werk - Wirkung. Stuttgart, Weimar 2011.

Link-Heer, Ursula: Zum Bilde Prousts. In: Lindner, Burkhardt (Hg.): Benjamin-Handbuch. Leben - Werk - Wirkung. Stuttgart, Weimar 2011, 507-521.

Lipowski, Krzysztof: Demiurg jest dwoistością. Alfred Kubin i Bruno Schulz - próba porównania. In: Fundacja Terytoria Książki (Hg.): Schulz forum. Gdańsk 2013, 35-49. Lipszyc, Adam: Rewizja procesu Józefiny K. i inne lektury od zera. Warszawa 2011.

Loers, Veit: Vom Wesen der Kunst oder von der Kunst als Wesen. Ein Jahrhundert Kandinsky »Über das Geistige in der Kunst«. artnet.de 2011, URL: http://www. artnet.de/magazine/ein-jahrhundert-kandinsky-uber-das-geistige-in-der-kunst/ vom 16.09.2012.

Lokotsch, Karl: Etymologisches Wörterbuch der europäischen (germanischen, romanischen und slavischen) Wörter orientalischen Ursprungs. Heidelberg 1927.

Löwy, Michael: Erlösung und Utopie. Jüdischer Messianismus und libertäres Denken. Unveränd. Nachdr. Berlin 2002. 
Lukas, Katarzyna: Mythos, Archetyp und Translation: Die Prosa von Bruno Schulz im Kontext der Ideen von Thomas Mann und Carl Gustav Jung. In: Convivium (2010), 213-234.

Makropoulos, Michael: Modernität als ontologischer Ausnahmezustand? Walter Benjamins Theorie der Moderne. München 1989.

-: Wirklichkeiten zwischen Literatur, Malerei und Sozialforschung. In: Graevenitz, Gerhard v. (Hg.): Konzepte der Moderne. Stuttgart: Metzler 1999, 69-81.

Mann, Thomas: Joseph und seine Brüder. 2. Aufl. Frankfurt a. M. 2008.

Marchesani, Pietro: Bruno Schulz il profeta sommerso. Milano 2000.

Markowski, Michał P.: Text and Theater. The Ironic Imagination of Bruno Schulz. In:

De Bruyn, Dieter/Van Heuckelom, Kris (Hg.): (Un)masking Bruno Schulz. New combinations, further fragmentations, ultimate reintegrations. Amsterdam 2009, 435-450.

-: Schulz - pisarz jako filozof. In: Fundacja Terytoria Książki (Hg.): Schulz forum. Gdańsk 2013, 7-14.

Marx, Karl: Das Kapital. Kritik der politischen Ökonomie (Band 1). Frankfurt a. M. 1968. Matthias, Agnes: Eine besondere graphische Technik: Zur Rezeptionsgeschichte des Cliché-verre. In: Matthias, Agnes/Mason, Rainer M. (Hg.): Zeichnungen des Lichts. Kupferstich-Kabinett. München 2007, 7-22.

-: /Mason, Rainer M. (Hg.): Zeichnungen des Lichts. München 2007.

Mendelsohn, Ezra: Painting a people. Maurycy Gottlieb and Jewish art. Waltham, Mass 2002.

Menninghaus, Winfried: Walter Benjamins Theorie der Sprachmagie. 1. Aufl. Frankfurt a. M. 1980.

Mitchell, William: Iconology. Image, text, ideology. Chicago 1986.

-: Picture Theory. Essays on Verbal and Visual Representation. Chicago 1995.

-: Bildtheorie. Frankfurt a. M. 2008.

Mosès, Stéphane: Eingedenken und Jetztzeit: Geschichtliches Bewußtsein im Spätwerk Walter Benjamins. In: Haverkamp, Anselm/Lachmann, Renate/Herzog, Reinhart (Hg.): Memoria. Vergessen und Erinnern. München 1993, 385-405.

-: Benjamins Judentum. In: Weidner, Daniel (Hg.): Profanes Leben. Walter Benjamins Dialektik der Säkularisierung. Berlin 2010, 141-151.

Nöth, Winfried: Werbung und die Künste: Parasitäre, symbiotische und paragonale Intermedialität. In: Degner, Uta/Wolf, Norbert C. (Hg.): Der neue Wettstreit der Künste. Legitimation und Dominanz im Zeichen der Intermedialität. Bielefeld 2010, 145-166.

Nünning, Ansgar (Hg.): Metzler Lexikon Literatur- und Kulturtheorie. Ansätze, Personen, Grundbegriffe. Stuttgart 2008.

Offenthaler, Eva: Ich, Anna Csillag - ein k. k. Marketingstar. Institut Österreichisches Biographisches Lexikon 2012, URL: http://www.oeaw.ac.at/oebl/Bio_d_M/bio_ 2012_04.htm vom 1.11.2014.

Osterkamp, Ernst: Däubler oder die Farbe - Einstein oder die Form: Bildbeschreibung zwischen Expressionismus und Kubismus. In: Boehm, Gottfried/Pfotenhauer, Helmut (Hg.): Beschreibungskunst - Kunstbeschreibung. Ekphrasis von der Antike bis zur Gegenwart. München 1995, 543-568. 
Ovidius Naso, Publius: Metamorphosen. 5. Aufl. Düsseldorf [u. a.] 2009.

Panas, Władysław: Księga blasku. Traktat o kabale w prozie Brunona Schulza. Lublin 1997.

Panofsky, Erwin: Problems in Titian. Mostly iconographic. New York, NY 1969.

-: Zum Problem der Beschreibung und Inhaltsdeutung von Werken der bildenden Kunst. In: Kaemmerling, Ekkehard (Hg.): Ikonographie und Ikonologie. Theorien, Entwicklung, Probleme 1979, 185-206.

-: Idea. Ein Beitrag zur Begriffsgeschichte der älteren Kunsttheorie. Berlin 1985.

Pestalozzi, Karl: Das Bildgedicht. In: Boehm, Gottfried/Pfotenhauer, Helmut (Hg.): Beschreibungskunst - Kunstbeschreibung. Ekphrasis von der Antike bis zur Gegenwart. München 1995, 569-591.

Pfisterer, Ulrich (Hg.): Lexikon Kunstwissenschaft. Ideen, Methoden, Begriffe. Stuttgart 2003.

Pinthus, Kurt (Hg.): Menschheitsdämmerung. Ein Dokument des Expressionismus. Hamburg 1991.

Prater, Andreas: Im Spiegel der Venus. Velázquez und die Kunst einen Akt zu malen. München 2002.

Probst, Jörg/Klenner, Jost P. (Hg.): Ideengeschichte der Bildwissenschaft. Siebzehn Porträts. Frankfurt a. M. 2009.

-: Vorwort. In: Probst, Jörg/Klenner, Jost P. (Hg.): Ideengeschichte der Bildwissenschaft. Siebzehn Porträts. Frankfurt a. M. 2009, 7-9.

Prokop-Janiec, Eugenia: Schulz und der galizische Schmelztiegel der Kulturen. In: Gelhard, Dorothee (Hg.): In und mit der Fremde. Über Identität und Diaspora im Ostjudentum. Frankfurt a. M. 2005, 87-100.

Raulet, Gérard: Chockerlebnis, mémoire involontaire und Allegorie: Zu Benjamins Revision seiner Massenästhetik in Über einige Motive bei Baudelaire. In: Zeitschrift für kritische Theorie (1996), 5-28.

Ritter, Joachim/Gründer, Karlfried (Hg.): Historisches Wörterbuch der Philosophie. Darmstadt 1989.

Ritter Santini, Lea (Hg.): Mit den Augen geschrieben. Von gedichteten und erzählten Bildern. München 1991.

Robertson, Theodosia: Bruno Schulz's Intimate Communication: From the True Viewer` of Xięga bałwochwacza to the `True Reader` of `Księga`. In: De Bruyn, Dieter/Van Heuckelom, Kris (Hg.): (Un)masking Bruno Schulz. New combinations, further fragmentations, ultimate reintegrations. Amsterdam 2009, 441-462.

Röthlisberger, Marcel/Cecchi, Doretta (Hg.): L’opera completta di Claude Lorrain. Milano 1975.

Sacher-Masoch, Leopold von: Venus im Pelz. 3. Aufl. Dresden 1904.

-: Venus im Pelz. Frankfurt a. M. 1957.

Sachs-Hombach, Klaus (Hg.): Bildwissenschaft. Disziplinen, Themen, Methoden. Frankfurt a. M. 2005.

-: Einleitung. In: Sachs-Hombach, Klaus (Hg.): Bildtheorien. Anthropologische und kulturelle Grundlagen des Visualistic Turn. Frankfurt a. M. 2009, 7-14.

Sandauer, Artur: Rzeczywistość degradowana: (Rzecz o Brunonie Schulzu). In: Jarzębski, Jerzy (Hg.): Proza. Kraków 1973, 6-35. 
Sauter, Michiel: Marmorbilder und Masochismus: Die Venusfiguren in Eichendorffs ,Das Marmorbild` und in Sacher-Masochs ,Venus im Pelz«. In: Neophilologus 75 (1991), 119-127.

Schlüpmann, Heide: Nietzsches ästhetische Opposition. Stuttgart 1977.

Schmid, Herta: Sprachursprungstheorien bei Bolesław Leśmian und Bruno Schulz.

In: Grözinger, Karl E. (Hg.): Sprache und Identität im Judentum. Wiesbaden 1998, 43-57.

Schmid, Ulrich: Die Realisierung der modernen Metaerzählungen bei Bruno Schulz (Kant, Kafka, Freud). In: Hodel, Robert (Hg.): Zentrum und Peripherie in den slavischen und baltischen Sprachen und Literaturen. Bern 2004, 119-134.

Schnackenburg, Rudolf: Das Johannesevangelium. T. 1 Einleitung u. Kommentar zu Kapitel 1-4 (= Herders theologischer Kommentar zum Neuen Testament / hrsg. von Joachim Gnilka u. Lorenz Oberlinner, Band 4,1). 1. Aufl., Sonderausg. Freiburg im Breisgau 2001.

Schneider, Pablo: Begriffliches Denken - verkörpertes Sehen: Edgar Wind (1900-1971). In: Probst, Jörg/Klenner, Jost P. (Hg.): Ideengeschichte der Bildwissenschaft. Siebzehn Porträts. Frankfurt a. M. 2009, 53-74.

Scholem, Gershom: Zur Entwicklungsgeschichte der kabbalistischen Konzeption der Schechinah. In: Fröbe-Kapteyn, Olga (Hg.): Mensch und Energie. Zürich 1952, 45-107.

-: Walter Benjamin und sein Engel. In: Unseld, Siegfried (Hg.): Zur Aktualität Walter Benjamins. Aus Anlaß des 80. Geburtstags von Walter Benjamin. Frankfurt a.M. 1972, 87-138.

-: Die jüdische Mystik in ihren Hauptströmungen. Frankfurt a. M. 1993.

-: Tagebücher; nebst Aufsätzen und Entwürfen bis 1923. Frankfurt a. M. 1995.

Schönle, Andreas: Sklepy Cynamonowe Brunona Schulza: apologia tandety. In: Kitowska-Łysiak, Małgorzata (Hg.): Bruno Schulz in memoriam. Lublin 1992, 59-77.

Schopenhauer, Arthur: Metaphysik des Schönen. 2. Aufl. München 1988.

Schöttker, Detlev: Einführung: Benjamins Bilderwelten. Objekte, Theorien, Wirkungen. In: Schöttker, Detlev (Hg.): Schrift, Bilder, Denken. Walter Benjamin und die Künste. Frankfurt a. M., Berlin 2004, 10-31.

Schulte, Jörg: Eine Poetik der Offenbarung. Isaak Babel Bruno Schulz Danilo Kiš (= Jüdische Kultur, Band 12). Wiesbaden 2004.

Schulz, Bruno: Die Mythisierung der Wirklichkeit. In: Die Zimtläden, 149-152.

-: Jesień. In: Jarzębski, Jerzy (Hg.): Proza. Kraków: Wydawnictwo Literackie 1973, 298-302.

-: Kometa. In: Jarzębski, Jerzy (Hg.): Proza. Kraków: Wydawnictwo Literackie 1973, 310-325.

-: Sanatorium pod Klepsydrą. In: Jarzębski, Jerzy (Hg.): Proza. Kraków: Wydawnictwo Literackie 1973.

-: Sklepy cynamonowe. In: Jarzębski, Jerzy (Hg.): Proza. Kraków: Wydawnictwo Literackie 1973, 82-91.

-: Brief an Anna Płockier vom 6.11.1941. (Aus dem Poln. v. Mikolaj Dutsch). In: Ficowski, Jerzy (Hg.): Gesammelte Werke. Die Wirklichkeit ist Schatten des Wor- 
tes. Aufsätze und Briefe. (Aus dem Poln. von Mikolaj Dutsch und Josef Hahn). München: Hanser 1992, 192-194.

-: Brief an das Kuratorium des Lemberger Schulsprengels vom 20.3.1935. (Aus dem Poln. von Mikolaj Dutsch). In: Ficowski, Jerzy (Hg.): Gesammelte Werke. Die Wirklichkeit ist Schatten des Wortes. Aufsätze und Briefe. (Aus dem Poln. von Mikolaj Dutsch und Josef Hahn). München: Hanser 1992, 15-16.

-: Brief an Georges Rosenberg vom 28.8.1938. (Aus dem Poln. v. Mikolaj Dutsch). In: Ficowski, Jerzy (Hg.): Gesammelte Werke. Die Wirklichkeit ist Schatten des Wortes. Aufsätze und Briefe. (Aus dem Poln. von Mikolaj Dutsch und Josef Hahn). München: Hanser 1992, 115-116.

-: Bruno Schulz an St. I. Witkiewicz. (Aus dem Poln. v. Mikolaj Dutsch u. Josef Hahn). In: Ficowski, Jerzy (Hg.): Gesammelte Werke. Die Wirklichkeit ist Schatten des Wortes. Aufsätze und Briefe. (Aus dem Poln. von Mikolaj Dutsch und Josef Hahn). München: Hanser 1992, 89-93.

-: Exposé über das Buch `Zimtläden`von Bruno Schulz. In: Ficowski, Jerzy (Hg.): Gesammelte Werke. Die Wirklichkeit ist Schatten des Wortes. Aufsätze und Briefe. (Aus dem Poln. von Mikolaj Dutsch und Josef Hahn). München: Hanser 1992, 325-327.

-: Ferdydurke. (Aus dem Poln. v. Mikolaj Dutsch). In: Ficowski, Jerzy (Hg.): Gesammelte Werke. Die Wirklichkeit ist Schatten des Wortes. Aufsätze und Briefe. (Aus dem Poln. von Mikolaj Dutsch und Josef Hahn). München: Hanser 1992, 280-288.

-: In den Werkstätten polnischer Schriftsteller und Gelehrter: Wiadomości Literackie, Nr. 17, 809/ 16.04.1939. (aus dem Polnischen von Mikolaj Dutsch). In: Ficowski, Jerzy (Hg.): Gesammelte Werke. Die Wirklichkeit ist Schatten des Wortes. Aufsätze und Briefe. (Aus dem Poln. von Mikolaj Dutsch und Josef Hahn). München: Hanser 1992, 328-329.

-: Legenden entstehen. (aus dem Poln. Josef Hahn). In: Ficowski, Jerzy (Hg.): Gesammelte Werke. Die Wirklichkeit ist Schatten des Wortes. Aufsätze und Briefe. (Aus dem Poln. von Mikolaj Dutsch und Josef Hahn). München: Hanser 1992, 227-230.

-: Samotność (O sobie). In: Chmurzyński, Wojciech (Hg.): Bruno Schulz 1892-1942. Katalog-Pamiętnik Wystawy Bruno Schulz. Ad. Memoriam w Muzeum Literatury im. Adama Mickiewicza w Warszawie. Warszawa 1995, 168.

-: Aneksja podświadomości: (Uwagi o Cudzoziemce Kuncewiczowej). In: KitowskaŁysiak, Małgorzata (Hg.): Szkice krytyczne. Lublin: Wydawn. Uniw. Marii CurieSkłodowskiej 2000, 34-41.

-: Bruno Schulz do St. I. Witkiewicza. In: Kitowska-Łysiak, Małgorzata (Hg.): Szkice krytyczne. Lublin: Wydawn. Uniw. Marii Curie-Skłodowskiej 2000, 18-21.

-: Do Witolda Gombrowicza. In: Kitowska-Łysiak, Małgorzata (Hg.): Szkice krytyczne. Lublin: Wydawn. Uniw. Marii Curie-Skłodowskiej 2000, 13-17.

-: Ferdydurke. In: Kitowska-Łysiak, Małgorzata (Hg.): Szkice krytyczne. Lublin: Wydawn. Uniw. Marii Curie-Skłodowskiej 2000, 94-100.

-: Książka o miłości. In: Kitowska-Łysiak, Małgorzata (Hg.): Szkice krytyczne. Lublin: Wydawn. Uniw. Marii Curie-Skłodowskiej 2000, 90-93.

-: Mityzacja rzeczywistości. In: Kitowska-Łysiak, Małgorzata (Hg.): Szkice krytyczne. Lublin: Wydawn. Uniw. Marii Curie-Skłodowskiej 2000, 11-12. 
-: Posłowie do polskiego przekładu Procesu Franza Kafki. In: Kitowska-Łysiak, Małgorzata (Hg.): Szkice krytyczne. Lublin: Wydawn. Uniw. Marii Curie-Skłodowskiej 2000, 22-25.

-: Powstają legendy. In: Kitowska-Łysiak, Małgorzata (Hg.): Szkice krytyczne. Lublin: Wydawn. Uniw. Marii Curie-Skłodowskiej 2000, 113-116.

-: Towarzysze snów. In: Kitowska-Łysiak, Małgorzata (Hg.): Szkice krytyczne. Lublin: Wydawn. Uniw. Marii Curie-Skłodowskiej 2000, 80-81.

-: [U korzeni tego nowego tomu prozy Schulza]. In: Kitowska-Łysiak, Małgorzata (Hg.): Szkice krytyczne. Lublin: Wydawn. Uniw. Marii Curie-Skłodowskiej 2000, 8.

-: W pracowniach pisarzy i uczonych polskich. In: Kitowska-Łysiak, Małgorzata (Hg.): Szkice krytyczne. Lublin: Wydawn. Uniw. Marii Curie-Skłodowskiej 2000, 9-10.

-: Wędrówki sceptyka. In: Kitowska-Łysiak, Małgorzata (Hg.): Szkice krytyczne. Lublin: Wydawn. Uniw. Marii Curie-Skłodowskiej 2000, 47-48.

-: Die Zimtläden. München 2009.

-: Das Sanatorium zur Sanduhr. München 2011.

Schvey, Henry I.: Doppelbegabte Künstler als Seher: O. Kokoschka, D.H. Lawrence und W. Blake. In: Weisstein, Ulrich (Hg.): Literatur und bildende Kunst. Ein Handbuch zur Theorie und Praxis eines komparatistischen Grenzgebietes. Berlin 1992, 73-85.

Sikorski, Dariusz K.: Symboliczny świat Brunona Schulza. Słupsk 2004.

-: »Humorysta przechadza się pośród nieskończoności« - Bruno Schulz wobec tworczości Tomasza Manna. In: Ruch Literacki 2006 (2006), 351-366.

Silberner, Regina: Strzępy wspomień. Przyczynek do biografii zewnętrznej Brunona Schulza. London 1984.

Šklovskij, Viktor: Theorie der Prosa. Frankfurt a. M. 1966.

Sontag, Susan: Über Fotografie. 20. Aufl. Frankfurt a. M. 2011.

Speina, Jerzy: Bankructwo realności. Proza Brunona Schulza. Warszawa, Poznań 1974. Sproede, Alfred: Between Avantgarde and Hassidic Redemption. In: De Bruyn, Dieter/Van Heuckelom, Kris (Hg.): (Un)masking Bruno Schulz. New combinations, further fragmentations, ultimate reintegrations. Amsterdam 2009, 473-498.

Stackelberg, Sophie v.: Illustrierte Magazine als Zeitschriftentyp und historische Quelle: Der »Uhu« als Beispiel. In: Kerbs, Diethart (Hg.): Fotografie und Bildpublizistik in der Weimarer Republik. Bönen 2004, 133-149.

Steiner, Uwe: Über Sprache überhaupt und über die Sprache des Menschen. In: Lindner, Burkhardt (Hg.): Benjamin-Handbuch. Leben - Werk - Wirkung. Stuttgart, Weimar 2011.

Stemmer, Peter: Sprachanalytische Philosophie (20. Jahrhundert). In: Borsche, Tilman (Hg.): Klassiker der Sprachphilosophie. Von Platon bis Noam Chomsky. München 1996, 401-420.

Stoichiţă, Victor I.: Das selbstbewußte Bild. Vom Ursprung der Metamalerei. München 1998.

Sulikowski, Andrzej: Projekt Księgi: Irzykowski, Schulz, Falszen. Janowi Błońskiemu. In: Sawicki, S./Gotfryd, J. (Hg.): Biblioteka a literatura. Lublin 1986. 
Suthor, Nicola: Augenlust bei Tizian. Zur Konzeption sensueller Malerei in der Frühen Neuzeit. München 2004.

Szondi, Peter: Hoffnung im Vergangenen: Über Walter Benjamin. In: Schriften II. Frankfurt a. M. 1978, 275-294.

Szymaniak, Karolina: Być agentem wiecznej idei. Przemiany poglądów estetycznych Debory Vogel. Kraków 2006.

Szymański, Wiesław P.: Outsiderzy i słowiarze. Wrocław 1973.

Tokarzewska, Monika: Bruno Schulz i Walter Benjamin: Między zachodnioeuropejską metropolią a środkowoeuropejską prowincją. In: przegląd filozoficznoliteracki (2010), 243-263.

Underhill, Karen: Bruno Schulz and Jewish Modernity. Dissertation.

-: Ecstasy and Heresy: Martin Buber, Bruno Schulz, ans Jewish Modernity. In: De Bruyn, Dieter/Van Heuckelom, Kris (Hg.): (Un)masking Bruno Schulz. New combinations, further fragmentations, ultimate reintegrations. Amsterdam: Rodopi 2009, 26-47.

Usener, Hermann: Götternamen. Versuch einer Lehre von der religiösen Begriffsbildung. Bonn 1896.

Van Heuckelom, Kris: Artistic Crossover in Polish Modernism. The Case of Bruno Schulz’s Xięga Bałwochwalcza (The Idolatrous Booke). Online Magazine of the Visual Narrative - ISSN 1780-678X 2006, URL: http://www.imageandnarrative.be/ inarchive/iconoclasm/heuckelom.htm vom 30.01.2012.

-: In Defense of Idolatrous Creativity: Bruno Schulz's Xięga Bałwochwalcza and Traktat o manekinach albo Wtóra Księga Rodzaju. In: Latek, Stanisław (Hg.): Bruno Schulz. New readings, new meanings [proceedings of the International Conference, Montréal, Québec, Canada, May 4-5, 2007]. Montréal: Polish Inst. of Arts and Sciences in Canada [u. a.] 2009, 69-83.

Vogel, Debora: Bruno Schulz. In: Chmurzyński, Wojciech (Hg.): Bruno Schulz 1892-1942. Katalog-Pamiętnik Wystawy Bruno Schulz. Ad. Memoriam w Muzeum Literatury im. Adama Mickiewicza w Warszawie. Warszawa 1995, 165-166.

Wais, Kurt: Symbiose der Künste: Forschungsgrundlagen. In: Weisstein, Ulrich (Hg.): Literatur und bildende Kunst. Ein Handbuch zur Theorie und Praxis eines komparatistischen Grenzgebietes. Berlin 1992, 34-53.

Walden, Herwarth: Einblick in Kunst. Expressionismus Futurismus Kubismus. 3.-5. Aufl. Berlin 1924.

Weigel, Sigrid: Entstellte Ähnlichkeit. Walter Benjamins theoretische Schreibweise. Frankfurt a. M. 1997.

-: Bildwissenschaft aus dem »Geiste wahrer Philologie«: Benjamins Wahlverwandtschaft mit der »neuen Kunstwissenschaft« und der Warburg-Schule. In: Schöttker, Detlev (Hg.): Schrift, Bilder, Denken. Walter Benjamin und die Künste. Frankfurt a. M., Berlin; Haus am Waldsee 2004, 112-127.

Weisstein, Ulrich: Einleitung: Literatur und bildende Kunst: Geschichte, Systematik, Methoden. In: Weisstein, Ulrich (Hg.): Literatur und bildende Kunst. Ein Handbuch zur Theorie und Praxis eines komparatistischen Grenzgebietes. Berlin 1992, 11-31.

Wenzel, Horst: Zur Narrativik von Bildern und zur Bildhaftigkeit der Dichtung: Plä- 
doyer für eine Text-Bildwissenschaft. In: Belting, Hans (Hg.): Bilderfragen. Die Bildwissenschaften im Aufbruch. München 2007, 317-331.

White, Hayden V.: Die Bedeutung der Form. Erzählstrukturen in der Geschichtsschreibung. Dt. Erstausg. Frankfurt a. M. 1990.

Witkiewicz, Stanisław I.: Twórczość literacka Brunona Schulza. In: O znaczeniu filozofii dla krytyki i inne artykuły polemiczne. Warszawa 1976, 189-203.

-: Wywiad z Brunonem Schulzem. In: O znaczeniu filozofii dla krytyki i inne artykuły polemiczne. Warszawa: PWN 1976, 184-188.

-: Einführung in die Theorie der reinen Form des Theaters. In: Wirth, Andrzej (Hg.): Verrückte Lokomotive. Ein Lesebuch. Frankfurt a. M.: Suhrkamp 1994, 43-83.

-: Wstęp do teorii czystej formy w teatrze. In: Teatr i inne pisma o teatrze. Warszawa: Państwowy Instytut Wydawniczy 1995, 13-42.

Wittlin, Józef: A la recherche des temps perdu. In: Wiadomości Literackie (1933), 13.

Witz, Ignacy: Obszary malarskiej wyobraźni. Kraków 1967.

Włodarska, Małgorzata/Włodarski, Zbigniew: Xiegga Bałwochwalcza Brunona Schulza: Kilka uwag o technologii i praktyce techniki ‘cliché-verre`. In: Chmurzyński, Wojciech (Hg.): Bruno Schulz 1892-1942. Katalog-Pamiętnik Wystawy Bruno Schulz. Ad. Memoriam w Muzeum Literatury im. Adama Mickiewicza w Warszawie. Warszawa 1995, 222-223.

Wohlfarth, Irving: Die Passagenarbeit. In: Lindner, Burkhardt (Hg.): BenjaminHandbuch. Leben - Werk - Wirkung. Stuttgart, Weimar 2011, 251-274.

Wohlgemuth, Matthias (Hg.): Rembrandt. [Aus Anlass der Ausstellung »Rembrandt seine Epoche, seine Themen, seine Welt. Der Meister der Radierkunst im Spiegel der Malerei des Goldenen Zeitalters«, 26. November 2005 bis 26. März 2006, Kunstverein St. Gallen Kunstmuseum]. St. Gallen 2005.

Wróblewski, Piotr: Stylistyczna funkcja określeń barw w prozie Brunona Schulza. In: Przegląd humanistyczny 22 (1978), 57-73.

Wurm, Sylvia: Düfte, Schminke und Hygiene. In: Forstner, Regina (Hg.): Drüber und Drunter. Wiener Damenmode von 1900-1914. Wien 1988, 14-18. 


\section{Bildnachweis}

Abb. 1: Schulz, »Undula odwieczny ideał«; »Undula wieczysty ideał«; »eszcze raz Undula« (Undula das ewige Ideal; Undula das immerwährende Ideal; Noch einmal Undula), Cliché-verre (Cv), 10,3×15,3 cm, Jagiellonen Universitätsbibliothek (BJ).

Abb. 2: $\quad$ Tizian, »Venus mit Spiegel«, um 1555, Öl auf Leinwand, $125 \times 105,5 \mathrm{~cm}$, National Gallery of Art, Washington, D.C.

Abb. 3: Tizian, »Venus mit Lautenspieler«, um 1565-70, Öl auf Leinwand, $165 \times 210$ $\mathrm{cm}$, Metropolitan Museum of Art, New York.

Abb. 4: Schulz, "Xięga bałwochwalcza II« (Das Götzendienerische Buch II), $\mathrm{Cv}, 14,4 \mathrm{~cm} \times 23,7 \mathrm{~cm}$, Inv. Nr. MNK III-ryc-7474, Nationalmuseum Krakau.

Abb. 5: Schulz, »Undula u artystów« (Undula bei den Künstlern), 1920-22, Cv, $1015 \mathrm{~cm}, \mathrm{BJ}$.

Abb. 6: Schulz, »Odwieczna baśń I« (Das ewige Märchen I), 1920-22, Cv, 11,5×18 $\mathrm{cm}, \mathrm{BJ}$.

Abb. 7: Schulz, »Autoportret przy pulpicie rysowniczym«; »Młodzieńczy autoportret ze sztalugami« (Selbstporträt vor der Staffelei; Jugendliches Selbstporträt mit Staffelei), 1919, Bleistiftzeichnung, $43 \times 29 \mathrm{~cm}$, Jüdisches Historisches Institut, Warschau (JHI).

Abb. 8: Schulz, »Portret Stanisława Weingartena« (Porträt von Stanisław Weingarten), 1919, Bleistiftzeichnung, 42,5×29 cm, Privatbesitz.

Abb. 9: Schulz, »Portret Marii Budrackiej« (Porträt von Maria Budracka), 1919, Bleistift- und Kreidezeichnung, $45 \times 30 \mathrm{~cm}$, Original verloren.

Abb. 10: Schulz, »Autoportret z przyjacielem Stanisławem Weingartenem i dwiema modelkami«; »W pracowni artysty« (Selbstporträt mit dem Freund Stanisław Weingarten und zwei Modellen; Im Atelier des Künstlers), 1921, Kreide- und Tuschezeichnung, $27 \times 33,5 \mathrm{~cm}$, JHI.

Abb. 11a: Werbung der Anna Csillag«, Wiener Mode, 15. Jg. 1. Oktober 1901, S. 51, aus: Katalog »Grosser Auftritt. Mode der Ringstrassenzeit.« Hrsg. von Regina Karner u. Michaela Lindinger, Wien 2009, S. 39.

Abb. 11b: Werbung der Anna Scillag«, vgl. Pogoń. 1900, Nr. 32 (22 IV), S. 4.

Abb. 12: Werbung der Anna Csillag«, Vasárnapi Ujság, Nr. 8, 1887.

Abb. 13: "Werbung Elsa Fluid«, Grudziądzki Kalendarz Maryański, 1934, S. 47.

Abb. 14: Schulz, »Plemię pariasów« (Das Volk der Paria), 1920-22, Cv, 8,8×12 cm, BJ.

Abb. 15: Schulz, »Pielgrzymi« (Die Pilger), 1920-22, Cv, 17,5 $\times 23,5 \mathrm{~cm}, \mathrm{BJ}$.

Abb. 16: Schulz, »Procesja« (Die Prozession), 1920-22, Cv, $17 \times 23$ cm, BJ.

Abb. 17: Schulz, »Święto bałwochwalców« (Das Fest der Götzenanbeter), 1920-22, $\mathrm{Cv}, 8,6 \times 11,7 \mathrm{~cm}, \mathrm{BJ}$. 
Abb. 18: Rembrandt, "Landschaft mit drei Bäumen«, 1643, Radierung, Kaltnadel und Kupferstich, ca. $21.5 \times 28.3$ cm, Inv. Nr. D 1146, Graphische Sammlung der ETH Zürich.

Abb. 19: Vincent van Gogh, „Die Sternennacht« (»Zypressen und Dorf«), SaintRémy, 1889, Öl auf Leinwand, $73 \times 92 \mathrm{~cm}$, Museum of Modern Art, New York, USA, Bridgeman Images. 


\section{Register}

Adela 146f., 162, 211

Allegorie 55, 58, 100, 105, 138, 148, 167

Augsburger, Janis 12, 22, 49, 56, 81 f., 140, 144

Barthes, Roland 66, 76, 84, 128

Baudelaire 73, 138, 148

Belting, Hans 15, 17, 32, 34, 66, 71 f., 75, $77-79,93,120,213,220$

Benjamin, Walter $12 \mathrm{f} ., 15-17,30,31 \mathrm{f} ., 36$, $41 \mathrm{f} ., 47-49,53,55-57-61,66,72-77,79$, $122,128,132-144,148,151,156,158 \mathrm{f}$. , 167-169, 207-209, 226-229, 232

Berlin 19, 24, 158, 208

Bild-Anthropologie 15, 17, 34, 77, 79

Bildidee 9, 14, 29f., 32, 34-36, 39, 77f., 225, 227

Bildverbot 10, 36, 46, $67 \mathrm{f} ., 70,103,108-110$, 121,125

Bildwissenschaft 15, 29, 32 f., 35, 39, 66, 71, 76 f., 80

Blumenberg, Hans 16, 30, 41, 52 f., 76

Boehm, Gottfried $32 \mathrm{f}$., $71 \mathrm{f}$., 77, 91, 178, 180, 183-186, 211, 213, 225, 230

Bolecki, Włodzimierz 8, 12, 44 f., 61, 170, $174,176,178,186-188,200,204$

Borysław 23

Breughel 11, 195

Buber, Martin 145

Buch (magisch, mystisch, metaphorisch, symbolisch) $10 \mathrm{f} ., 22,43,46,51,81 \mathrm{f}$., 89 , 96, 102-105, 108-112, 114, 121, 125, 142, 144-147, 156-158, 160-162, 188, 230-232

Cassirer, Ernst 48, 76, 80, 111, 186, 228

Chassidismus 13, 24, 114

Chazen, Maria 25

Cliché-verre 83-87, 123

Comte, Auguste 45, $47 \mathrm{f}$.

Csillag, Anna 128, 147-157, 160, 166, 168

Dialektik (dialektische Bilder) $31 \mathrm{f} ., 36,50$, 55, 58 f., 128, 132-136, 141, 156 f., 160, $168-170,227$ f., 230
Dionysos 9, 12, 56, 83, 116, 179

Drohobycz/Drogobytch 19, 21, 23, 25, 27-29, $81,123,131,166,230$

Dürer, Albrecht 11, 87, 195

Eichendorff, Joseph v. 93-96, 109, 182

Ekphrasis 11, 37, 112, 177-186, 189f., 194-196, 212, 220, 228, 231

Erkenntnis 33-35, 40, $47 \mathrm{f}$., 57, 61 f., 68, 105, $111,145,186,227,232$

Ernst, Max 205, 209

Erotik 9, 20, 67, 82, 96, 98, 100 f., 128 f., 138, $141,147,160-162,168,231$

Erstarren 15, 37, 39, 44, 65-79, 101, 177, 191, 225 f., 229

Expressionismus 8, 10, 26f., 51, 90, 176, 179, 196, 198 f., 205, 209, 215 f., 220

Ficowski, Jerzy 8f., 19-22, 81 f., 131, 144

Fieguth, Rolf 46, 63f., 145, 175, 214, 216

Fotografie 15, 17, 29 f., 35 f., 39, 65-79, 85 f., $122 \mathrm{f} ., 127 \mathrm{f} ., 131 \mathrm{f} ., 137-139,168,180$, $207,225 \mathrm{f}$.

Franko, Ivan 23

Franzos, Karl Emil 22

Fresken 29, 68

Freund, Gisèle 30, 35, 65-67, 73-75, 207

Fuchs, Eduard $162 \mathrm{f}$.

Galizien 22f., 29

Gombrowicz, Witold 22, 28, 81, 121, $170 \mathrm{f}$.

Gott/Göttin/Götter 30, 42-44, 46, 54 f., $60 \mathrm{f}$., 64, 68-72, 79, 81, 87-90, 93-110, $117,122-124,127,145,147,149-151$, 154-157, 161, 163, 166, 168, 180, 201, 210, 216, 230

Gottlieb, Leopold 23

Gottlieb, Maurycy $23 \mathrm{f}$.

Götzendienst 8, 10, 70, 81, $103 \mathrm{f}$., $108-110$

Groteske 26, 83 f., 86 f., 123, 131, 151, 163, 166,230 
Hayek, Friedrich A. von 49

Heuckelom, Kris Van: 10, 83, 93, $108 \mathrm{f}$.

(Achtung Schreibweise van/Van) 10, 83, 93, $108 \mathrm{f}$.

Huxley, Aldous 51

Idee 9, 14, 16f., 27, 29-32, 34-41, 45, 48-52, $54,56,58,64,68,77,89,93,101,104 \mathrm{f}$., $108,123,133,136,140,142,146,168$, 171, 177 f., 182, 185 f., 199 f., 214, 217-219, $222,225-227,232$

Iconic turn/pictorial turn 32-34, 77

Idol, Idolatrie $15,69,71 \mathrm{f} ., 83,86,93,96$,

$103-111,122,125,182,213,218,226,231$

Ikone 69, 71, 79, 114, 147 f., 154

Ikonoklasmus $71 \mathrm{f}$.

Illustrierte 11, 36, $66 \mathrm{f} ., 74,127,129-132$, 137-140, 143-148, 154, 157, 160-162, 168

Jakub 146, 176, 190, 194, 216

Jarzębski, Jerzy 9, 21, 43, 51, 81 f., 174,

176-178, 186-188, 218

Jerusalem 24, 114

Jonas, Hans 33

Józef 95, 146f., 154, 200 f., 216

Kabbala 13, 42, 54, 58, 70, 95, 127, 176, 218 Kafka, Franz 19, 21, 27 f., 63 f., 95, 214-216 Kalleia 25

Kamena 28

Kandinsky, Wassily 185, $202 \mathrm{f}$.

Kato, Ariko 9, 22, 81 f., 98, 104, 113 f., 116, 119f., 124, 145

Kitowska-Łysiak, Małgorzata 10 f., 14, 82, 88, 123, 148, 157, 167

Kontingenz 49, 57

Kracauer, Siegfried 29

Krakau 19f., 23 f., 26, 28

Kritik 14, 17, 31, 39, 47 f., 50, 53, 57-59, 64, 111, 140, 151, 157, 168, 170, 218, 226

Kubin, Alfred 19, 26f., 87

Kudowa Bad 26

Kuncewiczowa, Maria 11, 28

La Fouqué Motte, Friedrich de 111

Lachmann, Renate 11, 42, 91, 176, 212

Lemberg 18, $20 \mathrm{f}$., 23, $25 \mathrm{f}$.

Leśmian, Bolesław 21, 25, 46, 61, 95

Lessing, Gotthold 34, 68, 181, 187, 200

Lilien, Ephraim M. 24
Malerei 8-11, 15, 17 f., 20, 23 f., 27 f., 30 f., $36 f$., 69, 74-76, 80, 83, 85-93, 96, 98, 100, 102-105, 108, $113 \mathrm{f} ., 116,118,124 \mathrm{f}$., 130, 140 f., 154, 173-190, 192, 194, 196, 198-206, 208f., 211 f., 214, 218, 220 f., 226, 231

Mann, Thomas 19, 21, 60, 64, 95, 145, 214, 218 Marx, Karl 136, $142 \mathrm{f}$.

Masochismus $8 \mathrm{f}$., 12, 14, 21 f., 26, $28 \mathrm{f}$., $81 \mathrm{f}$., $88,121,124,140,231$

Messias 20, 58, $114 \mathrm{f}$.

Metabild 36, 84, 96, 101, 104, 112, 120, 122, $125,128,130,136,219,228,230-232$

Metatext/Metanarration/Metatheorie 18, $82,178,210,214,222,232$

Metamorphose $8,87,91,99,177$

Metapher 8, 29, 39, 44, 51, 53f., 72, 130, 137, 145 f., 168 f., 171, 175, 184, 195, 201, 212 f., 215, 221, 225

Metapoesie 179, 186, 215, 220, 222

Mitchell, William Theodor 67, 83, $95 \mathrm{f}$., 112, 123M 125, 141, 163, 177-186, 209, $213,218,230,232$

Mode 11, 36, 51, 66, 74, 127 f., 137-145, 148 f., 151, 154, 159, 161 f., 168, 229

Moderne 10, 12-15, 19, 25f., 31, 34, 36, 39, 44-50, 53-55, 57, 61, 64, 67f., 71f., 75, 81, $87,90,96,102,104,109,112,121,123 \mathrm{f}$., 127f., 131, 134, 138-145, 148, 167-170, 176, $178 \mathrm{f}$., 183-185, 202, 209, 213, 222, 229-231

Mosaik 43f., 68, 213, 232

München 24

Mythologie 9-12, 18f., 36, 41-46, 50, 54, $60,62-67,72,76,82$ f., 87-91, 98, 106, $113 \mathrm{f} ., 116,121-124,131,143,148,170 \mathrm{f}$., $176 \mathrm{f}$., 226, 228-230

Mythos 16, 26, 28, 41, 44-46, 48, $56 \mathrm{f}$., 60, $68,76,80-82,86,88$ f., 91, 94, 96, 100, 104, 108, 111, 114, 121, 124f., 133, 146, $157,170,228-230$

Nałkowska, Zofia, 18, 20, 28

Napoleon, Bonaparte 56, 190

Nielsen, Asta $155 \mathrm{f}$.

Nietzsche, Friedrich $26,42,45,56,83,95$, 109, 167, 170

Panofsky, Erwin 30, 76, 99-102, 121, 185

Paris 28, 133, 140, 148, 158

Piłsudski, Józef 28, 39, $56 \mathrm{f}$.

Pion 28 
Plakat 127, 147, 155, $158 \mathrm{f}$.

Płockier, Anna 78

Poetizität $46,186,188$

Positivismus 15, 35, 39, 45, 47, 49 f., 54-58, $70,74,76,130$

Prostituierte $140 \mathrm{f} ., 160,167$

Psychoanalyse 8, 14, 18, 39, 49, 52, $81 \mathrm{f}$., 171

Pygmalion 16, 88-91, 95, 99, $121 \mathrm{f}$., $124 \mathrm{f}$., 226, 230

Rembrandt 11, 16, 87, 178, 192-194

Rettung 16f., 32, 37, 54, 58f., 96, 226-228

Riff, Władysław 20

Rój 20, 28

Rom 24, 69, 100, 158, 193

Romantik 63, 86, 93, 95, 123, 167, 182, 229

Roth, Joseph, $21 \mathrm{f}$.

Sacher-Masoch, Leopold v. 22, 36, 81, 83, 90, 93, 96, $100 \mathrm{f} ., 104,109,121,230$

Sachs-Hombach, Klaus 33

Sandauer, Artur 19, 21, 81 f., 109, 167

Scholem, Gershom 13, 42, 51, 58 f., $69 \mathrm{f}$.

Schöpfung 11, 42, 52 f., 61, 131, 161, 176, 217, 229

Schuh 161 f., 166, 168, 229

Sinn 26, 34f., 40-49, 54, 57, 60-62, 64, 69, $76,80,86,91,121,163,170,177,184$, 188 f., 209, 218, 225 f., 231

Skamander $24 \mathrm{f}$., $27 \mathrm{f}$.

Sontag, Susan 66, 73, 128

Sprachphilosophie 12, 59f., 229

Statue/Plastik 54, 68, 78, 89-91, 94, 96, 98, $100,105,114,118,122,182,217 \mathrm{f} ., 230$

Studio 28, 40

Sygnały 28

Symbol 10, 40 f., 44, 48, 55, 69f., 77, 79 f., $83,100,111,116,122,125,129,134,137$, 142 f., 147, 161 f., 168, 201, 206, 215, 231

Symbolismus 18,27

Symbolische Form 48, 76f., 79f., 162, 186, 225,228

Synästhesie 187, 201-204

Szelińska, Józefina 21, 28

Szientismus 47, 49f., 63, 65

Technik 12, 25, 31, 35, 43-48, 54, 59 f., 64-67, 72-75, 78f., 83-88, 122 f., 134, $139,143,207,209,211,221,225 \mathrm{f}$.

Theorie/Theoretisierung 10-12, $16-18,20,29-37,40,45-50,52,54,57$,
60-63, 72, 75, 77, 79-84, 92, $95 \mathrm{f}$, $109,112,121,123-125,128,132 \mathrm{f}$., 136-138, 141, 171, 173, 176-180, 182-186, 199-203, 205, 207f., 215, 220-222, 225 f., 229, $231 \mathrm{f}$.

Tizian 16, 36, 89-91, 96, 98-103, 109, 114, 116,118

Trödel $63,86,89$

Truskawiec 26

Tuwim, Julian 24f., 27

Tygodnik Ilustrowany 28

Undula $84,88,92,96-98,101,105-107,111$, $122,163,167,230$

Van Gogh, Vincent 10, 16, 113, 178, 196-198, 220

Venus $21 \mathrm{f} ., 36,81,83 \mathrm{f} ., 88-108,111,114$, $116,118,121 \mathrm{f} ., 160,230$

Vernunft 33, 46, 96, 133, 227

Vilnius 26

Vogel, Debora 20, $24 \mathrm{f}$.

Wagner, Richard von 95

Wanda 84, 89-92, 98, 101

Warschau 19-21, 23, $26 \mathrm{f}$.

Weltanschauung 44, 47 f., 50, 52f., 55, 82 , 121,167

Werbung/Reklame 11, 17, 30, 36f., 64, 67, 74, 77, 128, 131 f., 137 f., 141 f., 144, 146-149, 151-159, 163 166-170, $225 \mathrm{f}$.

Wiadomości Literackie 28

Wien 19, 24-27, 45, 49, $148 \mathrm{f}$.

Wierzyński, Kazimierz, 24, $27 \mathrm{f}$.

Wirklichkeit $8,12,14,16-19,25,30 \mathrm{f}$., $35 \mathrm{f}$., 39-48, 52 f., 57, 59, 61, 63 f., 66, 70-80, 83-86, 88-90, 94-96, 101, 108, 110, 118-121, 124, 128, 130-132, 136f., 139, $144 \mathrm{f} ., 156 \mathrm{f}$., 160, $167 \mathrm{f} ., 170$ f., 175, $179 \mathrm{f}$., 184, 188-191, 194f., 199-201, 210, 215f., 218 f., 221 f., 226 f., $229-231$

Wissenschaft 24 f., 29 f., 32 f., 34 f., 39-41, $44 \mathrm{f} ., 47-53,55,64-67,69,72,74-77$, $80 \mathrm{f} ., 87,112,130,156,207$

Wit, Juliusz 23

Witkiewicz, Stanisław Ignacy 28, 43, 54, $62,78,87,176,183 \mathrm{f}$.

Wittlin, Józef 21, 147, 154

Witz, Ignacy 7, 87

Zakopane 21 